\title{
Surge Protection in Low Voltage AC Power Circuits - An Anthology Part 4 - Propagation and Coupling of Surges
}

François D. Martzloff

U.S. DEPARTMENT OF COMMERCE Technology Administration

Electronics and Electrical

Engineering Laboratory

Eiectricity Division

National Institute of Standards and Technology

Gaithersburg, MD 20899 
。 


\section{Surge Protection in Low-Voltage AC Power Circuits - An Anthology Part 4 - Propagation and Coupling of Surges}

François D. Martzloff U.S. DEPARTMENT OF COMMERCE Technology Administration Electronics and Electrical Engineering Laboratory Electricity Division National Institute of Standards and Technology Gaithersburg, MD 20899

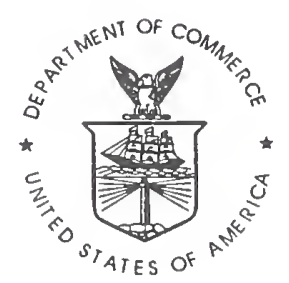

U.S. DEPARTMENT OF COMMERCE Donald L. Evans, Secretary TECHNOLOGY ADMINISTRATION Phillip J. Bond, Under Secretary for Technology NATIONAL INSTITUTE OF STANDARDS AND TECHNOLOGY

Arden L Bement, Jr., Director 


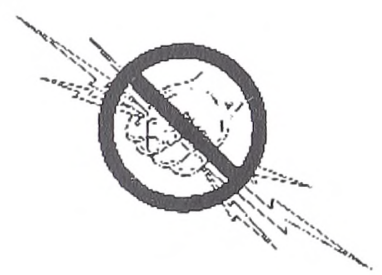




\section{FOREWORD}

The papers included in this part of the Anthology provide basic and tutorial information on the propagation of surges in low-voltage AC power circuits. The subject was approached by a combination of experiments and theoretical considerations. One important distinction is made between voltage surges and current surges. Historically, voltage surges were the initial concern because the objectionable consequence of surges was a breakdown of insulation - a voltage-related phenomenon. In particular, the breakdown phenomena were significant in low-voltage circuits for air clearances (wiring devices), solid insulation (windings) and surfaces (semiconductor edges). After the introduction and widespread use of currentdiverting surge-protective devices at the point-of-use, the propagation of current surges became a significant factor. Another significant aspect of the investigations was to note that many earlier studies on the propagation of surges were conducted from the point of view of transmission line theory with impulses having durations shorter than the travel time along the relatively long lines. For most of the surge waveforms occurring in AC power circuits and typical installations, the travel time is shorter than the impulse duration, so that the classical expectation of (characteristic) impedance mismatches effect in traveling waves are irrelevant. The papers included in this part reflect this dual dichotomy of voltage versus current and impedance mismatch effects versus simple circuit theory.

Industry interest in the matter also grew, to the point that the IEEE Surge Protective Devices Committee formed subcommittee focused on low-voltage concerns, which became an additional forum for many papers contributed by the researchers cited in Annex A. For obvious copyright limitations, these 38 papers from other researchers cannot be reprinted here. The pre-1985 papers in this Part 4 were copyrighted by the publisher, or were proprietary to General Electric; both graciously gave permission for reprinting in this anthology. The post-1985 papers, written thanks to the resources of the National Institute of Standards and Technology, are in the public domain.

Part I, Annotated Bibliography, was initially compiled by the author as a contribution to the IEEE SPD Trilogy of the Surge-Protective Devices Committee (a set of three standards on the surge environment). This initial compilation is now complemented with additional relevant papers and reports written by the author. Undertaking a listing of "relevant papers" entails the risk of offending researchers whose papers might have been overlooked in the compilation, which should be seen as a limitation of the compilation effort for the Trilogy, not a deliberate rejection. Given the large number of papers in the complete collection, the breakdown into seven topic categories makes the volume more manageable. Because some of the papers cover more than one topic, for the convenience of readers, they will be found repeated in successive parts as the compilation progresses. In addition to this printed format (available from the U.S. Superintendent of Documents), this Part 4 is also available on the Web, thus opening the door for suggestions of additional entries for additions and periodic updates of the listing that might be suggested by users (Contact point: f.martzloff@ieee.org). The Web version includes an html file of the collection of the anthology papers for each part, which is searchable for any word, with built-in links

allowing on-line downloading of the original paper itself in pdf format. The Website URL for the complete Anthology is: http://www.eeel.nist.gov/811/spd-anthology/ 


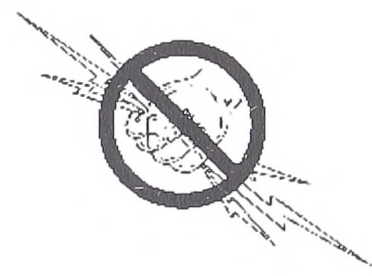




\section{Contents}

(By chronological order)

Surge voltage suppression in residential power circuits Declassified GE TIS Report 76CRD092

Lightning protection of residential $\mathrm{AC}$ wiring

Declassified GE Memo Report MOR-78-095, 1978 (Co-author: Crouch)

Coordination of surge protectors in low-voltage AC power circuits

IEEE Transactions, PAS-99, No. 1, Jan./Feb. 1980.

The propagation and attenuation of surge voltages and surge currents in low-voltage $A C$ circuits

IEEE Transactions PAS-102, No. 5, May 1983

Surge and high-frequency propagation in industrial power lines

IEEE Transactions IA-22, No.4, July/August 1986 (Co-author: Gauper)

Varistor versus environment: Winning the rematch

IEEE Transactions PWRD-1, April 1986.

Fast transient tests - Trivial or terminal pursuit ?

Proceedings, $7^{\text {th }}$ International Zürich Symposium on Electromagnetic Compatibility, 1987 (Co-author: Wilson)

Coupling, propagation, and side effects of surges in an industrial building wiring system

IEEE Transactions IA-26, No. 2, March/April 1990

Electrical fast-transient tests: Applications and limitations

IEEE Transactions IA-26, No. 1, Jan./Feb. 1990 (Co-author: Leedy)

Partial discharges in low-voltage cables

Conference record, IEEE International Symposium on Electrical Insulation, Toronto, 1990

Diverting surges to ground: Expectations versus reality

Proceedings, Open Forum on Surge Protection Application, NISTIR-4654, 1991.

On the propagation of old and new surges

Proceedings, Open Forum on Surge Protection Application, NISTIR-4654, 1991.

Surging the Upside-Down House: Looking into upsetting references

Proceedings, EPRI-PQA'94 Conference, Amsterdam, The Netherlands, 1994 (Co-author: Key)

Surging the Upside-Down House: Measurement and modeling techniques

Proceedings, PQA'95 Conference, New York, NY, 1995 (Co-authors: Mansoor, Phipps, and Grady)

Driving high surge currents into long cables: More begets less

IEEE Transactions PWRD-12, No.3, July 1997 (Co-author: Mansoor)

The effect of neutral earthing practices on lightning current dispersion in a low-voltage installation

IEEE Transactions PWRD-13, July 1998 (Co-author: Mansoor)

On the dispersion of lightning current for a direct flash to a building

Proceedings, $25^{\text {th }}$ International Conference on Lightning Protection, Rhodes, Greece, 2000.

The role and stress of surge-protective devices in sharing lightning current

Proceedings, EMC Europe 2002 Symposium, Sorrento, Italy (Co-author: Mansoor)

Annex A - Contributions by other researchers to coupling and propagation of surges 


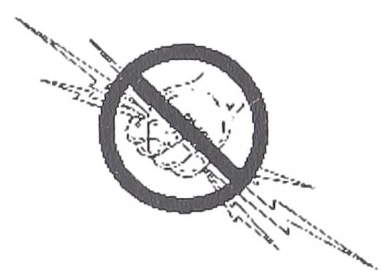




\title{
Surge Voltage Suppression in Residential Power Circuits
}

\author{
Francois Martzloff \\ General Electric Company \\ Schenectady NY \\ f.martzloff@ieee.org
}

Reprint, with permission, of declassified General Electric Technical Information Series Report 76CRD092

\section{Significance:}

Part 4 - Propagation and coupling of surges

Part 7 - Mitigation techniques

Part 8 - Coordination of cascaded SPDs

Laboratory tests on the effect of distance for coordination between a surge-protective device (SPD) at the service entrance and an SPD at the end of a branch circuit.

The service entrance SPD, 1960-1970 vintage, consisted of a silicon carbide disc with a series gap. The branch circuit SPD consisted of a simple MOV disc incorporated in a modified plug-andreceptacle combination. probably the first attempt at packaging an MOV for residential surge protection.

Tests were performed with a simple generator capable of delivering up to $8 \mathrm{kV}$ peak open-circuit voltage of $2 / 60 \mu$ s waveform and $2 \mathrm{kA}$ peak short-circuit current of $30 / 50 \mu$ s waveform. These values - dating back to pre-IEEE 587 consensus waveforms - were at the time deemed to represent a severe surge associated with a lightning flash to the power system, outside of the residence.

One objective of the tests was to determine the values of surge current and distance between SPDs that produced the threshold from no sparkover of the service entrance SPD (maximum stress on the MOV) to sparkover, thus limiting the stress on the MOV. This was one of the first illustrations of what became a series of experimental and theoretical studies of the "cascade coordination" concept. 

Goneral Elactric Company

\begin{tabular}{|c|c|c|}
\hline Martzloff, FD & $\begin{array}{l}\text { SUBJECT } \\
\begin{array}{l}\text { surge voltage } \\
\text { suppression }\end{array}\end{array}$ & $\begin{array}{l}\text { No } 6 \text { CRD } 092 \\
\text { INTay } 1976 \\
\end{array}$ \\
\hline \multirow{2}{*}{\multicolumn{2}{|c|}{$\begin{array}{l}\text { TIILE } \\
\text { Surge Voltage Suppression in Residential } \\
\text { Power Circuits }\end{array}$}} & \\
\hline & & NO. PAGES 11 \\
\hline \multicolumn{2}{|c|}{$\begin{array}{l}\text { ORIGINATING Electronic Power Conditioning } \\
\text { COMPONENT } \\
\text { and Control Laboratory }\end{array}$} & $\begin{array}{l}\text { CORPORATE } \\
\text { RESEACH AND DEVELOPMENT } \\
\text { SCHENECTAOY, M.Y. }\end{array}$ \\
\hline \multicolumn{3}{|c|}{$\begin{array}{l}\text { SUMMARy } \\
\text { wiring system with a Home Lightning Protector (HLP) and } \\
\text { a Voltage Spike Protector (VSP) installed on the service } \\
\text { box and an outlet, respectively, indicate good coordination } \\
\text { between the characteristics of the two devices. For surge } \\
\text { of relatively small amplitude, the VSP performs all of the } \\
\text { voltage clamping functions. As the energy (current) of the } \\
\text { surge increases, a point is reached where the HLP spark- } \\
\text { over voltage is reached, and this device takes over the } \\
\text { function of diverting the surge energy while the VSP keeps } \\
\text { the voltage clamped at low levels. The current for which } \\
\text { this transfer takes place depends on the distance between } \\
\text { the two devices. For practical situations, enough distance } \\
\text { (wiring length) will exist to limit the duty imposed on the } \\
\text { VSP to acceptable levels, giving the HLP an opportunity } \\
\text { to divert high energy surges. }\end{array}$} \\
\hline \multicolumn{3}{|l|}{ KEY WOROS } \\
\hline
\end{tabular}

INFORMATION PREPARED FOR

Additionol Hard Copies Availoble From

Microfiche Copies Available From
Corporate Research \& Development Distribution P.O. Box 43 Bldg. 5, Schenectody, N.Y., 12301 Technical Information Exchange

P.O. Box 43 Bldg. 5 , Schenectody, N.Y., 12301 
Q 


\author{
SURGE VOLTAGE SUPPRESSION \\ IN RESIDENTIAL POWER CIRCUITS \\ - F.D. Martzloff -
}

\section{INTRODUCTION}

Surge voltages occurring in residential power circuits have two origins: external surges, produced by power system switching operation or by lightning, and internal surges produced by switching of appliances in the home. The voltage levels of these surges are sufficient to cause failure of sensitive electronic appliances. and some of the higher surges can even fail the more rugged electromechanical devices (clocks, motors and heaters) ${ }^{1,2}$.

For many years, the General Electric Company has offered a secondary surge arrester under the name of "Home Lightning Protector" (HLP). which is very effective in protecting non-electronic devices against high energy, high voltage surges associated with lightning or power system switching. However, the protective level of this arrester, consistent with the limitations imposed by the design of such a device, is still too high for sensitive electronic devices. Furthermore, its installation requires a competent electrician

A new suppressor has been developed and introduced by the Wiring Device Department under the name "Voltage Spike Protector" (VSP); this device incorporates a GE-MOV varistor in a plug-in device allowing purchase and easy installation by the user. The protective level of this device is substantially lower (that is, better protection is provided) than the HLP, so that protection of sensitive electronic appliances is now possible. However, the energy handling capability of this suppressor is lower than that of the HLP. so that large currents associated with lightning strikes cannot be handled by the device.

The availability of these two different types of suppressors now makes it possible to obtain a coordinated protection of all the appliances in a home. Installation of the HLP at the service entrance will deal with the larger surges, while the VSP installed at a wall receptacle will protect the more sensitive devices. For the lower surges, the VSP will clamp the voltage to a low level. For the higher surges, the VSP will first attempt to absorb all the surge current, but the voltage developed across the varistor plus the voltage drop in the wiring between the receptacle where the VSP is installed and the service box where the HLP is installed will reach the sparkover voltage of the HLP. The HLP then takes over, diverting the high current surge from the VSP, so that no excessive energy is applied to the latter.

This report describes how this coordination takes place, based on simulated surges in a representative wiring system. The levels of voltage and current in these tests show when the HLP and VSP respectively assume all of the protective function, and where the transfer takes place, depending on the distance between the VSP in an outlet and the service box where the HLP is installed.

\section{THE HOME LIGHTNING PROTECTOR}

The Home Lightning Protector (HLP), is produced by the Distribution Transformer Business Department. It is a surge arrester of the valve and series gap type (Fig. 1). Earlier designs involved lead oxide pellets, with the oxide pellet acting as a nonlinear resistor and the multiple contact points between the pellets as a multiple gap. A more recent design uses a Thyrite@ disc in series with a low voltage gap.

This UL-1isted arrester is rated for lightning surge duty, and is described in the GE Handbook as having a sparkover of $2 \mathrm{kV}$ crest under a $10 \mathrm{kV} / \mu \mathrm{s}$ impulse with discharge voltages of $1,1.2$ and $1.4 \mathrm{kV}$ respectively at 1500, 5000 and 10,000 A for a $10 \times 20$ us current wave (see Appendix I).

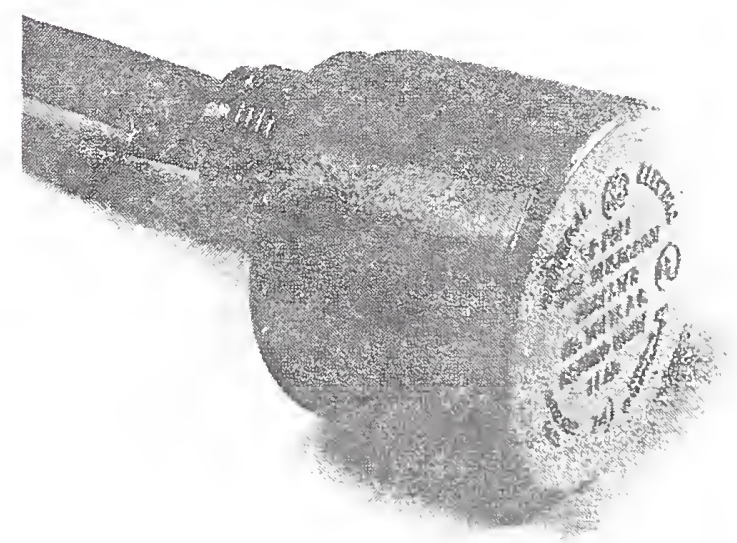

Eigure 1. Home Lightning Protector

(9) Registered trademark of the General Electric Company. 
As any gap-type arrester will, the HLP has a volt-time characteristic exhibiting some increase in the sparkover voltage as the rate of rise of the impinging surge increases. Typical sparkover voltages for the sample tested under the particular waveform used here were in the order of $2000 \mathrm{~V}$ or less. This represents an effective clamping to protect electromechanical appliances, heaters, etc. However, sensitive electronic appliances may well have failure levels below $2000 \mathrm{~V}$. This is recognized in the box label which describes the HLP. as a protector for "home and farm non-electronic equipment, wiring appliances and water heaters".

Thus, while the HLP offers reliable protection for non-electronic appliances and a respectable energy handling capability, a device with a lower voltage clamping characteristic is required to protect sensitive electronics. This need is now met through the Voltage Spike Protector, described in the next section.

\section{THE VOLTAGE SPIKE PROTECTOR}

The heart of this device is a GE-MOV० varistor, connected line-to-line in a combination plug-socket (Fig. 2). This package, developed and produced by the Wiring Devices Department, makes it convenient for the user to install the protector at any outlet in the house, and the socket end allows the user to plug the protected appliance directly into the protector. In fact, protection is afforded to devices in all other wall outlets (to a varying degree, depending on the branch circuit configuration) and it is not mandatory to plug the appliance into the suppressor (it is a shunt, not a series device). One of the reasons for the socket end is just a convenience, so as not to lose the use of a recentacle or reauire a cube tan.

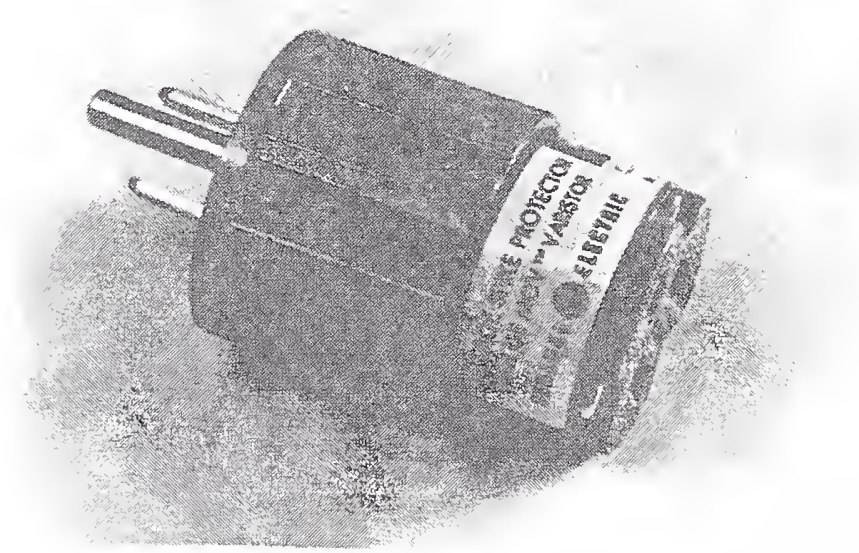

Figure 2. Voltage Spike Protector
In addition to the varistor, a nonresettable, one-shot thermal protection is inserted in series with the varistor, as insurance against thermal runaway of the varistor in case of excessive environmental conditions.

The protective characteristics of the varistor are such that a 15 A surge, typical of large internally-generated surges, will limit the voltage across the suppressor to $500 \mathrm{~V}$, as opposed to values exceeding $2000 \mathrm{~V}$ which have been recorded during monitoring of houses known to contain a switching device producing such surgesl. For large current values such as those associated with "lightning remnants", i.e. surge entering the house when a lightning stroke occurs near the house (but not a direct stroke), one can expect currents in the order of 1000 to $2000 \mathrm{~A}$. These would produce a voltage of 800 to $1000 \mathrm{~V}$ across the varistor. However, as we will see, the presence of an HLP device at the service box, ahead of the varistor, will limit the current flowing toward the varistor to a lower value, by diverting the current through the HLP because of the additional drop in the wire which raises the voltage across the HLP to its sparkover voltage.

\section{TEST CIRCUIT}

The test circuit (Fig. 3) consisted of a terminal board from which two lines, one $25 \mathrm{ft} .(7.5 \mathrm{~m})$ and the other $100 \mathrm{ft}$. (30 m) long were strung in the test area. A short $10 \mathrm{ft}$. ( $3 \mathrm{~m}$ ) line simulated the service drop. All of these were made of 3-conductor non-metaliic sheath wire (Etcoflex type NM) \#12 AWG. The neutral and the ground wire of the three lines were connected together at the terminal board, and thence to the reference ground of the test circuit.

A11 surge currents were applied between the Iine conductor (black) at the end of the service drop and the reference ground. These impulses were obtained from a $5 \mu F$ capacitor, charged at a suitable voltage, and discharged into the wiring system by an ignitxon switch. Figure 4 shows the connections and parameters of the surge generator circuit. The resultant open-circuit voltage waveform, a unidirectional wave of 1 us rise time $x 50$ us to $1 / 2$ value time, corresponds to the standard test wave in utility systems. It is a much more severe test than the recommended TCL waveshape 2,4 and as such provides very conservative results. Figure 5 shows typical open-circuit voltage and short-circuit current waveforms. Voltages were recorded by a Tektronix 7633 storage oscilloscope through a P6015 attenuator probe (1000:1); currents by a Tektronix 7633 oscilloscope through a current probe P6042 with a CT-5 1000:1 current transformer. Thus, the calibrations displayed on the oscillogram are to be multiplied by 1000 for the voltage, 


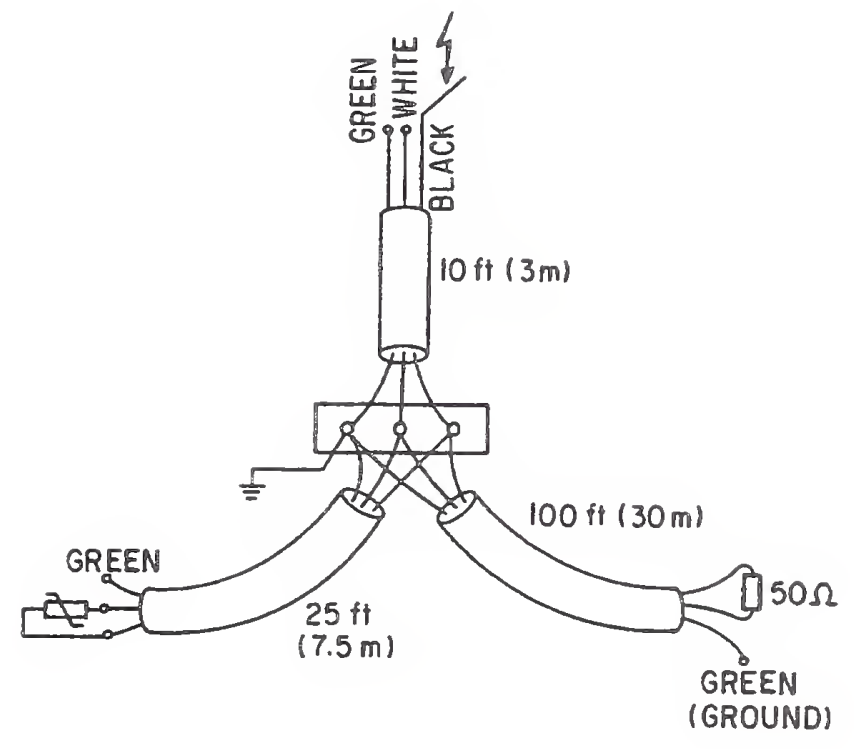

Figure 3. Test Circuit

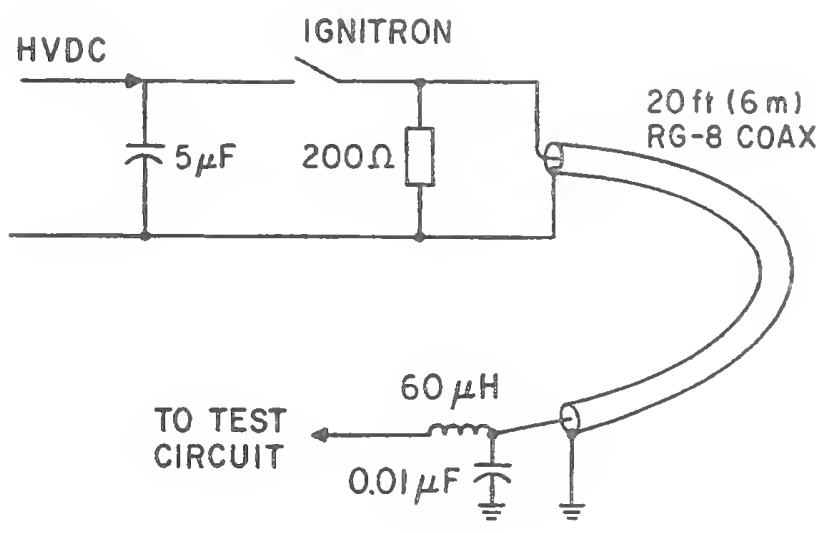

Figure 4. Pulse Generator Circuit

condition. The results will be discussed with reference to specific sets of oscillograms showing voltages and currents in various parts of the circuit, each time for the same setting of the surge generator.

\section{HLP AND VSP RESPONSE}

Figure $5 \mathrm{a}$ shows a $3000 \mathrm{~V}$ open-circuit voltage surge at the service box, with neither suppressor connected. Figure $5 \mathrm{~b}$ shows the corresponding 600 A short-circuit current for a jumper connected at the service box. Figure $6 a$ shows the voltage across the HLP when subjected to the surge defined by Figures $5 \mathrm{a}$ and $5 \mathrm{~b}$. Note that the sparkover voltage reaches $2200 \mathrm{~V}$ with several oscillations before the voltage settles down to the impulse discharge voltage at about $1000 \mathrm{~V}$ at its start.

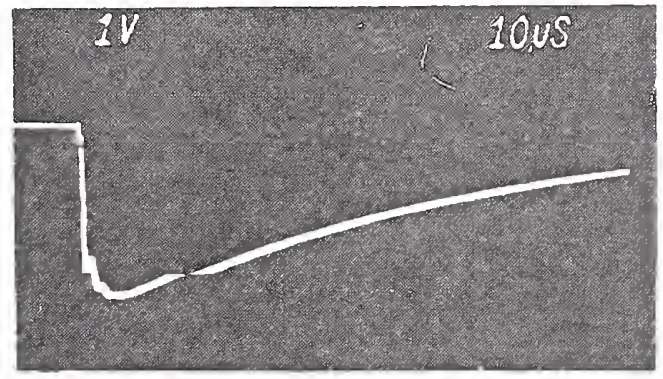

(a)
Figure 5

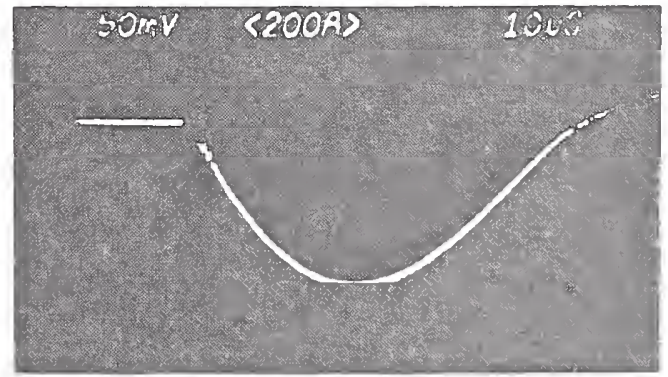

(b)

Open Circuit Voltage and short-Circuit current (without any protector) 


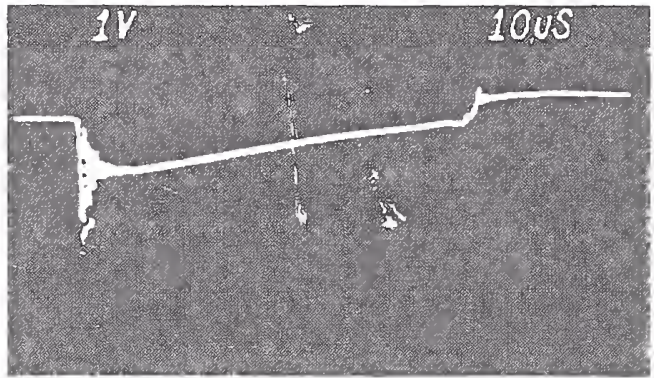

(a)

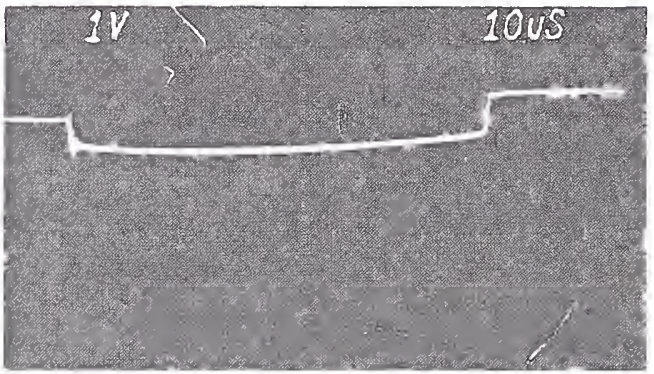

(b)

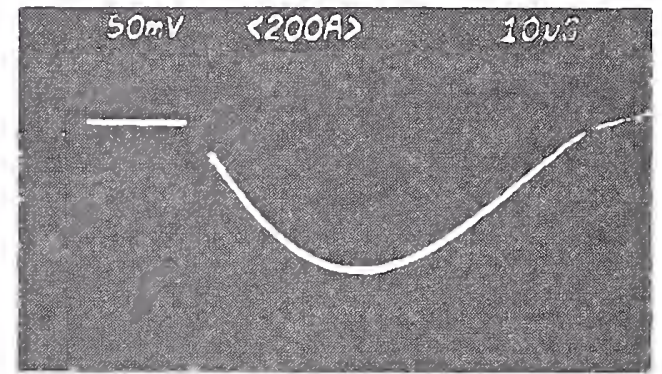

(c)

Figure 6

Response of HLP \& VSP

Figures $6 \mathrm{~b}$ and $6 \mathrm{c}$ show respectively the voltage and current across the varistor. Note that the maximum voltage is $600 \mathrm{~V}$, for a 550 A current on the varistor. (The current in the varistor is lower than the available short-circuit current because of the reduced available voltage since the varistor holds off 600 .

\section{PROPAGATION OF SURGES}

Figure 7 shows several oscillograms indicating how the surge propagates in the wiring in the absence of any suppressor, and how the installation of one VSP device at an outlet is reflected elsewhere in the system. Figures $7 \mathrm{a}$ and $7 \mathrm{~b}$ show respectively the open-circuit voltage and short-circuit current at the service box. At the openended $25 \mathrm{ft} .(7.5 \mathrm{~m})$ line, the voltage is substantialiy the same as at the box (Fig. 7c). However, at the end of the $100 \mathrm{ft}$. (30 m) line with a $50 \Omega$ termination, a significant decrease of the slope is noticeable, while the crest remains practically unchanged (Fig. 7d).

In Figures $7 \mathrm{e}-\mathrm{g}$, a VSP varistor has been added at the end of the $25 \mathrm{ft}(7.5 \mathrm{~m})$ line. Voltage and current at the varistor are shown in Figures $7 e$ and $7 f$, with a maximum voltage of $500 \mathrm{~V}$ for a 200 A surge. Meanwhile, the voltage at the box is limited to $750 \mathrm{~V}$, an appreciable reduction from the $1500 \mathrm{~V}$ that would exist without the remote
VSP under this surge condition (Fig. $7 \mathrm{~g}$ ).

\section{TRANSFER OF SURGES}

With the voltage limiting at the box provided by the installation of a VSP, even at a remote outlet (Fig. $7 \mathrm{~g}$ ), an HLP connected at the service box cannot reach its sparkover voltage until substantial surge currents are involved. For a short distance between the service box and the VSP, a larger current will be required than for a greater distance. The value of the current required to reach sparkover as a function of the distance is therefore of interest.

For a distance of $25 \mathrm{ft} .(7.5 \mathrm{~m})$, the threshold condition where sparkover of the HLP just occurs is depicted in Figure 8. In Figures $8 \mathrm{a}$ and $8 \mathrm{~b}$, the open-circuit voltage and short-circuit current are shown for this threshold setting of the generator. Inspection of the oscillograms shows an open-circuit voltage of $8.1 \mathrm{kV}$ and a shortcircuit current of $1.9 \mathrm{kA}$, hence a calculated source impedance of $4.2 \Omega$. * This low value of the source impedance (compared

* This is only a crude approximation since the current waveform does not match the voltage waveform. Therefore, the circuit impedance is not a pure resistance or characteristic impedance. 


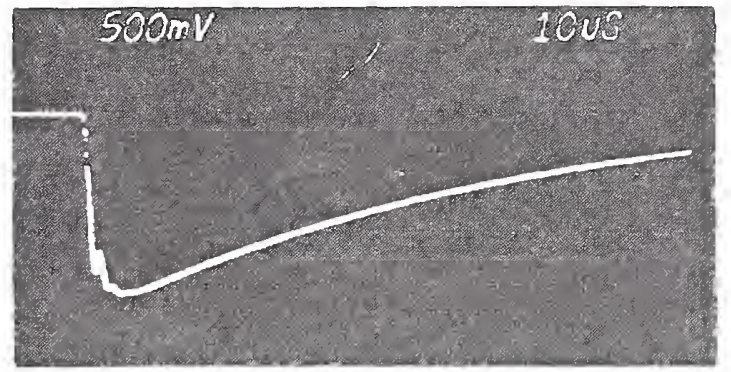

(a) open-circuit voltage - at box

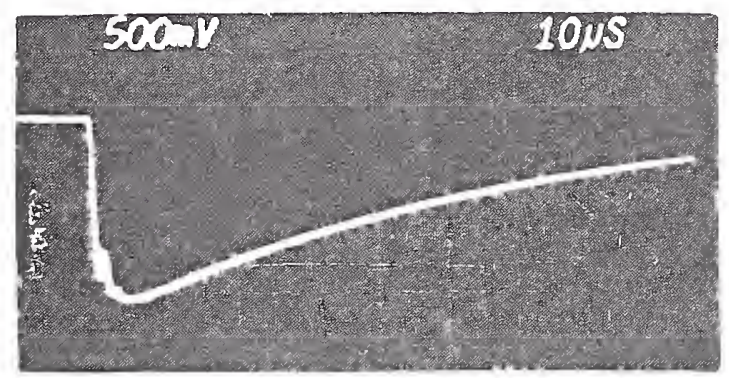

(c) open-circuit voltage - $25 \mathrm{ft} .(7.5 \mathrm{~m})$

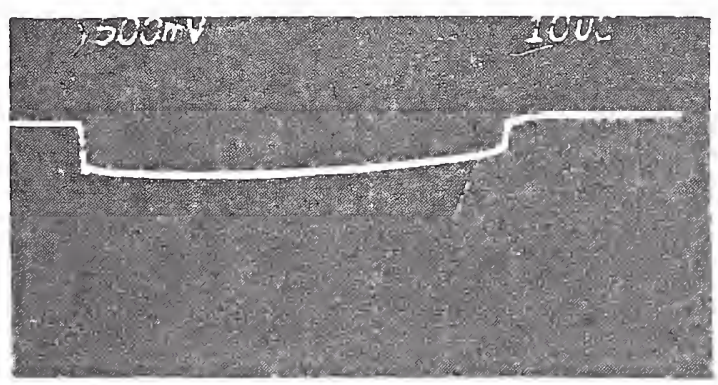

(e)

voltage at VSP - $25 \mathrm{ft} .(7.5 \mathrm{~m})$

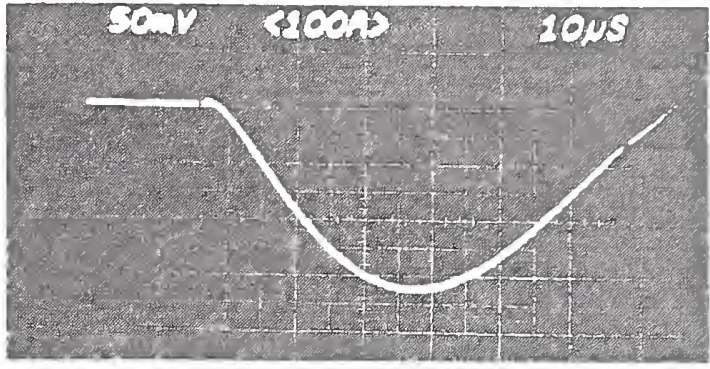

(b)

short-circuit current

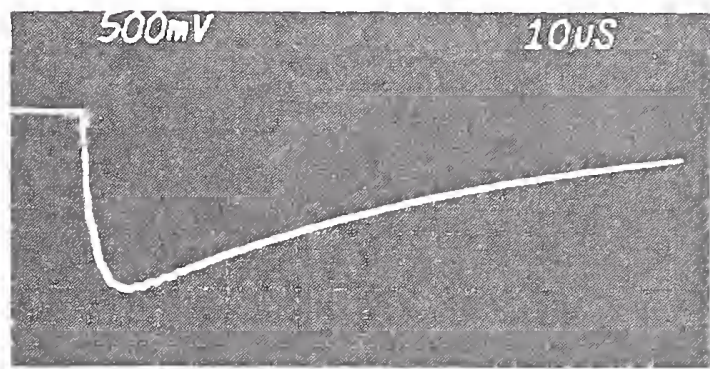

(d) open-circuit voltage - $100 \mathrm{ft} .(100 \mathrm{~m})$

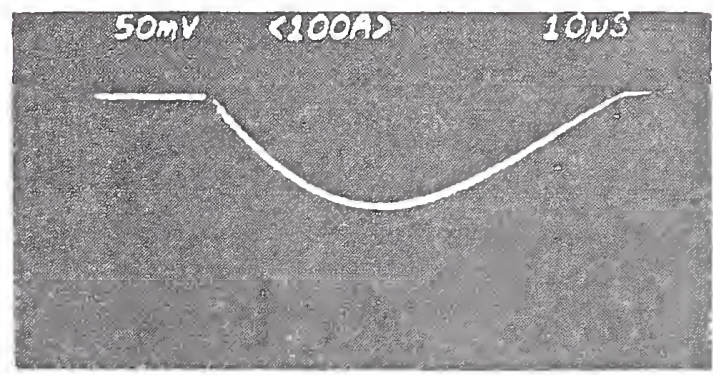

(f)

current in VSP - $25 \mathrm{ft} .(7.5 \mathrm{~m})$

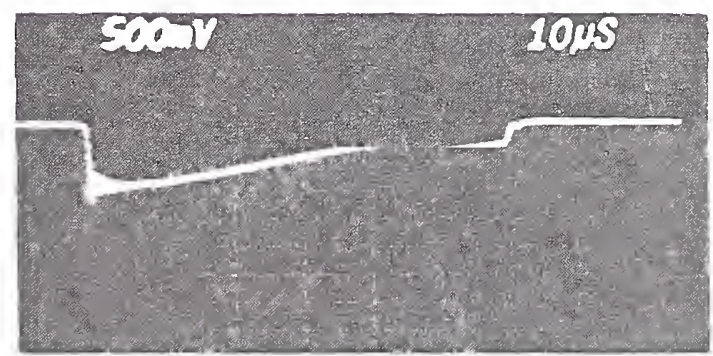

(g) voltage at box with VSP e $25 \mathrm{ft} .(7.5 \mathrm{~m})$

Figure?

Propagation of Surges 
to proposed values ${ }^{2},{ }^{3}$ ) provides a very conservative evaluation of the system performance. For the same setting as Figures $8 \mathrm{a}$ and $8 \mathrm{~b}$, the oscillograms of Figures $8 \mathrm{c}$ and $8 d$ show the case where the HLP has sparked over, as indicated by its voltage $(8 c)$ and current ( $8 d$ ) traces. In Figures $8 e$ and $8 f$, the traces show the voltage ( $8 e$ ) and current (8f) in the VSP for a case where the HLP did not spark over (due to the scatter of sparkover or a slight difference in the output of the surge generator). This case represents the most severe duty to which the VSP would be exposed, for a distance of $25 \mathrm{ft} .(7.5 \mathrm{~m})$, and in reality is already likely to be an actual lightning stroke on the power system, rather than just a "lightning remnant"

associated with a remote or indirect stroke. Figure $8 \mathrm{f}$ indicates a crest current of $1200 \mathrm{~A}$ in the varistor, which just exceeds the published surge rating of the varistor,

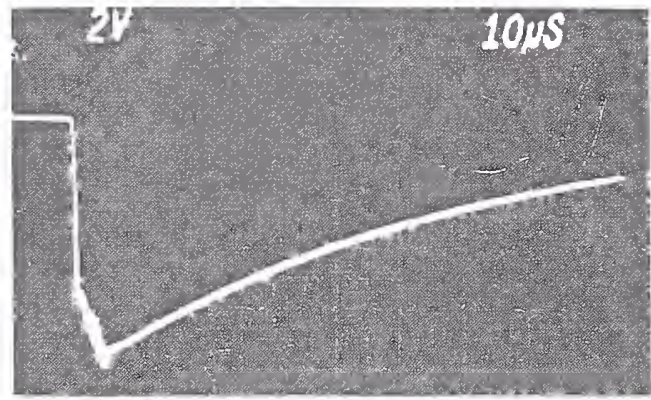

(a)

open-circuit voltage

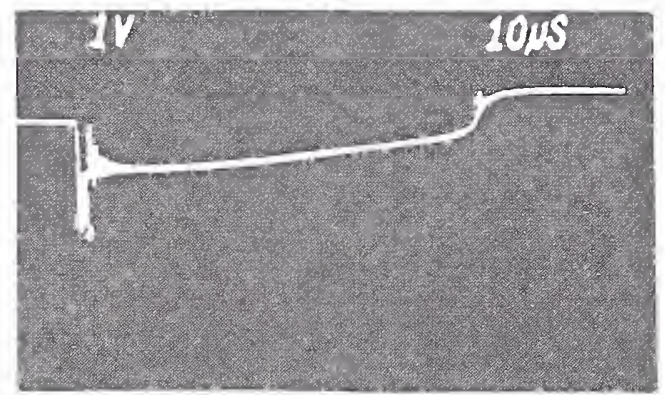

(c)

voltage at HLP when HLP does sparkover - VSP at $25 \mathrm{ft} .(7.5 \mathrm{~m})$

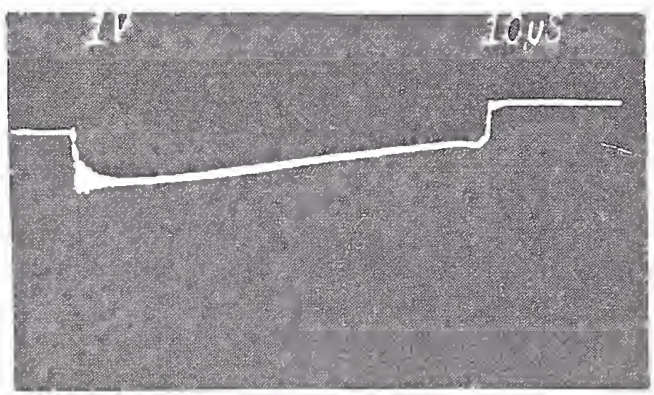

(e) voltage at VSP when HLP does not sparkover - VSP at $25 \mathrm{ft} .(7.5 \mathrm{~m})$ however, as an isolated occurrence, this current level has been found acceptable during laboratory tests. As stated above, this level of current would be reached only for direct strokes, and for a VSP connected fairly close to the service box. In a case where there would be no HLP installed at the box, but only the VSP installed at an outlet, the voltage rise in the wiring and the meter coils would most likely result in a flashover of the system, which would then divert the excessive energy away from the VSP, just as the HLP did in the test. Of course, this diversion may take place in an undesirable manner, which is precisely what the HLP is supposed to eliminate when installed. On the other hand, the sale literature for the VSP also specifically excludes direct lightning strokes from the protective ability of the VSP.

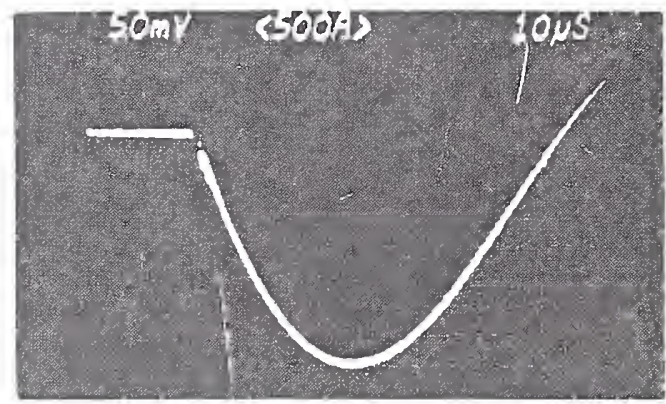

(b)

short-circuit current

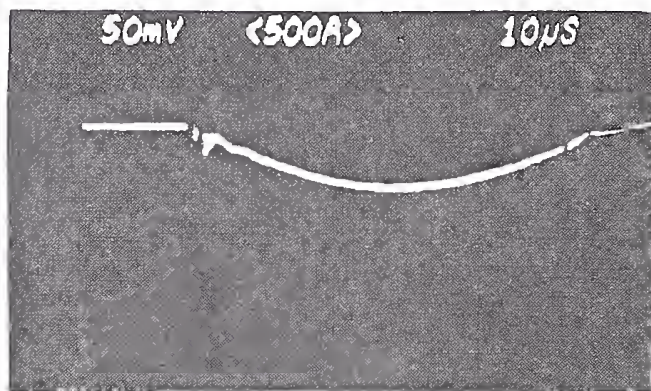

(2) current in HLP after sparkover VSP at $25 \mathrm{ft} .(7.5 \mathrm{~m})$

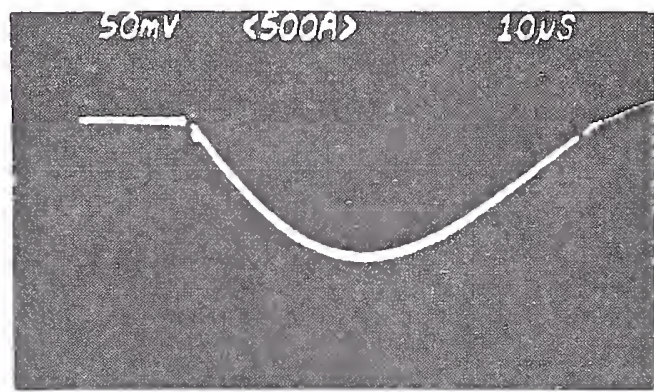

(f)

Figure 8

Transfer of Surge conduction 
For greater distances between the VSP and the service box, the surge transfer will occur at lower current. For instance, with $100 \mathrm{ft} .(30 \mathrm{~m})$, the oscillograms of Figure 9 document the transfer of the surge to the HLP at much lower current levels. Opencircuit voltage and short-circuit current are indicated in Figures $9 a$ and $9 b$ as previously. With the VSP at $25 \mathrm{ft}$, only the VSP carries the surge as indicated in

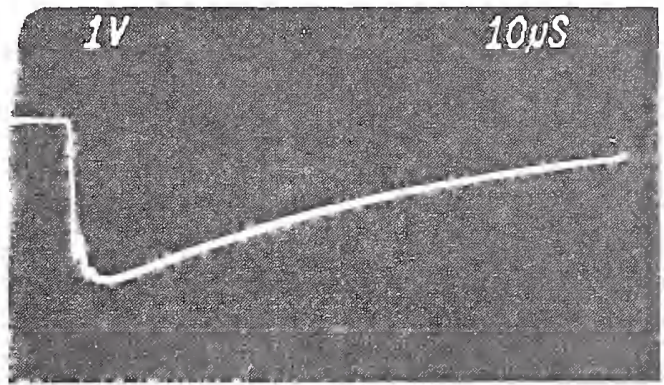

a)

open-circuit voltage

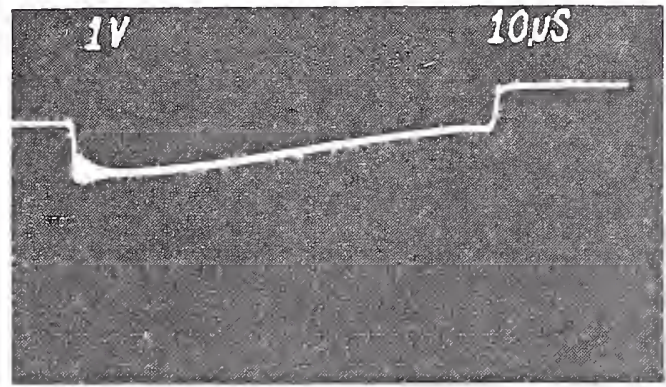

(6) VSP at $25 \mathrm{ft} .(7.5 \mathrm{~m})$ - Voltage of VSP

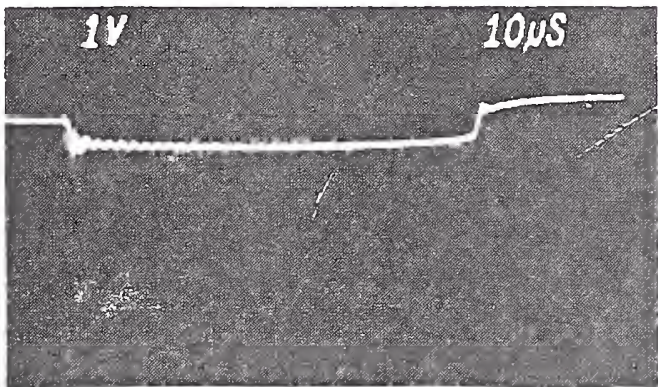

(e)

VSP at $100 \mathrm{ft} .(30 \mathrm{~m})$ - Voltage of VSP

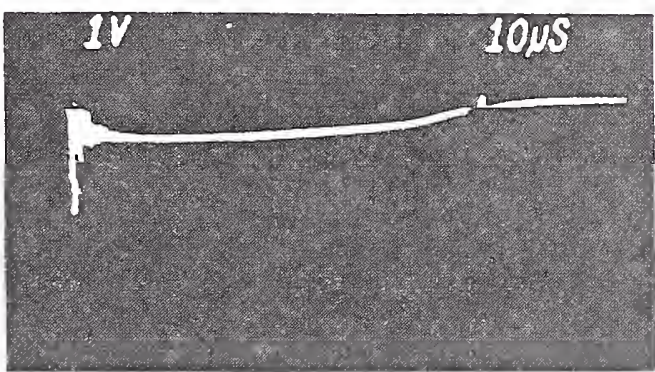

(g)
VSP at $100 \mathrm{ft} .(30 \mathrm{~m})$ - Voltage of $H L P$
Figures $9 \mathrm{c}$ and $9 \mathrm{~d}$. However, with the VSP removed $100 \mathrm{ft}$. ( $30 \mathrm{~m}$ ) away from the HLP, the latter takes over for this lower available current ( $700 \mathrm{~A}$ ) and relieves most of the surge from the VSP, as indicated in Figures $9 e$ through $9 \mathrm{~h}$. The current flowing in the VSP is now only $125 \mathrm{~A}$ (Fig. 9f) with 500 A flowing in the HLP (Fig. 9h). The corresponding voltage at the VSP and HLP are shown in Figures $9 \mathrm{e}$ and $9 \mathrm{~g}$.

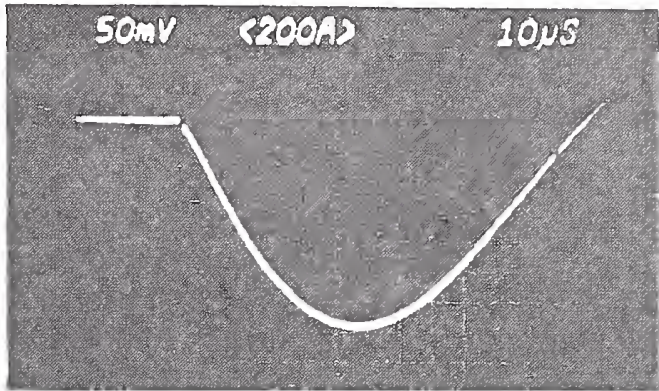

(b)

short-circuit current

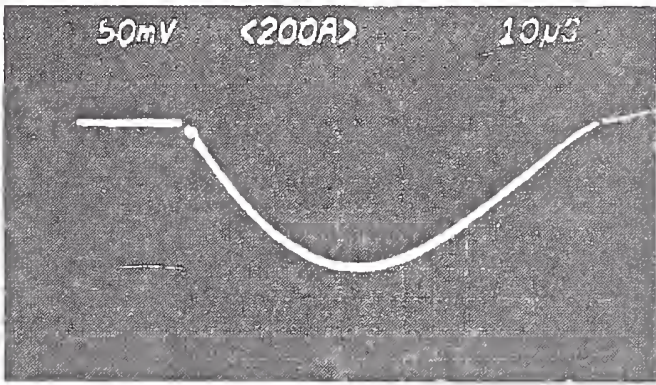

(d) VSP at $25 \mathrm{ft} .(7.5 \mathrm{~m})$ - Current in VSP

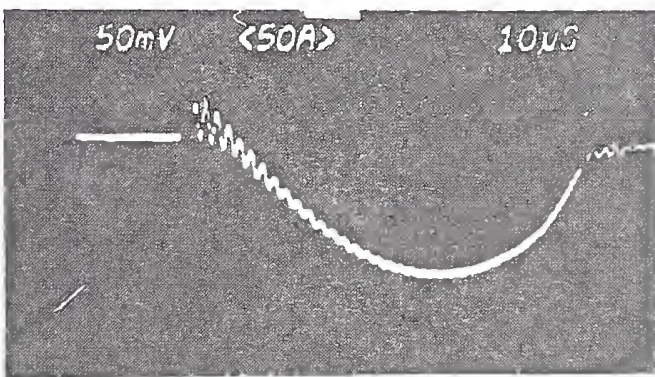

(f)

VSP at $100 \mathrm{ft} .(30 \mathrm{~m})$ - Current in VSP

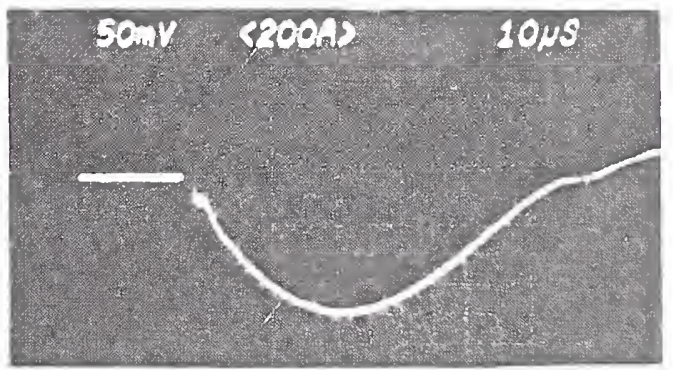

(h)

VSP at $100 \mathrm{ft.}(30 \mathrm{~m})$ - Current in HLP

Eigure 9

Transfer of Surges 
Further information is presented in Figure 10, with oscillagrams recorded at the same generator setting as in Figure 9. Figure $10 \mathrm{c}$ shows the voltage at the end of the $100 \mathrm{ft}$. ( $30 \mathrm{~m})$ line, between the line wire and the ground wire (not the ground reference, but the ground carried with the wire); likewise, Figure lob shows the voltage at the same point between the neutral wire and the ground wire, both oscillograms recorded with the HLP at the service box and the VSP at that line end. These volt- ages should be compared to the line-to-line (more precisely, line-to-neutral) voltage of only $500 \mathrm{~V}$ recorded for the same surge condition in Figure $9 \mathrm{e}$. To check that these voltages were not spurious recording, the oscillogram of Figure $10 \mathrm{c}$ was recorded with the probe tip connected to its ground connection, and both of these connected to the ground wire at the $100 \mathrm{ft}$. Iine end. The noise background there is insignificant compared to the recordings of Figures $10 \mathrm{a}$ and $10 \mathrm{~b}$.

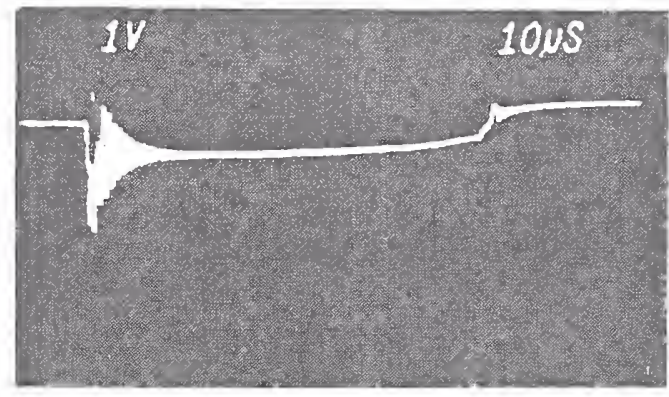

(a) Voltage between line (black) to ground (green) VSP connected hot.ioon. h7mal mat shita UTD at semice box.

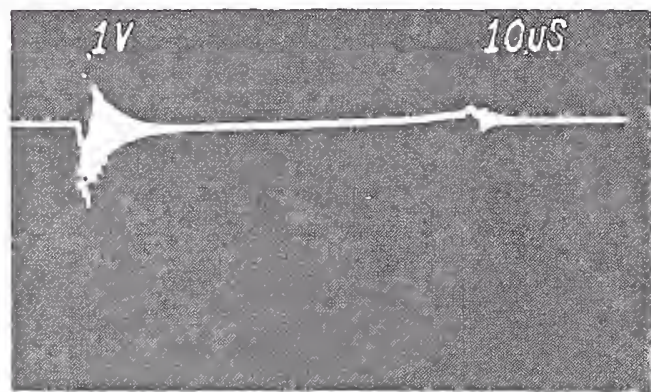

(b)
Voltage between neutral (white) to ground (green) VSP connected between black and white. HLP at service box

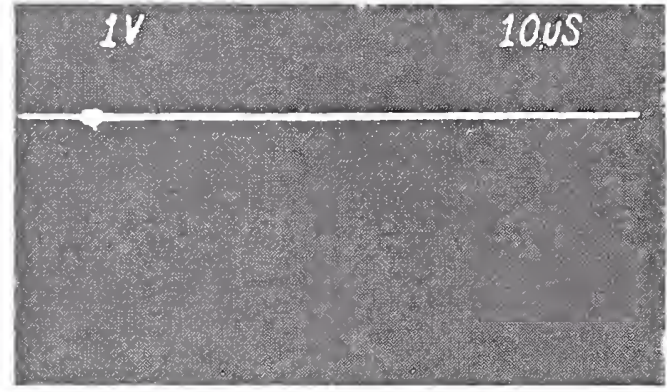

(c) Noise background check

Figure 10

Voltages between Conductors and Ground at End of $100 \mathrm{ft}$. $(30 \mathrm{~m})$ Line

\section{CONCLUSIONS}

The tests on simulated high energy surges indicate that a transfer occurs from the VSP to the HLP at some current level depending on the distance between the two devices.

Even for a short length of wire, the VSP is relieved from the surge by sparkover of the HLP before excessive energy can be deposited in the varistor of the VSP. At lower current levels where the voltage in the system is clamped by the VSP and thus prevents sparkover of the HLP, the VSP $a b-$ sorbs all of the surge energy.
In all instances, the voltage level at the VSP is held low enough to protect all electronic appliances having a reasonable tolerance level ( $600 \mathrm{~V}$ in most cases, $1000 \mathrm{~V}$ in extreme cases). Furthermore, the installatioli of only one VSP in the house already provides substantial protection for other outlets, although optimum protection requires the use of a VSP at the most sensitive appliance, with additional VSP's if further protection is required for other sensitive appliances. 
VII. REFERENCES

1. F.D. Martzloff and G.J. Hahn, "Surge Voltage in Residential and Industrial Power Circuits," IEEE PAS-89, July/ August 1970, pp. 1049-1056.

2. F.A. Fisher and F.D. Martzloff, "Transient Control Levels - A Proposal for Insulation Coordination in Low-Voltage Systems," IEEE PAS-95, January/February 1976 , pp. 120-129.

3. J.H. Bull, "Impedance of the Supply Malns at Radio Frequencies," Proceedings of the lst Symposium on EMC, Montreux, 1975. IEEE 75-CH1012, 4 MOIYT.

4. E.K. Howell and F.D. Martzloff, "High Voltage Impulse Testers," TIS

75CRD075, Corporate Research and Development, General Electric Company, Schenectady, NY, March 1975. 
APPENDIX I

Home Lightning Protector Specifications

HOME HGMTNANG POTECTOR

Mome Lighthing Propetior

D.12

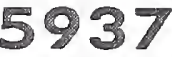

Page I

Lisfed by Underwriviers' Laboratories (UL)

Sept. 2, 1975

fiecrive Aug. B, 1975

\section{DESCIRTION}

The Home Lightning Protector is designed to prevent lightnisg surges (entering through the wising) from damaging electrical wiring and appliances. The Protector is a sturdy, weatherproof service-proven device that immediately drains lightring surges harmiessly to ground. Installed at either the weatherhead or service-entrance box, the Protector discharges a surge in a fraction of a second. It will perform this protective function over and over again, without any maistenance required, possessing the same long-life valve-type characteristics obtainable in higher-voltage distribution arresters.

The Protector is two-pole, three-wire device designed primarily for single-phase 120/240-volt three-wire grounded neutral service. It can also be applied to protect three-phase circuits where the line-to-ground 60 Hertz voltage does not exceed 175 volts. Connection diagrams are inciuded on the isside of each carton

\section{MHERE TO USE}

Farwers-whose livelihood depends on milking machines, incubators, coolers, submersible pumps, and other electrical eguipment.

Suburbantos-with considerable dependency on (and investment in) electrical appliances of all gorts.

Rural Homeowneps $\rightarrow$ often far from fire-fighting equipmest. and repair facilities.

Evoryomo-with electrical equipment exposed to the destructive lightring surges that can enter through directlyconnected overhead secondary power lines.

\section{*FEATURES}

The General Electric Home Lightning Protector

- can prevent costly appliance repair - can help provide uninterrupted electrical service

-1-year unit replacernent guarantee

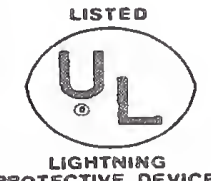

PRICES AND DATA

\begin{tabular}{|c|c|c|c|c|c|}
\hline \multicolumn{6}{|c|}{ Distributien Iransformer-Pros2 } \\
\hline $\begin{array}{l}\text { Circubi } \\
\text { Q aring } \\
\text { vollos }\end{array}$ & 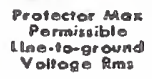 & $\begin{array}{l}\text { Prolector } \\
\text { Mad al No. }\end{array}$ & 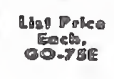 & $\begin{array}{c}\text { Nel Wr } \\
\text { Eoch } \\
\text { ln Oz. }\end{array}$ & $\begin{array}{l}\text { Sud } \\
\text { Poctoge }\end{array}$ \\
\hline $\begin{array}{l}120 / 240 \\
\text { Ground } \\
\text { Neutrol }\end{array}$ & 175 & $90150 C 8002$ & $+\$ 4.95$ & 6 & Unips \\
\hline
\end{tabular}

\section{PERFORMANCE CMARACTERHSTCS *}

\begin{tabular}{|c|c|c|c|c|}
\hline \multirow{2}{*}{$\begin{array}{l}\text { Propector } \\
\text { Rollne } \\
\text { IVols } \\
\text { Rrast }\end{array}$} & \multirow{2}{*}{ 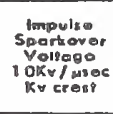 } & \multicolumn{3}{|c|}{ 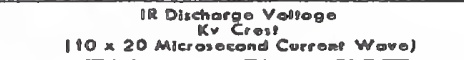 } \\
\hline & & $\begin{array}{l}A_{0} 0 \\
3_{A m p}\end{array}$ & $\begin{array}{c}A P \\
\text { SOOO } \\
\text { Amp }\end{array}$ & $\begin{array}{c}A^{A t} \\
\text { so, } 000 \\
\text { Amp }\end{array}$ \\
\hline $0-175$ & 2 & 1.० & 1.2 & 1.4 \\
\hline
\end{tabular}

- Average values.

* Changed since May 13, 8974 fssue.

PAA $700,701,702,711.714,721.723,731.737$

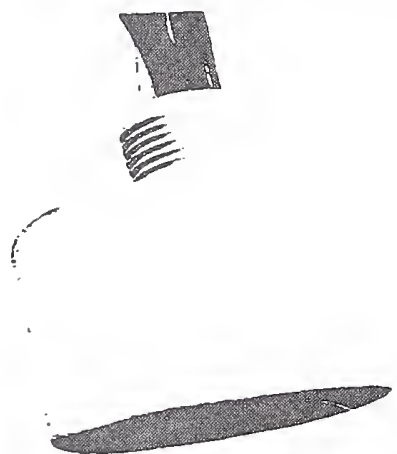

(Photo 1219173)

Fig. B. Mome Llghinling Prolotior. Hardworo (nol shown) is ineludod in corton ond delollod bolow.

Note -

Service protector moy be

with tountod elitar side up -

suspended by ifs

leods or mounted in

knockousts In load center or fuBe boxes.

All $\{21$ bock leads No.14 AWO

All
loda
ore $\{(2)$ block leads

linnsd (1) white lood No
copper
(ground)

(2) $0.18^{\text {"I }}$ hales

Ser note No. 4

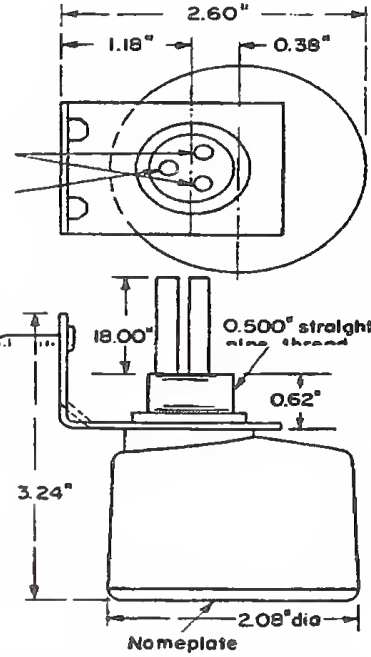

included with protector

I Aluminum mounling brocket.

2. Aluminum screw with

slatted hood.

3. Aluminum conduil locknus.

4. An oluminum noil t.inch long

mound the orrester.

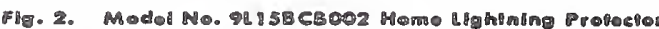

NOTE: Minimum order quantity is one (1) standard pacikage containing twenty-four (24) units. Orders will be accepted for shipment from factory stock in lots of one or more standard packarges only. Orders for less than standard package quantities
should be referred to local distributors.

PUSLEATRONS: (Use latert issue)

Deberiptive Bulletin..........GED-4835

Prices and data subject to change without natice 
APPENDIX II

Voltage spike Suppressor Product Information

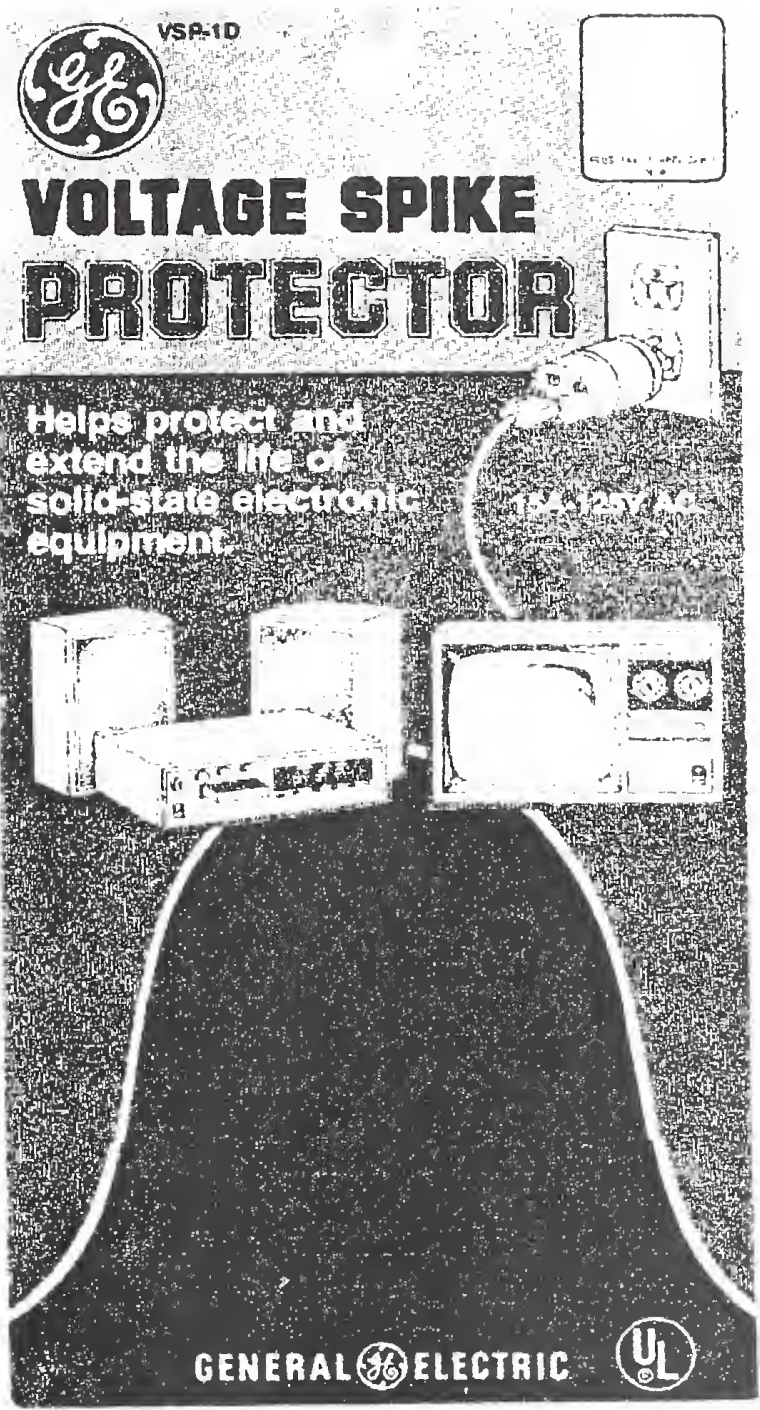

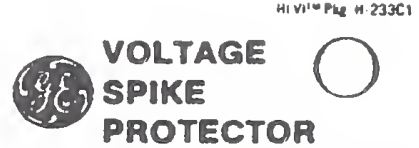

VOLTAGE SPIKES are bnet high vollage surges which may occur in any electrical system. They may arise from several sources, but in a home the two mosi

- switching OFF and ON appliances.

eir conditioners, or fumaces within the house.

- surges on the power lines to the house caused by lightning.

\section{MAJOR CAUSE OF ELECTROMIC EOUIPMENT FAILURE}

While sotid-state equipment is much more retiable than tubetype equipment, it is more susceptible lo voltage apike damage. Small apikes shorien the life of solid-state components while largo spikes - such as those which may occur during lightinting storms - can destroy them instantly.

\section{SIMPLE, RELIABLE PROTECTION}

Plug the Prolector into any $125 \mathrm{~V}$ AC receplacle. Plug equipment into the Protector. To protect more than one piece of - quipment, plug a multiple outlel adaplor into Protector.

The Voltage Spike Protector conteins a GE.Mov's varistor which absorbe dangeroue spikes but does not intertere with normal current flow. It la designed to prolect sensitive electronic equipment from voltaos spikes caused by the "swiching of loade" or Hehtning striking the power lines. Prolector will not protect againt those rare circumstances where lightning strikes the house, power service takeof. or antenna directly.

\section{VOLTAGE SPIKE PROTECTOR HELPS PROTECT}

\section{MOME}

APPLIANCEB

TV Sets

Radios

$\mathrm{H}_{1}$-Fi Equipment

Electronic Organs

Major Appliances

INDUSTRIALCOMMEACIAL -EQUIPMENT

Computer

Businoss Machines

industrial Controls

Test Equipment

Medical Equipment

Some TV manufecturers are incorporating GE-Movit varistors

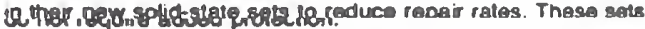

- Wiring Device Department

(C) GE General Electric Co., Prov., R. 1.02840 (f) GENERAL AT. ELETTIC

Cot. No. VSP.10 
16 


\title{
Lightning Protection of Residential AC Wiring
}

\author{
Keith E. Crouch \\ Lightning Technologies * \\ Pittsfield, MA
}

\author{
François D. Martzloff \\ General Electric Company \\ Schenectady NY \\ f.martzloff@ieee.org
}

Reprint, with permission, of declassified General Electric memo report MOR-78-095

\begin{abstract}
Significance:
Part 4 - Propagation and coupling of surges

Part 8 - Coordination of cascaded SPDs
\end{abstract}

Laboratory tests on the coupling of lightning current (flowing in the service drop grounded neutral conductor) onto the phase conductors, inducing overvoltages that were limited by candidate surge suppressors.

While the injected lightning-simulation current was unidirectional, the induced voltages in the house wiring circuits had oscillatory components. This observation was used in support of the development of the "Ring Wave" concept that was adopted by IEEE 587 (now C62.41).

Three possible types of service entrance SPD of 1960-1970 vintage were investigated

- The then-commercially available silicon carbide/gap arrester

- Metal oxide varistors mounted external to the load center

- Metal oxide varistors fitted in a panel breaker housing for easy plug-in connection

The branch circuit SPD consisted of a simple MOV disc incorporated in a modified plug-and-receptacle combination, probably the first attempt at packaging an MOV for residential surge protection.

\footnotetext{
* The expenimental work, reported by F.D. Martzloff, involved performing the tests, recording of nearly 300 Polaroid oscillograms, and was conducted by K.E. Crouch at the General Electric High Voltage Laboratory prior to his change to Lightning Technologies, Inc.
} 
Q 


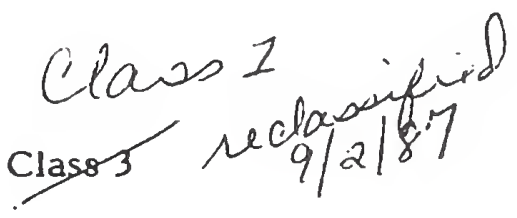

\title{
LIGHTNING PROTECTION OF RESIDENTIAL AC WIRING
}

\author{
K.E. Crouch* and F.D. Martzloff
}

Automation and Control Laboratory

\begin{abstract}
New transient suppressors using metal oxide varistors offer improved protection of appliances and consumer electronics against overvoltages. This improvement, however, could be at the risk of imposing excessive duty on the suppressor in case of a very severe lightning stroke near the house where these suppressors are installed.

A simulated house wiring system was subjected to three levels of lightning currents injected into the ground wires (moderate, severe, extremely severe), with various combinations of suppressors installed alone or in a coordinated combination.

Test results show that an effective and safe combination of devices can be specified for full protection of the loads in the house.
\end{abstract}

*Lightning Technologies, Inc., Pittsfield, Massachusetts

\section{GEHEAAL GS ELETRIC}

\section{G}

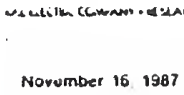

Buldug K.1, Room 2 A 16

DrFD Martioll

Rooin B162, Building 220

National turoau of Siandurds

Gulihersbury. PAD 20059

Dear Di. Marketell

Allocined are copies ol tecnnical milormation series rapons that you requesied liom Dr. Bornstern Several other reponts that woro roquested by you have not boon seclassified to Cluss 1 , and thereloro. may not oo releasus.

If you have eny questions of al I cail he w lurtier bssistanca. pluasu do not he silate to contact me

sincervily.

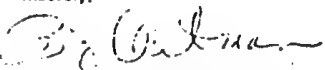

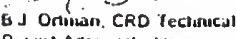

Repuli Adilumisliator

Altuchonutus

\section{CLASS 3 - LIMITED AVAILABILITY INFORMATION}

Original distribution to those individuals with specific need for information.

Subsequent Company availability requires originating component approval.

Disclosure outside General Electric Company requires approval of originating component.

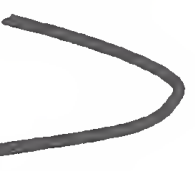

July 1978 
20 
TABLE OF CONTENTS

Page

INTRODUCTION

OVERVIEW 3

1.0 ASSUMPTIONS

1.1 Current Magnitudes 3

1.2 Waveshape 5

1.3 Lightning Current Path 5

1.4 Induced Voltages 5

2.0 TEST CIRCUIT AND TEST PROCEDURE 6

2.1 Power Circuits $\quad 6$

2.2 Instrumentation 7

2.3 Candidate Suppressors 8

2.4 Test Procedure 9

$\begin{array}{lll}3.0 & \text { TEST RESULTS AND DISCUSSION } & 12\end{array}$

3.1 Test Results 12

Distribution Transformer Arrangement 14

Effect of Terminal Impedance 16

Effect of Branch Terminations 18

Load Center Protectors 20

Duty on Outlet Protectors 22

Comparison of Inboard/Outboard Protectors 24

Effect of Lead Length 26

Effect of Wiring Sparkover 28

3.2 Discussion of the Results 30

3.3 A Coordinated Protection Scheme 33

REFERENCES 34

$\begin{array}{ll}\text { TABLE } 1 & 32\end{array}$

FIGURES $1-17$

$\begin{array}{ll}\text { APPENDIX } & 35\end{array}$ 


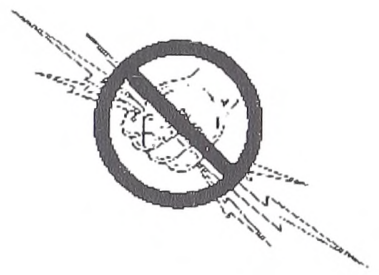




\title{
LIGHTNING PROTECTION OF RESIDENTIAL AC WIRING
}

\author{
K.E. Crouch* and F.D. Martzloff
}

\section{INTRODUCTION}

The development of metal oxide varistors has opened new oppo:tunities for transient suppression in residential power circuits. The Wiring Device Department of the General Electric Company has introduced the VSP-1 protector, which contains a $14 \mathrm{~mm}$ GE-MOV varistor. The HLP (Home Lightning Protector) has been available for many years, but the hot-line work required for its installation has been a deterrent; and, consequently, this protector has not been very widely applied. The new $32 \mathrm{~mm}$ GE-MOV ${ }^{\oplus}$ varistor of fers higher capacity than the 14 and $20 \mathrm{~mm}$ discs. Prior to reassignment of the product scope to the Distribution Transformer Department and later the Circuit Protective Devices Department, tests made in Pittsfield by J.S. Kresge had demonstrated that this $32 \mathrm{~mm}$ disc could meet the ANSI secondary requirements. By different packaging, the hot-line work might be eliminated and performance improved, opening the opportunity for greater acceptance.

Therefore, the possibility of a coordinated protection system in residential power circuits meeting ANSI requirements became a more likely prospect than an earlier investigation had predicted for coordination between the present design of the HLP and the VSP-1. ${ }^{(1)}$ While there is little evidence that extremely high currents caused by lightning strokes enter far into the house wiring, it seemed worthy of investigation to postulate a condition of "severe" lightning discharge near the house and to attempt recording on a simplified model wiring system how the currents and voltages would be distributed. This report describes the assumptions, test procedures, results, and conclusions of such an investigation.

\footnotetext{
*Lightning Technologies, Inc., Pittsfield, Mass.

- Registered trademark of the General Electric Company
} 


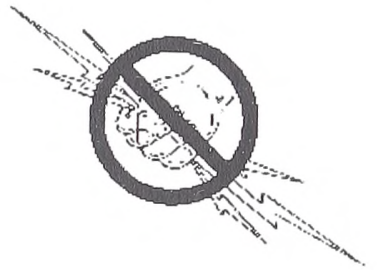




\section{OVERVIEW}

The injection of a high current - presumably a lightning discharge - in to the ground conductor of the service drop, without direct injection into the phase wires, is sufficient to induce voltage in excess of the clearance withstand of wiring devices. The transmission characteristics of the model and the relative sparkover levels were such that internal devices (receptacles) flashed over before the watt-hour meter gaps could flash over.

Coordination between a centrally located surge arrester and an outlet-connected protector is possible; substantial, but within rating, currents flow in the outlet protector (VSP-1) when coordinated with a Home Lightning Protector (silicon carbide and gap) or its candidate successor, the $32 \mathrm{~mm} \mathrm{GE-MOV}{ }^{\circledR}$ varistor.

For extreme strokes ( $100 \mathrm{kA}$ at the pole), current in excess of rating can flow in VSP- 1 protectors located close to the service entrance without other arresters. While they could fail there, the protectors do not present a greater hazard than an air clearance, which would flash over were there no protector; and, in fact, the presence of the VSP-I is more likely to reduce the hazard of a flashover with subsequent $60 \mathrm{~Hz}$ power-follow.

The addition of a $32 \mathrm{~mm}$ varistor to the system, either in a plug-in (inboard) version or as an external addition (outboard) to the load center, will provide protection consistent with the ANSI requirements for secondary arresters.

\subsection{ASSUMPTIONS}

\subsection{Current Magnitudes}

It was postulated that a lightning stroke attaching to the primary side of an overhead distribution system would produce a branching of the current flow into the ground, following sparkover of the surge arrester, which was presumed connected at the polemounted distribution transformer. Figure 1 shows the assumed circuit and the division of current flow. 


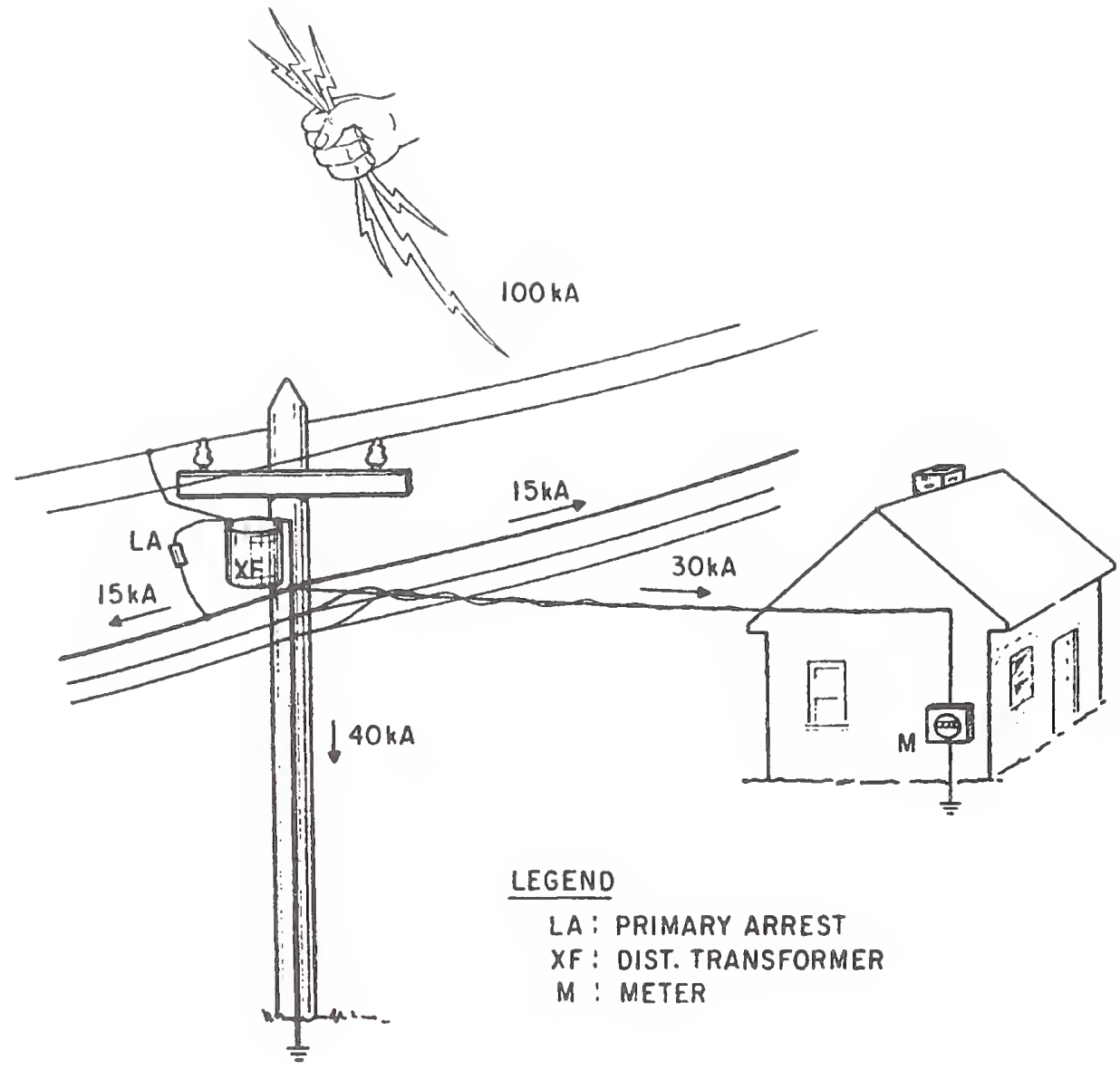

Figure 1. Division of Current Assumed for a $100 \mathrm{kA}$ Stroke

In their study of lightning environments, Cianos and Pierce ${ }^{(2)}$ indicate that only $5 \%$ of all ground strokes exceed a peak current of $100 \mathrm{kA}$. The frequency of the strokes is quite dependent upon geographic location (isokeraunic levels), ${ }^{(3)}$ as well as upon local configurations. An average expectation of a stroke involving the utility pole near a house with no adjacent tall trees or buildings may be in the order of one per 400 years for most of the U.S. Thus, for a $5 \%$ probability, the likelihood is one stroke in excess of $100 \mathrm{kA}$ per 8,000 years. With nearby tall objects, this likelihood can be reduced 10 times; in areas of high lightning activities, this likelihood can be increased 10 times. The level of $100 \mathrm{kA}$, then, represents an expectation of being exceeded at one location only one time in perhaps 10,000 years (but there are millions of poles in the U.S.).

From these assessments, the maximum current to be injected for the house model under discussion was selected to be $30 \mathrm{kA}$. From this maximum of $30 \mathrm{kA}$ injected into the ground wire of the house service drop, two more values were used during the test 
series: $10 \mathrm{kA}$, corresponding to the requirement for the ANSI high-current, short-duration test; and $1.5 \mathrm{kA}$, corresponding to the requirement for the ANSI duty-cycle test - both specified by ANSI Standard C 62.1 for secondary valve arresters. (4)

Another reason for selecting this low level $(1.5 \mathrm{kA})$ is that no sparkover occurs in the wiring at this level. For the 10 and $30 \mathrm{kA}$ levels, multiple flashovers would occur at variable times and locations, making exact duplication of tests impossible. By staying below sparkover levels, repeatability of the results was ensured, allowing comparisons among several alternate circuit configurations.

\subsection{Waveshape}

From ANSI Standard C 62.1, a waveshape of $8 \times 20$ us would have been desirable. However, limitations in the test circuit required for driving $30 \mathrm{kA}$ in the model loop forced a compromise of $10 \times 25 \mu$ as the test wave.

\subsection{Lightning Current Path}

It should be noted that, in this test series, the assumption was made that the lightning current, applied first to the distribution primary (the highest wire on the pole) is transferred to the ground system by sparkover of an assumed surge arrester on the primary at the pole. In fact, if there were no arrester, an equivalent effect by direct flashover could be expected.

For the secondary side, however, the assumption was made that both sides (phases) of the center-tapped (grounded) secondary remained uninvolved in conducting the direct lightning current, while the ground wire (messenger) from pole to house carried its share, as defined in Figure 1.

\subsection{Induced Voltages}

The generation of transient voltages in the house is attributed to electromagnetic coupling of the field established by the lightning current flowing in the messenger into the loop formed by the two phase wires encircling the messenger. In addition, there is some capacitive coupling between the wires (Figure 2). 


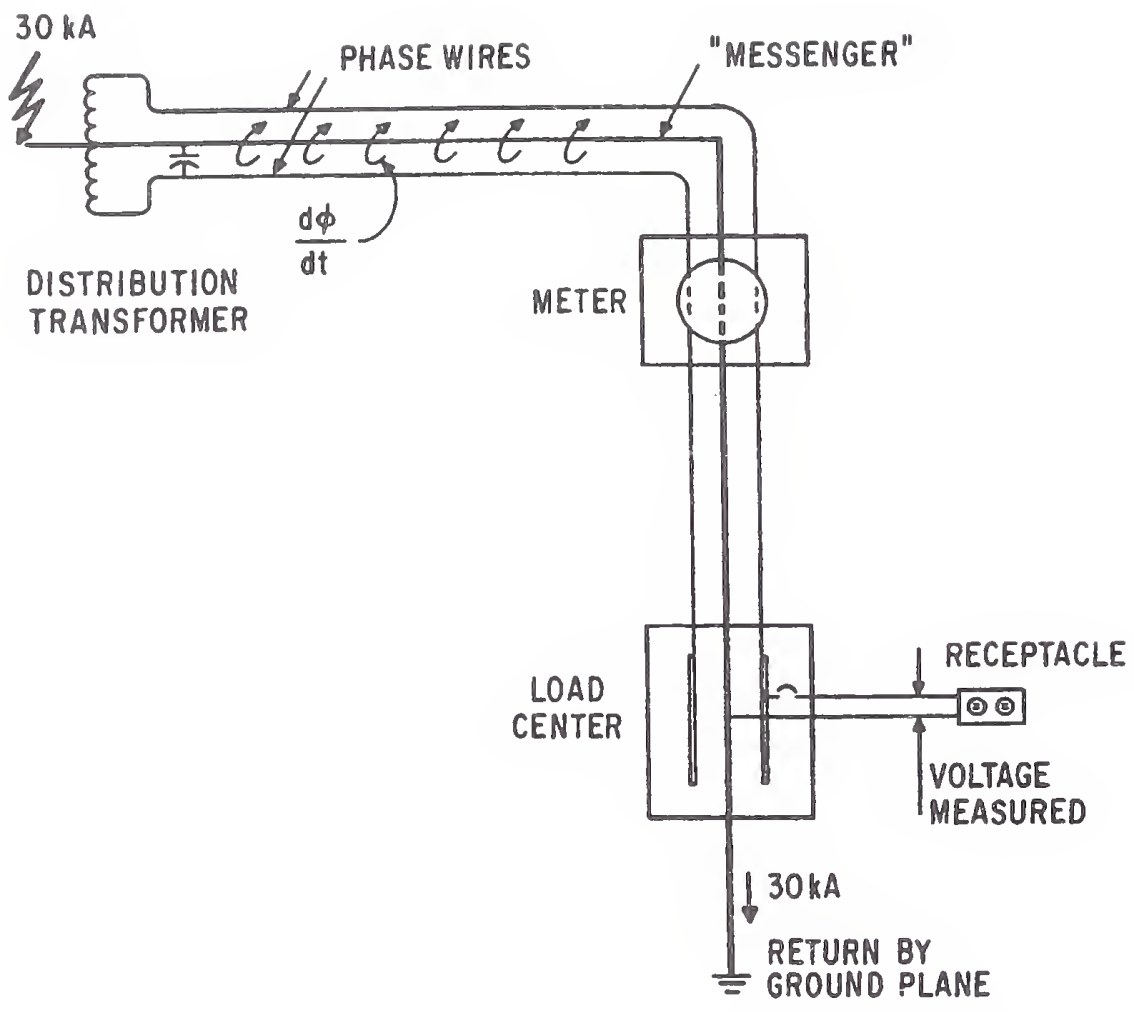

Figure 2. Voltages lnduced in the House Wiring Systems

\subsection{TEST CIRCUIT AND TEST PROCEDURE}

\subsection{Power Circuits}

The test circuit consisted of a high-current impulse generator, a distribution transformer with service drop, a simulated simplified house wiring system, and the necessary shielded instrumentation (Figure 3). Details of the catalog numbers, characteristics, etc., are given in the Appendix.

The service drop connection between the distribution transformer and the meter socket was made with three AWG 非 6 wires, twisted at a pitch of about 5 turns $/ \mathrm{m}(1.5$ turns/ft), $13 \mathrm{~m}$ (45 ft) long. This service drop was folded in a loose "S" shape, at about $0.5 \mathrm{~m}(1.5 \mathrm{ft})$ above the ground plane serving as the return path for the lightning current, in order to reduce the loop inductance seen by the generator. This configuration does not influence the coupling between the messenger and the wires wrapped around it, coupling which has been identified as the voltage-inducing mechanism. 


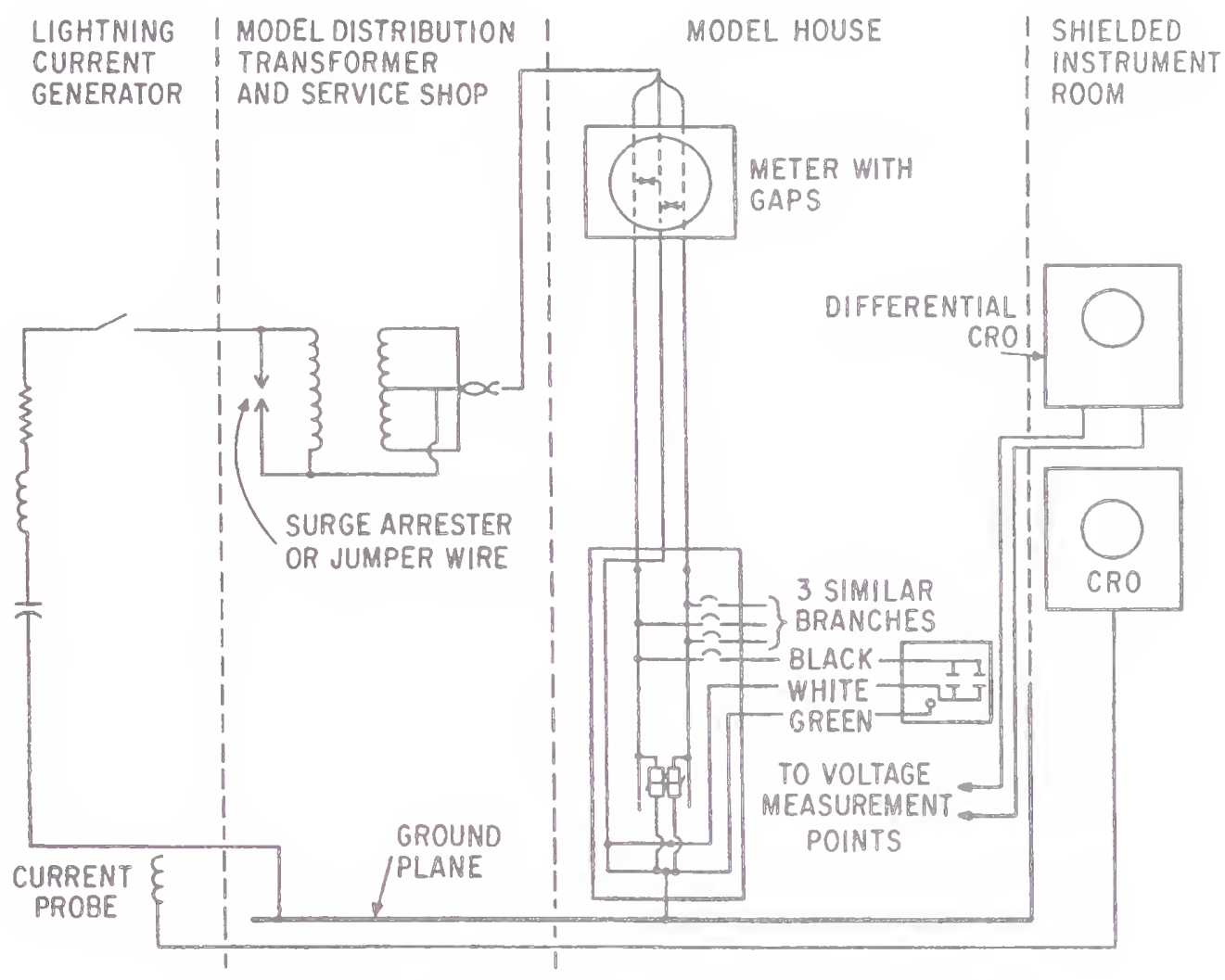

Figure 3. Schematic Representation of Test Circuit

The simulated house wiring started at the meter socket and continued to a load center by a $3 \mathrm{~m}$ (10 ft) length of AWG \#6 aluminum entrance cable. The meter socket, watt-hour meter, and load center were typical General Electric Company hardware (see Appendix), except as noted in the detailed procedure description. From this load center, four "branch circuits" connected to the load center breakers were established, each terminating at a wall receptable mounted on the same 1.2 by $2.4 \mathrm{~m}$ ( 4 by $8 \mathrm{ft}$ ) plywood panel on which the watt-hour meter and load center were also mounted. The branch circuits' lengths were (one each) $6,12,24$, and $48 \mathrm{~m}(20,40,80$, and $160 \mathrm{ft}$ ), the wire being loosely coiled between the load center and receptacles (Figure 4).

\subsection{Instrumentation}

Recordings of currents and voltages were made at several points on the wiring system with cathode ray oscilloscopes (CRO); differential measurements were made for the voltages with especially built 100:1 probes. These probes were built by placing a $5000 \Omega$ resistor in series with a terminated $50 \Omega$ coaxial cable - all of these contained 


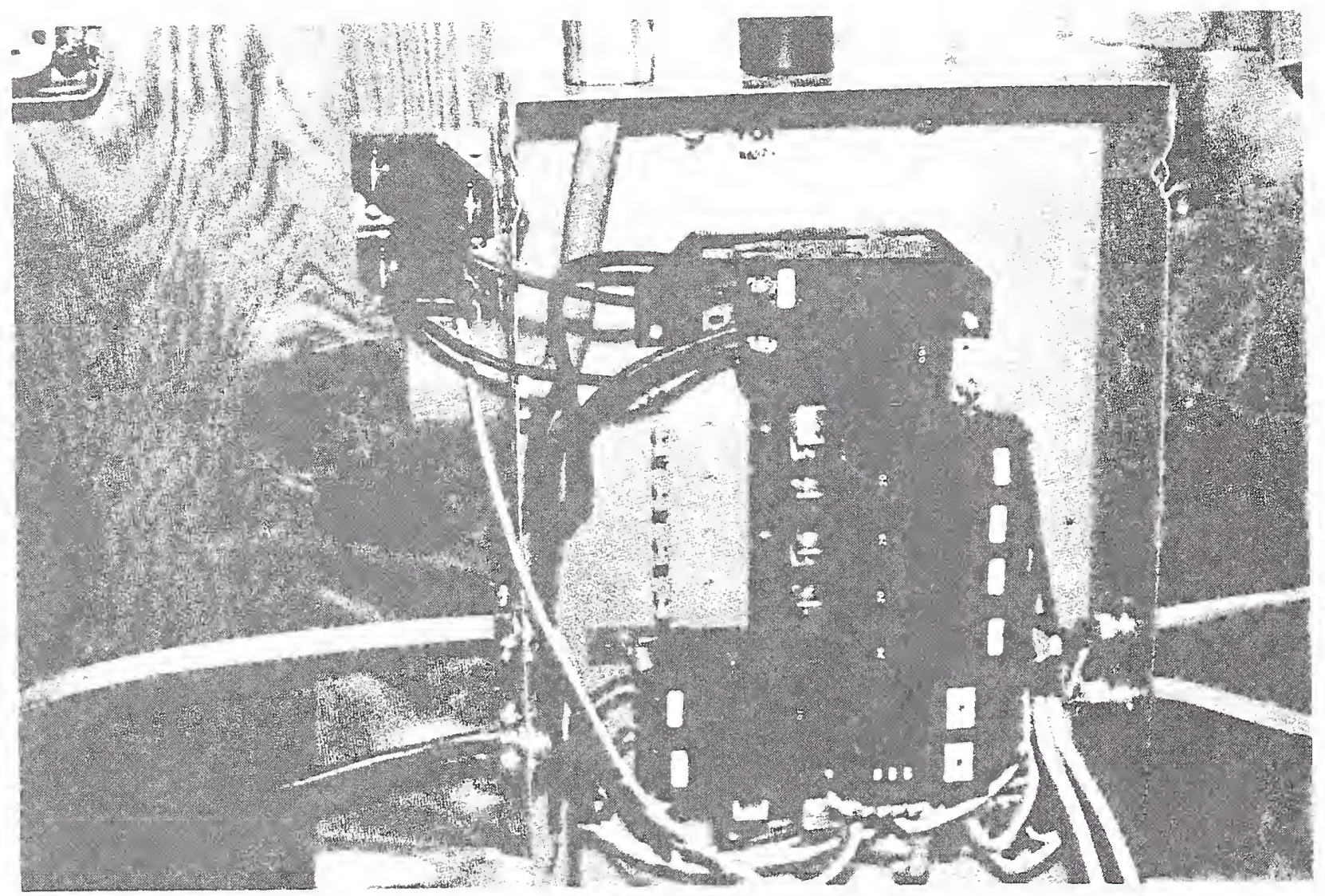

Figure 4. Connections at Load Center

in a shield tied to the ground plane part of the shielded instrument room. Currents flowing in the suppressors were measured by means of a Pearson Model $110 \mathrm{~A}$ wide-frequencyband current transformer. The oscilloscopes were located inside the shielded control room adjacent to the test area, providing satisfactory protection against spurious signals (see Figure 6 in Section 2.4).

\subsection{Candidate Suppressors}

Four candidate suppressors were installed at various locations in the system, for various comparisons of performance:

1. One Home Lightning Protector (HLP, GE Cat. 9L15DC B002) was installed at the load center; when connected to the circuit, the connection was at 
the incoming lugs of the load center, as it would normally be when connected by an electrician.

2. Two V250HE80 varistors were mounted near the load center and connected to the incoming lugs of the load center. This connection required about $45 \mathrm{~cm}$ (18 in) of 非10 copper wire. The return to ground was common to the two discs, as it is for the HLP device.

(The varistor package contains a $32 \mathrm{~mm}$ disc with characteristics suitable for secondary arrester duty. ${ }^{(4)}$ It is the candidate metal-oxide varistor substitute for, or successor of, the Thyrite ${ }^{\circ}$ gap combination currently used in the HLP, and has an RMS voltage of $250 \mathrm{~V}$.)

3. Two $32 \mathrm{~mm}$ varistor discs of the same characteristics as (2) (above) were installed by the Circuit Protective Device Department in a breaker housing so that they could be connected to the load center bus with a minimum of lead ( $10 \mathrm{~cm}$, or $4 \mathrm{in})$. This connection can be made while the load center is energized without requiring "hot work," in the same manner as inserting additional breakers on the load center.

4. VSP-1 spike protectors, produced by the Wiring Device Department, were inserted in the receptacle at the end of the branch circuits. (The VSP-1 protector contains a $14 \mathrm{~mm} \mathrm{GE-MOV}{ }^{\bullet}$ varistor with a voltage rating of 170 V RMS. ${ }^{(5)}$

5. In addition, the meter contained its standard gaps rated for a $10 \mathrm{kV}$ sparkover.

\subsection{Test Procedure}

Preliminary tests indicated that flashover at the receptacles would occur with $10 \mathrm{kA}$ injected into the ground messenger, but no sparkover of the meter gaps was apparent. Therefore, a first test series was conducted at only $1.5 \mathrm{kA}$ in order to provide consistent patterns of wave propagation undisturbed by flashover (Figure 5).

It was also found that the auxiliary impulse generator used to trigger the main gap of the high-current generator induced voltages into the test circuit that could exceed those induced by the main discharge. A mechanical switch for closing the circuits was then substituted for the triggered gap.

Registered trademark of the General Electric Company for molded composite dielectric material 


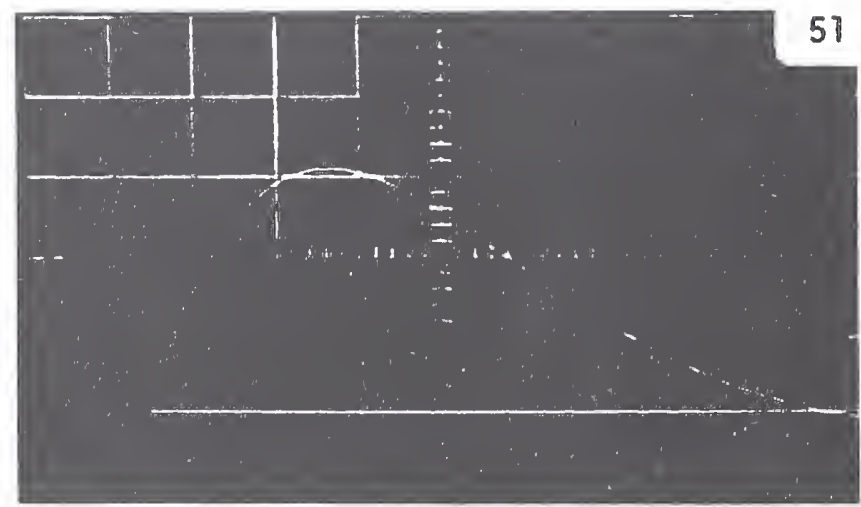

$$
\begin{aligned}
& \text { VERTICAL }-500 \mathrm{~A} / \mathrm{div} \\
& \text { HORIZONTAL }-5 \mu \mathrm{s} / \mathrm{div}
\end{aligned}
$$

Figure 5. Applied Current Waveshape $-1.5 \mathrm{kA}$ Crest, $10 \times 25 \mathrm{\mu s}$

Noise checks were made for the voltage measurement system by shorting the probes together and attaching them to the neutral point on the circuit under test. Similarly, the center conductor of the cable to the current transformer was removed from the transformer output and connected to its sheath. No significant voltages (greater than 5\% of measured signal) were measured. A typical noise check oscillogram is shown in Figure 6.

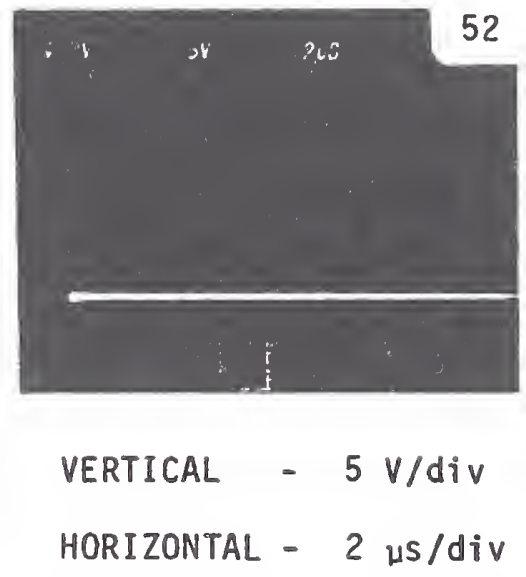

Figure 6. Typical Noise Response of Measurement System with $1.5 \mathrm{kA}$ Injection 
Since the worst case (little attenuation) is expected when there is little load connected to the system, most test measurements were made without loads at tached to the outlets in the simulation. Measurements were also made with typical house loads connected to the outlets. These loads were a $100 \mathrm{~W}$ light bulb, which was represented by a $130 \Omega$ resistor, a $1 / 2 \mathrm{hp}$ single-phase induction appliance motor, and the input stage of a television circuit, as shown in Figure 7.

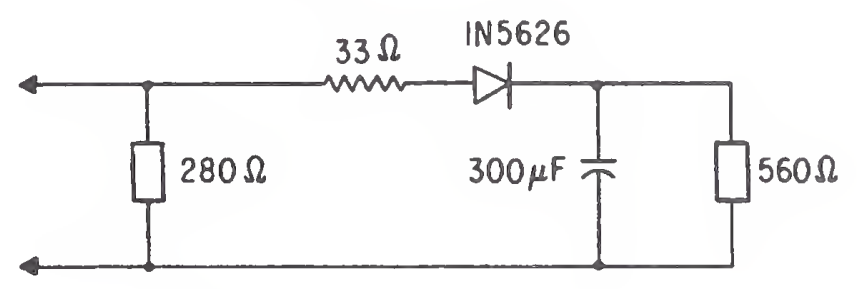

Figure 7. Television Input Stage

Various combinations of loads and suppressors at various locations were investigated. The specific test conditions are described for each particular test in Section 3, which presents the results and discussions of the tests. 


\subsection{TEST RESULTS AND DISCUSSION}

\subsection{Test Results}

A large number of tests were performed to investigate the effects of various com binations. From several hundred recorded oscillograms, a selection was made, as shown in this section, to illustrate these effects. The results are presented in the form of a matrix of oscillograms with corresponding commentary, generally providing a comparison of voltage and currents with or without protectors installed. First, a qualitative summary is presented, then some comparative oscillograms are shown to illustrate various effects.

Figure 8 gives a qualitative summary of the effects obtained by installing a single protector at various locations in the system. The oscillograms are arranged in horizontal rows corresponding to the circuit configuration indicated in the legend. The vertical columns correspond to the location at which the oscillograms were recorded. From left to right appear Lines 1 and 2 of the load center, and the ends of the branch circuits at $6,12,24$, and $48 \mathrm{~m}(20,40,80$, and $160 \mathrm{ft})$, which will be referred to as $B 20, B 40, B 80$, and B160. Quantitative information will be given in subsequent figures.

In the first row, open-circuit voltages are shown. Note that the voltages at three locations of the Line 1 conductor are very similar, while there is a small difference between Line 1 and Line 2.

The installation of a protector in Line 1 of the load center (second row of oscillograms) clamps the voltage on all Line $\downarrow$ points, with some oscillations induced at the end of the B 160 branch. While the initial peak of the Line 2 points is not changed, subsequent oscillations have lower frequency than in the open-circuit mode. For the oscillograms corresponding to the location where a protector is installed, the upper trace shows the current flowing in the protectors.

The installation of a protector in Line 2 of the load center (third row) produces results analogous to the Line 1 case. Installation of a protector at the end of a branch rather than at the load center (last four rows) produces clamping of the voltage at the point of installation. At the other points of the same line, the effectiveness of the clamping decreases as the protector is farther away. For the line with no protector, there is a minor voltage reduction and a frequency change similar to that noted in the first two rows. 
Power Lood Center

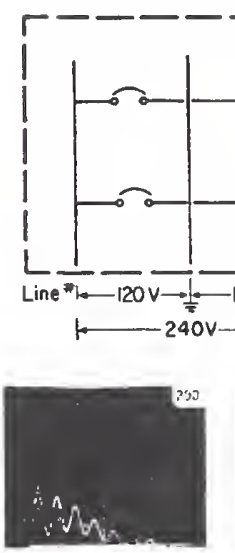

A VSP-I in

Line "I only

Open Circuit Voltoge No Protectors Installed

Line 1 only

A VSP-I in Lood Center Line \#2 only

A VSP-I In the $20 \mathrm{f1}$. Broneh

Cireuit Outlet only
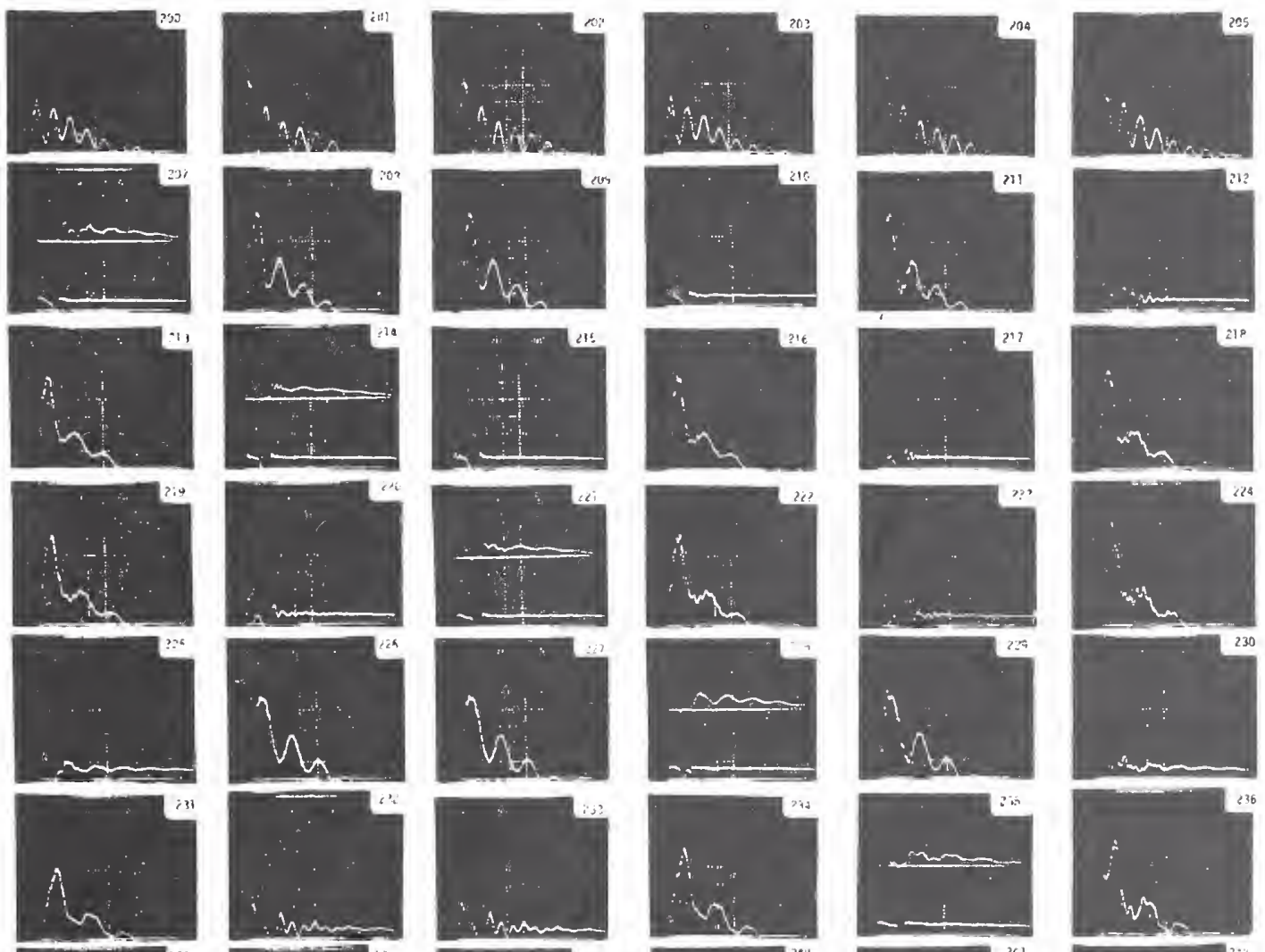

A VSP-1 in the

A VSP-I in the

$80 \mathrm{ff}$. Branch
Circuit Ouflel only

A VSP-I in the

$160 \mathrm{f1}$. Branch

Cireuli Outlet only
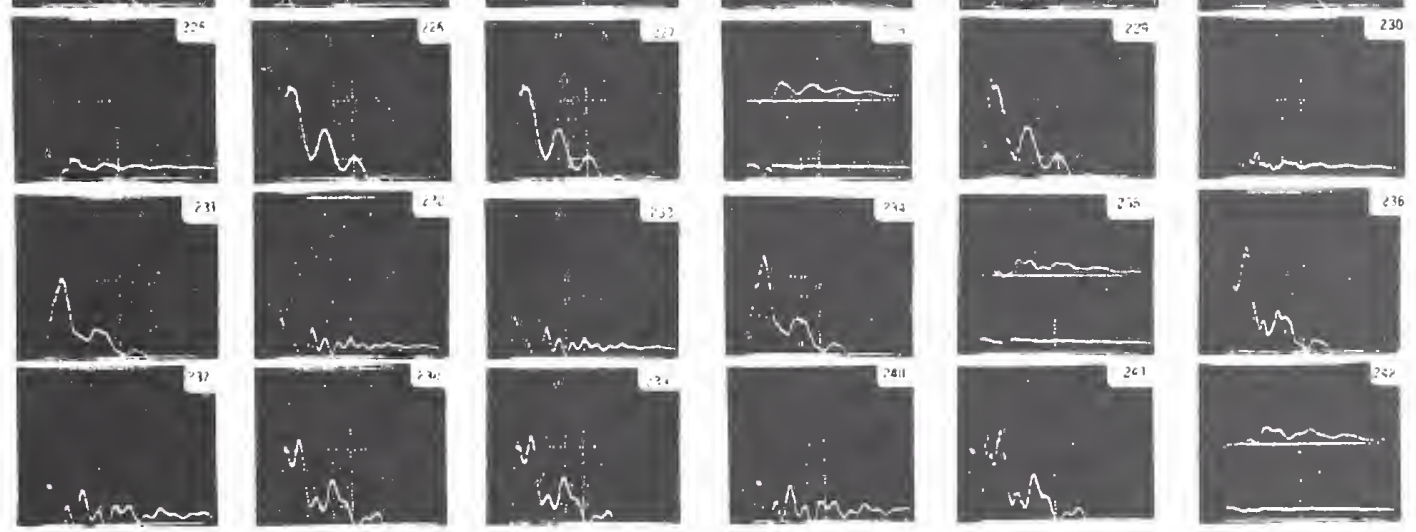

Simuloted Household Wiring System With Meosurements of Vorious Branches With and

Without a VSP-1 Protector Installed at a Single Point in the System.

1500 Amperes, $10 \times 25$ Microsecond Current Pulse Applied to Service Neutral.

Figure 8. Summary of Protector Effects 


\section{DISTRIBUTION TRANSFORMER ARRANGEMENT}

In the simulation of the system, the circuit configuration at the pole and distribution transformer assumed that the lightning stroke had terminated on the primary conductor and that the primary arrester installed to protect the distribution transformer had sparked over.

For all tests with no specific reference to that assumption, the simulation circuit had, in fact, the high side ( $\mathrm{HI}$ ) of the transformer primary connected to the neutral/ ground of the transformer by a jumper wire (see Figure 4).

Replacing this jumper by an air gap (Oscillogram 156 in Figure 9) or by a distribution arrester (Oscillogram 157) did not produce a significant change in the voltage observed at the bus in the load center. Furthermore, the current injected for the case of the arrester (Oscillogram 1571) is slightly, but not significantly, affected during its rise time. These two observations validate the use of a jumper around the transformer primary. 
VOLTAGE AT BUS WITH HT OF TRANSFORMER TIED TO

NEUTRAL (GROUND)

Current in HLP: $400 . A / d i v$

Voltage Across Bus: $500 \mathrm{~V} / \mathrm{div}$

VOLTAGE AT BUS WITH AIR GAP BETWEEN H1 OF TRANSFORMER AND NEUTRAL

Current in HLP: $400 \mathrm{~A} / \mathrm{div}$

Voltage Across Bus: $500 \mathrm{~V} / \mathrm{div}$

VOLTAGE AT BUS WITH

DISTRIBUTION ARRESTER ON

TRANSFORMER PRIMARY

Current in HLP: $400 \mathrm{~A} / \mathrm{div}$

Voltage Across Bus: $500 \mathrm{~V} / \mathrm{div}$
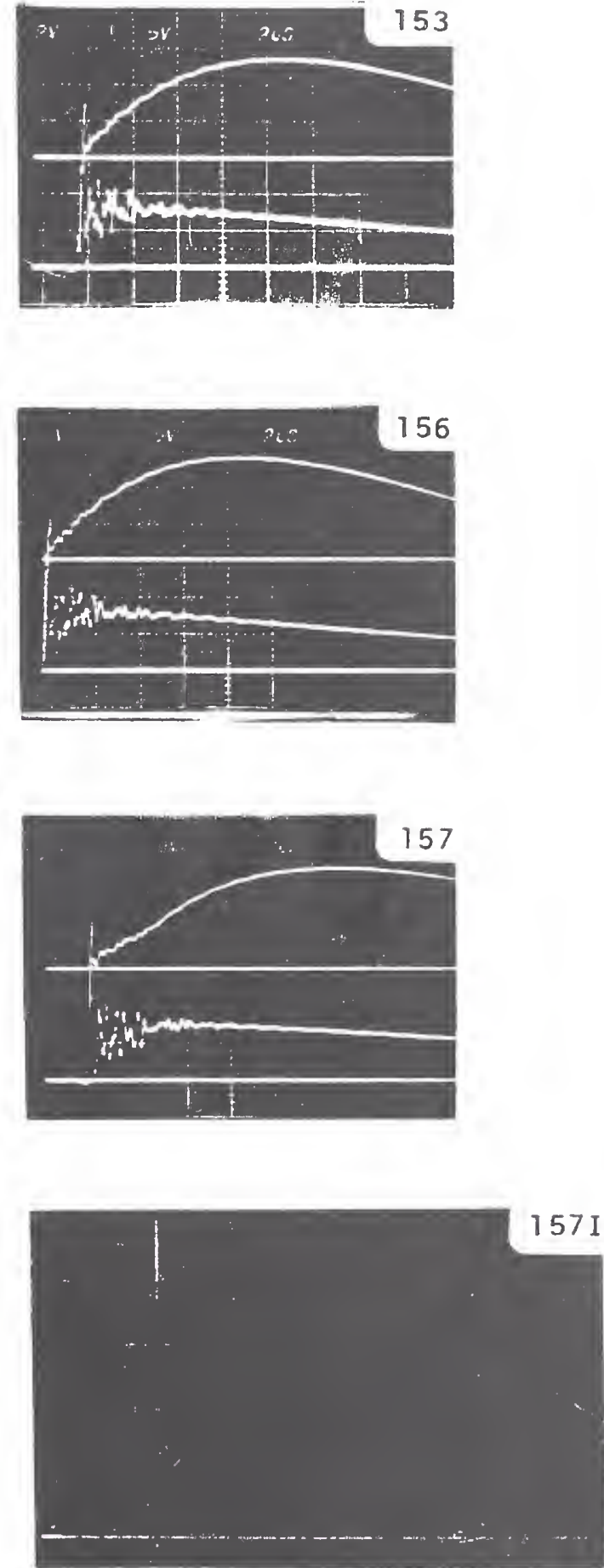

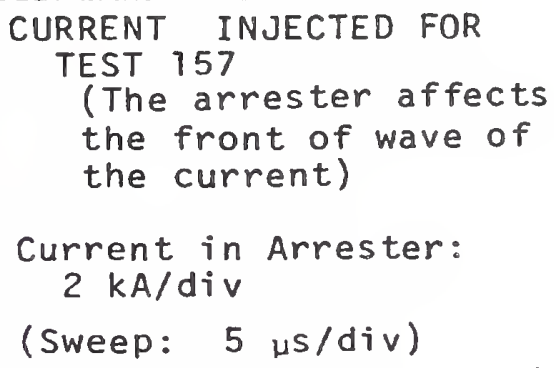

Test Condition: $10 \mathrm{kA}$ injected.

A11 sweeps: 2 Hs/div, except 157 I

Figure 9. Comparison of Protector HLP Response for Various Protective Devices at the Primary of the Distribution Transformer 


\section{EFFECT OF TERMINAL IMPEDANCE}

With no load connected at the end of the branch circuits, even with an outboard protector at the load center, there can be large "open-circuit" voltages at branch outlets. These voltages are caused by reflections as well as oscillations of the circuits.

Oscillograms 265 and 267 of Figure 10 show these open-circuit voltages reaching 1.5 and $2.3 \mathrm{kV}$. Loading the terminal with the $100 \mathrm{~W}$ bulb simulation reduces the opencircuit reflections to a maximum of $1.3 \mathrm{kV}$ from the $2.3 \mathrm{kV}$ level (oscillogram 269).

With the installation of a VSP-1 protector at each outlet (Oscillograms 266 and 268 ), the voltage is reduced to $400 \mathrm{~V}$, with a maximum current of $900 \mathrm{~A}$ in the B-80 outlet and $600 \mathrm{~A}$ in the B-160 outlet. (Oscillogram 266A shows the complete waveform which was not obvious on Oscillogram 266.) 
B -80

(LINE 2)

\section{$2 6 \longdiv { 2 6 7 }$}

VOLTAGE AT OUTLET WITH

(1) OUTBOARD PROTECTOR

ONLY AT EACH BUS

Voltage at Dutlet: $500 \mathrm{~V} / \mathrm{div}$
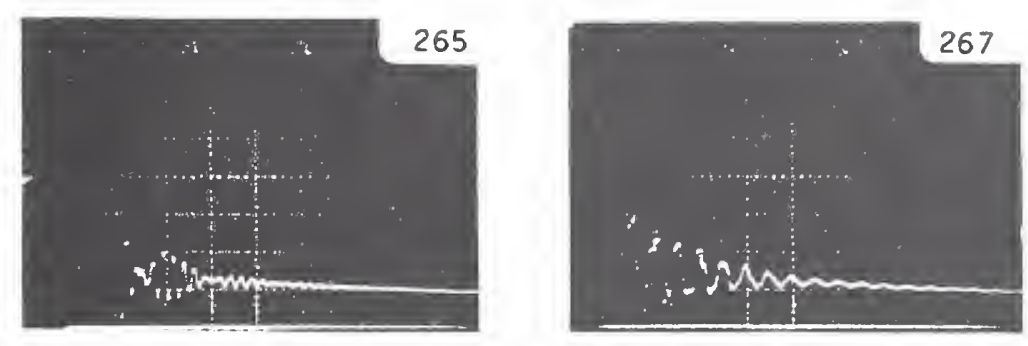

LINE I)

\section{9}

VOLTAGE AT OUTLET WITH

(1) OUTBOARD PROTECTOR

AT EACH BUS, PLUS (1)

"100 W LOAD" AT B-160

Voltage at outlet:

$500 \mathrm{~V} / \mathrm{div}$

\section{$266 / 268$}

VOLTAGE AT OUTLET WITH

(1) OUTBOARD PROTECTOR

AT EACH BUS, PLUS (1)

VSP-1 AT EACH B-80 AND

B-160 OUTLET

Current in VSP-1: $500 \mathrm{~A} / \mathrm{div}$

voltage at outlet:

$500 \mathrm{~V} / \mathrm{div}$

\begin{tabular}{|l}
\hline $266 A$ \\
VOLTAGE AT OUTLET WITH \\
( I) OUTBOARD PROTECTOR \\
AT EACH BUS, PLUS ( 1 ) \\
VSP-1 AT EACH B-80 AND \\
B- 160 OUTLET \\
Current in VSP-1: $500 \mathrm{~A} / \mathrm{div}$ \\
Voltage at Outlet: \\
$500 \mathrm{~V} / \mathrm{div}$ \\
\hline
\end{tabular}
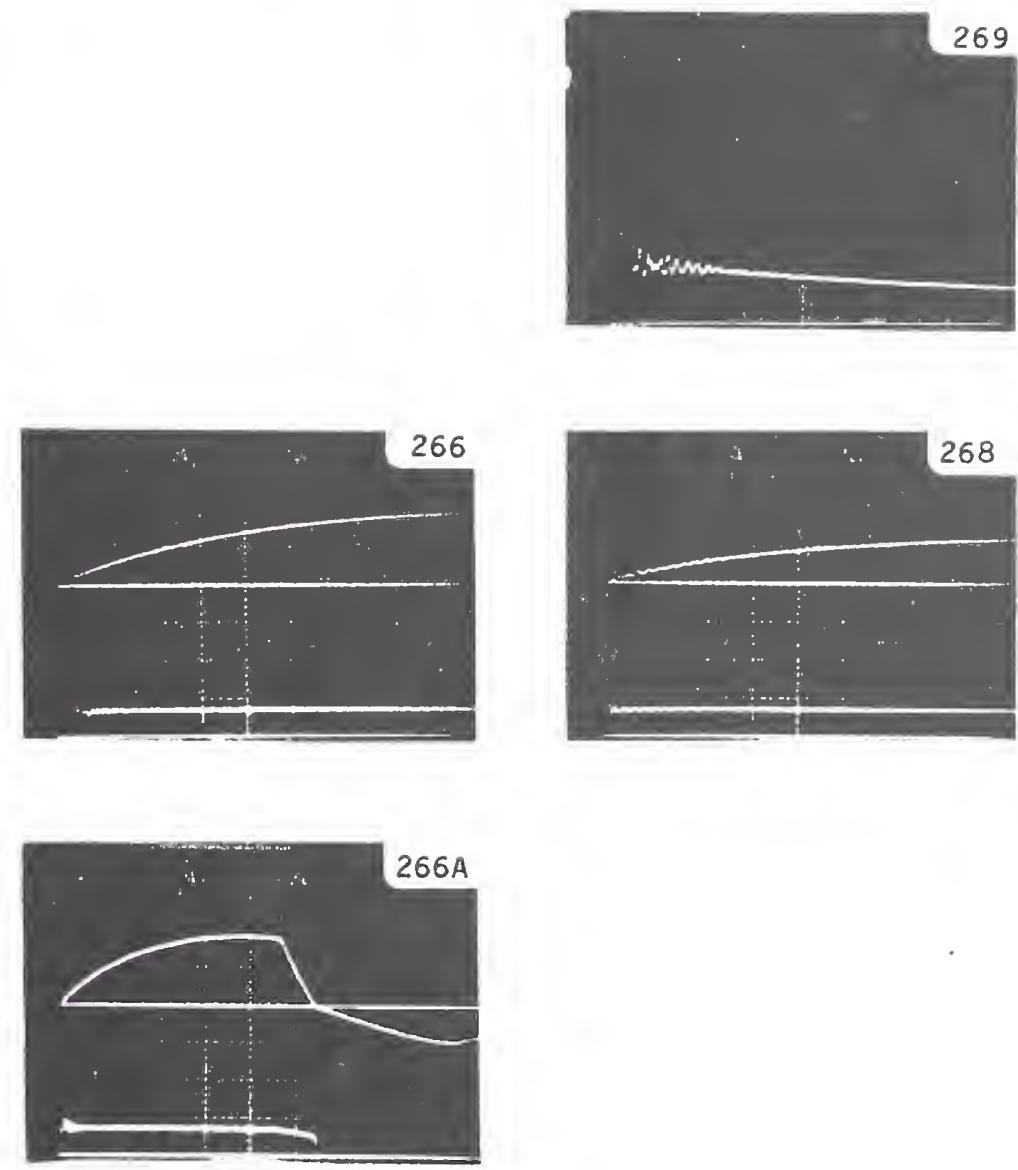

$5 \mu s / d i v$

Test Condition: $10 \mathrm{kA}$ injected -

Protectors and loads.

All sweeps: 2 us/div, except as noted.

Figure 10. Comparisons of Performances with Various Devices at Outlets, All with Protectors at Load Center

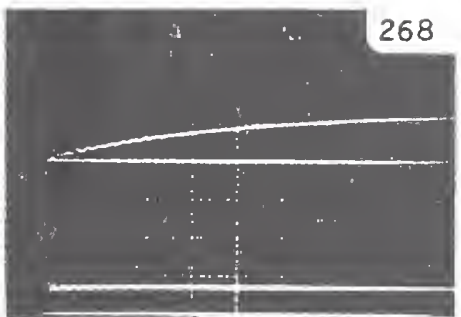

268

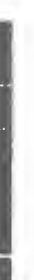




\section{EFFECT OF BRANCH TERMINATIONS}

Open-circuit voltages recorded as indicated in the preceding oscillograms show decaying oscillations. In Figure 11 a systematic comparison is presented of open-circuit voltages at the four line ends, as well as a comparison for each line end of the voltage without and with various loads.

Inspection of the no-load oscillograms (202 to 205) reveals two interesting phenomena. First, the frequency of the major voltage oscillation is constant for all four line lengths (period = $2 \mu \mathrm{s})$. Thus, we can conclude that this frequency is not affected by the line length and that other circuit parameters, rather, are responsible for inducing this $500 \mathrm{kHz}$ oscillation from a $10 \times 25$ us current wave. Second, the minor oscillations visible during the first loop in each oscillogram are spaced apart at a distance which increases with line length. Thus, one can conjecture that these may be caused by reflections.

Loading the line termination with a $130 \Omega$ resistor (Oscillograms 243A, 245, 247, and 249) eliminates the later oscillations and reduces the first peak to about $60 \%$ of the value without load. From this reduction, a Thevenin's calculation of circuit parameters (Figure 12), if applicable in an oversimplified form, would show that $130 \Omega$ is $60 \%$ of the total loop impedance. Hence one can conclude that the source impedance is four/sixths of 130 , or about $85 \Omega$ 。

When a VSP-1 protector is added to the $130 \Omega$ resistor (Oscillograms 244, 246, 248, and 250 ), the clamping action of the varistor limits the voltage at the outlets to about $400 \mathrm{~V}$, which is consistent for the currents of about $20 \mathrm{~A}$ flowing in the varistor. 


$$
\begin{aligned}
& \text { B-20 } \\
& \text { (LINE 2) }
\end{aligned}
$$
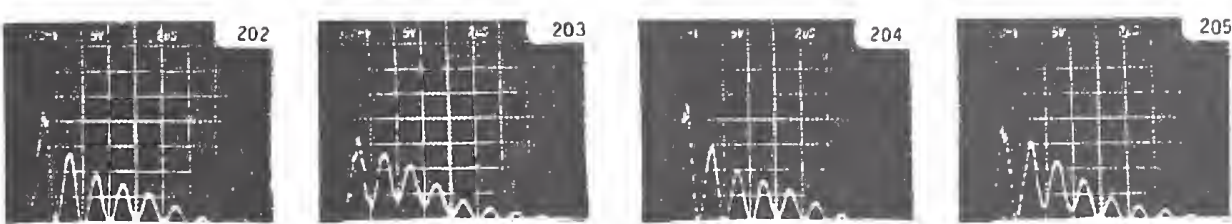

VOLTAGE WITH (1) "100 W"
INSTALLED AT OUTLET
INOICATEO
Voltage at Out let
Indicated: $500 \mathrm{v} / \mathrm{div}$
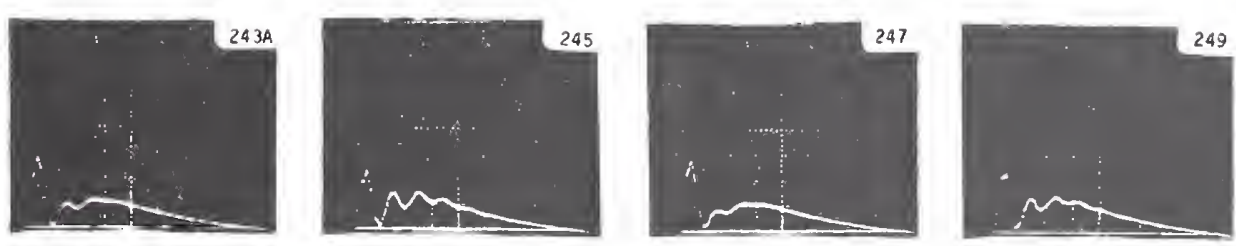

VOLTAGE AND CURRENT UITH
(1) VSP-1 and (1)
"1OO W" INSTALLEO AT
OUTLET INOICATEO
Current in VSP-1:
$20 \mathrm{~A} / \mathrm{div}$
Vol tage Across VSP-1:
$500 \mathrm{~V} /$ div
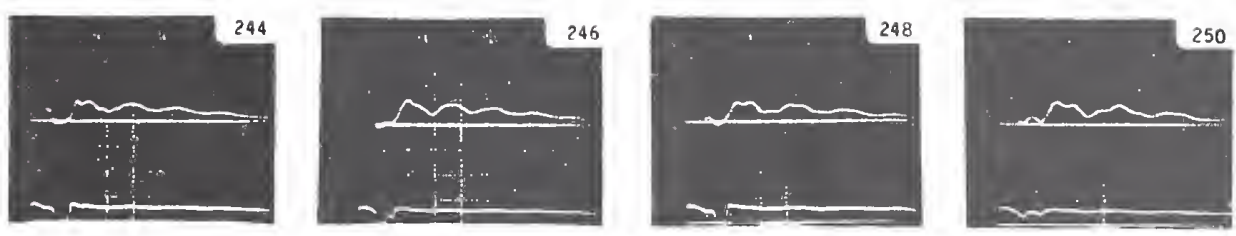

Test Condition: $1.5 \mathrm{kA}$ injected -
Protectors and load installed at outlets as shown.

All sweeps: 2 us/div.

Figure 11. Effect of Load (100 W Light Bulb) on Voltages at Branch Outlets
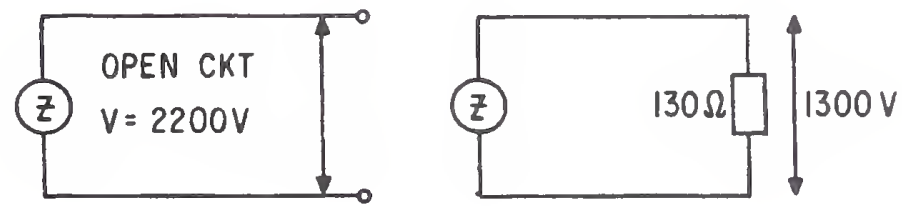

Figure 12. Thevenin's Equivalent for Oscillogram 202 


\section{LOAD CENTER PROTECTORS}

With no protectors at the load center nor at any outlets, the wiring is flashing over at $10 \mathrm{kA}$ injected current, but not before crests in the range of $8 \mathrm{kV}$ have been reached (Oscillograms 143 and 145). (See also Oscillograms 271 and 272 on Figure 17.)

Installation of inboard protectors reduces the voltage peaks to 500 or $600 \mathrm{~V}$, with about $1200 \mathrm{~A}$ drawn through the protectors (a substantial improvement), as shown in Oscillograms 261 and 262 of Figure 13.

With outboard protectors rather than inboard protectors, the peak voltages are in the 1000 to $1100 \mathrm{~V}$ range (Oscillograms 263 and 264). These higher voltages are attributable to the longer leads required to connect the outboard protector, compared to the inboard protector. (Figure 16 shows a comparison of lead length effects, which removes any question that the difference between inboard and outboard protectors might have been the result of an intrinsic difference in the varistors.)

While not a recommended installation location, two VSP-1 were also installed directly at the load center (on the bus) in an arrangement that approximates the "inboard protector" geometry. Oscillograms 255 and 256 show the clamping voltage at 500 to $600 \mathrm{~V}$ with current crests at 1100 to $1200 \mathrm{~A}$. Scaling up these varistor current values for higher lightning currents than the $10 \mathrm{kA}$ injected would indicate probable excessively large currents in the $14 \mathrm{~mm}$ varistor used in the VSP-1 protector.

Finally, a HLP protector was installed at the center, as shown for one bus on Oscillogram 153. The voltage is higher and the initial rise before sparkover of the gap takes place at about $2.2 \mathrm{kV}$. The current crest, after the sparkover, is of the same magnitude $(1100 \mathrm{~A})$ as that of other tests. 
BUS 1

(LINE 1)

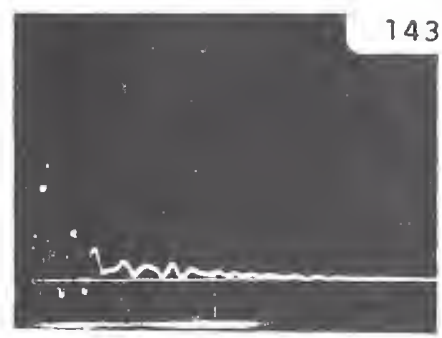

Voltage at Bus Indicated: $2 \mathrm{kV} / \mathrm{div}$

OPEN-CIRCUIT VOLTAGE

VOLTAGE AND CURRENT WITH (1) INBOARD PROTECTOR AT EACH BUS

Current in Protector: $500 \mathrm{~A} / \mathrm{div}$

Voltage Across Bus: $500 \mathrm{~V} / \mathrm{div}$

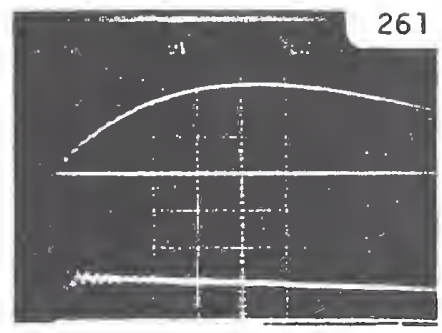

BUS 2

( LINE 2)
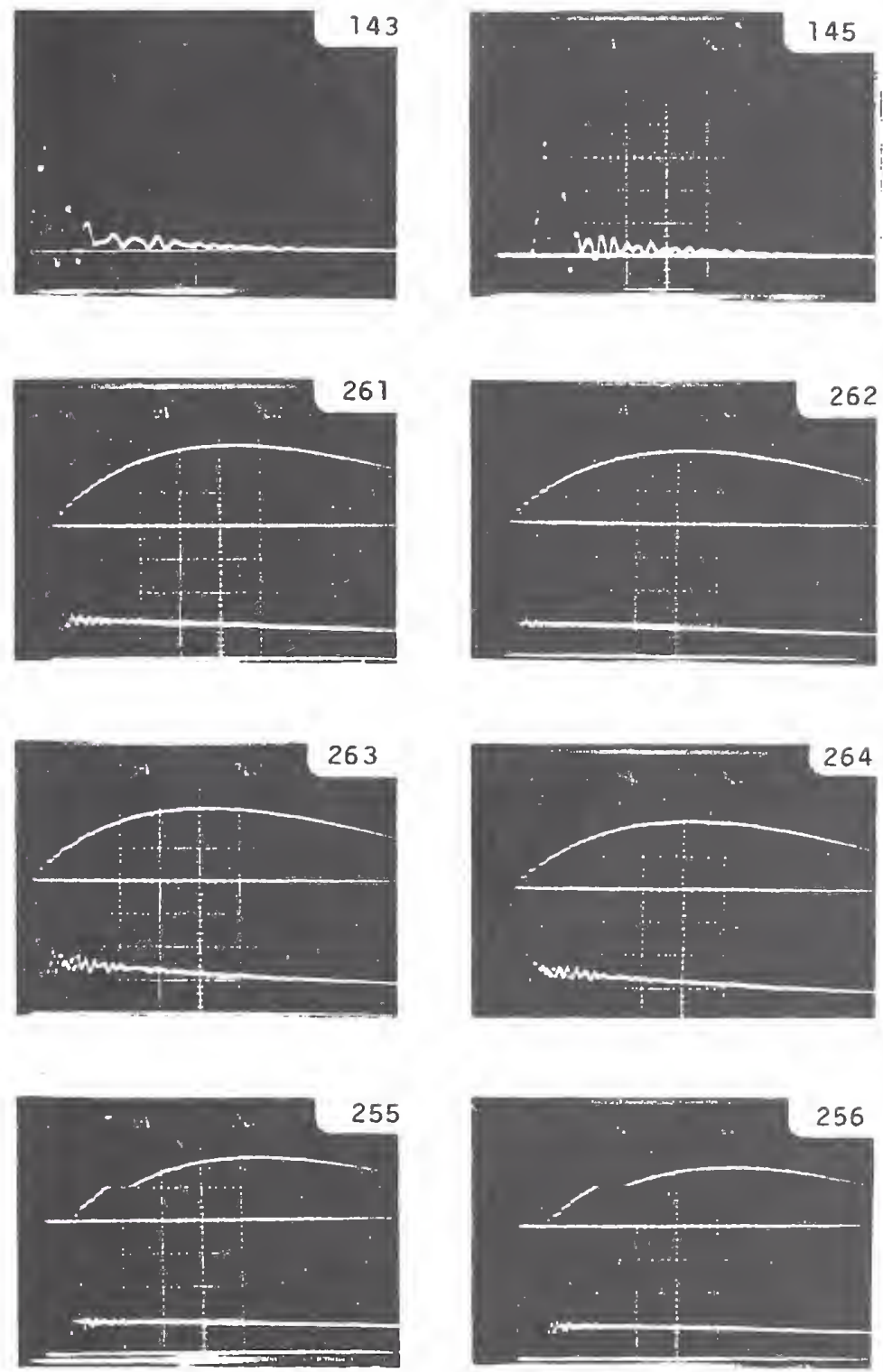

VOLTAGE AND CURRENT WITH

(1) VSP-1 AT EACH BUS

Current in VSP-1:

$500 \mathrm{~A} / \mathrm{div}$

Voltage Across VSP-1: $500 \mathrm{~V} / \mathrm{dtV}$

VOLTAGE AND CURRENT WITH

(1) HLP ON LOAD CENTER

Current in HLP Line 1 : $400 \mathrm{~A} / \mathrm{div}$

Voltage Across Bus: $500 \mathrm{~V} / \mathrm{div}$

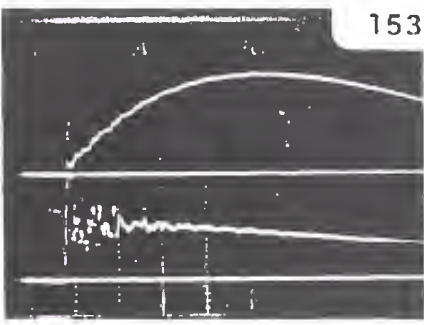

153

$10 \mathrm{kA}$ injected -

All sweeps: 2 us/div.

Figure 13. Comparison of Alternate Protectors at Load Center 


\section{DUTY ON OUTLET PROTECTORS}

While a properly coordinated protection scheme would certainly include installation of a high-energy protector at the load center, the VSP-1 spike suppressor is likely to be installed in locations where no other protector would be provided.

The three sets of oscillograms in Figure 14 illustrate the increasing duty imposed on the VSP-1 protector at short and medium distances (B-40, B-80) when the load center includes an effective protector, a less effective protector, and, finally, no protector. Note that for the $30 \mathrm{kA}$ injection (a very pessimistic value) the current peak in the $14 \mathrm{~mm}$ varistor of the B-40 VSP-1 is about $2200 \mathrm{~A}$, which is high but tolerable for infrequent lightning strokes.

The difference in current peak resulting from the branch circuit length (B-40 vs B-80) is also quite apparent, while the clamping voltages are not very different from those of the envelope, being at 400 to $600 \mathrm{~V}$, with initial bursts at 800 to $1100 \mathrm{~V}$.

In the case of Oscillogram 284, flashover of the wiring at the load center limited the current impressed on the VSP-1 protector. This is a result of an unintentional wiring flashover, which occurs frequently. 
$\left(\begin{array}{l}\text { B-40 } \\ \text { (LINE 1) }\end{array}\right.$

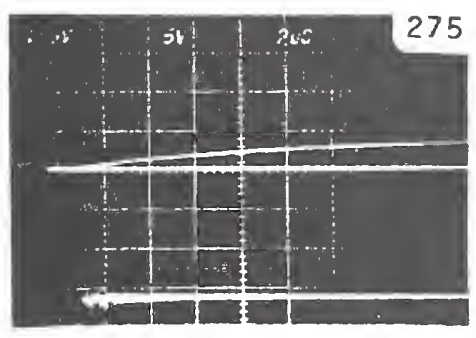

VSP-1 AT OUTLET SHOWN WITH INBOARD PROTECTOR AT LOAD CENTER

Current in VSP-1: $500 \mathrm{~A} / \mathrm{div}$

Vol tage at Outlet: $500 \mathrm{~V} / \mathrm{div}$

VSP-1 AT OUTLET SHOWN WITH OUTBOARD PROTECTOR AT LOAC CENTER

Current in VSP-1: $200 \mathrm{~A} / \mathrm{div}$

Voltage at Outlet: $500 \mathrm{~V} / \mathrm{div}$

VSP-1 AT OUTLET SHOWN WITH NO OTHER PROTECTOR

Current in VSP-1: $1000 \mathrm{~A} / \mathrm{div}$

Voltage at Outiet: $500 \mathrm{~V} / \mathrm{div}$

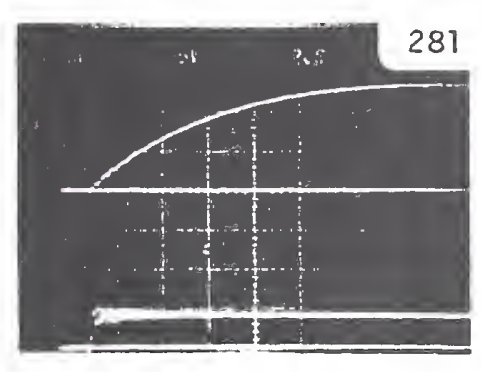

B-80

(LINE 2)
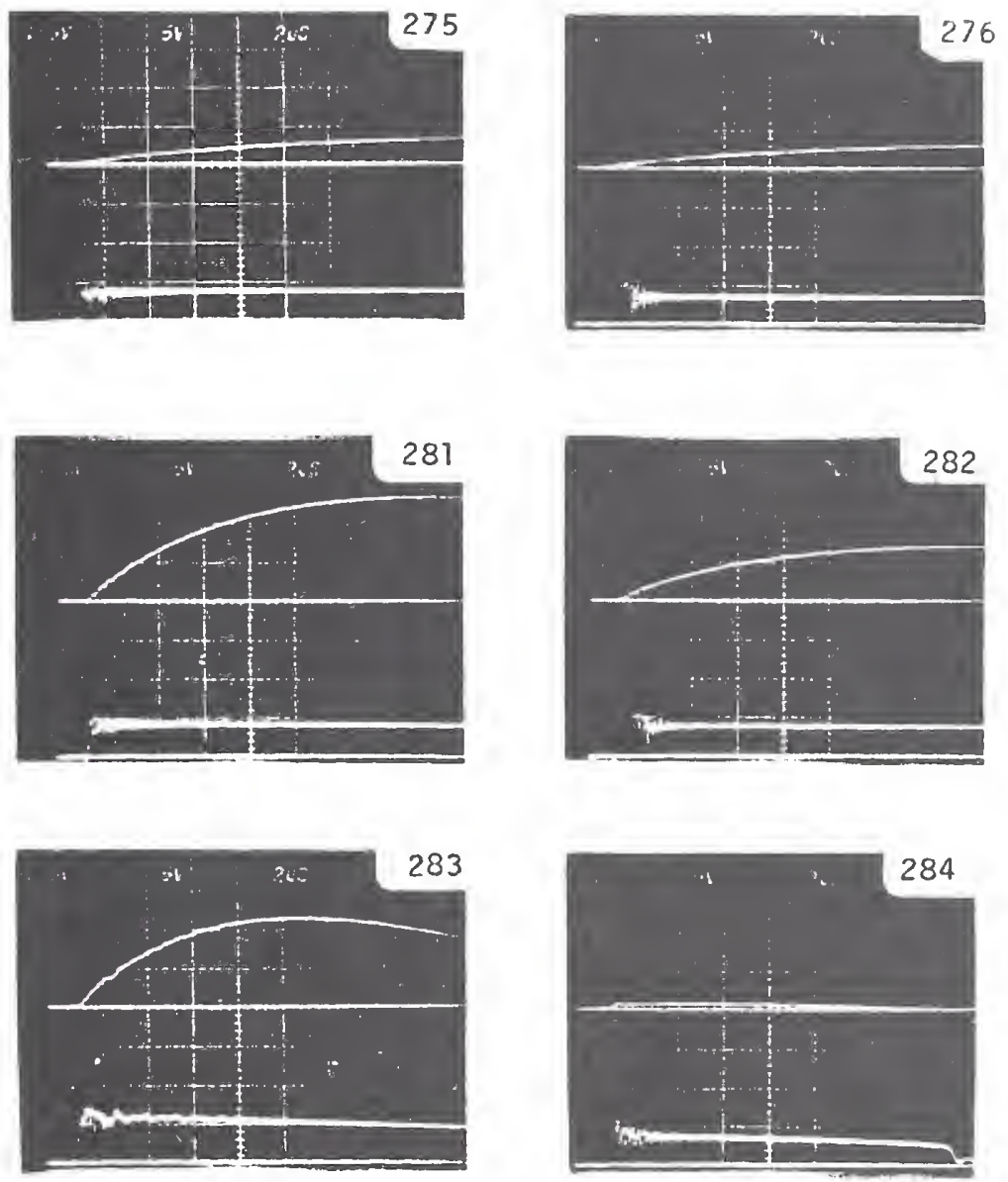

(Flashover at B-20

limits the current.)

Test Condition: $30 \mathrm{kA}$ injected

All sweeps: $2 \mu s / d i v$.

Figure 14. Comparison of Duty Imposed on VSP-1 Installed at Outlets for Various Load Center Protections 


\section{COMPARISON OF INBOARD/OUTBOARD PROTECTORS}

The difference in length required to connect the inboard or outboard protectors at the load center raises the question of induction effects on the clamping voltage achieved with one or the other protector. Oscillograms 273 and 274 of Figure 15 show a maximum voltage limited to less than $1000 \mathrm{~V}$ with the inboard arrangement, while the outboard arrangement (Oscillograms $277 \mathrm{~A}$ and 278) shows as much as $2000 \mathrm{~V}$ maximum voltage.

(To remove any doubt on a possible difference caused by a difference in disc characteristics, the separate test discussed in conjunction with Figure 16 was performed, showing that indeed the additional voltage is attributable to lead length.) 


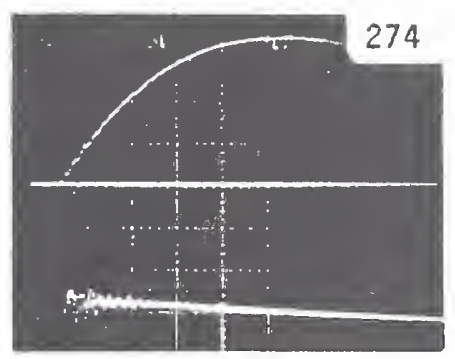

oltage Across Bus: $500 \mathrm{~V} /$ div

(1) OUTBOARD PROTECTOR ON EACH BUS

Current in Protector $1000 \mathrm{~A} / \mathrm{div}$

Voltage Across Bus $500 \mathrm{~V} / \mathrm{div}$
BUS 1

(LINE 1)

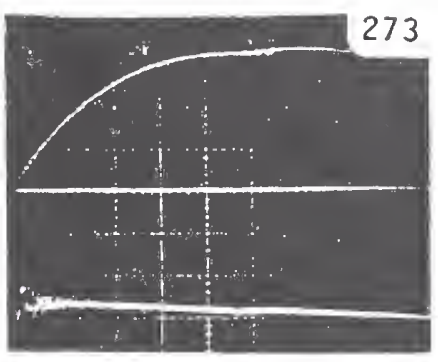

BUS 2

(LINE 2)

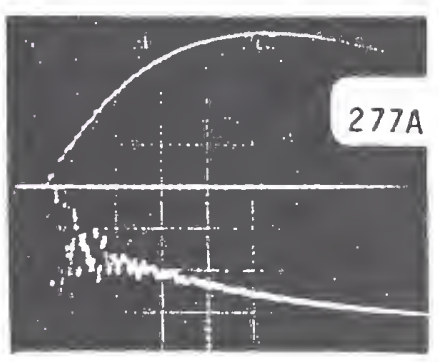

Test Condition: $30 \mathrm{kA}$ injected -

Protectors at load center.

Al1 sweeps: $2 \mu \mathrm{s} / \mathrm{div}$.

Figure 15. Comparison of Performances Between Inboard and Outboard Protectors Installed at Load Center 


\section{EFFECT OF LEAD LENGTH}

The oscillograms of Figures 13 and 15 show a difference in the performance of the outboard and inboard protectors. These two protectors, although identical for the disc size $(32 \mathrm{~mm})$, used discs from different production lots with potentially different characteristics. A separate test was made to determine if lead length or disc characteristic was the cause of this difference.

One each of the inboard and outboard protectors was removed from the simulation circuit. These were connected in series across the output of an impulse generator. The total lead length ( $60 \mathrm{~cm}$, or $24 \mathrm{in}$ ) was approximately equal to that involved in separately connecting the outboard protector $(45 \mathrm{~cm}$, or $18 \mathrm{in})$ and the inboard protector ( $15 \mathrm{~cm}$ or $6 \mathrm{in}$ ) at the load center of the simulation circuit. Current pulses of constant magnitude ( $3.2 \mathrm{kA}$ crest, $10 \mu \mathrm{s}$ rise time) were injected in the loop, and voltages across the protectors and their corresponding leads were recorded as shown in Figure 16.

Oscillogram 1 shows a $1000 \mathrm{~V}$ maximum voltage across the outboard protector and its associated $45 \mathrm{~cm}$ (18 in) lead, compared to only $600 \mathrm{~V}$ for the inboard protector and its $15 \mathrm{~cm}$ ( $6 \mathrm{in}$ ) lead (Oscillogram 2). Changing the lead of the inboard device to $45 \mathrm{~cm}$ (1 8 in) (Oscillogram 3) raised the voltage to $1000 \mathrm{~V}$, demonstrating that the difference is attributable to lead length, not disc characteristics, and illustrating the benefits obtainable by making the protector an integral part of the load center. 


(1)
VOLTAGE ACROSS "OUTBOARD
SUPPRESSOR" PLUS $78 "$
LOOP OF WIRE
voltage: $500 \mathrm{~V} / \mathrm{div}$
Current: $1000 \mathrm{~A} / \mathrm{div}$

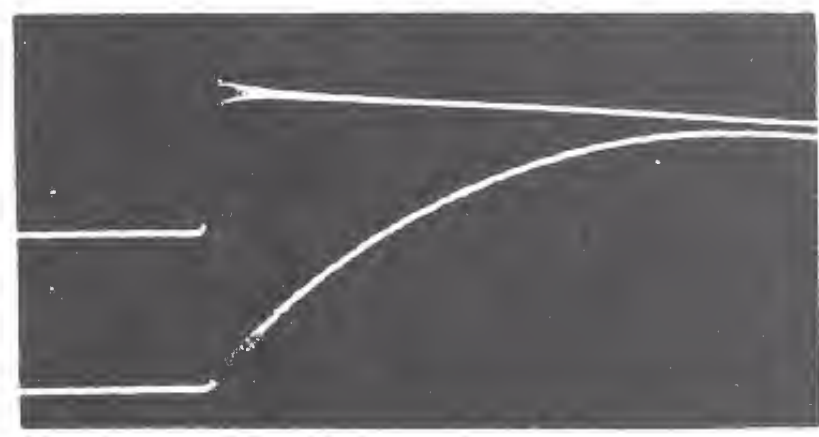

(2)
VOLTAGE ACROSS "INBOARD
SUPPRESSOR" PLUS 6"
LOOP OF WIRE
Voltage: $500 \mathrm{~V} / \mathrm{div}$
Current: $1000 \mathrm{~A} / \mathrm{div}$

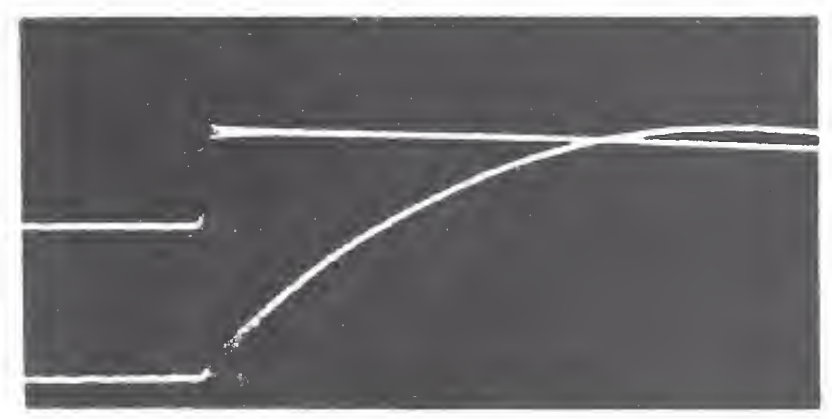

(3)
VOLTAGE ACROSS SAME
SUPPRESSOR AS ( 1 ) BUT
18 " LOOP OF WIRE
Voltage: $500 \mathrm{~V} / \mathrm{div}$
Current: $1000 \mathrm{~A} / \mathrm{div}$

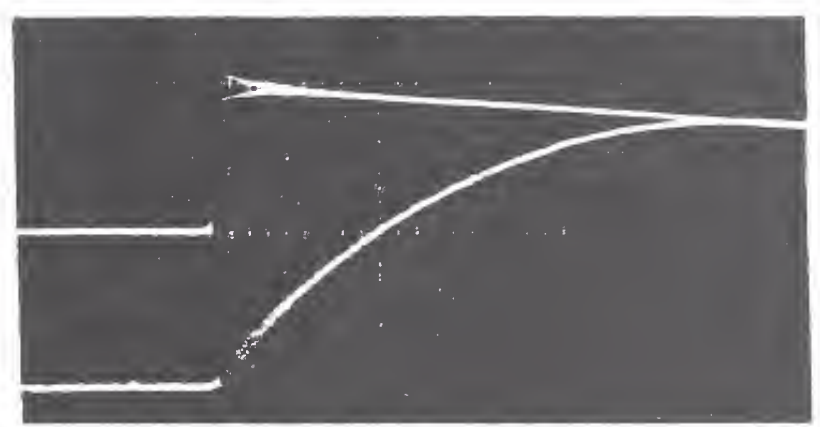

Test Condition: Laboratory bench, not house simulation. Current injection in the two suppressors connected in series: $2.7 \mathrm{kA}$.

A11 sweeps: $2 \mu s / d i v$.

Figure 16. Effect of Lead Inductance on Clamping Voltage 


\section{EFFECT OF WIRING SPARKOVER}

With no protector at the load center and the only loads or suppressors installed at remote outlets, the induced voltages can reach such high values as 6 to $8 \mathrm{kV}$ for the $10 \mathrm{kA}$ injected current (Oscillograms 271 and 272 of Figure 17, and Oscillograms 143 and 145 of Figure 13).

Oscillogram 272 shows that, with no relief produced by wiring flashover, the volt age envelope decays, becoming similar to that observed at lower current injection (Figure 14). However, as indicated in Oscillogram 271, flashover of the wiring (in this case the B-40 outlet) limited the voltage but not until a first crest of $7 \mathrm{kV}$ had occurred and consequently started propagating in all branches of the system. 


\begin{tabular}{|l|} 
VOLTAGE AT BUS \#2 \\
(1) VSP-1 and "100 W" at \\
B-160 \\
(1) VSP-1 at B-80 \\
(Outlet Sparking Over at \\
B-40) \\
Vortage Across Bus: \\
1000 V/div
\end{tabular}

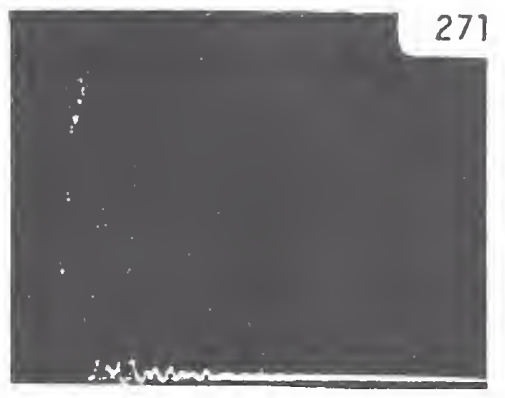

VOLTAGE AT BUS \#1
(1) VSP- 1 at B-160
(1) VSP- 1 and "100 W" at
B-80
Vol tage Across Bus:
1000 V/div

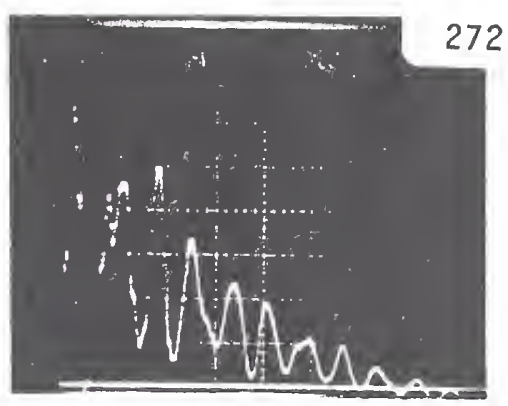

Test Condition: Injected current $10 \mathrm{kA}$.

Ali sweeps: $2 \mu \mathrm{s} / \mathrm{div}$.

Figure 17. Voltages at Load Center with VSP-1 and "100 W load," at Remote Outlets, No Protector at Load Center 


\subsection{Discussion of the Results}

From the oscillograms collected during the test series, a summary of maximum values has been compiled as shown in Table 1. The three levels of current injection are included in this table, illustrating a mild, severe, and extremely severe lightning incident near the house. For the sake of simplicity in this table, only one protector is included in the arrangement matrix. A subsequent discussion will address the case of a coordinated scheme involving more than one protector.

Injection of the maximum values recorded on the protector current shows that no rated values are exceeded, even at $30 \mathrm{kA}$ injection. Voltages observed are consistent with the corresponding currents, from the V-I characteristics of the varistors.

In the first group at $1.5 \mathrm{kA}$ injection, voltages that are particularly damaging to appliances (2500 V) are observed throughout the system. Installation of a protector (on both lines) at the load center eliminates the hazard and would suffice to protect all of the house. Installation of a VSP-1 at only one close or remote outlet provides protection at that outlet and moderate protection on all locations of the same line. The other line is not protected.

The unsymmetrical load (diode) of the TV input circuit behaved in a predictable mar.ner: when the polarity of the voltage was such that a forward bias was applied, the diode clipped the voltage, with the series resistance limiting the current. With reverse bias polarity, the diode failed when the $2500 \mathrm{~V}$ transient occurred at that outlet.

In the second group, representing a severe incident, flashover can be expected throughout the system in the absence of protection, with the associated fire hazards as well as damage to electronics during the initial voltage rise. Installation of a HLP at the load center eliminates the flashover hazard but does not lower the voltage sufficiently to assure protection of sensitive electronics, nor does an outboard installation of varistors assure protection. Installation of an inboard set of varistors is effective, for the voltage is limited at the load center (and consequently on the whole system) to $700 \mathrm{~V}$. Installation of a VSP-1 at a cluse uutlet (producing the maximum current flow, hence highest voltage) is effective for that outlet only; on the basis of the differential observed at $1.5 \mathrm{kA}$, one can presume that the voltage at the load center would be too great to consider any other point but that outlet as being protected. 
In the third group, representing an extremely severe incident, the inboard protector at the center is, alone, still effective to protect the house, but the outboard protector is not. A VSP-1 installed at a close outlet is exposed to a high current $(2500 \mathrm{~A})$, still within its rating ( $4000 \mathrm{~A}$ ), in excess of the maximum allowable 10-pulse value of the Pulse Lifetime Rating (1000 A), but still acceptable for 2 pulses. Installation of a VSP-1 alone, closer to the load center, would be likely to result in failure of the varistor when exposed to repetitive, severe lightning incidents. However, this failure hazard may still be less objectionable than the behavior of the wiring (flashover) in the absence of any protector, on an objective basis but not a subjective basis (the user is now expecting infallible protection). 
Table 1

SUMMARY

MAXIMUM VALUES OF VOLTAGES AND CURRENT OBSER VED DURING TEST SERIES

\begin{tabular}{|c|c|c|c|c|}
\hline Protector Arrangement + & $\begin{array}{c}\text { Injected } \\
\text { Current } \\
\text { kA }\end{array}$ & $\begin{array}{l}\text { Load } \\
\text { Center } \\
\text { V }\end{array}$ & $\begin{array}{c}\text { Protected } \\
\text { Outlet } \\
\text { V }\end{array}$ & $\begin{array}{c}\text { Protector } \\
\text { Current } \\
\text { A }\end{array}$ \\
\hline $\begin{array}{l}\text { None } \\
\text { Inboard Protector at Load Center } \\
\text { Outboard Protector at Load Center } \\
\text { VSP-1 at B-20 } \\
\text { VSP-1 at B-160 }\end{array}$ & $\begin{array}{l}1.5 \\
1.5 \\
1.5 \\
1.5 \\
1.5\end{array}$ & $\begin{array}{r}2500 \\
500 \\
700 \\
800 \\
1100\end{array}$ & $\begin{array}{l}2500 \\
500 \\
700 \\
400 * \\
350 *\end{array}$ & $\begin{array}{r}100 \\
70 \\
30 \\
20\end{array}$ \\
\hline $\begin{array}{l}\text { None } \\
\text { Inboard Protector at Load Center } \\
\text { Outboard Protector at Load Center } \\
\text { HLP at Load Center } \\
\text { VSP-1 at B- } 20 \\
\text { VSP-1 at B-160 }\end{array}$ & $\begin{array}{l}10 \\
10 \\
10 \\
10 \\
10 \\
10\end{array}$ & $\begin{array}{r}8800 \\
700 \\
1200 \\
2200 \\
\text { NR } \\
\text { NR }\end{array}$ & $\begin{array}{l}\text { F/o } \\
700 \\
2000 \\
\text { NR } \\
700^{*} \\
600^{*}\end{array}$ & $\begin{array}{r}1200 \\
1100 \\
1100 \\
950 \\
600\end{array}$ \\
\hline $\begin{array}{l}\text { Inboard Protector at Load Center } \\
\text { Outboard Protector at Load Center } \\
\text { VSP-1 at B-20 } \\
\text { VSP-1 at B-160 }\end{array}$ & $\begin{array}{l}30 \\
30 \\
30 \\
30\end{array}$ & $\begin{array}{r}950 \\
2200 \\
\text { NR } \\
\text { NR }\end{array}$ & $\begin{array}{l}\text { NR } \\
\text { NR } \\
800 \\
500\end{array}$ & $\begin{array}{r}3500 \\
3500 \\
2500 \\
250\end{array}$ \\
\hline $\begin{array}{l}\text { Notes - } \\
\text { NR - No Record } \\
\text { * "Protected outlet" is on same line as } \\
\text { other line close to unprotected value }\end{array}$ & rotector. & oltages & utlets of & \\
\hline + Only one protector at a line in this & & & & \\
\hline
\end{tabular}




\subsection{A Coordinated Protection Scheme}

Installation of a varistor protector at the load center, if incorporated with very short leads, as in the "inboard" arrangement, effectively protects all of the wiring in the house. However, this installation is difficult to implement in existing systems and will continue to be difficult until a package is developed to allow connection to the load center bus bars with very short leads.

Until such an integral package is marketed for new systems, a coordinated protection scheme can be implemented, as a retrofit, that would still provide reliable protection for millions of sensitive appliances in existing systems.

The coordination involves a protector at the load center, either the commercially available HLP or a packaged $32 \mathrm{~mm}$ disc set (two lines) with reasonably short leads in a package similar to the HLP. This protector will limit the voltage at the load center to about $2200 \mathrm{~V}$. This $2200 \mathrm{~V}$ level is below the flashover level of the wiring but can still cause damage to sensitive appliances. The currents passing through the protector at that location will not exceed the protector capability. In addition, VSP-1 protection should be installed at those outlets where a sensitive appliance is plugged. The voltages allowed by the VSP-1, typically 400 to $600 \mathrm{~V}$, will be low enough to assure survival of all but excessively sensitive appliances, while the VSP-1 will not be exposed to currents that can lead to a failure in case of frequent exposure to severe lightning incidents.

Thus, a coordinated protection scheme is technically feasible. The cost should be acceptable to do-it-yourself homeowners, although it might be a deterrent to those owners who have to call in an electrician to install a protector at the load center. Based on increasing awareness in the technical and regulatory agencies community of overvoltage protection, the incorporation of protection to load centers offers the best approach to new installations. 


\section{REFERENCES}

1. Martzloff, F.D., Surge Voltage Suppression in Residential Power Circuits, 76CRD092, General Electric Company, Schenectady, N.Y., 1976.

2. N. Cianos and E.T. Pierce, A Ground-Lightning Environment for Engineering Usage, Stanford Research Institute, Menlo Park, Cal. 94025, August 1972.

3. Electrical Transmission and Distribution Reference Book, Westinghouse Electric Corporation, 4th edition, East Pittsburgh, Pa., 1950.

4. Surge Arresters for Alternating-Current Power Circuits, ANSI C62.1.1975, American National Standards Institute, 1975.

5. Specifications for GE-MOV II Varistors, General Electric Company, Semiconductor Products Dept., Syracuse, N.Y., 1978. 


\section{APPENDIX}

\section{DEVICES USED FOR SIMULATION}

Meter: GE Cat. $720 \times 070$ G001

Meter Socket: GE Cat. $743 \times 001$ G003

Home Lightning Protector: GE Cat. 9L15DC B002

Load Center Suppressor

(Inboard and Outboard): GE CAT. V250 HE250

Outlet Suppressor: GE Cat. VSP-ID 
$\theta$ 


\title{
Coordination of Surge Protectors in Low-Voltage AC Power Circuits
}

\author{
François D. Martzloff \\ General Electric Company \\ Schenectady NY \\ f.mantzloff@ieee.org
}

Reprinted, with permission, from IEEE Transactions on Power Apparatus and Systems, PAS-99, Jan/Feb 1980
First presented at IEEE Summer Meeting, Vancouver, July 1979

\section{Significance: \\ Part 4 - Propagation and coupling of surges \\ Part 8 - Coordination of cascaded SPDs}

This paper presents a summary of two earlier and detailed proprietary General Electric reports describing experiments conducted in Schenectady NY and in Pittsfield MA, respectively by Martzloff and Crouch. (These have now been declassified by General Electric and are included in this Anthology - see Coordination 1976 and Propagation 1978.) The prime purpose of that paper at the time was to report in a non-classified platform experimental results that could be useful for the development of IEEE Std 587 (later known as IEEE Std C62.41). That contribution was acknowledged by an SPD Committee Paper Award.

In the first experiment, a simple test circuit of two branch circuits originating at a typical service entrance paper was subjected to relatively high-energy unidirectional impulses, with various combinations of surge-protective devices installed at the service panel and/or at the end of the branch circuits. That 1976 experiment was the beginning of recognition of the "cascade coordination" issue that became the subject of intense interest in the 80's and 90's (see the listing of contribution by many authors in Part 1 , Section 8 ).

In the second experiment, the coupling and subsequent propagation of surges was investigated in a more complex circuit that included a distribution transformer, service drop, entrance panel, and several branch circuits. The surge was injected in the grounding system, not into the phase conductors. This experiment thus brought new evidence that ning waves can be stimulated by unidirectional surges. Nevertheless, the threat was considered at that time as a surge impinging onto the service entrance from the utility, not resulting from a direct flash to the building grounding system. On that latter subject, see Dispersion and Role of SPDs. 


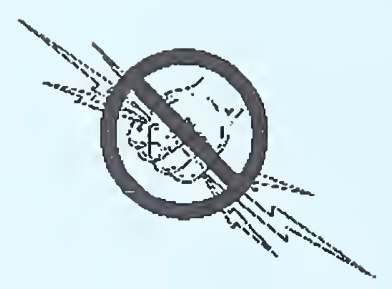


Reprinted by permission of the Institute of Electrical and Electronics Engineers from:

IREE Transactions on Power Appsratus and Systems, Vol. PAS-99, No. 1 Jsn./Feb. 1980

\title{
COORDINATION OF SURGE PROTECTORS IN LOW-VOLTAGE AC POWER CIRCUITS
}

\author{
F.D. Martzloff, Member, IEEE \\ General Electric Company \\ Schenectady, NY 12345
}

\begin{abstract}
Absiract - Surge protectors can be installed in low-voltage ac power systems to limit overvoltages imposed on sensitive loads. Available devices offer a range of voltage-clamping levels and energy-handling capability, with the usual economic trade-off limitations. Coordination is possible between lowclamping-voltage devices having limited energy capability and high-clampingvoltage devices having high energy capability. The paper gives two examples of coordination, as well as additional experimental results on surge propagation.
\end{abstract}

\section{INTRODUCTION}

Surge voltages occurring in low-voltage ac power circuits have iwo origins: external surges, produced by power system switching operation or by lightning. and internal surges, produced by switching of loads within the local system. Typical voltage levels of these surges are sufficient to cause the failure of sensitive electronic appliances or devices, and high surges can cause the failure of rugged electromechanical devices (clocks, motors, and heaters) $[1,2)$.

For many years secondary surge arresters from a number of manufaciurers have been available. These arresters are effective in protecting nonelectronic devices against the high-voltage surges associated with lighining or power system switching. However, the voltage allowed by an arrester is still too high for sensitive electronic devices. Furthermore, installation requires an electrician to connect the device on hot terminals.

The advent of the metal oxide varistor packaged as a convenient plugin device or incorporated into the appliances makes possible a voltage clamping which is more effective than that of the conventional secondary arrester. How ever, the energy-handling capability of such packages is lower than that of an arrester, so that large currents associated with lightning strikes cannot be handled by these packages.

The availability of these two different types of suppressors now makes it possible to obtain a coordinated protection of all the appliances in a home or all the equipment in an industrial environment. Improper coordination, however, could force the lower voltage device to assume all the current, leaving the high-energy protector uninvolved; this situation could then cause premature failure of the low-voltage suppressor. This paper discusses the elements of coordinated protective system based on experimentation.

\section{SECONDARY ARRESTERS AND LOW-VOLTAGE SUPPRESSORS}

Typical secondary arresters for $120 \mathrm{~V}$ service consist of an air gap in series with a varistor made of silicon carbide. The device is generally packaged with two arresters in the same housing; the physical arrangement is designed for in. stallation on the outside of a distribution panel, through a knockout hole of the panel enclosure or at the entrance to the building.

Limitations on the gap design imposed for the purpose of reliable operation and clearing after a high current discharge $(10 \mathrm{kA}, 8 \times 20)$ do not allow the sparkover of the gap to be less than about $2000 \mathrm{~V}$. This sparkover and the time required to achieve it allow injection of a potentially damaging surge into the "protected" power system downstream from the arrester." While this $2000 \mathrm{~V}$ level provides better protection than the protective characteristics indicated in ANSI standards [3], lower voltage clamping is desirable for the protection of sensitive electronics.

In this paper the high-energy suppressor, typically installed at the service entrance, will be called arrester. The low-energy, low-voltage suppressor, typically installed at an outlet or incorporated into an appliance or connected load, will be called suppressor.
Metal oxide varistors suitable for $120 \mathrm{~V}$ line applications can clamp surge volıages at less than $1000 \mathrm{~V}$, typically at $50010600 \mathrm{~V}$ for surge currenis of less than $1000 \mathrm{~A}$. These varistors provide excellent protection for electronic systems. The economics of device size, however, limits the wide use of large varistors, especially since smaller varistors can do an acceptable job if they are not exposed to excessive currents. Proper coordination among the devices used is required to obtain a reliable protection system.

\section{PROTECTION COORDINATION}

While the installation of surge protective devices functions effectively for high-voltage utility systems coordinated by centralized engineering, the current trend toward regulatory installation in low-voltage systems, because they are seldom centrally engineered and coordinated, can result in damaged equip. ment and system failure. The successful application of protective devices to a low-yoltage system demands a perspecuive of the total system, as well as a knowledge of individual device characteristics. Where such knowledge and coordination are lacking, a low-voltage suppressor installed in conjunction with an arrester can prevent the voltage at the terminals of an arrester from reaching its sparkover level. As a result, all of the surge current may be forced into the suppressor, which may not have been intended to withstand extreme conditions.

Proper coordination in an arrester/suppressor system requires some impe. dance between the two devices. This impedance is generally provided by the wiring: at the beginning of the surge, the rapidly changing current produces an inductive voltage drop in this wiring, in addition to the drop caused by the resistance of the wiring. Thus, the voltage at the terminals of the arrester during the current rise of the surge is equal to the clamping voltage of the suppressor, plus the voltage drop in the line (tests reported below indicate that this voltage drop is indeed appreciable). This voltage addition can then raise the terminal voltage of the arrester sufficiently to reach sparkover. In this way the arrester will divert most of the surge current at the entrance, rather than permitting it to flow in the suppressor.

The application of a suppressor alone is likely to occur because electronic appliance manufacturers increasingly provide suppressors incorporated into their products. With no arrester at the service entrance, the wiring clearances can become a voltage-limiting device, thus establishing a clearance/suppressor system. The suppressor would again tend to assume all of the surge current flow. The voltage drop in the line, in a manner similar to that of the arrester/ suppressor system, would raise the voltage at upstream points to levels that may spark over the clearances of wiring devices, providing unplanned relief for the suppressor. When sparkover of the clearances occurs, there are three possible results:

a. A power-follow current occurs, with destructive effects on the components.

b. A power-follow current occurs, but overcurtent protection (breaker or fuse) limits the damage. The system can be restored to operation after a mere nuisance interruption.

c. No power-follow current takes place; the overvoltage protective function of the system can be considered as accomplished.

The concept of protecting solid insulation by allowing clearances to spark over first is actively promoted by the Low Voltage Insulation Coordination Subcommittee of the International Electrotechnical Commission [4]. Further discussion of it is oulside the scope of the present paper; nevertheless, the concept is worth attention because cost reductions and system reliability could be obtained through its proper application.

Two examples of protection coordination will now be discussed in detail. These examples represent two scenarios on surge injection; they are based on experiments involving an arrester and suppressors in simulated lightning surge conditions. In the first scenario the surge is assumed to be injected between one of the phase wires and the center conductor (ground) of the service entrance. In a second scenario the surge current is assumed to be injected directly into the ground system of a service entrance only. Both experiments show the benefits and importance of proper coordination. In both tests the arrester was a gap-silicon carbide combination (Fig. 1) and the suppressor, a melal oxide varistor in a plugin package (Fig. 2)

\section{SURCE APPLIED BETIVEEN PHASE AND GROUND}

\section{Test Circuits}

The test circuit (Fig. 3) consisted of a terminal board from which two lines, one $7.5 \mathrm{~m}(25 \mathrm{ft})$ long and the other $30 \mathrm{~m}(100 \mathrm{ft})$ long were strung in the test area. A short, $3 \mathrm{~m}(10 \mathrm{ft})$, line simulated the service drop. All of these lines Power Engineering society for presentation at the IEEE PES Sumer leeting, Vancouver, British Columbia, Canada, July 15-20, 1979. Manuscript submitted February 6 , 1979; made available for printing Apri1 3, 1979. were made of three-conductor, nonmelallic, 12 AWG sheath wire. The neutral and ground wires of the three lines were connected together at the terminal board and from there to the reference ground of the test circuit. 


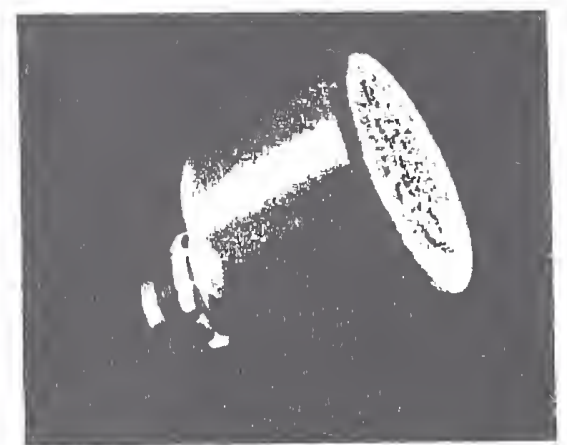

Fig. 1. Typical arrester for service entrance installation.

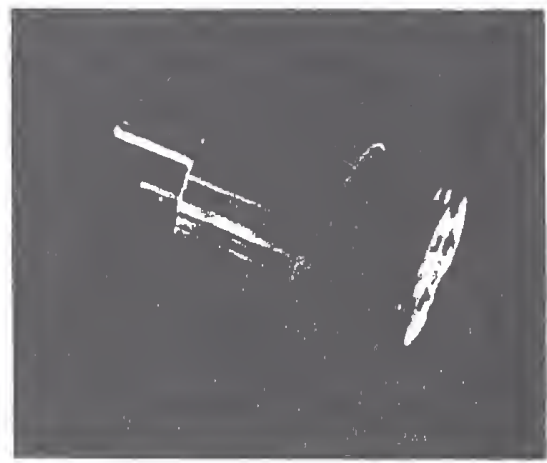

Fig. 2. Typical suppressor for plugin installation.

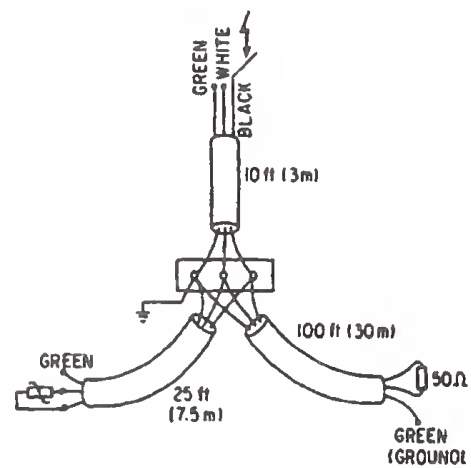

Fig. 3. Test circuit.

All surge currents were applied between the line conductor (black) at the end of the service drop and the reference ground (green and white). These impulses were obtained from a $5 \mu \mathrm{F}$ capacitor charged at a suitable voltage and discharged into the wiring systern by an ignitron switch. The resultant open-circuit voltage waveform, a unidirectional wave of I $\mu$ s rise time $x 50 \mu \mathrm{s}$ to one/half value time, corresponds to the standard test wave in utility systerns. Fig. 4 shows typical open-circuit voltage and short-circuit current waveforms. Voliages were recorded by a storage oscilloscope through an attenuator probe (1000:1); currents, through a current probe and a current transformer. Thus, the calibrations displayed on the oscillogram are to be multiplied by 1000 for the voltage. The current traces show the $50 \mathrm{mV}$ setting corresponding to the rated ousput of the current probe, with the amperes per division shown in parentheses corresponding to the current transformer ratio and current probe input setting for a direct reading. The sweep rate is also shown on the oscillograms, at $10 \mu \mathrm{s} /$ div. ror all the tests.

\section{Test Results}

Fig. Sa shows the voltage across the arrester when subjected to the surge defined by Figs. $4 \mathrm{a}$ and $4 \mathrm{~b}$. Note that the sparkover voltage reaches $2200 \mathrm{~V}$, with several oscillations, before the voltage settles down to the impulse discharge voltage at about $2000 \mathrm{~V}$ at its start.

Figs. $5 \mathrm{~b}$ and $5 \mathrm{c}$ show, respectively, the voltage and current across the varistor in the suppressor. Note that the maximum voltage is $600 \mathrm{~V}$ for a $550 \mathrm{~A}$

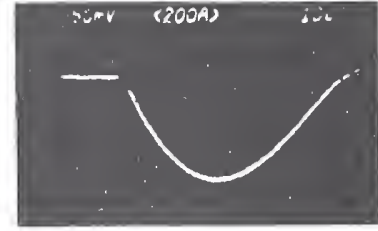

(a)

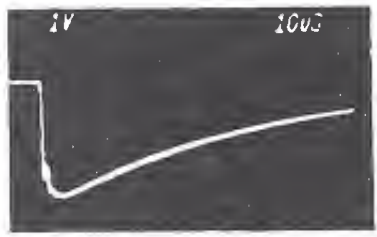

(b)
Fig. 4. Open-circuit voltage and short-circuit current (without any protector).

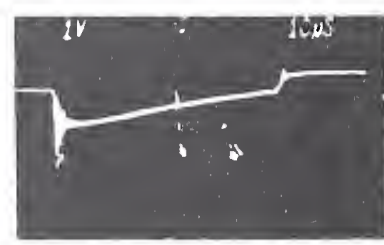

(a)

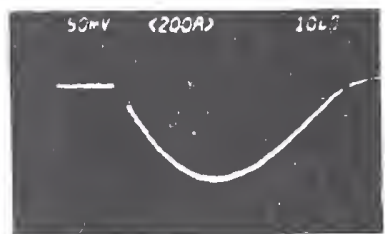

(c)

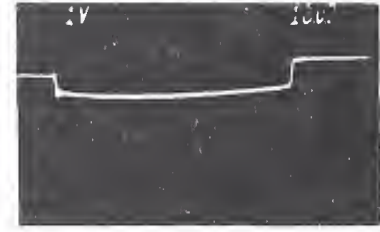

(b)

Fig. 5 Response of arrester and suppressor. currellt on the varistor. (The current in the suppressor is lower than the available short-circuit current as a result of the reduced driving voltage, because the varistor holds off $600 \mathrm{~V}$.

Fig. 6 shows several oscillograms indicating how the surge propagates in the wiring in the absence of any suppressor. Fig. 6a shows the open-circuit voltage at the service box. At the open-ended $7.5 \mathrm{~m}$ ( $25 \mathrm{ft})$ line, the voltage is substantially the same as at the box (Fig. 6b). However, at the end of the $30 \mathrm{~m}$ (100 ft) line with a $50 \Omega$ termination, a significant decrease of the slope is noticeable, while the crest remains practically unchanged (Fig. 6c).

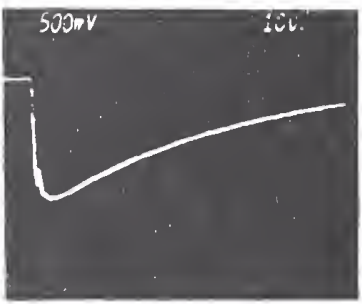

(a) open-circuil voliage-ar box

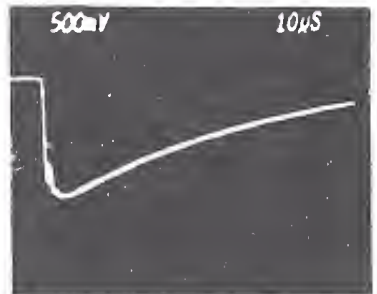

(b) open-circuil voliage- $7.5 \mathrm{~m}$ (25 fi)

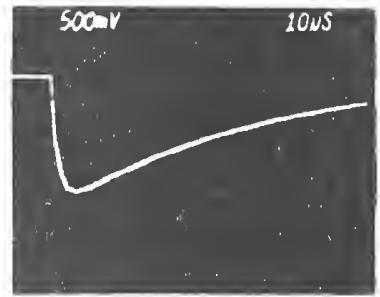

(c) open-circuil voliage $\cdot 30 \mathrm{~m}(100 \mathrm{ft})$
Fig. 6. Propagation of surge.

With voltage limiting at the box provided by the installation of a suppressor, even at a remote oullet. an artecter connerled al the servire hox would not reach its sparkover voltage until substantial surge currents were involved. A larger current was required for a short distance between the service box and the suppressor than for a greater distance. The value of the current required to reach sparkover as a function of the distance is therefore of interest.

For a distance of $7.5 \mathrm{~m}(25 \mathrm{ft})$ the threshold condition for sparkover of the arrester is shown in Fig. 7. In Figs. $7 \mathrm{a}$ and $7 \mathrm{~b}$ the open-circuit voltage and short-circuit current are shown for this threshold setting of the generator. Inspection of the oscillograms shows an open-circuit voltage of $8.1 \mathrm{kV}$, with a calculated equivalent source impedance of $4.2 \Omega$. This low value of the source 
impedance, compared to proposed values [5], provides a conservative evaluation of the system performance. For the same setting as Figs. $7 \mathrm{a}$ and $7 \mathrm{~b}$, the oscillograms of Figs. $7 \mathrm{c}$ and $7 \mathrm{~d}$ show the case in which the arrester has sparked over, as indicated by its voltage (7c) and current (7d) traces. In Figs. 7e and $7 f$ the traces show the voltage (7e) and current (7n) in the suppressor for a case in which the arrester did not spark over (as a result of the scatter of sparkover or a slight difference in the output of the surge generator). This case represents the most severe duty to which the suppressor would be exposed, for a distance of $7.5 \mathrm{~m}(25 \mathrm{ft})$.

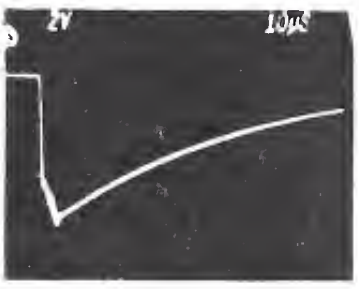

(a) open-circuil voltage

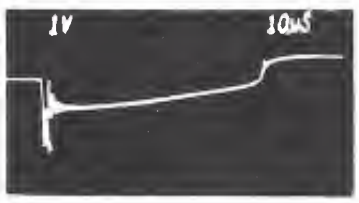

(c) voluge al arrester when arrester does sparkover - suppressor al $7.5 \mathrm{~m}$ (25 fi)

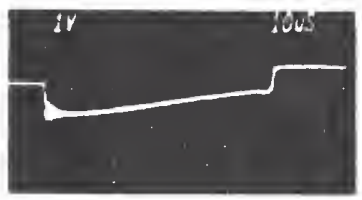

(e) voluge at suppressor when arrestor doea not sparkover - suppressor at $7.5 \mathrm{~m}$ (23 f)

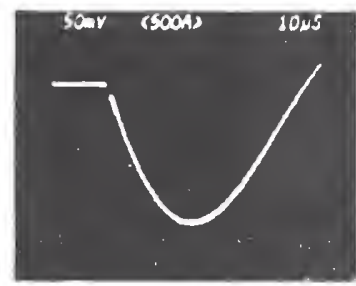

(b) short-circuil curren!

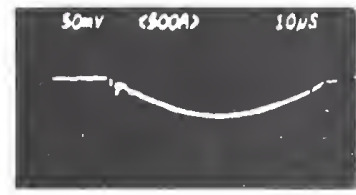

(d) current in arrester after sparkover suppreseor at $7.3 \mathrm{~m}$ (25 (i)

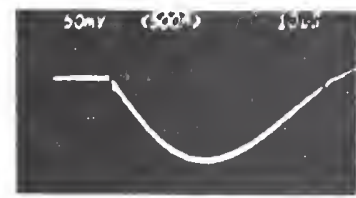

(I) current in suppressor when arrester does no sparkover - suppressor at $7.5 \mathrm{~m}$ ( $25 \mathrm{ft}$ )
Fig. 7. Transfer of surge conduction.

From these tests it is apparent that the $1200 \mathrm{~A}$ nowing in the line to the suppressor (7ก) and establishing $1000 \mathrm{~V}$ at the varistor terminals (7e) causes an additional $1000 \mathrm{~V}$ drop in the line. The resulting $2000 \mathrm{~V}$ appearing at the arresier terminals may cause sparkover of the arresier (7c).

For a case in which there is no arrester installed at the box but only the suppressor installed at an outlet, the voltage rise in the wiring and the meter coils will most likely result in a nashover of the system, which would then divert the excessive energy away from the suppressor, just as the arrester did in the test. Of course, this diversion may be destructive, a result that the arrester. when installed, is precisely designed to prevent.

For greater distances between the suppressor and the arrester, the transfer of the surge will occur at lower currents. For instance, with the suppressor installed at the end of the $30 \mathrm{~m}(100 \mathrm{ft})$ line, only $700 \mathrm{~A}$ were required in the suppressor to reach sparkover of the arrester.

\section{Discussion}

The tests on simulated high-energy surges indicate that a transfer occurs from the suppressor to the arrester at a current level which depends on the distance between the iwo devices. Even for a short length of wire, the suppressor is relieved from the surge by sparkover of the arrester before excessive energy can be deposited in the varistor of the suppressor. At lower current levels. where the voltage in the system is clamped by the suppressor and thus prevents sparkover of the arrester, the suppressor absorbs all of the surge energy.

In all instances, the voliage level at the suppressor is held low enough to protect all electronic appliances having a reasonable tolerance level $(600 \mathrm{~V}$ in mosi cases, $1000 \mathrm{~V}$ in some cases). Furihermore, ihe installation of only one suppressor in the house provides substantial protection for other ourlets, although optimum prolection requires the use of a suppressor at the most sensitive appliance, with additional suppressors for other sensitive appliances.

\section{SURGE INJECTED INTO GROUND SYSTEM}

\section{Assumptions}

For this experiment it was postulated that a lightning stroke attaching to the primary side of an overhead distribution system would produce a branching of the current flow into the ground after sparkover of the pole-mounted utility's surge arrester (which was presumed connected at the pole-mounted distribution transformer). Fig. 8 shows the assumed circuil and the division of current flow.

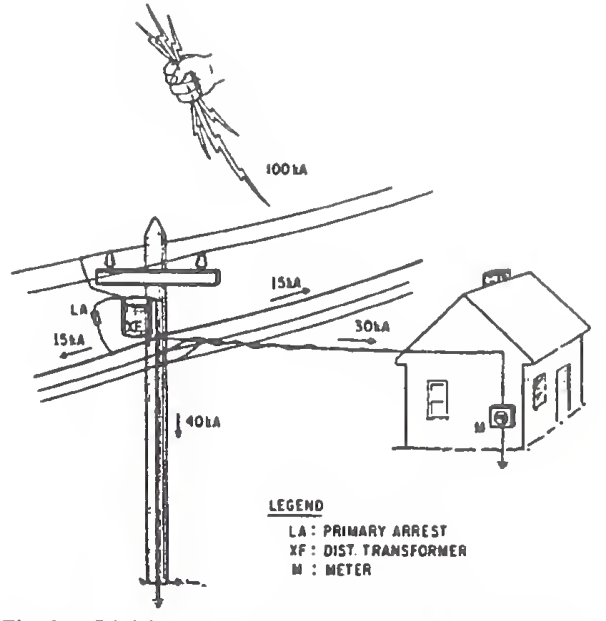

Fig. 8. Division of current assumed for a $100 \mathrm{kA}$ stroke.

In their study of lightning environments, Cianos and Pierce [6] indicate that only $5 \%$ of all ground strokes exceed a peak current of $100 \mathrm{kA}$. The frequency of the strokes is dependent upon the geographic location (isokeraunic levels) (7), as well as upon local configurations. The probable occurrence of a stroke involving the utility pole near a house with no adjacent tall trees or buildings is 1 per 400 years for most of the U.S. For a $5 \%$ probability, the likelihood can be reduced 20 imes; in areas of high lightning activity, this likelihood can be reduced 10 rimes. A stroke exceeding $100 \mathrm{kA}$ at one location, therefore, can be expecied to occur only once in 10,000 years (but there are millions of poles in the U.S.)

From these assessments, the maximum current to be injected for the house model under discussion was selected to be $30 \mathrm{kA}$. From this maximum of $30 \mathrm{kA}$ injected into the ground wire of the house service drop, two more values were used during the test series: $10 \mathrm{kA}$, corresponding to the requirement for the ANSI high-current, short-duration test; and $1.5 \mathrm{kA}$, corresponding to the requirement for the ANSI duty-cycle test - both specified by ANSI Standard C 62.1 for secondary valve arresters [3]. All had waveshapes of $8 \times 20 \mu \mathrm{s}$.

Another reason for selecting this low level (1.5 kA) was that no sparkover occurs in the wiring at this level. For the 10 and $30 \mathrm{kA}$ levels, multiple flashovers occur at variable times and locations, making exact duplication of tests impossible. By limiting current to below sparkover levels, repeatability of the results was ensured, allowing comparisons among several alternate circuit configurations.

The generation of transient voliages in the house is attributed to electromagnetic coupling. The lightning current in the messenger establishes a field that couples into the loop formed by the two phase wires encircling the messenger. In addition, there is some capacitive coupling between the wires (Fig. 9).

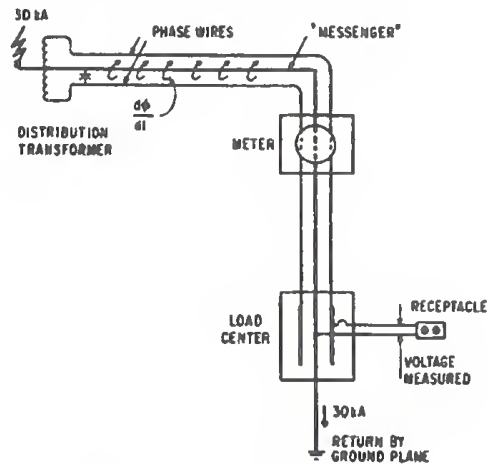

Fig. 9. Voltages induced in the house wiring system.

\section{Test Circuit}

The lest circuit consisted of a high-current impulse generaror, a distributinn transformer with a service drop, a simulated cimplified house wiring sye tem, and the necessary shielded instrumentation.

The service drop connection between the distribution transformer and the meter socket was made with three 13 in. - (45 ft-) long AWG $\# 6$ wires, i wisied at a pilch of about 5 turns $/ \mathrm{m}$ (1.5 turns/ft). This service drop was folded in a loose " $\mathrm{S}$ " shape at about $0.5 \mathrm{~m}(1.5 \mathrm{ft})$ above the ground plane serving as the return paih for the lighıning current, in order to reduce the loop inductance seen by the generator. This configuration does not influence the coupling beiween the messenger and the wires wrapped around it, coupling which has been identified as the voltage-inducing mechanism. 
The simulated house wiring started at the meter sock ct and continued to a load center over a distance of $3 \mathrm{~m}$ ( $10 \mathrm{ft}$ ). From this load center four " branch circuits" connected to the load center breakers were established, each terminating at a wall receptacle. Individual lengths of the branch circuits were 6 , 12,24 , and $48 \mathrm{~m}(20,40,80$, and $160 \mathrm{ft})$.

\section{Test Results}

Many tests were performed to investigate the effects of various combina. tions. A selection was made from several hundred recorded oscillograms to il. lusirate these effects. The results are presented in the form of oscillograms with corresponding commentary, generally providing a comparison of voltages and currents with or without protectors installed.

The first striking result noted was that the injection of a unidirectional impulse into the ground system produces oscillatory voltages between the phase and ground wires. Inspection of the no-load oscillogram (Fig. 10a) reveals two interesting phenomena. First, the frequency of the major voltage oscillation is constant for all branch circuit lengths (period $=2 \mu \mathrm{s}$ ). Thus, we can conclude that this frequency is not affected by the line length and that other circuit parameters, rather, are responsible for inducing this $500 \mathrm{kHz}$ oscillation from a $8 \times 20$ us current wave. Second, the minor oscillations visible during the first loop in each oscillogram are spaced apart at a distance that increases with line length. One can conjecture that these may be caused by reflections.

Loading the line termination with a 130 Q resistor (Fig. 10b) eliminates the later oscillations and reduces the first peak 10 about $60 \%$ of the value without load. From this reduction, a Thevenin's calculation of circuit parameters, if applicable in an oversimplified form, would show that $130 \Omega$ is $60 \%$ of the total loop impedance, while the source impedance is $40 \%$ of the toral loop impedance. Hence, one can conclude that the equitalent source impedance is in the order of four-sixths of 130 , or about 85 Q, in this scenario.
OPEN.CIRCUIT VOLTAGE

$$
\text { Sween 2uv/div }
$$

Voltage at oullel indicated: $500 \mathrm{~V} / \mathrm{div}$
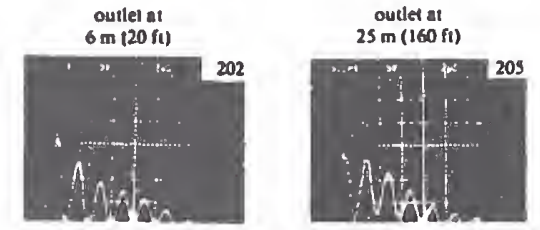

VOLTAGE WITH 1300 CONNECTED AT OUTLET INDICATED

Sweep: 2ugdiv

b) Vohage al oultel indicaled: $500 \mathrm{~V} / \mathrm{div}$
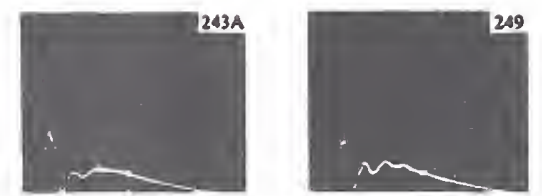

Fig. 12 shows the recordings made during a $30 \mathrm{kA}$ current injection. This extreme condition is capable of producing a $3500 \mathrm{~A}$ current in an arrester installed at the service entrance (Fig. 12a). If now we postulate a pessimistic situation where there is no artester at the service entrance, but only a suppres. sor at an outlet, there are two possible outcomes. When no wiring sparkover occurs, as discussed in Section 111, all the surge is indeed forced upon the suppressor (Fig. 12b). This current may be excessive for some suppressors, but this example is certainly a limited case. The more likely scenario is illustrated in Fig. I2c, where sparkover of the wiring upstream of the suppressor limits the current in the suppressor. In this last scenario, protection is obtained downstream from the suppressor. It is important to note that no additional hazard is created by installing the suppressor: the undesirable sparkover would occur even without the suppressor; in fact, without the suppressor, sparkover would be even more likely to occur.

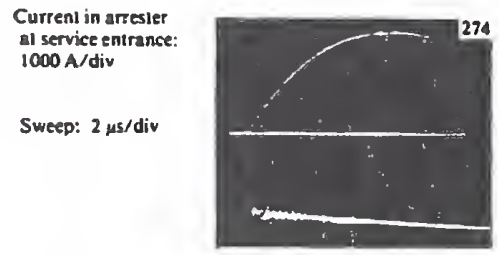

(a)

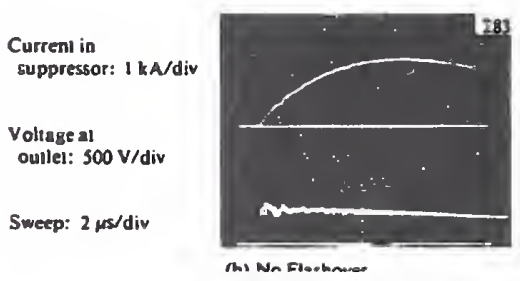

Current in suppressor: $1 \mathrm{kA} / \mathrm{div}$

Voltageal outlel: $500 \mathrm{~V} / \mathrm{div}$

Sweep: $2 \mu \mathrm{s} / \mathrm{div}$

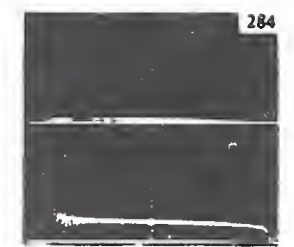

(c) Wiring Flashover
Fig. 10. Open-circuit volıages and effect of terminal impedance. Injected current: 1.5 kA.

With no protectors at the load center nor at any outlets, the wiring flashes over at $10 \mathrm{kA}$ injected current, but not before crests in the range of $8 \mathrm{kV}$ have been reached (Fig. 11 a). With an arrester installed at the load center, voltages are limited to $2.2 \mathrm{kV}$, with about I kA current discharge in the arrester (Fig. 11b). While eliminating the hazard of a wiring flashover or the failure of a typical electromechanical device, this $2.2 \mathrm{kV}$ protective level may still be excessive for sensitive electronics.

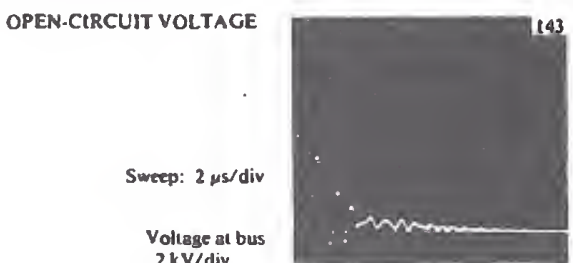

\section{VOLTAGE AND CURRENT WITH} ARRESTER ON LOAD CENTER

Sweep: 2 ms/div
Current in arrester
$400 \mathrm{~A} / \mathrm{div}$
voluago Aoroce Due
$500 \mathrm{~V} / \mathrm{diy}$

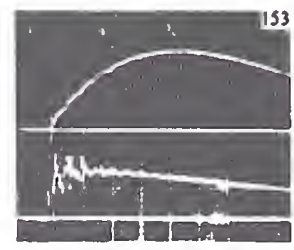

Fig. 11. Protection provided by arrester at service entrance. Injected current: $10 \mathrm{kA}$.

"Not to be confused with the surge impedance $(\mathrm{L} / \mathrm{C})^{1 / 2}$ of the line.

\section{CONCLUSIONS}

Coordination of surge protectors is feasible with existing devices, even if device characteristics vary. The experiments reported in the paper show three facts from which conclusions can be drawn:

Fact 1. Where a unidirectional current is injected into the ground system only, the response of the system is an oscillating voltage, at $500 \mathrm{kHz}$ for the system described.

Fact 2. The equivalent source impedance, as determined by loading the system, is in the range of 50 to $100 \Omega$ for the particular system investigated.

Fact 3. Without substantial connected loads in the system, the open-circuit surges appearing at the service entrance propagate along the branch circuits with very little altenuation.

Concl. 4. Coordination of surge suppressors requires a finite impedance 10 separate the two devices, enabling the lower voltage device to per. form its voltage-clamping function while the higher voltage device performs the energy-diverting function.

Concl. 5. The concept that surge voltages decrease from the service entrance to the outlets is misleading for a lightly loaded system. Rather, the protection scheme rrust be based on the propagation of unatienuated voltages.

Concl. 6. Indiscriminate application of surge protecıors may, aı besı, fail to provide the intended protection and, at worst, cause disruptive operation of the suppressors. What is needed is a coordinaled approach based on the recognition of the essential factors governing devices and surge propagation.

\section{ACKNOWLEDGMENT}

The contribution of K. E. Crouch in oblaining the current injection test results is gratefully acknowledged. 


\section{REFERENCES}

1. Martzloff, F.D., and G.J. Hahn. "Surge Voltage in Residential and Industrial Power Circuits," IEEE PAS-89.6. July/A ug. 1970, 1049-1056.

2. Lenz, J.E., "Basic Impulse Insulation Levels of Mercury Lamp Ballast for Outdoor Applications," Illuminating Engrg.. February 1964. pp. 133-140.

3. Guide for Application of Valve-Type Lightning Arresters For Alternating Current Systems, ANSI Standard C62.2-1969.

4. Insulation Coordination Within Low-Volıage Systems Including Clear. ances and Creepage Distances for Equipment, International Electrotechnical Commission Report SC28A (Central Office) S, to be published in 1979.

5. Guideline on Surge Voltages in AC Power Circuits Rated Up to $600 \mathrm{~V}$. IEEE Project P587.1. First draft, 1978.

6. Cianos, N. and E.T. Pierce "A Ground-Lightning Environment for Engineering Usage," Stanford Research Institute, Menlo Park. CA 94205. August 1972 .

7. Electrical Transmission and Distribution Reference Book, Westinghouse Electric Corporation, 4th Edition, East Pittsburgh, $\mathrm{Pa} ., 1950$.

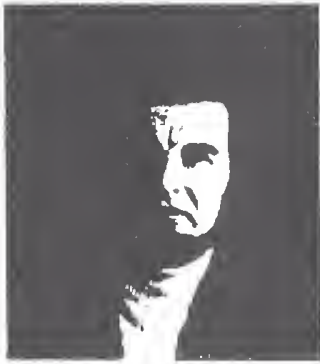

Francois D. Martzloff (M, 1956) was born in France and received his undergrónluate degree at the Ecole Spéciale De Mécanique et d'Electricité in 1951: he received the MSEE degree from Georgia Tech in 1952 and the MSIA degree from Union College in 1971 .

Since 1956 he has been with the General Electric Company, where he first gained experience in the Transformer and Switchgear Divisions. Upon joining General Electric Corporate Research and Development in 1961, he became involved in power semiconductor circuits and overvoltage protection. He has participated in the introduction and application of metal oxide varistors since 1971 .

In IEEE Mr. Martzloff has been active on the Surge Protective Devices Commiltee and chairman of the Working Group on Surge Voltages in AC Power Circuits Rated $600 \mathrm{~V}$ or Less. He is also a member of the Ad Hoc Advisory Subcommittee of the USA Advisory Committee on IEC S/C $28 \mathrm{~A}$. He has been awarded 10 U.S. patents, primarily in the field of varistors and transient protection. 


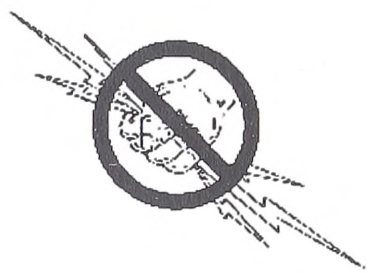




\title{
The Propagation and Attenuation of Surge Voltages and Surge Currents in Low-Voltage AC Circuits
}

\author{
François D. Martzloff \\ General Electric Company \\ Schenectady NY \\ t.martzloff@ ieee.org
}

\begin{abstract}
Reprinted, with permission, from IEEE Transactions on Power Apparatus and Systems, PAS-102, May 1983
First presented at IEEE Summer Meeting, San Francisco, July 1982

Also reprinted as "High Interest Paper" in IEEE Power Engineening Review, January 1984

Paper Award, 1985, Surge-Protective Devices Committee
\end{abstract}

\section{Significance: \\ Part 4 - Propagation and coupling of surges}

Examples are given showing the propagation of voltage and current surges in low-voltage wining systems. The difference between surge impedance (characteristic impedance $\mathrm{Z}_{0}$ ) of a transmission line and the impedance to the surge of wire runs is pointed out and illustrated.

The relationship between front time/duration of a voltage surge on the one hand, and the travel time (length-related) along the circuit, on the other hand, is placed in the perspective of transmission line theory and makes clear the point that the classical doubling of an impulse at the end of an open line requires a travel time greater than the front time of the impulse.

A comparison is made between the propagation of a surge through isolating transformers and through a ferro-resonant line conditioner. The isolation transformers do not provide effective attenuation of voltage surges in the differential mode but the ferro-resonant line conditioner does, in addition to its prime function of voltage regulator.

For current surges of the type encountered in AC power circuits (not short pulses), their propagation is impeded - as in "impedance" - not by the characteristic impedance of the line nor appreciably by skin effects, but mostly by the inductance of the line for a frequency spectrum in the range of $5 \mathrm{kHz}$ to a few hundred $\mathrm{kHz}$. This provides some relief for SPD connected at the end of branch circuits. The issue was revisited and confirmed several years later in the 1995 "Upside-Down House" experiments (see Upsdown measure in this Part 4)

The effects of connection options are shown for one, two or three SPDs connected at the end of a 3-wire line. 


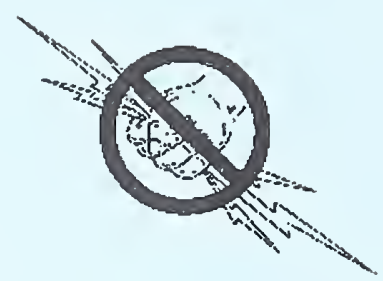




\title{
THE PROPAGATION AND ATTENUATION OF SURGE VOLTAGES AND SURGE CURRENTS IN LOW-VOLTAGE AC CIRCUITS
}

\author{
F.D. Martzloff, Senior Member
}

Corporate Research and Development

General Electric Company Schenectady, Schenectady, New York

\begin{abstract}
Examples are given showing the propagation of voltage and current surges in low-voltage wiring systems. The difference between surge impedance (characteristic impedance) of a transmission line and the impedance to the surge of wire runs is pointed out and illustrated. A comparison is made between the propagation of a surge through an isolating transformer and a ferro-resonant line conditioner. The effect of connection options are shown for one or several surge protective devices connected at the end of a 3 -wire line.
\end{abstract}

\section{INTRODUCTION}

Considerable progress has been made during the last decade toward recognizing the occurrence of surge voltages in low-voltage circuits, particularly in ac power circuits; at the same time, improved protective devices have become available. New standards and guides have been published on the subject [1-5], but practical information is still scarce on the propagation of these surges in circuits. In fact, misconceptions are sometimes encountered, such as an expectation that surges will always attenuate substantially as they propagate in the wiring system of a building or through transformers.

This paper provides concrete examples on the propagation of surges and on some possible means to divert or attenuate them, from which some conclusions can be drawn and sound practices recommended.

The tests reported here have been performed with the voltage and current waveshapes recommended by the recently published "IEEE Guide for Surge Voltages in Low-Voltage AC Power Circuits," IEEE Std 587-1980.

Starting from the basic propagation of a pulse along a transmis. sion line, the examples show how real wiring systems differ from an idealized transmission line, how complex systems transform pure standard waves, and how some connection practices for surge protective devices can introduce adverse effects by producing residual voltage surges between conductors. Merits and misconceptions regarding isolating transformers are compared with ferroresonant line conditioners which, in addition to their regulating function, block the propagation of fast transients, such as the IEEE 587 ring wave.

This paper does not propose to present a comprehensive treatment of surge suppression, but rather to show how the propagation of surges affects the voltages appearing at the loads. The examples reported are given in order to alert the reader against some pitfalls resulting from occasional misconceptions observed by the author during discussions and reviews of many surge-related problems.

82 SM 453-9 A paper recommended and approved by the IEEE Surge Protective Devices Committee of the IEEE Power Engineering Soclety for presentation at the IEEE PES 1982 Summer Meet1ng, San Franc1sco, Callfornla, July 18-23, 1982. Manuscr1pt subm1tted February 2, 1982; made avallable for printing May 17, 1982.

\section{TEST CIRCUITS AND TEST GENERATORS}

The test circuits selected to represent typical low-voltage ac circuits include runs of nonmetallic jacketed $600 \mathrm{~V}$ wire such as that found in residential wiring and runs of rigid conduit with wires pulled in the conduit, such as that found in industrial installations. In these tests, all use two-conductor configurations with a third grounding wire, AWG \#12 size (2.05 mm dia.).

The test waves, in accordance with IEEE Std 587.1980, include the $0.5 \mu \mathrm{s}-100 \mathrm{kHz}$ voltage ring wave, the $1.2 / 50 \mu \mathrm{s}$ voltage impulse, and the $8 / 20 \mu \mathrm{s}$ current impulse. The $0.5 \mu \mathrm{s}-100 \mathrm{kHz}$ wave is produced by a KeyTek 424 surge generator, capable of superimposing the voltage pulse at a controllable time of the $60 \mathrm{~Hz}$ line voltage, with crest up to $6 \mathrm{kV}$ (Figure 1). The 1.2/50 impulse is produced by a Haefely P6R generator, capable of supplying up to $6 \mathrm{kV}$ (Figure 2). The $8 / 20$ impulse is produced by the same KeyTek 424 with a different plug-in unit (Figure 3) or by a laboratory circuit using storage capacitors and an ignitron switch. The initial test involving transmission line propagation is made with a narrow pulse obtained from a Velonex 350 pulse generator.

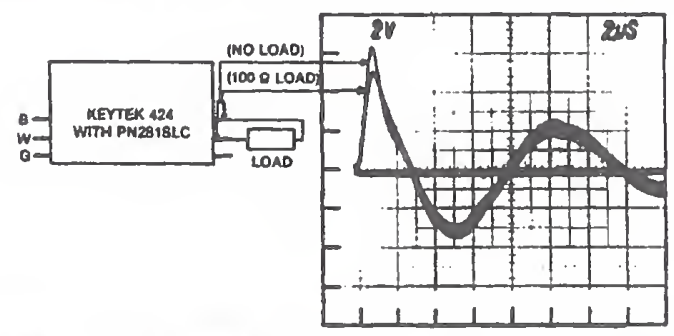

Figure 1. Test waves of $0.5 \mu s-100 \mathrm{kHz}$, open circuit and loaded, produced by KeyTek 424 generator and PN281LSC plug-in

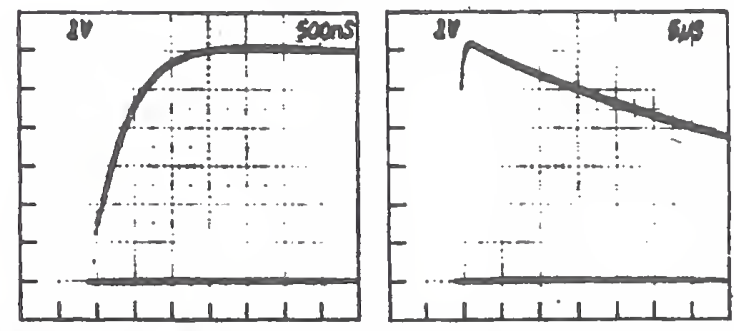

Figure 2. Test wave of $1.2 / 50 \mu \mathrm{s}$, open circuit, produced by Hsefely P6R pulse generator

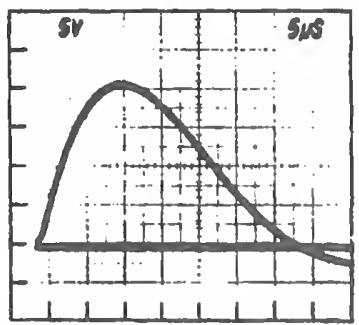

Figure 3. Test waves of $8 / 20 \mu s$, short circuit produced by KeyTel 424 pulse generator with PN247 plug-in 
The oscillograms were recorded with a Tektronix 7633 oscilloscope. Voltage measurements were made with two 1000:i Tektronix P6015 probes in differential configuration, so that the display calibration of the oscillograms is to be multiplied by 1000 . Current measurements were made with a $0.010 \Omega$ T\&M Research coaxial shunt, so that the display calibration is to be multiplied by $100 \mathrm{~A} / \mathrm{V}$.

The oscillograms are shown together with a schematic of the circuit configuration. The three wires of the various lines are shown as B (black), W (white), and G (green), with the usual convention on color. The impulse was applied between the point shown by the lightning bolt and the ground symbol. The points of connection of the differential probes and the resultant recording are connected by the arrows.

\section{PROPAGATION OF VOLTAGE SURGES}

\section{Transmission lime behavior}

To establish the baseline of the propagation characteristics, a $75 \mathrm{~m}$ line of 2-wire plus ground nonmetallic plastic jacket cable is subjected to pulses of 100 ns duration, with the voltages measured at the sending end and at the receiving end of the line. Figure 4 shows the oscillograms recorded at the sending end, with the out going pulse and the reflected pulse appearing $740 \mathrm{~ns}$ later, from which a propagation speed of $150 \mathrm{~m} / 740 \mathrm{~ns}$, or $200 \mathrm{~m} / \mu \mathrm{s}$, can be computed. As a side experiment, the classical nonreflection obtained by terminating the line with a resistance equal to the line surge impedance" is also observed for a terminating resistance of $100 \Omega$. The slight mismatch indicated by the small reflection remaining, even with the optimum value of $100 \Omega$ termination, is attributable to the connection of the line with closely spaced wires fanning out to the ends of the noninductive wire-wound resistor card. Resistor cards of $90 \Omega$ and $110 \Omega$ produce a positive-going or a negative-going reflection, respectively, indicating that the matching impedance is between these two values.

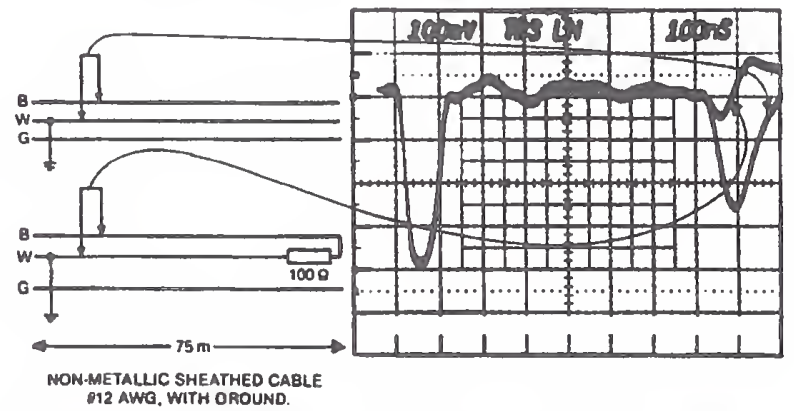

Figure 4. Transmission line behavior of non-metallic, piastic jacket wire

From this first test, we can draw the conclusion (predictable, but too often not recognized in qualitative discussions of reflections in wiring systems) that it is not appropriate to apply classical transmission line concepts to wiring systems if the front of the wave is not shorter than the travel time of the impulse. For a $1.2 / 50 \mu$ impulse, this means that the line must be at least $200 \mathrm{~m}$ long before one can think in terms of classical transmission line behavior. In the next example, we can observe reflections on the front of the impulses, but they are not significant to the final voltages at the crest values of the impulses.

\section{Short lines behavilor}

The response of lines shorter than the $200 \mathrm{~m}$ limit identified above is illustrated in Figures 5 and 6 . Figure 5 shows the response of a $25 \mathrm{~m}$ line of nonmetallic plastic jacket wire to a $1.2 / 50 \mu \mathrm{s}$ impulse; Figure 6 shows the response of conduitenclosed wires to the same impulse, for the same line length.

\footnotetext{
-A difference between surge impedance (also known as "characteristic impedance") and impedance to the surge will be discussed in the section dealing wilh current surges propagation.
}

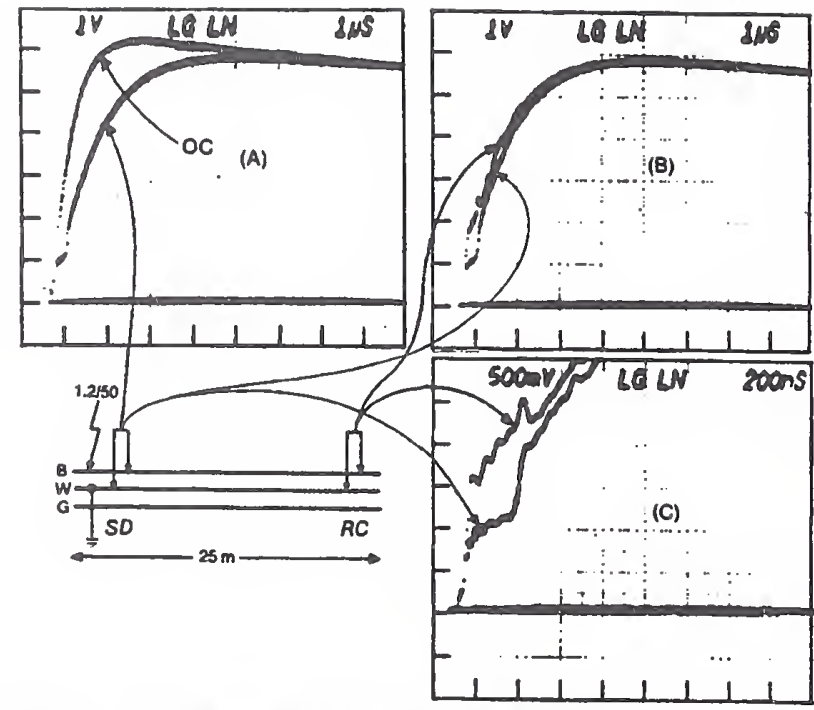

Figure 5. Response to a $1.2 / 50 \mu \mathrm{s}$ impulse of wiring in nonmetallic jacket

(A) Output of unloaded generator and with line consected

(B) Sending end and receiving end, open receiving end

(C) Expanded trace of oscillogram (B)
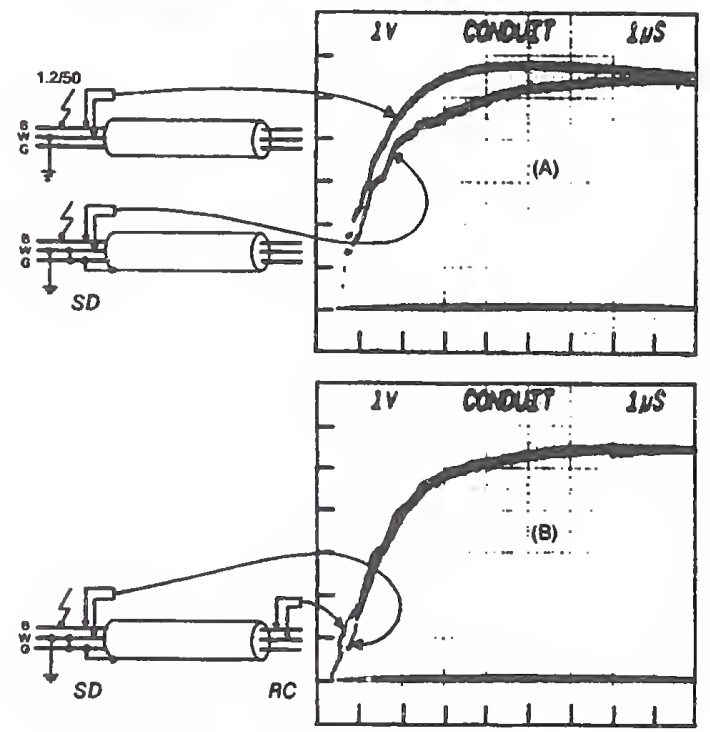

Figure 6. Response to a $1.2 / 50 \mu \mathrm{s}$ impoise of wiring In metal conduit

(A) Effect of grounding options at the sending end

(B) Sending end and receivlng end voltages

In both Figures 5 and 6, the front of the wave (SD side) is slower than $1.2 \mu \mathrm{s}(\mathrm{OC})$; this effect is caused by the line impedance loading the impulse generator. It is even more noticeable in Figure $6(\mathrm{~A})$, which shows the voltages at the sending end for the connection with white, green, and conduit tied together. The greater capacitance of this configuration, compared to white only at ground, produces a greater load on the generator, including the multiple reflections occurring at the mismatches produced by a conduit fitting at the mid-point of the conduit run; hence, the jagged appearance of the oscillogram.

The front of the impulse is further expanded in Figure $S(C)$, showing the difference between the sending and receiving ends of the line. Nevertheless, for an open-end line, as shown in Figure $5(B)$, the final volitage crest is not affected by the reflections occurring during the rise time of the impulse. Likewise, the slight differences between the sending end and the 
receiving end occurring early in the rise do not affect the final voltage at the receiving end of the conduit line.

These tests show that the propagation of voltage surges in open-ent' lines of lengths likely to be encountered in buildings does not proc'ice appreciable attenuation of the surges, nor does it cause a + llage buildup by reflection of the surges. This fact is significant for the case of an appliance or industrial equipment with a control circuit drawing very little load while the power circuit being controlled is off. During the on cycle of the power circuit, there will be some attenuation of the surge by the combined effect of the line impedance and load impedance, but that beneficial effect is not available during the off-cycle of the power circuit with standby condition of the control circuit, the very circuit containing the most sensitive electronic components of the appliance or equipment.

\section{Branched circuits}

Departing further from the simple and sanitary behavior of a transmission line, a still simplified branch circuit behavior is illus. trated in Figure 7. In this semi-idealized case of a real circuit, a $10 \mathrm{~m}$ line feeds 4 branches, each $10 \mathrm{~m}$ long. Three of the branches are left open ended, and the fourth has a heavy load - a short circuit. The interaction of this circuit with the impulse generator, set for the $1.2 / 50 \mu$ s impulse of Figure 2, produces the wave shown at the sending end, while the voltage at one of the open receiving ends goes through oscillations that only vaguely resemble the sending-end wave shape; of course, the idealized unidirectional impulse has vanished.

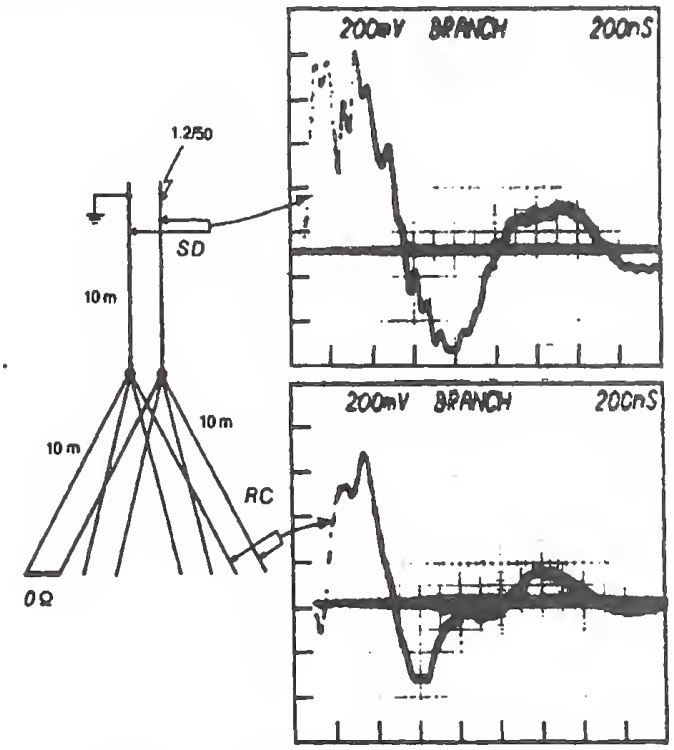

Figure 7. Response to a $1.2 / 50 \mu$ s impuise of a branched circult

This simple branch circuit behavior demonstrates why it would be an illusion or fallacy to cling to the concept that nature can be simulated with simple test waves."

\footnotetext{
- This dicholomy between simulating aature and performing standard tests has been recognized $[6,7]$, but still needs to be emphasized. A test wave is applied 10 a device, not to demonstrate that it can survive any of the waves that it will encounter in nature, but only to demonstrate for the benefit of bolh manufacturer and purchaser that the device can survive an agreed-upon, arbitrary, simple, clean impulse. From surviving the test impulse, the inference is made, subject to confirmation by field experience, that the device does have the capability to survive the infinite variety of surges that it will encounter during its life in the real world. In other words, simple (and clean) test waves are useful because they can be reproduced over a period of time at the same facility, and between different facilities, providing a common language and a standard of comparison that is essential to conduct orderly transactions. Test waves should not, however, be misconstrued as representing natural phenomena. They are "realistic" (which is not the same thing as "representing reality") only to the extenl that the conclusion drawn from surviving the test wave is validated by better survival in the field than for those devices that do not survive the test wave.
}

\section{Does an isolatiog transformer help?}

The author has witnessed and engaged in many discussions on the merits of isolating power transformers, sparked by the misconception indicated by statements such as "spikes are attenuated by transformers" or "spikes do not pass through transformers." Figures 8 through 12 are offered to support the position that these quotations are misconceptions. When properly applied, isolating power transformers are useful to break ground loops, but they do not by themselves attenuate surges that occur line-to-line or in the normal mode.

Figure 8 shows the propagation - or worse, the enhancement - of a voltage impulse in a $1: 1$ isolating power transformer. The $6 \mathrm{kV}$ impinging ring wave appears as $7 \mathrm{kV}$ crest on the secondary side of this "isolating" transformer.

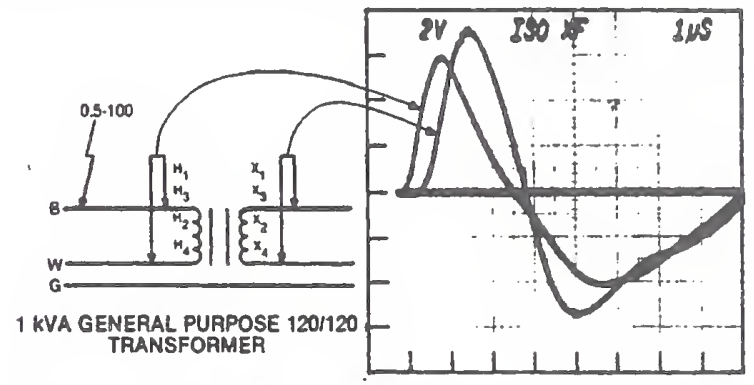

Figure 8. Propagation of a $0.5 \mu \mathrm{s}-100 \mathrm{kHz}$ Iing wave through an Isolating transformer

Figure 9 shows similar behavior in a transformer offered as a "line isolator." This product is intended to provide ground loop isolation and low effective capacitance between primary and secondary windings, but here again, the author has observed that users of this device expect attenuation of surges. The response of this isolator, due to its internal construction, is different from that of the simple two-winding transformer of Figure 8, but we also note that a crest of $8 \mathrm{kV}$ occurs on the secondary side, during the second half-cycle. Hardly an improvement.

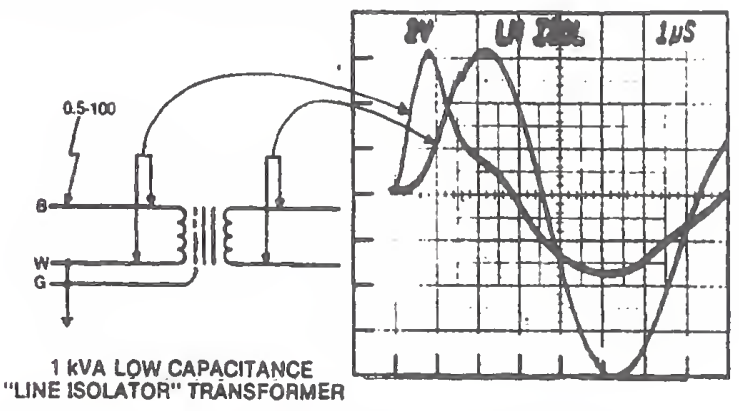

Figure 9. Propagation of a $0.5 \mu \mathrm{s}-100 \mathrm{kHz}$ ring wave through " "line isolator" transformer

Figures 8 and 9 were recorded with no load on the transformer secondary, which represents the extreme case of a low-power electronic control in the standby mode. Figure 10 shows the primary and secondary voltages of the transformer with a $10 \mathrm{~W}(1500 \Omega)$ and a $100 \mathrm{~W}(150 \Omega)$ load on the secondary side, at the same generator setting as Figure 8 . With the $10 \mathrm{~W}$ load that might be typical of an electronic control in standby mode, the combined series reactance of the transformer and shunt resistance of the load produce the output shown in Figure 10(A), still slightly higher than the input.

With the $100 \mathrm{~W}$ load shown in Figure 10(B), the attenuation is now apparent, but is only 2:1. Capacitive loads would, of course, produce a greater attenuation than resistive loads for the inductive series impedance of the transformer, at the frequency spectrum of this fast $2 \mu \mathrm{s}$-wide surge. For surges of longer duration, the attenuation would be smaller. 


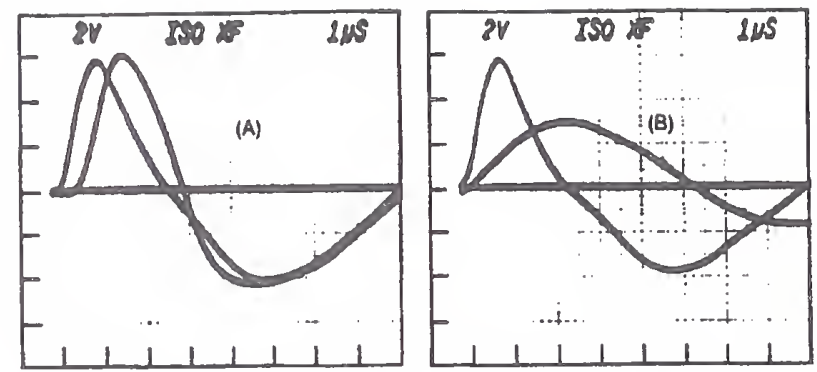

Figure 10. Effect of loading on the secondary side

These examples show that, unless a well-defined load is connected to the transformer, expecting attenuation from the transformer may prove to be hazardous to the health of low-power electronics connected on the secondary side of the transformer.

In contrast, decoupling of the surge is possible with a ferroresonant line conditioner, which is primarily intended for line voltage regulation, but which also provides a high degree of surge suppression. Figure 11 shows a $6 \mathrm{kV}$ impinging ring wave attenuated to $60 \mathrm{~V}(100: 1)$ on the secondary side of the unloaded line conditioner, and to $40 \mathrm{~V}$ (150:1) with a load of only $10 \%$; at full load, less than $10 \mathrm{~V}$ was observed. The nature of the ferroresonant line conditioner is such that the decoupling improves with loading, while the simple transformers of Figures 8, 9, and 10 can only act as linear dividers with load changes. Conversely, the decoupling between primary and secondary sides of the line conditioner is further seen on the oscillogram recorded on the input side of the line conditioner. This oscillogram is, in fact, a photograph of two successive measurements, one with no load on the line conditioner and one with a $100 \mathrm{~W}$ load. The input waves are exactly superimposed. Compare this with the regulation of the generator output voltage noticeable in Figure 1, where a $100 \Omega$ resistor is connected directly at the terminals of the generator.

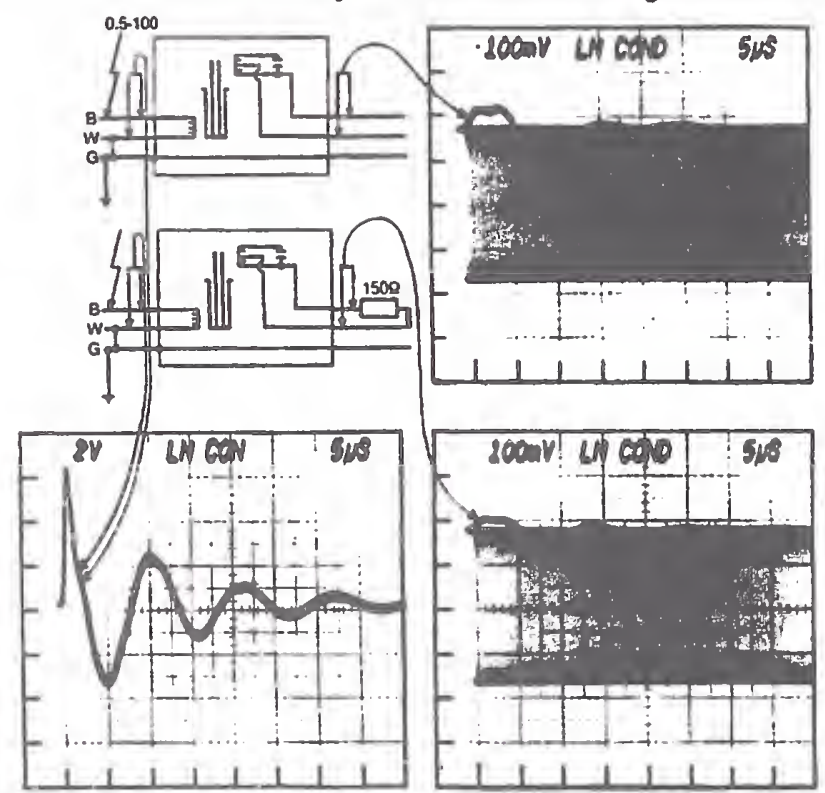

Figure 11. Decoupling of a $0.5 \mu \mathrm{s}-100 \mathrm{kHz}$ ring wave by a ferro-resonant line conditioner

This decoupling reflects the nonlinear behavior of the ferroresonant line conditioner, which is significant in this case, compared to the linear behavior of transformers: for surge sources of lower impedance than the generator used in these tests, or for frequencies lower those than contained in the $0.5 \mu \mathrm{s}-100 \mathrm{kHz}$ ring wave, the transformer attenuation would become lower, in direct proportion to the corresponding impedance change, while the ferro-resonant transformer would keep the decoupling unchanged.
The two oscillograms of the output were recorded with the surge timed to occur at the peak of the $60 \mathrm{~Hz}$ line voltage, for worst-case demonstration. The peak-to-peak amplitude of the line voltage is indicated by the gray band recorded on the oscillograms by photographically superimposing repetitive traces of the line voltage. For timings other than the peak, the small voltage oscillation on the output voltage would be completely contained within the normal peak-to-peak band of the $60 \mathrm{~Hz}$ line voltage.

While these measurements were being taken, an additional observation was made. Figure 12 shows the response of the line conditioner to surges occurring at different times in the $60 \mathrm{~Hz}$ cycle, as indicated by the different vertical position of the traces at their beginning. The ferro-resonant mechanism is responsible for this different response. In itself, this is not very important in the present context, but it does provide another example of the importance of performing surge testing at different angles along the power-frequency cycle (as recommended in the discussions presented in IEEE Std 587) because the outcome of the test may be influenced by the timing of the surge.

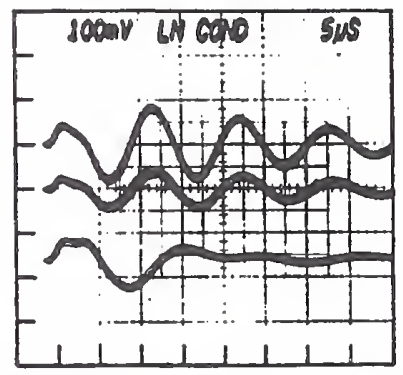

Figure 12. Effect of timing of the surge with respect to the power frequency voltage

\section{PROPAGATION OF CURRENT SURGES}

Line impedance: surge impedance or impedance to the surge?

As mentioned in the transmission line behavior, a distinction has to be made between two concepts that unfortunately can be confused because of the language: surge impedance of the transmission line, and impedance of the line to the surge. The first is the classical transmission line parameter, also called "characteristic impedance", $Z_{o}-\sqrt{L / C}$, and applies for long lines and short pulses. It is independent of the line length and frequency. The second, impedance to the surge, is indeed dependent on the line length, and is the impedance of the complex (real and imaginary) network of distributed parameters, $R, L, C$, of the wiring configuration. This impedance is also dependent on the frequency, so that rigorous analysis would involve computation over the frequency spectrum of the impulse of interest. For practical applications, it would be more convenient, although not rigorous, to define the impedance of a line to the surge as the ratio of voltage to current, stating the current wave form.

Thus, inspection of Figure 13 shows a current crest of $400 \mathrm{~A}$ flowing in the line with shorted end and a voltage crest of $1700 \mathrm{~V}$ at the sending end, with a current wave form of $25 / 70 \mu \mathrm{s}$. It is noteworthy that the short-circuit impulse of $8 / 20 \mu$ s produced by the generator has been stretched out by the effect of the line impedance. This impedance is mostly inductive, as shown by the fact that the crest of the voltage occurs during the initial current rise where di/dt is large, with a resistance detectable by a finite voltage at the time di/dt is zero - that is, at the crest of the current, not counting the capacitance. Thus, one might define the impedance to the surge of this $75 \mathrm{~m}$ line as being 1700 V/400 A for a $25 / 70 \mu \mathrm{s}$ wave, or 4.25 'ohms', a far cry from the $100 \Omega$ characteristic impedance determined by the first measurement reported in this paper. This impedance is essentially proportional to the line length, in contrast to the constant value of the characteristic impedance. 


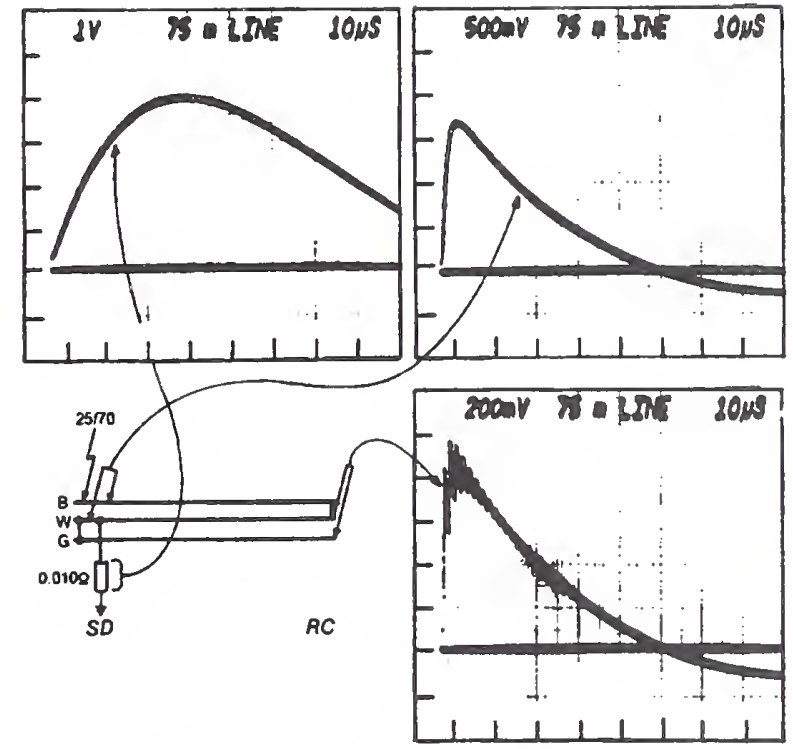

Figure 13. Current and voltage in $75 \mathrm{~m}$ line, unidirectional Impuise

The complex nature of the line configuration is also evident in the voltage observed between the shorting jumper at the receiving end of the line and the green ground wire: the voltage is not just half of the sending voltage but, rather, the superposition of that half-voltage and higher frequency components which are not seen in the sending-end voltage.

Likewise, Figure 14 shows a first current crest of $48 \mathrm{~A}$ in the shorted $75 \mathrm{~m}$ line with a sending-end voltage of $5000 \mathrm{~V}$ when the $0.5 \mu \mathrm{s}-100 \mathrm{kHz}$ generator is driving the line. This corresponds to an impedance to the surge of 100 'ohms', not very different from the characteristic impedance, For the second crest, however, the current crest is $30 \mathrm{~A}$ with a voltage crest of $1300 \mathrm{~V}$, or about 45 'ohms' for the significant frequency of the second crest.

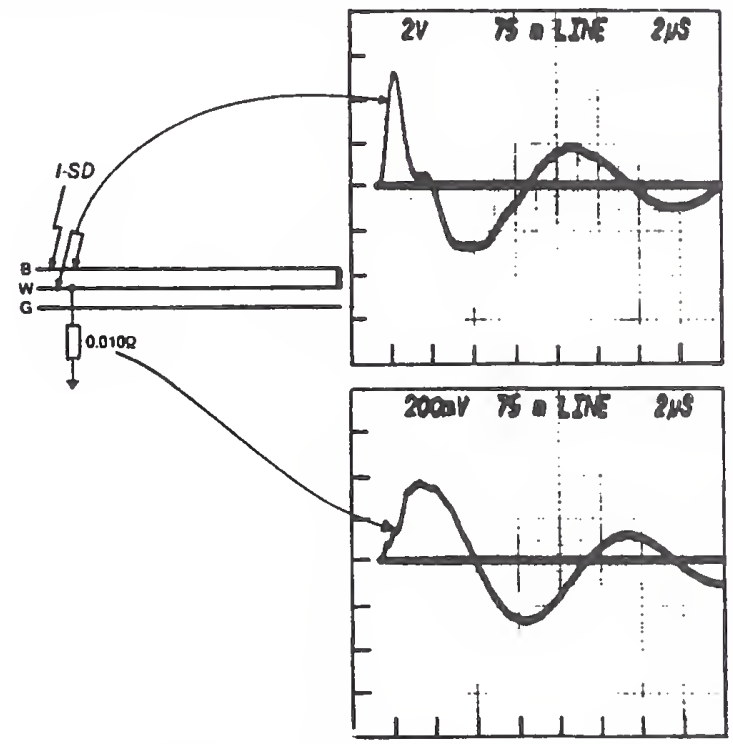

Figare 14. Current and voltage in $75 \mathrm{~m}$ line, oscillatory wave

The addition of the grounding wire (Figure 15) to the circuit of Figure 14 does not considerably change the crests of voltage and current but introduces the added complexity of a secondary oscillation superimposed on the driving oscillation.

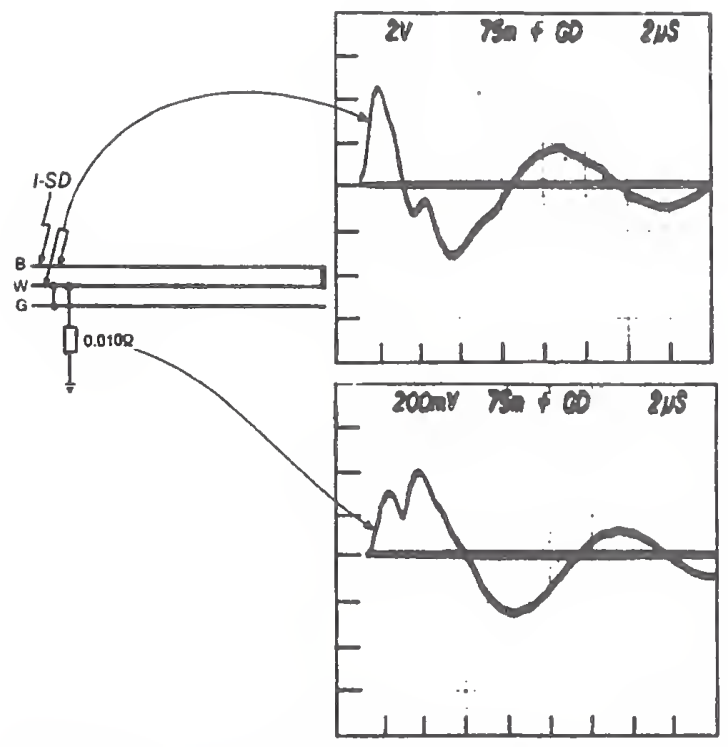

Figure 15. Effect of added grounding wire for $75 \mathrm{~m}$ line, oscillatory wave

Figure 16, similar to Figure 13, shows the propagation of a current surge in conduit-enclosed lines. For the same generator short-circuit wave form of $8 / 20 \mu \mathrm{S}$, the resultant current and voltages are shown for a $25 \mathrm{~m}$ conduit run. The ratio of voltage/current yields a value of $1500 \mathrm{~V} / 850 \mathrm{~A}$ for the $20 / 50 \mu \mathrm{s}$ current wave form, or an impedance of 1.8 'ohms'.

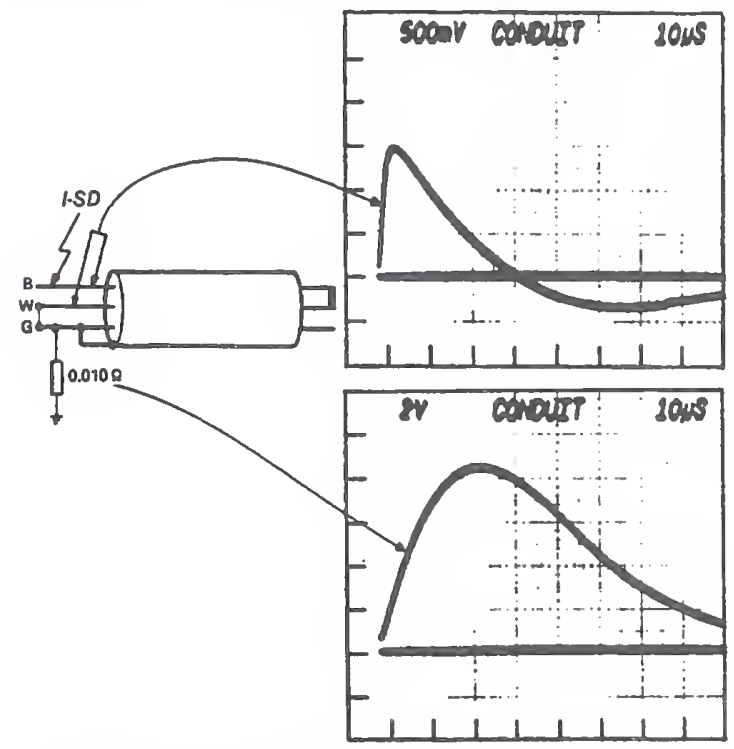

Figure 16. Current and voltage in $25 \mathrm{~m}$ conduit run, unidirectional impulse

Figure 17 shows the impedance of the $75 \mathrm{~m}$ line as a function of frequency, as measured by an impedance vector meter. The values of impedance defined as approximations for impulses are also shown on this graph.

Therefore, as a first approximation, a more useful view of the relative impedance values in a wiring system can be derived from this concept of "impedance to the surge" than from the use of characteristic impedance, provided that the user of this approximate concept does not lose sight of the approximations implied in the concept. 


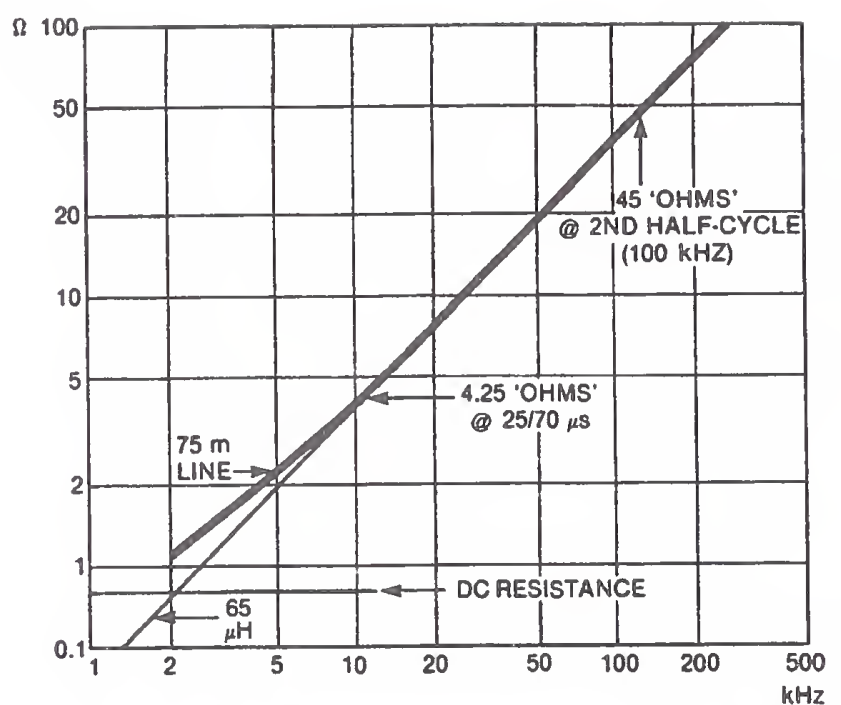

Figure 17. Impedance versus frequency of $75 \mathrm{~m}$ line

For instance, consider the case of a wiring system where a decreasing "staircase" of voltage surges is expected as the wiring progresses within the building, starting from the service entrance. Such a staircase is described in the IEC recommendations on Insulation Coordination [2]. The staircase is obtained by using the interface effect of the series and shunt impedances of the wiring, including line impedance, transformer (if any) series impedance, and shunt impedance of connected loads. While the series impedances are likely to constant for a given system, the shunt impedances will vary with the loads. Alternatively, the decreasing voltages can be the result of installing surge protective devices at interfaces between sections of the wiring where the voltage decrease is to take place. Such a coordinated wiring system will require careful consideration of the line impedances for the various ranges of surge-effective frequency to be expected, so that proper coordination can be ensured between the successive protective devices installed at the interfaces [8].

\section{The pitfalls of unsanitary wave forms}

While an impulse generator is essentially an energy storage element (capacitor, line or inductance) discharged into the test specimen through some wave-shaping network, producing a clean wave shape as described in standards specifications is not a trivial undertaking. Unless precautions are observed, the stray inductance of capacitors or the stray capacitance of inductors as well as the wiring impedances can introduce unwanted oscillations - an "unsanitary" wave form.

Figure 18 gives an example of the problems that an unsanitary wave form can introduce. An attempt was made to apply a laboratory surge generator (built for energy deposition testing) to force a $8 / 20 \mu$ s current into the $75 \mathrm{~m}$ line, since the $8 / 20 \mu$ s short-circuit wave becomes stretched as discussed previously. The reasonably clean current wave form of Figure 18(A) would be quite acceptable as a test wave where total current, crest current, or energy are

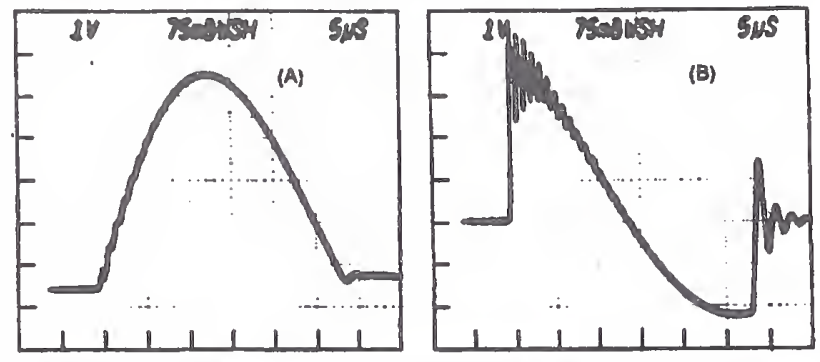

Figare 18. Efiect of unsanitary current wave on line voltage the significant parameter. However, when applied for the purpose of evaluating line impedance by measuring and computing $V / I$, the small ripple occurring on the current rise produces the $L(d i / d t)$ oscillations seen in Figure 18(B). Thus, such an unsanitary wave form is totally useless for that purpose.

The effect on residual surges

of connections options for suppressors

A noticeable lack of agreement has been observed among various application information sources on the most effective transient suppression configuration to be applied. Taking, as an example, the task of specifying the protection of an appliance or equipment connected at the end of a line with no opportunity to divert the transient closer to the source (for instance, at the service entrance), the options would be to connect one, two, or three surge suppressors between the three wires (black, white, and green) at the end of the line. However, more needs to be known: Will the impinging surge be in the normal mode (black to white) or in the common mode ([black-and-white]-to-green)? Where in the equipment is the most sensitive component: line-to-line (most likely) or line (black OR white)-to-green? Clearly, the situation is confusing, and there will not be a single, simple answer applicable indiscriminately to all cases. The National Electrical Code [9] specifically allows the connection of surge arresters (Article 280-22) if the interconnection occurs only by operation of the surge arrester during the surge. Since the standby current of a varistor or the leakage current of an avalanche diode suppressor is very low, the intent of this requirement can be met. Furthermore, there will not be any interference with the operation of Ground Fault Circuit Interrupters if the total number of suppressors does not result in a large current.

The set of measurements recorded in Figure 19 shows an example of these many options with increasing protection, albeit at increasing cost, from a single suppressor to three suppressors. The selection would depend on the vulnerability level and location of the equipment to be protected. The impinging surge is assumed to be black-to-[white and green], since white and green are tied together at the service entrance. The line is the $75 \mathrm{~m}$ line previously investigated, and the surge is that available from the generator set for a 2000 A $8 / 20 \mu$ s short-circuit impulse. Rather than attempt to modify the setting of the generator for each case in order to maintain constant current crest for the various configurations (an impossible task if wave form is also to be maintained), the generator was left unchanged, to discharge a constant total energy in the system - not a bad hypothesis for the real world. This test was performed with $20 \mathrm{~mm}$ diameter varistors rated for $130 \mathrm{~V}$ ms line voltage, as an example. Similar results would be obtained with other types of clamping suppressors. The point is not so much the clamping voltage measured, as it is the relative differences for the various options shown. The current crests are all in the range of 300 to $380 \mathrm{~A}$, which is not a significant change for comparing clamping voltages.

If only one suppressor is allocated to protect the equipment, the black-to-white suppressor connection affords maximum protection for the electronics which are also likely to be connected blackto-white. However, the voltages between either black or white and green are large; this is the stress that will be applied to the clearances of the equipment. This example shows a current surge, which might seem relevant only to surge suppressor applications, becomes a voltage surge issue, which is relevant to insulation coordination of clearances.

The configuration with suppressor black-to-green does not afford very good protection for components connected black-towhite; therefore, it should be used only if there is a special need to clamp black-to-green at a low voltage.

An improved protection is obtained with a suppressor black-towhite complemented by a second suppressor white-to-green. Another option, not investigated here but often used in applications of three-electrode gas tubes, would be the connection two 


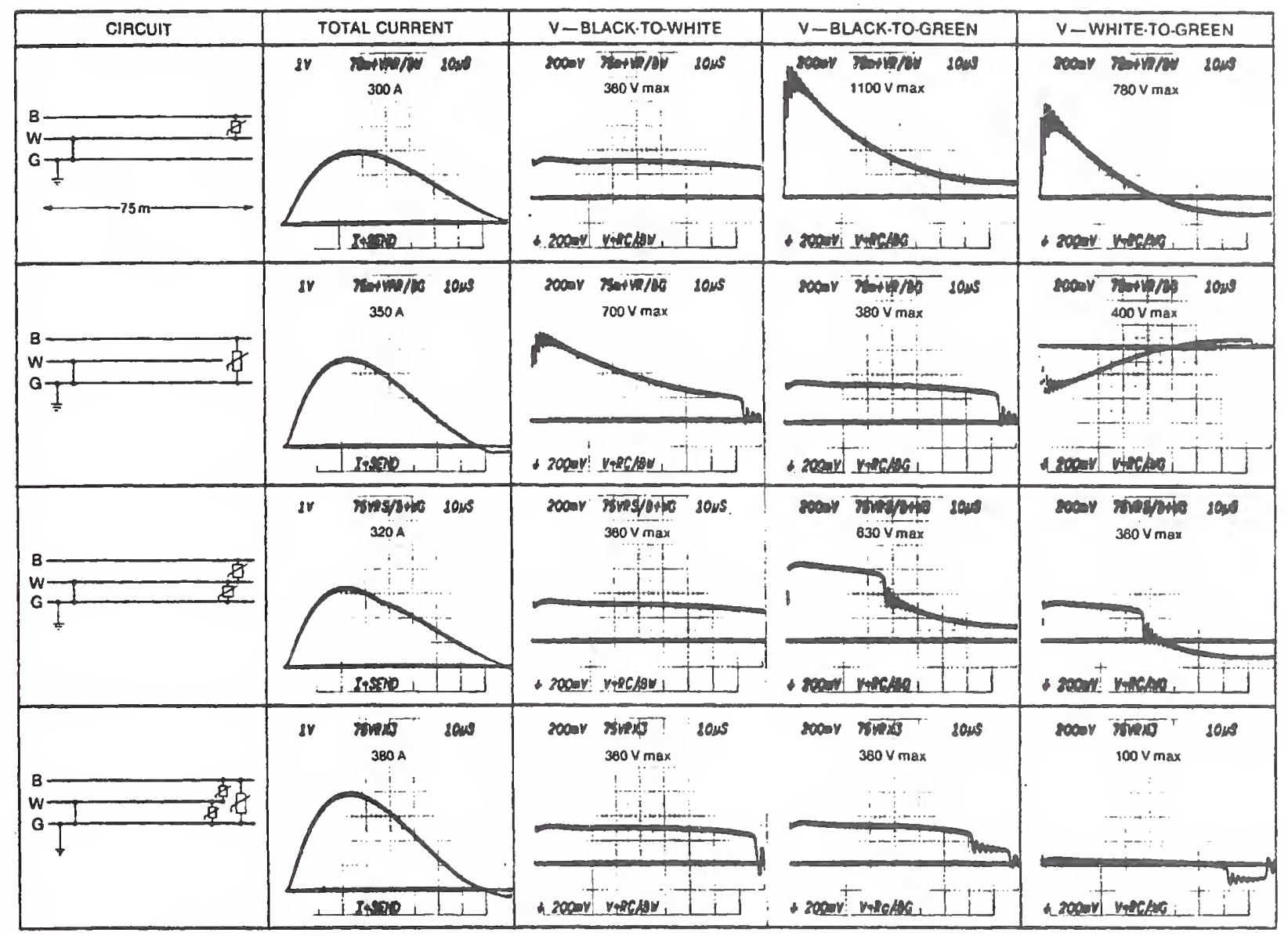

Figure 19. The effect on residual voltage surges of connections options for one, two, or three suppressors

suppressors, one between a line and the grounding conductor, the other between the second line and the grounding conductor. The ultimate protection is, of course, one suppressor in every position, but this should be required only for exceptionally sensitive loads.

\section{CONCLUSIONS}

The examples of surge propagation described provide the basis for several practical conclusions that should provide guidance in designing or evaluating surge protection schemes.

1. Surge propagation in wiring systems should be considered as a case of classical transmission lines only if the lines are long enough to contain the surge front.

2. For typical voltage or current surges produced by lightning or switching, the surge impedance (characteristic impedance) is not the significant parameter. Rigorous analysis requires considering the frequency spectrum of the impulse and the line impedance at the significant frequencies of that spectrum. Approximations can be made for specific current surge wave forms.

3. Isolating power transformers are intended to serve as ground isolators, or ground-loop breaks. They do not provide appreciable attenuation of line-to-line transients unless they are operating with their series reactance combined with a welldefined shunt load on the secondary.

4. Ferro-resonant line conditioners can provide attenuation of fast line-to-line transients with ratios of 100:1 or higher. Adding a small fixed load on the output side can raise this attenuation to $150: 1$, or more.
5. The connection options for surge suppressors must be matched to the protection requirements for optimum protection at minimum cost. Universally applicable solutions always tend to be more expensive.

6. Careful design is required for impulse generators. Improvisation can lead to meaningless results and wasted time.

7. In testing for surge protection evaluation, the timing of the surge with respect to the power line frequency can be significant.

8. The pure and sanitary test waves specified by test standards are intended to obtain reproducible results rather than to duplicate surges occurring in reality. Complex wiring system (within a building or within equipment) will promptly transform the pure wave form into a distorted form, but that does not prevent consistent results, since an agreement exists on the initial test wave.

\section{ACKNOWLEDGMENTS}

Discussion of surge protection techniques among members of the IEEE Working Group on Surge Characterization (for instance, the effect of connection options) has provided valuable insights into the problems and has motivated the examples presented in this paper. The contributions made by reviewers of the paper provided further insight on the subject and are gratefully acknowledged. 


\section{REFERENCES}

1. IEEE Std 587-1980, "IEEE Guide for Surge Voltages in Low-Voltage AC Power Circuits," The Institute of Electrical and Electronics Engineers, Inc., New York.

2. IEC Publication 664, "Insulation co-ordination within lowvoltage systems including clearances and creepage distances for equipment," International Electrotechnical Commission, Geneva, Switzerland, 1980. (Available in the United States from ANS1.)

3. IEEE Std 465.1-1977, "IEEE Standard Test Specifications for Gas Tube Surge Protective Devices," The Institute of Electrical and Electronics Engineers, Inc., New York.

4. IEEE Std C62.32-1981, "IEEE Standard Test Specifications for Low-Voltage Air Gap Surge-Protective Devices," The Institute of Electrical and Electronics Engineers, Inc., New York.

5. IEEE Std C62.33-1982, "IEEE Standard Test Specifications for Varistor Surge-Protective Devices," The Institute of Electrical and Electronics Engineers, Inc., New York.

6. F.A. Fisher and F.D. Martzloff, "Transient Control Levels," IEEE Transactions on Power Apparatus and Systems 95 (1), January/February, 1976.

7. F.D. Martzloff and F.A. Fisher, "Transient Control Level Philosophy and Implementation," paper presented at the 2 nd EMC Symposium on Electromagnetic Compatibility, Montreux, June 28-30, 1977.

8. F.D. Martzloff "Coordination of Surge Protectors in LowVoltage AC Power Circuits," IEEE Transactions on Power Apparatus and Systems 99 (1), January/February, 1980.

9. National Electrical Code 1981. National Fire Protection Association, Boston, Massachusetts.

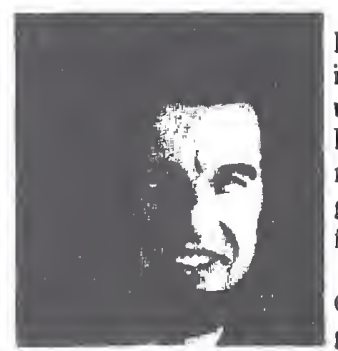

François D. Martzlofi (M'56) was born in France, and received his undergraduate degree at the Ecole Spéciale De Mécanique et D'Electricité in 1951; he received the MSEE degree from Georgia Tech in 1952 and the MSIA degree from Union College in 1971.

Since 1956 he has been with the General Electric Company, where he gained experience in the Transformer and Switchgear Divisions. Upon joining General Electric Corporate Research and Development in 1961, he became involved in power semiconductor circuits and overvoltage protection. He has participated in the introduction and application of metal oxide varistors since 1971 .

In IEEE, Mr. Martzloff is active on the Surge Protective Devices Committee. He is chairman of the Working Group on Surge Characterization in Low-Voltage Circuits. He is also a member of the Ad Hoc Advisory Subcommittee of the USA Advisory Committee on IEC S/C 28A and ANSI C.62 Subcommittee on Low-Voltage Surge Protective Devices. He has been awarded 10 U.S. patents, primarily in the field of varistors and transient protection.

\section{Discussion}

A. C. Liew (National University of Singapore, Kent Ridge, Singapore): The author has once again presented us with an interesting and practically useful paper.

Regarding the application of classical transmission line concepts to wiring systems and the concept of surge impedance, it is well known that surge impedance or characteristic impedance is applicable directly only until the time of arrival of the first reflection. A fter that, a lumped equivalent circuit is usually used or great effort in keeping track of the reflected and transmitted waves must be taken. This is evident in figure 14 of the paper.

The author's comments of the following observation made by us are appreciated.

We have found that for nearby lightning strokes, the induced voltages on the wiring system of a building (even when supplied by an underground cable at the service entrance) does not have to be very large to cause operation of sensitive Ground Fault Circuit Interrupters or Earth Leakage Circuit Breakers (current-operated type). Even with the installation of low voltage lightning arresters ( $500 \mathrm{~V}$ or $380 \mathrm{~V}$ type for a $415 \mathrm{~V}$ system) before the Ground Fault Circuit Interrupter, sufficient unbalance surge currents to ground can flow to cause its operation. This was traced to the distributed capacitances to ground of the wiring system. With the liberal connection of suppressers to the input terminals of sensitive equipment, the situation is likely to be further aggravated. Thus, while no damage occurs as with successful surge suppression, this nuisance tripping may be intolerable in certain cases.

Manuscript received August 9, 1982.

F. D. Martzloff: Indeed, as pointed out by Liew and myself, there are limitations to the application of classical transmission line concepts to wiring systems. However, while Liew states that these are well known, my experience in discussing the topic has shown me that in many instances, in the heat of a discussion, or under the pressure of a postmortem, some erroneous or misapplied concepts can surface.
To avoid these situations, some repetition of known facts, presented with concrete examples, may be helpful and provide useful guidance. Thus, the purpose of the paper is not to report discoveries, but to make better known the limitations and pit falls cited in the paper, in the context of concerns on surge propagation and attenuation.

E. K. Howell: While Liew reports operation of Ground Fault Circuit Interrupters coincident with nearby lightning strokes and attributes this operation to surge currents resulting from distributed capacitance of the wiring system, the information provided is not sufficient to warrant any specific conclusions, explanations, or recommendations.

Most Ground Fault Circuit Interrupters (GFCI) today use electronic signal processing and provide limiting and integration of the fault current signal, which tends to prevent operation by the fast surge currents. However, a flash-over in the wiring system may initiate a sub-cycle follow-through current, at power system frequency, having sufficient magnitude and duration to require operation of the interrupter. Furthermore, spark-gap types of low voltage ligntning arresters have, inherently, a follow-through current which is limited by a varistor but may be large enough to properly cause $\mathrm{GFCl}$ operation if that current is allowed to pass through the ground fault current sensor.

There is also the possibility that the electronic circuit was susceptible to the surge voltage, rather than the current, as the result of insulation breakdown or some parasitic high-frequency coupling within the GFCl device. The present Underwriters Laboratory GFCI Standard No. 943 requires immunity (no tripping) to $3 \mathrm{kV}$ crest of the $0.5 \mu 5-100 \mathrm{kHz}$ voltage surge waveform. No current surge response requirement exists today. If tripping in response to a surge of voltage or current is sufficiently intolerable, then specifications defining acceptable performance should be considered, for either general use or special-purpose devices.

We both thank Professor Liew for the opportunity to clarify this subject.

Manuscript received Oclober 12, 1982. 


\title{
Surge and High Frequency Propagation in Industrial Power Lines
}

\author{
François D. Martzloff \\ and Harold A. Gauper \\ General Electric Company \\ Schenectady NY \\ t.martzloff @i ieee.org
}

Reprinted, with permission, from IEEE Transactions on Industry Applications IA-22, July/August 1986

First presented at IEEE ICPS, May 1985

\section{Significance: \\ Part 4 - Propagation and coupling of surges}

The propagation and attenuation of surges or high-frequency disturbances in power lines has been described in different terms by workers hailing from time-domain or frequency-domain schools of thought. Nature, of course, recognizes neither one in particular, and the phenomena are the same. This paper is an attempt at unification of the description, reporting measurements made on the same specimen by the two different techniques.

Unidirectional pulses with duration ranging from $200 \mathrm{~ns}$ to $50 \mu \mathrm{s}$, and the $0.5-\mu \mathrm{s}-100-\mathrm{kHz}$ ring wave were injected in a metal-enclosed line as well as a non-metallic jacketed line. Data are presented in graphical form for the continuousfrequency measurements and as typical oscillograms for the pulse measurements.

From the time-domain surge measurements, it becomes apparent that long lines will attenuate single-shot impulses for very short duration (less than $1 \mu \mathrm{s}$ ), but no appreciable attenuation can be expected for longer pulses. An open-end line will produce the classical doubling effect when the line length is sufficient to contain the surge front. If the line if shorter than this value, reflections occur while the surge front is still rising, so that the doubling effect produces steps on the front but no doubling of the ultimate peak of this surge. 



\section{Surge and High-Frequency Propagation in Industrial Power Lines}

FRANÇOIS D. MARTZLOFF, FELLOW, IEEE, AND HAROLD A. GAUPER, JR., SENIOR MEMBER, IEEE

\begin{abstract}
Abstraci-Laboratory measurements were made on a three-conductor line, with or without steel conduit sheath (typical of single-phase $120 / 240-\mathrm{V}$ systems), to determine the attenuation of surges and the response to steady excitation at frequencies in the range of $100 \mathrm{~Hz}-10 \mathrm{MHz}$. Lime length ranged from 75 to $225 \mathrm{~m}$. Impedance matching was maintained at the sending end, while at the receiving end various loads (matched or mismatched) were included. A nonlinear load was also used, illustrating the side effects of connecting a surge protective device at the end of the line.
\end{abstract}

\section{INTRODUCTION}

$\mathrm{T}$ HE PROPAGATION and attenuation of surges or high-frequency disturbances in power lines has been described in different terms by workers hailing from timedomain or frequency-domain schools of thought. Nature, of course, recognizes neither one in particular, and the phenomena are the same. This paper is an attempt at unification of the description, reporting measurements made on the same specimen by the two different techniques. In a second phase of this work, numerical methods would be applied to correlate and convert the data from one domain to the other.

A typical industrial power line was deployed in the laboratory, consisting of three conductors in a steel conduit. The line was folded into a zig-zag arrangement to allow both ends and two intermediate points to be within short reach of the instruments. The parameters of a three-conductor nonmetallic jacket line were also examined. Pulses of different shapes and continuous swept-frequency signals were applied at one end of the line. Measurements of voltages or currents were made to characterize the propagation and attenuation (or enhancement) of the signals.

From the measurement results, data are presented in graphical form for the continuous-frequency measurements and as typical oscillograms for the pulse measurements. Implications are discussed for application to typical situations.

\section{LINE AND INSTRUMENTATION}

The line consisted of $225 \mathrm{~m}$ of 20 -mm (3/4-in) steel conduit, arranged in a zig-zag configuration to bring the start, the end,

Paper IPCSD 85-34, approved by the Power Systems Engineering Committee of the IEEE Industry Applications Society for presentation at the 1985 Industrial and Commercial Power Systems Technical Conference, May 13-16. Manuscript released for publication March 7, 1986.

F. D. Martzloff was with the General Electric Company, Schenectady, NY. He is now with the Electrosystems Division, National Bureau of Standards, Building B 162, Room 220, Gaithersburg, MD 20899.

H. A. Gauper, Jr., was with the General Electric Company, Schenectady, NY. He is now at 826 Sanders Avenue, Scotia, NY 12302.

IEEE Log Number 8608868. and two intermediate points at $75 \mathrm{~m}$ and $150 \mathrm{~m}$ close to each other, allowing connection of recording instruments without change of probe length. Three wires of $3.3 \mathrm{~mm}^{2}$ cross section (12 AWG) were pulled through the conduit, representing the line, neutral, and grounding conductors of a typical singlephase installation. In all measurements, the neutral and grounding conductors were bonded to the conduit at the sending end, representing a typical service entrance configuration. At the intermediate points and at the far (receiving) end, the neutral was not connected to the grounding conductor. At the receiving end, the grounding conductor was also bonded to the conduit. Limited measurements were also performed on a 75-m-long line of nonmetallic three-wire conductor to investigate the differences between the "open line" configuration and the "quasi-coaxial" configuration of the conduit-enclosed line.

Because the conduit-enclosed line is practically insensitive to its surroundings, it could be zig-zagged in a steel-walled room without undue effects. In contrast, the nonmetallic jacket line might be sensitive to the proximity of walls and, very likely, to its own adjacent turns if not stretched out in "free space." To evaluate the importance of this concern, measurements were made on the three-conductor wire left in its original coiled package ( $50-\mathrm{cm}$ average diameter) before the line was stretched out in a long hairpin shape, with only the sending and receiving ends inside the building, the rest of the line being held at least $4 \mathrm{~m}$ away from the building and ground. In these measurements the grounding conductor and neutral conductor were bonded at the sending end.

Surges and signals were generally injected and measured between the line conductor and the neutral conductor, across which the sensitive loads are expected to be connected. In the experiment concerned with connection effects at the line end, measurements were also made between the neutral and the grounding conductors at the end of the $75-\mathrm{m}$ line, where various configurations of surge suppressors were installed.

Surges were generated by a Velonex 350 or KeyTek 711 generator, monitored by a Tektronix 7633 oscilloscope with two P6015 probes in differential mode, allowing measurements at the four access points of the line. For the fast repetitive pulses generated by the Velonex 350 generator, a trigger signal allowed synchronized sweep of the oscilloscope for all four measurements, so that propagation time would be displayed on the recordings. For single pulses generated with the KeyTek 711 generator, internal triggering of the oscilloscope in single-sweep storage mode provided the recording of the pulses. Continuous frequency measurements were per- 


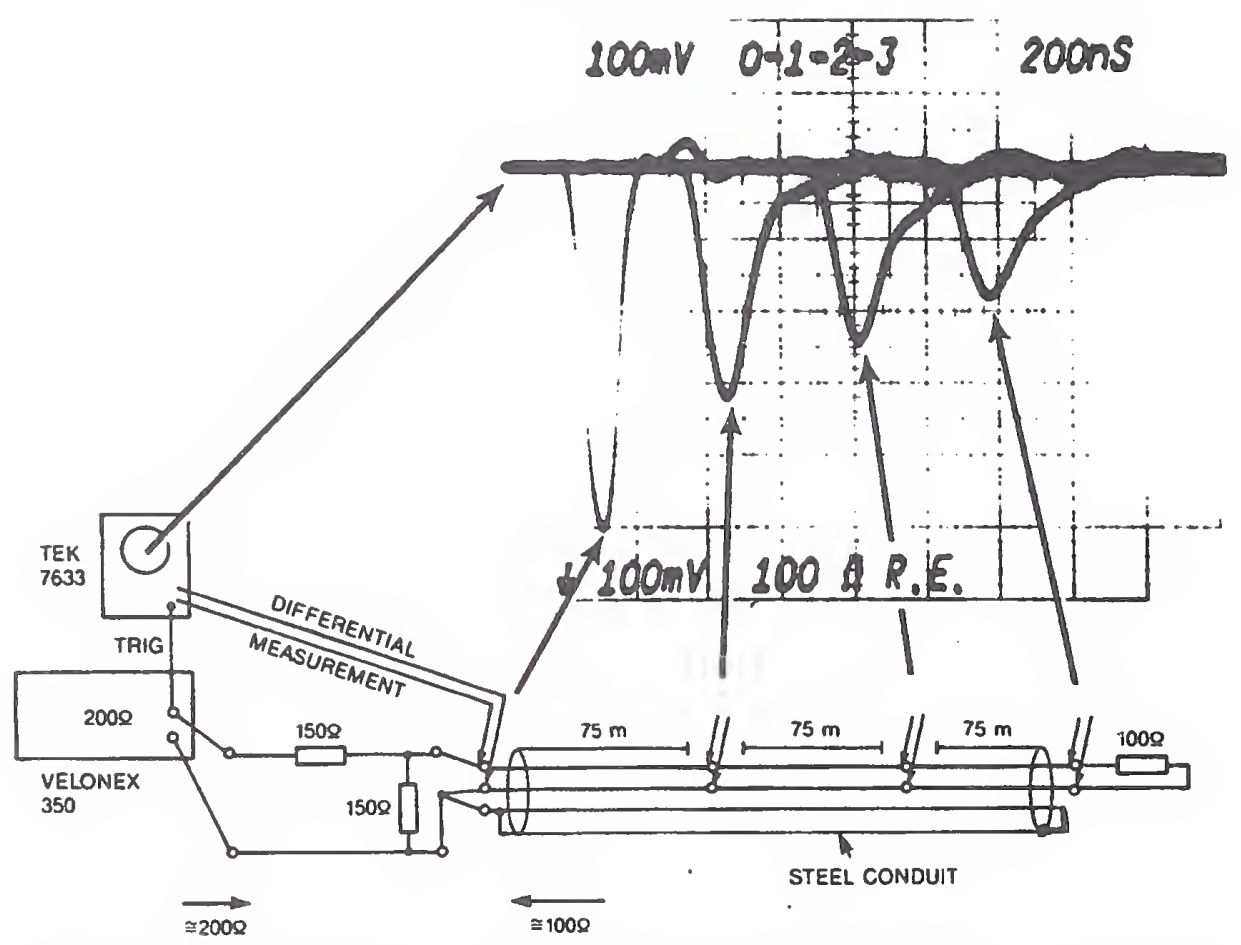

Fig. 1. Recordings at sending and intermediate points and receiving end of line, terminated with matching impedance, for 200-nswide pulse.

formed with a Hewlett-Packard system consisting of a Model $8553 \mathrm{~A}$ spectrum analyzer and a $8443 \mathrm{~A}$ tracking generator.

\section{Surge Propagation Measurements}

Four types of surges were injected into the line, with different waveforms:

- a 200-ns-wide unidirectional pulse,

- a 2- $\mu \mathrm{s}$-wide unidirectional pulse,

- a 1.2/50- $\mu$ s surge, as described by [3],

- a $0.5-\mu \mathrm{s} 100-\mathrm{kHz}$ ring wave, as described by [3].

\section{A. 200-ns Pulse}

Fig. 1 shows schematically the test line and a composite oscillogram of the voltages at the sending end, intermediate points, and receiving end. Note the impedance-matching network between the generator and the line, providing an optimum waveform for the generator output $(200 \Omega)$ and minimizing reflection of the surges returning from the line $(100 \Omega)$. A $100-\Omega$ matching termination was connected at the receiving end for this recording.

The attenuation of this pulse along the line is quite apparent, with an average 0.7 ratio between the voltages of points separated by $75 \mathrm{~m}$ of line. The propagation time for the $225 \mathrm{~m}$ can be seen as $1.1 \mu$ s.

Fig. 2 shows the propagation of the same 200-ns-wide pulse with open-ended line. The voltage enhancement at the receiving end ( 3.75 divisions compared to the 1.9 divisions in Fig. 1) illustrates the classical doubling effect at the open end. In spite of this doubling effect, enough attenuation of the short spike occurs over the total $225 \mathrm{~m}$ of the line that the pulse at the receiving end is lower than that at the sending end. For a line length of $150 \mathrm{~m}$, the doubling effect would result in a receiving-end crest of $2 \times 2.5=5$ divisions, i.e., equal to the sending-end pulse. For a line length of $75 \mathrm{~m}$, the doubling effect would result in a receiving-end crest of $2 \times 3.1=6.2$ divisions, i.e., a 20-percent enhancement of the sending-end pulse. Note also that, while the amplitudes are attenuated, the rise times tend to be increased, so that the volt-time integral of the pulse (and therefore its potential for damaging energysensitive components) is not attenuated as quickly as the amplitude.

\section{B. 2- $\mu$ s Pulse}

Fig. 3 shows the propagation characteristics of a 2- $\mu \mathrm{S}$-wide pulse along the same line, with matched termination at the receiving end. For this slower pulse the attenuation is lower, with a ratio of 0.94 between the voltages of points separated by $75 \mathrm{~m}$ of line. The change of slope, which was quite apparent for the 200-ns pulse, is hardly noticeable in this recording, the four pulse traces having essentially parallel rises and falls. This lesser distortion is easily explained by the lesser effect of the line shunt capacitance on the lower frequencies associated with the 2- $\mu$ s-wide pulse.

\section{C. $1.2 / 50-\mu s$ Surge}

Fig. 4 shows the test circuit for surge tests with matched terminations. The $R_{s}$ series resistance at the sending end provides matching for the low-impedance $(0.6$ or $12 \Omega)$ generator plug-in networks, and the $R_{t}$ terminating resistance at the receiving end eliminates reflections.

Fig. 5 shows three recordings for the $75-\mathrm{m}$ conduit line excited by a 1.2/50- $\mu$ s surge, with open end and with a matching termination at the receiving end. Fig. 5(a) shows the 


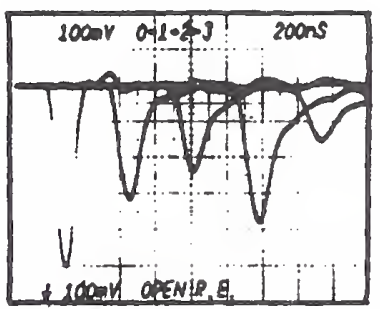

Fig. 2. Recordings at four points of line, open end, for 200-ns-wide pulse.

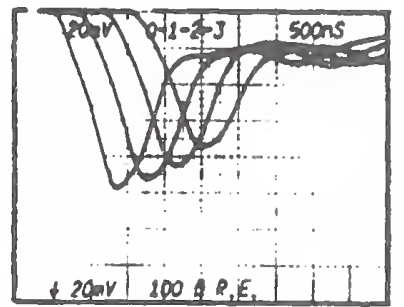

Fig. 3. Recordings at four points of line, matched termination, for $2-\mu \mathrm{s}-$ wide pulse.

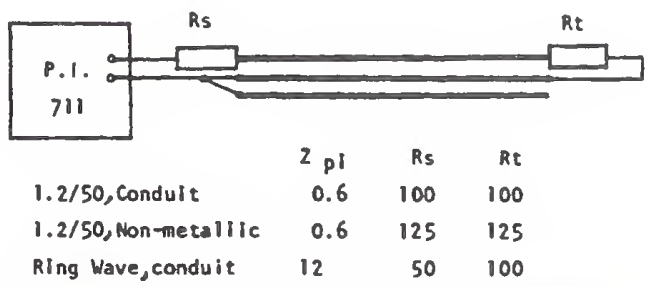

Fig. 4. Test circuit for recordings with 1.2/50- $\mu$ s surge and with ring wave.

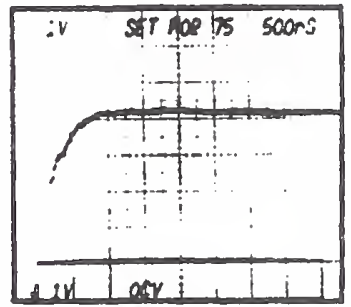

(a)

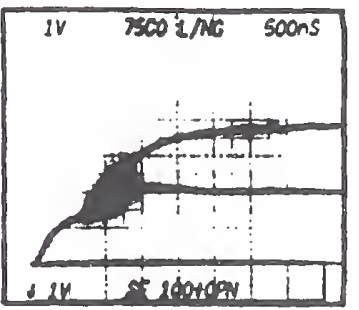

(b)

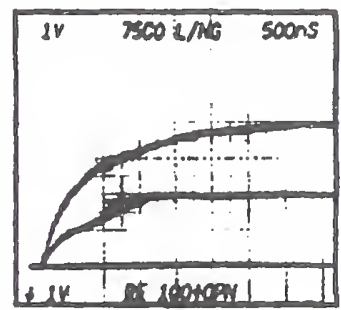

(c)

Fig. 5. Recordings on 75-m conduit line with $1.2 / 50-\mu$ s surges. All oscillograms: vertical $=1 \mathrm{kV} / \mathrm{div}$, sweep $=500 \mathrm{~ns} / \mathrm{div}$. (a) Open-circuit voltage produced by generator. (b) Voltage at sending end. Top: open at receiving end. Bottom: $100 \Omega$ at receiving end. (c) Voltage at receiving end. Top: open at receiving end. Bottom: $100 \Omega$ at receiving end.

open-circuit voltage delivered by the surge generator. Because a series resistor is present at the sending end, a 2:1 voltage divider effect is produced at the sending end for the long-term voltages when a terminating resistor is connected at the receiving end. Therefore, the terminated-end trace (bottom) shows half of the voltage of the open-end trace (top). For the first 750 ns of the sweep, the reflection from the receiving end bas not arrived, and, consequently, the two traces are identical. Fig. 5(c) shows the voltages at the receiving end, with and without termination. Observe that the long-term voltages match the sending-end voltages of Fig. 5(b). Only the rising part of the top trace of Fig. 5(c), for the first 1500 ns, shows a doubling of the voltage applied at the sending end, but this doubling would not change the stress at the receiving end, except for the steeper rate of rise.

The behavior of the nonmetallic (stretched) $75-\mathrm{m}$ line shown in Fig. 6 is similar to that of the conduit line, but the traces are not quite as smooth. From the differences in high-frequency response of the conduit and nonmetallic line shown by the continuous-frequency measurements discussed later, these irregularities in the nonmetallic line can be expected.

\section{0.5- $\mu$ s 100-kHz Ring Wave}

Fig. 7 shows the recordings for the $75-\mathrm{m}$ conduit line excited by a ring wave, with open end and with matched termination. The voltages at the sending end (Fig. 7(a) and (c))

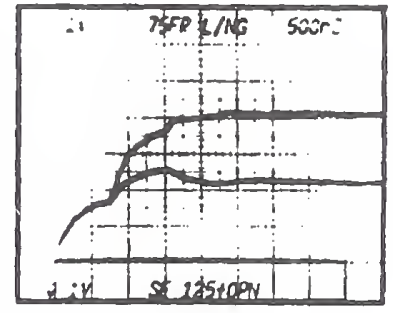

(a)

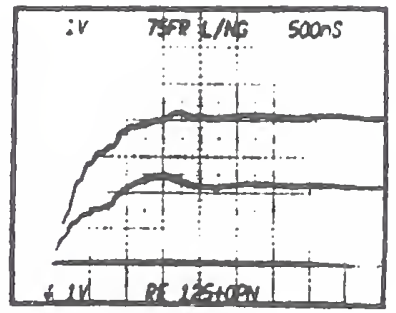

(b)
Fig. 6. Recordings on 75-m nonmetalic stretched line with $1.2 / 50-\mu \mathrm{s}$ surges. Vertical: $1 \mathrm{kV} / \mathrm{div}$. Sweep: $500 \mathrm{~ns} / \mathrm{div}$. (a) Voltages at sending end. Top: open at receiving end. Bottom: $125 \Omega$ at receiving end. (b) Voltages at receiving end. Top: open at receiving end. Bottom: $125 \Omega$ at receiving end.

differ by the reflection during the first loop, producing the double peak in Fig. 5(a). Furthermore, the voltage divider effect of the series resistance also lowers the sending-end voltage when a terminating resistor is connected at the receiving end. At the receiving end the difference between an open or terminated condition is apparent.

1) With a matched termination, the receiving-end voltage of the first loop is $2.5 \mathrm{kV}$ for a $3-\mathrm{kV}$ sending-end voltage, indicating attenuation of the high frequencies as previously noted in the case of the 200-ns pulse. Later loops show less attenuation.

2) With an open end the reflection effect is less than 


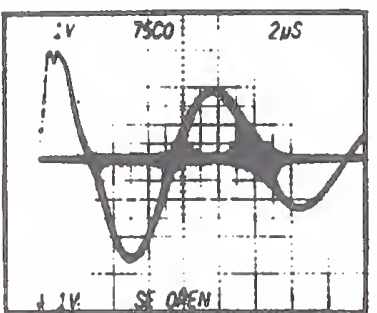

(a)

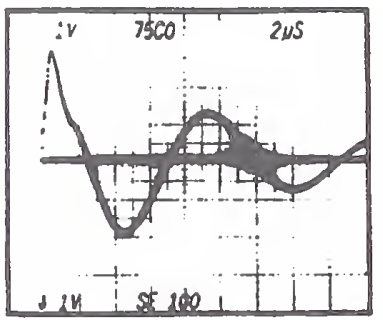

(c)

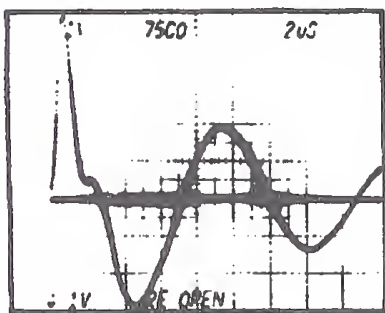

(b)

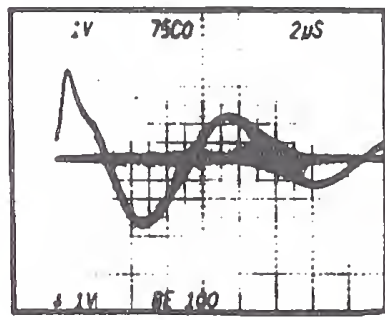

(d)
Fig. 7. Recordings on $75-\mathrm{m}$ conduit line with $0.5-\mu \mathrm{s} 100-\mathrm{kHz}$ ring wave. All oscillograms: vertical $=1 \mathrm{kV} / \mathrm{div}$, sweep $=2 \mu \mathrm{s} / \mathrm{div}$. (a) Voltage at sending end, line open at receiving end. (b) Voltage at receiving end, line open at receiving end. (c) Voltage at sending end, 100- $\Omega$ termination at receiving end. (d) Voltage at receiving end, 100- $\Omega$ termination at receiving end.

doubling-5 $\mathrm{kV}$ against $3 \mathrm{kV}$-as the result of the highfrequency attenuation and again little attenuation in later loops.

\section{Continuous Frequency Measurements}

Two types of frequency domain measurements were performed over the frequency range of $100 \mathrm{~Hz}-10 \mathrm{MHz}$ with the spectrum analyzer and tracking generator.

1) The input impedance versus frequency of the line was determined by measuring the voltage applied to the line and then the current drawn by the line.

2) The transfer ratio of the line versus frequency was determined by measuring the voltage applied to the line and the voltage at the far end of the line.

To assure adequate decoupling of the tracking signal generator output, a resistive pad was connected to the output. This pad consisted of a $47.5-\Omega$ resistor in series with a $2.5-\Omega$ resistor to a coaxial shield ground. The test line was thus driven by the 2.5- $\Omega$ source. All data were recorded with an $X-Y$ recorder, and then calculations were made to establish the reported data.

The transfer ratio measurements required ungrounded instrumentation in order to eliminate ground loops and the influence of undesired grounding at the remote end of the test line. Therefore, a relatively high resistance of a $7500-\Omega$ noninductive resistor was connected at the remote end of the test line and a Genistron current transformer was used to measure the current flowing in the resistor, thus establishing the voltage at the quasi-open-ended line. The voltage at the sending end was obtained through a Hewlett-Packard 1121A ac voltage probe.

Fig. 8 illustrates the input impedance of the conduit line under this type of excitation. The two curves labeled $\mathrm{Z} 75$ and

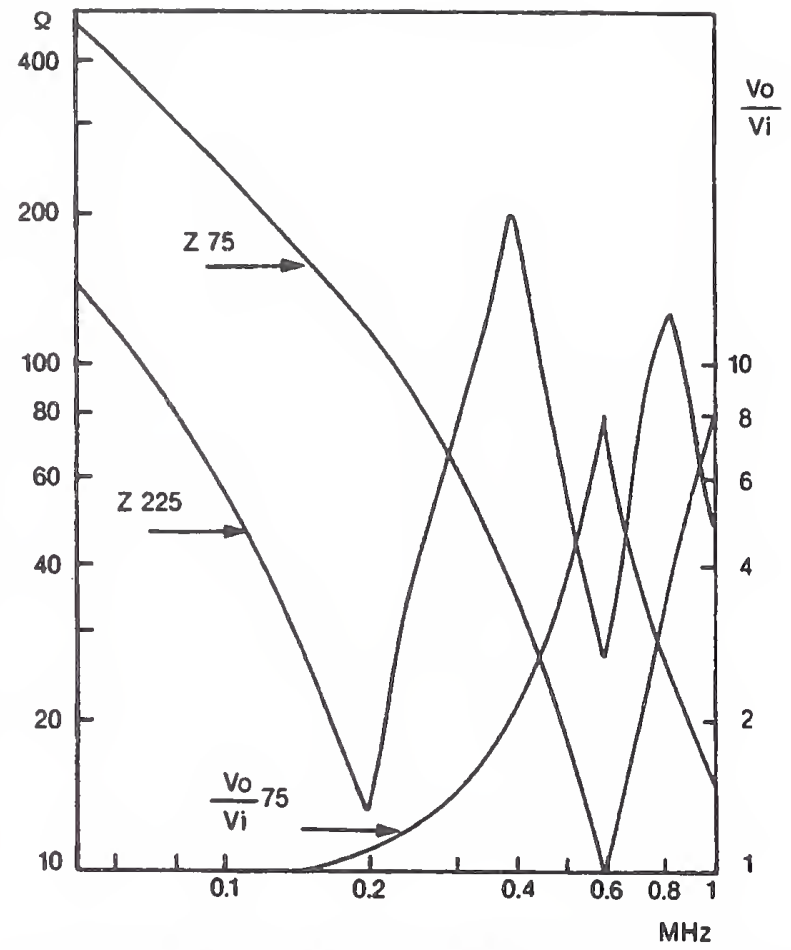

Fig. 8. Impedance of 225- and 75-m lines and $V_{0} / V_{i}$ ratio of 75-m line as function of frequency.

Z225 show the impedance of the line seen from the sending end when a $100-\Omega$ matching resistance is connected at the receiving end, as a function of the frequency of the applied signal.

Referring to the Z225 curve, the behavior of this 225 -m line shows the standing wave effects at $1 / 4,1 / 2,3 / 4$, and 1 wavelength. At 0.2 and $0.6 \mathrm{MHz}$ the line impedance is low, typical of $1 / 4$ and $3 / 4$ wavelengths, while it is high at 0.4 and $0.8 \mathrm{MHz}$, typical of half and full wavelengths. For the 0.8$\mathrm{MHz}$ frequency, the period is $1.25 \mu \mathrm{s}$; with a line length equal to one full wavelength, the speed of propagation determined by this measurement is $225 \mathrm{~m} / 1.25 \mu \mathrm{S}=180 \mathrm{~m} / \mu \mathrm{s}$, which is close to the result obtained by the pulse propagation time of $1.1 \mu \mathrm{s}$ shown in Fig. 1, i.e., $225 \mathrm{~m} / 1.1 \mu \mathrm{s}=204 \mathrm{~m} / \mu \mathrm{s}$. The difference between these two results is well within the limits of calibration and reading of the different instruments used for the measurements.

Referring to the Z75 curve of Fig. 8, the first low point occurs at three times the frequency of the first low on the Z225 curve, which is consistent with the 1:3 ratio of line length. Note also that this shorter line involves a lower total resistance; hence the 1/4-wave resonance effect is larger than the 3/4-wave resonance. This resonance is quite apparent on the $V_{o} / V_{i} 75$ curve, which shows the ratio of the voltages at the receiving end to the sending end, with a quasi-open (7500 ฉ) receiving end.

Fig. 9 is a plot of the input impedance versus frequency of three configurations of open-ended $75-\mathrm{m}$ lines: the conduitencased line, the nonmetallic coiled line, and the nonmetallic stretched line. The differences of input impedance for the three configurations should come as no surprise. The conduit line appears well controlled, with more damping that the 


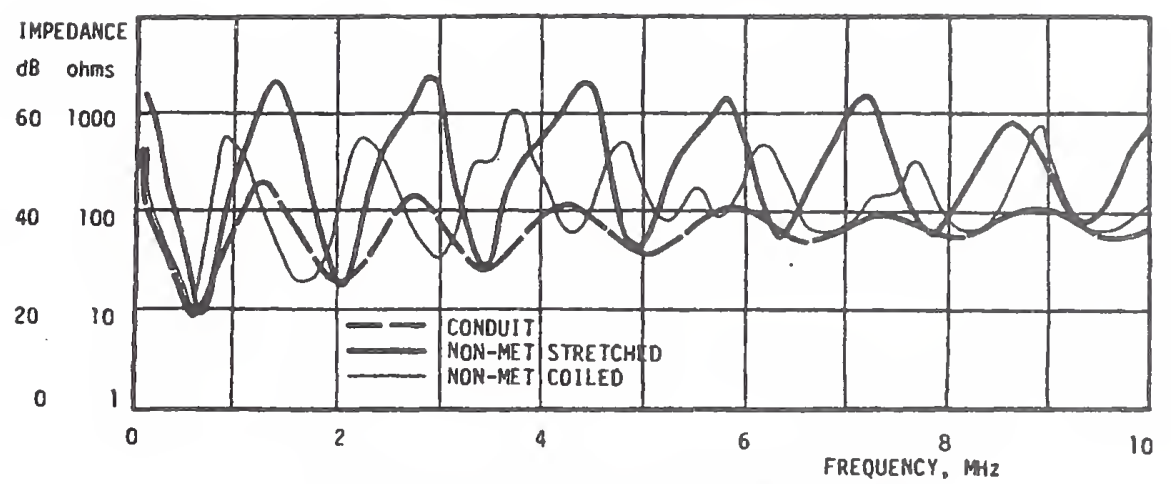

Fig. 9. Input impedance for open-ended 75-m lines.

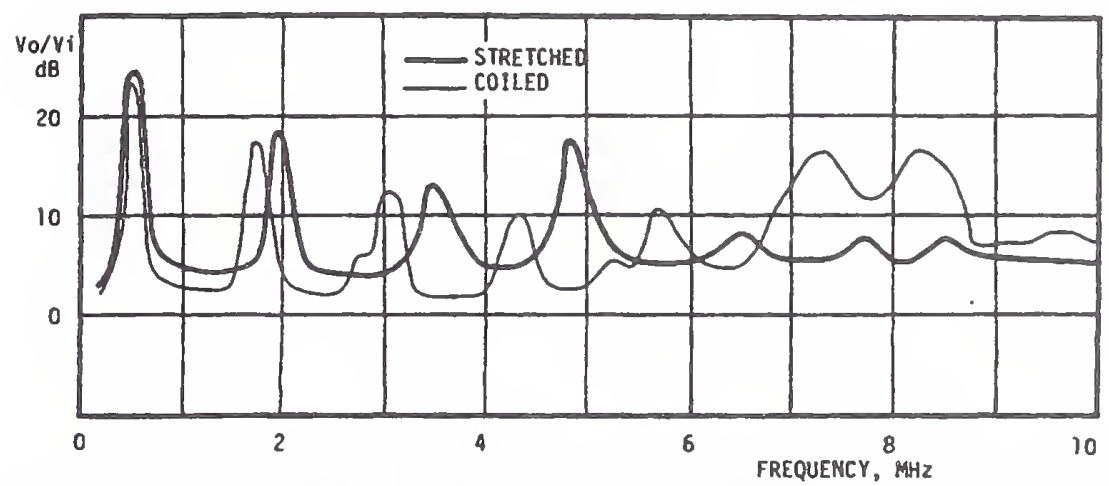

Fig. 10. Ratio of receiving/sending voltages for open-end nonmetallic 75-m line, coiled and stretched.

nonmetallic line of amplitude between the 1/4-wave minima and 1/2-wave maxima of the lines. The simple response of the conduit line is also apparent, compared to the parasitic effects that appeared in the coiled configuration.

Fig. 10 shows a comparison between coiled line and stretched line for the ratio between sending-end and receiving-end voltages. The voltage multiplication seen at the far end at about $0.6 \mathrm{MHz}$ agrees with the $V_{o} / V_{i} 75$ curve of Fig. 8 for the 1/4-wavelength condition. Both stretched and coiled lines show a multiplication of about $24 \mathrm{~dB}$ (15 times) with little difference between the responses. The second peak begins to show some shift between the two lines, and the differences increase at higher frequencies, showing the need to stretch out the line for obtaining results free from the parasitic effects of the coiled configuration. The ratio drops to a minimum of 5-6 $\mathrm{dB}$ rather than zero (no voltage enhancement) because the measurement system used had a noise background which precluded recording of any lower current measurements at the receiving end.

Fig. 11, reproduced from [1], shows an earlier measurement of line impedance in the low-frequency region made with a Hewlett-Packard Model $4800 \mathrm{~A}$ vector impedance meter, with the line shorted at the far (receiving) end, which is the converse situation of the measurements reported here, where the voltages at the receiving end are recorded with the line in quasi-open condition.

\section{Relations Between Impulse and Continuous Wave MEASUREMENTS}

The time-domain impulse measurements illustrate directly the propagation of a surge of the type encountered in actual

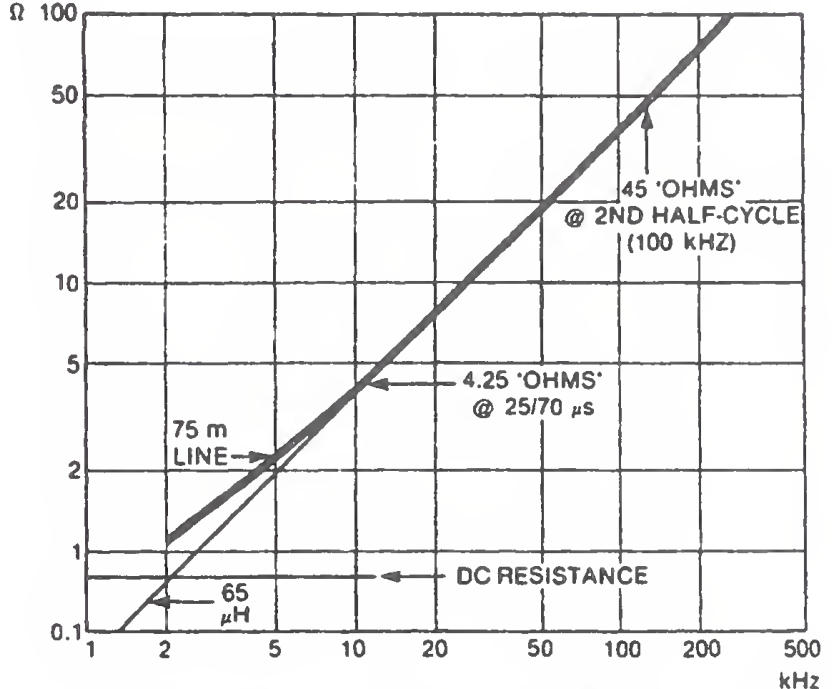

Fig. 11. Input impedance of 75-m line, nonmetallic type, with shorted receiving end.

power systems. The effects of an open end, or a high impedance at the far end, are quite apparent.

The frequency-domain measurements indicate the importance of standing wave effects for specific frequencies, which may be frequencies of low-level communication carriers or the frequency of a particular point of the transform spectrum of a single impulse. To predict performance of a particular configuration, it may then be possible to model the line, which would then become a simple case of conventional network analyses by numerical methods [2]. On the other hand, setting up a real line or network of lines may be cumbersome but 
yields immediate results, such as those illustrated in the next section on the effect of connecting surge suppressors at the end of the line.

Comparisons of impulse measurements sometimes give considerable emphasis to crest values, neglecting the effect on waveform, as noted in connection with Fig. 2. A continuousfrequency spectrum, however, will readily identify the change.

\section{Effects of Connecting a Surge Suppressor}

With the advent of increasingly sophisticated electronic devices, a proliferation of add-on surge suppressors has been offered for insertion at the point of use of these devices, that is, at the receptacle located at the end of a line, such as those discussed in the preceding sections. The actual configuration of these suppressors is generally not disclosed, but they may be classified into three categories, for the case of a singlephase two- or three-wire power supply. A first category involves only one protective device, which may be connected line-to-neutral or line-to-ground. A second category would involve two devices, and the third, three devices. The differences among these three categories is shown in [1]; however, ring-wave surges [3] may present a more insidious situation than the unidirectional surges used in [1]. The insidious nature of the effect is associated with the inductive characteristics of the line discussed here, when carrying fastrising surge currents associated with the presence of a surge suppressor at the end of the line.

Fig. 12 shows four possible combinations of protective devices that may be connected at the user's end of a branch circuit when the user has no control on what protection could be added at the service entrance. Fig. 12(a) shows a single protective device connected between the line and neutral conductors, under the perception that this is the location of the most sensitive components of the connected load $(L)$. Fig. 12(b) shows again a single device, connected between the line and grounding conductors, under the perception that the surge current should be returned to "ground." Fig. 12(c) shows two devices, one between line and neutral conductors, the second between neutral and grounding conductors. Fig. 12(d) shows three protective devices. The effects of various connections when a slow-front current is involved were described in [1]. With faster surges, while lower energies are involved, ironically, a greater voltage spike is produced, as revealed by Fig. 13.

Fig. 13 shows the result of connecting a surge suppressor device that provided clamping only between the line and neutral conductors, as shown in Fig. 12(a). Fig. 13(a) shows the voltage set at a peak of $3 \mathrm{kV}$ at the sending end of the line. With that setting of the generator, the current in the line is shown in Fig. 13(b). The generator is capable of delivering 6 $\mathrm{kV}$ open-circuit and 500-A short-circuit. The load-dependence of this type of circuit is evident in Fig. 13(b) where the current peak is limited to 40 A. Fig. 13(c) shows the voltage between line and neutral which, predictably, is correctly clamped at about $400 \mathrm{~V}$. However, the voltage between neutral and grounding conductors (Fig. 13(d)) reaches a peak of $2300 \mathrm{~V}$ during the initial current rise and $1300 \mathrm{~V}$ during the fall of the

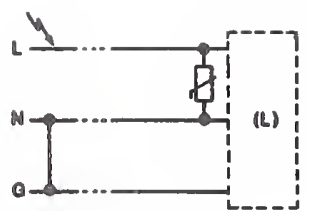

(a)

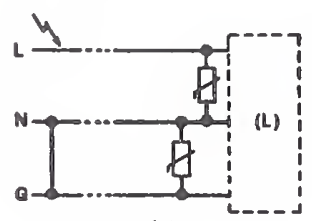

(c)

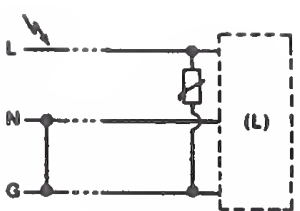

(b)

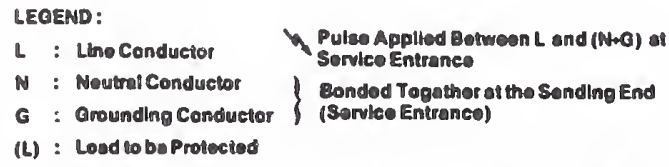

Fig. 12. Connection options for protective devices at end of branch circuit.

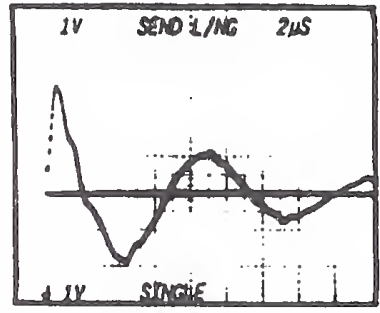

(a)

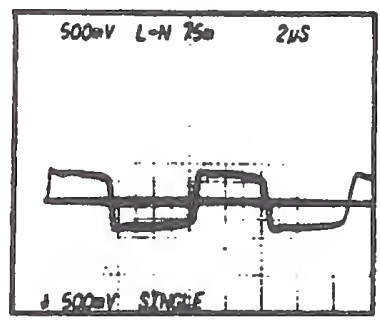

(c)

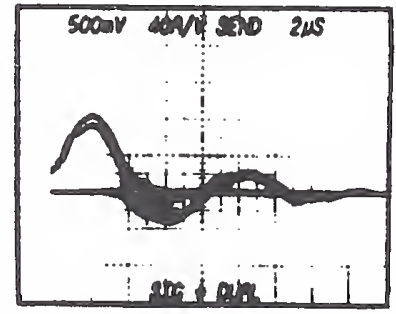

(b)

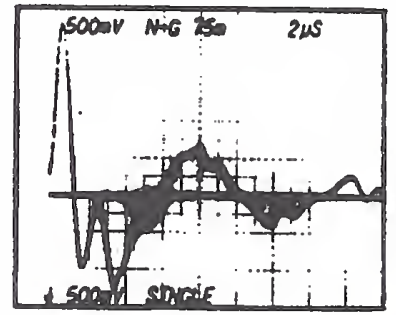

(d)
Fig. 13. Effect of connecting single surge suppressor between line and neutral at end of 75- $\mathrm{m}$ line, with neutral and grounding conductor bonded at origin of line. (a) Voltage at sending end while line is carrying current of Fig. 12(b). Vertical: I kV/div. Sweep: $2 \mu \mathrm{s} / \mathrm{div}$. (b) Current in line with ring-wave surge generator excitation. Vertical: 20 A/div. Sweep: $2 \mu$ s/div. (c) Voltage between line and neutral with surge current of Fig. 12(b). Vertical: $500 \mathrm{~V} / \mathrm{div}$. Sweep: $2 \mu \mathrm{s} / \mathrm{div}$. (d) Voltage between neutral and grounding conductor with surge current of Fig. 12(b). Vertical: $500 \mathrm{~V} / \mathrm{div}$. Sweep: $2 \mu \mathrm{s} / \mathrm{div}$.

current at the end of the first loop. The correspondence between peaks of voltage during fast current change and zero voltage during peaks of current is quite apparent in a comparison of Fig. 13(b) and (d). This correspondence is attributable to the inductive voltage drop in the neutral conductor, which elevates the neutral terminal of the line-end receptacle with respect to the grounding terminal. The grounding terminal remains at the potential of the ground at the sending end.

A load connected at the receptacle and "protected" by the single device will then be exposed to substantial peaks of voltage between its neutral and chassis, if any. Because of the expectation that neutral and grounding conductors should not 


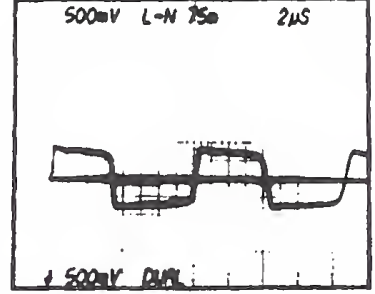

(a)

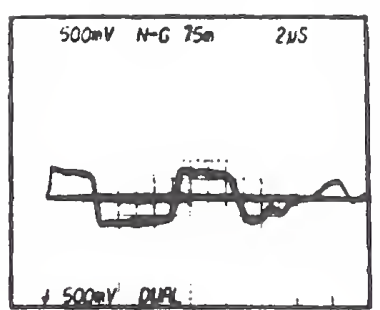

(b)
Fig. 14. Effect of connecting suppressor having clamping devices between both line-neutral and neutral-ground pairs, at end of same line and same applied surge as in Fig. 13. (a) Voltage between line and neutral with surge current of Fig. 13. (b) Voltage between neutral and grounding conductor with surge current of Fig. 13.

drift far apart in voltage, being bonded at the service entrance, the designer of the load equipment might not have provided for this $2300-\mathrm{V}$ peak in the insulation between neutral and chassis. If the function of the equipment can be disturbed by fast voltage changes, there is also a good probability that disturbances may occur. Thus what was intended to be a simple protective scheme can result in unwanted and unexpected problems.

An effect similar to that shown in Fig. 13 would be obtained for the connection of Fig. 12(b), but with the 400-V clamping voltage occurring between line and grounding conductors and the uncontrolled voltage of $2300 \mathrm{~V}$ produced between line and neutral conductors, placing any components connected across the line in severe jeopardy.

In contrast, the performance of a surge suppressor that provides clamping between line and neutral and between neutral and grounding conductors is shown in Fig. 14, for the same surge-injection conditions as those of Fig. 13(a) and (b). Both voltages are clamped below $400 \mathrm{~V}$, and while the initial rates of voltage changes are not affected by the clamping action, the total excursion is limited. Clearly, this mode of protection with added clamping between neutral and grounding conductors offers a substantial improvement over the case of Fig. 12(a).' Further protection of equipment sensitive to fast voltage changes may be obtained by insertion of a filter that will decrease the rate of voltage changes shown in Fig. 14.

\section{IMPLICATIONS AND CONCLUSION}

The data obtained by these measurements should be a source of useful information for the application of preventive measures for equipment connected at the end of lines, such as those reported here.

1) From the time-domain surge measurements, it becomes

\footnotetext{
1 This improvement is obtained from the point of view of equipment protection, where a surge of $1-\mu$ s duration as seen in Fig. 13(d) can cause failure. The National Electrical Code, in Section 280-22. specifically permits the connection of a surge arrester between any two conductors of a three-wire single-phase system. However, with the surge current now returning to the service entrance by the parallel combination of the neutral conductor and the grounding conductor, a brief surge will appear between the equipment chassis connected to the grounding conductor and other local grounded structures, unless a bond is installed at that point to bridge the chassis and the other local grounded structures. The occurrence of this brief surge would be limited to the duration of high rates of current change, but its implication on personnel safety has not yet, to our knowledge, been evaluated in this context.
}

apparent that long lines will attenuate single-shot impulses of very short duration (less than $1 \mu \mathrm{s}$ ), but no appreciable attenuation can be expected for longer pulses.

2) An open-end line (e.g., a line feeding a low-power control circuit) will produce the classical doubling effect when the line length is sufficient to contain the surge front. If the line if shorter than this value, reflections occur while the surge front is still rising, so that the doubling effect produces steps on the front but no doubling of the ultimate peak of this surge.

3) While conduit-enclosed lines may be folded for convenience in making indoor testing, nonmetallic lines need to be stretched away from surrounding conductors to obtain valid results at high frequencies.

4) Connecting surge protective devices at the end of a line is a typical action undertaken by prudent users; however, unless the behavior of the circuit is well understood, simple protective schemes can backfire unless adequate connections are provided.

\section{REFERENCES}

II] F. D. Martzloff, "The propagation and attenuation of surge voltage and surge currents in low-voltage ac power circuits," IEEE Trans. Power App. Syst., vol. PAS-102, pp. 1163-1170, May 1983.

12] H. W. Dommel, "Digital computer solution of electromagnetic transients in single and multiphase networks," IEEE Trans. Power App. Syst., vol. PAS-88, pp. 388-399, Apr. 1969.

13] IEEE Guide for Surge Voltages in Low-Voltage AC Power Circuits, ANS1/1EEE Standard C62.41, 1980.

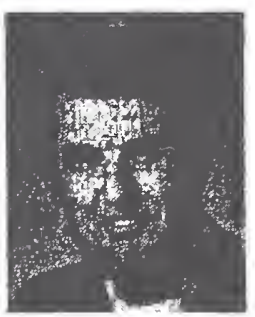

François D. Martzloff (M'56-SM'80-F'83) was born in Strasbourg, France, on June 9, 1929. He received the degree from Ecole Spéciale de Mécanique et d'Electricité, the M.S.E.E. degree from the Georgia Institute of Technology, Atlanta, and the M.S.I.A. degree from Union College, Schenectady, NY, in 1951, 1952, and 1971, respectively.

He was with the General Electric Company for many years, working on transient measurements, surge protection of electronics, and applications of varistors. He is presently with the National Bureau of Standards, Gaithersburg, MD, focusing on conducted electromagnetic interference.

Mr. Martzloff has received numerous Awards and he is active in writing standards with the IEEE, IEC, and ANSI.

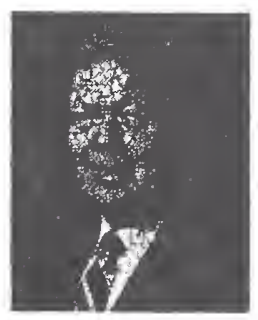

Harold A. Gauper, Jr. (M'49-SM'55) received the B.S. degree in electrical engineering from the University of Wisconsin, Madison, in 1943.

He joined the General Electric Company shortly after graduation. Since his assignment to the field of Electromagnetic Compatibility in 1950, he has continued to specialize in the development of measurement methods, prediction and control of EMI. NEMP. and immunity associated with a broad range of consumer, industrial, electrical power, and military products and programs. He holds three patents on EMC-related control techniques. Among his assignments for many years was the responsibility to represent the General Electric Company interests in EMI/EMC technical standards and regulations. As a result he was. and continues to be, involved with Federal Communications Commission rulemaking with regard to Pan 18 (ISM Equipment) and Part 15 (Radio Frequency Devices). He was Chairman of the NEMA Electromagnetic Compatibility Committee and active in the EMC standards work of ANSI C63, IEEE EMC Society, and other IEEE standards committees, as well as the IEC-CISPR and TC-77. He continues to be involved in IEEE EMC standards matters since his recent retirement from the General Electric Company.

Mr. Gauper has served on the IEEE EMC Society Board of Directors, most recently in 1978-1981, and served as a Charter Member of the Federal Electromagnetic Radiation Management Advisory Council which advised on RF biohazard matters. 
․ 


\title{
Varistor versus Environment: Winning the Rematch
}

\author{
François Martzloff, Life Fellow, IEEE \\ National Institute of Standards and Technology \\ Gaithersburg MD 20899 USA \\ f.martzloff@ieee.org
}

(C) 1986 IEEE

Reprinted, with permission, from IEEE Transactions on Power Systems, Vol.PWRD No.3, April 1986

\section{Significance:}

This paper is listed under four categories of the Annotated Bibliography as it bears on the corresponding topics. The multiple listing reflects the sections in which this paper is cited as supporting material for IEEE Std C62.41.1 and C62.41.2. Therefore, it can be found in the following four parts of the Anthology:

Part 2 Development of standard - Reality checks

Provides an example of the need to recognize capacitor switching transients when characterizing the surge environment

Part 3 Recorded occurrences, surveys and staged tests

Provides an example of monitoring and staged tests motivated by field failure, leading to a better understanding of the environment in which SPDs were expected to perform.

Part 4 Propagation and coupling of surges

Provides an example of how far ( 3000 meters) the low-frequency transients generated by capacitor switching can propagate, unabated, in a path involving two step-down transformers.

Part 7 Mitigation techniques

Provides an example of improved mitigation design based on field experience 
$\varnothing$ 


\title{
VARISTOR VERSUS ENVIRONMENT: WINNING THE REMATCH
}

\author{
Françols D. Martzlofi, Fellow IEEE \\ Corporate Research and Development \\ General Electric Company \\ Schenectady, New York 12345
}

\begin{abstract}
An unusual case of difficult application of surge protective devices was solved by field measurements with retrofit of protective devices suitable for the particular environment. Onsite measurements indicated that capacitor switching transients were causing excessive current surges in the varistors and fuses protecting the input to a thyristor motor drive. Knowledge of the environment gained by the measurements allowed understanding of the problem and specification of matching surge protective devices.
\end{abstract}

\section{SUMMARY}

During the initial startup of a solid-state motor drive in a chemical processing plant, difficulties arose with the varistor and its protective fuse at the input of the thyristor circuits. Frequent blowing of the fuse was observed, with occasional failure of the varistor. On-site measurements of the voltages and currents at the input to the drive indicated that switching transients associated with the operation of a remote substation capacitor bank and the relatively low clamping level of the varistor were producing current above the fuse and varistor ratings; hence the short lives of these two components. When the actual conditions at that site were determined by measurements, it became possible to specify surge protective devices capable of withstanding that environment. Im. mediate relief was secured by the installation of a larger varistor at the same point of the circuit; long-term protection was obtained by the addition of a gapless metal-oxide varistor arrester on the primary side of the step-down transformer feeding the drive. The situation has been changed from failures occurring every few days to no further problems in the 3 years since the larger varistor was installed.

\section{INTRODUCTION}

This paper presents a case history illustrating how surge protective devices that are successfully applied for the majority of cases can occasionally suffer failure when exposed to exceptionally severe surge environments. This paper also shows how little attenuation occurs, at the frequencies produced by switching surges, between the distribution level $(23 \mathrm{kV})$ and the utilization level $(460 \mathrm{~V})$, even though a long line and two step-down transformers exist between the source of the transient and the point of measurement.

85 SM 365-2 A paper recommended and approved by the IEEE Surge Protective Devices Committee of the IEEE Power Englneering Soclety for presentation at the IEEE/PES 1985 Sumner Meeting, Vancouver, B.C., Canada, July $14-19,1985$. Manuscr1pt submltted February 1, 1985; made available for printIng Apr11 22, 1985.
The problem involved a $460 \mathrm{~V}$ power supply to a thyristor drive circuit in a chemical processing plant extending over several square miles. During the initial startup, difficulties arose with the varistor and its protective fuse at the input of the thyristor circuits. Frequent blowing of the fuse was observed, with occasional failure of the varistor. The plant substation, fed at $23 \mathrm{kV}$ from the local utility, included a large capacitor bank with one-third of the bank switched on and off to provide power factor and system voltage regulation. These frequent switching operations were suspected of generating high-energy transients that might be the cause of the failure of the fuses and varistors, because literally thousands of similar drive systems have been installed in other locations without this difiliculty. On-site measurements performed after repeated blowing of fuses and occasional failure of varistors connected at the input to the thyristor drive indicated that indeed the devices were not matched to their environment. From this point on, specifying larger sizes, sizes appropriate to the environment [1], solved the problem.

\section{POWER SYSTEM AND SWITCHING TRANSIENTS}

Figure 1 is a simplified one-line diagram of the significant elements of the power system causing the varistor failures. The incoming $115 \mathrm{kV}$ power is stepped down to $23 \mathrm{kV}$. Three banks of $5400 \mathrm{kVAR}$ capacitors are connected to the $23 \mathrm{kV}$ bus. Typical operating conditions involve two banks connected at all times, with the third bank switched on or off automatically to provide voltage regulation. Power distribution throughout the site is done at the $23 \mathrm{kV}$ level.

The various drive systems which experienced the difficulty are supplied at $460 \mathrm{~V}$ by a $2300 / 460 \mathrm{~V}$ transformer in their control house. A substation close to the control house supplies the $2300 \mathrm{~V}$ power from the $23 \mathrm{kV}$ distribution system.

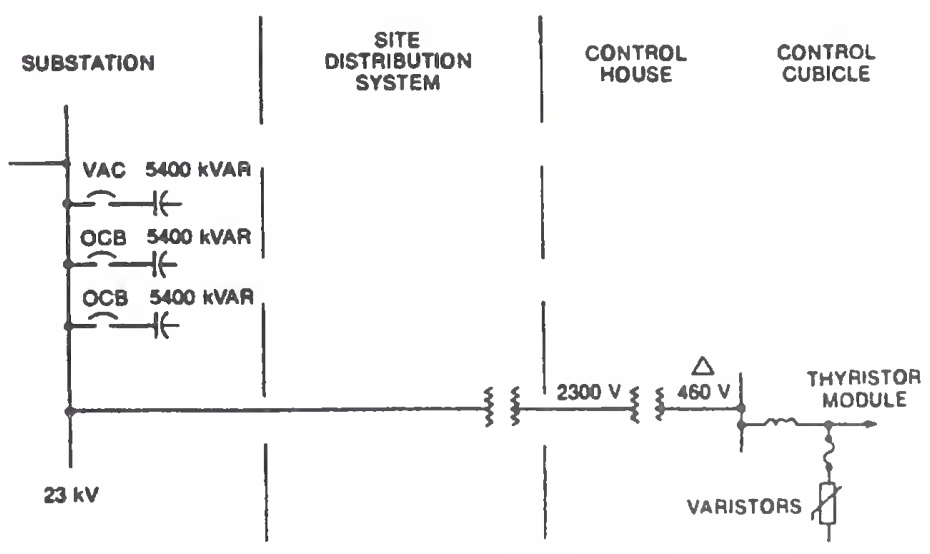

Figure 1. Simplifled one-line dlagram 
Figure 2 is a simplified three-phase schematic of the power input. In the original circuit, the thyristor modules were protected by varistors at the power input of the $1250 \mathrm{hp}$ drive, where the measurements were made. A $6 \mu \mathrm{H}$ line inductance, Ll, was inserted between the bus and the thyristor modules; $20 \mathrm{~mm}$ varistors rated $510 \mathrm{~V}$ were connected in a delta configuration, in series with a current-limiting fuse in each line. The varistor connection was about $80 \mathrm{~cm}$ long, introducing an estimated $\mathbb{1} \mu \mathrm{H}$ inductance into each lead.

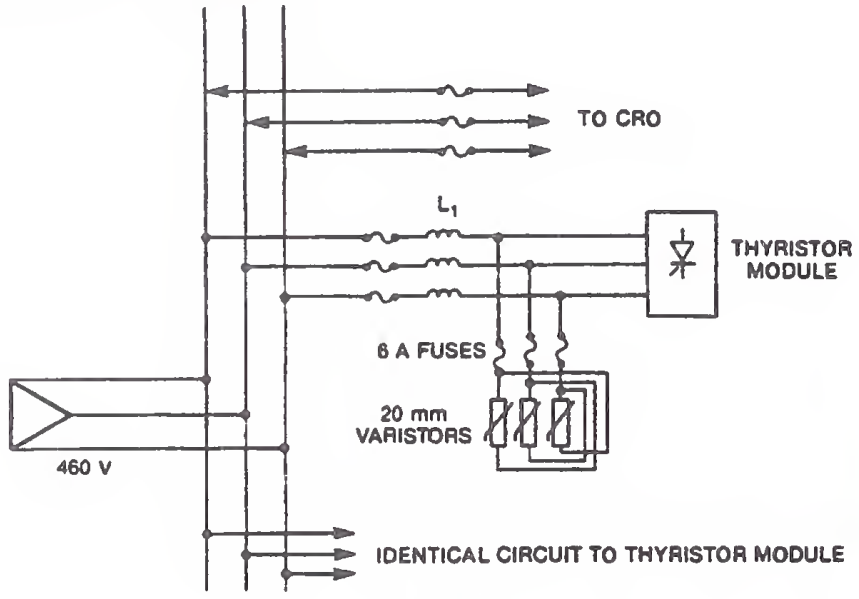

Figure 2. Simplifed three-phase schematic

\section{Instrumentation and Measurements}

Oscilloscopes were used to measure voltage across one varistor and its connection and currents through all varistors. Voltage measurements were made phase-to-phase on the Iloating delta $460 \mathrm{~V}$ bus bars with Tektronix P6015 1000:1 probes, connected to a Tektronix 7633 storage oscilloscope in differential mode. Current measurements were made with a Tektronix CT5 20:1 current transformer coupled with a P6021 current probe and connected to a second Tektronix 7633 storage oscilloscope.

The trigger modes used during a two-hour monitoring period included positive or negative slopes for both slow ac and highfrequency modes. For the various modes, the level was adjusted to produce a trigger for a voltage exceeding the normal line voltage crest by about $20 \%$, or a varistor current in excess of 2 A. No trigger occurred during the monitoring period. A low-frequency voltage recorder installed by plant personnel produced a recording characterized as representative of an unusually quiet day in the power system operations.

Manual off-on switching of the $5400 \mathrm{kVAR}$ capacitor bank at the $23 \mathrm{kV}$ utility substation was the next step in the measurement procedures because the switching of a capacitor bank is always a prime suspect for producing transients. Measurements were performed with one oscilloscope monitoring the line voltage upstream of the line inductors (Figure 2) and another oscilloscope monitoring the sum of the currents in the three varistors (Figure 3 ).

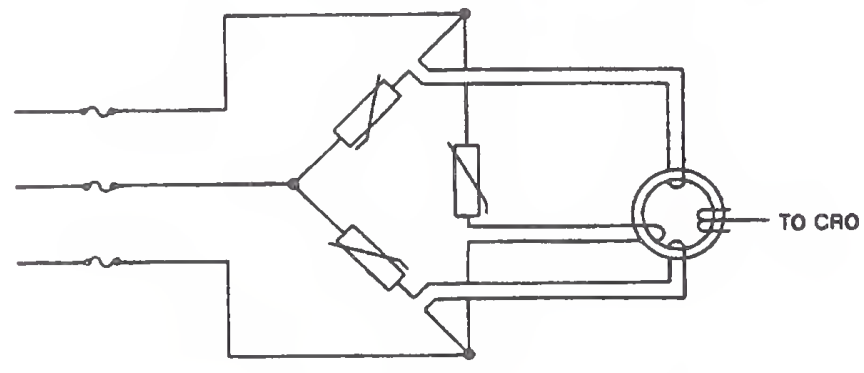

Figure 3. CT connection for recording all three varistor currents

\section{Results}

The oscillograms of Figure 4 show typical voltage recordings made during this sequence. The voltages are not open-circuit transient voltages. They are instances of the voltage appearing at the bus entrance point. This voltage is the sum of the varistor clamping voltage, the voltage drop in the varistor connections, and the voltage across two $\mathrm{Ll}$ inductances.

A typical total event recorded on one of the phases during a capacitor bank closing is shown in Figure 4A. A low-frequency oscillation with a period of $3 \mathrm{~ms}(330 \mathrm{~Hz})$ and initial peak-to-peak amplitude of $450 \mathrm{~V}$ decayed in about $10 \mathrm{~ms}$. The high-frequency oscillations are resolved in the recording of Figure $4 \mathrm{~B}$ (recorded during a similar switching sequence). This high frequency has an initial peak-to-peak amplitude of $2000 \mathrm{~V}$, decaying in about $5 \mathrm{~ms}$. The period is $180 \mu \mathrm{s}(5.5 \mathrm{kHz})$. A similar, third event is shown in Figure $4 \mathrm{C}$. For scaling the amplitudes, the steady-state voltage is shown in Figure 4D.

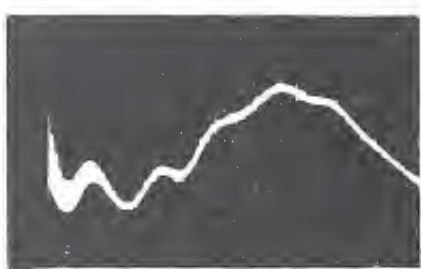

A Sreep: $2 \mathrm{~ms} / \mathrm{all}$ Vertlead: $500 \mathrm{~V} / \mathrm{dlv}$

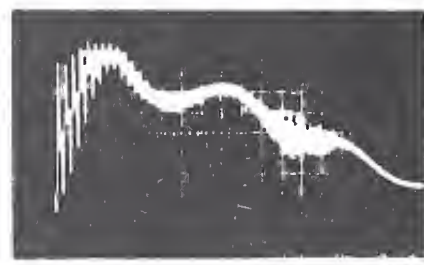

C Sซerp: 1 ase/div Verticeal: 500 V/div

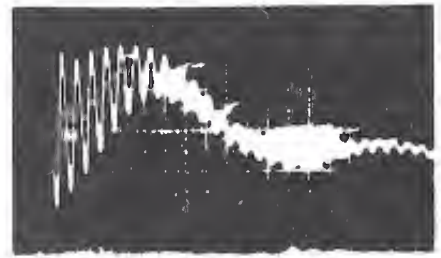

B Snowp: $0.5 \mathrm{~ms} / \mathrm{dly}$ Vertlcal: $500 \mathrm{~V} / \mathrm{d}$

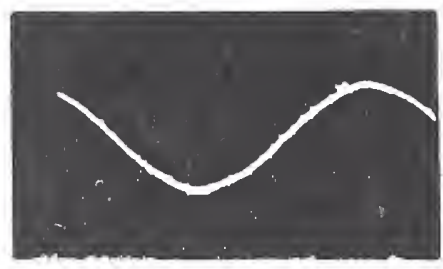

D Sreep: 2 as/div Vertleal: $300 \mathrm{~V} / \mathrm{dl}$
Figure 4. Capacitor switching transients and steady-state voitage

Observe that, depending on the time of closing with respect to the $60 \mathrm{~Hz}$ voltage, the $5.5 \mathrm{kHz}$ oscillation varies in amplitude; furthermore, the modulation by the $330 \mathrm{~Hz}$ oscillation pushes crests of the $5.5 \mathrm{kHz}$ oscillation above the $1000 \mathrm{~V}$ level some time after the beginning of the trace, at a time when the $5.5 \mathrm{kHz}$ amplitude is already lower, producing a burst of pulses above the $1000 \mathrm{~V}$ level.

The significance of this finding will be discussed next, with reference to Figure 5, which shows recordings of transient currents in all of the three varistors. The $510 \mathrm{~V}$ varistor has a nominal voltage at $1 \mathrm{~mA}$ [2] in the range of $735 \mathrm{~V}$ to $970 \mathrm{~V}$. For a varistor with a nominal voltage in the middle of this range, a current in the order of tens to hundreds of amperes will flow if a voltage of $1000 \mathrm{~V}$ is applied to the varistor. Figure $5 \mathrm{~A}$ shows a train of current pulses in the range of 10 to $40 \mathrm{~A}$. In the burst of Figure $5 \mathrm{~B}$, the recorded current pulses range from $5 \mathrm{~A}$ to $200 \mathrm{~A}$. The current and voltage traces are not simultaneous events because each of the two oscilloscopes was triggered by its internal circuit. The nearly symmetrical appearance of this burst can be compared to the symmetry of the voltage peaks exceeding the $1000 \mathrm{~V}$ level in Figure 4, the one correlating with the other.

The oscillograms of Figures 4 and 5 were selected as most severe from a series of 20 capacitor switching sequences. Some sequences could not even produce a current or voltage trigger; four sequences produced bursts with the ceniral peak exceeding $120 \mathrm{~A}$, two of these reaching $200 \mathrm{~A}$ peaks. 


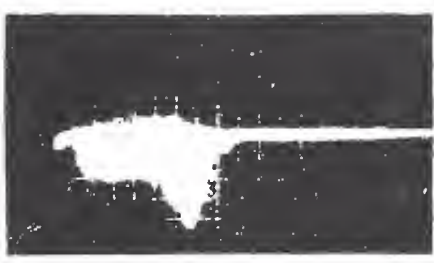

A Sweep: $0.2 \mathrm{~ms} / \mathrm{div}$ Verilcal: $20 \mathrm{~A} / \mathrm{di}$

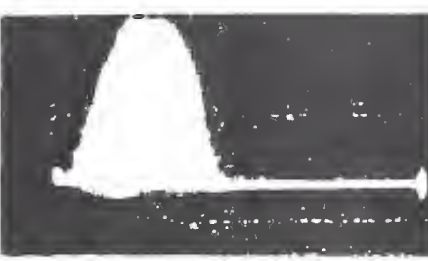

$B$ Sweep: $0.5 \mathrm{~ms} / \mathrm{dlv}$ Vertical: $40 \mathrm{~A} / \mathrm{div}$
Flgure 5. Current surge bursts during capacitor switching

These recordings establish the nature of the current surges that are conducted by the varistors, with an estimate of $10 \%$ reaching $200 \mathrm{~A}$ maximum crests and another $10 \%$ reaching $120 \mathrm{~A}$ crests, for all capacitor bank switching.

In Figures 4 and 5, we note that the characteristic appearance of the voltage and current usually observed during a switch restrike is absent [3], indicating a clean switching action of the vacuum interrupters used for switching the capacitor bank. Restrikes are most likely to occur during de-energizing. In all the offon switching sequences of this test series, no significant transient was observed during de-energizing; all occurred during energizing.

The oscillograms of Figures 4 and 5 establish and explain the pattern of current pulses. The voltages of Figure 4 are not the open-circuit voltages impinging the drive input but, rather, the voltages resulting from the clamping action of the varistors. To better evaluate the magnitude of the switching transients, opencircuit voltages were recorded in a next sequence, with all fuses to the drive open, thus disconnecting both the varistors and all sensitive loads. Figure 6 shows two typical recordings of open-circuit voltages and two of voltages resulting from varistor clamping, recorded during a series of 10 switching sequences for each condition. Table 1 shows the recorded crests of the five highest voltages in each condition; the difference between the two groups, with due allowance for the imperfect statistical basis of the observations, indicates that the $510 \mathrm{~V}$ varistors reduced the peaks from a typical high of $1450 \mathrm{~V}$ to a typical high of $1100 \mathrm{~V}$.
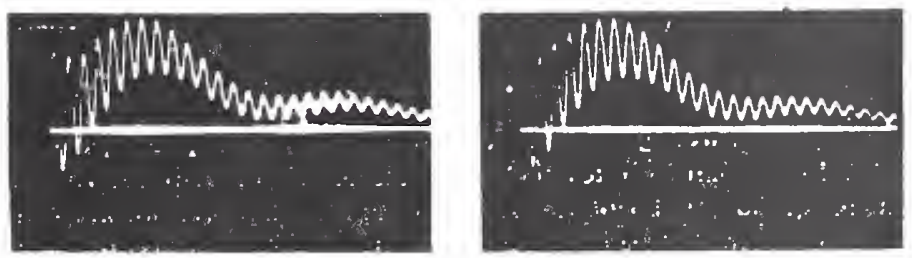

Open-Clrcull Voltages
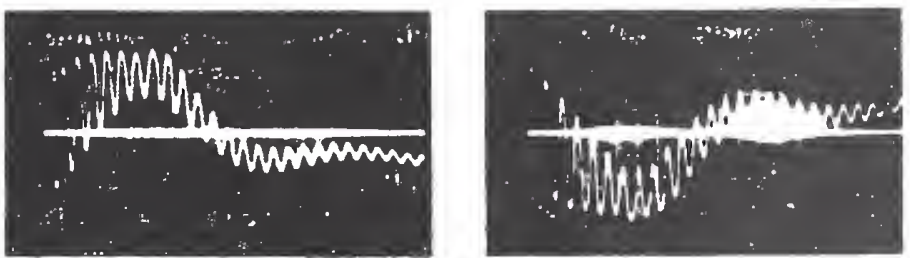

Wilh $20 \mathrm{~mm}$ Varlstors

All Traces: Sweep: $0.5 \mathrm{~ms} / \mathrm{div}$

Vertleal: $500 \mathrm{~V} / \mathrm{div}$
Table 1

FIVE HIGHEST TRANSIENTS IN SRQUENCE OF 10 SWITCHINGS

\begin{tabular}{c|c}
\hline Without Varistors & With Varistors \\
\hline 1450 & 1100 \\
1400 & 1100 \\
1300 & 1050 \\
1300 & 1050 \\
1300 & 1050 \\
\hline
\end{tabular}

\section{DISCUSSION}

\section{Nature of the Transients}

The absence of any transient (over $120 \%$ of normal crest) during the 2-hour monitoring period was somewhat surprising, in the context of earlier reports of high counts recorded with Dranetz disturbance analyzers. Frequent checks of threshold levels and variations of the possible trigger modes were made, maximizing the chance of catching an overvoltage, but indeed none occurred. This unusual quiet was also reflected in the chart recording made by the plant personnel, so that the absence of random transients for that period can be accepted at face value.

Therefore, conclusive evidence was obtained that substantial current pulses were absorbed by the varistors during capacitor switching. The magnitude and duration of these pulses were excessive for the capability of a $20 \mathrm{~mm}$ disc; many similar drives installed elsewhere do not experience the failures encountered at that particular location.

Another significant finding from these measurements is the fact that the switching transients, generated at the $23 \mathrm{kV}$ level, propagate down to the point of utilization at the $460 \mathrm{~V}$ level. Numerical discussion of this finding is given later in this paper.

\section{Effect of Transients on Varistors}

Published varistor specifications include the "pulse ratings," a family of curves that define, for each varistor type, the number of isolated pulses that a varistor can absorb until its "rating" is reached [4]. The curves show lines relating amplitude, duration, and total number of pulses. Figure 7 shows this family of curves for the original $20 \mathrm{~mm}$ varistor.

Figure 8 shows the same curves for a proposed $32 \mathrm{~mm}$ varistor. It should be noted that the pulse rating does not mean catastrophic failure of the varistor at the end of this rating, but only a $10 \%$ change in the varistor nominal voltage. Although some change is indicated, the varistor is quite capable of staying on line voltage and of clamping surges.

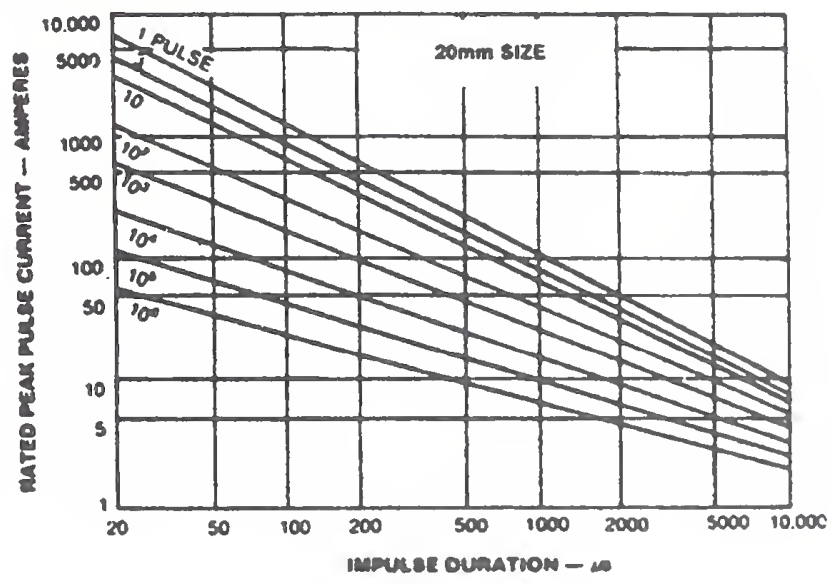

Figure 7. Pulse ratings of $20 \mathrm{~mm}$ varistor 14 I 


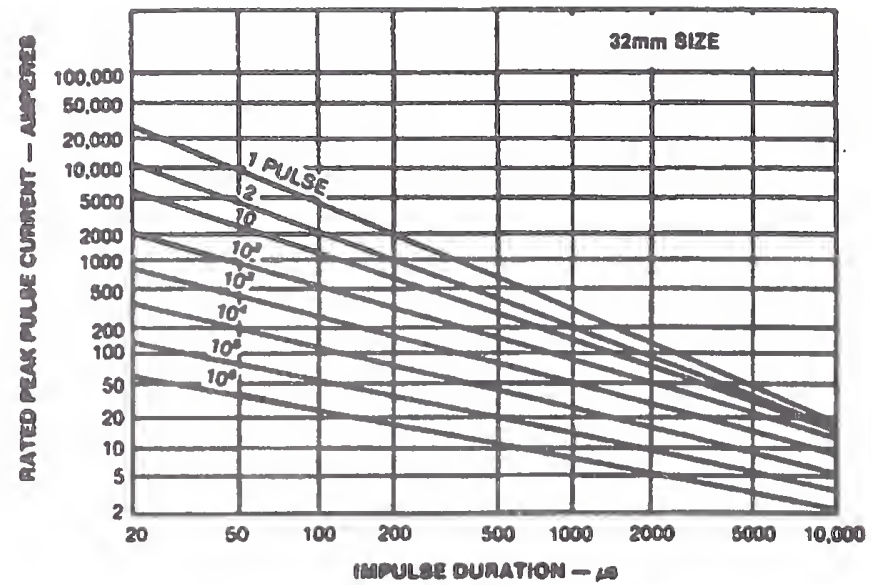

Figure 8. Pulse ratings of $32 \mathrm{~mm}$ varistor [5]

A careful examination of the pulse rating curves will show that the duration of the pulses has a strong influence on the number of permissible pulses. Furthermore, the relationship between the increased duration of the pulses and the decreased number of permissible pulses is not proportional. For instance, consider pulses of $100 \mathrm{~A}$ peak and $100 \mu \mathrm{s}$ duration (Figure 9A): the curves show 5000 pulses allowed. Now increase the duration of the pulses to $1000 \mu \mathrm{s}$ (a ten-fold increase), while keeping the amplitude at $100 \mathrm{~A}$ : the curves show the permissible number as one pulse only. Thus, the ten-fold increase in duration does not result in a ten-fold decrease in the number of permissible pulses; the reduction in that number is much greater than the inverse of the increase in duration. Conversely, taking a pulse duration of $1000 \mu \mathrm{s}$, and seeking the amplitude allowable for the same 5000 pulses, Figure 9B shows that the current is $20 \mathrm{~A}$, which is five times less than the original $100 \mathrm{~A}$, not ten times less. Therefore, it would be incorrect to treat the multiple pulses of Figure 5 as five separate short pulses; rather, one equivalent long pulse has to be defined.

The five-pulse burst of Figure 5 has been redrawn in Figure 10 in order to plot an equivalent continuous pulse of approximately equal duration, with a crest such that the i.t integral of the burst and the it of the equivalent pulse are approximately the same. The use of $\mathrm{i} \cdot t$ rather than the $\mathrm{i}^{2} \cdot t$ integral typically used for fuses or other linear loads is justified by the fact that heat deposited in the varistors is the significant parameter because the nominal voltage change process is temperature related; this heat is the product of the variable $i$ and the nearly constant voltage across the nonlinear varistor during the burst.

The equivalent pulse of Figure 10 can then be used to evaluate, from the pulse ratings of Figure 7, the number of highamplitude switching transients that will consume $100 \%$ of the varistor pulse rating. Inspection of Figure 6 shows that fos a $800 \mu$ s duration and $100 \mathrm{~A}$ amplitude, the pulse rating of the $20 \mathrm{~mm}$ varistor (6 kA rating at $8 / 20 \mu \mathrm{s}$ ) is reached with two such events. With a probability of about $10 \%$ that this highest switching transient would occur during random timing of the switching (the effect decreases rapidly for transients other than the highest) and with 2 to 4 switching operations each day, the pulse rating of the varistors could be reached with 20 operations, failure perhaps starting at 40 to 50 operations, or after about 10 days of exposure to that power system environment. This estimate is unavoidably imprecise because the pulse rating curves represent a conservative minimum; actual failures will occur only for amplitudes or numbers of pulses exceeding the rating by a large but imprecise margin to allow for manufacturing variations. However, the order of magnitude of this estimated time to failure is in accord with the observations made at that installation.

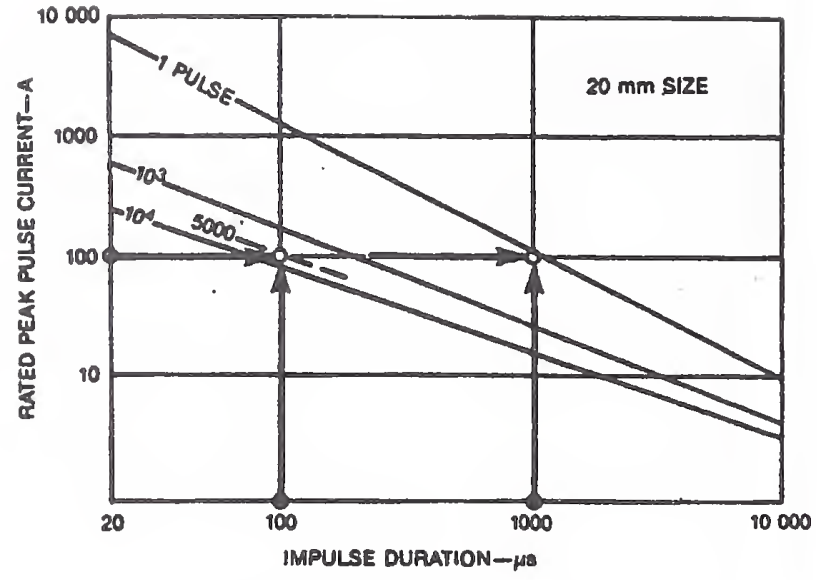

A. Same current, Increasigg duration

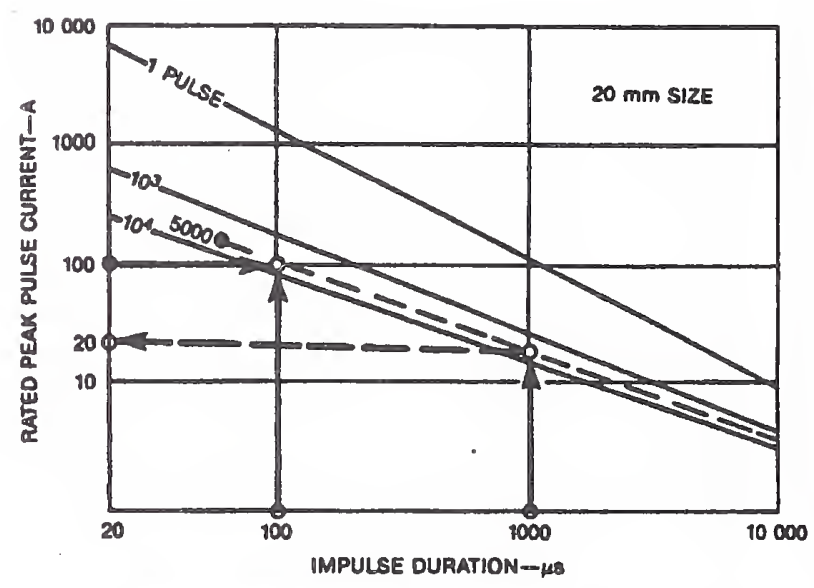

B. Same namber of pulses, increasing duration

Flgure 9. Readlug pulse ratings curves

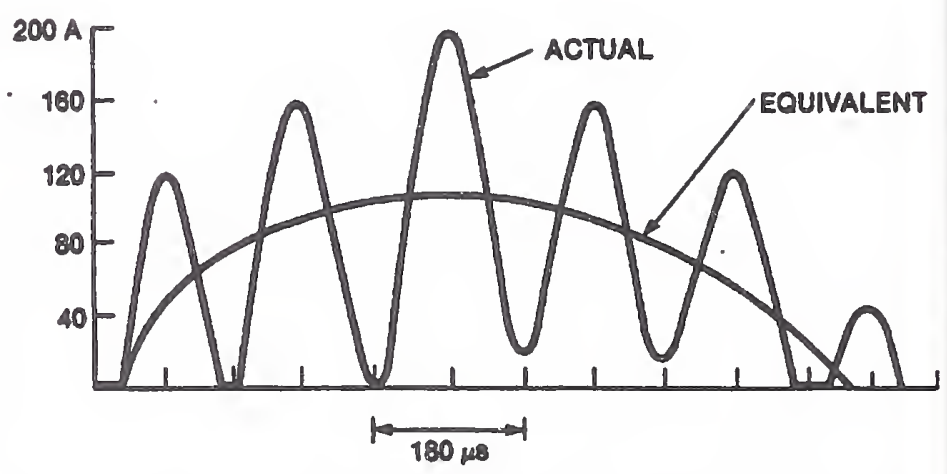

Figure 10. Slogle-pulse equivalent palse for multiple pulses

Note that two types of events occur. One is the premature blowing of the fuse, which is not caused by a varistor failure but by the $t^{2} \cdot t$ capacity of the fuse being exceeded by the environment [1]. The other is the fuse blowing caused by the varistor end-of. life ultimate failure. 


\section{Alternate Veristor Selection}

An obvious remedy would be to use a varistor with greater energy-handling capability. The $32 \mathrm{~mm}$ size offers such a possibility. Inspection of Figures 7 and 8 shows that the equivalent pulse of Figure $10(800 \mu \mathrm{s}$ and $100 \mathrm{~A}$ ) corresponds to a permissible occurrence of 100 pulses for the $32 \mathrm{~mm}$ varistor, in contrast to the two for the $20 \mathrm{~mm}$ varistor. The improvement in the number of pulses is 50 times more pulses until pulse rating is reached. The improvement in the number of pulses until varistor failure occurs, however, is not necessarily 50 times more pulses. Because of the imprecision mentioned previously in the margin between end of pulse rating and ultimate failure, that margin is not necessarily the same for the two sizes, $20 \mathrm{~mm}$ and $32 \mathrm{~mm}$, but it is reasonable to expect the same order of magnitude improvement in the ultimate failure as in the pulse rating. This expectation of a 50 times improvement would change the time between failures from the few days observed with the $20 \mathrm{~mm}$ size to perhaps one year with the $32 \mathrm{~mm}$ size, providing immediate relief and time to make further changes for the long term. Therefore, the change to a $32 \mathrm{~mm}$ size, connected at the same point of the circuit, was immediately implemented for that particular environment.

Further gains could be obtained in the length of time between varistor failures by increasing the clamping voltage of the varistors. This increase would result in lower current pulses for the same open-circuit transient voltage. A $510 \mathrm{~V}$ rating had been selected by the designer of the drive as the result of a trade-off between varistor clamping voltage and the withstand voltage of the thyristors protected by the varistors. If thyristors with higher voltage withstand were used, the solution would be easy.

of course, the standard varistor product line has a certain tolerance band, reflecting normal production lot variations. In principle, a selection could be requested from the manufacturer that varistors with a narrower band be supplied for this application. The maximum clamping voltage allowed by the drive specifications would be retained, but those varistors in the lower half of the distribution, which draw larger current pulses for a given open-circuit transient voltage, would have been removed from the population of varistors. For instance, the range of nominal voltages for a $575 \mathrm{~V}, 32 \mathrm{~mm}$ varistor (the next higher voltage offered) is 805 to $1005 \mathrm{~V}$ for $1 \mathrm{~mA} \mathrm{dc}$, while the maximum nominal voltage of the same diameter but rated $510 \mathrm{~V}$ is $910 \mathrm{~V}$ for $1 \mathrm{~mA}$ dc. Thus, for a normal distribution of nominal voltages of the $575 \mathrm{~V}$ varistor, $50 \%$ of the devices could theoretically be used without exceeding the upper limit of the $510 \mathrm{~V}$ varistor that is consistent with the drive specifications. To achieve this end, it would be necessary for the supplier or user to make a careful determination of the nominal voltage on a population of $575 \mathrm{~V}$ varistors in order to retain only the lower half of the distribution (Figure 11).

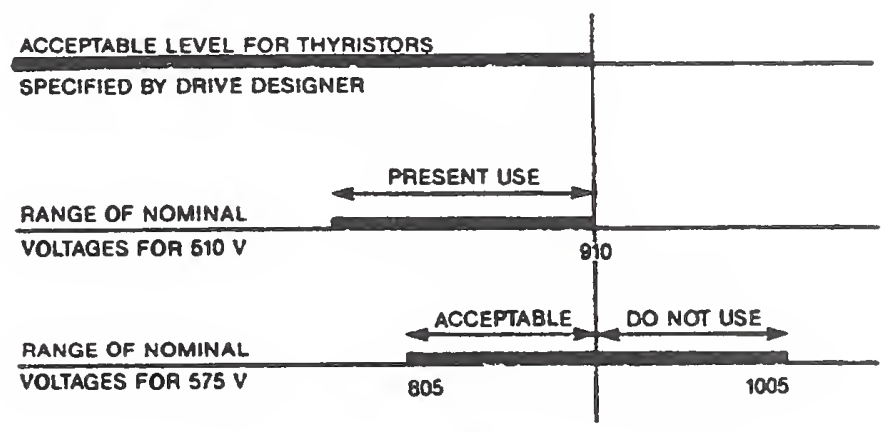

Figure 11. Tolerances bands of $510 \mathrm{~V}$ and $575 \mathrm{~V}$ varistors

\section{Other Remedies}

In addition to the proposed upgrading of protection at the $460 \mathrm{~V}$ level, three other remedies could be considered: installa. tion of surge arresters at the $2300 \mathrm{~V}$ level, installation of surge arresters at the $23 \mathrm{kV}$ level, or a change in the circuits involved in the capacitor switching, designed to reduce the severity of the transients at their origin.

In general, the protection available from surge arresters tends to improve when the arresters are installed at higher circuit voltages. Thus, it is quite possible that arresters installed at the $2300 \mathrm{~V}$ primary of the $2300 / 460$ transformer could provide a more effective clamping (and at the same time relieve some of the energy stress) than the varistors at the $460 \mathrm{~V}$ level. (It is of course implied that these would be the zinc-oxide type, gapless arresters.) The full benefit of these arresters depends on the configuration of the $2300 \mathrm{~V}$ system and its grounding (solidly grounded neutral in a wye system, resistance-grounded wye, or floating delta) when the arrestors are connected in the conventional line-to-ground mode. In a second phase of the retront described here, $2300 \mathrm{~V}$ arresters were installed at the transformer primary. A discussion of their expected performance, validated by the success of the retrofit, is given later on.

Likewise, arresters on the $23 \mathrm{kV}$ side could be installed at the $23 \mathrm{kV}$ substation to mitigate the capacitor switching transients at their origin, or at the primary of the $23 \mathrm{kV} / 2300 \mathrm{~V}$ substation near the control house, where they would also serve as lightning protection for the overhead $23 \mathrm{kV}$ incoming power line. These arresters, again, must be of the gapless type to obtain the most effective protection.

The final remedy in the list of alternatives, but perhaps the first in effectiveness when the opportunity exists, would be to attempt reducing the severity of the capacitor switching transients at their origin. Series inductors or damping resistors may be considered, the effectiveness of which would be predictable if a simulation of the power system behavior were performed by computer modeling. While that remedy could not be applied to this particular loca. tion, it is a remedy that should be considered for a similar case of exceptionally severe environment.

\section{EXPECTED PERFORMANCE OF THE 2300 V ARRESTERS}

The measurements made first with open-circuit, then with the $20 \mathrm{~mm}, 510 \mathrm{~V}$ varistors on the $460 \mathrm{~V}$ side have shown a reduction of maximum voltage from $1450 \mathrm{~V}$ to $1100 \mathrm{~V}$ (Table 1) when a current of approximately $200 \mathrm{~A}$ is flowing in the line and varistors (Figure 5).

We can assume that the voltage drop in the line from the substation and two step-down transformers is mostly inductive at $5.5 \mathrm{kHz}$, and that the voltage in the varistors can be treated as the voltage across a resistor at the time of the crest of the current wave. The diagram of Figure 12 shows the relationship between the three voltages VOC, VL, and VV, respectively, the open-circuit voltage generated by the capacitor switching action, the voltage drop in the line and two transformers, and the varistor voltage at the current peak. Treating this highly nonlinear circuit as a linear circuit is an approximation that will provide at each point of the full range of voltage and current conditions a valid order of magnitude for the purposes of this discussion. Numerical methods are available for rigorous treatment at any instant over the full range of conditions [6]. With this simpifying assumption, we can determine the order of magnitude of the $5.5 \mathrm{kHz}$ current that would flow in an arrester installed at the primary terminals of the 2300 $\mathrm{V} / 460 \mathrm{~V}$ transformer as follows. 
1. From the actual measured voltages shown in Figure 12, we derive the volkage drop, $V_{L}$, in the $23 \mathrm{kV}$ line and two stepdown transformers:

$$
\begin{aligned}
V L & =\left(1450^{2}-1100^{2}\right)^{1 / 2} \\
& =940
\end{aligned}
$$

Thus, at $5.5 \mathrm{kHz}$, the impedance between the source and the varistor is

$$
\begin{aligned}
Z L & =\frac{V_{L}}{I} \\
& =\frac{940 \mathrm{~V}}{200 \mathrm{~A}} \\
& =4.7 \Omega
\end{aligned}
$$

Note that this $4.7 \Omega$ impedance means that the $5.5 \mathrm{kHz}$ switching transient, generated at a distance of about $3000 \mathrm{~m}$ ( 2 miles) from the point of messuremenh, and at the $23 \mathrm{kV}$ level, car travel long distance and pass through two step-down transformers with less attenuation than might be expected from the unsound but popular view that "surges cannot travel that far without substantial attenuation."

2. We now arbitrarily assign equal values to the three elements of this impedance, $\mathrm{ZL}$ : (1) the $23 \mathrm{kV}$ line impedance; (2) the $23 \mathrm{kV} / 2300 \mathrm{~V}$ transformer; and (3) the $2300 / 460 \mathrm{~V}$ transformer. The impedance between the source and the primary of the $2300 / 460 \mathrm{~V}$ transformer is then two-thirds of the total impedance, $\mathrm{ZL}$, or about $3 \Omega$ for the $460 \mathrm{~V}$ side of the transformer.

3. On the $2300 \mathrm{~V}$ side, the impedance of $3 \Omega$, calculated above, becomes $3 \Omega \times(2300 / 460)^{2}=75 \Omega$ and the open-circuit voltage of $1450 \mathrm{~V}$ which was measured on the $460 \mathrm{~V}$ side becomes $1450 \mathrm{~V} \times(2300 / 460)=7250 \mathrm{~V}$.

4. Knowing the open-circuil vollage and the impedance between the source and the $2300 \mathrm{~V}$ arrester, we can compute the current in the arrester by iteration if we assume some current value and read the corresponding clamping voltage on the I-V characteristic of the arrester:

a) Assume a current crest of $50 \mathrm{~A}$, producing a drop of 50 $\times 75=3750 \mathrm{~V}$ in the line and $23,000 / 2300 \mathrm{~V}$ iransformer. Adding this voltage to the varistor voltage, corresponding to $50 \mathrm{~A}$, which is read as about $5700 \mathrm{~V}$ on the arrester characteristic curve for minimum discharge voltage (Figure 13), we have $\left(3750^{2}+5700^{2}\right)^{1 / 2}=6780 \mathrm{~V}$, or somewhat below the expected $7250 \mathrm{~V}$ open-circuit voltage, which is to equal the quadratic sum of the two voltages VL and VV.

b) Assume, for a new iteration, a crest of $60 \mathrm{~A}$, producing a drop of $60 \times 75=4500 \mathrm{~V}$, while the varistor voltage remains essentially the same, i.e., $5700 \mathrm{~V}$. The quadratic addition becomes $\left(4500^{2}+5700^{2}\right)^{1 / 2}=7210 \mathrm{~V}$, or a value close to the goal of 7250 .

5. Thus, we can expect that the $2300 \mathrm{~V}$ arrester will experience current pulses occurring in bursts not exceeding 60 to $70 \mathrm{~A}_{\text {, }}$ with durations similar to those found on the $460 \mathrm{~V}$ varistors, i.e. 5 to 7 pulses per train, or a total duration in the order of $1 \mathrm{~ms}$. Information on arrester dury available from the manufacturer indicates that, for a pulse train of that duration and a crest of less than $100 \mathrm{~A}$, no limitation of the number of pulses need be imposed on the arrester as long as enough time is allowed between pulses to permit cooling of the arrester.

Furthermore, the $5700 \mathrm{~V}$ clamping level predicted for the $2300 \mathrm{~V}$ surge arresters at $60 \mathrm{~A}$ would be rellected as a crest of $5700 \mathrm{~V} \times 460 / 2300=1140 \mathrm{~V}$ on the $460 \mathrm{~V}$ side. The $510 \mathrm{~V}$, $32 \mathrm{~mm}$ varistors, connecied in series with the impedance of the $2300 / 460 \mathrm{~V}$ transformer, would then be exposed to this maximum
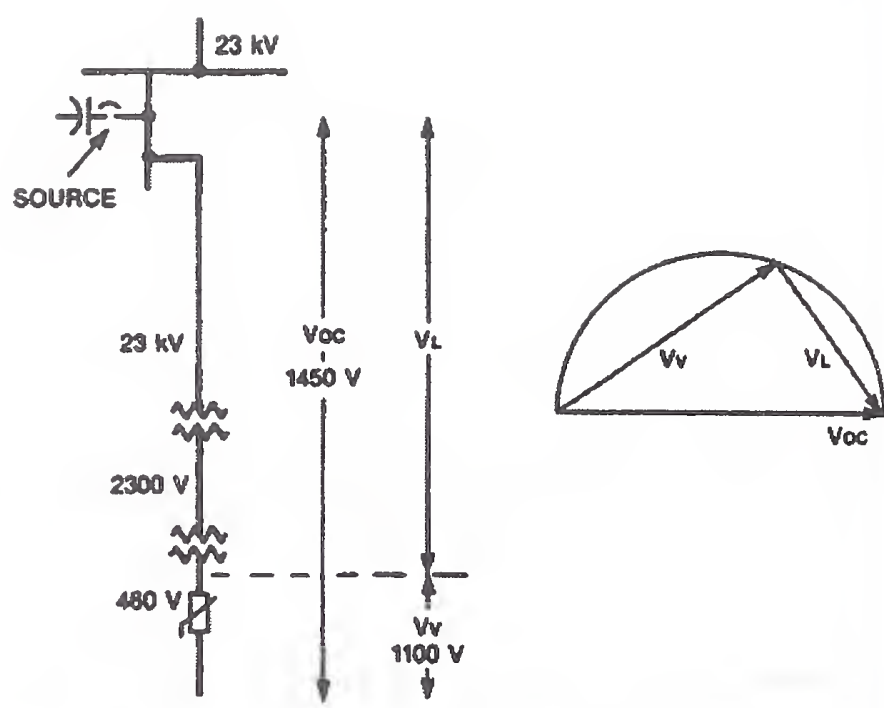

Figure 12. Open-circult roltage and roltage drope In the syatem

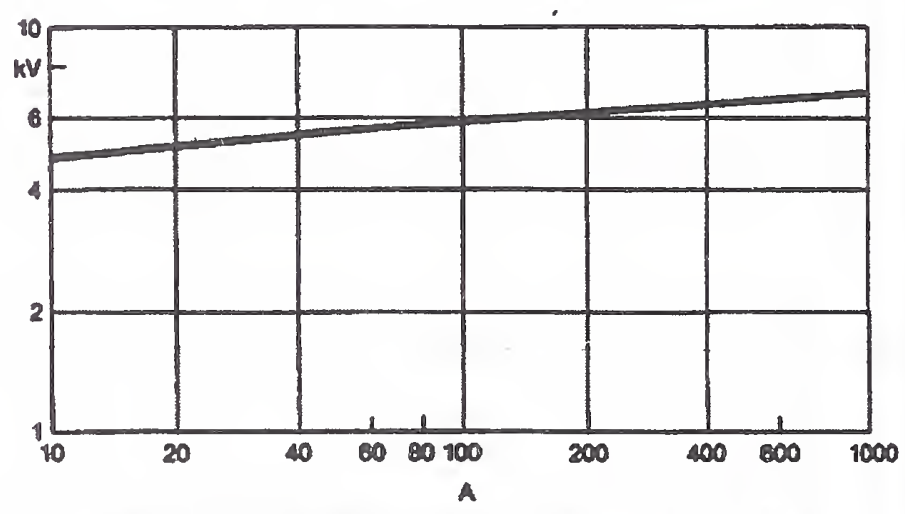

Flgure 13. Minimum clamplos voltage characteristle for $2300 \mathrm{~V}$ anrester

open-circuit voltage of $1140 \mathrm{~V}$, \&alue much lower than the $1450 \mathrm{~V}$ open-circuit voltage that was applied to them in the absence of the $2300 \mathrm{~V}$ arresters. For that applied voltage, the current drawe by the varistor would be in the range of 10 to $20 \mathrm{~A}$, values much lower than the $200 \mathrm{~A}$ measused without the $2300 \mathrm{~V}$ arrester. Computiog the equivalent pulse, as was done in Figure 10 for the $200 \mathrm{~A}$ crests, would yield an equivalent crest of about $10 \mathrm{~A}$, for which the pulse rating curves of the $32 \mathrm{~mm}$ series show more than 100,000 pulses before its rating is reached.

To place these large differences of performance and withstand capability into perspective, Table 2 shows the relative sizes and volumes of varistor material applied to the taming of the capacitor switching transient. In other words, the environment bas now beec matched by the capablitity of the varlators.

Table 2

VARISTOR AND ARRESTER DIMENSIONS

\begin{tabular}{l|c|c|c}
\hline Type & Diameter & Thickness & Volume \\
\hline $20 \mathrm{~mm}$ & $1.8 \mathrm{~cm}$ & $0.35 \mathrm{~cm}$ & $0.9 \mathrm{~cm}^{3}$ \\
$32 \mathrm{~mm}$ & $3.0 \mathrm{~cm}$ & $0.35 \mathrm{~cm}$ & $2.5 \mathrm{~cm}^{3}$ \\
2300 V Arr. & $6.1 \mathrm{~cm}$ & $2.4 \mathrm{~cm}$ & $30 \mathrm{~cm}^{3}$ \\
\hline
\end{tabular}




\section{CONCLUSIONS}

Voltage and current measurements made on the $460 \mathrm{~V}$ input to a thyristor motor drive, during staged capacitor switching operations, showed current surges in the varistors originally used in the system that could consume the pulse rating life of these varistors in a few days of typical operation. Short-and long-term remedies were achieved.

For the short term, the change to a larger varistor connected on the $460 \mathrm{~V}$ side of the system was readily implemented to main. tain the originally specified protective level, while the fuse-blowing nuisances were eliminated by use of a larger fuse. Available devices for this $460 \mathrm{~V}$ circuit may still have a relatively short life (a few hundred days) in the prevailing environment of the site, but they offered immediate relief and therefore allowed successful startup of the system.

For the long term, further protection was oblained by the installation of conventional station-class surge arresters, of the zinc-oxide, gapless type, at the $2300 \mathrm{~V}$ level. The system has now operated for 3 years without problems.

This case history also illustrates the low attenuation of the switching transient between the distant source at $23 \mathrm{kV}$ (about $3000 \mathrm{~m}$, or 2 miles) and the point of utilization at $460 \mathrm{~V}$.

\section{ACKNOWLEDGMENTS}

J.S. Kresge and B.I. Wolff provided information and guidance on the surge arrester and the varistor characteristics; C.L. Fisher contributed advice in clarifying and unifying the presentation of the concepts. Their contributions are gratefully acknowledged.

\section{REFERENCES}

[1] F.D. Martzloff, "Matching Surge Protective Devices to their Environment," Proc. IEEE/AS Meeting. October 1983, pp. 387.392. (Also scheduled for IAS Transactions, Jan/Feb 1985.)
[2] ANSI/IEEE Sid C62.33-1982, IEEE Standard Test Specifications for Varistor Surge Protective Devices, The Institute of Electrical and Electronic Engineers, Inc., New York.

[3] A. Greenwood, Electrical Transients in Power Systems, Wiley Interscience, New York, 1971.

[4] Transient Voltage Suppression Manual, Fousth Edition, General Electric Company, Auburn, NY, 1983.

[5] Transient Voltage Suppression Manual, Third Edition, General Electric Company, Auburn, NY, 1983.

[6] H.W. Dommel, "Digital Computer Solution of Electromagnetic Transients in Single and Multiphase Networks," IEEE Transactions on Power Apparatus and Systems, Vol. PAS-88, pp. 388-399, April 1969.

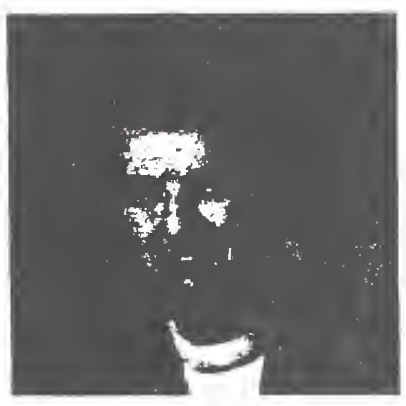

Françols D. Martzlof (M'56, F'83) was born in France, and received his undergraduate degree at the Ecole Spéciale de Mécanique et d'Elecıricité in 1951; he received the MS in Electrical Engineering degree from Georgia Tech in 1952 and the MS in Industrial Administration degree from Union College in 1971.

Since 1956 he has been with the General Electric Company, where he gained experience in the Transformer and Switchgear Division. Upon joining General Electric Corporate Research and Development in 1961, be became involved in power semiconductor circuits and overvoltage pro. tection. He has participated in the introduction and application of metal oxide varistors since 1971 .

In IEEE, Mr. Martzloff is active on the Surge Protective Devices Committee. He is chairman of the Working Group on Surge Characterization in Low-Voltage Circuits. He is also a member of the Ad Hoc Advisory Subcommittee of the USA Advisory Committee on IEC S/C 28A, ANSI C.62 Subcommittee on Low-Voltage Surge Proteclive Devices, and Chairman of the NEMA Low-Voltage Arresters Technical Committee. He has been awarded 13 U.S. patents, primarily in the field of varistors and transient protection. 


\section{Discussion}

J. L. Koepfinger (Drquesne Light Company, Pitsburch, PA): The author has addressed one of many mechanisms for producing repetitive overvoltages on low-voltage circuits. In this particular instance, it was possible to obtain controlled conditions so that a measurement could be made of the voltage and currents resulting from the capacitor switching. It would be useful if there was an analytical method presented that correlated the generation of the 5.5.kMz pulses with those measured. Did the author attempt to make such a correlation?

This paper points out the need to know the characteristic of the surge so that proper sizing of the protection can be achieved. Therefore it would be desirable to be able to have some analytical tool to permit calculation of the frequency of the surge due to remote capacitor switching.

Manuscript received July 24, 1985.

Fraveols D. Martaloff: The paper reported a case history from which useful information may be derived on retrofitting corrections of similar problems or, better, on avoiding the problem by foresight. The situations confronting the author was the need for immediate corrective action rather than complete investigation and mutual validation of analytical methods and field measurements.

The literature is fairly rich in both theoretical and practical papers on the problems associated with capacitor switching, both for energizing and for de-energizing, the latter involving the risk of restrikes. Because of this availability and the limited space available in the TRANSACTIONS on one hand, and because of the limitations in scope of the field retrofit mission on the other hand, no atternpt was made to correlate the measurements with the power system parameters (which were not readily available to the author). In response to Mr. Koepfinger's suggestion, abstracts are cited below to provide references to both analytical tools and practical results published by other workers.

\section{Bibliography, 1970-1985 : REFERENCES}

[1] M. F. McGranaghan, W. E. Reid, S. W. Law, and D. W. Gresham, "Overvoltage Protection of Shunt-Capacitor Banks Using MOV Arresters," IEEE Trans. Power App. Syst., PAS-103, No. 8, Aug. 1984, pp. 2326-2333.

Protection requirements and surge arrester duties are analyzed for both digital and transient network analyzer (TNA) simulations. Simple analytical expressions are developed for evaluating arrester duty as a function of capacitor bank size. Guidelines and limitations for applying arresters at grounded-and ungrounded-wye capacitor banks are developed based on overvoltage characteristics and arrester capabilities.

[2] J. H. Brunke and G. G. Schoeckelt "Synchronous Energization of Shunt Capacitors at 230 kV," IEEE PES (Power Eng. Soc.) Winter Meeting, New York, NY; Jan. 20-Feb. 3, 1978; Publ. by IREE 1977. Paper A78-148-9, p. 4.

This paper reports on the application of synchronous switching to reduce inrush transients when switching a $230-\mathrm{kV}$ shunt capacitor bank. Computer studies determined the required switch performance.

[3] J. D. Cuffman, John Linders, M. A. Zucker, and S. Willims, "Power Factor Correction Capacitors and Their Side Effects," IEEE Conf. Rec., 28th Ann. Conf. Electr. Ens. Probl. Rubber Plast. Ind., Akron, OH, April 5-6, 1976, pp. 37-49.

The major reason for applying capacitors to an electrical distribution system is to correct poor power factor. In the greater majority of installtions it is a routine procedure. In some instances capacitors may cause problems with other in-plant equipment and in other instances they may suffer undesirable side effects that originate in other equipment. Among these problems are switching surges, voltage unbalance due to fuses blowing, and harmonics generated by SCRcontrolled equipment.

[4] H. 3. Yelland, and C. P. Yellma, "Vacuum Contactors: Latest Development in Their Design and Application," Certif. Ens. V S4, No. 1, Jan. 1981, pp. 824-841.

The paper includes the following topics: Design of vacuum bottles (glass and ceramic); design of the complete vacuum contactor and their panels; panels with on-load isolation, and panels with off- load isolation; vacuum contactor applications (motor control), capacitor switching, arc and other (furnace-switching, transformer switching, mine-winder-reversers). Surge generation by vacuum contactors is considered under the following heads: basic energization and de-energization transients; transients generated when switching inductive loads; assessment of a vacuum contactor from a surge generation point of view; types of surge suppression devices; switching of capacitive loads. An extensive discussion of the paper is appended.

[5] Jack R. Harbaugh and John E. Harder, "Important Considerations for Capacitor Applications in the Petroleum and Chemical Process Industries," IEEE Pet. Chem. Ind. Conf., 27th Ann. Rec. of Conf. Prp., Houston, TX, Sept. 8-10, 1980; IEEE, H80CH1549-5 IA), Piscataway, NJ, pp. 157-167.

The location of capacitors may have a significant effect of the (I**2R losses within the plant transformers and conductors, which is wasted energy. Transients generated by capacitor switching may require attention in the selection of arresters, system insulation, or other equipment. The presence of capacitors amy require some special attention to large motors during system reclosing or load transfer. This study addresses each of these considerations, providing some guidelines for effective, reliable capacitor application. In addition, a checklist is provided for general industrial capacitor applications.

[6] J. F. Burser, R. J. Santoro, J. W. Stolle, R. E. Owen and C. R. Clinkenbeard, "Comparative Evaluation of Field Test Data and Computer Results on Capacitor Switching Transients," Meeting Minutes PA Electr. Assoc., Eng. Sect., Trans. and Distrb. Comm. West Middlesec, PA, May 15-16, 1979; PA Electr. Assoc., Eng. Sect., Harrisburg, PA 1979.

An arrester failure case was analyzed occurring at the time of substation capacitor bank switching with the use of a transient network analyzer (TNA) and digital computer techniques. The case involved a 12.5-kV ground-wye distribution sytem. Results of the INA study, which were validated by field tests, showed the effects of system configuration magnitude of transient over voltages.

[7] Eldon J. Rosers, and Don A. Gilles, "Shunt Capacitor Switching EMI Voltages, Their Reduction in Bonneville Power Administration Substations," IEEE Trans. Power Appar. Syst. PAS-93, No. 6, Nov.-Dec. 1974, pp. 1849-1860.

Back-to-back switching of grounded wye shunt capacitors cause high frequency, high-magnitude current flow in overhead bus and ground mat conductors. Measurements of induced voltages on control cables and receptacles, transverse voltages on fuse blown PT secondaries and personnel intercept voltages are reported. BPA methods of confining transients to capacitor areas and shielding techniques are reviewed.

[8] Paul C. Krause and Willian C. Mauser, "On-Line Transient Control of Capacitor Switching to Improve System Stability," IEEE Trons. Power Appar. Syst. PAS-92, No. 1, Jan-Feb. 1973, pp. 321-329.

A simplified voltage-reactance equivalent of the one-machine infinite bus system was used. The material presented in this paper shows that this simplified model does not predict the performance of a onemachine infinite bus system with the accuracy necessary to determine the capacitor switching times so as to achieve the control objectives. However, it is shown that computation accuracy may be improved by including system losses. It appears that in order to apply optimal control techniques it will be necessary to develop more accurate models of the power system components. Also, faster than real time iterative, on-line computation techniques as simulated in this paper should be implemented and used to calculate the switching times. Until these obstacles are overcome, optimal control theory will have little impact upon the power industry.

[9] D. O. Wiitanen, J. D. Morgan, and G. L. Gaibrois, "Station Capacitor Switching Transients, Analytical and Experimental Results," IEEE Trans. Power App. Syst. PAS-90, No. 4, July-Aug. 1971. pp. 1639-1645.

Station capacitor bank energization transients predicted by a circuit model are compared to field-test results. Selection of a suitable model is discussed. A computer solution of the model is presented.

Manuscript received September 19, 1985 


\title{
Fast Transient Tests: Trivial or Terminal Pursuit ?
}

\author{
François D. Martzloff and Perry F. Wilson \\ National Bureau of Standards \\ f.martzloff@ieee.org
}

Reprinted, with permission, from Proceedings, $7^{\text {th }}$ International Zürich Symposium on Electromagnetic Compatibility, 1987

\section{Significance: \\ Part 4 - Propagation and coupling of surges}

In the earty 80 's, considerable interest arose in developing an IEC standard test method to assess the immunity of electronic equipment against "fast transients" such as those that can be produced by contact bouncing in power circuits. Such transients could propagate from their source - the bouncing contact - to the power port of equipment, or be coupled by proximity into control cables connected to the equipment of interest. The issue was not so much the potential for damaging the equipment - as in surge occurrences - - but rather the possibility of disturbing proper operation of the equipment.

Motivated by some skepticism on how far such fast transients can propagate, measurements, augmented by theoretical numerical simulations were conducted on representative power wining configurations. The findings, showing good agreement between theory and expeniments, validated the expectation, that is, substantial attenuation occurs when these fast transients travel more than a few tens of meters away from their source. See also Propag EFT2 for additional tests on a vaniety of cable configurations. 
(2. 
FAST TRANSIENT TESTS - TRIVIAL OR TERMINAL PURSUIT ?

\author{
François D. Martzlorf \\ Electrosystems Division \\ National Bureau of Standards \\ Gaithersburg. MD 20899 \\ Perry F. Wilson \\ Electromagnetic Fields Division \\ National Bureau of Standards \\ Boulder, CO 80303
}

\begin{abstract}
SUMMARY
Measurements, augmented by theoretical simulation techniques, have been performed to determine the attenuation of fast transients propagating in typical indoor (conduitenclosed) power lines. The rise time of the applied pulses ranges from 0.7 to $50.0 \mathrm{~ns}$, including the International Electrotechnical Commission (IEC) $5 / 50$ ns pulse recently recommended for fast transient tests. Theory and measurements confirm that pulse amplitude attenuation increases significantly for shorter pulses. For comparison and validation of the theoretical model, the IEC pulse was also applied to a conventional coaxial cable.
\end{abstract}

\section{INTRODUCTION}

Surge testing requirements are of increasing interest among manufacturers and users of electronic equipment. Performance progress is often obtained with fast $10 \mathrm{l}$ ic devices which can be quite sensitive to external overvoltages, both amplitude and rate of change. The operation of electronic equipment in potentially hostile environments mandates realistic surge testing in order to better understand fallure modes and to validate advanced protection schemes.

Existing standards such as those of the IEC, IEEE, and ANSI require surge test waveforms with rise times generally longer than 100 ns $[1]-[3]$. However, recent proposals [4]-[5] advocate fast-transient tests with waveforms representative of electrostatic discharge events or relay contact bounces. The rationale for such proposals is based on an increased awareness of the significance of fast transients. This awareness results from two factors; (1) increases in the bandwidth and writing speed of oscilloscopes which reveals the characteristics of these phenomena, and (2) unexplained field fallures of equipment which pass conventional surge tests.

There is a risk that unrealistic emphasis might be placed on these steep-front waves. Their occurrence and effect on nearby equipment have been documented. However, the propagation characteristics of power and (some) data lines 1 ight produce fairly rapid attenuation of the high frequency components of these rast transient surges. Comprehensive data on surge attenuation at these frequencies have not been published to our knowledge. Thus, quantitative laboratory tests, augmented by theoretical simulation techniques, should contribute to better decisions on the importance and applicability of proposed fasttransient standards, as well as complement previous studies on surge propagation involving lower frequencles [6]. The experimental (Martzloff) and theoretical (Wilson) portions of this investigation were performed independently by the two authors. The results are compared in this paper.

\section{EXPERIMENTAL CONFIGURATION AND SIMULATION}

A representative low-voltage, indoor, single-phase power line with three conductors in a steel conduit was set up in a laboratory. A length of $63 \mathrm{~m}$ was selected (20 standard conduit sections). The line was built with normal industrial components and practices but in a zig-zag pattern with both ends at essentially the same location. This allowed both send and receive measurements to be performed with the same instrumentation and without physically moving any equipment. Three insulated $(600 \mathrm{~V})$, stranded-copper conductors of \# 14 AWG ( $1.6 \mathrm{~mm}$ diam.) were pulled in a steel conduit ( $20 \mathrm{~mm}$ diam.) and connected as shown in Figure 1. At the sending end, the neutral conductor is bonded
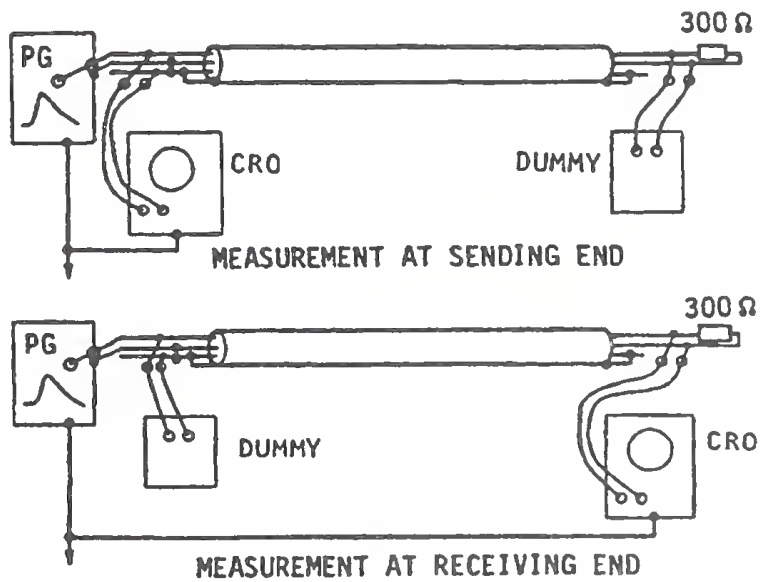

F1g. 1. Connection of conductors and 1 nstrumentation for the measurement of at tenuation of steep-front pulses in a condult 11 ne. 
to the grounding (safety) conductor and to the conduit. At the recelving end, the neutral wire was not bonded to the grounding conductor or conduit. This type of connection is typlcal U.S. practice for a branch circuit originating at a service entrance.

A family of fast surges, ranging from 0.7 to $50 \mathrm{~ns}$ in rise time and of duration three times the rise time were generated for propagation alons the line. The IEC EFT (Electrical Fast Transient) pulse of $5 / 50 \mathrm{~ns}$ was also used as an input $31 \mathrm{gnal}$. For a baseline comparison, a $63 \mathrm{~m}$ length of conventional RG58 coaxial cable was also subjected to the IEC EFT pulse. Details of the instrumentation are given in Appendix A.

Pulse propagation on a transmission line depends on the pulse shape (rise time, width. frequency content, etc.) and the transmissionline characteristics (geometry, materials, etc.). The analysis of the pulse propagation follows the previous work of Wingington and Nahman [7]. The transmission line characteristics for various lines will be primarily derived from King [8]. The detalls are left to Appendix $B$. The general problem of multiconductor lines within a circular condult is beyond the scope of this paper. Thus, we consider a coaxial line, which models the RG58 cable, and a palr of wires symmetrically located within a conduit (see Fig. B2). This latter case neglects the grounding conductor in the actual experimental setup but is a reasonable idealization of the power-line configuration. These transmission lines are assumed to be uniform. In practice, the location of the inner conductors may vary within the conduit due to sag, bends, and so forth. Thus, we consider two special cases; (1) wires near the center separated only by the thickness of the wire insulation, and (2) wires near the wall of the conduit again to within the thickness of the wire insulation. Because the insulation has a higher dielectric constant than does air. its presence will increase the attenuation of the surges. However, the insulation thickness about each wire is small and for simplicity their effect is ignored.

\section{EXPERIMENTAL RESULTS}

Figure 2 shows composite oscillograms of the pulse applied at the sending end and arriving at the receiving end for a family of four unidrectional pulses with comparable duration/rise-time ratios. We rind substantial attenuation ( $97 \%$ ) for the fastest pulse $(0.7$-ns rise time), and still appreciable attenuation (40\%) for the slowest pulse (50-ns rise time). In addition to the attenuation of the peaks, the rise time of the pulse is increased at the far end, with a stretching of the duration, sometimes referred to as 'smearing the pulse'. The oscillograms for each type of pulse also show that while the peaks are attenuated, the integrals of the voltages with respect to time of the pulses at the sending and recelving ends are comparable. This last observation implies that equipment sensitive to peaks or to steep fronts will be somewhat protected by a line of sufficient length. However, if the equipment is

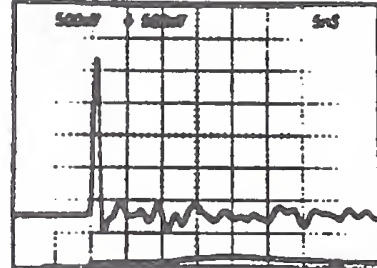

SEND: $100 \%, 0.7 / 2 \mathrm{~ns}$ RECEIVE: $3 \%, 10 / 30$ ns

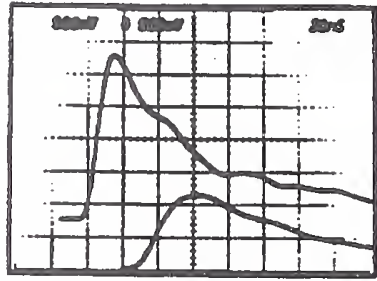

SEND: $100 \%, 12 / 45$ ns RECEIVE: $46 \%, 22 / 90$ ns

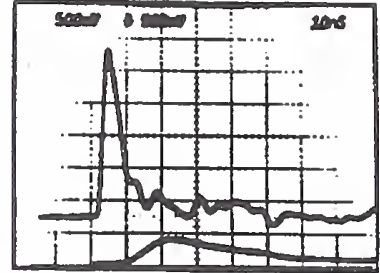

SEND: $\quad 100 \%, 2.5 / 8 \mathrm{~ns}$ RECEIVE: $15 \%, 12 / 40$ nS

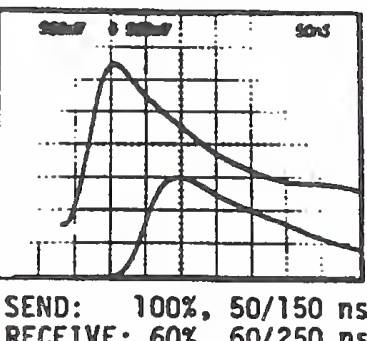

Flg. 2. Composite osell lograms of sending-end and recelving-end pulses for four pulses of Increasing rige time duration in the 63-m conduit ine.

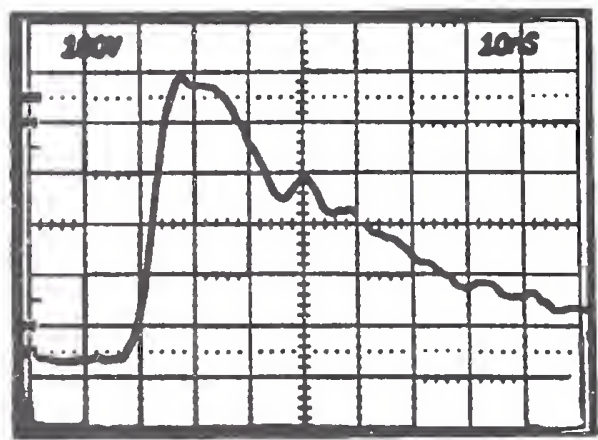

(A) Commerclai IEC EFT generator outDut

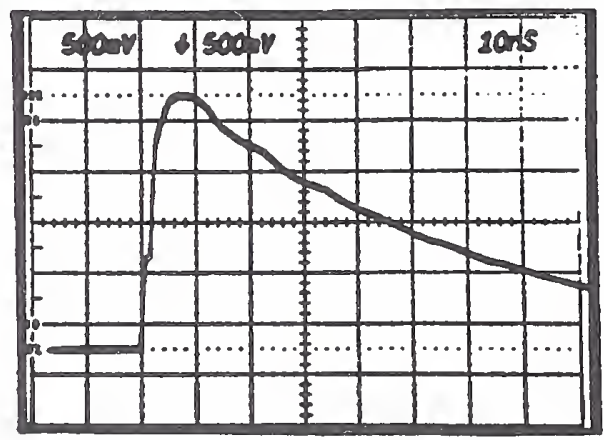

(B) NBS pulse-forming circuit output

F1g. 3. Typlcal waveforms in accordance with IEC EFT requirements.

sensitive to energy, the presence of the line will not significantly decrease its exposure.

The IEC is currently developing a requirement for EFT tests with a repetitive burst of pulses [5], each having a 5-ns rise tIme and a 50-ns duration above $50 \%$ of the peak value. This type of transient is typical of local switching of loads which potentially can be coupled into adjacent power or data lines. Commercial generators are now avallable for simulating these transients with preset amplitudes in the range of 0.5 to 4.0 $k V$. An example is shown in Figure $3 A$. For more repeatable waveforms in this study, such as shown in Figure 3B, a 5/50-ns pulse of 
lower voltage was obtained by discharging a 1$n F$ capacitor through a mercury-wetted relay into $20 \mathrm{~m}$ of RG58 cable. Furthermore, the lower voltage pulse allowed direct connection into the 50- $\Omega, 10-\mathrm{V}$ maximum input of the preamplifiers, instead of requiring an attenuator with attendant effect on the risetime response (see the artificially smooth rise of the trace on Fig. 3A). Figure 4 shows the sending-end and recelving-end oscillograms for this idealized pulse waveform for 25,38 , and $63-\mathrm{m}$ lengths in the condult line.

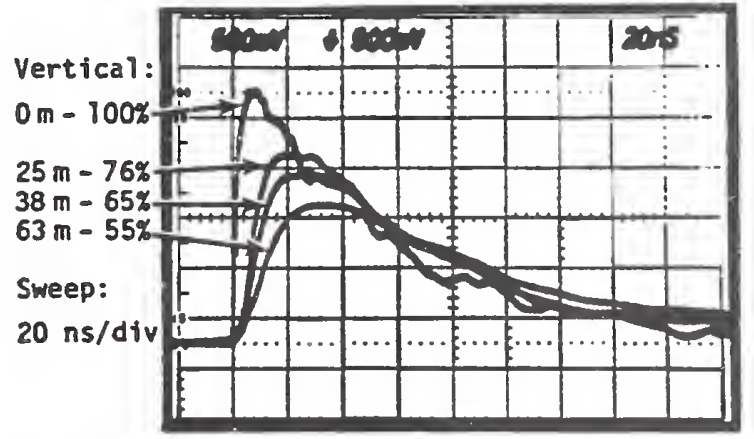

F18. 4. Sending-end and recelving-end oscillograms for the IEC EFT pulse in 25, 38, and 63-m lengths of condult line.

Finally, a comparable length of RG58 coaxial cable was also subjected to the same measurements with the $5 / 50-n s$ pulse. Figure 5 shows the results. The expected lesser attenuation, compared to that of the power ine. Is quite apparent. Coaxial cables are intended to provide a minimum attenuation of high frequency signals. A slightly slower propagation speed due to the solid dielectric of the coaxial cable was noticed, in contrast with the composite solid-air dielectric of the conduit line.

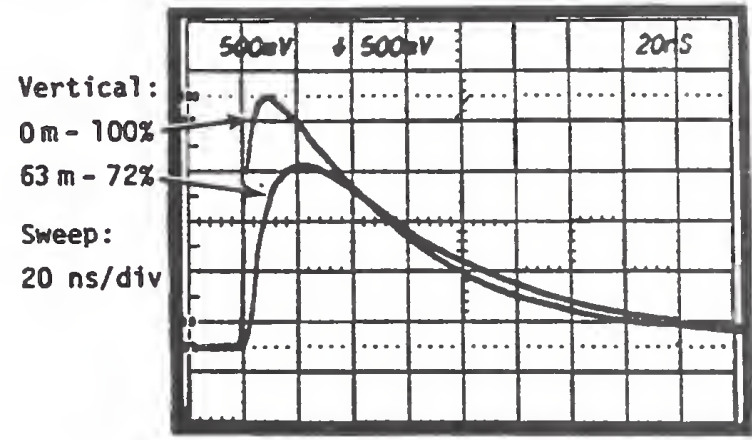

F18. 5. Sending-end and recelving-end osclllograms for the IEC EFT pulse in 63 m of RG58 coaxial cable.

\section{THEORETICAL SIMULATION RESULTS}

Table I summarizes the results obtained from the analytical model and experimental measurements. In the theoretical approach, there is a marked difference between results for the two model cases (wires near center or conduit wall) as might be expected. For comparison with the experimental results, an intermediate value between the two limiting cases should be selected. The combined effect of gravity and residual curvature of the conductors pulled from a spool may place the conductors against the wall. Therefore, the actual configuration should give results similar to those of the theoretical case with the wires near the wall. Indeed, these agree within $\pm 16 \%$ for the various pulses.

Figure 6 shows simulated results for the IEC EFT pulse in the $63 \mathrm{~m}$ conduit line. The input pulse is approximated from Figure 4 with linear splines (* curve, see Appendix, eq. B5). The resulting output pulses (eq. B10) for the two-wire configurations are shown. For comparison, an approximation to the actual measured output pulse (Fig. 4) is also included. The measured pulse lies between the two special cases, with the wires-near-conduit curve better predicting the measured pulse as expected. Qualitatively, the theoretical pulses look very much like the measured pulses. We can in fact choose the model parameter $\mathbf{k}(=0.000114)$ such that attenuation for the $63 \mathrm{~m}$ line $1 \mathrm{~s}$ accurately matched. Given this empirically determined value we, then consider the effect of varying the line

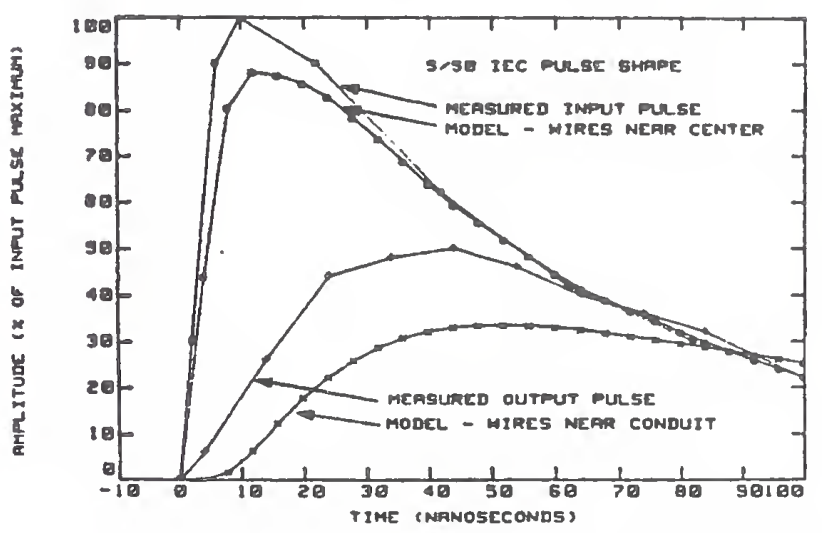

F18. 6. Sending-end and recelving-end curves for the IEC EFT pulse in the 63-m condult line. Both theoret 1 cal curves and 1 inear approximations to the measured data are shown.

Table I

Comparison of theoretical prediction and experimental results

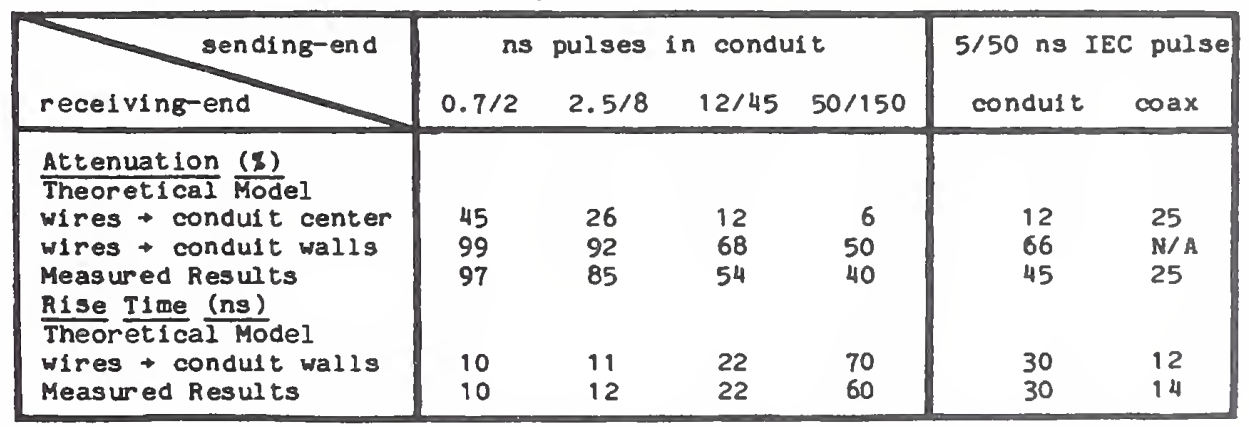


length. The results are depicted in Figure 7 . Measured data show maximum amplitudes of $76 \%$ and $65 \%$ for the 25 and $38 \mathrm{~m}$ line lengths. The predicted amplitudes (Fig. 7) are $75 \%$ and $67 \%$ respectively, and thus are in good agreement. Also shown are the predicted pulse shapes for 120 and $240 \mathrm{~m}$ lengths with the expected continued attenuation and smearing of the pulse.

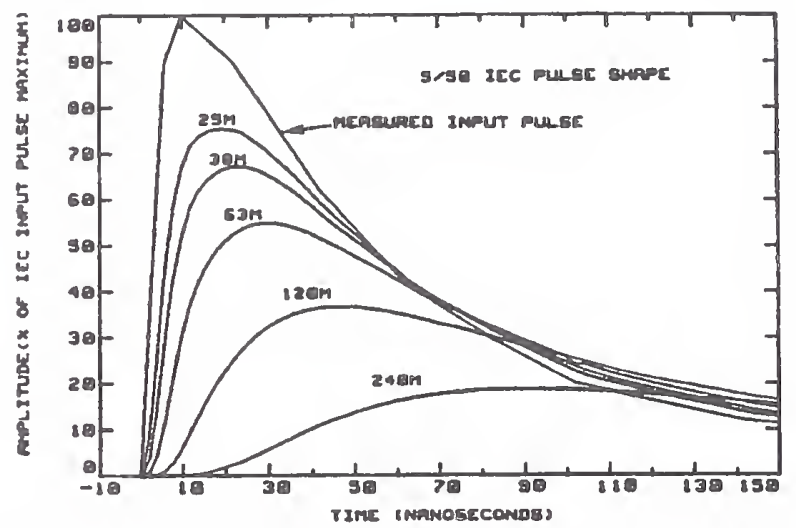

F1g. 7. Attenuation for the IEC EFT pulse in representative condult line as a function of I1ne length.

Figure 8 shows results for the $63-\mathrm{m}$ length of RG58, again for the IEC EFT pulse. The input and output linear approximations are taken from the waveforms in Figure 5. The results of the theoretical model agree very well with the measured data. This is expected since in this case the transmission line cross section is uniform and the line paraneters are well defined.

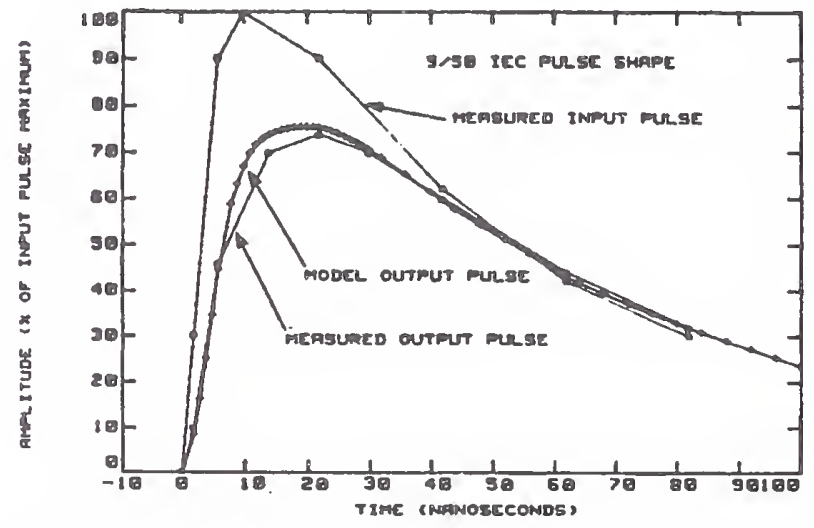

F1g. 8. Sending-end and recelving-end curves for the IEC EFT pulse in 63 of of RG58 coaxial cable.

\section{CONCLUSIONS}

1. Theoretical modeling based on a physical description of the line parameters yields results which agree with laboratory measurements, even for steep-pront surges such as those currently proposed by new standards.

2. These steep-front surges suffer appreciable attenuation when propagating in power lines. Both amplitude and steepness of the surge front are reduced, with steep, short pulses affected more than longer pulses.

3. This attenuation will be a welcome mitigating effect for load equipment connected at the end of a long line and not exposed to transients generated by nearby equipment.

4. The attenuation is greater for steepness and amplitude than for the voltagetime integral of the surge. This suggests that dispersion dominates wall losses in reducing the pulse maximum. Therefore, this attenuation will benefit equipment sensitive to noise interference more than those sensitive to energy interference.

5. Coaxial cable, as opposed to a power line made of wires somewhat randomly located in a steel conduit, produces far less at tenuation. The model-measurement correlation is improved because the coaxialcable geometry is well defined.

\section{APPENDIX A - INSTRUMENTATION}

Voltages were recorded with a Tektronix 7104 (* see refs.) oscilloscope provided with two 7 A29 (* see refs.) vertical amplifiers. The mainframe of the oscilloscope performed the differential combination of the two signals. In this configuration, the bandwidth of the system is only $500 \mathrm{MHz}$, compared to the 1 GHz capability of the single-ended measurement with only one amplifier. This reduction in performance is an acceptable trade off to obtain the differentlal connection while the condult, oscilloscope chassis and low side output of the generator are bonded together, and hence assure minimum nolse coupling. Where high voltages are involved, this configuration provides improved safety. This was not a concern here as the measurement on this linear system were conducted with signals in the 5-V range. A check on the common mode rejection of the system indicated less than $5 \%$ residual signal, an insignificant effect compared to the attenuation levels measured.

The amplifiers have a 50-ohm input impedance, so that the effective impedance of the differentially connected probe is 100 ohms. To make the measurements at the sending end, the voltages of the line and neutral conductors with respect to chassis ground were each fed to one of the preamplifiers. In this manner, the pulse delivered by the generator impinges on an impedance consisting of the two anplifiers in series and in parallel with the line. To make measurements at the receising end, the same oscilloscope was used, with the same connection. However, the pulse arriving at the receiving end would experience a reflection due to any impedance mismatch. To obtain an impedance match, time-domain reflectometry was used to trim the terminating load until no reflection occurred. Good matching was obtained with a 75-ohm termination. With the two conductors isolated from the conduit, but still contained in the conduit, the characteristic impedance determined by this method was 280 ohms, typical of a twin-conductor line. With the 100-ohm impedance of the probe, a 300-ohm parallel resistance at the line end brought the termination to 75 ohms, avoiding mismatching enhancements or attenuation at the line end. 
A dummy was constructed to provide the same matching impedance as that of the oscilloscope-probe combination (see Fig. 1). When recording the recelving-end waveforms with the oscilloscope, the dummy was connected in parallel with the line at the sending end. Thus, the impinging pulse from the generator would be presented the same load impedance as during measurements at the sending end.

\section{APPENDIX B - THEORETICAL MODEL}

A uniform line may be characterized by a series impedance $\mathrm{Z}(\mathrm{s})$ and shunt admittance $Y$ ( $s$ ) where $s$ is the Laplace transform varlable. These in turn depend on the internal impedance $R(s)$ (internal resistance and inductance), the (static) external inductance $\mathrm{L}$, the (stat $1 \mathrm{C}$ ) capacitance $\mathrm{C}$, and the conductance $G(s)$ of the material filling the transmission line [7] $Z(s)=R(s)+s L$ and $Y(s)=G(s)+s C$. We define the transmission-line characteristic lmpedance $\mathrm{Z}_{0}(\mathrm{~s})$ and propagation function $\gamma(s)$ in the

usual fashion. Most transmission lines, including those of interest here, are filled with a nearly lossless material. This implies that $G(s)=0$. For a well designed, practical transmission line the series internal resistance should also be relatively small, even at higher frequencles. Making this assumption allows us to expand $Z_{0}(s)$ and $Y(s)$

in terms of a Taylor series in $R(s)$. We will retain only the first order loss perturbation term which yields

$$
\begin{aligned}
& Z_{0}(s)=Z_{0}+\frac{1}{2} \frac{R(s)}{s \gamma_{0}} \text {, and } \\
& r(s)=s \gamma_{0}+\frac{1}{2} \frac{R(s)}{Z_{0}},
\end{aligned}
$$

where $z_{0}$ and $\gamma_{0}$ are the usual loss-free values associated with the line. These approximations appear in the paper by Wingington and Nahman [7].

Consider the generic transmission line of length $\&$ shown in Figure $B 1$ which will serve to model the experimental line depicted in Figure 1. It is excited by a generator voltage $V_{g}(s)$, with a generator impedance $z_{g}(s)$, and terminated in a load 1 mpedance $z_{t}(s)$. We are interested primarily in comparing the voltage appearing at the input end $v_{i}(s)$ to the voltage recelved at the output $v_{0}(s)$. We find that

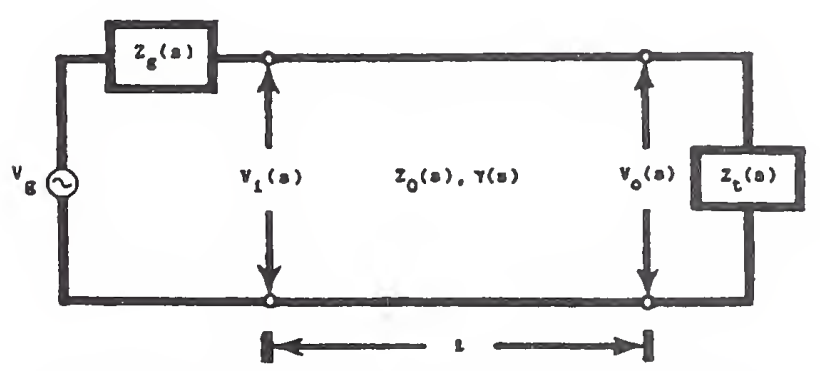

F1g. B1. Transmission I1ne model of surge propagation experiment.

$$
\begin{aligned}
& \frac{v_{0}(s)}{V_{1}(s)}=2\left[\frac{Z_{t}(s)}{Z_{0}(s)+Z_{t}(s)}\right]\left[\frac{e^{-\gamma(s) l}}{1+\Gamma_{r}(s) e^{-2 Y(s) l}}\right], \\
& \Gamma_{r}(s)=\frac{Z_{t}(s)-Z_{0}(s)}{Z_{t}(s)+Z_{0}(s)} .
\end{aligned}
$$

Substituting ( $B 1$ ) into (B2) will yield an approximate form for the voltage $r$ atio of interest; however, we need not be so general. For this analysis we may assume that the line is terminated in a resistive load equal to the lossless characteristic impedance of the line, that is $\mathrm{Z}_{t}(\mathrm{~s})=\mathrm{Z}_{0^{\circ}}$. Further, if the resistive contribution at high frequencies is small compared to the characteristic impedance, the reflection terms in (B2) do not contribute. Combining results we $r$ ind that the output voltage may be written in terms of the input (to the line) voltage as

$$
\begin{aligned}
& V_{0}(s)=V_{i}(s) e^{-s \gamma_{0} \ell} A(s) \text {, and } \\
& A(s)=e^{-R(s) \ell / 2 Z_{0}},
\end{aligned}
$$

where $A(s)$ represents the attenuation due to line losses. In other words, we will consider the line to be well matched, consistent with the experimental procedure. The term exp($\left.s \gamma_{0} l\right)$ is simply the lossless case propagation delay due to the line length $\ell$.

We may now make use of Laplace transform properties to find $v_{0}(t)$ given $v_{i}(t)$. The inverse Laplace transform of the recelving-end voltage is given by

$$
v_{0}(t)=\left\{v_{1}\left(t-\gamma_{0} l\right) * a\left(t-\gamma_{0} l\right)\right\} u\left(t-\gamma_{0} l\right),
$$
where the lower case symbols represent the respective inverse Laplace transforms, * denotes a convolution integral, and $u(t)$ is the unit step function at $t=0$.

The input voltage is typically not given in analytical form. Thus, for simplicity we will use a series of linear functions $r_{n}(t)$ to approximate $v_{1}(t)$. The function $r_{n}(t)$ is simply a ramp rising from zero at time $t_{n}$ to a value $a_{n}$ at $t i m e t_{n+1}$, and then remaining at this level for $t \geq t_{n+1}$. By using a combination of these, with positive and negative slopes, we may approximate a given pulse. That is, we let

$$
v_{1}(t)=\sum_{n=0}^{N} r_{n}(t) .
$$

This form may be used to evaluate the convolution integral (B4) being careful to use the proper expression for $r_{n}(t)$ over the various time intervals.

The attenuation function $a(t)$ requires that we specify $R(s)$ and $z_{0}$. It is worthwhile to first examine the relatively simple case of a circular coaxial line with central inner conductor. We then will look at a pair of conductors within a conduit. Let the inner 
and outer coaxial conductor radii be designated $a_{1}$ and $a_{2}$. This type of line may be readily analyzed with the result that [8]

$$
\begin{aligned}
& \mathrm{Z}_{0}=60 \varepsilon_{r}^{-1 / 2} \ln \left(\mathrm{a}_{2} / \mathrm{a}_{1}\right) \text {, and } \\
& \mathrm{R}(\mathrm{s})=\mathrm{Ks}^{1 / 2}=\frac{1}{2}\left[\frac{1}{\mathrm{a}_{1}}\left(\frac{\mu_{0}}{\sigma_{1}}\right)^{\mathrm{\gamma} / 2}+\frac{1}{\mathrm{a}_{2}}\left(\frac{\mu_{0}}{\sigma_{2}}\right)^{1 / 2}\right] \mathrm{s}^{1 / 2}
\end{aligned}
$$

where $\varepsilon_{r}$ is the relative permittivity of the material filling the coaxial line, all materlals are assumed to have a permeability $\mu_{0}, \sigma_{1}$ and $\sigma_{2}$ are the conductivity of the Inner and outer conductors, and $K$ simply denotes the terms preceeding $\mathrm{s}^{1 / 2}$ for convenience. The expression for $R(s)$ is a high-frequency approximation for two wires with uniform current distributions. From Laplace transform tables we find that

$$
a(t)=\frac{k}{2} \pi^{-1 / 2} t-3 / 2 e^{-k^{2} / 4 t},
$$

where we have let $k=\mathrm{K} / 2 \mathrm{Z}_{0}$. Substituting in (B5) for $v_{1}(t)$ and (B7) for $a(t)$ yields

$$
v_{i}(t) * a(t)=\frac{k}{2} \pi-1 / 2 \sum_{n=0}^{N} g_{n}(t),
$$

where for $t<t_{n} B_{n}(t)=0$, for $t_{n} \leq t \leq t_{n+1}$

$$
g_{n}(t)=\frac{a_{n}}{\Delta_{n}}\left\{\Delta t_{n} I\left(\frac{3}{2}, \Delta t_{n}\right)-I\left(\frac{1}{2}, \Delta t_{n}\right)\right\} \text {, }
$$

and for $t_{n+1} \leq t$

$$
\begin{aligned}
g_{n}(t) & =a_{n} I\left(\frac{3}{2}, \Delta t_{n+1}\right)+\frac{a_{n}}{\Delta_{n}}\left\{\Delta t _ { n } \left[I\left(\frac{3}{2}, \Delta t_{n}\right)\right.\right. \\
& \left.\left.-I\left(\frac{3}{2}, \Delta t_{n+1}\right)\right]-I\left(\frac{1}{2}, \Delta t_{n}\right)+I\left(\frac{1}{2}, \Delta t_{n+1}\right)\right\} .
\end{aligned}
$$

where $\Delta_{n}=t_{n+1}-t_{n}, \Delta t_{m}=t-t_{m}$, and

$$
\begin{aligned}
& I\left(\frac{3}{2}, a\right)=\frac{2}{k^{\pi}}{ }^{1 / 2} \operatorname{erfc}\left(\frac{k}{2} a^{-1 / 2}\right) \text {, and } \\
& I\left(\frac{1}{2}, a\right)=2 a^{1 / 2} e^{-k^{2} / 4 a}-\frac{1}{2} k^{2} I\left(\frac{3}{2}, a\right) .
\end{aligned}
$$

collecting results we find that

$$
v_{0}(t)=\frac{k}{2} \pi-1 / 2 \sum_{n=0}^{N} g_{n}\left(t-\gamma_{0} l\right) \text {. }
$$

A coaxial line is simple to analyze, but it does not model well the power-line condult configuration. A more realistic idealization is the shlelded pair line shown in figure B2. Although it 1 gnores the third grounding wire and the effects of wire insulation, it should provide reasonable results. The model assumes that the ine is driven in a balanced conflguration with the two inner conductors in series carrying equal and opposite currents. The two inner conductors have radius $a_{1}$ and

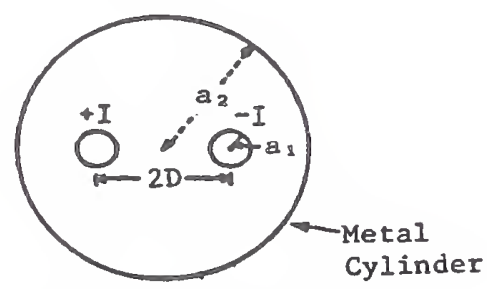

F18. B2. Shlelded palr 11ne. are separated by a distance 2D, and the outer sheath has a radius $a_{2}$. We also assume that the inner conductors are removed from the sheath sufficiently that we may 1 gnore proximity effects. This requires that $a_{2}^{2}-D^{2}$ $>a_{1}^{2}$. This condition is met in our modeled results due to the assumed insulation thickness, even for the case of wires near the wall. The internal impedance will consist of the two inner conduct or impedances in series, similar to (B6) except that now the conductors have equal radil, plus the impedance of the outer shield which carries anti-symmetric currents on each side. We find that [8]

$$
\begin{aligned}
& z_{0}=30 \varepsilon_{r}^{-1 / 2} \ln \left[\frac{2 D\left(a_{2}^{2}-D^{2}\right)}{a_{1}\left(a_{2}^{2}+D^{2}\right)}\right] \text {, and } \\
& R(s)=\frac{1}{\pi}\left[\frac{1}{a_{1}}\left(\frac{\mu_{0}}{\sigma_{1}}\right)^{1 / 2}+\frac{4}{a_{2}}\left(\frac{\mu_{0}}{\sigma_{2}}\right)^{1 / 2} \frac{\left(D / a_{2}\right)^{2}}{1-\left(D / a_{2}\right)^{2}}\right] s^{1 / 2} .
\end{aligned}
$$

The remaining analysis is the same as in the symmetric coaxial case with $K$ defined as in (B6).

\section{REFERENCES}

[1] IEC Report 664, "Insulation coordination within low-voltage systems, including clearances and creepage distances for equi pment," 1980.

[2] ANSI/IEEE C62.41, "IEEE guide for surge voltages in low-voltage ac power circuits," 1980 .

[3] ANSI/IEEE C37.90a, "IEEE guide for surge withstand capability (SWC)," 1983.

[4] IEC Standard 802-2, "Electromagnetic compatibility for industrial-process measurement and control equipment electrostatic discharge requirements." 1984.

[5] IEC Standard 802-4, "Electrical rast transient requirements," Draft.

[6] F. D. Martzloff, and H. A. Gauper, "Surge and high-frequency propagation in industrial power Iines," IEEE Trans. Ind. Appl.. vol. IA-22, pp. 63/4-640, July $/ \overline{A u g . ~}$ 1986.

[7] R. L. Wingington, and N. S. Nahman, "Transient analysis of coaxial cables considering skin effect," IRE Proc., vol. 45, no. 2, pp. 166-174, Feb. 1957.

[8] R. W. P. King, Transmission-line Theory, McGraw-H11l, New York, NY, Ch. 1, 1955.

* Certain commercial instruments are identified in this paper in order to adequately specify the experimental procedure. such identiflcation does not imply recommendation or endorsement by the National Bureau of Standards, nor does it imply that the instruments identified are necessarily the best avallable for the purpose. 


\title{
Coupling, Propagation, and Side Effects of Surges in an Industrial Building Wiring System
}

\author{
François D. Martzloff \\ National Institute of Standards and Technology \\ Gaithersburg MD \\ f.martzloff@ieee.org
}

Reprinted, with permission, from IEEE Transactions on Industry Applications IA-26, March/April 1990

First presented at the IEEE-IAS Annual Meeting, Pittsburgh, 1989

\section{Significance:}

Part 4 - Propagation and coupling of surges

The paper reports a rare opportunity for injecting surges in a full-size building, before and after it became populated with manufacturing and information technology equipment. The surges, of the unidirectional type or the ring-wave type described In ANSI/IEEE Standard C62.41-1980, were injected at one point of the system and the resulting surges arriving at other points were measured.

The results show how unidirectional surges couple through transformers and can produce a ring wave component in the response of the system. Once again, it was observed that even in this relatively large building, a 40-m long branch circuit produces the transmission line reflection effect of an open-ended line only on the front part of the $0.5 \mu \mathrm{s}-100 \mathrm{kHz}$ ring wave. (At $200 \mathrm{~m} / \mu \mathrm{s}$ propagation speed, the travel time for a $40-\mathrm{m}$ long line is only $0.2 \mu \mathrm{s}$.)

Limited tests on the injection of the $5 / 50$ ns EFT burst verified again the loss of steepness in the front of a nominal $5 \mathrm{~ns}$ arriving as a $100 \mathrm{~ns}$ front after traveling along $95 \mathrm{~m}$ of branch circuits. (See Propagation EFT1 1987 and Propagation EFT2 1990 in this Part 4.)

An unexpected side effect of these surges, applied to the power lines only, was the apparent damage suffered by the data line input components of some computer-driven printers. That particular finding became significant in developing the concept of "surge reference equalizers" - a surge protective device through which both power wires and data wire are routed, also known as "multi-port surge protector." 


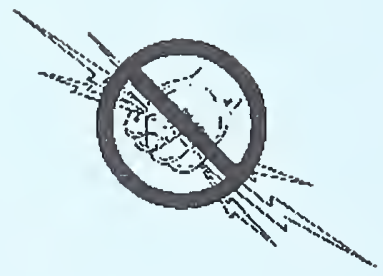




\section{Coupling, Propagation, and Side Effects of Surges in an Industrial Building Wiring System}

FRANÇOIS D. MARTZLOFF, FELLOW, IEEE

\begin{abstract}
Measurements were made in an industrial building to determine the propagation chancteristics of surges in the ac power wiring of the facility. The surges, of the unidirectional type or the ring-wave type described in ANSI/IEEE Standard C62.41-1980, were injected at one point of the system and the resulting surges arriving at other points were measured. The results show how unidirectional surges couple through transformers and produce a ring wave component in the response of the system. An unexpected side effect of these surges, applied to the power lines only, was the apparent damage suffered by the data line input components of some computer-driven printers.
\end{abstract}

\section{INTRODUCTION}

$\mathrm{P}$ REVIOUS MEASUREMENTS have been reported on the propagation of surges in the lines used for industrial and residential power systems. These measurements were made in the laboratory on a point-to-point line, isolated from the building wiring system or grounds. These measurements indicate little attenuation of slow-front surges as they propagate along the line [1], [2]. In contrast, the propagation of the fast-front surges follows the behavior expected from classical transmission line analysis [3]-[5]. For fast-front surges, the amplitude changes at interfaces where an impedance mismatch exists. The difference between slow and fast is relative and is only a way to relate the duration of the surge rise time to the travel time of the surge along the line. In the wiring of an actual building, the configuration is more complex, involving multiple branch circuits, transformers, and changing loads.

An opportunity arose to perform new surge propagation measurements during two stages of a new building project: before any loads were connected, and after the owner had moved in and various loads had been installed in the building. Surges representative of the types encountered in low-voltage power circuits were injected at various points of the wiring system. The resulting surges appearing at other points of the system were measured and synchronized with the injected surges by several disturbance monitors, in conjunction with two storage oscilloscopes. The results of these measurements give new insights on the coupling of surges into other parts of the wiring system not directly connected to the part being surged, as well as on their propagation along the various branch circuits in the building. Some of the more important

Paper IPCSD 88-24, approved by the Power Systems Engineering Commince of the IEEE Industry Applications Society for presentation at the 1988 Industry Applications Society Annual Meeting, Pittsburgh, PA, October 2-7. Manuscript released for publication May 11, 1989.

The author is with the National Institute of Standards and Technology, Building 220, Room B344, Gaithersburg, MD 20899.

IEEE Log Number 8932121.

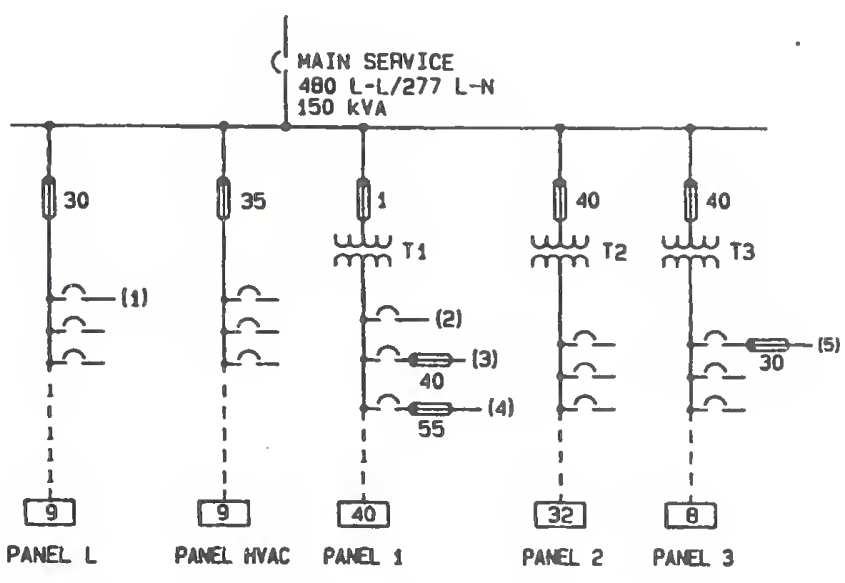

LEGEND

$\mathrm{TI}=480 \Delta / 208 \Delta-120 \mathrm{Y} 75 \mathrm{kVA} \longrightarrow-40 \mathrm{~m}$ CONOUIT LENGTH

$T 2=480 \Delta / 208 \Delta-120 \mathrm{Y} 75 \mathrm{kVA}$

T3 - $480 \Delta / 208 \Delta-120 \mathrm{Y} 45 \mathrm{kVA} \quad \mathrm{g}$ - NUMBER OF BAANCH CIACUITS

Fig. 1. Simplified one-line diagram of building power wiring.

findings will be described:

- coupling of the surges through the system stepdown transformers;

- conversion of unidirectional surges into oscillatory surges;

- propagation of the surges in branch circuits;

- difference in the propagation of fast-front versus slowfront surges;

(these four types of measurements were the intended prime objective); and

- measurement of the coupling into adjacent but not connected wiring;

- anecdotal discussion of component failures in data ports of printers during surge tests on the power lines.

\section{Experimental Procedure}

\section{Building Power System}

Fig. 1 shows a simplified one-line schematic of the building power system. Three-phase service is provided at the $480 / 277-V$ level by a step-down transformer outside the building. A $480 / 277-\mathrm{V}$ bus provides power directly to a lighting panel and a heating-ventilation-air-conditioning panel. Other loads in the building are supplied at $208 / 120 \mathrm{~V}$ through three transformers, each with a distribution panel feeding the individual branch circuits. Special efforts were 

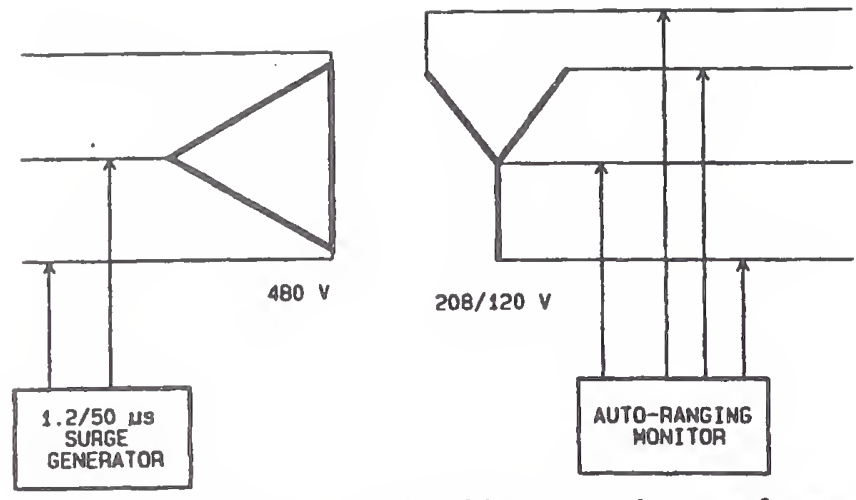

Fig. 2. Coupling of surge through delta-wye step-down transformer.

made during the construction to record the actual length of the branch circuits for accurate documentation of the system.

Surges were injected and measured at various points on the system that were accessible at the panels or at the end of branch circuits. The resulting surges arriving at other points of the system were measured simultaneously with the injected surge, to characterize the propagation of the surges. These points of injection (sending end) and arrival (receiving end) are shown by the numbers in parentheses in Fig. 1. The length of conduit between the panel and the end of the branch circuit is also shown in the figure. These numbers will be used in describing the various configurations of the tests reported in this paper.

\section{Instrumentation}

Three types of instruments were used in the tests:

- a surge generator capable of delivering either the $1.2 / 50$ $8 / 20-\mu$ s combined surge or the $100-\mathrm{kHz}$ ring wave, as described in [6], [7];

- storage oscilloscopes for monitoring the surge at the sending end and at the receiving end;

- disturbance monitors with auto-ranging and graphic output capability.

A complete description of the instruments and the surge coupling method is given in the Appendix, together with some practical suggestions on making field tests.

\section{Test Schedule}

Widely varying configurations were explored; those reported here are the most illustrative of the propagation characteristics of typical surges in this typical installation. The tests were performed in two phases: first when the building was unoccupied, so that a no-load condition existed; and second, with the building operational and under representative loading conditions. Two types of surges were applied:

- a $1.2 / 50-\mu$ s unidirectional surge representative of a conventional lightning surge, applied to the service entrance and impacting the whole building;

- a $100-\mathrm{kHz}$ ring wave representative of a conventional switching surge, applied at some point of the building and propagating in the system, for each of various combinations of the connected loads.
Measurement Results

\section{Unidirectional Surge Propagation}

The unidirectional $1.2 / 50-\mu \mathrm{S}$ surge is generally considered representative of lightning surges on the incoming service entrance [6], [8]. A scenario equivalent to having such a surge impinge on the building was created by injecting the surge at an accessible point (1) of the lightning panel $L$ in Fig. 1. From that point, the surge propagated to the $480-\mathrm{V}$ bus, through the $480 / 208 \mathrm{~V}$ transformers, to the distribution panels and the branch circuits. In a first set of measurements, the surge arriving at point (2) of the panel fed by transformer $\mathrm{T} 1$ was recorded for a surge injected at point (1). These measurements were made at the initial stage, in the empty building, before any of the load equipment was connected.

The surge was injected between two lines on the primary side and coupled to the corresponding line-to-neutral pair of lines on the secondary side of the 480/208-V delta-wye transformer (Fig. 2). To find which of the three secondary phases is coupled to the primary phase of surge injection, the auto-ranging disturbance monitor was connected to all three phases on the secondary side.

Fig. 3 shows the graphic display obtained with that instrument. Phase $B$ has the highest amplitude and thus corresponds to the direct coupling on one leg of the transformer. Phases $A$ and $C$ correspond to the coupling by the two other legs of the transformer, effectively connected in series on the delta-coupled primary side. Note how the auto-ranging feature of the instrument changes the time scale of the graphics to display a longer time sweep for phase $B$, where the disturbance remains high for a longer time than for the smaller disturbances on phase $A$ and $C$. The direct coupling path having been identified, the storage oscilloscope used for the recordings of Figs. 4-7 was then connected across phase $B$. One probe was connected to the line conductor, the other to the neutral conductor. A differential connection was thus obtained, according to the recommended practice for surge measurements [9].

Figs. 4 and 5 show the recordings for a circuit condition with minimum wiring connected to the $480-\mathrm{V}$ bus. Only breakers at points (1) and (2) in Fig. 1 are closed on panels $L$ and 1. Transformers $T 1, T 2$, and $T 3$ have their primaries connected to the $480-\mathrm{V}$ bus, but their secondaries are connected only to input lugs of the distribution panels. With the main service circuit breaker open, the utility connection is severed.

In Fig. 4, a 600-V 1.2/50- $\mu$ s surge is generated and injected at point (1) (Fig. 1). In this configuration, the connection from the lighting panel is used as an equivalent to the service entrance connection for bringing the surge to the $480-\mathrm{V}$ bus. Fig. 4(a) shows the open-circuit voltage of the surge generator before connection to the sending end point (1). Fig. 4(b) shows the voltage recorded at point (1), indicating interaction between the surge generator and the circuit under test. Fig. 4(c) shows the voltage recorded at the receiving end point (2), where the unidirectional surge has acquired an oscillatory component. This conversion of a unidirectional surge into an offset oscillatory wave illustrates the basis for introducing the concept of ring waves into [6]. 

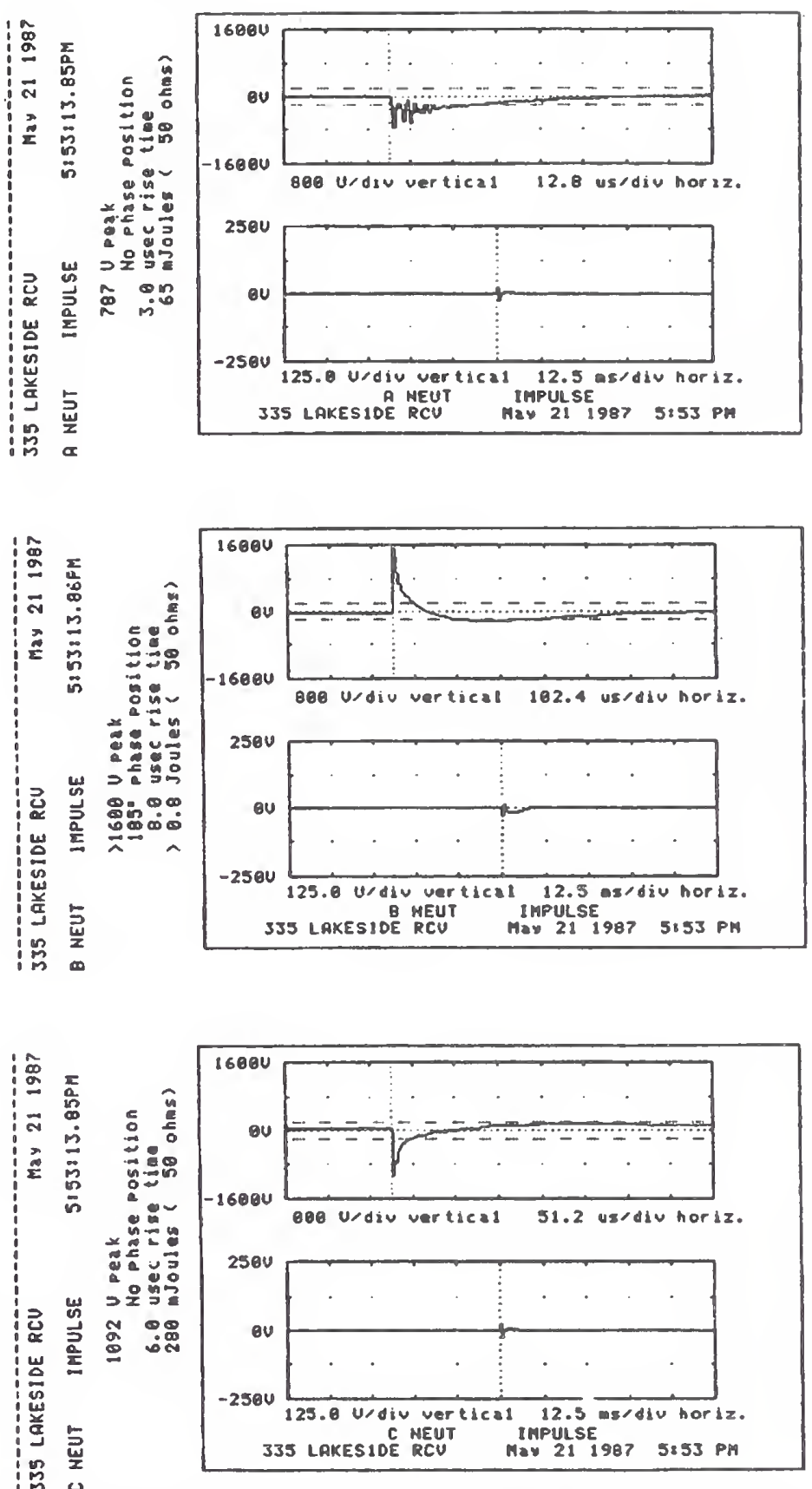

Fig. 3. Graphic display of surges on three phases at receiving end (2). Note highest impulse on phase B, indicating direct coupling, and auto-ranging of two sweep rates.

Fig. 5 shows the recordings at the sending end and at the receiving end for an open-circuit voltage setting of $3000 \mathrm{~V}$ by the surge generator. A comparison of Figs. 4 and 5 yields interesting results. First, on a qualitative basis, the voltage at the receiving end in both cases contains a unidirectional component with superimposed oscillation. A line has been marked on the oscillograms to show the unidirectional component at the center of the oscillation.

Second, quantitative inspection of the results yields further insight into the coupling of the surge through the transformer. For the 600-V sending-end condition (Fig. 4), the resulting unidirectional component is $150 \mathrm{~V}$, or a $4: 1$ ratio, which is precisely the 480/120 turns ratio of the step-down transformer. For the 3000-V sending-end condition (Fig. 5), the unidirectional component is $750 \mathrm{~V}$, again a $4: 1$ ratio. This constant ratio demonstrates the linearity of the transformer in coupling unidirectional surges over a 5:1 range of overvoltages.

The response of the combined transformers $\mathrm{T} 1, \mathrm{~T} 2$, and $\mathrm{T} 3$, and the $480-\mathrm{V}$ bus is a $370-\mathrm{kHz}$ ringing overshoot, peaking, respectively, at $380 \mathrm{~V}$ (Fig. 4) and at $1900 \mathrm{~V}$ (Fig. 5). The corresponding overshoot ratios are $380 / 150=2.53$ and $1900 / 750=2.53$, again showing the linearity of the response. Thus tests for propagation only (no nonlinear protective devices in the system) could be performed at low surge 


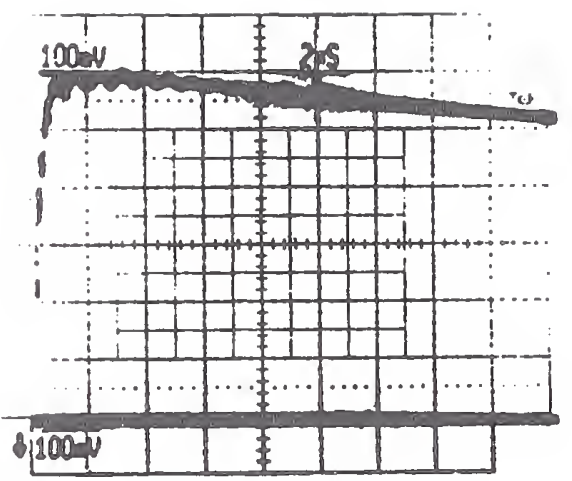

(a)

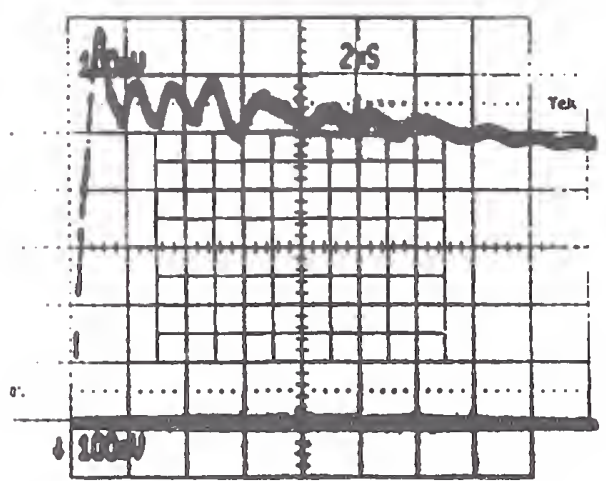

(b)

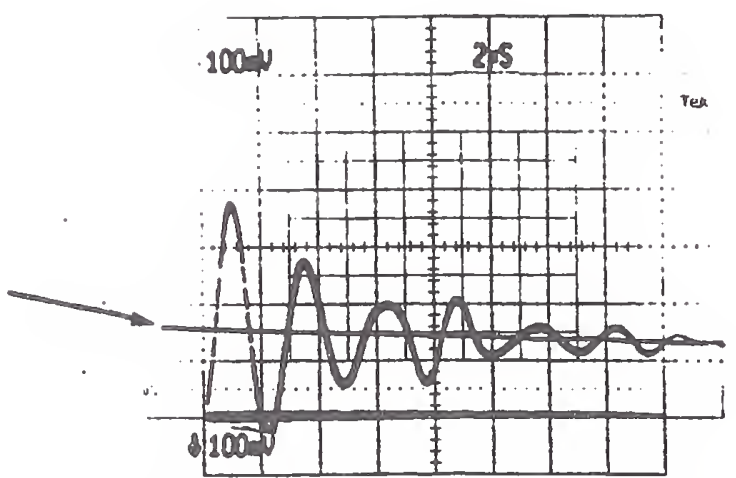

(c)

Fig. 4. Recordings at sending end (1) and receiving end (2), for $600-\mathrm{V}$ unidirectional surge. Minimum wiring connected $480-\mathrm{V}$ bus (breakers to $277 \mathrm{~V}$ branch circuits and $120 \mathrm{~V}$ branch circuits open). Voltage: $100 \mathrm{~V} /$ div: sweep: $2 \mu \mathrm{s} / \mathrm{div}$. (a) Open-circuit output of surge generator. (b) Voltage at sending end. (c) Voltage at receiving end. Note line showing unidirectional component.

voltages and produce valid results for higher surges. However, interest in evaluating the effects of surge-protective devices was a motive for making further tests with relatively higher surge levels. This paper, however, is primarily concerned with the propagation aspects. Surge-protective devices will by fully discussed in a later paper.

Figs. 6 and 7 show the recordings, for the same injected unidirectional surge, when more of the wiring system is connected to the circuit under test, with the system still isolated from the utility supply. In the test illustrated by Fig. 6 , lighting circuits were connected. Although the fluorescent lights were not operating, the built-in capacitors of the ballasts

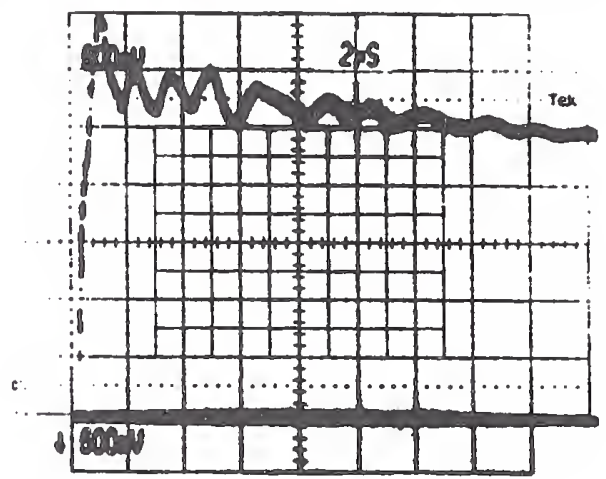

(a)

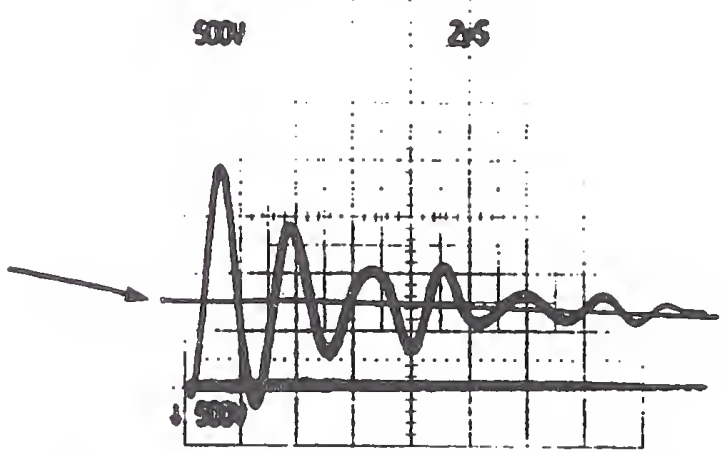

(b)

Fig. 5. Recordings at sending end (1) and receiving end (2), for 3-kV unidirectional surge. Minimum wiring connected $480-\mathrm{V}$ bus (all breakers to $277 \mathrm{~V}$ branch circuits and $120 \mathrm{~V}$ branch circuits open). Voltage: $500 \mathrm{~V} /$ div; sweep: $2 \mu \mathrm{s} / \mathrm{div}$. (a) Voltage at sending end. (b) Voltage at receiving end. Note line showing unidirectional component.

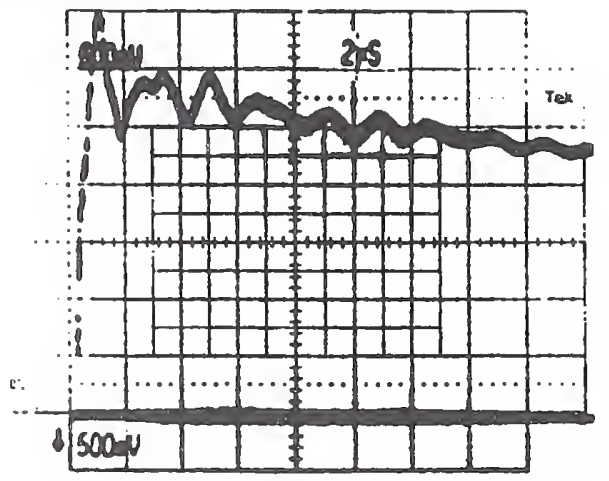

(a)

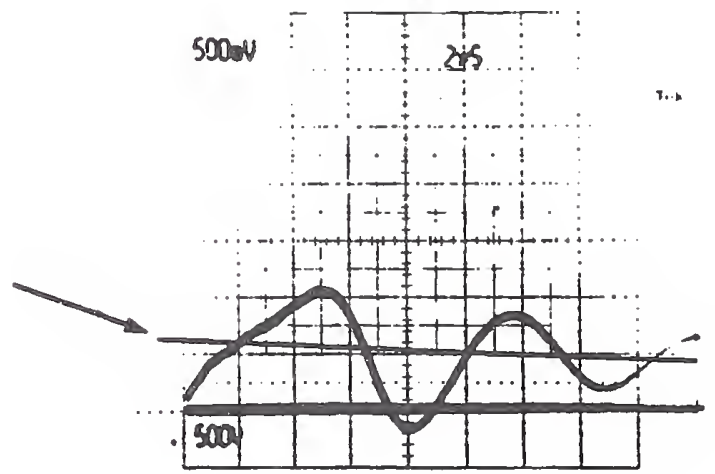

(b)

Fig. 6. Recordings at sending end (1) and receiving end (2), for $3-\mathrm{kV}$ unidirectional surge. All 277-V lighting branch circuits connected to $480-\mathrm{V}$ bus. Voltage: $500 \mathrm{~V} / \mathrm{div}$; sweep $2 \mu \mathrm{s} / \mathrm{div}$. (a) Voltage at sending end. (b) Voltage at receiving end. Note line showing unidirectional component. 


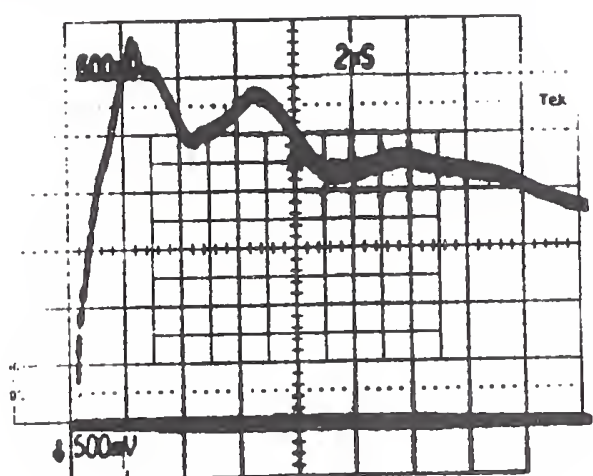

(a)

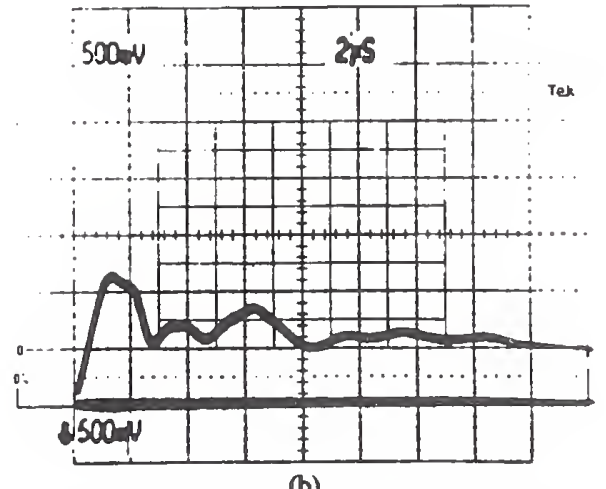

(b)

Fig. 7. Recordings at sending end (1) and receiving end (2), for 3-kV unidirectional surge. All $120-\mathrm{V}$ branch circuits connected to $480-\mathrm{V}$ bus through three 480/208-120-V step-down transformers. Voltage: $500 \mathrm{~V} / \mathrm{div}$; sweep $2 \mu \mathrm{s} / \mathrm{div}$. (a) Voltage at sending end. (b) Voltage at receiving end.

were effectively added to the circuit. At the receiving end, a unidirectional component of $700 \mathrm{~V}$ with a $150-\mathrm{kHz}$ ringing overshoot with a ratio of about 1.25 can be observed.

In the test illustrated by Fig. 7, all of the circuit breakers at panels 1,2 , and 3 of Fig. 1 were closed, adding the corresponding branch circuits, but without loads at the receptacles. The response at the receiving-end, point (2) in Fig. 1, still shows a unidirectional component of $700 \mathrm{~V}$, but the ringing overshoot is now quickly damped out.

These three circuit conditions illustrate the wide range of ring waves that occur when a wiring system is stimulated by a unidirectional surge. The general prevalence of ring waves in building wiring systems was confirmed by these initial tests, so that most of the other tests were made with the $100-\mathrm{kHz}$ ring wave.

\section{Ring-Wave Surge Propagation}

Further measurements were made with the ring waves injected at the sending-end, point (3) in Fig. 1. Arriving surges were recorded at the receiving-end, point (4). This scenario corresponds to a surge being generated by some equipment within the building, or the surge resulting from system stimulation by lightning. A few measurements were also made to investigate propagation from point (3) to point (5), to illustrate coupling through two cascaded wye-delta and deltawye transformers, but these did not produce remarkable results.

The ring wave used for these measurements is defined in [7]; Fig. 8 shows the open-circuit voltage of a generator

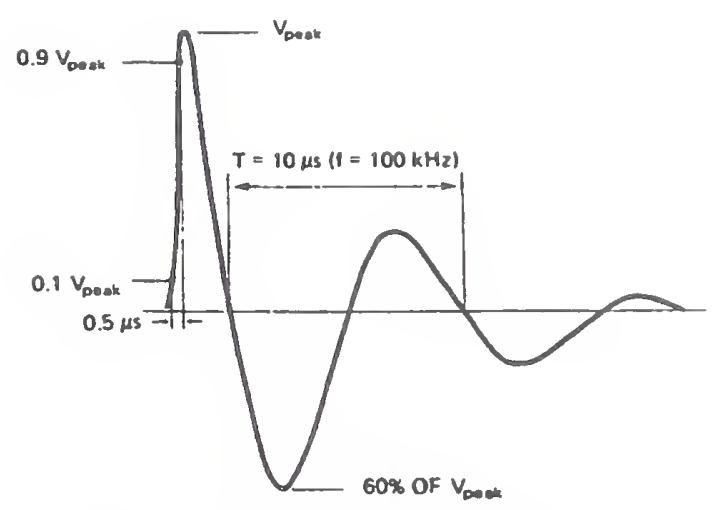

Fig. 8. $0.5 \mu \mathrm{s}-100 \mathrm{kHz}$ ring wave defined in [6].

producing such a wave. The use of a $100-\mathrm{kHz}$ ring wave with a $0.5-\mu \mathrm{s}$ rise time for the tests introduces an additional parameter: the reflections at the ends of the lines become significant for the lengths of some branch circuits found in this building. For a velocity of propagation on the order of $200 \mathrm{~m} / \mu \mathrm{s}$, a length of line greater than $50 \mathrm{~m}$ means a travel time longer than the rise time of the surge, so that reflections become significant [2].

The measurements covered a series of tests; the propagation path between the sending and receiving ends was progressively modified. Starting with simple point-to-point configurations, branch circuits were added by closing all breakers at Panel 1, connecting the secondary of transformer T1, and terminating the line at point (4) with various loads.

Figs. 9, 10, and 11 show typical recordings for three of these configurations. Fig. 13 will present a summary of the various configurations with resulting propagation characteristics for the ring wave, after first discussing in detail the features of the three recordings of Figs. 9-11.

\section{Simple Line from Point to Point}

For the case of Fig. 9, no breakers other than 2, 3, and 4 are closed at Panel 1; the configuration is a simple point-to-point line from point (3) to (4). Fig. 9(a) is the recording at the sending end, located $40 \mathrm{~m}$ from Panel 1. The waveform shows the interaction occurring between the surge generator and the wiring system. Fig. 9(b) shows the recording at intermediate point (2) and presents some interesting features, as follows.

1) The initial peak of $1100 \mathrm{~V}$ at the sending end has been attenuated to $750 \mathrm{~V}$, a ratio of 0.68 , after $40 \mathrm{~m}$ of travel from point (3) to point (2).

2) A second peak is visible, about $0.6 \mu \mathrm{s}$ after the first: the pulse arriving at the open end of point (4) is reflected with twice the amplitude and travels back toward Panel 1. It arrives at Panel 1 after a $2 \times 55-\mathrm{m}$ travel, requiring about $0.6 \mu \mathrm{s}$ for the round trip at a velocity of $200 \mathrm{~m} / \mu \mathrm{s}$; this expected time matches the time observed between the two peaks.

3) The returned pulse, arriving at Panel 1 after $110 \mathrm{~m}$ round-trip travel in the line, has lost some its higher frequency components [3] and is less sharp than that coming from the sending point.

4) The returned pulse travels further back to sending point (2), where it arrives to produce a discontinuity in the trace visible at the first zero crossing of the trace in Fig. 9(a). 


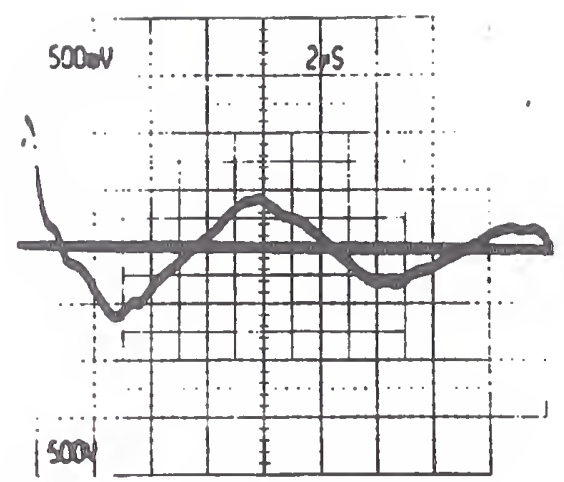

(a)

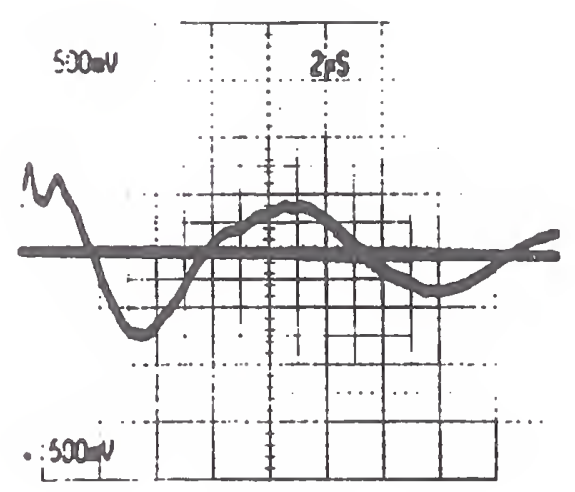

(b)

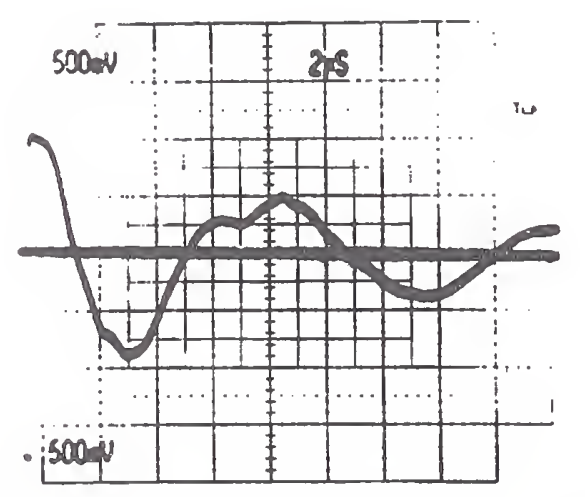

(c)

Fig. 9. Recordings at sending end (3), intermediate point (2) of Panel 1, and receiving end (4) for 100-kHz ring wave and point-to-point propagation in simple line. No additional branch circuits have been connected between points (3) and (4). Voltage: $500 \mathrm{~V} / \mathrm{div}$; sweep: $2 \mu \mathrm{s} / \mathrm{div}$. (a) Volrage at sending end. (b) Voltage at Panel 1. (b) Voltage at receiving end.

5) The second peak of the ring wave (negative peak) and the third peak (positive peak) do not show very significant changes in amplitude among the three oscillograms. These peaks do not contain the high-frequency components associated with the initial fast rise, and thus are not significantly attenuated by the $40-$ or $95-\mathrm{m}$ travel along the line.

Finally, Fig. 9(c) shows the initial peak, which traveled $95 \mathrm{~m}$ from the point of origin and, therefore, might be expected to have been attenuated about twice as much as between points (3) and (2), a 40-m travel. (The attenuation is not quite proportional to distance, as the higher frequency components suffer greater attenuation in the early parts of the

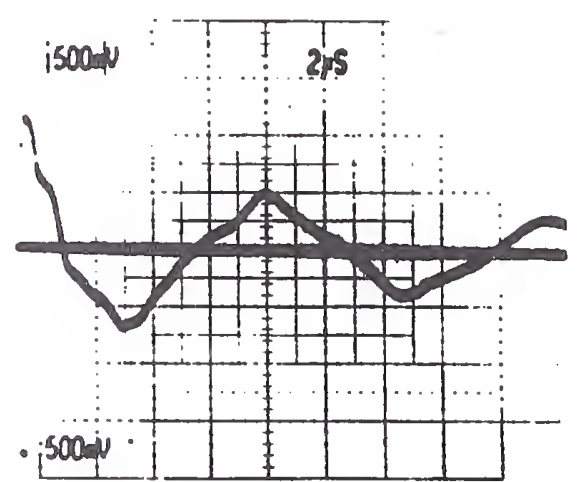

(a)

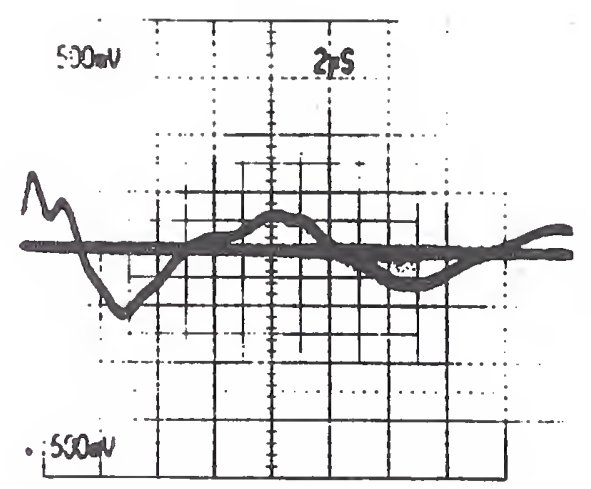

(b)

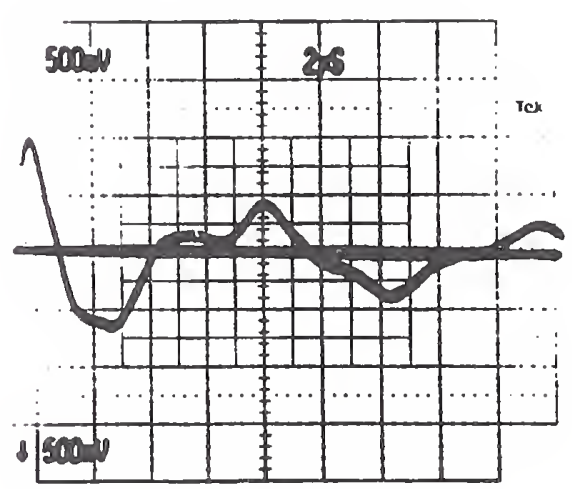

(c)

Fig. 10. Recordings at sending end (3), intermediate point (2) of Panel 1, and receiving end (4) for $100-\mathrm{kH} / 2$ ring wave. Transformer $\mathrm{T} 1$ is connected at Panel 1 and supplies power to branch circuits 3 and 4. Voltage: $500 \mathrm{~V} /$ div; sweep $2 \mu \mathrm{s} / \mathrm{div}$. (a) Voltage at seading end. (b) Voltage at Panel 1. (c) Voltage at receiving end.

travel; the waveform contains fewer of them, and is therefore less attenuated in the end parts of the travel [4].) The expected amplitude of the attenuated pulse arriving at point (4) should be about $1100 \mathrm{~V}$, the initial value, attenuated by about two times (twice the distance) the 0.68 -ratio noted between points (3) and (2): $1100 \times 0.68^{2}=510$. The oscillogram shows, on the contrary, a 1050-V peak, or close to twice the expected arriving pulse value-the doubling effect at the open-ended transmission line.

To summarize the observations from Fig. 9 data, the first peak, with a duration shorter than the travel time in the line, exhibits all the behavior of pulses traveling in a transmission line. Later peaks, with durations longer than the travel time, 


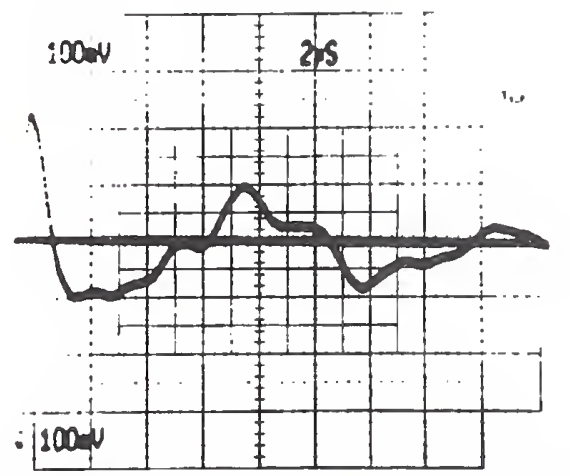

Fig. 11. Recording at receiving end point (4) for $100-\mathrm{kHz}$ ring wave. Transformer $\mathrm{T} 1$ is connected at Panel 1 and supplies power to all loads connected to branch circuits of that panel. Voltage: $100 \mathrm{~V} / \mathrm{div}$; sweep: $2 \mu \mathrm{s} / \mathrm{div}$.

exhibit little attenuation for the $40-$ and $95-\mathrm{m}$ travel distances in this building.

\section{Adding Complexity to the System}

Fig. 10 shows the recordings at the same three points discussed for Fig. 9 but with transformer $\mathrm{T} 1$ connected to Panel 1 and supplying power to that panel. All other branch circuits of that panel are still left disconnected.

Fig. 10(a) shows the sending end to be little different from Fig. 9(a), except that later reflections have modified subsequent peaks. Fig. 10(b) shows again the double peak at Panel 1 , resulting from the initial pulse arriving from the sending end, followed by a reflected pulse coming back from the receiving end. Fig. $10(\mathrm{c})$ shows the initial pulse arriving at the receiving end, doubled by the effect of the open-ended line in the same manner as discussed for Fig. 9(c). The same conclusions as those drawn from Fig. 9 apply here: the initial peak behaves as a pulse in a transmission line, and subsequent peaks are not significantly attenuated. The inspection of subsequent peaks is no longer as simple as it was for Fig. 9, because with the added elements in the transmission path, the cumulative effect of the reflections distorts these peaks.

One further stage in the reconstitution of the building wiring system is illustrated by Fig. 11, where all branch circuits at Panel 1 are now connected, supplying their normal loads with power obtained from transformer $\mathrm{Tl}$, which is energized. For the same ring wave of $1100 \mathrm{~V}$ applied at the sending end, point (3) in Fig. 1, the first peak at the receiving end, point (4), is only $220 \mathrm{~V}$, down from the $1000 \mathrm{~V}$ of Fig. 10 . This large drop is caused by the impedance mismatch resulting from connecting the many parallel transmission lines at Panel 1 . Even the subsequent peaks show a reduction (down to $100 \mathrm{~V}$ from the $400 \mathrm{~V}$ of Fig. 10), but the waveform is so distorted by the cumulative effect of the multiple reflections that a simple analysis by inspection is no longer possible. Computer modeling might be an interesting task for specific cases where a rigorous prediction would be of interest [10], [11].

Summarizing now all the observations from the ring-wave measurements, three major conclusions emerge.

1) In a building with no or few loads, fast-front surges propagate in a manner that can be readily predicted by classical transmission line analysis.

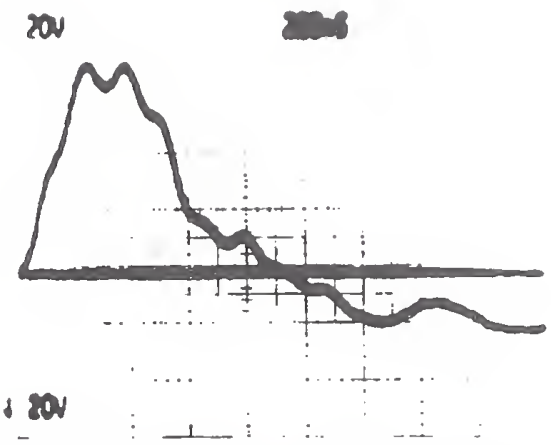

Fig. 12. Recording at receiving end point (4) for fast-front surge, injected at sending end (3) by generator with $5 \mathrm{~ns}$ nominal rise time.

2) Adding many parallel branch circuits produces amplitude reductions, predictable by the impedance mismatch at the point of parallel connections.

3) Surges having durations longer than the travel time within the building propagate with very little attenuation for a relatively simple configuration. In a building of complex configuration, cumulative effects of reflections from branch circuits with random lengths tend to reduce subsequent peaks by averaging out their interaction. This observation, however, leaves open the possibility of a random combination that could enhance subsequent peaks, or at least not reduce them by the averaging effect.

\section{Propagation of Fast Transients}

The unplanned availability of a surge generator having a rise time of a few nanoseconds made possible incidental tests of the propagation of fast transients in the building. However, suitable probes were not available to record accurately the fast rise time at the sending end. Only the receiving-end surges could be observed with confidence, because the rise time observed there was indeed longer than the response time of the probes. For a nominal 5-ns rise time available at the generator output and injected at the sending end, point (3), the rise time observed at the receiving end, point (4), was $100 \mathrm{~ns}$ (Fig. 12). This increase in rise time confirms the findings reported earlier in [4] and [5]. This observation also confirms that concerns over the presence of surges with rise times of a few nanoseconds are not generally applicable to power systems for locations remote from the source of the fast transients [12].

\section{Summary of Ring Wave Propagation}

Fig. 13 presents a summary of the attenuation observed for various configurations of the building wiring. The many values obtained show how difficult a prediction would be for a complex system, but such data are helpful in providing some upper and lower bounds. In this figure, the transmission path is represented by a branch circuit from the sending end (left line) to Panel 1 (box at center) and an emerging branch circuit to the receiving end (right line).

From the top to the bottom of Fig. 13, various combinations of added circuits are shown at Panel 1 and at the receiving end, labeled $A$ through $K$. The numbers shown at the right of each configuration, $A$ through $K$, are the observed values at the receiving end. For the first column, the numbers are the value 

AECEIVING END
PERCENTAGES SENDING ENO
ARNG WAYE
(100\%)

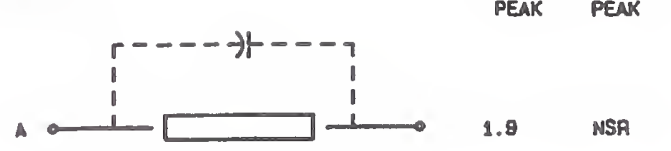

$r---\rightarrow-\infty$
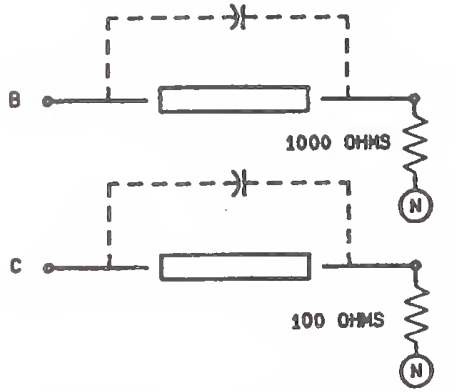

1.7 NSP

1.1 NSP

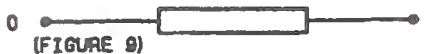

85

100

E

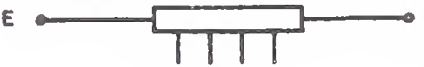

70

NSP

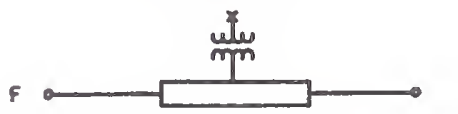

80

75

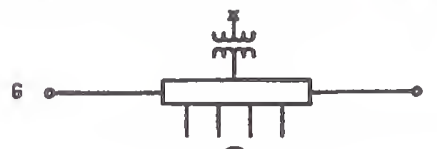

65

NSR

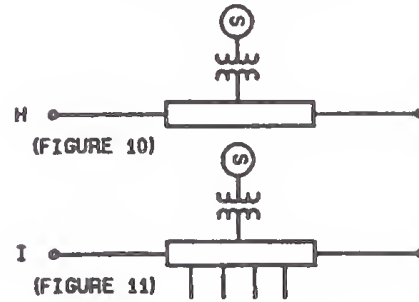

90

90

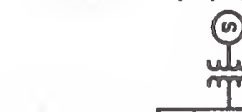

$\checkmark$

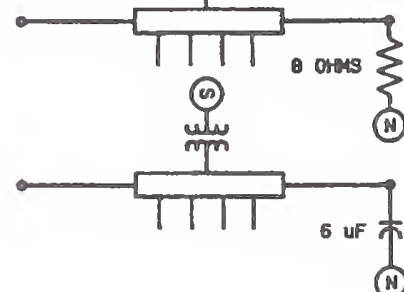

LEGEND:

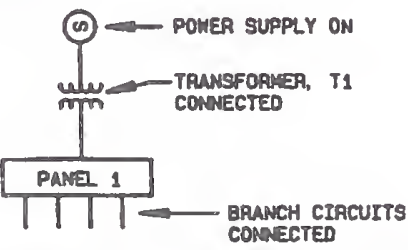

Fig. 13. Schematic representation of configurations for propagation path from sending end (3) to receiving end (4). Numbers at right are receivingend percentages of first and third peaks of arriving surges for ring wave of 100 percent applied at sending end.

of the first peak; for the second column, the numbers are the value of the third peak (second positive peak of the ring wave). These numbers are given as percentages of the sending-end values of the first peak. In some cases, the response of the circuit was so complex that no simple reading could be made at the time of the third peak, hence the entry "NSR" in the second column.

Configurations $A, B$, and $C$ show all breakers open at Panel 1, so that no direct metallic connection exists between the sending and receiving ends. However, the proximity of the wires in common conduits shared for part of the distance is sufficient to couple some of the surge by the stray capacitance. Adding load at the receiving end between the line and the neutral (configurations $B$ and $C$ ) provides a measure of the transfer impedance of that coupling.

Configurations $D$ to $G$ show increasing complexity in the transmission path, with added branch circuits at Panel $1 E$, added transformer $F$, and both added $G$, but still no power applied to the primary of the transformer. For configurations $H$ to $K$, the transformer primary is energized, supplying power to Panel 1 and its loads. In $H$, only the transformer is connected; in $I$ the branch circuits have been added. In $J$ and $K$, two different types of loads have been connected at the receiving end, between line and neutral, to show how a lowimpedance termination reduces the reflections observed with higher impedance terminations.

\section{Side EfFects}

An unexpected side effect of the surges was found only upon the resumption of normal weekly operations, after the tests (which were performed on a weekend). Two laser printers shared by several personal computers and thus linked by a data cable had become inoperative. Repair by the service organization of the manufacturer diagnosed failed components in the data line port of the printer. Yet, all the surges had been injected into the power lines, and at levels initially deemed high but not hazardous to equipment designed for connection to typical ac power systems.

The exact nature of the failure is unknown because the service organization performed repairs as a routine operation, not associated with this surge measurement project, and its repair records were not available. However, with hindsight, this side effect might well be explained by the following hypothetical, but plausible scenario. (Anecdotal information on problems encountered at other facilities indicates that this type of problem is not at all unusual. A detailed description of a scenario that could lead to this failure of information technology systems should be useful for understanding the problem-a first step toward avoiding it in the future.)

Many applications of information technology equipment require that peripheral terminal devices (video displays, data entry keyboards, printers) be located at some distance from the computer. Frequently, terminal devices are powered by a line cord plugged into a wall receptacle which is on a different branch circuit from that of the computer. Sometimes, the branch circuits are supplied by different transformers (Fig. 14). This situation produces multiple ground references and loops of communication cables, with the possibility of substantial differences in the potentials of points expected to be at the same zero-reference potential.

The general practice is to have the device chassis bonded to the grounding conductor of the power cord. Also as a general practice, the zero reference of the signal circuit is bonded to 


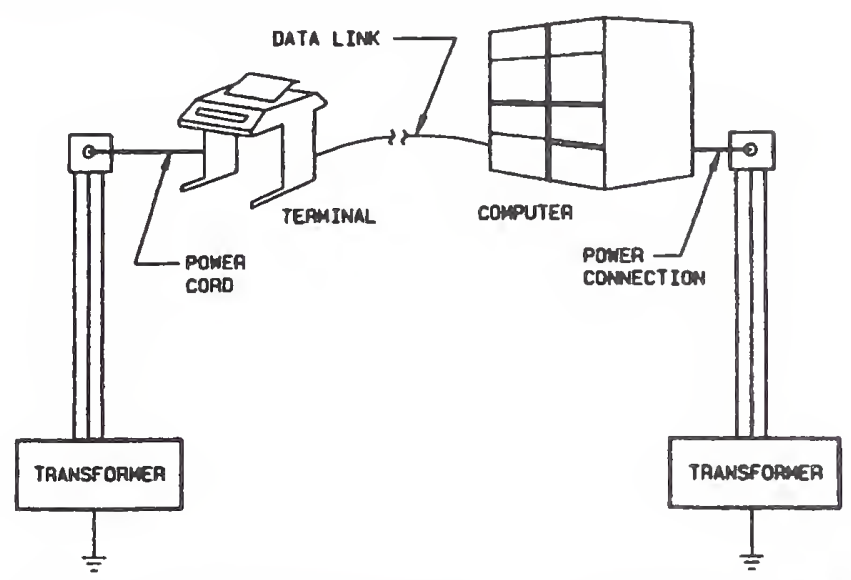

Fig. 14. Typical arrangement for powering computer and its peripherals.

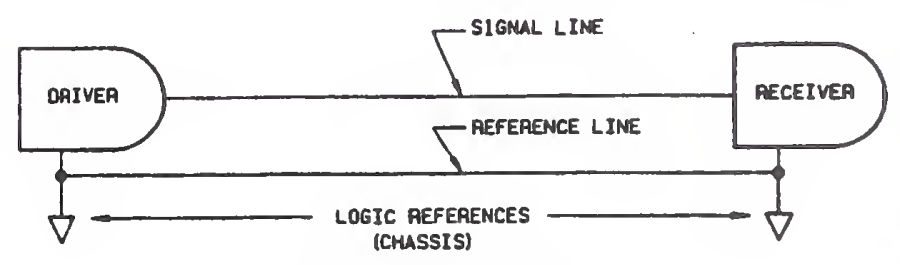

A - Single-ended cIRcuit

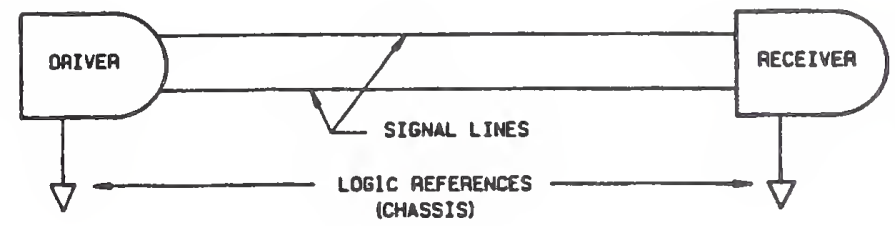

B - oIfFERENTIAL CIRCUIT

Fig. 15. Links between driver and receiver of computer and remote terminal.

the chassis. Fig. 15 is a schematic of the receiver and driver circuits used to communicate between the computer and its terminals. This figure shows that the designer has the option of using single-ended transmission, where the signals are developed with respect to a zero-reference plane, or a differential transmission, where signals are developed as a voltage difference between the two signal lines.

Typically, a twisted-pair cable or a coaxial cable is used between the computer and the terminal. Various types of shielding may be included with these cables. Intuitively, one might expect that the receivers and drivers linked by a shielded cable should be least susceptible to interference or damage. However, the problem encountered here does not involve transients coupled capacitively or inductively onto the data communication cables. Rather, the problem is a difference in the reference potentials of the chassis of the two devices, resulting from surges being diverted in the separate grounding connections of the two devices.

Fig. 16 shows a schematic of a system consisting of a computer and a terminal, powered by different sources and linked by a shielded two-wire differential data line with zero reference bonded to the chassis of each device. In each power supply, an electromagnetic interference (EMI) filter or surge suppressor has been provided between the ac lines and the grounded chassis.

Let us now examine the scenario unfolding when surges arrive on the power supply line of the computer. The expected role of the EMI filter is to divert these surges to ground-that is, by passing the current $i$ through the filter, retuming it to the power source by the grounding conductor $G$. This path unavoidably has a finite inductance $L$. Consequently, the fast-changing current $i$ produces a voltage drop $L \cdot d i / d t$ between the computer chassis (which is the signal reference at the sending end) and the grounding connection of the power supply. At the terminal, no surge event is occurring at that time; the terminal chassis (which is the signal reference at the receiving end) stays at the potential of the grounding connection $G^{\prime}$ of its own power supply. The two chassis, therefore, the two references of the data link ports are now at different potentials. This difference is the $L \cdot d i / d t$ voltage from the surge, plus any other voltage that might develop in the undefined path linking the two grounding points $G$ and $G^{\prime}$. This scenario explains how surges, initially limited to the power lines, can impact the data port components of a system powered without the installation of coordinated surge suppressors on both power port and data port.

Thus, with hindsight, this anecdote illustrates the need for developing and applying means of surge protection that will avoid the potential difference between ends of the data link. This need presents a challenge to the designers of an information technology system and an opportunity for the manufacturers of packaged surge-protective devices: coordinating protection of the power supply port with protection of the data link port in a single unit, with the same return path for surges diverted by the two protective devices. Such coordinated surge suppressors built for protecting both ports and using a single ground reference are now commercially available. They are sometimes referred to as "local ground window" [12].

\section{Conclusion}

1) The response of the step down transformer and its associated bus wiring to stimulation by a $1.2 / 50-\mu$ s unidirectional surge contains two components:

- a unidirectional component matching the stimulation, and

- a ringing overshoot at a frequency dependent upon the circuit characteristics.

2) The unidirectional surge couples through the transformer according to the turns ratio, with negligible attenuation. The ringing overshoot frequency depends on the circuit parameters; its peak can exceed twice the peak of the stimulus.

3) The existence of multiple branch circuits in the building wiring reduces the overshoot and affects its frequency but does not change the unidirectional component.

4) A ring wave with a rise time shorter than the travel time in a simple point-to-point line produces the expected enhancement of the surge at an open-circuit receiving end. Adding loads at the end of the line reduces the amplitude of the surge at that point in a predictable manner, according to the classical transmission line theory. 


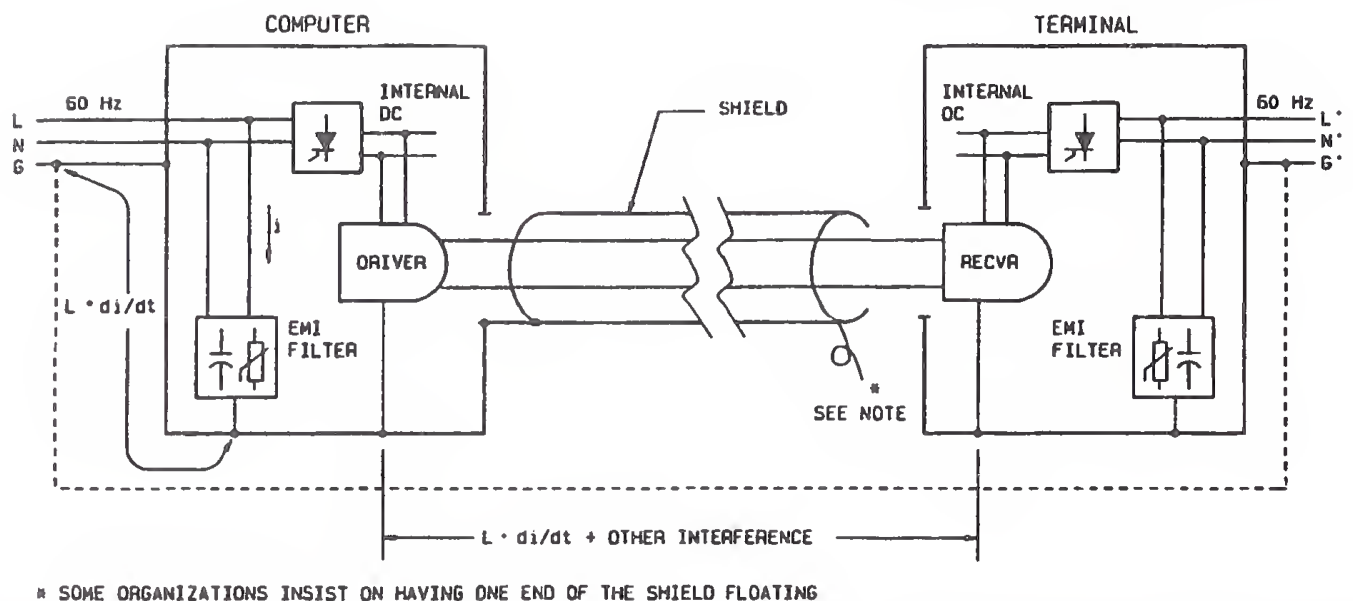

Fig. 16. Scenario for creating difference of potential between signal references by diverting surge through grounding conductor of one side of the system.

5) Adding branch circuits and other circuit elements along the propagation path introduces mismatches in the line impedance, reducing the amplitude of the initial peak of the surge arriving at the receiving end. Subsequent parts of the surges, however, are less affected.

6) Providing protection against power line surges at the power line interface of devices linked by a data communication circuit does not guarantee that surges occurring in the power line environment will not cause damage to the devices. A more comprehensive protection scheme, coordinating both the power line and the data line, is required to ensure protection.

\section{APPENDIX}

\section{Instrumentation and Experimental Procedures}

For complete documentation of the test procedure, the instrumentation used in the tests is listed in this Appendix ${ }^{1}$. Also, some practical aspects of the procedure and logistics are recited here; some were planned, some resulted from hindsight. These are offered as helpful hints to anyone planning this type of field test.

\section{Instrumentation}

Surge Generator: A KeyTek Model 711 was used, with F31 coupling network and plug-in pulse waveshaping networks: P7 for $1.2 / 50 \mu$ s unidirectional waveform, and P1 for $100-\mathrm{kHz}$ ring wave as described in [6].

Storage Oscilloscopes: Two Tektronix 7934 with 500MHz bandwidth were used, each with pairs of matched 1000:1 P6015 probes or 100:1 P6009 probes. The probes were connected differentially with a 7A26 vertical preamplifier performing the differentiation.

Auto-ranging Monitors: A BMI 4800 Powerscope with three-phase multimode monitoring capability, graphic display, auto-ranging of sweep rate, and adjustable threshold was employed.

\footnotetext{
${ }^{1}$ Certain commercial instruments are identified in this paper to specify the experimental procedure adequately. Such identification does not imply a recommendation or endorsement by the National Institute of Standards and Technology, nor does it imply that these instruments are necessarily the best available for the purpose.
}

\section{Procedure}

Surge Coupling: The surges produced by the generator were injected into the building wiring by a $2-\mu \mathrm{F}$ coupling capacitor for the initial unpowered tests. For subsequent tests with power on, a coupling circuit was used so that the surge was applied at a fixed phase of the sine wave.

Differential Measurements: All measurements were made with a differential connection of two matched probes. Admittedly, the 7A13 differential preamplifier would be more appropriate for this type of connection, but it was not available for these field tests. The common-mode rejection and noise background were checked by connecting the two probes together and then to the high and low side of the point of measurement.

One of the planned measurements was to measure the voltage between the building grounding system and one of the so-called "isolated separate dedicated ground" ground rods, deliberately installed in the building as a tutorial example of questionable practice. For this measurement, however, the differential connection with the 7A26 preamplifier and unshielded oscilloscope was not successful. The levels of voltages observed across the desired points of measurement had the same order of magnitude as the noise background observed in the check just described. Instrumentation less sensitive to this interference was not available for these field tests, but new attempts might be made in the future.

\section{Helpful Hints}

While these hints might seem trivial, they are offered after successful planning or hindsight and as a counterpoint to the more fundamental conclusions of the paper. If they can save time or reduce problems for future experimenters, including them in this paper will have been worthwhile. In random order of importance, here is a list.

- Whenever field measurements involve several people at different locations, walkie-talkies are far superior to direct voice communication (attenuated by distance), fast-footed couriers, or an internal telephone network.

- Whenever the work is carried on outside of normal working hours, be sure that the team includes one 
individual thoroughly familiar with the facility, and custodian of all keys to rooms, cabinets, and interlocks.

- The availability of monitoring instruments that combine logging and timing of events provides a very useful correlation of recordings made by independent oscilloscopes.

- Always bring at least twice as much film as you think you will need. The same remark applies to materials for filing oscillograms at the site, and to extension cords.

- Bring some spare fuse holders for the instruments. These protruding accessories have a unique capability of coming loose during shipment and getting lost in the packing material.

- When scheduling the rate of progress in the tests, remember that Murphy was an optimist!

\section{ACKNOWLEDGMENT}

The measurements and the analysis of the results were made possible by the cooperation and contributions of many organizations and individuals, as follows:

- Building Industry Consulting Service International, for coordinating an informal consortium of private sector companies in support of this work;

- Alex McEachern, for making the facilities of Basic Measuring Instruments available as a measurement site;

- Joseph Connolly, Robb Gould, Jim McDaniels, and Christine Mihelich, for their participation in the measurements;

- Maurice Tetreault, for participating in the measurements and suggesting the principles underlying the analysis of the surge side effects on the data ports;

- Catherine Fisher, for suggestions on reporting these results.

These contributions to improved understanding of the problems, and thus greater system reliability, are most gratefully acknowledged.

\section{REFERENCES}

[1] F. D. Martzloff, "The propagation and attenuation of surge voltages and surge currents in low-voltage ac power circuits," IEEE Trans. Power App. Syst., vol. PAS-102, no. 5, May 1983.
[2] F. D. Martzloff and H. A Gauper, "Surge and high-frequency propagation in industrial power lines," IEEE Trans. Ind. Appl., vol. IA-22. no. 4, July/Aug. 1986.

[3] L. V. Bewley, Traveling Waves on Transmission Lines. New York: Dover, 1963

[4] F. D. Martzloff and P. F. Wilson, "Fast transient tests: Trivial or terminal pursuit?" in Proc. Int. Zürich Symp. Electromagnetic Comparibility, 1987.

[5] F. D. Martzloff and T. F. Leedy, "Electrical fast transient tests: applications and limitations," IEEE Trans. Ind. Appl., vol. 26, no. I. pp. 15I-159. Jan./Feb. 1990.

[6] IEEE Guide on Surge Voltages in Low-Voltage AC Power Circuits, ANSI/IEEE Standard C62.41-1980.

[7] R. B. Standler, "Equations for some transient overvoltage test waveforms," IEEE Trans. Electromagn. Compat., vol. EMC-30, no. 1, Feb. 1988.

[8] Insulation Coordination within Low-Voltage Systems, Including Clearances and Creepage Distances for Equipment, IEC Pub. 6641980.

[9] IEEE Guide on Surge Testing for Equipment Connected to LowVoltage AC Power Circuits, ANSI/IEEE Standard C62.45-1987.

[10] A. K. Agrawal, H. M. Fowles, and L. D. Scon, "Experimental characterization of multiconductor transmission lines in inhomogenous media using time-domain techniques," IEEE Trans. Electromagn. Compat., vol. EMC-21, no. 1, Feb. 1979.

[11] A. H. Paxton and R. L. Gardner, "Application of transmission line theory to networks with a large number of component wires," in Proc. Int. Zürich Symp. Electromagnetic Compatibility, 1987.

[12] F. D. Martzloff, "Protecting computer systems against power transients," IEEE Spectrum, April 1990.

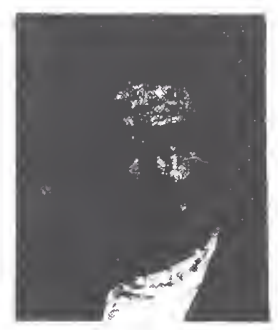

François D. Martzloff (M'56-SM'80-F'83) completed his undergraduate studies in France and received the M.S.E.E. degree from the Georgia Institute of Technology, Atlanta, and the M.S.I.A. degree from Union College, Schenectady, NY.

After a long career at General Electric, he joined the staff of the National Bureau of Standards (now renamed National Institute of Standards and Technology) to work on conducted electromagnetic interference issues. His early experience covered high-voltage fuses, high-voltage bushings, and electronic power conversion; the latter marked a turning point to issues of overvoltage effects on semiconductors, surge suppression, metal oxide varistor applications, and interference mitigation. In addition to his research work on surge propagation and mitigation, he is contributing to the development of standards on surge environment and surge suppression within IEEE, ANSI, and IEC by documenting his measurements, as in the present paper, by presenting tutorials, and by drafting new standards. 


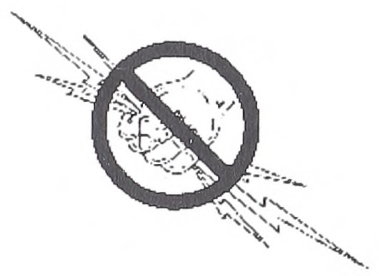




\title{
Electrical Fast-Transient Tests: Applications and Limitations
}

\author{
François D. Martzloff and Thomas F. Leedy \\ National Institute of Standards and Technology \\ Gaithersburg MD \\ f.martzloff @ieee.org
}

Reprinted, with permission, from IEEE Transactions on Industry Applications IA-26, Jan/Feb 1990

First presented at IEEE PCIC Conference, San Diego, September 1989

Also at IEEE-IAS Annual Meeting, San Diego, October 1989

\section{Significance: \\ Part 4 - Propagation and coupling of surges}

In the early 80 's, considerable interest arose in developing an IEC standard test method to assess the immunity of electronic equipment against "fast transients" such as those that can be produced by contact bouncing in power circuits. Such transients could propagate from their source - the bouncing contact - to the power port of equipment, or be coupled by proximity into control cables connected to the equipment of interest. The issue was not so much the potential for damaging the equipment - as in surge occurrences - but rather the possibility of disturbing proper operation of the equipment.

Motivated by some lingering skepticism among US industry on the necessity to require these tests across-the-board for industrial equipment, measurements, augmented by theoretical numerical simulations were conducted on representative power wiring configurations to help determine how distance of propagation will reduce the threat. The findings, showing good agreement between theory and experiments, validated the expectation, that is, substantial attenuation occurs when these fast transients travel more than a few tens of meters away from their source. See also Propag EFT1 in this Part 4 for earlier tests on different cable configurations and numerical modeling technique. 
120

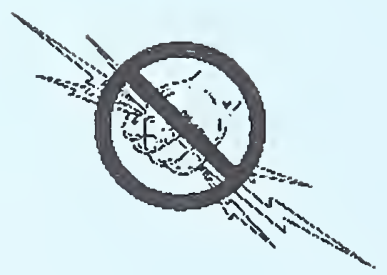




\section{Electrical Fast-Transient Tests: Applications and Limitations}

FRANÇOIS D. MARTZLOFF, FELLOW, IEEE, AND THOMAS F. LEEDY, MEMBER, IEEE

\begin{abstract}
According to a new standard of the International Electrotechnical Commission (IEC), a fasl-transient test must be applied to the connecting cables of electronic equipment. The purpose of the test is to demonstrate equipment immunity to fast transients resulting from switching. Tests and simulations of the propagation and attenuation of these fast transients in typical connecting cables are described, placimg the IEC requirements in perspective.
\end{abstract}

\section{INTRODUCTION}

CONTINUING technical progress in the performance of -electronic control systems has been made possible by fast logic devices operating at low levels of voltage and power, with high component density and interactive peripherals. These undisputed advantages, however, can make the circuits increasingly sensitive to external interfering overvoltages resulting in amplitude-related hardware failures or rate-ofchange-related system upsets. To guard against such effects, immunity to such failure must be demonstrated by realistic tests which validate the design rules and installation practices of the equipment. However, a balance must be found between overdesign and cost limitations.

In contrast with traditional surge testing aimed at validating insulation levels or the energy-handling capability of surge protection devices, recent proposals advocate fast-transient tests demonstrating interference immunity. The new test waveforms represent electrostatic discharge effects or reignitions occurring during switching sequences. The basis for such proposals is an increasing awareness of the significance of fast transients. This new awareness results from two factors: 1) increases in the bandwidth and writing speed of oscilloscopes which makes possible the detailed observation and measurement of these phenomena, and 2) field failures of equipment which pass traditional tests but fail when subjected to the new fast-transient tests.

The rationale for requiring the new tests is based on the assumption that interfering transients generated by power circuit switching will couple into adjacent power or signal lines. These interfering transients will then propagate toward sus-

Paper PID 89-09, approved by the Petroleum and Chemical Industry Committee of the IEEE Industry Applications Society for presentation at the 1989 Petroleum and Chemical Industry Committee Technical Conference, San Diego, CA, September I1-13, and at the 1989 IEEE Industry Applications Society Annual Meeting. San Diego, CA. October 1-5. Manuscript released for publication February 22, 1989.

The authors are with the Electricity Division, National Institute of Standards and Technology, Building 220, Room B-344. U.S. Department of Commerce, Gaithersburg, MD 20899.

IEEE Log Number 8931459.

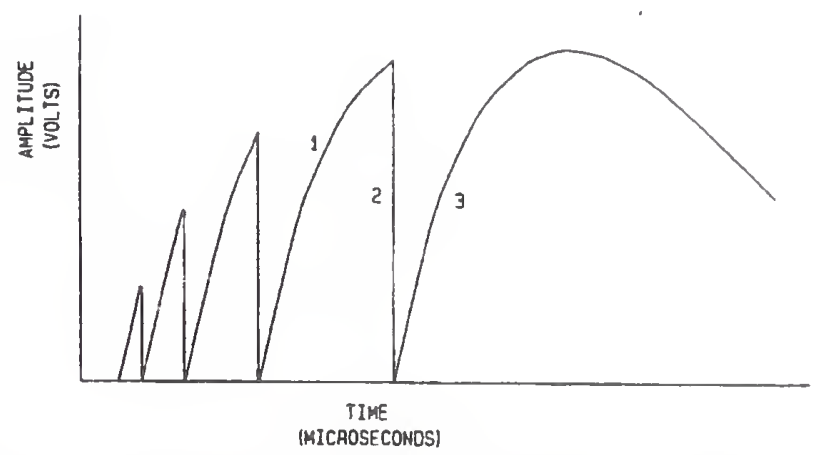

Fig. 1. Typical transient produced by contact opening. 1: voltage recovery of circuit ( $\mathrm{kHz}$ frequency); 2: reignition (ns collapse): 3: complete recovery ( $\mu$ s duration).

ceptible equipment. The fast transients contain high-frequency components that are expected intuitively to suffer greater attenuation than low-frequency components as they propagate in the lines. Verifying and quantifying this intuitive expectation provides a perspective on the severity of the situation and helps define realistic test requirements. To that end, this paper describes specific measurements conducted for typical low-voltage power line configurations. An attenuation model is proposed which provides a tool for understanding the significance of the line parameters and extends the usefulness of the results to general cases.

\section{The IEC Electrical Fast Transient Test}

The Technical Committee TC65 of the International Electrotechnical Commission (IEC) has completed a document [1] requiring immunity of industrial process control equipment to fast transients be demonstrated. According to that document, fast transients must be applied to the incoming power lines as well as to the input/output data lines of this equipment.

The origin of fast transients is the well-known behavior of some air contactors when they interrupt an inductive-capacitive circuit: as the contacts part, the arc drawn between the contacts becomes unstable and the current is then interrupted, only to be re-established promptly by reignition across the gap. A race occurs between the dielectric strength of the increasing gap, and the voltage recovery of the circuit. Consequently, a sequence of clearing and reignition ensues, with an eventual full clearing of the circuit. As shown in Fig. 1, each of the clearings produces the beginning of an oscillation at relatively low frequency depending on the local circuit parameters. As the voltage across the gap increases at a rate corresponding to this frequency, reignition occurs if the gap withstand voltage is exceeded. The waveform of each 

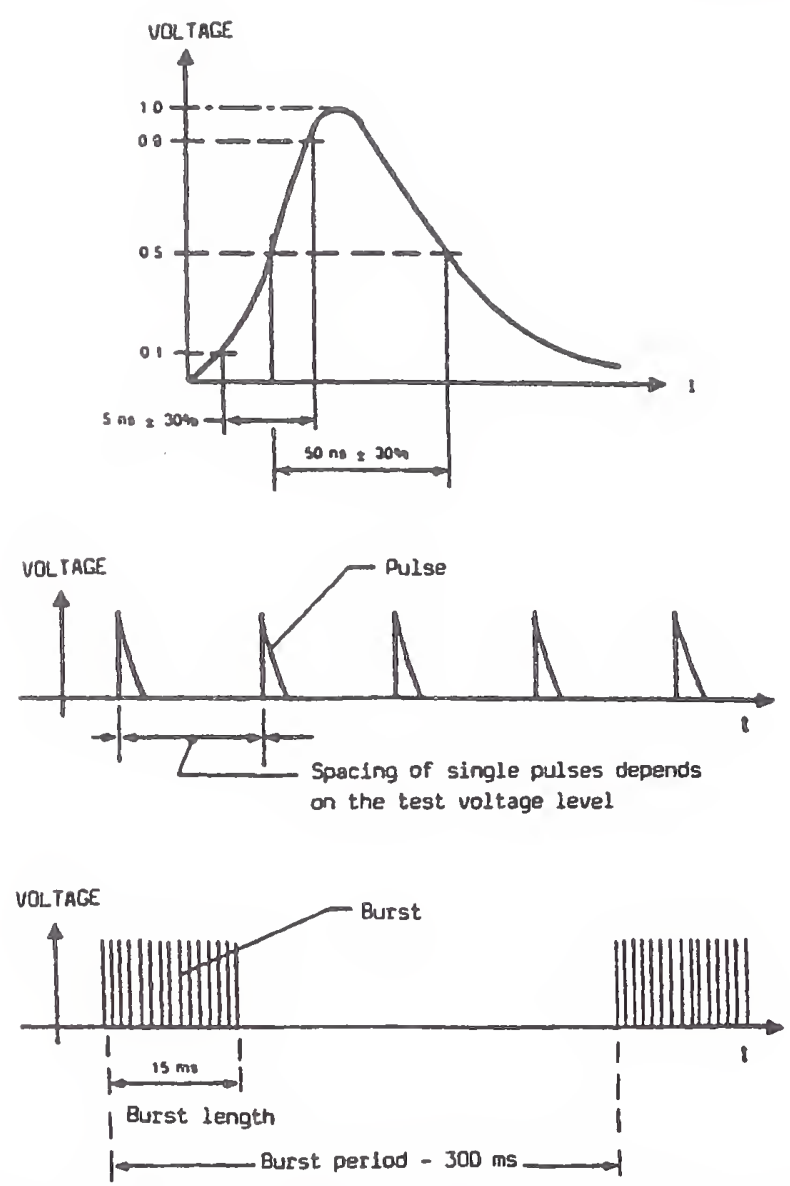

Fig. 2. Fast-transients specified by IEC $801-4$. Top: waveshape of single pulse for $50-\Omega$ load.

sequence is then a series of pulses, each with a relatively slow voltage rise followed by collapse in a few nanoseconds.

Thus the circuit behaves as a generator of transient pulse bursts. Each pulse has a slow rise ending in an abrupt collapse. Because the pulses occur in bursts, these single pulses have the same effect as pulses with fast rise time and slower decay. For standardization purposes, the IEC document specifies an electrical fast transient (EFT) $5 / 50$-ns waveform as shown in Fig. 2, where the rise time is 5 ns and the duration (full width at half maximum) is $50 \mathrm{~ns}$. The repetition rate of the pulses within a burst is not specified. However, the duration of the burst and the interval between bursts are specified.

Three limitations exist in the severity of the situation, resulting from the fast transient nature of the test and the conditions of application.

1) As described in the IEC test procedure, the test transients are coupled to the equipment under test (EUT) by a capacitive "clamp" through which the power or data cable is inserted. This clamp is a mechanical test fixture consisting of two hinged metallic plates designed to provide a fixed and repeatable capacitance between the output of the pulse generator and the input cables. Discrete capacitors can also provide the coupling. This coupling method produces a capacitive divider: the high side of the divider is the coupling capacitor, and the low side is the internal capacitance to ground of the EUT (Fig. 3). This effect, therefore, is influenced by the design of the

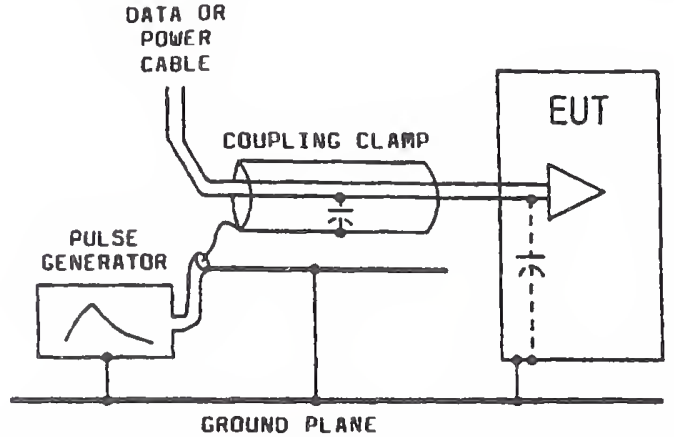

Fig. 3. Coupling electrical fast transient (EFT) pulses into equipment cables.

equipment and becomes a design parameter controlled by each manufacturer.

2) The freedom left to those who perform the test on setting the repetition rate of the pulses leaves some ambiguity on the total number of the pulses applied to the EUT. The test presumably aims at identifying an interference with the logic of the circuit. That interference is likely to occur during critical state transitions of the semiconductor circuitry of the equipment, making timing and coincidence very significant. Advocates of electrostatic discharge tests make a case that up to 10000 pulses should be applied at random to produce a high degree of confidence that the issue of pulse timing has been addressed [2].

3) In an actual installation, attenuation between the point of coupling and the victim equipment will reduce the severity of the impinging transient. The line propagation characteristics reduce the peak amplitude and increase the rise time of the pulse as it travels down the line. This effect, therefore, is influenced by the line regardless of this equipment design. Although our measurements and modeling address this third limitation, the two other limitations should also be kept in mind.

\section{Line Configurations}

Two line configurations were selected as typical of lowvoltage power lines: a three-conductor line in a steel conduit, and a three-conductor cable with a nonmetallic jacket. The steel conduit line is easy to set up in the laboratory by arranging conduit sections in a zig-zag pattern. This arrangement allows placing the start and the end of the line next to each other to minimize the distance between the oscilloscope used for measuring the signals at either end of the line. At one end of the line, called the "sending end," single pulses with the IEC EFT waveform were injected. At the other end, called the "receiving end," the arriving pulses were recorded for various line terminating impedance configurations. The same oscilloscope was used to measure the waveforms at the two ends of the line. Thus the voltage ratios of the waveforms do not depend on the absolute accuracy of the instrumentation. In addition, the differential connection of the oscilloscope probes allows measurement without introducing an additional ground in the line, which is already grounded by its connection to the pulse generator. This arrangement also removes any question of variations of the stray capacitances to ground, provided that 
the instruments stay in the same position for the two measurements, at both the sending and receiving end. The experimental details of the measurements are discussed in Appendix 1 .

Because the conduit contains the electromagnetic fields associated with the propagating pulse, there is no need to be concerned with coupling between adjacent sections of the line in the zig-zag, nor with losses by radiation from the line acting as an antenna. For the nonmetallic jacketed line, however, these effects must be addressed.

To investigate the effect of radiation losses from the nonmetallic jacketed line, three experiments were performed outdoors. First, measurements were made with the line arranged in a wide loop, elevated from ground and away from metallic objects. To assess the importance of the proximity of the line to ground, the line was later dropped to ground level and a second set of measurements was made. Last, a coil of identical cable was also subjected to the same measurements. The observed difference of the three sets of measurements was negligible for practical purposes.

For the case of the conduit-enclosed line, a previous paper reports in detail the experimental results and theoretical expectations from a model solely based on the geometry of the line [3]. As a convenience for the readers and for comparison with the new results on nonmetallic jacket line, the results of the first configuration are summarized here. For the nonmetallic line, we used a new model based on measurable electrical parameters of the line, rather than the geometry of the line. Appendix I gives details on instrumentation considerations; Appendix II gives details on the line propagation model.

\section{Steel Conduit Line}

A representative low-voltage indoor single-phase power line was installed in the laboratory, with three conductors in a steel conduit. The line length was $63 \mathrm{~m}$ (20 thin-wall conduit sections, each the standard 10-ft length), using typical industrial components such as wire nuts at the splices in the wire. Three insulated $(600 \mathrm{~V})$ copper conductors of number $14 \mathrm{AWG}$ ( $1.6 \mathrm{~mm}$ diameter), pulled in the $20 \mathrm{~mm}$ diameter conduit ( $1 / 2$ EMT), represent the phase, neutral, and grounding conductors. At the sending end, the neutral conductor was bonded to the grounding conductor and to the conduit.

At the receiving end, the neutral conductor was not bonded to the grounding conductor, nor to the conduit. This type of connection is typical U.S. practice for a branch circuit originating at a service entrance.

For modeling purposes, it is much easier to assume that the line is uniform. In practice, the location of the conductors vary within the conduit due to sag, bends, or crossed wires. Therefore, we considered two limiting cases: 1) the wires are located at the center of the conduit, separated from each other by the thickness of the wire insulation, and 2) the wires are located against the wall of the conduit. In the numerical analysis, a model parameter $k$ accounted for these two positions. A detailed description of the analysis is given in [3].

Fig. 4 shows the composite results of the measurements and modeling for the IEC EFT pulse arriving at the receiving end. The results are expressed as a percentage of the pulse applied

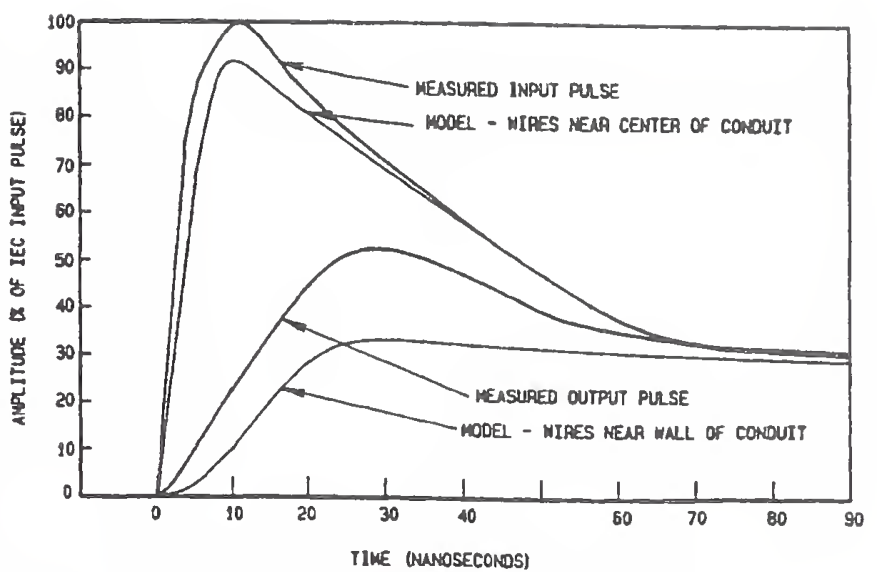

Fig. 4. Composite plot of measured and modeled pulses, as percent of amplitude, for wires enclosed in metal conduit.

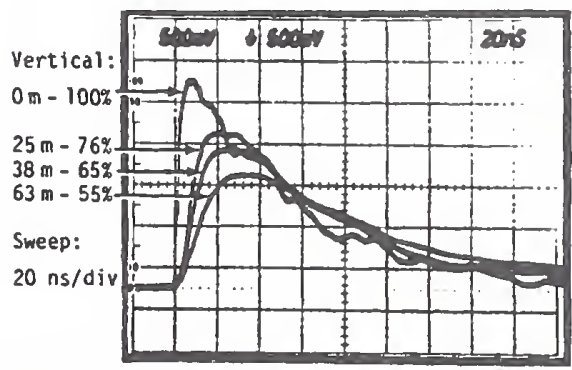

Fig. 5. Oscillograms of measured pulses, as percent of input amplitude $(0 \mathrm{~m})$, for various lengths of wires enclosed in metal conduit $(25.38$, and $63 \mathrm{~m})$.

at the sending end. All the measurements were made with a injected pulse of 2.5 or $5 \mathrm{~V}$, to avoid the problems of electromagnetic interference or safety associated with the levels of 500-4000 V specified by the IEC standard. The linearity of the circuits allows this simplification. The pulse, measured at the receiving end, is 50 percent of the sending-end pulse and lies between the two limiting cases of the model. Qualitatively, the model pulses look very much like the measured pulses. From the position of the measured pulse with respect to the two limiting cases, we can then assign a value to the model parameter $k$ such that attenuation for the $63-\mathrm{m}$ line is accurately matched. Given this empirically determined value, the model will show the effect of varying the line length.

Measurements for several line lengths (Fig. 5) show receiving-end peak amplitudes of 76 and 65 percent of the sending-end peak amplitude for 25 - and 38 - $\mathrm{m}$ lines, respectively. Corresponding peak amplitudes predicted by the model are 75 and 67 percent (Fig. 6). For the greater line lengths, where measurements would be cumbersome, the model can now readily provide the answers. Fig. 6 includes examples for 120 - and $240-\mathrm{m}$ lengths, showing the continued attenuation and smearing of the pulse as the line length increases.

\section{Nonmetallic Jacketed Line}

For this type of line, the insulation holds the conductors in a fixed and uniform geometry relative to each other, in contrast with the random location of the conductors pulled in a conduit. It is possible to determine, by a simple set of measurements or calculations, the parameters of the transmission 


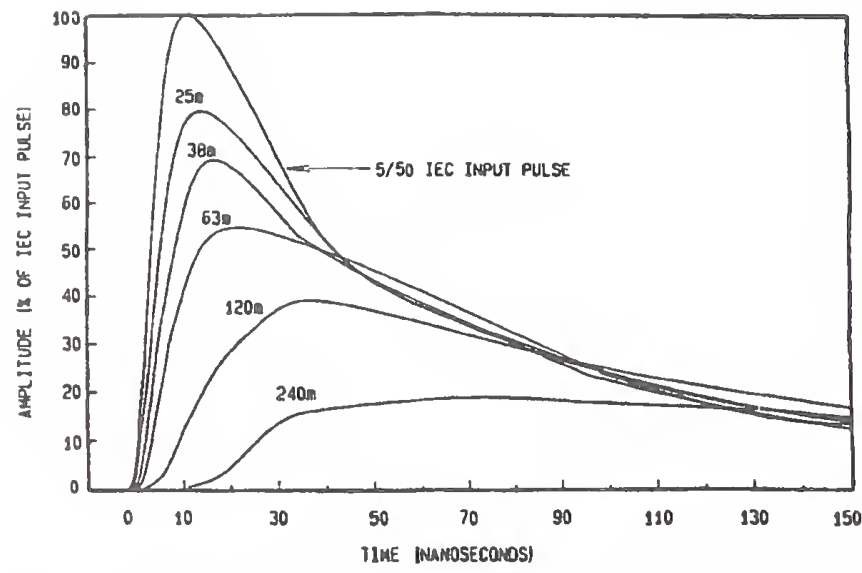

Fig. 6. Model prediction, as percent of input amplitude, for various lengths of wires enclosed in metal conduit.

line: the series inductance $L$; the shunt capacitance $C$; and the series resistance $R$. The shunt admittance, normally included in the model of a transmission line, is negligible in a wellinsulated power line. For the high-frequency components of the fast-transient pulse, skin effect influences the effective series impedance. The model includes an approximation of this effect.

\section{Experimental Measurements on Nonmetallic JaCketed Lines}

The 75-m line (250 ft) consisted of a neoprene-jacketed cord with three number 14 AWG (1.6-mm diameter) neopreneinsulated copper conductors. The line was suspended $2 \mathrm{~m}$ above ground. The line was arranged in a triangular loop with the sending end and the receiving end at one corner of the triangle. In this manner, either end could be connected to the oscilloscope. As described in Appendix I, a constant impedance load was maintained at the sending end by using a dummy load when switching the oscilloscope from the sending end to the receiving end. In all the measurements, two of the conductors were bonded at the sending end, representing the neutral and the grounding conductors. At the receiving end, the arriving pulse was recorded for various terminating load combinations. Fig. 7 shows an EFT signal with $2.5 \mathrm{~V}$ peak and $5 / 50$-ns waveform injected at the sending end, arriving as a 30/110-ns signal at the end of the line. This peak amplitude of 48 percent is very close to the 50 -percent value found for the steel conduit. The small difference between the two values is due to the oscillogram reading uncertainty rather than to a significant difference between the characteristics of the two lines. The question raised in the introduction, concerning radiation losses, is answered in the negative-or at least in the form, "not discernable at this level of significance."

\section{Need to Consider Loading at Receiving End}

Classical transmission line theory points out that reflections occur at the receiving end of the line when the terminating impedance differs from the characteristic impedance of the cable: 1) doubling the arriving pulse for an open end (and thus reflecting a pulse of the same polarity); 2) maintaining zero for a shorted end (and thus reflecting a pulse of reverse polarity); and 3) maintaining the level unchanged for a terminating

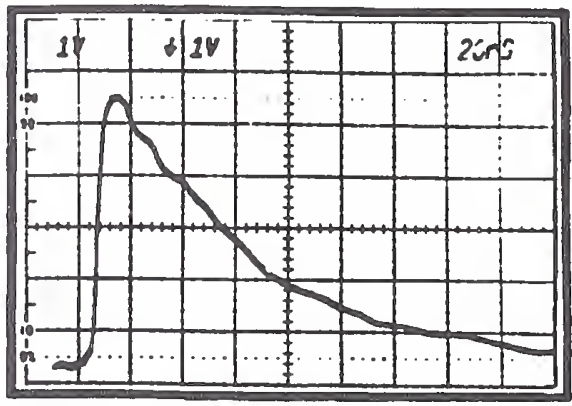

(a)

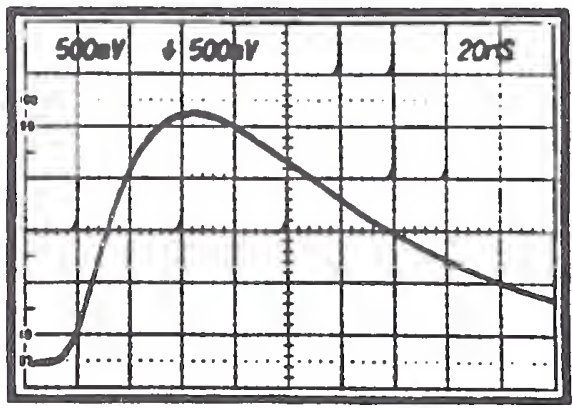

(b)

Fig. 7. Pulses for nonmetallic jacketed cable. (a) Sending-end pulse. Vertical: I V/div, sweep: $20 \mathrm{~ns} / \mathrm{div}$. Signal parameters: amplitude $=5 \mathrm{~V}$ (100 percent), rise time $=5 \mathrm{~ns}$, FWHM $=50$ ns. (b) Receiving-end pulse. Vertical: $0.5 \mathrm{~V} / \mathrm{div}$, sweep: $20 \mathrm{~ns} / \mathrm{div}$. Signal parameters: amplitude $=2.4$ $V$ (48 percent), rise time: 30 ns, FWHM: $110 \mathrm{~ns}$.

impedance that matches the line characteristic impedance (and thus having no reflection).

Measurements made with "slow" $1.2 / 50-\mu$ s impulses have shown that, while correct, this analysis does not produce useful results if applied to line lengths that do not contain the whole impulse front [4]. For a $1.2-\mu \mathrm{s}$ front in a line where the propagation velocity is approximately $2 / 3$ the speed of light in vacuum $(300 \mathrm{~m} / \mu \mathrm{s})$, this lower limit on line length is approximately $200 \mathrm{~m}$. For the 5/50-ns IEC EFT pulse, the 63-m line produces at the receiving end a 30 -ns front time. According to the model, a $240-\mathrm{m}$ line would produce a $60-\mathrm{ns}$ front time (Fig. 6). Clearly, then, for this short an impulse, the receiving-end terminating impedance effects must be considered according to classical transmission line theory.

Because the measurement system has an impedance of $100 \Omega$ while the characteristic impedances of the lines investigated are approximately $60 \Omega$, the case of an open-ended line cannot be measured. In actual installations and in the absence of a low-impedance instrument, the pulse would have twice the amplitude shown in Fig. 7. An open end is the limiting case for a very light load such as a control circuit during the off cycle of the power circuit. Adding even a small admittance at the end of the line substantially reduces the doubling effect.

\section{Common-Mode and Normal-Mode Coupling}

The method specified by IEC $801-4$ for coupling the test transients to the power or the data cables introduces them as a common-mode signal in the cable (Fig. 3). This situation is not explicitly pointed out in the IEC document, but it must be clearly understood. Another standard advocating fast transients [5] specifies the application of the test transients in any 


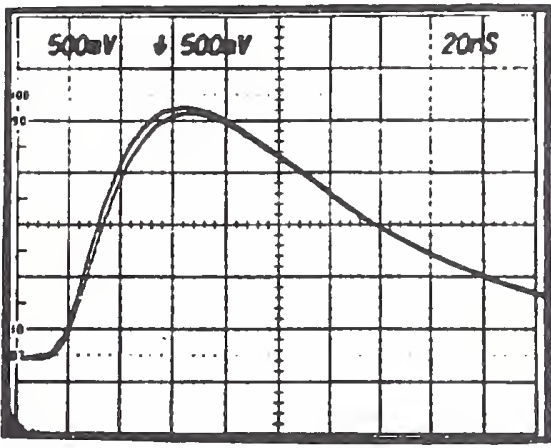

Fig. 8. Superimposed oscillograms of pulses at receiving-end, showing small difference between overhead line (left) and coiled line (right).

possible combination of the conductors for all input and output ports. While space and scope limitations for this paper prevent a comprehensive discussion of the subject, alerting readers to the issue is worthwhile.

The IEC EFT test focuses on installed equipment rather than on stand-alone equipment. The coupling clamp method for injecting the transients into the circuits is a very convenient procedure when cables are accessible. Practitioners of this test also report useful results by coupling the transients with foil wrapped around installed bundles of cables. The document provides detailed descriptions of the configuration for a laboratory test in an effort to ensure reproducible results. However, propagation, coupling, and attenuation effects associated with the capacitive divider nature of the test application will be strongly affected by small changes in the test circuit geometry, making the test difficult to describe and reproduce in absolute terms.

These remarks should not be construed as a criticism of the test. Anecdotal field experience shows that equipment with demonstrated immunity to the IEC $801-4$ EFT procedure is less likely to be disturbed than equipment not meeting this requirement. The addition of the new test procedure has contributed to improved reliability. Experience is the ultimate validation of the usefulness of any performance standard.

\section{No Practical Need for Outdoor Tests}

After completing the tests on the suspended aboveground line, the line was lowered to ground (dry grass) level, and one set of measurements was made under that condition. The same measurements were also made on a control coil of identical cable, left in its original packing carton. These two control measurements show detectable but insignificant differences (Fig. 8) in the pulse arriving at the receiving end. Thus concern over line geometry and coiled versus "free space" configurations, while technically correct, is a negligible factor in practical applications. Therefore, future experimenters need not go outdoors to perform measurements, even at the higher frequencies since the coiled versus free space configurations appear to produce similar results. This finding extends the conclusion previously reached for $100-\mathrm{kHz}$ ring waves [6].

Modeling the Propagation

\section{Line Model}

An electrical circuit analysis model was devised to investigate the changes in the voltage amplitude and waveform shape

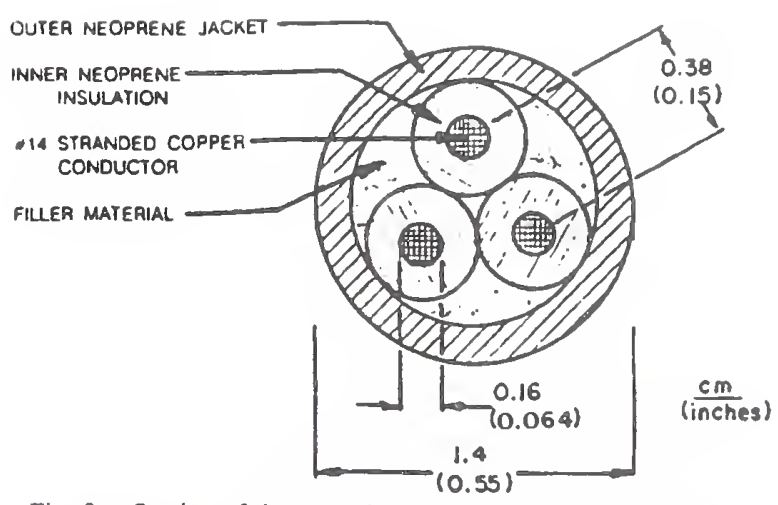

Fig. 9. Section of three-conductor, nonmetallic jacketed cable.

of the 5/50-ns EFT pulse as it propagates along a length of typical low-voltage power line. The low-voltage cable consists of three number 14 (1.6-mm diameter) conductors, with individual neoprene insulation and covered with a neoprene jacket. Fig. 9 shows a cross section of this cable.

A $63-\mathrm{m}$ length of cable was simulated as $631 \mathrm{~m}$ lengths connected in series (Fig. 10). Each 1-m length was represented by the equivalent twoport subcircuit shown in Fig. 11. The subcircuit values represent the series and parallel elements of the two-conductor line, to which a capacitance from each wire to a hypothetical ground plane was added. Numerical values were assigned to these parameters as described in Appendix II.

Electrical circuit analysis simulations were performed using the SABER software system ${ }^{1}$ which allows the $1-\mathrm{m}$ subcircuit of Fig. 11 to be described only once as a "template." The software template is then replicated as many times as necessary to represent the transmission line. To investigate the effects of a change of a modeling parameter, such as a resistance or capacitance, the parameter need be changed only once in the data set. The 5/50-ns IEC EFT pulse was digitized from an oscillogram recorded during the experimental measurements so that a piecewise linear voltage source could be constructed for the circuit simulation.

\section{Modeling Results}

Fig. 12 shows the comparison of the observed (solid line) and the simulated (dashed line) waveforms at the end of $63 \mathrm{~m}$ of cable in response to the 5/50-ns IEC EFT pulse. The pulse simulated by the simple model described demonstrates the same general waveshape, rate of voltage rise, and amplitude as the observed pulse. The simulated pulse, however, has a shorter time duration than the observed pulse. In addition, the propagation velocity of the pulse, as predicted by the model, is slightly greater than the propagation velocity measured in the cable.

The discrepancies between the simulated and the observed waveforms and the velocities may be explained by several limitations of the model. First, the model did not consider the skin effect of the conductors. The skin effect would raise the resistance and inductance of the conductors for the high-frequency components of the waveform. Secondly, the cable consisted of

\footnotetext{
'SABER is a product of Analogy, Inc., Beaverton, OR.
} 


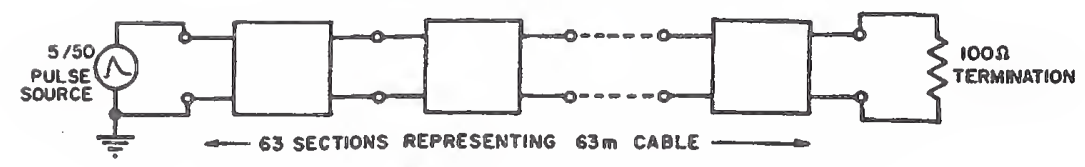

Fig. 10. Building line with repeared sections.

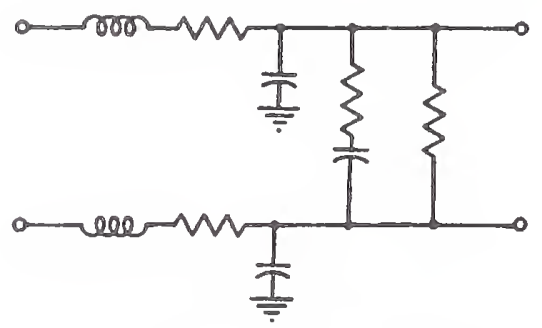

Fig. 11. Circuit parameters for indjvidual sections.

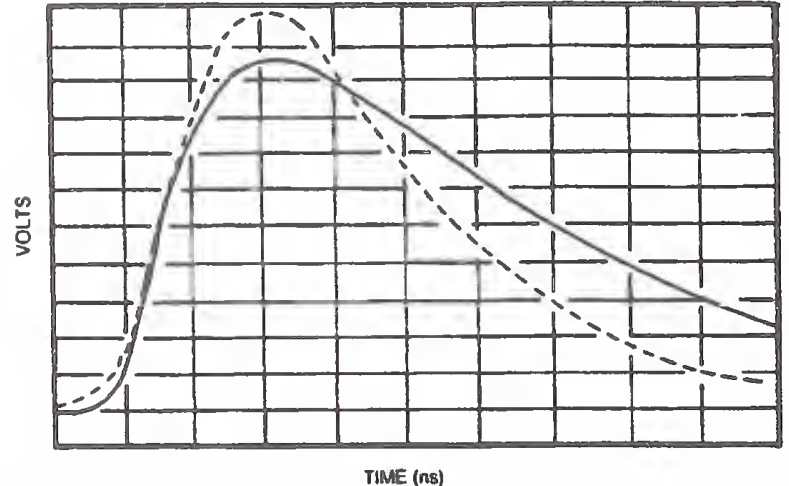

Fig. 12. Comparison between measured and modeled pulses at receiving end of nonmetallic jacketed line. Solid line: measured data; dashed line: predicted data.

three conductors of which only two were modeled. The third conductor was connected to ground at the pulse generator end of the cable and left open at the receiving end of the cable. The presence of this third conductor would change the propagation characteristics of the cable slightly. Finally, a simple loss model (a series $R C$ network) has been assumed for the capacitance associated with the neoprene dielectric of the cable. The response at high frequencies of organic dielectrics may be considerably more complicated than this model reflects.

\section{CONCLUSION}

The two line configurations and their models yield similar results for measurements and for computations. Some difference might be expected between the quasi-coaxial configuration of a conduit-enclosed line and the open-line configuration with unshielded conductors of a nonmetallic jacket.

The effects of propagation of an EFT pulse in the lines are a reduction in the amplitude, a decrease in the steepness of the front, and an increase in the duration of the pulse. The first two effects reduce the severity of a pulse arriving at the victim equipment; the third effect is less significant for victim equipment sensitive to rate-of-change disturbances.

The two models provide the tools for analysis of other configurations. The choice of the geometry model or the electrical parameter model will depend on the available soffware and preferences of the investigator.
A pragmatic conclusion on the quantification of the EFT pulse propagation is that equipment likely to be installed close to sources of such disturbances would benefit from immunity demonstration; equipment intended to be located away from such sources, however, might not be required to be subjected to a complete set of EFT tests.

\section{ACKNOWLEDGMENT}

P. F. Willson (former staff member of the National Bureau of Standards, Boulder, $\mathrm{CO}$ ) developed the model [3] for the conduit line, which is only summarized here. The nonmetallic jacket measurements were funded in part by a consortium of private sector companies coordinated by Building Industry Consulting Service International of Tampa, FL.

\section{APPENDIX I}

\section{INSTRUMENTATION}

The voltages were recorded with a 1-GHz bandwidth oscilloscope and two $50-\Omega$ input vertical preamplifiers. The mainframe of the oscilloscope performed the differential combination of the two signals. In this configuration, the bandwidth of the system is only $500 \mathrm{MHz}$, compared to the $1-\mathrm{GHz}$ capability of the single-ended measurements with one preamplifier. This reduction in performance is an acceptable trade-off to obtain the differential connection of the probes. In the experiments, the conduit, oscilloscope chassis, and low-side output of the generator are bonded together and hence ensure minimum noise coupling. Where high voltages are involved, this configuration also provides improved safety. This was not a concern here as the measurement on this linear system were conducted with signals in the $5-\mathrm{V}$ range. A check on the common mode rejection of the system indicated less than fivepercent residual signal, an insignificant effect compared to the attenuation levels measured.

The preamplifiers have a $50-\Omega$ input impedance, so that the effective impedance of the differentially connected probe is $100 \Omega$. At the sending end, the voltages of the line and neutral conductors with respect to chassis ground were each fed to one of the preamplifiers (Fig. 13). Thus the pulse delivered by the generator impinges on an impedance consisting of the two amplifiers in series, in parallel with the line. To make measurements at the receiving end, the same oscilloscope was used with its differential probes. However, the pulse arriving at the receiving end would experience a reflection due to any impedance mismatch. To obtain an impedance match, timedomain reflectometry was used to trim the terminating load until a minimal reflection occurred.

Good matching occurred with a $75-\Omega$ termination for the steel conduit line $(300-\Omega$ trim in parallel with the $100-\Omega$ probes). For the nonmetallic-jacketed cable, a $50-\Omega$ termination gave best result (100- $\Omega$ trim and $100-\Omega$ probes in parallel). For the steel conduit line, a dummy load was used, made 


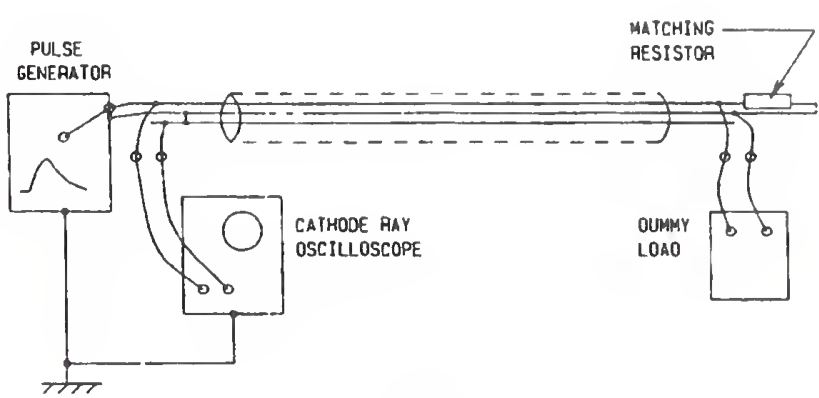

(a)

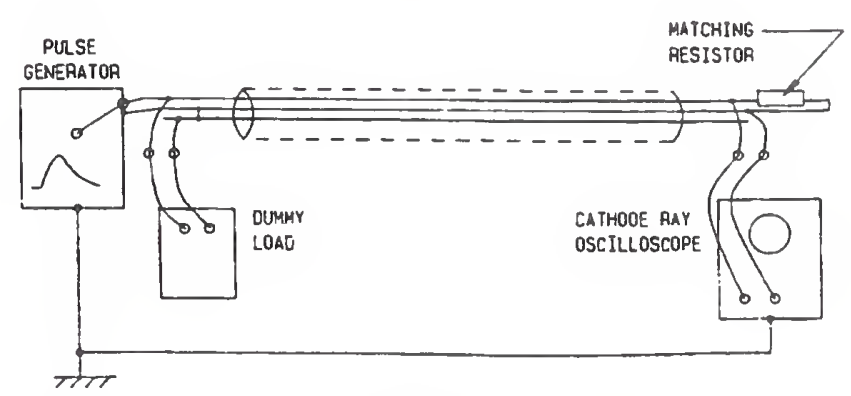

(b)

Fig. 13. Configuration for constant-load measurements with dummy load and single oscilloscope. (a) Measurement at sending end. (b) Measurement at receiving end.

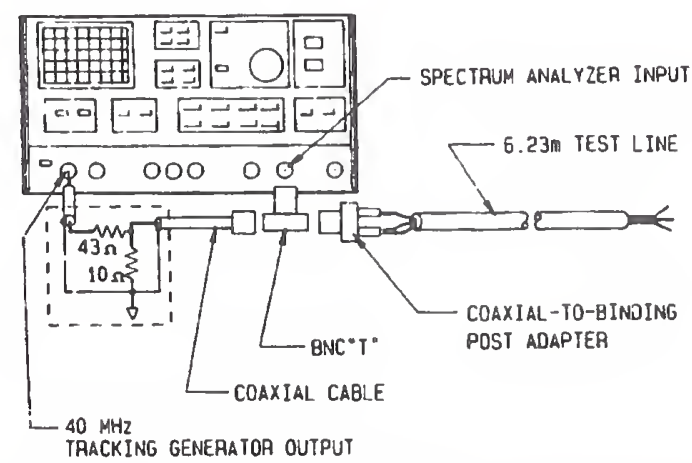

Fig. 14. Configuration for determiring velocity of propagation in nonmetallic jacketed line.

of two $50-\Omega$ coaxial terminators to provide the same matching impedance as that of the oscilloscope probes, as shown in Fig. 13. For the nonmetallic-jacketed cable measurements, two preamplifiers of the same type as the measuring preamplifiers. in a compatible mainframe, were used as the dummy load. In this manner, when recording the receiving-end waveforms with the measurement oscilloscope, the dummy load connected in parallel with the line at the sending end maintained a constant impedance load on the pulse generator.

The propagation velocity in the cable was measured as reported previously: a $40-\mathrm{MHz}$ spectrum analyzer, with a tracking generator output, was used to determine the frequencies at which the input impedance of a length of cable is minimum [6]. Fig. 14 shows schematically the test line, the spectrum analyzer, and a resistive attenuator to improve the decoupling of the tracking generator output from the test line.

Fig. 15 shows the spectrum for a $6.23-\mathrm{m}$ length of opencircuited test line. Voltage minima occur at $5.64,19.4$, and $30.4 \mathrm{MHz}$, corresponding to wavelengths of $\lambda / 4,3 \lambda / 4$,

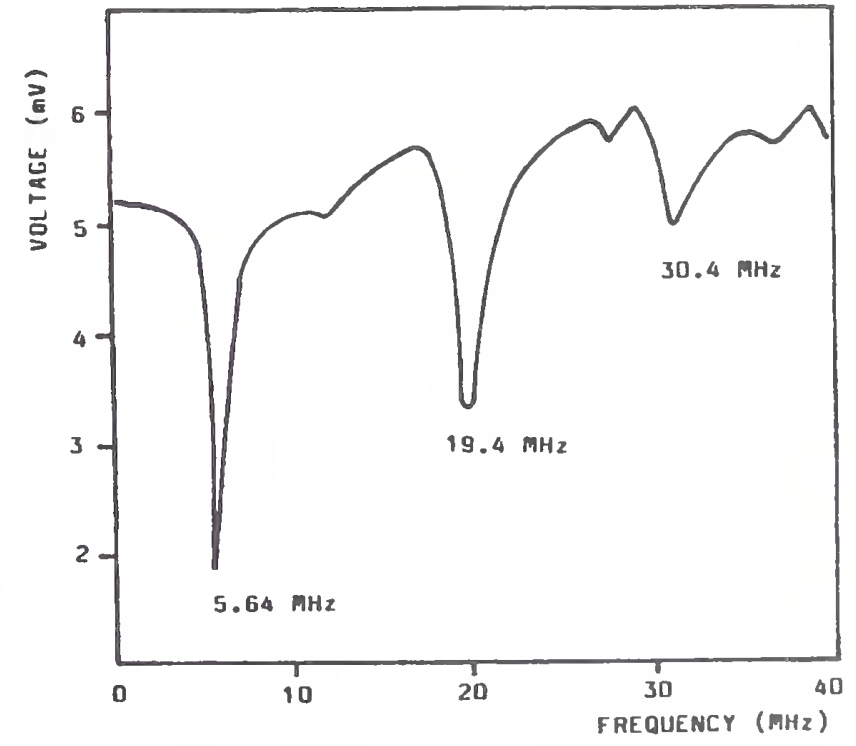

Fig. 15. Spectrum of 6.23-m length of test line. 


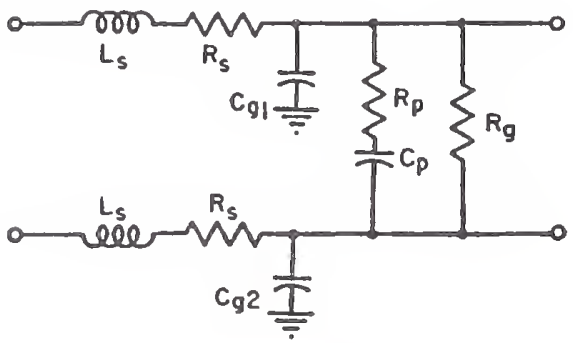

Fig. 16. Circuit parameters for line sections.

and $5 \lambda / 4$, respectively. The average propagation velocity, the product of $\lambda$ and frequency, is $155 \mathrm{~m} / \mu \mathrm{s}$.

\section{APPENDIX II \\ LINE MODEL}

The series inductance of the $1-\mathrm{m}$ section $L_{s}$ was calculated using the formula for the inductance of two parallel conductors in close proximity to each other, with current in opposite directions in each conductor [7]. For such a situation, the effective inductance $L_{e}$ is given in engineering handbooks as

$$
L_{e}=5 \cdot l\left[\ln \frac{d}{r}+\mu \cdot \delta-\frac{d}{l}\right]
$$

where

$L_{e}$ effective inductance ( $\mathrm{nH}$ ),

I length of the cable (in),

$d$ distance between the conductors (in),

$r$ radius of the conductors (in),

$\mu$ relative magnetic permeability (copper $=1.0$ ),

$\delta$ skin depth factor.

The skin effect is a phenomenon affecting the conduction of cables because current passing along the surface of the conductor encounters less inductance and resistance than current passing through the center of the conductor. The skin-depth factor $\delta$ (over a range of $0<\delta \leq 0.25$ ) may be expressed as

$$
\delta=\frac{K}{r \cdot \sqrt{\rho / \mu \cdot f}}
$$

where

$K=3168$, a conversion constant,

$\rho$ volume resistivity $\left(\Omega\right.$-in) $\left(=0.68 \cdot 10^{-6}\right.$ for copper $)$,

$f$ frequency $(\mathrm{Hz})$.

For a low-frequency approximation of the response of the cable to a 5/50-ns pulse, the skin effect term can be neglected.

There are two types of capacitance associated with the cable (Fig. 16). The first is associated with the conductor-toconductor capacitance, $C_{p}$. The other type of capacitance consists of equal valued capacitors $C_{g 1}$ and $C_{g 2}$, which represent the two conductor-to-ground capacitances. The equation of the capacitance between two parallel cylinders representing the conductor-to-conductor capacitance may be written as [8]

$$
C_{p}=\epsilon_{r} \cdot \frac{8.467 \cdot 10^{-3}}{\cosh ^{-1}(d / 2 r)}
$$

where $C_{p}$ is the capacitance per unit length $(\mu F / 1000 \mathrm{ft})$ and $\epsilon_{r}$ is the relative dielectric constant of the material filling the space between the two conductors. The equation for the capacirance between a wire and a ground plane is similar; this capacitance is

$$
C_{8}=\epsilon_{r} \cdot \frac{7.354 \cdot 10^{-3}}{\log _{10}(2 H / r)}
$$

where $C_{g}$ is the capacitance per unit length $(\mu \mathrm{F} / 1000 \mathrm{ft})$ and $H$ is the distance between the conductor and the ground plane.

The resistance of the conductor is represented by resistance $R_{s}$ in series with each inductance $L_{s}$. A resistance, $R_{p}$ is in series with the capacitance $C_{p}$ to simulate the losses encountered in the dielectric surrounding the two conductors. One additional resistance $R_{g}$ simulates the resistance associated with the conductor-to-conductor leakage to complete the model.

Using the equations given, the following values were computed for a $1-m$ length of number 14/3 Type SO cable:

$L_{s} \quad 26 \mathrm{I} \mathrm{nH}$, the series inductance of each conductor where $d=0.45 \mathrm{~cm}(0.177 \mathrm{in})$ and $r=0.016 \mathrm{~cm}(0.032 \mathrm{in})$;

$C_{p} 53 \mathrm{pF}$, the conductor-to-conductor capacitance assumes $\epsilon_{r}=3$ for neoprene dielectric;

$C_{g} \quad 17 \mathrm{pF}$, the conductor-to-ground capacitance;

$R_{s} \quad 0.003 \Omega$, the series resistance of conductor (obtained from wire tables);

$R_{p} 10 \Omega$, the estimated resistance in series with $C_{p}$;

$R_{g} 10 \mathrm{M} \Omega$, the estimated leakage resistance.

The velocity of propagation predicted by the model is approximately $170 \mathrm{~m} / \mu \mathrm{s}$ for the $5 / 50$-ns pulse traversing the neoprene-jacketed cable. In contrast, the higher velocities of propagation would be expected in the line enclosed by the steel conduit where the conductors have only a thin insulation surrounded by air. Measurements of the velocity of propagation confirm the difference between the two lines: $210 \mathrm{~m} / \mu \mathrm{s}$ for the air-surrounded conductors in the conduit and $155 \mathrm{~m} / \mu \mathrm{s}$ for the neoprene covered conductors. 


\section{REFERENCES}

[1] Electrical Fast Transient Requirements, IEC Publication 801-4, Geneva, Switzerland, 1988.

[2] R. B. Bush, "Statistical considerations of electrostatic discharge evaluations," in Proc. Int. Zurich Symp. Electromagnetic Compatibility. 1987.

[3] F. D. Martzloff and P. F. Wilson, "Fast transient tests: Trivial or terminal pursuit?" in Proc. Int. Zurich Symp. Electromagnetic Compatibility. 1987.

[4] F. D. Martzloff, "The propagation and atcenuation of surge voltages and surge currents in low-voltage ac power circuits," IEEE Trans. Power App. Syst., vol. PAS-102, no. 5, May 1983.

[5] Standard Surge Withstand Capability (SWC) Tests for Protective Relays and Relay Systems, ANSI//EEE C37.90.1, 1989.

[6] F. D. Martzloff and H. A. Gauper, "Surge and high-frequency propagation in industrial power lines," IEEE Trans. Ind. Appl., vol. 1A-22. no. 4, July/Aug. 1986.

[7] P. M. Rostek, "Avoid wiring-inductance problems," Electron. Design, Dec. 6, 1974.

[8] H. Pender and W. A. Del Mar, Electrical Engineers' Handbook. New York: Wiley (Engineering Handbook Series), 1949, p. 14-33.

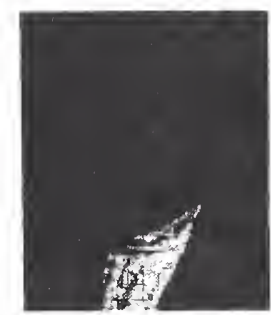

François D. Martzloff (M'56-SM'80-F'83) completed his undergraduate studies in France and received the M.S.E.E. degree from the Georgia Institute of Technology, Atlanta, and the M.S.1.A. degree from Union College, Schenectady, NY.

After a long career at General Electric, he joined the staff of the National Bureau of Standards (now renamed National Institute of Standards and Technology) to work on conducted electromagnetic interference issues. His early experience covered highvoltage fuses, high-voltage bushings, and electronic power conversion; the latter marked a turning point to issues of overvoltage effects on semiconductors, surge suppression, metal oxide varistor applica- tions, and interference mitigation. In addition to his research work on surge propagation and mitigation, he is contributing to the development of standards on surge environment and surge suppression within IEEE, ANSI, and IEC by documenting his measurements, as in the present paper, by presenting cutorials, and by drafting new standards.

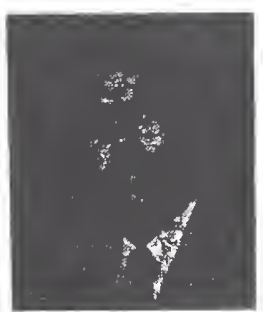

Thomas F. Leedy (S'64-M'65) received the B.S. degree in physics from the American University, Washington, DC, and the M.S. degree in electrical engineering and the E.Ad. degree in engineering administration from George Washington University. Washington, DC, in 1965, 1972, and 1984, respectively.

From 1965 to 1980 he did research in microelectronics at the National Bureau of Standards where he developed and validated measurement methods for determining the effects of transient high-energy radiation on integrated circuits and for evaluating materials and processes of microelectronic device fabrication. Since 1980 , he has been a member of the technical staff of the Electronic Instrumentation and Metrology Group of the Electrosystems Division where he has participated in the research program directed toward assuring the accuracy of automatic test equipment.

Mr. Leedy has served on numerous standards commintees in microelectronics, computers, radiation effects, and electronic instrumentation for $1 E E E$, ASTM, and the U.S. Department of Commerce International Trade Administration. 


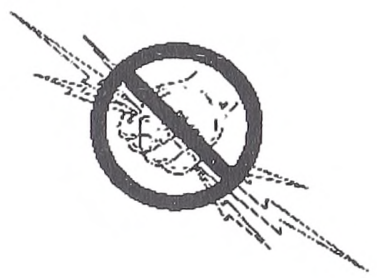




\section{Partial Discharges in Low-Voltage Cables}

\author{
J. P. Steiner \\ Biddle Instruments \\ Blue Bell PA
}

\author{
François D. Martzloff \\ National Institute of Standards and Technology \\ Gaithersburg MD \\ f.martzloff@ieee.org
}

Reprinted, with permission, from

Conference record of the IEEE International Symposium on Electrical Insulation, Toronto, 1990

\section{Significance}

Part 4 - Propagation and coupling of surges

This paper is only indirectly related to the topic of surge propagation in the context of surge-protective devices, but is included here as it might be a gateway to further information on pulse propagation - the basic technique used in the investigation summarized by this paper 
Q 


\section{PARTIAL DISCHARgES IN LOW-VOLTAGE CABLES}

\author{
J.P. Steiner \\ Biddle Insiruments \\ Blue Bell, PA 19422
}

\author{
F.D. Martzloff \\ National institute \\ of Standards and Technology \\ Gidthershurg, MD 20899
}

\begin{abstract}
Testing of high voltage apparatus for partial discharges has long been recognized as an important part of quality control for these devices. Recently, interest has been focused on methods for testing low voltage cables to determine their integrity under adverse operating conditions such as a loss of coolant accident. A new method, utilizing partial discharges, is presented which has the potential for locating breaches in the insulation of in situ, low voltage, multi-conductor cables.
\end{abstract}

\section{INTRODUCTION}

Cables used in power plants are selected on the basis of qualification tests [1] which provide a sufficient degree of confidence in the ability of the cables to maintain operational readiness for a well-defined "life" duration. As the cables age under the various environmental stresses prevailing in a power plant, nuclear plants in particular, the question arises of how much "residual life" exists in the cables as they approach their rated, qualified life. There is considerable interest in assessing this readiness, and a number of investigators have proposed various test methods [2]. In particular, a method that could allow nondestructive, in situ assessment would be extremely valuable. The detection of partial discharges at identifiable sites along a cable offers a method for assessing the likelihood of a fault to occur during a loss of coolant accident on a cable containing an incipient defect. Sucl an incipient defect might be a breacls of the insulation that would remain undetected under normal operating conditions.

Low-voltage cables, in contrast with cables designed for highvoltage service, are not provided with an insulation structure aimed at making them free from partial discharges under moderate overvoltage conditions such as the application of a test voltage. Therefore, the occurrence of a partial discharge at an incipient defect sitc has to be differentiated from the background of the expected partial discharges that will occur over the length of the cable in the absence of any significant defect. The test method described in this paper offers the opportunity to make this differentiation and locate the discharge sites associated with insulation breaches. Three representative types of cables in which artificial defects had been created were subjected to the test; every defect was successfully located.

\section{PRINCIPLE OF THE METHOD}

Partial discharges will occur along the entire length of a cable when voltages greater than the partial discharge inception voltagc are applied. To develop a strategy for analyzing experimental data from a cable that also contains defects resulting in partial discharges at specific sites, several assumptions need to be made.

The first is that there are no preferred partial discharge sites in the cable under test. Therefore, it would be expected that, ideally and in the absence of any defect, the partial discharges would be uniformly distributed along the length of the cable.
The second assumption is that, in the absence of a defect, the partial discharge pulses occur as random events in time, i.e., the observed process is a marked random point process [3]. Using thesc assumptions causes the observed partial discharge process to resemble, asymptotically, a Poisson shot noise process [3,4], with pulses emanating from all positions along the cable. If a sample of data were analyzed by calculating a histogram of the positions from which each pulse in the sample emanated, then, using this model, the histogram would correspond to a uniform distribution.

The third assumption is that amplitudes of the pulses, expressed in units of charge at each partial discharge site, are gammadistributed [4] with the parameters of the probability density being independently and identically distributed. The observed probability density of the charge will then have the form

$$
\mathrm{p}(q)=\int_{z, w} \mathrm{p}(q \mid z, w) \mathrm{p}(z) \mathrm{p}(w) d z d w
$$

where $\mathrm{p}(q)$ is the probability density of the observed charge in the entire cable, $\mathrm{p}(q \mid z, w)$ is a conditional probability density of the charge at a single site, $\mathrm{p}(z)$ is the probability density of the locations of the partial discharge sites along the cable and $p(w)$ is the probability density of the parameter $w$, such as the degree of imperfection in the insulation (local field enhancements) that control the most probable discharge amplitude $q$ at that site. By assumption, there is no preferred site and experimental evidence indicatcs that the physical behavior at each site is similar. This suggests that the superposition of these infinitesimal processes will yield a seemingly well behaved, predominantly unimodal probability density for the charge and this has been obscrved experimentally.

Now consider the model for a defect. The goal of this mcasurement technique is to detect an insulation flaw which is defined, for these purposes, as a complete crack through the insulation to the conductor. Partial discharge in electrode arrangements that consist of a conductor-conductor interface or conductor-dielectric interface is often more active than when the clectrodes are a diclectric-dielectric intcrface. The implication is that the partialdischarge sites at the flaws will be more active than the sitcs in the rest of the cable and consequently cause significant deviations from the ideal model.

The basic idea of the measurement technique is to identify whether the data significantly deviate from the behavior defincd by equation (1). In this case, equation (1) is modified by adding a tcrm in which $\mathrm{p}(w)$ is replaced by $\mathrm{p}(w \mid z)$

$$
\begin{aligned}
\mathrm{p}(q)= & \int_{z, w} \mathrm{p}(q \mid z, w) \mathrm{p}(z) \mathrm{p}(w) d z d w \\
& +\Sigma_{1} \int_{z, w} \mathrm{p}(q \mid z, w) \mathrm{p}\left(w \mid z_{i}\right) \mathrm{p}(z) d z
\end{aligned}
$$

where $w$ depends on $z$ and is highly localized to particular points $z_{i}$. Admittcdly, the model is a gross idcalization of the expected 


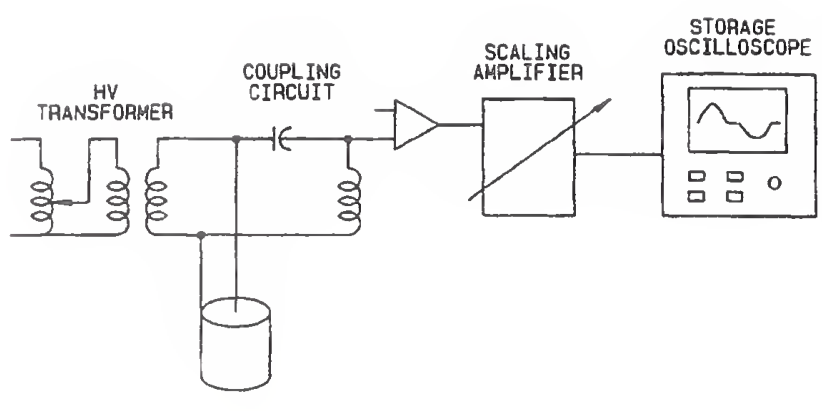

Figure 1. Block diagram of partial discharge detection and recording.

behavior, however, the general concept has merit if the defects do behave differently from the normal background partial discharge in the cable. In practice, there will be naturally occurring, preferred partial discharge sites that are not flaws but cause variations in the expected background count rates. In fact two such preferred locations have already been identified, the ends of the cable.

\section{EXPERIMENTAL APPARATUS}

The experimental apparatus implemented is a general purpose system designed for acquiring broadband partial discharge waveforms and processing the acquired signals as shown in the block diagram of Figure 1. The key elements are the high-voltage system, the coupling circuit and the data acquisition and analysis system. The high-voltage system used to apply the necessary voltages to the cables under test consists of a $60 \mathrm{~Hz}$ high-voltage transformer with appropriate noise filtering. Measurements on the cables are made at voltage levels exceeding the partial discharge inception voltage by 10,20 , and 40 percent. The inception level is defined as that voltage which causes at least one partial discharge pulse above a specified charge level $q$ per second.

The partial discharge signals are coupled from the cable under test to the measurement system through a coaxially mounted, $1 \mathrm{nF}$ capacitor. The capacitor is the first element in a high-pass filter having a lower cutoff frequency of $30 \mathrm{kHz}$ and a $1000 \Omega$ input impedance. Initial testing with sensitivities ranging down to $0.05 \mathrm{pC}$ did not produce useful results because the partial discharge magnitudes at inception are in excess of $10 \mathrm{pC}$. Since the predominant partial discharge levels are greater than $10 \mathrm{pC}$, an attenuator and input protection are included in the circuit which limits the input sensitivity to $1 \mathrm{pC}$. The capacitance of the input protection limits the bandwidth of the system to approximately $10 \mathrm{MHz}$. This input bandwidth is adequate for these experiments since the cables under test are lossy and limit the usable bandwidth to within this range. A variable attenuator is included between the input preamplifier and the gain block of the system to provide amplitude scaling which prevents saturation of the amplifier for larger partial discharge amplitudes.

Partial discharge pulses are recorded using a LeCroy $9400 \mathrm{~A}^{1}$ digital oscilloscope which has an 8-bit digitizer that can sample 32000

\footnotetext{
${ }^{1}$ The identification of commercial materials and their sources is made to describe the experiment adequately. In no case does this identification imply rcommendation by the National Institute of Standards and Technology, nor does it imply that the instrument is the best available.
}

points at a $100 \mathrm{MHz}$ rate. The advantage of using this oscilloscope is its ability to segment its $32 \mathrm{kB}$ acquisition memory so that it can acquire up to 250 separate waveforms at its maximum sampling rate before having to transfer them to a computer over an IEEE 488 interface. The computer is a PC-AT class computer. The ASYST ${ }^{1}$ scientific software package is used for acquisition control and data analysis. Up to 20000 waveforms can be collected before the available disk space limits the computer's ability to process the data; typically 5000 waveforms are collected. Active data collection occurrs only during a few seconds of the voltage application to the cable under test, however, voltage is typically applied for 8 minutes since the high voltage system is not under control of the computer and time is needed to archive the data. Since the system uses a computer with only moderate computational ability, all processing has to be performed off line.

\section{MEASUREMENTS}

Two fundamental estimates are made from each recorded waveform: an estimate of the charge, and an estimate of the location of the partial discharge site in the cable. It would be desirable to calculate estimates for all detectable pulses; however, since the measurcment system is gencral purpose, trade-offs for cost, speed, and data handling capabilities liave been made. With these constraints, only a limited number of waveforms can bc collected and analyzed.

The method used to calculate the charge in the partial discharge waveform is the same as that used in [4] and has been shown to be more accurate than the usual measurement of the peak value of the pulse. The technique uses the pulse energy derived from the waveform to develop an estimate of the charge and assumes that the measured partial discharge waveform is similar to calibration pulses injected into the cable. The calibration pulses are generated by applying a fast-rise step of known amplitude through a known capacitance into the cable under test. Further corrections in the estimates to account for the cable attenuation were not decmed necessary.

If the flaw is detectable, then the histogram of the charge will no longer be unimodal. Using this fact, the measurement can be enhanced by setting a lower discrimination level so that the instrument measures only those partial discharges which appear to be anomalous. The lower discrimination level is also referred to as the trigger level, the level which the partial discharge pulse must exceed to initiate the recording cycle of the digital oscilloscope.

The basic principle used to determine the location of the partial discharge can be understood by referring to Figure 2. When a partial discharge pulse originates at some point interior to a cable it splits evenly into two pulses which travel in opposite directions. One pulse, referred to as the direct pulse, proceeds toward the detector end arriving at time $t_{1}$. The other pulse proceeds toward the open end of the cable and is reflected from the open circuit back toward the detector end, arriving at the detector at time $t_{2}$. Knowing the velocity of propagation, $v$, for the cable, the location, $\ell$, is given by

$$
\ell=\frac{v\left(t_{2}-t_{1}\right)}{2}
$$

where the location is referenced from the open circuit end of the cable.

To save time in processing, a simple but accurate method is used to calculate the locations. The technique applies an approximate matched filter to the recorded pulses whose shape resembles a 


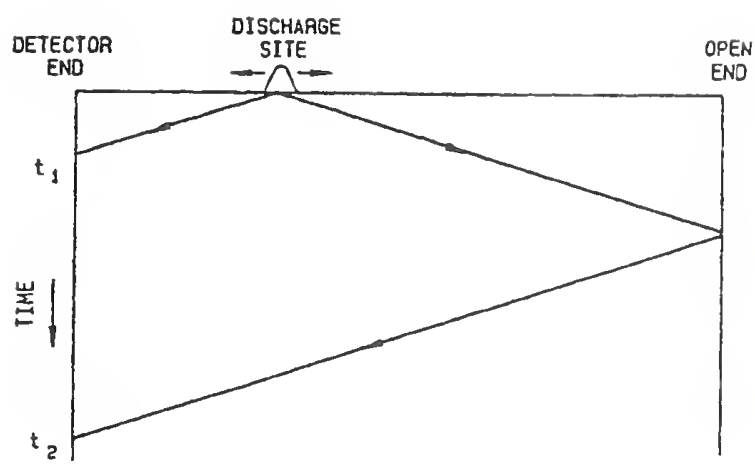

Figure 2. Position versus time diagram of direct pulse and reflected pulse propagation.

partial discharge pulse. In effect, this assumed pulse is crosscorrelated with the pulses in the measured data. The time delay between the two largest pulses in the waveform is determined and converted into a location using a measured propagation velocity. More accurate delay estimators are not justified since the increased computational effort does not provide enough increase in accuracy. When the two largest pulses in the data record are from two distinct discharge sites, the estimate is referred to as a phantom delay. The probability of calculating a phantom delay is small at the voltage levels used, with less than 1 percent of the estimates being phantoms. These phantoms are not a problem since the time delay between the pulses is random and does not lead to a count rate that favors any particular site. A limitation of this technique is the existence of a measurement blind spot in the cable: when the arrival times of the direct pulse and reflected pulse are nearly the same, it becomes difficult to differentiate between a single pulse and two closely spaced pulses. Without special, computationally intensive processing, these sites all appear to be at a distance range near the end of the cable, in effect creating a blind spot.

\section{TEST RESULTS}

In this case, the measurement technique is intended for use in situ on $600 \mathrm{~V}$ class nuclear power plant cables and so representative cable types were used in the experiments. These cables can be grouped into three categories: shielded cables, unshielded multiconductor cables, and unshielded single conductor cables. The following samples were used in a series of experiments:

- An unaged, unshielded, two conductor, \#14 AWG, 600 V class, neoprene jacketed cable of the same type used for control cabling in nuclear power plants.

- An unaged, 50 ohm, coaxial cable of the same type used for instrumentation cabling in nuclear power plants.

- An aged, unshielded, 15 conductor, \#18 AWG cable of the same type used for instrumentation cabling in nuclear power plants.

No experiments were conducted on unshielded single conductor cables since the techniques to be discussed require that the cable have some transmission line properties; a single conductor, in the absence of ground plane, does not.
Vertical:

Number of pairs

counted per bin of

the histogram

Horizontal:

Distance in feet

from the open end

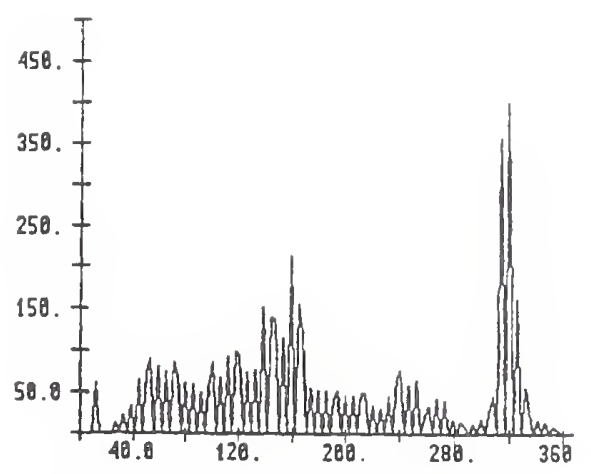

Note the scattering of counts over the length of the cable

Figure 3. Histogram of delay times between the two major pulses in each event of a 5000-element record containing true pairs and random pairs.

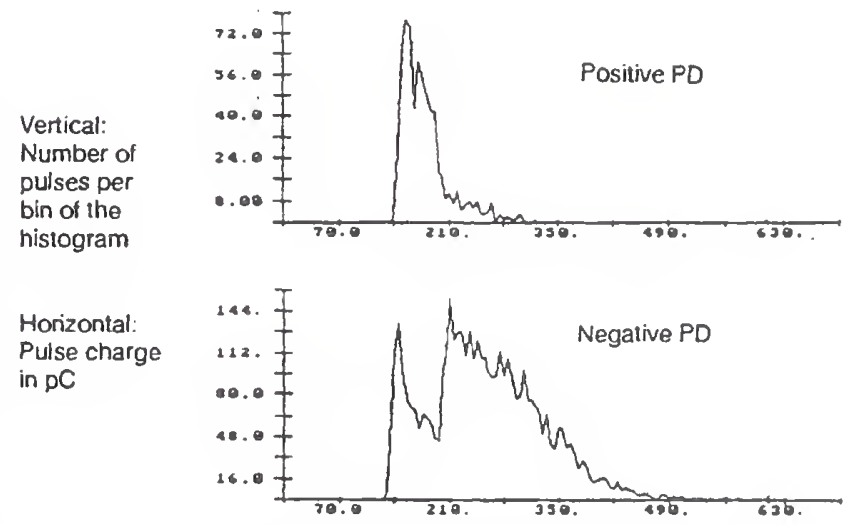

Figure 4. Histogram of the distribution of partial discharge pulses (PD) as a function of their charge transfer magnitude ("pulse height").

Tests were performed on $100-\mathrm{m}$ ( $330 \mathrm{ft}$ ) length of unaged, twoconductor cable with artificial defects introduced at three locations. A small portion of the jacket was removed at three locations and the insulation was carefully pierced through to the conductor using a \#60 twist drill in two of the locations; a small razor knife was used to slit the wire insulation in the third. In neither case was any of the insulation removed; only a break was created from the conductor surface to the surrounding atmosphere. The partial discharge inception voltage of the cable was $4500 \mathrm{~V}$ and measurements were made at voltages levels 10,20 , and 40 percent above inception. With a small lower discrimination level, the low-level background partial discharges have dominant count rates indicating that the partial discharges are distributed along the length of the cable as shown in Figure 3. If the lower discrimination level is increased, then the count rates of the partial discharges from the defect sites dominate the background count rate as indicated by the charge histograms of figure 4; note that the histograms are not unimodal. The locations of the individual damage sites were found using those delay values which corresponded to data near the peaks of the charge histograms. Each of the damage sites was correctly identified as can be seen in figures 5,6 and 7. Other measurements were made on a $20 \mathrm{~m}$ ( $66 \mathrm{ft}$ ) length of coaxial cable with artificial damage inflicted by slightly abrading the shield. The partial discharge inception voltage was $5200 \mathrm{~V}$. In this case, the defect was immediately 


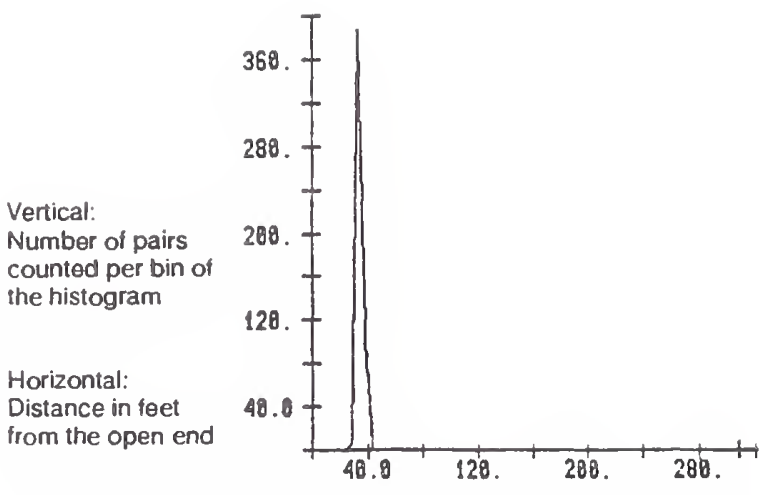

Note the emergence of a defect signal at 70.2 feet, location of an actual defect.

Figure 5. Histogram of time delays for $5000 \mathrm{~V}$ and pruned data.

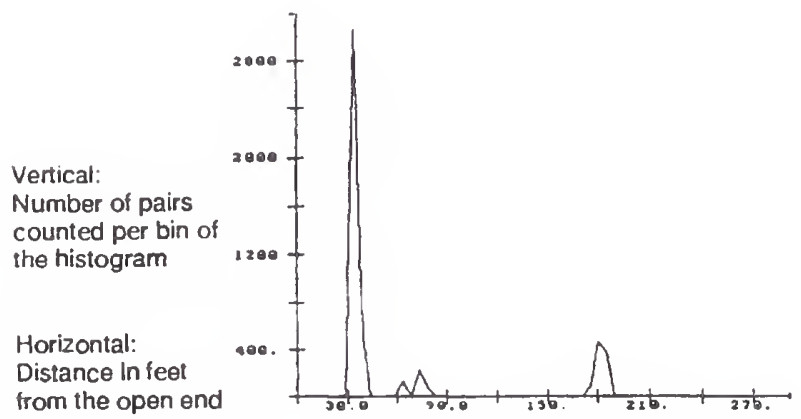

Note the emergence of a defect signal at 34 feet (actual defect). with minor indications at 70 feet (already detected in Figure 5). and at 178 feet (no known defect at that point).

Figure 6. Histogram of time delays at $5200 \mathrm{~V}$ and pruned data.

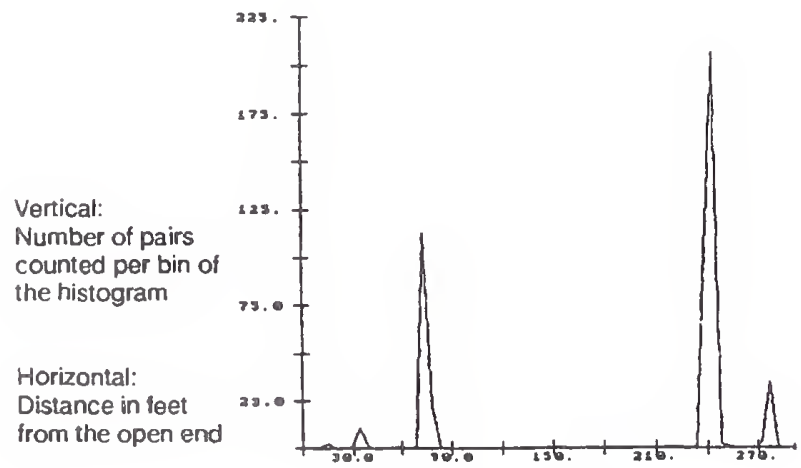

Note the emergence of a defect signal at 240 feet (actual defect), with substantial signal at 70 feet (already detected in Figure 6). small signal at 34 feet (as in Figure 5), and new signal at 280 feet.

Figure 7. Histogram of time delays at $6000 \mathrm{~V}$ and pruned data. identifed because the partial discharge activity at the damage site was much greater than the background partial discharges. Similar results were also obtained while measuring a $12-\mathrm{m}(40 \mathrm{ft})$ length of aged multiconductor cable containing an artificial defect. The artificial defect was created by piercing the insulation on one of the 15 conductors with a small razor knife, similar to the slit described above. The partial discharge inception voltage was $2300 \mathrm{~V}$. Similar to the previous case, the partial discharge activity at the damage site was greater than the background of the rest of the cable allowing easy identification of the flaw.

\section{CONCLUSIONS}

The test method based on partial discharge detection using signal processing makes possible the identification and location of insulation breaches, undetectable under normal service conditions, that may become a fault under additional environmental stresses, or may progress into a fault under further aging.

Tests performed on three representative types of low-voltage cables have demonstrated that the method can differentiate between signals emanating at incipient defect sites and the background of partial discharges occurring over the length of the cable.

In order to induce partial discharges, the test voltage must clearly be raised above the inception voltage. Depending on the cable structure, this test voltage will be on the order of a few thousand volts, a subject of possible concern, but not a fatal limitation for a test method offering the reward of definite identification of defects that could become fault locations.

The demonstration was obtained with a general-purpose PC-type computer, using a commercial software package augmented by moderately complex custom-designed software. In a more dedicated system, with further software enhancement, additional benefits are possible, such as the detection of incipient defects with only brief exposure of the insulation to the test voltage, automated scanning of the data for most significant content, and optimization of the test procedure into an expert system approach.

\section{ACKNOWLEDGEMENTS}

The authors acknowledge the contributions of S. Clevenger and D.R. Flach in the development and implementation of the menudriven software used in the application of the principle of the method. The signal processing concepts were developed by J.P. Steiner as described in Reference 4 and implemented prior to his new position with Biddle Instruments. The implementation and demonstration tests were performed by J.P. Steiner and F.D. Martzloff with funding provided by the USNRC Nuclear Plant Aging Research Program.

\section{REFERENCES}

[1] IEEE Std 383-1974 Standard for Type Test of Class IE Electrical Cables, Field Splices, and Connection for Nuclear Power Generating Stations.

[2] Proceedings: Workshop on Power Plant Cable Condition Monitoring EPRI EL/NP/CS-5914-5R, July 1988.

[3] Snyder, D.L., Random Point Processes, John Wiley and Sons, New York NY, 1975.

[4] Steiner, J.P. "Digital Measurement of Partial Discharge", Ph.D. Theoic, Purdue University, W. Lafayette IN, May 1988.

[5] Steiner, J.P., Weeks, W.L. and Furgason, E.S., "Digital Estimation of Partial Discharge", 1987 Annual Report, Conference on Electrical Insulation and Dielectric Phenomena, Gaithersburg MD, October 1987. 


\title{
Diverting Surges to Ground: Expectations versus Reality
}

\author{
François D. Martzloff \\ National Institute of Standards and Technology \\ Gaithersburg MD \\ f.martzloff@ieee.org
}

Reprinted from Proceedings, Open Forum on Surge Protection Application, NISTIR-4654, August 1991

\section{Significance}

Part 4 - Propagation and coupling of surges

A misconception is sometimes encountered, that surges can be eliminated by sending them on a one-way trip to "ground" in a manner similar to leftovers that disappear in the kitchen sink disposall, never to be seen again. Unfortunately, electricity travels along closed loops, and no special SPD configuration nor amount of "grounding" - be it 'dedicated', isolated', 'separated', 'delayed', or otherwise - can dispose of unwanted electrons. Sending them down the drain of a grounding conductor only makes them reappear within a microsecond about 200 meters away on some other conductor.

This paper presents a brief review of some of the fallacies, with illustrative measurement results, and proposes two approaches for remedy, rather than counterproductive grounding practices based on misconceptions. 


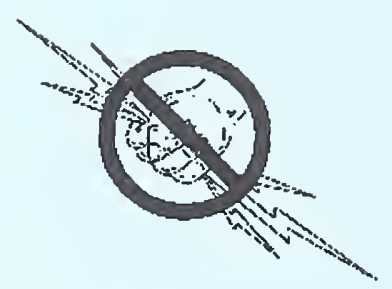




\title{
Diverting Surges to Ground: Expectations versus Reality \\ François D. Martzloff \\ National Institute of Standards and Technology
}

\begin{abstract}
Preamble - A misconception is sometimes encountered, that surges can be eliminated by sending them on a one-way trip to "ground" in a manner similar to leftovers that disappear in the kitchen sink disposall, never to be seen again. Unfortunately, electricity travels on closed loops, and no amount of "grounding" - be it dedicated, isolated, separated, or otherwise - can dispose of unwanted electrons. Sending them down the drain of a grounding conductor makes them reappear in a microsecond about 200 meters away on some other conductor. The cycle for the waste through the environment takes longer, giving the illusion of disposal (at least as seen from the point of view of the kitchen sink - from the global point of view, one should take a different view, but that is another story). This paper presents a brief review of some of the fallacies, with illustrative measurement results, and proposes two approaches for remedy, rather than counterproductive grounding practices based on misconceptions.
\end{abstract}

\section{SURGE PROTECTION SCHEMES}

The usual method of providing surge protection involves diverting the surge current into some low-impedance path, so that the voltage drop resulting from the flow of the surge current through the diverter will produce only a small fraction of the voltage that would appear if no diversion were provided. This diversion can be performed by devices acting as a "crowbar" or as a "clamp." Another method of providing surge suppression involves attempting to block propagation of the surge, for instance with a low-pass filter. This method, however, would not succeed with the filter alone because the typical surge is originating from a current source so that an attempt to prevent the current flow would mean a very high voltage across the filter input components. As a second stage, a filter will work if another means is provided for diverting the surge before it reaches the filter (Figure 1). This approach is sometimes implemented in a single packaged device; another possible implementation is the "cascade" arrangement [1], [2], [3], [4] where a high-energy surge arrester is provided at the service entrance of the building to effect diversion of the surge before it would enter the building and propagate down the branch circuits.

A surge having the capability of delivering substantial currents and propagating down the branch circuits will result in large voltages at the end of the branch. Depending upon the relative values of the time for the surge to travel the length of the branch, and the duration of the surge, the propagation can be described in terms of traveling waves (surges shorter than the travel time) or in terms of a circuit analysis with lumped $L, R$, and $C$ components (surges longer than the travel time) [5]. In the absence of a diverter at the service entrance, users can protect their connected equipment by installing a readily available plug-in protective device at the end of the branch circuit, that will divert the surge from the line conductor to the neutral conductor or to the equipment grounding conductor, or both. 
Figure 2 shows the configuration of the conductors of a branch circuit extending from the service entrance panel to a receptacle at the end of the branch: $L$ and $N$ are the two currentcarrying conductors, EG is the equipment grounding conductor, and LG is the "local ground" which can be building steel, piping, ducts, or the equipment grounding conductor of another outlet connected to another branch circuit. In Figure 2a, a plug-in surge suppressor is connected between line and neutral; in Figure 2b, a generic-type filter is plugged in the receptacle. Both types of devices at the end of the branch circuit will effectively limit the surge voltage between the line and neutral conductors, the two conductors feeding the power input components of the (sensitive) equipment. However, the surge current 'returning to ground' in the neutral conductor $\mathrm{N}$ will produce an inductive voltage drop along this conductor. With respect to the equipment grounding conductor EG at that point, a voltage will appear that can be magnified by the traveling wave effect of the branch circuit for the short inductive spike in the neutral conductor [6]. If the surge-protective device arrangement involves a path by way of the equipment grounding conductor (most electronic equipment, even if not provided with a built-in surge protector, have an EMI filter containing capacitors connected line-to-ground), then a voltage will be developed between the end of the equipment grounding conductor EG and other local grounded points at the potential of LG.

When a system is made of several pieces of equipment that are powered from such separate branch circuits, their respective chassis which are connected to their own equipment grounding conductors will be at different potentials at the instant a surge occurs on one branch circuit, but not the other. A data transmission link between the elements of the system typically has its reference connected to the equipment chassis. Thus, the data link becomes involved in attempts to equalize the potential between the two chassis, and may fail in the process. This scenario is well recognized [7]. Thus, protecting the power port of the equipment transfers the problem to the data port: the surge did not disappear!

\section{CLAMPING OR FILTERING PROTECTION}

In an attempt to overcome this problem, an alternate approach has been proposed whereby the protection would be obtained by a filter action rather than a diverter action. The expectation is that the filtering action would not involve the flow of current in the surge return path that was found to be the cause of the data link problem. However, even the filter, in order to provide the necessary closed-loop path for the surge current, has to accept the surge current at the rate which is imposed by the surge source. On the output side of the filter, the let-through voltage may well be very low, but on the input side, current will flow. If this filter is installed at the end of a branch circuit, the same effects of developing potential differences among grounded elements should be expected in the final analysis, a disappointing result in view of the hoped-for elimination of the data link problem.

The situation is illustrated by a series of simple laboratory experiments where a 30-meter length of three-conductor wire was used to simulate a branch circuit. Surges were injected at one end, and the effects of connecting surge-protective devices at the other end were observed by measuring the voltages between several combinations among the neutral conductor, the equipment grounding conductor, and the local building ground. Figure 3 shows a $0.5 \mu \mathrm{s}-100$ $\mathrm{kHz}$ Ring Wave [8] with 3-kV peak applied at the origin of the branch circuit (Figure 3a) and the $4.2-\mathrm{kV}$ surge arriving at the other end (Figure $3 \mathrm{~b}$ ). 
Note that the first peak of the surge is higher at the end than at the origin, illustrating the enhancement of the traveling wave arriving at the open end of the transmission line. Figures 4 and 5 show the effects, desirable and undesirable, of connecting a clamp-type device at the end of the branch in an attempt to limit the line-to-neutral surge voltage.

Figure 4a shows the desired effect, that is, clamping of the Ring Wave at about $400 \mathrm{~V}$ between line and neutral conductors (L-N). Figure $4 \mathrm{~b}$ shows the classic side-effect, a spike of $1300 \mathrm{~V}$ between the neutral conductor and the equipment grounding conductor (N-EG), occurring during the fast rise of the Ring Wave. Figure 5a shows the voltage between the neutral conductor and the local ground (N-LG), still a $1300-\mathrm{V}$ spike. Figure $5 \mathrm{~b}$ shows the voltage between the equipment grounding conductor and the local ground (EG-LG). The voltage of Figure $5 \mathrm{~b}$ is a burst of $80-\mathrm{V}$ oscillations that could be damaging to a data link connecting two pieces of equipment, each with its own signal reference but separated by this difference of potential.

With a filter-type device installed at the end of the branch, the voltages shown in Figure 6 and Figure 7 were observed. Figure 6a shows the voltage between the neutral conductor and the local ground (N-LG), a 1100-V spike similar to that produced by the clamp in Figure 5a. Figure $6 \mathrm{~b}$ shows the voltage between equipment grounding conductor and the local ground (EGLG), with a brief oscillation and peak of about $500 \mathrm{~V}$, significantly higher than the $80-\mathrm{V}$ burst of Figure 5b. Figure 7 shows a simultaneous recording of the initial part of the surge event: current in the line conductor, upstream from the filter (upper trace), and line-neutral voltage ( $L$ N) at the output of the filter (lower trace), which is essentially free from significant overvoltage. Note in Figure 7 the 70-A peak current in the line conductor, with a rise time of $400 \mathrm{~ns}$ (about $170 \mathrm{~A} / \mu \mathrm{s}$ ) which has to be returned by way of the neutral. Figure 8, in a similar manner for the case of a clamp, shows the 120-A peak current in the line conductor, with a rise time of 700 ns (probably by happenstance, also about $170 \mathrm{~A} / \mu \mathrm{s}$ ). Thus, both approaches involve a return current path with substantial rates of current change, which are at the root of the ground differential side-effect.

Two possible methods (and perhaps more, still to be developed) can overcome the problem. The first is to avoid the problem altogether by not allowing large surges to enter the building. This desirable situation can be obtained by providing a suitable surge arrester at the service entrance. While earlier proposals to recommend or even to mandate such installation by means of the National Electrical Code have not been accepted by the Code Panels, growing recognition of the benefits may eventually lead to a more general application of this method. Of course, proper coordination, as discussed in Refs [2]-[4] will have to be implemented. With the high-current surges effectively diverted before they enter the building, there is still room for an effective application of surge-protective devices at inside receptacles, to deal with the (low-energy) surges generated within the building by normal and abnormal operation of the array of diverse equipment installed in the building.

The second approach, available to users who do not have the opportunity or means to install an arrester at the service entrance, is to provide a combined surge protection that covers both the power port and the communication port of the equipment to be protected. Dubbed 'local ground window' [9], this approach consists in routing both the power cord and the communication line (telephone, cable TV, RS232 link) through a single 'window', with any protective device on either line diverting any surge through the same path. 
Thus, regardless of the length of that path, both ports are kept at the same potential, correcting the root problem of potential differences. These local ground windows are now becoming available from many sources; however, no generic standards have yet been developed to evaluate their effectiveness. The electric utility industry is attempting to develop 'performance criteria' that will help in the process. The author invites comments and inquiries on the development of these criteria, an objective of this Open Forum.

\section{CONCLUSIONS}

1. Effective protection against surges unavoidably requires diversion of the surge through a closed-loop path, which can involve two or more branch circuit conductors if the surgeprotective device is installed at the end of a branch circuit.

2. While the main function of the device, limiting overvoltages between line and neutral, is accomplished, the returm path for the surge current will produce differences of potential among the conductive parts at the end of the branch circuit, differences that can be damaging to certain components of connected equipment.

3. A more effective protection scheme is to divert the surges at the service entrance, rather than allow them to flow in the branch circuits. This cascading of a device at the service entrance and one at the end of branch circuit (the latter still necessary for protection against internally-generated surges) needs appropriate coordination.

4. Users who do not have control over their facility to the extent of providing a service entrance arrester may obtain relief and avoid side effects by applying a combined 'local ground window' to both the power port and communication port of their equipment.

\section{REFERENCES}

[1] Martzloff, F.D., Coordination of Surge Protectors in Low-Voltage AC Power Circuits, IEEE Transactions PAS-99, Ian/Feb 1980, pp 129-133.

[2] Standler, R.B. Coordination of Surge Arresters and Suppressors for use on Low-Voltage Mains, Proceedings, Zurich EMC Symposium, 1991.

[3] J.S. Lai, Coordination of Cascaded Surge-Protection Devices, Proceedings, Open Forum on Surge Protection Application, 1991.

[4] Striagfellow, M., Measurement and simulation of coordination between service-entrance and internal arresters, Proceedings, Open Forum on Surge Protection Application, 1991.

[5] Martzloff, F.D., The propagation and attenuation of surge voltages in low-voltage ac power circuits, IIEEE Transactions PAS-102, May 1983, pp 1163-1170.

16] Martzloff, F.D. and Gauper, H.A., Surge and bigh-frequency propagation in industrial power lines, IEEE Transactions LA-22, July 1986, pp 634-640.

[7] Martzloff, F.D., Coupling, propagation, and side-effects of surges in an industrial building wiring system, IEEE Transactions LA-26, March 1990, pp 193-203.

[8] ANSI/IEEE C62.41-1991, Recommended Practice on Surge Volsages in Low-Volsage AC Power Circuirs.

[9] Martzloff, F.D., Protecting computer systems against power transients, IEEE Spectrum, April 1990, pp $37-40$. 


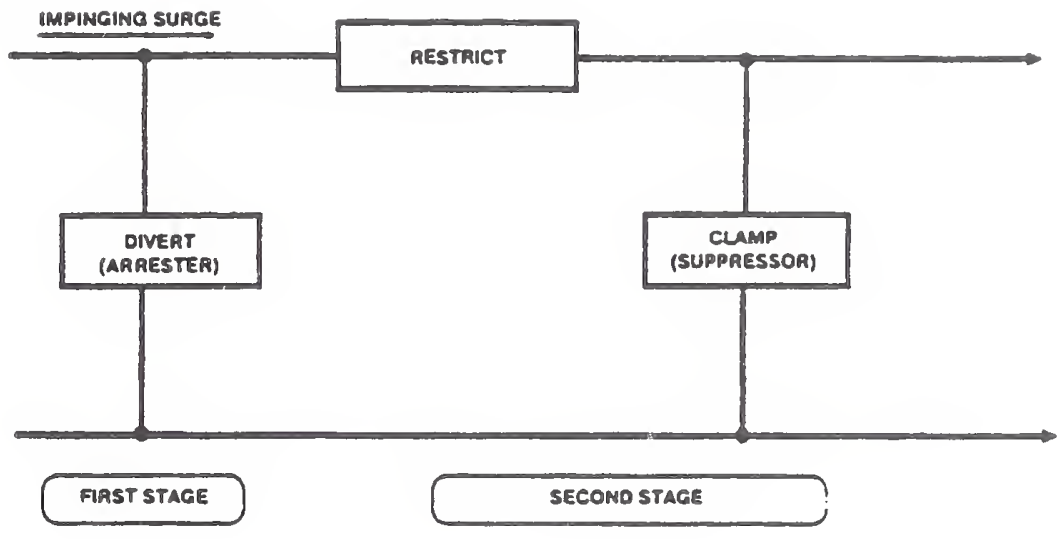

Figure 1

Basic approach for two-stage protection schemes

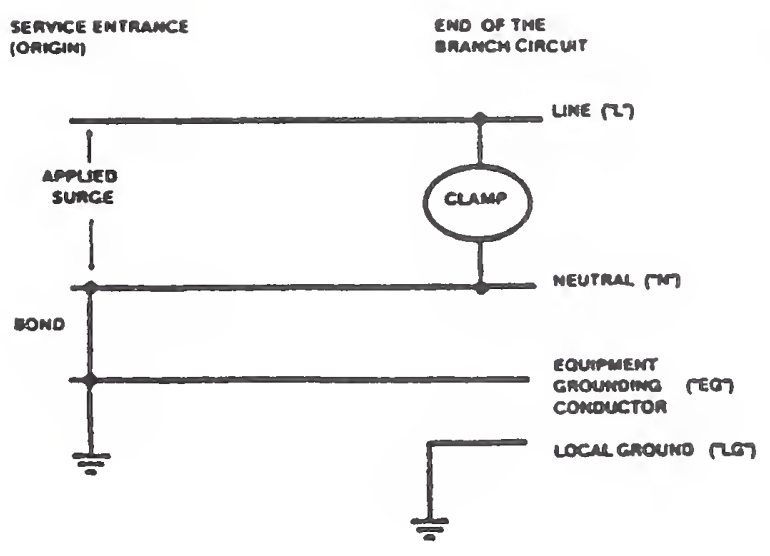

(a) Clamp-type suppressor

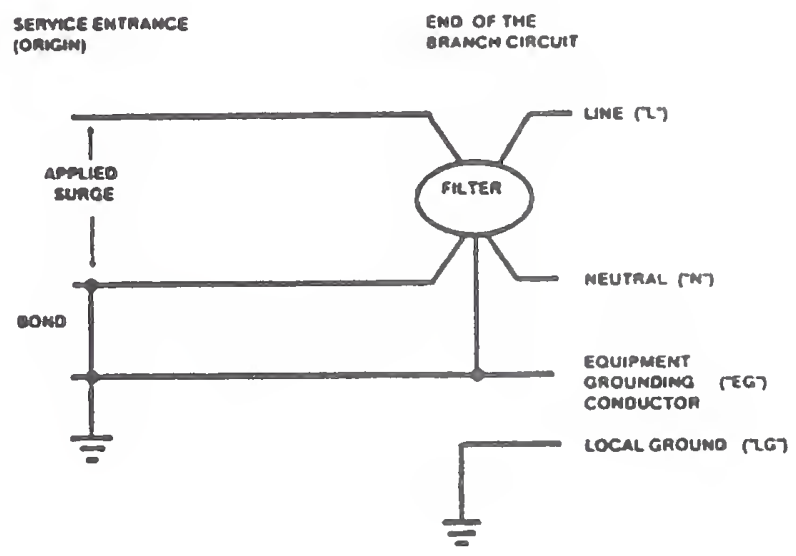

(b) Filter-type suppressor

Figure 2

Configuration of branch circuit conductors and suppressors 


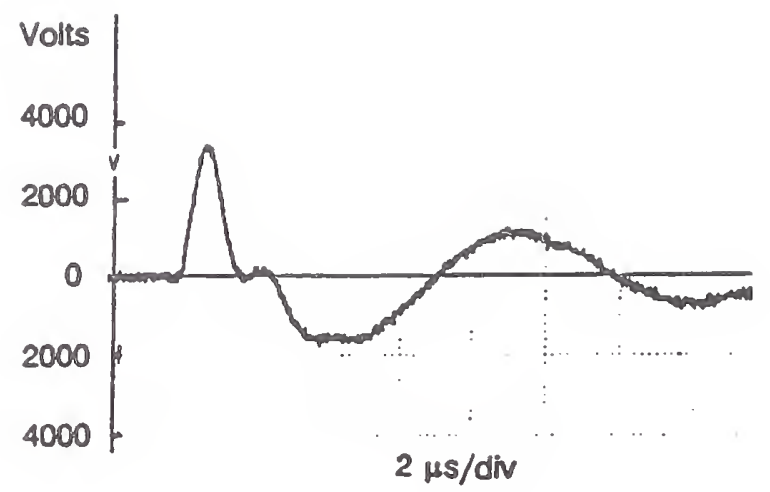

(a) At origin

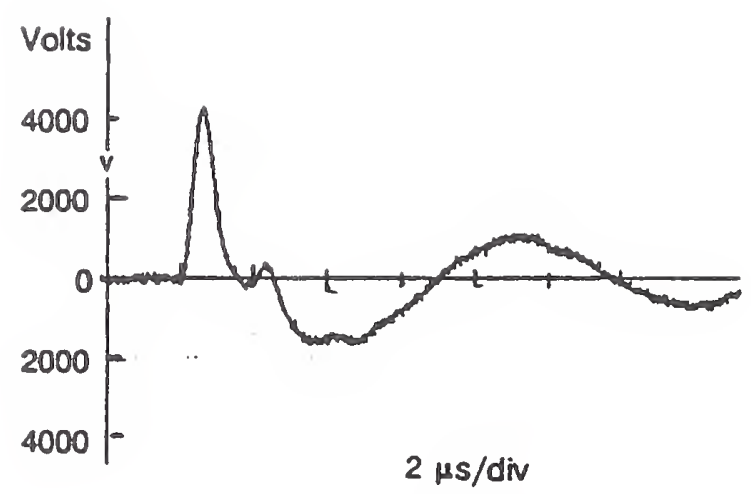

(b) At end of branch

Figure 3

Voltages at origin and at end of $30-\mathrm{m}$ branch circuit, with a 3-kV Ring Wave applied between the line and neutral conductors

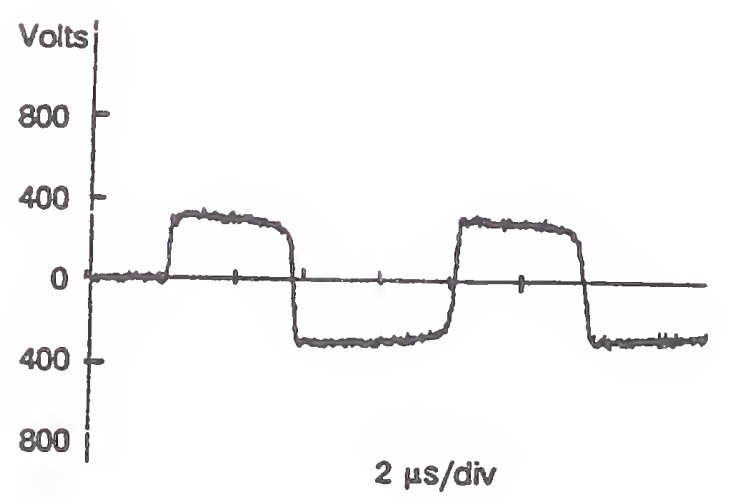

(a) L-N Voltage

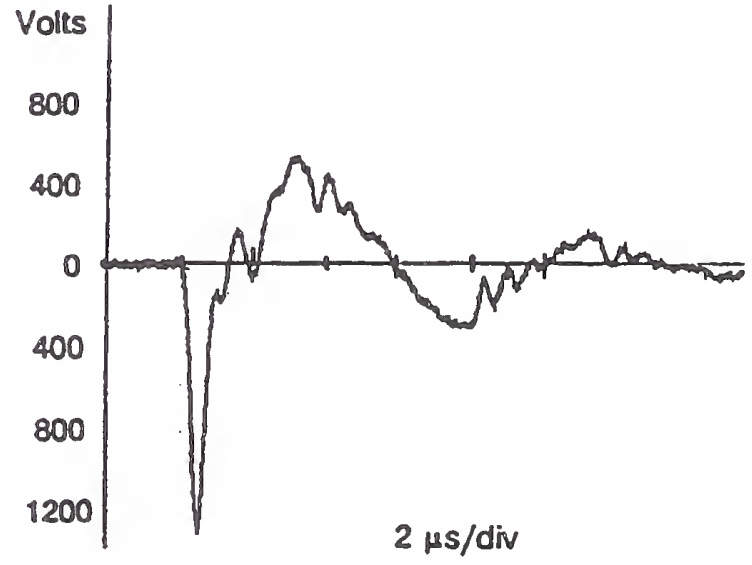

(b) N-EG Voltage

Figure 4

Voltages between lime and neutral conductors (L-N)

and between meutral and equipment grounding conductors (N-EG)

at end of branch, with single varistor connected between line and neutral conductors 


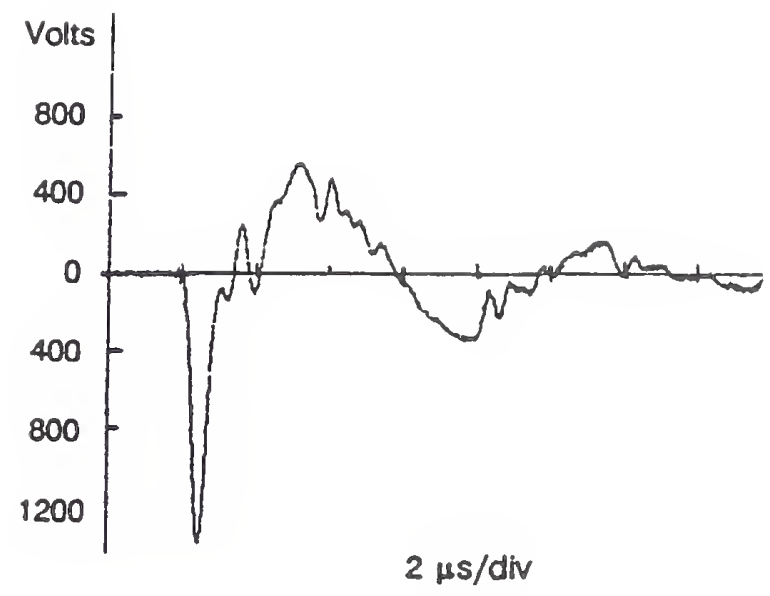

(a) $\mathrm{N}-\mathrm{LG}$

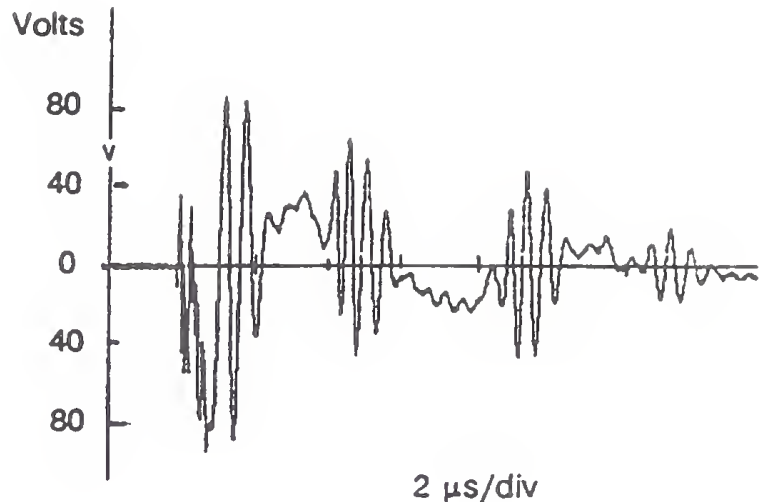

(b) EG-LG

Figure 5

Voltages between neutral and local ground (N-LG) and between equipment grounding conductor and local ground (EG-LG) at end of branch, with single varistor connected between line and neutral conductors

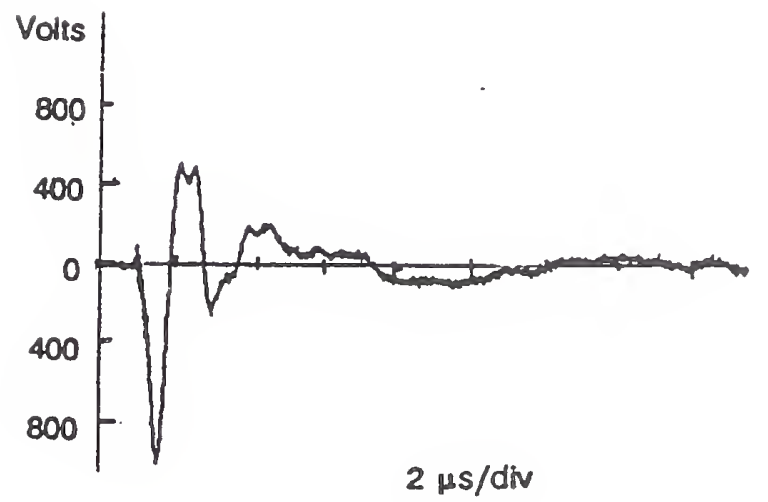

(a) N-LG

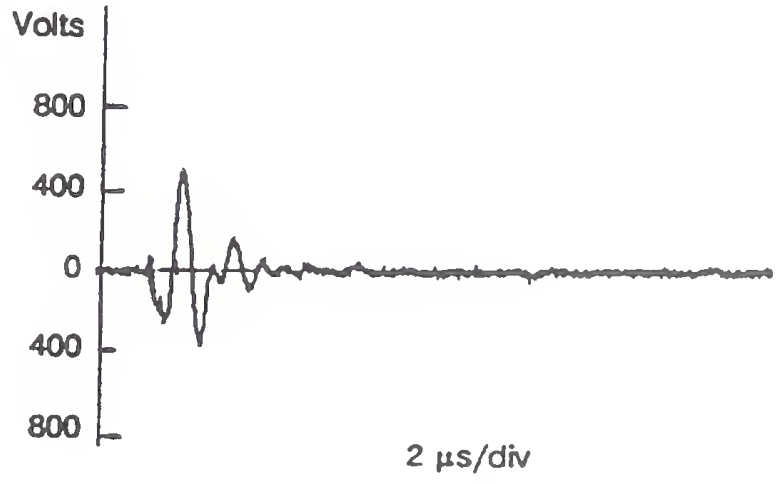

(b) EG-LG

Figure 6

Voltages between neutral and local ground (N-LG) and between equipment grounding conductor and local ground (EG-LG) at end of branch, with filter-type suppressor connected at end of branch 


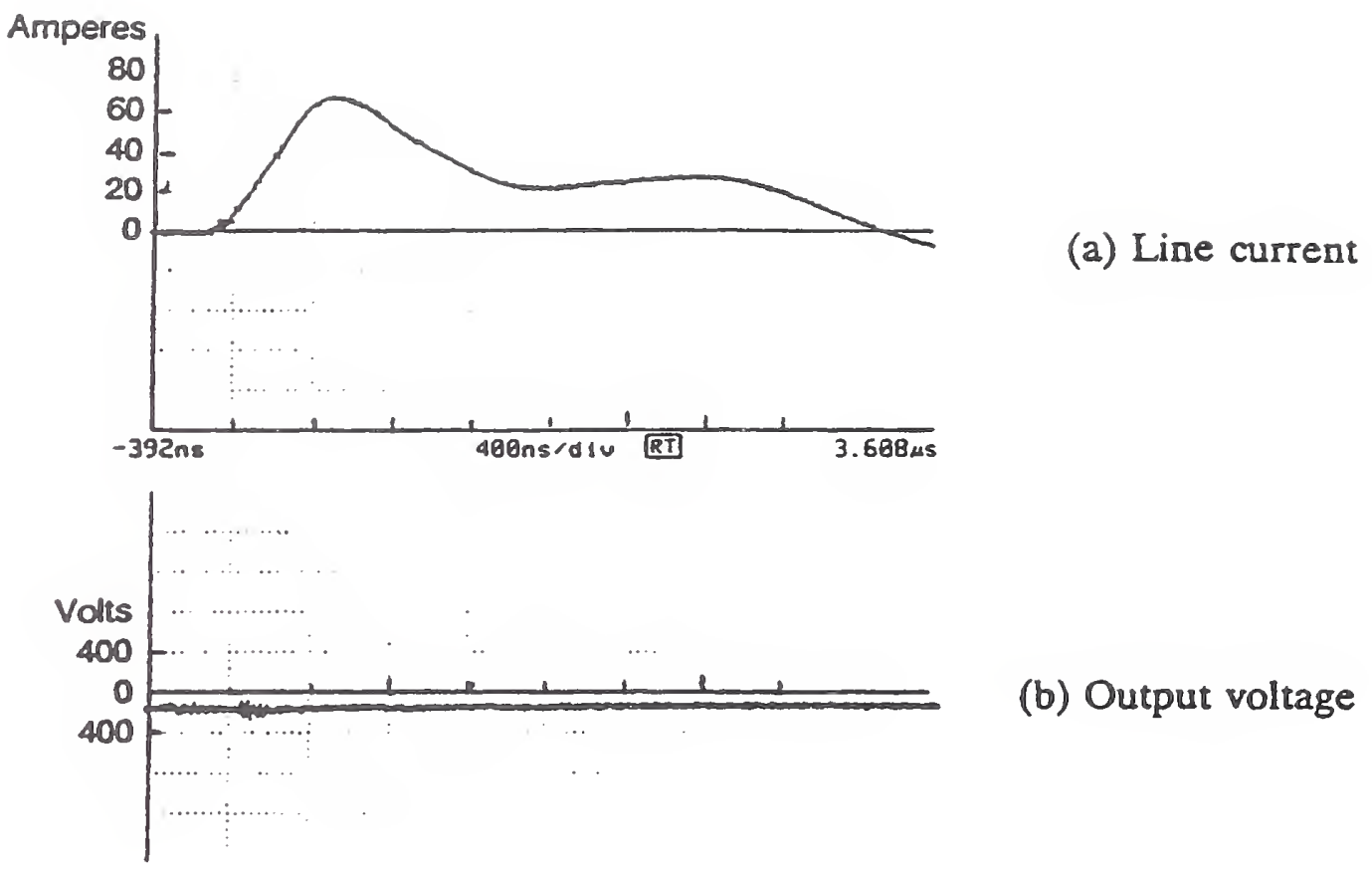

Figure 7

Current in line conductor upstream of filter and voltage output of the filter (synchronous traces) with filter-type suppressor connected at end of $30-\mathrm{m}$ branch

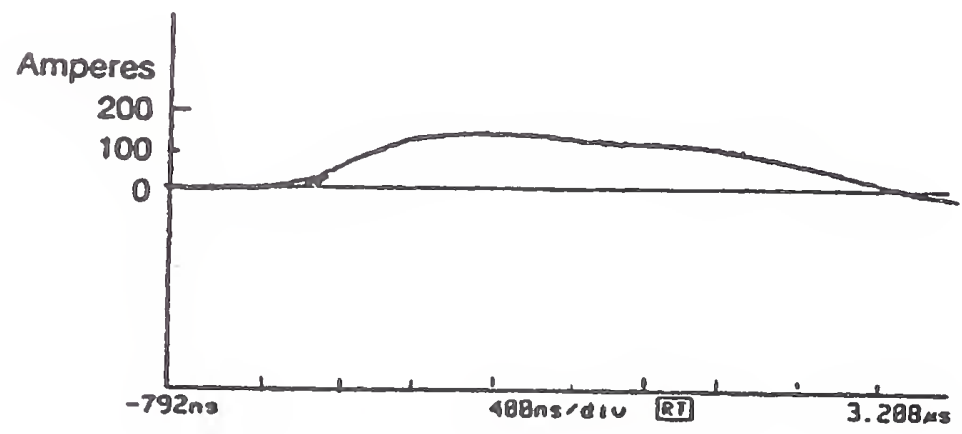

Figure 8

Current in line conductor upstream of varistor, with varistor connected between line and neutral at end of 30-m branch 


\title{
On the Propagation of Old and New Surges
}

\author{
François D. Martzloff \\ National Institute of Standards and Technology \\ Gaithersburg MD \\ f.martzloff@ieee.org
}

Reprinted from Proceedings, Open Forum on Surge Protection Application, NISTIR-4654, August 1991

\section{Significance \\ Part 4 - Propagation and coupling of surges}

The 1991 revision of the IEEE Recommended Practice on Surge Voltages C62.41 introduced a new generation of surge waveforms; how they travel in low-voltage power systems will affect some of the earlier tenets on surge propagation characteristics. The emergence of cascaded surge-protective devices also raised a new set of concerns in which propagation characteristics play an important role, where system designers rely on the inherent impedance of the wiring between the two devices to provide the electrical separation necessary to obtain coordination.

During the development of the revised IEEE Recommended Practice in the late eighties, some reluctance was encountered in deleting the mention of wire diameter for the branch circuits. The wire size was included in the definition of the 'Location Categories' given in the 1980 version of the IEEE Std 587 Guide

The paper presents a review the propagation characteristics of the old and the new generation of surges waveforms encountered in low-voltage ac power systems. To complement information developed on this subject over the last ten years, measurements results are reported for the new 10/1000 $\mu$ s waveform, and the effect (or, rather, the lack of significant effect) of wire diameter is documented by a simple experimental demonstration. 


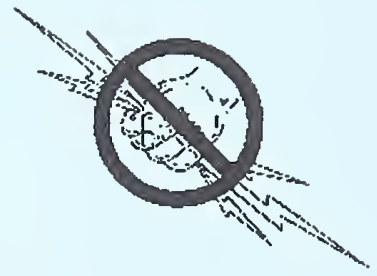




\title{
On the Propagation of Old and New Surges
}

\author{
François D. Martzloff \\ National Institute of Standards and Technology
}

\section{INTRODUCTION}

The revised IEEE Recommended Practice on Surge Voltages [1] has introduced a new generation of surge waveforms; how they travel in low-voltage power systems will affect some of the earlier tenets on surge propagation characteristics. The recent emergence of cascaded surge-protective devices [2], [3], [4], [5], raises a new set of concerns in which propagation characteristics play an important role. Until recently, the application of surgeprotective devices was primarily based on the tenet that the classical $8 / 20 \mu \mathrm{s}$ current waveform presents the most severe stress to the device. Whenever two devices were to be installed in a system with one device at the service entrance and one further into the building (the so-called cascade connection), system designers had relied on the inherent impedance of the wiring between the two devices to provide the electrical separation necessary to obtain coordination.

During the development of the revised IEEE Recommended Practice, some reluctance was encountered in deleting the mention of wire diameter for the branch circuits. The wire size was included in the definition of the 'Location Categories' given in the 1980 version of the IEEE Guide [6].

The objective of this paper is to review the propagation characteristics of the old and the new generation of surges waveforms encountered in low-voltage ac power systems. To complement information developed on this subject over the last ten years, measurements results are reported for the new $10 / 1000 \mu \mathrm{s}$ waveform, and the effect (or, rather, the lack of effect) of wire diameter is documented by a simple experimental demonstration.

\section{THE PROPAGATION OF SURGES - OLD AND NEW WAVEFORMS}

Users of the new Recommended Practice now face the need to consider five representative surge waveforms. This section presents a summary of the propagation characteristics, with relevant references. These characteristics should be kept in mind during the discussions at this Forum.

\section{The $100 \mathrm{kHz}$ Ring Wave}

The short duration of the first half-cycle of this waveform ( $0.5 \mu$ s rise time, compared to the travel time in a typical building) produces a propagation characteristic similar to that of traveling waves in transmission lines: reflections at impedance mismatches, and peak enhancement at unloaded (or lightly loaded) ends of lines [7], [8]. The subsequent oscillations at $100 \mathrm{kHz}$ do not present these characteristics. For shorter lines $(30 \mathrm{~m}$ or less), the inductance of the wiring is the dominant factor in the propagation. 


\section{The $1.2 / 50 \mu s-8 / 20 \mu s$ Combination Wave}

The relatively slow rise time of the voltage waveform, $1.2 \mu \mathrm{s}$, is long compared to the travel time in building wiring systems ( $200 \mathrm{~m} / \mu$ s propagation speed). Reflections die down during the rise time, so that there is no enhancement of the peaks (nor attenuation) at the open ends of the branch circuits [9]. The dominant parameter is the inductance of the wire. At the equivalent frequency of the $8 \mu$ s rise time of the current, typical wiring offers an impedance of about 0.2 $\Omega / \mathrm{m}$. Thus, a substantial driving voltage would be necessary to force a full $3 \mathrm{kA}$ crest surge in a long branch circuit. The sparkover of wiring devices (or of a [gap + silicon carbide] arrester at the service entrance) will limit the driving voltage so that large $8 / 20 \mu$ s current surges are not expected in long branch circuits [10]. This conclusion had been at the root of the cascade coordination studies performed until recently.

\section{The $\mathbf{5 / 5 0}$ ns burst of the Electrical Fast Transient (EFT)}

This test waveform was initially developed in the IEC community for revealing any deficiency in the electromagnetic compatibility (susceptibility) of electronic equipment. The new IEEE Recommended Practice has endorsed the EFT as an 'Additional Waveform' to be considered. The fast rise of this waveform results in substantial stretching of the rise time, as well as attenuation of the surge peak, when more than a few meters of propagation are involved [11], [12]. Thus, the domain of application of this waveform is limited to interactions between adjacent equipment within the same building and propagation characteristics relieve users from concerns about EFT surges of remote origin.

\section{The $5 \mathrm{kHH}$ Ring Wave}

This waveform has been included, as an 'Additional Waveform', in the new IEEE Recommended Practice. While there is an abundance of data from computer simulations of capacitor switching transients, little experimental data are available on the propagation of this waveform [13]. However, the relatively low frequency of this waveform makes it readily amenable to theoretical analysis based on simple lumped parameters of the power system, provided of course that the nonlinear characteristics of varistors are included.

\section{The $10 / 1000$ us Unidirectional Wave}

This waveform has been included, as an 'Additional Waveform', in the new IEEE Recommended Practice. Its relatively longer rise time, and more important, its long duration, raise new questions about a coordination based on the inductive impedance separating two cascaded devices [4]. Refer to the measurements reported in the next section, showing that inductance still dominates the initial portion of the $10 / 1000 \mu \mathrm{s}$ event, but that the long tail of the waveform will force a resistive element, rather than an inductive element, to enter in a successful coordination scheme. 


\section{IMPEDANCE MEASUREMENTS FOR DIFFERENT WIRE SIZES AND WAVEFORMS}

Three pieces of "Romex" cable [2 conductors + ground] of different conductor diameter (AWG $\# 14,12$, and 10 ), each $10 \mathrm{~m}$ long and having its two current-carrying conductors joined at one end, were connected in series. The ground conductor was left floating. This set of three was then connected across the output of a surge generator capable of producing the $100 \mathrm{kHz}$ Ring Wave, the Combination Wave, or the $10 / 1000 \mu$ s Unidirectional Wave (Figure 1). Thus, all three cables were exposed to the same current waveform. The impedance of this load circuit caused a departure from the nominal short-circuit waveforms delivered by the surge generator, which was recorded in each case.

A differential voltage probe was used to record the voltage drop at the origin of each cable (Figure 1), corresponding to each of the three successive current waveforms (Figures 2-4 and Table 1). Note in the voltage traces that during the portion of the waveform when current is changing, there is little difference in the voltage drop along the three cables $\# 14, \# 12$, and $\# 10$. In other words, the length of the cable is the dominant factor, in spite of the nearly $3: 1$ difference in the specific resistance of the $\# 10(3.3 \Omega / \mathrm{km})$ and $\# 14(8.3 \Omega / \mathrm{km})$ conductors. If any skin effect is involved in the propagation, that factor is also included in the comparison.

This lack of difference for surge propagation should be contrasted with the concerns about voltage drop for $60 \mathrm{~Hz}$ loads, covered in a fine print note ${ }^{2}$ of the National Electric Code [14]. In keeping with the accepted practice in the surge-testing community, the ratio of current and voltage peaks is reported as the effective impedance for that particular waveform.

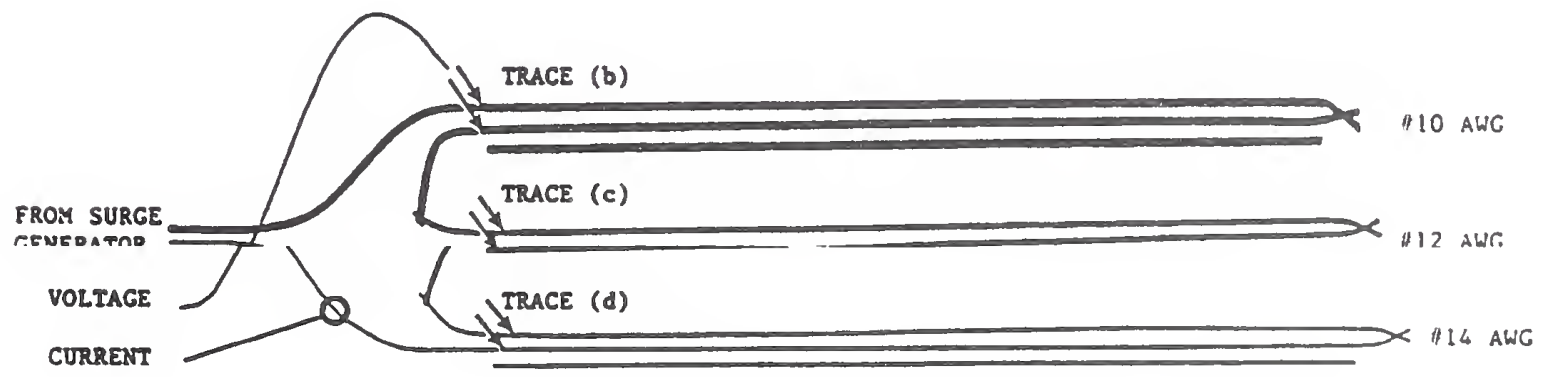

Figure 1. Series connection of test cables

\footnotetext{
'Fine print notes (FPN) of the NEC are only 'Explanasory Maserial', in contrast with 'Mandased Rules'.
} 

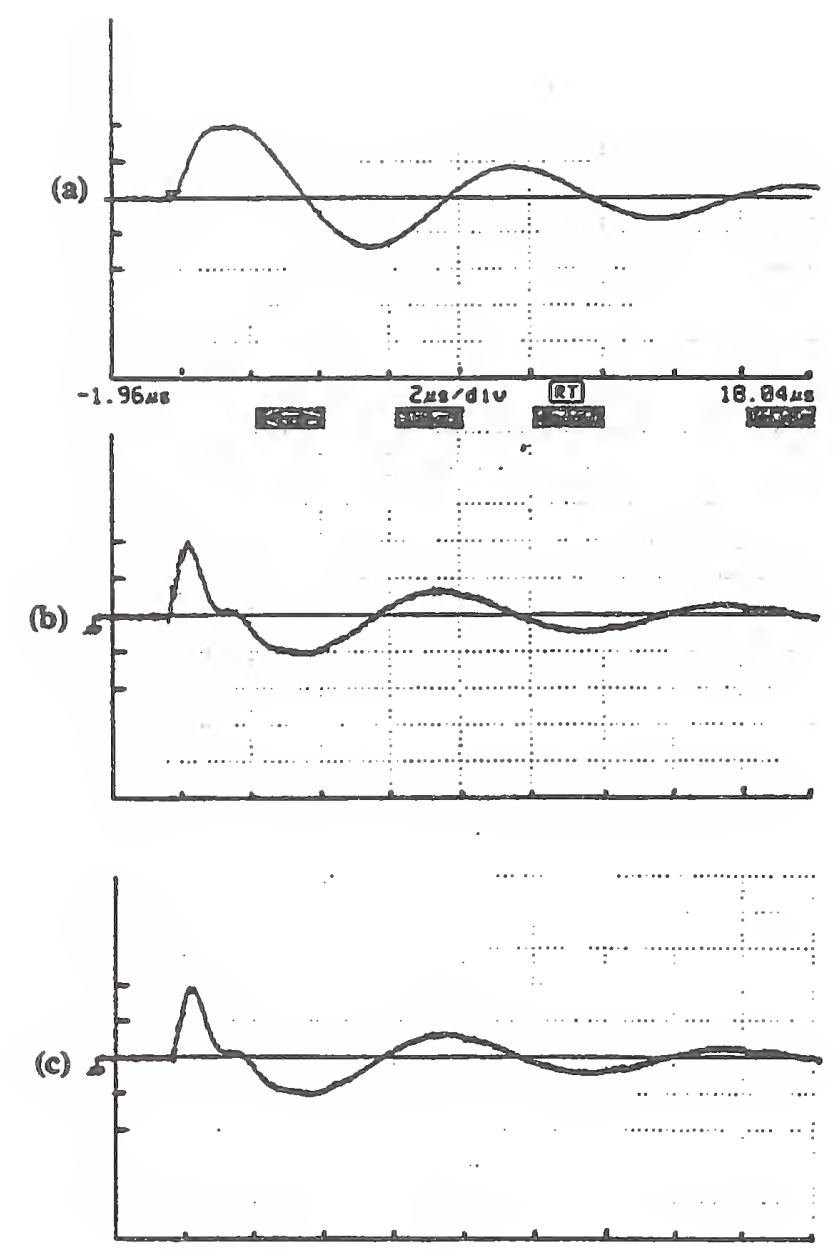

(d)

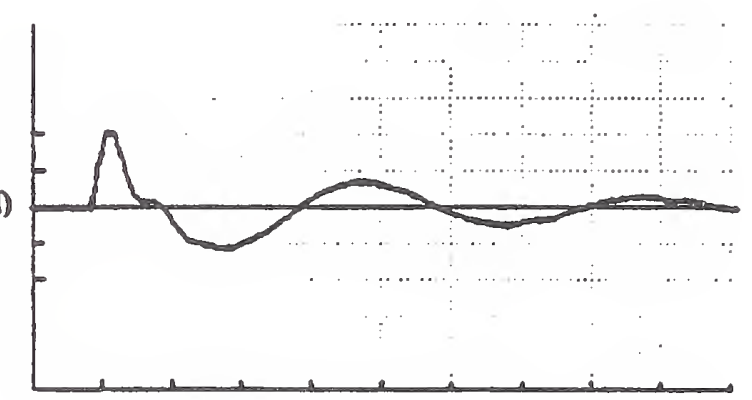

(a) Current trace: $50 \mathrm{~A} / \mathrm{div}$

(b) Voltage trace, 10 )

(c) Voltage trace, 12 ) $400 \mathrm{~V} / \mathrm{div}$

(d) Voltage trace, 14 )

(All at $2 \mu s / d i v$ )

Figure 2. Voltage drops with Ring Wave 

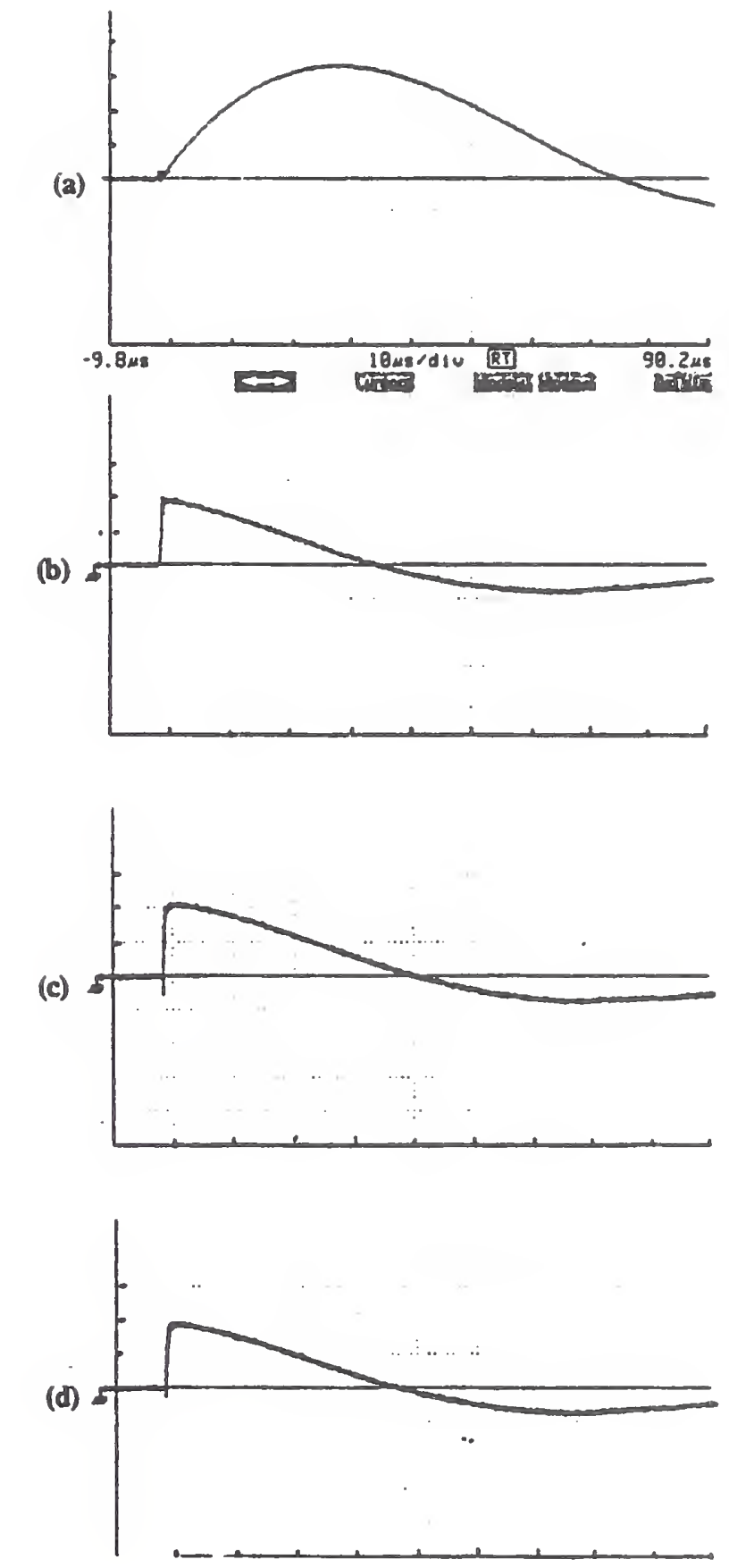
(a) Current trace: $50 \mathrm{~A} /$ div
(b) Voltage trace, $\# 10$ )
(c) Voltage trace, $\# 12$ ) $400 \mathrm{~V} /$ div
(d) Voltage trace, \#14 )
(All at $10 \mu \mathrm{s} / \mathrm{div}$ )

Figure 3. Voltage drops with Combination Wave 

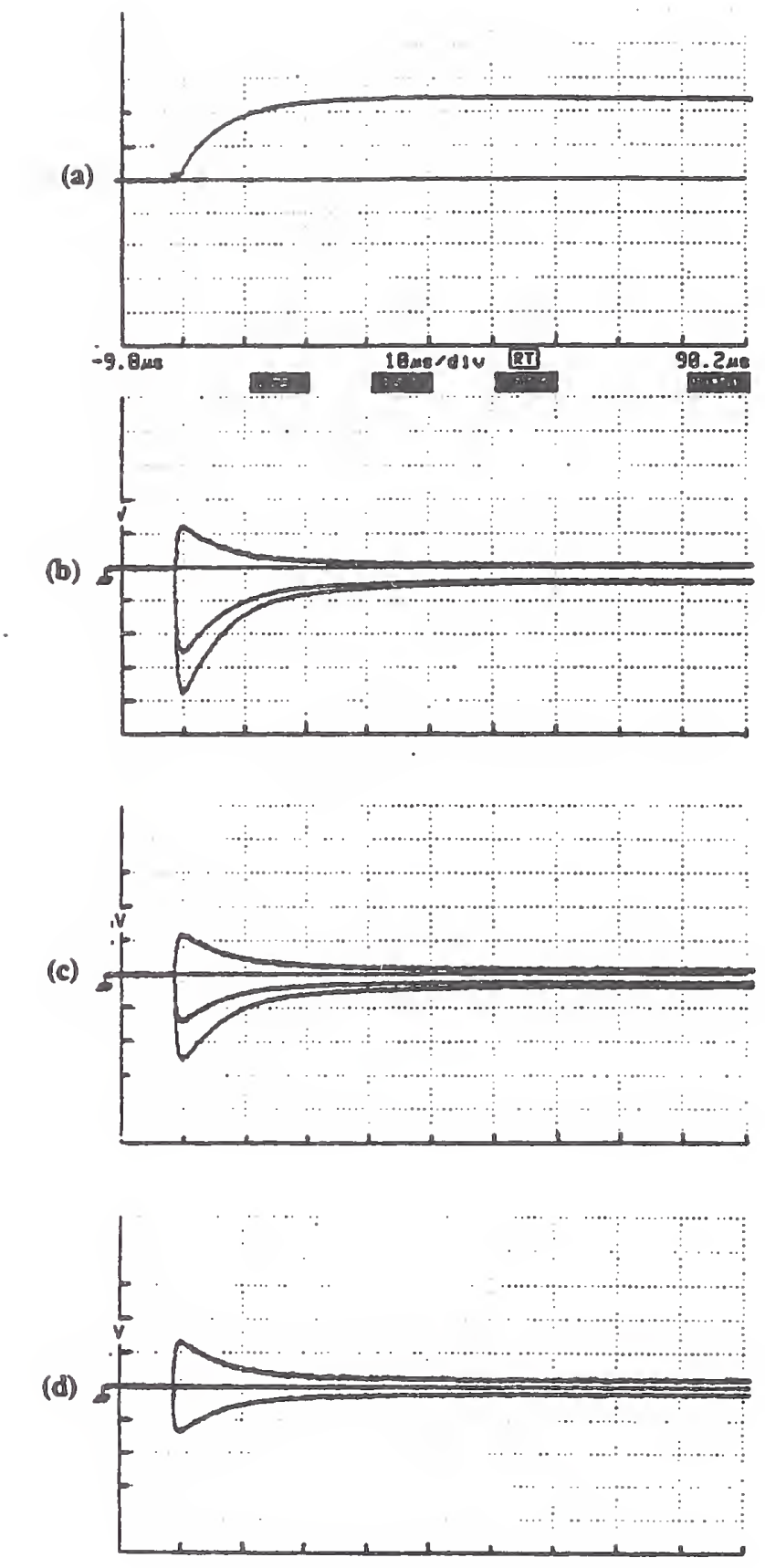

(a) Current trace: $50 \mathrm{~A} / \mathrm{div}$

(b) Voltage trace,

(c) Voltage trace, 12 ) $400 \mathrm{~V} / \mathrm{div}$

(d) Voltage trace, \#14)

(All at $10 \mu \mathrm{s} /$ div)

Figure 4. Voltage drops with $10 / 1000 \mu$ s unidirectional wave 
TABLE 1

MEASURED CURRENTS AND VOLTAGES, CALCULATED IMPEDANCE $110 \mathrm{~m}$ CABLE) FOR THREE WIRE SIZES AND THREE WAVEFORMS

\begin{tabular}{|c|c|c|c|c|c|c|c|c|c|}
\hline Nominal generator waveform & \multicolumn{3}{|c|}{ Ring Wave } & \multicolumn{3}{|c|}{ Combination Wave } & \multicolumn{3}{|c|}{$10 / 1000$ us Wave } \\
\hline Peak current, $I_{0}(A)$ & \multicolumn{3}{|c|}{100} & \multicolumn{3}{|c|}{170} & \multicolumn{3}{|c|}{120} \\
\hline Actual rise time of current ( $\mu \mathrm{s}$ ) & \multicolumn{3}{|c|}{0.8} & \multicolumn{3}{|c|}{22} & \multicolumn{3}{|c|}{25} \\
\hline Wire size (AWG) & 10 & 12 & 14 & 10 & 12 & 14 & 10 & 12 & 14 \\
\hline Peak voltage during surge $\left(V_{p}\right)$ & 800 & 790 & 800 & 760 & 780 & 800 & 100 & 100 & 110 \\
\hline Effective impedance $V_{p} / I_{p}(\Omega)$ & 8.0 & 7.9 & 8.0 & 4.5 & 4.6 & 4.7 & 0.8 & 0.8 & 0.9 \\
\hline
\end{tabular}

\section{REFERENCES}

[1] IEEE C62.41-1991, IEEE Recommended Practice on Surge Voltages in Low-Voltage AC Power Circuits (To be published July 1991).

[2] Standler, R.B., Coordination of Surge Arresters and Transient Voltage Surge Suppressors, Proceedings, 1991 Zarich EMC Symposium.

[3] Stringfellow, M.F. and Stonely, B.T., Coordination of Surge Suppressors in Low-Voltage AC Power Circuits, Proceedings, Open Forum on Surge Prosection Application, June 1991.

[4] Lai, J.S., Performance Criteria for Cascading Surge-Protective Devices, Proceedings, Open Forum on Surge Protection Application, June 1991.

[5] Luebke, C.M., The development of IEC documents for insulation coordination application, Proceedings, Open Forwm on Surge Protecrion Applicarion, June 1991.

[6] ANSI/IEEE C62.41-1980, Guide on Surge Voltages in Low-Voltage AC Power Circuits.

[7] Martzloff, F.D. and Gauper, H.G., Surge and High-Frequency Propagation in Industrial Power Lines, IEEE Transactions LA-22, July/August 1986, pp. 634-640.

[8] Martzioff, F.D., Coupling, Propagation, and Side Effects of Surges in an Industrial Building Wiring System, IEEE Transactions LA-26, March/April 1990, pp. 193-203.

[9] Martzloff, F.D., The Propagation and Attenuation of Surge Voltages and Surge Currents in Low-Voltage AC Power Circuits, IEEE Transactions PAS-102, May 1983, pp. 1163-1170.

[10] Martzloff, F.D., Coordination of Surge Protectors in Low-Voltage AC Power Circuits, IEEE Transactions PAS.99, January/February 1980, pp. 129-133.

[11] Martzloff, F.D. and Wilson, P.F., Fast Transient Tests: Trivial or Terminal Pursuit?, Proceedings, Zürich 1987 EMC Symposium, pp. 283-288.

[12] Martzloff, F.D. and Leedy, T.F., Electrical Frst Transients: Application and Limitations, IEEE Transactions LA-26, January/February 1990, pp. 151-159.

[13] Martzloff, F.D., Varistor Versus Environment: Winning the Rematch, IEEE Transactions PWRD-1, April 1986, Pp. 59-65.

[14] ANSI/NFPA-\%-1990, National Electrical Code. 


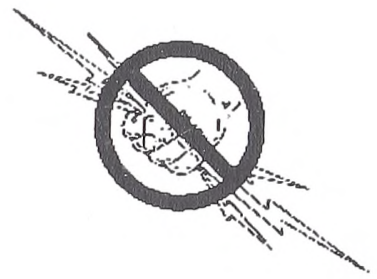




\title{
Surging the Upside-Down House: Looking into Upsetting Reference Voltages
}

\author{
Thomas S. Key \\ Power Electronics Applications Center \\ Knoxville TN
}

François D. Martzloff

National Institute of Standards and Technology

Gaithersburg MD

f.martzloff@ieee.org

Paper presented at PQA'94 Conference, Amsterdam, October 1994

\section{Significance \\ Part 4-Propagation and coupling of surges \\ Part 5 - Laboratory measurements}

\begin{abstract}
Electronic equipment with two input ports - power and communications - can be exposed to damaging differences of voltage across the two ports during surge events. Two exposure scenarios of producing such differences of voltages are explained and illustrated by measurements performed in a replica of a residential or light commercial installation of power, telephone, and cable TV wiring.
\end{abstract}

Several mitigation methods are described, and one possible retrofit solution is shown. In a later paper, (see Upsdown measure) numerical simulations were performed on a model of the system in order to expand the range of conditions and identify significant variables. Nevertheless, there are still very few published data on quantifying the stress that can be produced by these scenarios, and hopefully mitigated by "surge reference equalizers" -- also known as "multi-port surge protectors." 


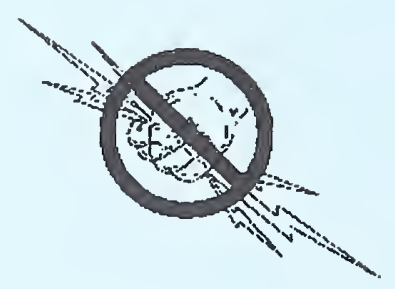


Preprint of paper to be presented at POA'94 Conference, Amsterdam. October 1994

\title{
Surging the Upside-Down House: Looking into Upsetting Reference Voltages
}

\author{
Thomas S. Key and Françols D. Martzlot *
}

\begin{abstract}
Electronic equipment with two inpul ports - power and communications - can be exposed to damaging differences of voltage across the two ports during surge events. Two axposure scenarios of producing such differences of voltages are explained and illustrated by measurements performed in a replica of a residential op light commercial installation of power. telephone, and cable IV wiring. Several mitigation methods are described, and one possible retrof it solution is shown. It is planned that in a further phase of this reseanch, numerical simulation will be perfomed on a model of the system in order to expand the range of conditions and identity significant variables.
\end{abstract}

\section{INTRODUCTION}

As more and more electronic equipment enter the home and business environment, these often involve a communications port as well as their usua! power cord port. In this paper, we will use the term "two-port appliance" or "appliance" for short, being understood that it covers two-port information technology equipment. Examples of such two-port appliances include fax machines, telephono answering machines, personal computers with modem communications or printer connections. and cable-connected TV receivers. Although each of the power and communications systems may include a scheme for protection against surges, the surge current flowing in the surged systern causes a shift in the voltage of its reference point while the other. non-surged system reference point remains unchanged. The difference of voltage between the two reference points appears across the two pons of one appliance, or between the communications ports of two appliances linked by a data cable. Depending. On the nature of the appliance and its immunity. which is not often defined, this difference of voltage may have some upsetting or damaging consequences. In this paper.w we will present just two examples of measurements illustrating the broad variety of possible exposure scenarios.
To ddentify and quantify the significant variables and their effects, a representative configuration of the circuitry in residence (metablic cold water pipe. power and grounding conductors, telephone and cosxial calole TV wiring has been set up in the laboratory, according to U.S. practice. The circuits have been hung from the laboratory ceiling, $10 \mathrm{de}$ couple them from nearby metallic masses and get them out of the way of laboratory personnel, hence the name "Upside-Down House" given to the project.

To evaluate the threat of frrpinging surges in an actual installation, surges of various types. as defined in standards covering AC power circusts and communications, can be injected at various points of the Upside-Down House clrcutts. Combinations of surge-protective devices (SPDs) can also be placed at various focations of the Upside-Down House. corresponding to a variety of real-world exposure scenarios. A measurement can then be made of the resulting differences of voltage appearing between the power and communications ports of a single appliance, of between the communications ports of iwo appliances instalied at some location within the Upside-Down House. No conclusions are drawm in this paper on the withstand capability of any particular appliance for this type of threat, because the manufacturers typically do not provide immunity data for any exposure scenario of this type of interaction. However, some of the voltages thus recorded in the Upside-Down House confirm the suspicion derived from field failures that damaging differences of voltages can occur.

\section{APPROACHES}

Various mitigation schemes have been proposed by researchers and industry, but not quantified. to remedy upsetting or damaging voltage differences. The most effective is likely to be a fiber optic decoupling inserted in the communications link, but the expense may be objectionable for residential 
and small commercial applications. Close attention to good wiring practices in new installations can offer some degree of remedy, but leaves out all existing installations. Increasing the appliance withstand capabiliny. may raise objections of market oconomics, and may not be practical for some of the voltages that can appear.

Many different exposure scenarios can be identified, oven in a simple residential circuit replica. Reference voltage shifts are a multi-dimensional problem in the real world. In this paper, the problem has been simplified to looking at the effect of only two variables: spatial relationships of conductors and effectiveness (including some side-effects) of SPDs. Other important variables that were identified but not addressed at this stage of the research are cited in the discussion section of this paper.

In this paper, two simple exposure scenarios are illustrated: a voltage difference occurs between the ports of an appliance connected to two systems when a surge impinges on one of the systerns, and a voltage difference occurs between the communications ports of two appliances powered by separate circuits of the same power system when a surge impinges on that system. In the final discussion, we will look into some ways of expanding these results and perhaps identifying a recurring set of variables that can be mitigated or avoided.

\section{SETUP AND MEASUREMENTS}

Measurements reported in this paper describe exposure scenarios leading to voltage differences being developed during surge events across the power and telephone systems of the Upside-Down House, as well as between the signal reference points of two interconnected appliances linked by their communications ports, such as a personal computer (PC) and associated printer. For each case, the Upside-Down House circuits may include some form of upstream surge protection on the telephone service entrance or appliance port, as well as on the power service entrance or appliance port. It is planned to continue the project with similar measurements involving the cable TV port.

Figure 1 shows an isometric of the Upside-Down House configuration, with the arrangement of the three tiers of conductors shown in Figure ?. The power wiring includes two tiers of 3-conductor cable (2.05 mm dia - \#12 AWG, non-metallic jacket).

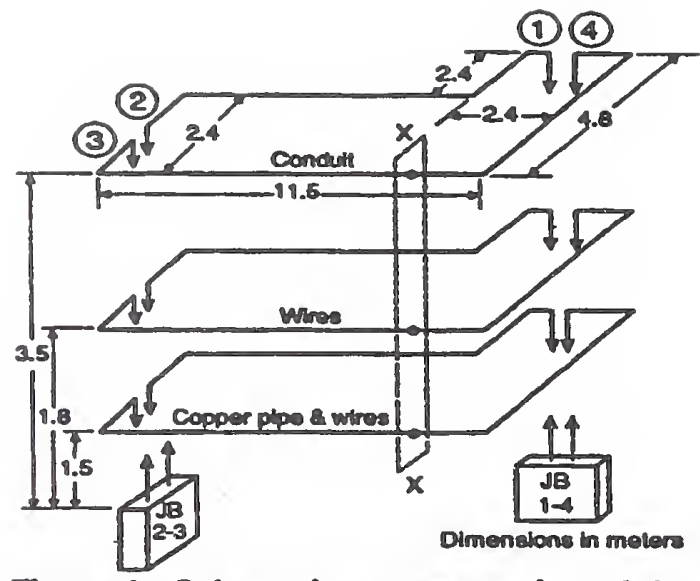

Figure 1-Schematic representation of the Upeide-Down House conductors

typical of residential wiring, and one tier of three 2.05-rmm dia. conductors in a steel conduit, typical of commercial or office installation. A 4-conductor, two-pair telephone cable and a 70- 2 TV coaxial cable also run along the 3 -conductor power cables.

To illustrate the expected benefit from good wiring practice (cables routed close to the earth reference - the copper water pipe in the UpsideDown House), one tier has been lashed to the copper pipe. Of course, such idealized practice is not practical, but will serve here as baseline and illustration of EMC principles [Nan Deursen. 1993]. In an actual installation, the system would exist in all three dimensions. For the sake of simplification, the Upside-Down House has been reduced to only two dimensions, one horizontal run spanning the house. and the vertical separation indicated in Figure 1. For the purpose of accessing both ends when injecting surges and measuring voltages and currents, the horizontal span has been folded into a hairpin with both ends accessible in junction box JB $1-4$.

$x$

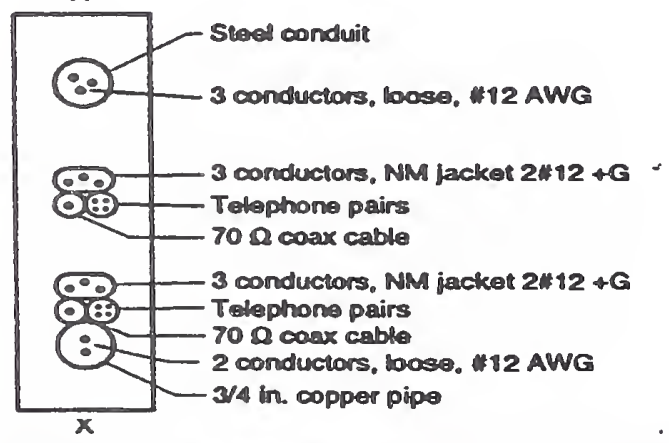

Figure 2 - Vertical arrangement of conductors in the Upside-Down House (X-X of Figure 1) 
Junction box JB 2-3 provides access to an intermediate point of the span. Short cable runs $(3 \mathrm{~m})$. not shown on the diagram, provide for appliances located close to the service entrance.

Neglecting the vertical separation of the three tiers. the length of the span from end to end is $36 \mathrm{~m}$. This number is cited to give an idea of the size of the house. Any numerical computations will, of course, use the exact values.) A typical service entrance breaker panel and revenue meter have been provided at one end, upstream of junction box JB 1-4. A Network Interface Device (NID), typical of the U.S. practice for entry of the telephone service. has been installed next to junction box JB 1-4.

By connecting the NID grounding conductor (U.S. code terminology) to one or the other end of the copper plpe, it is possible to represent the scenario where telephone and power service enter at the same end of the house (the preferred practice) or at opposite ends (not preferred, but often encountered). All of the conductors are insulated from the existing earthing arrangement of the laboratory building. making it possible to represent various configurations of the earthing arrangement of the Upside-Down House.

Surges were injected into the power system in the line-to-ground (L-G) mode. Note that the U.S. practice of bonding the neutral and grounding conductors at the service entrance makes any impinging L-G surge become also a line-10-neutral surge. Surges injected into the balanced-pair telephone system were in [tip \& ring]-to-ground mode, with the NID acting to divert them to the common earthing point of the laboratory building and Upside-Down House via the copper pipe.

The waveform and amplitude of the injected surges were selected to hamonize with the values cited in Industry standards. Because of the different values of the impedance of the various circuits into which the surges were Injected, the resulting waveforms reflect the interactlon of the surge generator and load impedances and do not exactly duplicate the familiar standard waveforms. Nevertheless, the resulting waveforms are representative and provide examples of the threat and needs of mitigation. These results will provide experimental data for later validation of computer modeling. so that the modeling can then expand the results to other waveforms and circuit impedances.

\section{FIRST EXPOSURE SCENARIO: TWO SYSTEMS SERVING ONE APPLIANCE}

In this exposure scenario, a modem-equipped PC is connected by its power port to a branch circuit, and by its modem port to the telephone service of the house. For a worst-case scenario, the power and telephone services enter the house at opposite ends (Figure 3 ).

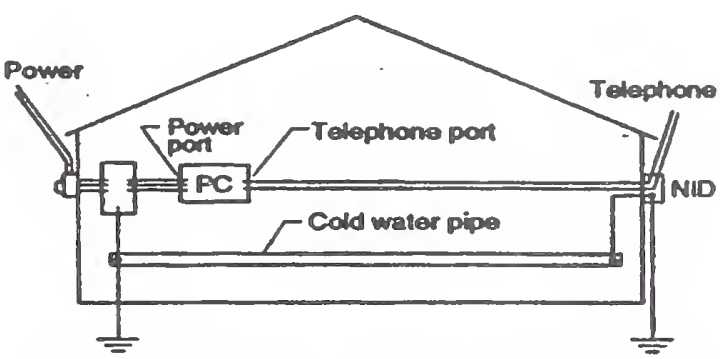

Figure 3 - Power and telephone services enterlng the house at opposite ends, with PC connected across the two systems

An open loop is formed by the copper pipe, the protective conductor (international symbol "PE") of the branch circuit feeding the PC, and the telephone wires from the NID to the PC. If a surge impinges on the extemal telephone plant, it is diverted by the NID via the copper pipe to the common earthing point of the house, at the power service entrance. The surge current In the copper pipe creates a changing magnetic flux around the pipe, which induces a voltage in the loop. This voltage will appear between the two PC ports if they are separated by a high impedance (of unknown surge voltage withstand capability).

With the telephone wires routed away from the copper pipe - which can be expected in residential wiring - a large loop is formed, embracing the flux produced by the surge current flowing in the copper pipe. With the telephone wires lashed to the copper pipe - a theoretical more than practical routing the loop embraces less flux and one can expect a lower induced voltage across the two ports.

Figure 4 shows the recording obtained with the telephone wire routed away from the pipe. For a rate of change in the surge current of $75 \mathrm{~A}_{\mu \mathrm{s}}$, a peak of $4.3 \mathrm{kV}$ is induced in the loop and appears between the two ports. For the same injection of current, a peak of only $1.3 \mathrm{kV}$ was noted with the telephone wires lashed to the copper pipe. 


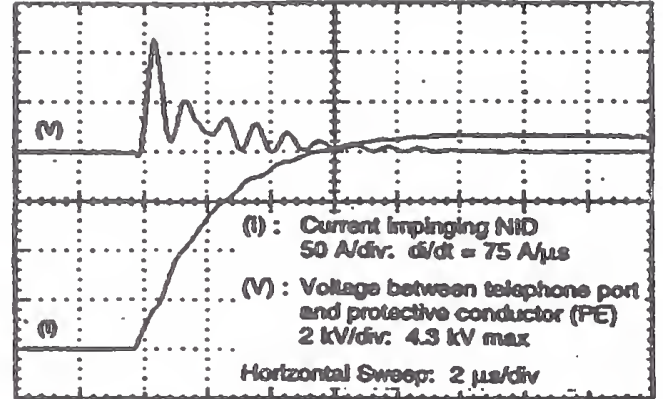

Figure 4-Voltage difference recorded with telephone and power services entering at opposite ends of the house

A relatively simple retrofit solution is to oqualize the difference of voltage between the two systems by a device designed for the pupose and inserted in both communications and power links just before they enter the appliance. This device, defined in IEEE standards [IEEE Std 1100-1992] as a "Surge Reference Equalizer" is commercially available in the U.S. as a unit featuring a plug and receptacle for the power link, as well as a pair of telephone jacks or TV coaxial fittings for the communications link. However, its necessary oflectiveness has not yot been quantified in any performance standard.

To illustrate the effectiveness. Figure 5 shows. the reduction of the voltage obtained by inserting a typical surge reference equalizer in the power and telephone lines at the point of connection of the PC. The generic design of such a device includes insertion in the two telephone wires of two matched gas tubes. two series resistors, and two silicon avalanche diodes, with a shared earthing reference. Figure 5 shows the immediate clamping effect of the diodes down to $200 \mathrm{~V}$. followed by a further reduction of voltage as the gas tube sparks over.

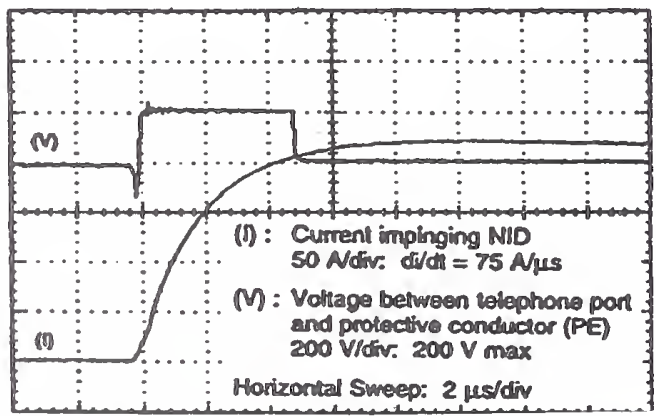

Figure 5 - Mitigation obtained by Inserting a surge reference equalizer in the power and telephone lines
A amaller loop would exist if the telephone and power service entered at the same end of the house, the recommended practice. With such a configuration, a reduction in the voltage difference of about $75 \%$ of the large loop value was found in the test series. Available space limits the number of records that can be shown in this paper for various combinations, but a more comprohensive report will be prepared and published later.

\section{SECONO EXPOSURE SCENARIO: ONE SYSTEM SERVING TWO APPLANCES VIA TWO BRANCH CIRCUTSS}

In this scenario, a PC and the associated printer are connected by the usual communications cable, and each is powered by a separate branch circuit. This situation is often encountered when a printer is shared among several users, or when an installation has been deliberately configured to provide a separation of the "clean" branch cincuit supplying the PC from the "noisy" branch circuit supplying the printers and other peripherals (Figure 6). Both branch circuits originate at the service panel, but might not have the same length.

In a first case of this scenario, a slight difference may occur in the time of arrival at the two ports of a surge originating outside of the building ( $E X$ in Figure 6). A greater difference in the time of arrival would occur if the surge were internally generated ("IN") along a branch circusit, propagating directly in that branch toward the PC and in a roundabout path via the service entrance and the other branch circuit toward the printer. With the internally generated surges having steeper fronts that the extemally generated surges [Martzloff. 1990], the difference in arrival time would be significant since the voltage spike occurs upon the initial current rise, not at the peak of the current surge.

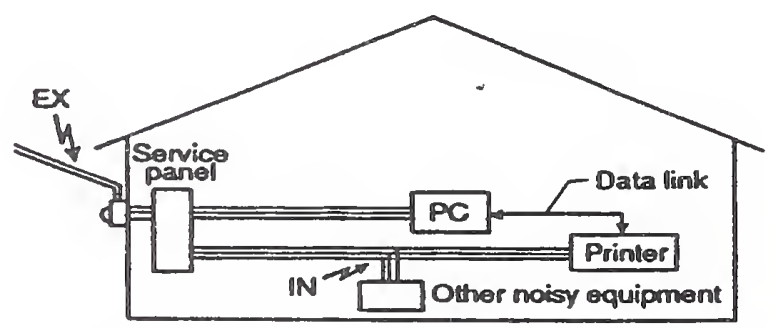

Figure 6 - Personal computer and printer linked by a data cable and powered from two separate branch circuits 
As a second case of this scenario, a more severe situaticn is created by mismatched protective devices at the power ports of the two appliances. A shitt in the reference voltage can occur if one SPD provided in either the printer or the PC invites a disproportionate surge current in its PE conductor. These can be built in the appliance or be a plug-in device installed by the user. Such a device, if it includes an SPD connected L-G, will return the surge to the service entrance through the protective conductor PE ("equipment grounding conductor" is the U.S. term) and produce a shitt in the voltage of the corresponding chassis. The resulting difference of voltage between the two chassis will be applied across the communications link with possible upsetting or damaging consequences.

The effect of such difference in SPDs is illustrated in Figure 7, for the worst case scenario of one SPD connected L-G in one appliance, and none in the other. An oscillatory difference of voltage peaking at $3.2 \mathrm{kV}$, with a spike in the nanosecond range, occurs at the time of the initial rise, for the 400 A pus rate of current change corresponding to an $8 / 20$ us 1400 A peak surge injected at the service entrance. Note the decay of the voltage to a low value at the time of the current peak

\section{DISCUSSION}

The two exposure scenarios described in this paper represent the mechanisms most likely responsible for many of reported, but seldom welldocumented, field failures of two-port appliances.

The variables considered in these two scenarios are marked in the cells of Table 1. (1) for the first scenario, (2) for the second. The columns in the

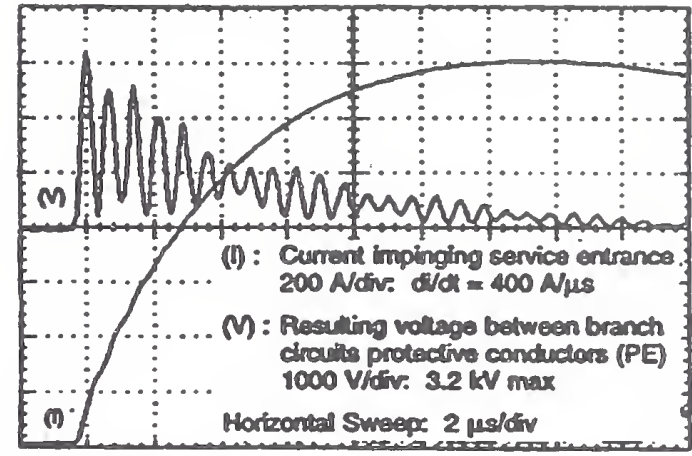

Figure 7 - Difference of neference voltages caused by different protections In the two separate branch clicuits

table correspond to spatial variables; only a few of all the possible variables are shown. The rows in the table show a few of the possible variables corresponding to the nature and combinations of the SPDs. This table is a beginning toward defining the multi-dimensional matrix of all possible variables.

Many other variables need consideration, such as the presence of more than two ports in the appliances, different types of ports (serial RS232. Ethernet ...). different power system configurations (single-phase 120/240 V or three-phase 120/208 V in the U.S., three-phase systerns in other countries). wiring errors and poor practices, lack of coordination between upstream and downstream SPDs, larger or higher buildings. separate buildings, immunity levels of equipment and consequences of insutficient immunity (upset vs. failure, failure modes), and, last

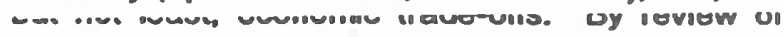
these many variables, it may be possible to identify a limited number of scenarios and thus define effective mitigation means.

Table 1

Two-dimension matrix of variables consldered for reference voltage shifts in two scenarios

\begin{tabular}{||l|c|c|c|c||}
\hline \multicolumn{1}{|c|}{$\begin{array}{c}\text { Spatial variables } \\
\text { SPD variables }\end{array}$} & $\begin{array}{c}\text { Single entrance } \\
\text { of services } \\
\text { (ground windown) }\end{array}$ & $\begin{array}{c}\text { Muttiple points of } \\
\text { entrance of power \& } \\
\text { telephone service }\end{array}$ & $\begin{array}{c}\text { Wing routing } \\
\text { and } \\
\text { practices }\end{array}$ & $\begin{array}{c}\text { Other spatial } \\
\text { variables of the } \\
\text { installation ... }\end{array}$ \\
\hline Power service entrance SPD & (1) & (1) (2) & (1) (2) & \\
\hline Equipment power port SPD & (1) & (1) & (1) (2) & \\
\hline Telephone service entrance SPD & & & & \\
\hline Equipment telephone pont SPD & & & & \\
\hline $\begin{array}{l}\text { Other SPD locations and types } \\
\text {.......... }\end{array}$ & & & & \\
\hline
\end{tabular}

- Built in the appliance, or extemal, user-provided plug-in SPD 
Mitigation of the threat can take many forms. One solution, mllustrated in this paper, is the insertion of a properly designed surge reference equalizer. One cause of the problem is the flow of large surge currents in the wiring system of the building. With a telephone service entrance located at the opposite ond of the power service entrance, the required bonding of the NID unavoidably involves the surge current in the long bonding connectlon, hence the need for preventive miligation for this type of nonrecommended telephone service installation, unless adequate between-ports Immunity of the appllance is documented. Whille these examples of two such exposure scenarios have lllustrated the mechanisms, only a computer-driven model might cover all possible combinations of the many variables that could be encountered In all existing or future Installations. Hence, it is essential that a comprehensive and well-documented experimental data base be established for validation of the model.

For surges impinging on the power service entrance, the problem is associated with large surge currents flowing in the branch circuits. If the surge current were diverted at the service entrance by a suitable SPD, the problem would be reduced. However, the specification of a "suitable SPD" at the service entrance involves the issue of coordinating cascaded SPDs [Martzloff-Lai, 1992]. The ongoing program of measurements at the Upside-Down House will Include measurements and numerical sirnulation of cascaded SPDs. A joint Working Group of the IEC is developing guidelines for cascade coordination, based on the work of many researchers [Goedde, 1990]: [Standler, 1991]; [Hostfet et al., 1992]: [Hasse of al., 1993].

\section{CONCLUSIONS}

1. Quantitative measurements in the Upside-Down House clearly show objectionable differences in reference voltages. These occur even when, or porhaps because, surge-protective devices are present at the point of connection of appliances.

2. fuccounting for all the vaniables may be done in a multi-dimensional matrix, a task for computer analysis, the next step of this project.

3. The analysis should be directed toward oblaining a limited set of typlcal scenarlos resunting irom the many combinations of many variables.

\section{ACKNOWLEDGMENTS}

The laboratory measurements were made with the kind assistance of Doni Nastasi and Kemit Phipps. Glenn Grotz and Donald Worden provided peer-review comments on the test procedure and interpretation of the results.

This project was made possible by a sabbatical granted by NIST to Mantzloff, allowing hirn to experiment with his concept of the "Upside-Down House." This Upside-Down House was Installed at PEAC, with support of the Electric Power Research Institute, as a permanent facility of the Power Quality Testing Network

The authors also explicitly Invite their peers to conduct similar experiments and computations to build a consensus on the threat represented by shifting reference voltages. Such a consensus would be an important step toward the development of standards for system compatibility.

\section{REFERENCES}

Gooddo, G.L. Marz, M.B., and Menry, D.C., Coordinating Lightning Stroke Protedion. From the Uiirity System to Load Dovicos. Procoodings. Second International Power Quality ASO Conference, October 1990, Philadelphia.

Hasse, P. of al., Lightning current arroster containing spark gaps for AC supply mains, Elektrie, June 1993.

Hostfel, O.T. et al., Coordination of surgo-protedive devicas in power supply systems: Noeds for secondary protection. Procoodings, Anternational Conference on Lightning Prolection, Berlin. Seplomber 1992.

IEEE SId 1100-1992, IEEE Rocommended Practice for Powering and Grounding Sensitive Eloctronic Equipment ("Emerald Book" of the IEEE Color Books series).

Marizloff, F.D., Coupling, Propagation, and Side Effeds of Surges in an industrial Building Wiring System. IEEE Transactions MA-26, March April 1990, pp. 193-203.

Martzloff, F.O. and Laj. J.S.. Cascading Surgo-Proloctive Dovices: Coordination vs. the IEC 664 Staircase. Proceodings, POA'91 Conforenos, pp 191-198.

Standler, 4.B. Coordination of Surge Arresters and Suppressors for Use on Low-Voltage Mains. Proceedings, 1991 Zürich EMC Symposium, pp 517-524.

Van Deursen. A.P.J.. Eloctromagnetic Compatibility, Part S. Installation and Mhigation Guidelines, Section 3, Cabling and Wiring, EUT Aeport 93-E-275, Eindhoven University of .

Technology, July 1993. 


\title{
Surging the Upside-Down House: Measurements and Modeling Results
}

\author{
François D. Martzloff \\ National Institute \\ of Standards and Technology \\ Gaithersburg MD 20899 \\ f.martzloff@ieee.org
}

\author{
Arshad Mansoor \\ and \\ Kermit O. Phipps \\ Power Electronics Applications Center \\ Knoxville TN 37932
}

\author{
W. Mack Grady \\ University of Texas at Austin \\ Austin TX 78712
}

Paper presented at PQA'95, New York NY, 1995

\begin{abstract}
Significance
Part 4-Propagation and coupling of surges

Part 5-Laboratory measurements
\end{abstract}

Electronic equipment with two input ports - power and communications - can be exposed to damaging differences of voltage between the two ports during surge events. To identify and quantify the significant variables and their effects during surge events in residential or commercial facilities, a representative configuration of the circuitry in a residence (metallic cold water pipe, power and grounding conductors, telephone and coaxial cable TV wiring) was set up in the laboratory, under the name of "Upside-Down House."

To evaluate the threat of surges impinging upon an actual installation, surges of various types, as defined in standards covering AC power circuits and communications circuits, can be injected at selected points of the UpsideDown House. Typical surge-protective devices (SPDs) can be placed at suitable locations of the Upside-Down House, corresponding to a variety of real-world exposure scenarios. Preliminary experimental results of two exposure scenarios were reported in a PQA'94 paper (see Upsdown upset). Additional measurements and parametric variations are reported here to characterize the impedance of the various components of the wiring system and the source impedance of the resulting overvoltages appearing between the ports. 


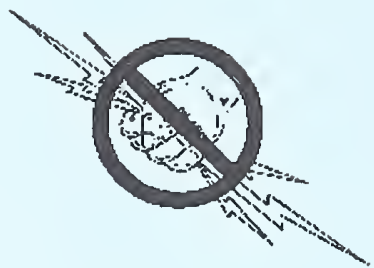




\title{
SURGING THE UPSIDE-DOWN HOUSE: MEASUREMENTS AND MODELING RESULTS
}

\author{
François D. Martzloff \\ National Institute of Standards \\ and Technology" \\ Gaithersburg MD 20899
}

\author{
Arshad Mansoor ${ }^{2} \&$ Kermit O. Phipps \\ Power Electronies Applications Center \\ 10521 Research Drive \\ Knoxville TN 37932
}

\author{
W. Mack Grady \\ University of Texas \\ at Austin \\ Austin TX 78712
}

\begin{abstract}
Electronic equipment with two input ports - power and communications - can be exposed to damaging differences of voltage between the two ports during surge events. To demonstrate real-world scenarios, a replica of the wiring system in a typical residence was installed in the laboratory. This paper reports selected results from many measurements, and presents the corresponding numerical modeling, thereby leading to mutual oalidation of the two processes. Two exposure scenarios for producing differences of voltages between the power and data ports of appliances are illustrated. Additional measurements and parametric variations are reported here to characterize the impedance of the various components of the wiring system and the source impedance of the resulting overooltages appearing between the ports.
\end{abstract}

\section{Summary}

To identify and quantify the significant variables and their effects during surge events in residential or commercial facilities, a representative configuration of the circuitry in a residence (metallic cold water pipe, power and grounding conductors, telephone and coaxial cable TV wiring) has been set up in the laboratory. The circuits have been suspended from the laboratory ceiling to de-couple them from nearby metallic masses and move them out of the way of laboratory personnel, hence the name "Upside-Down House".

To evaluate the threat of impinging surges in an actual installation, surges of various types, as defined in standards covering AC power circuits and communications circuits, can be injected at selected points of the Upside-Down House circuits. Typical surge-protective devices (SPDs) can be placed at suitable locations of the Upside-Down House, corresponding to a variety of real-world exposure scenarios. Preliminary experimental results of two exposure scenarios were reported in a PQA'94 paper [Key \& Martzloff, 1994] ${ }^{3}$.

In this paper, the next step of the research is presented. Using the Electromagnetic Transient Program (EMTP) 4 [EPRI, 1989], computations were made for several combinations of applied surges, SPD characteristics, and wiring configurations. The results of these computations closely track the measurement results, thereby providing mutual validation.

1. Contributions from the National Institute of Standards and Technology are not protected by U.S. Copyright.

2. The initial part of Mansoor's modeling work was performed while at the University of Texas.

3. Limited references are given at the end of this paper, shown in the text as [Name, year].

4. Certain commercial instruments and software packages are identified in this paper in order to adequately specify the experimental procedure. Such identification does not imply recommendation or endorsement by the National Institute of Standards and Technology, nor does it imply that the instruments or software identified are necessarily the best available for the purpose. 


\section{Physical Replica and Measurements}

Figure 1 shows a simplified three-dimension diagram of the wiring of the UpsideDown House. The wiring includes a representative service entrance (revenue meter and service panel, not shown) and is made of typical components according to U.S. residential wiring practice, with the possibility of various combinations of branch circuit lengths and topology. As discussed later in the paper, the worst case scenario of shifting reference voltages for a combination of power and communications system occurs when the two services enter at opposite ends of the residence. In the UpsideDown House, this situation would require that the wiring replica be stretched out in a straight line. However, because the measurements of interest need to be performed at both ends of the straight line, they could not be performed simultaneously by the same instrument. Consequently, the ideal straight line was folded on itself, so that both ends of all lines (1) and (4) in Figure 1) were accessible within a few centimeters

Figure 1

Three-dimension schematic of the wiring of the Upside-Down House

The conduit, wires, and copper pipe are suspended by insulators from the metal roof of the building (equivalent to "earth"). In the lower tier, wires are lashed to the copper pipe, maintaining an average distance of $16 \mathrm{~mm}$ from the copper surface. In the middle tier, designated as "loose". the wires are $300 \mathrm{~mm}$ away from the pipe. The upper tier (conduit) is not used here.

The simplified straight-line configuration of a residence wiring with utilities entrances at opposite ends has been folded in two halves: Section 1-2 and Section 3-4. See Figure 2 for justification of this folding. Each end is accessible in junctions boxes (JB) at working level in the room for easy connection of surge generators, SPDs. and instrumentalion.

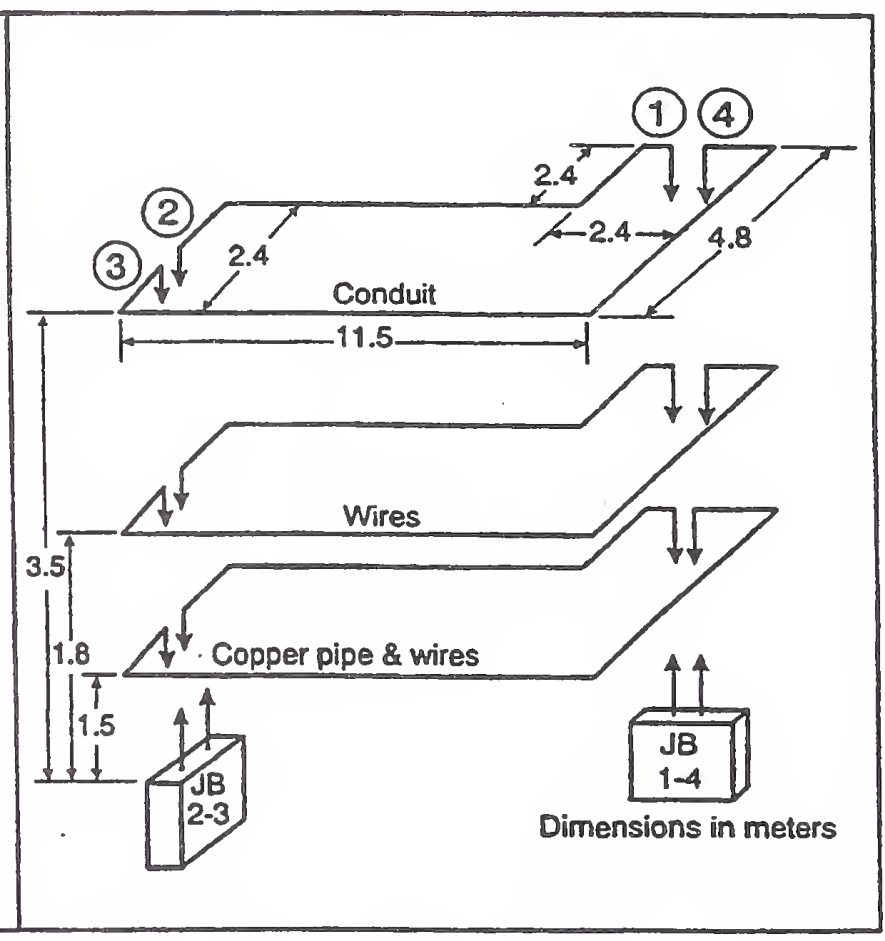

This configuration raises the question of possible flux interaction between the two halves of the line, which would introduce errors in the measurements. The question is how much of the flux radiated from one half of the loop, say the Section 1-2, would be coupled into the other half, Section 3-4, and induce spurious voltages.

To answer that question, a computation was made of the magnetic flux induced in a rectangular loop of which one side is the conductor carrying the surge current, and the perpendicular sides extend from the conductor. The classical equations for this computation and the resulting plot are given in Appendix A. 
Figure 2 shows a plot of the voltage induced into the rectangular loop, normalized for a given waveform and a unit length of conductor, as a function of the radius (long side) of the rectangular collecting loop. While Appendix A shows this plot with semi-logarithmic scales for greater resolution near the conductor, Figure 2 uses linear scales to emphasize the very rapid rise of induced voltage near the conductor and the small additional gain after a few meters.

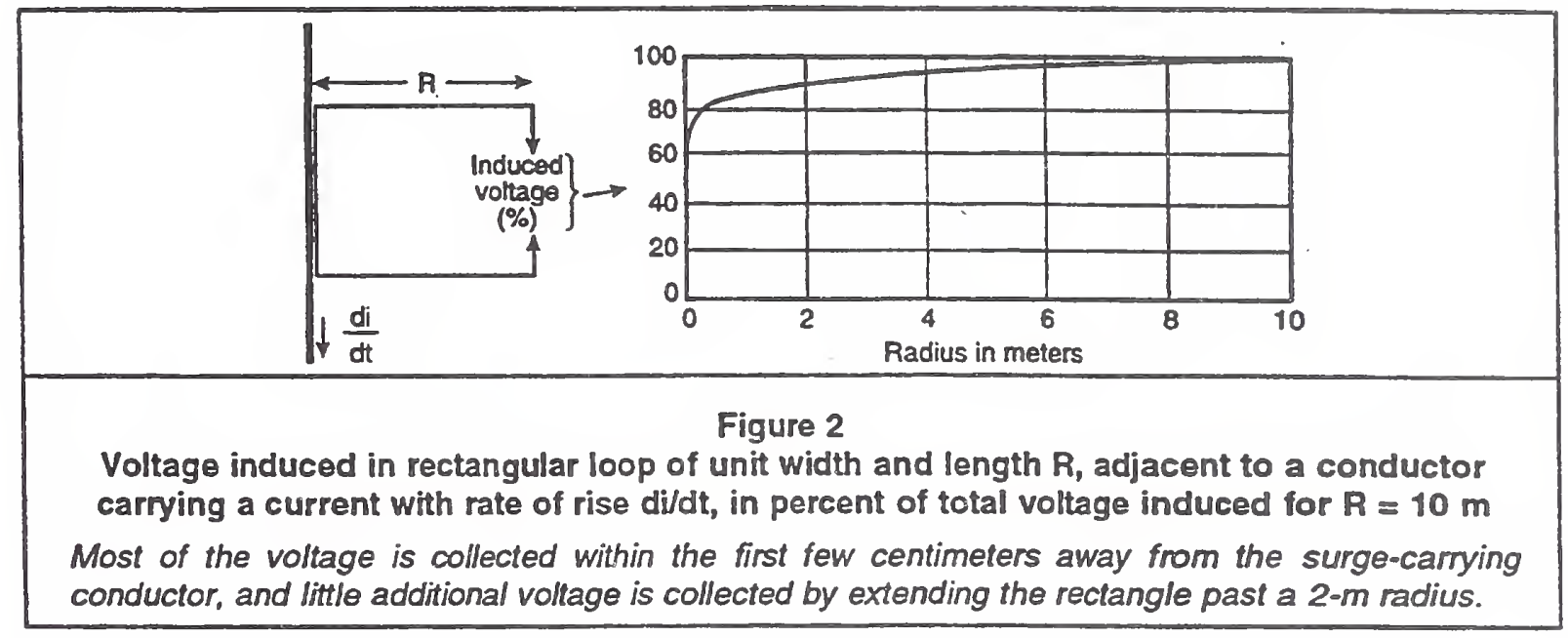

The plot of Figure 2 yields two practical conclusions:

1. The distance between the two halves of the Upside-Down House replica $(2.4 \mathrm{~m})$ is sufficient to ensure very little coupling between the two halves. This small coupling justifies the folding of the straight line into a hairpin-shaped loop.

2. Common wisdom on electromagnetic compatibility (EMC) practices recommends routing cables as close as possible to any available ground plane or additional grounding conductors. However, if "close to" were interpreted by an installer as a few centimeters, all the expected benefits from the "close" installation would be lost - in other words, it is not very effective to attempt minimizing induced voltages by casual routing of unshielded cables "near" the ground planes. More effective means would be required - beyond the scope of this paper.

This paper presents results from two scenarios. The first scenario is the situation created by a two-port appliance connection involving the power supply system and the telephone system, such as a Personal Computer (PC) with modem. Similar topologies would be produced by a Fax machine or an answering machine. Not treated here, but again a similar topology, would be the case of a TV receiver connected to the power system and to a cable TV system.

The second scenario is the situation created by two appliances powered by two separate branch circuits and linked by a communication cable. This situation is often encountered where attempts are made to supply the PC with "clean" power from a branch circuit separate from the "noisy" printer branch circuit. 
The worst case of the first scenario occurs when the power service entrance and the telephone service entrance are located at opposite ends of the building. (Figure 3$)^{5}$. Postulating a surge impinging on the telephone system, the telephone service entrance SPD and test point, called "Network Interface Device" (NID) in the telephone industry, will perform its intended function and divert the surge toward the "best". grounding point. This best grounding point - with lowest impedance to earth - is the multi-grounded neutral in the building rather than the dubious or nonexistent grounding rod at the telephone entrance. Thus, most if not all of the impinging current flows via the copper pipe or a dedicated grounding conductor, which are of necessity spanning the length of the building. This surge current then induces a voltage in the loop formed by the long copper pipe (or the dedicated, but equally long grounding conductor) and the long telephone line between the NID and the PC. This voltage then appears between the two ports of the PC with modem.

Figure 3

First scenario - One appliance connected to two different systems

As a worst-case scenario, the telephone and power service entrances are postulated to be at opposite ends of the building. This is not the preferred practice, but it is not uncommon.

The surge impinges on the telephone entrance and seeks the multi-grounded neutral via the Network Interface Device (NID) and water pipe.

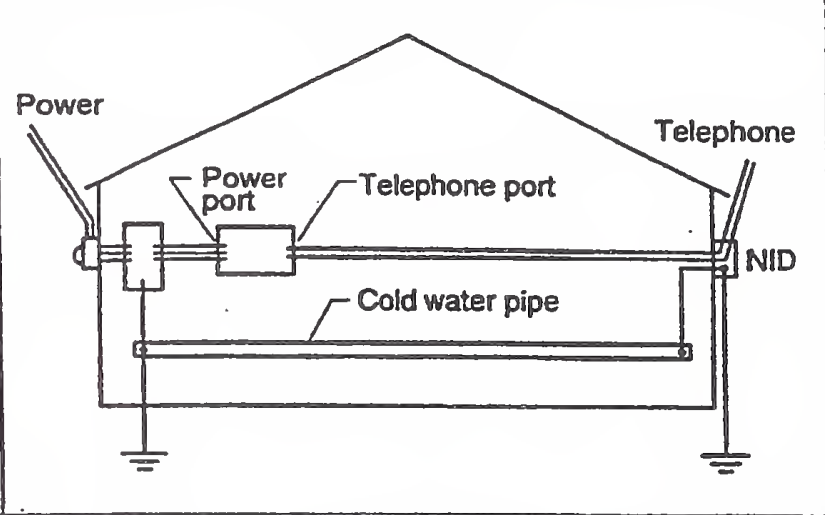

The second scenario, Figure 4, is another example of intended behavior producing unexpected side effects. The commendable attempt to separate the power supply to the two appliances can involve provision of a line-to-ground SPD at the end of one branch circuit, while none is provided at the end of the other branch circuit. Because the two appliances have a signal-reference point which is generally the chassis, (connected to the equipment grounding conductor - the "gireen wire"), the surge current returned to ground in the branch circuit outfitted with an SPD will create a shift in the reference voltage of the corresponding appliance. This shift creates a difference of voltage with respect to the signal reference of the other appliance -a difference which appears at the data ports of the PC and printer.

5. After completion of the test series and publication of this figure in the referenced Key \& Martzloff paper, comments were received from G.J. Bagnall and E.H. Marrow that the NID grounding methods shown do not meet the current National Electrical Code requirements. The Code prohibits the use of an external ground rod as the only ground for communications or bonding more than $1.5 \mathrm{~m}(5 \mathrm{ft})$ away from where the pipe enters the premises. However, many such installations, which met the Code at the time of installation, still exist; for the purpose of illustrating the mechanism of voltage induction with widely separated service entrances, the geometry of the loop is applicable. The authors acknowledge and appreciate this clarification. 
Figure 4

Second scenario - Two appliances connected to two branch circuits

One appliance (the PC or the printer) is postulated as provided with a line-to-ground SPD at its power port (builtsin or as plug-in by the user), while the other has none.

Surges can be expected as injected externally ("EX") or internally ("IN").

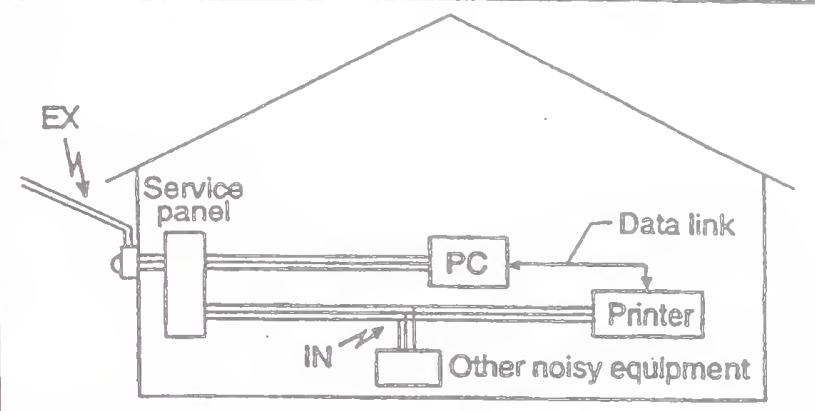

\section{impedance Measurements}

To provide the necessary parameters for numerical modeling reported in the paper, or to be made by other researchers, impedance measurements were made with an impedance analyzer (Hewlett-Packard 4194A). ${ }^{6}$ These measurements included the impedances of the various power and communication circuits in the Upside-Down House, as well as combinations of power and communication wiring loops. For the first scenario, the impedance was measured for a loop consisting of half the copper pipe and half the telephone line as shown in Figure 3. The Section 1-2 of the telephone line is routed $0.3 \mathrm{~m}$ above the corresponding Section 1-2 of the copper pipe. The end-points (2) (Figure 1) are jumpered and the impedance is measured at end-points (1) between telephone wire and copper pipe. Figures 5 and 6 show the impedance and the effective resistance of this loop as a function of frequency.

\section{Figure 5}

Impedance as a function of frequerey for the loop formed by the copper pipe and telephone line in the first scenario.

The "loose" telephone line, Section 1-2 (see Figure 1) is routed $0.3 \mathrm{~m}$ above the corresponding Section 1.2 of the copper pipe.

The logarithmic plot sweep starts at $100 \mathrm{~Hz}$ until $40 \mathrm{MHz}$. For simplicit; only the scalar impedance was requesled from the automatic

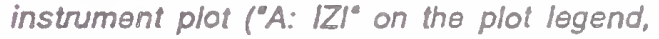
from a minimum of $500 \mathrm{~m} \Omega$ to a maximum of $50 \mathrm{k} \Omega$, auto-ranging on a logarithmic plot).

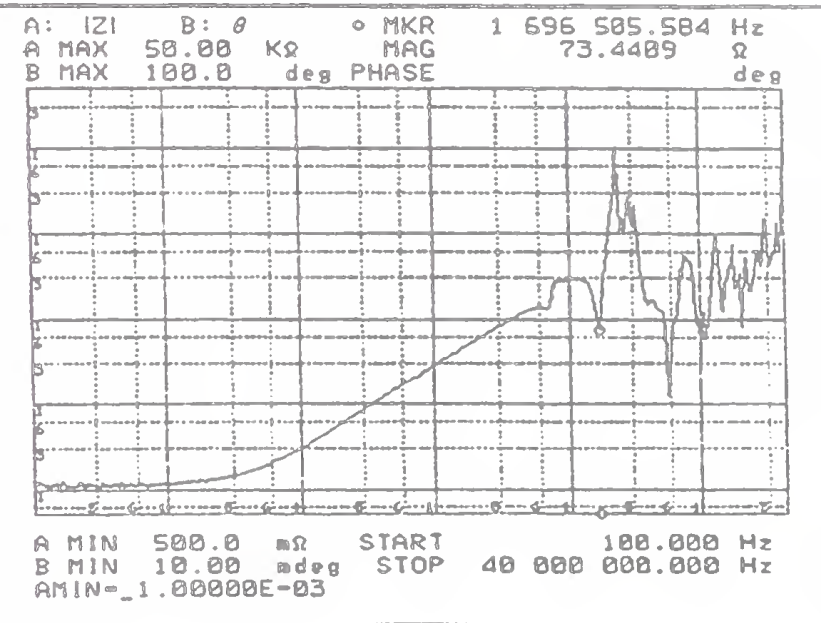

6. The measurements reported in this paper have been made with instruments, transducers and attenuators for which the cumulative uncertainty should not exceed 5 to 6\%. Given the process of applying the measurement results to the response of the Upside-Down House when exposed to environment characteristics that are at best known within an order of magnitude, this level of uncertainty does not affect the conclusions. Numerical modeling results and some automated print-out plots are reproduced here as delioered by the instruments, including a number of digits that are not really significant, but are only reproduced for the sake of authenticity. 
Figure 6

Effective resistance, including skin effect, as a function of frequency for the loop formed by the copper pipe and telephone line in the first scenario.

The logarithmic plot sweep starts at $100 \mathrm{~Hz}$ until $40 \mathrm{MHz}$ For simpliclty, only the resistance has been requested from the instrument ("A: $A$ " on the plot scales).

The apparent collapses of the resistance at higher frequencies are caused by the parallel capacitance of the circuit, resulting in phase angles greater than $90^{\circ}$ which the instrument interprets as a negative resistance.

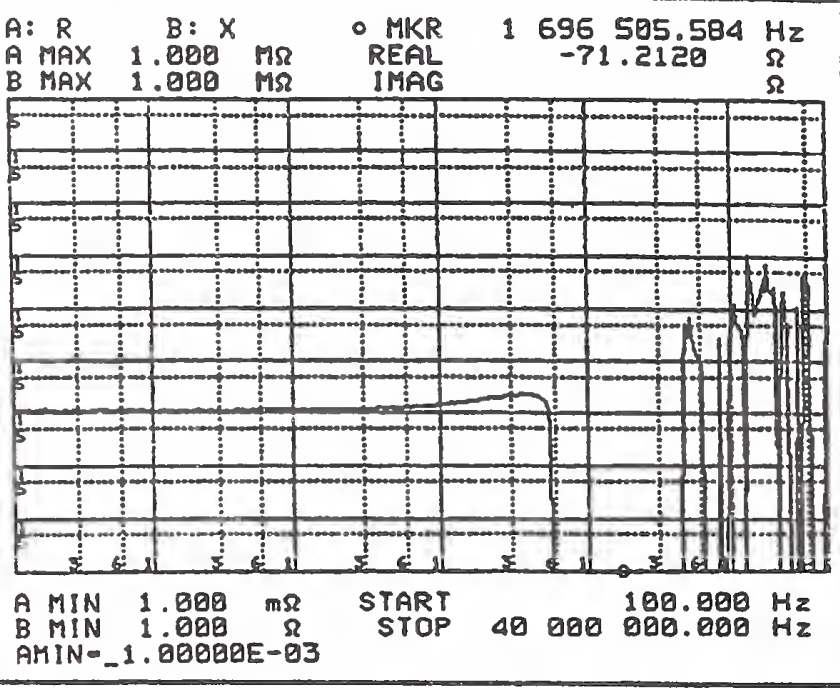

For the second scenario, the loop is formed by the two branch circuits and the communications link between the two appliances, as shown in Figure 4. In this case, only the impedance characteristics of the branch circuit conductors are involved. Figures 7 and 8 show respectively the impedance and effective resistance of one power branch circuit (Section 1-2). The measurements were initially conducted to serve as input for computer modeling of the Upside-Down House. As it turned out, the modeling was done by using built-in routines of the EMTP program to provide more flexibility for the parametric variations. Nevertheless, the availability of these impedance data will be useful if other models based on lumped R-L-C should be used by other researchers. In particular, the impedance characteristics of the branch circuit wiring will be useful when studying coordination of cascaded SPDs, another topic of research for the Upside-Down House [Annotated Bibliography, 1995].

\section{Figure 7}

Impodance as a function of frequency for one power branch circuit supplying one of the two aboliances of the second scenario.

The nonmetallic jacket line, Section 1.2 is used for this measurement. The ends 2 (line and neutral) are joined and the impedance is measured between line and neutral at ends 1.

The logarithmic plot sweep starts at $100 \mathrm{~Hz}$ until $40 \mathrm{MHz}$. For simplicity, only the scalar impedance was requested frum the automatlc instrument plot ("A: $\mid Z I^{\circ}$ on the plot scales).

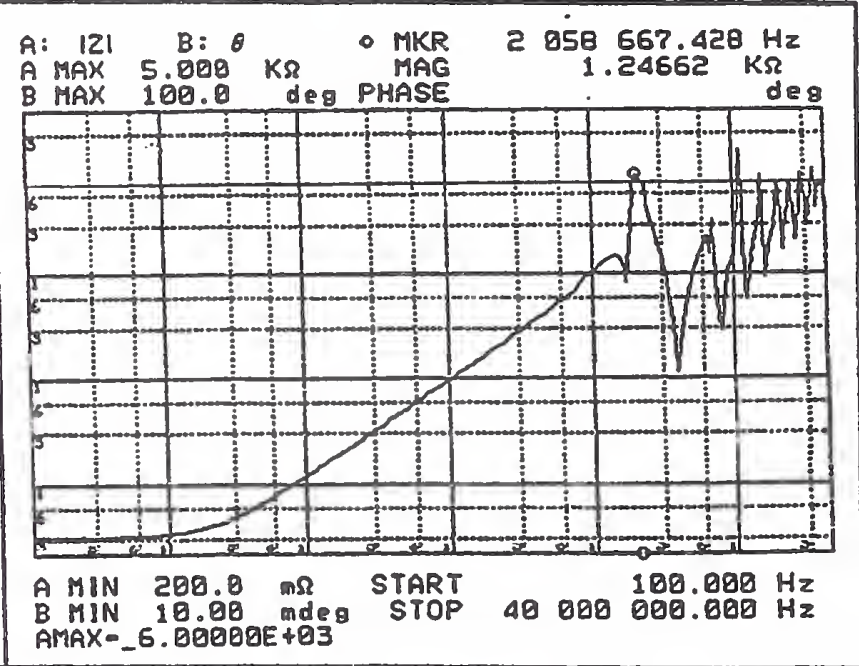


Figure 8

Effective resistance, including skin effect, for one power branch circuit supplying one of the two appliances of the second scenario.

The logarithmic plot sweep starts at $100 \mathrm{~Hz}$ until $40 \mathrm{MHz}$. For simplicity, only the resistance has been requested from the instrument (" $A: R$ " on the plot scales).

The line overwritten on the instrument plot shows a typical normalized rise in effective resistance $\left(R_{A C} / R_{D C}\right)$ resulting from the skin effect, as computed with the EMTP.

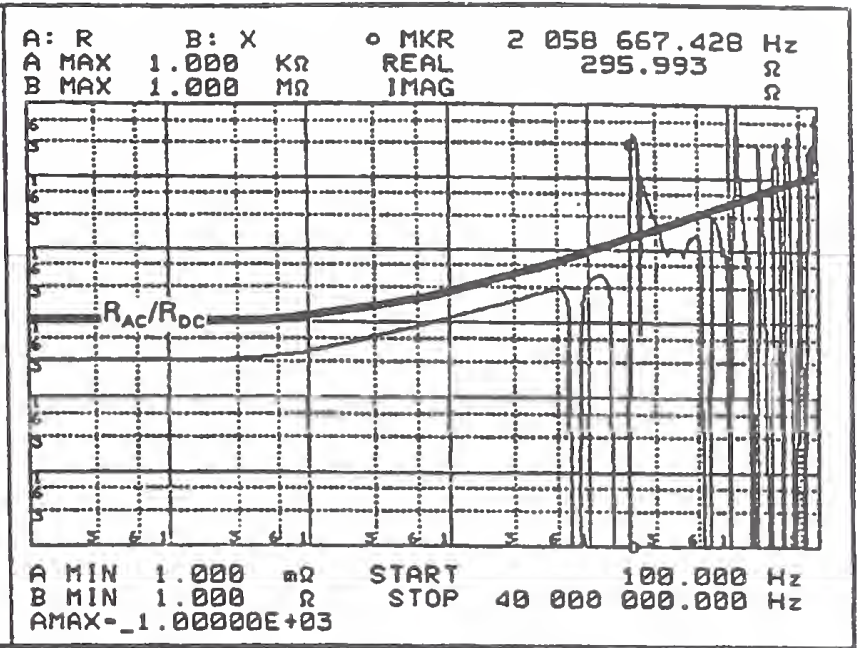

These measurements clearly demonstrate that inductance is the dominant factor over the frequency range corresponding to the applied surges. ${ }^{7}$ The skin effect in the conductors is only a second order factor ( $R$ on Figure 8 is $10 \Omega$ at $1 \mathrm{MHz}$, while $Z$ in Figure 7 is $100 \Omega$ at $1 \mathrm{MHz}$ ). The skin effect is significant for damping subsequent oscillations, but not for significantly limiting the propagation of the surges. It is also worthwhile to compare the measured effective resistance, which includes skin effect, to the skin effect computations embedded in the EMTP model. In Figure 8, a curve has been manually overwritten on the resistance plot, showing the ratio of $R_{A C} / R_{D C}$ computed with EMTP, where $R_{A C}$ is the effective resistance including skin effect and $R_{D C}$ the pure resistance.

\section{Transfer (Source) Impedance}

Because the voltages developed between appliance ports result from electromagnetic induction in the loop formed by the two systems, the transfer impedance of this coupling is of interest. Measuring only the open-circuit voltage between the two ports does not quantify the overvoltage threat. Any SPD that would be considered as a mitigation means for this scenario would "see" that transfer impedance as the impedance of the surge that the SPD would have to mitigate. To quantify that parameter, the classic technique of impedance matching was applied. Decreasing impedances were connected between the ports under measurements, until the recorded voltage reached half of its open-circuit value. The corresponding impedance is then equal to the "source impedance" - the interaction between the two systems. In this manner, information is provided for the design of any mitigation means that could or should be applied.

7. The frequency spectra of common surge test waveforms is given in [Standler, 1989]. With the exception of the Electrical Fast Transient Burst (EFT), all spectra show at least $80 \mathrm{~dB}$ down at $1 \mathrm{MHz}$. 
Table 1 shows the values of this source impedance for the loose and lashed configurations of the first scenario. It is interesting to note that the loose configuration produces higher open-circuit voltages than the lashed configuration, but that the "source impedance" of the loose configuration is greater than that of the lashed configuration.

\begin{tabular}{|c|c|c|c|}
\hline \multicolumn{4}{|c|}{$\begin{array}{c}\text { Table } 1 \\
\text { Effective source impedance of surge occurring between power and telephone ports }\end{array}$} \\
\hline \multirow{2}{*}{$\begin{array}{c}\text { Telephone wire and copper } \\
\text { pipe configuration }\end{array}$} & \multicolumn{2}{|c|}{ Measurement across loaded circuit } & \multirow{2}{*}{$\begin{array}{l}\text { Nominal effective } \\
\text { source impedance } \\
(\Omega)\end{array}$} \\
\hline & Load $(\Omega)$ & Voltage $(N)$ & \\
\hline \multirow{3}{*}{ Loose (300 mm apart) } & none & 5040 & \multirow{3}{*}{300} \\
\hline & 546 & 3200 & \\
\hline & 303 & 2560 & \\
\hline \multirow{3}{*}{ Lashed (16 mm apart) } & none * & 1300 & \multirow{3}{*}{120} \\
\hline & 303 & 800 & \\
\hline & 120 & 620 & \\
\hline \multicolumn{4}{|c|}{$\begin{array}{l}\text { This measurement was made for a } 75 \mathrm{~A} \mu \mathrm{s} \text { surge current rise time in the copper pipe, } \\
\text { using a differential probe with } 10 \mathrm{k} \Omega \text { input impedance. } \\
\text { Adding a load of } 10 \mathrm{k} \Omega \text { between the two ports (total load impedance now } 5 \mathrm{k} \Omega \text { ) did not } \\
\text { change substantially the measured voltage. }\end{array}$} \\
\hline
\end{tabular}

\section{Numerical Modeling with EMTP}

Concurrently, a numerical model of the wiring was developed with the EMTP code for the equivalent parameters of the circuit, as measured in the real Upside-Down House. The selection of the EMTP code for this modeling is based on its widespread use among researchers and engineers in the power systems area. While it was initially developed for modeling transmission systems, it can be applied successfully, as demonstrated in this paper and various other papers, for end-use circuitry. Its ready availability for easy replication, corroboration or expansion of our results among our colleagues made the EMTT desirable. Other researchers might prefer other codes, and would be welcome in applying them to the Upside-Down House data base for even wider acceptance of shared conclusions.

The 'Line Constants' subroutine of EMTP was used to generate various line models which were subsequently used in the main data file to compute the response of the circuit to various surge waveforms. A time step of $0.01 \mu \mathrm{s}$ was used for the EMTP simulation. Measurements taken with the impedance analyzer could have been directly used in the EMTP code. However, to provide greater flexibility for further parametric variations of circuit configurations, the Line Constants routine was used to generate the line models. This is only one example of the computational power available through the EMTP code. 
The surge current waveforms postulated (from the measurement recordings) in the two scenarios were generated in EMTP using the Type-15 double-exponential current source with a damping resistance in parallel. Experimentally-recorded waveforms of surge current were digitized and, using the least-square fitting technique, parameters for the Type-15 source were determined. The source parameter values, along with other necessary input data for simulation of the Upside-Down House components are given in Appendix B.

With the "Freeform FORTRAN" expression of the EMTP code, any surge current waveform that can be expressed as a closed form equation can be modeled. This capability provides a means for analyzing circuit response to various other surge waveforms now under consideration by standards-writing organizations. In view of the prime importance of initial rate of rise - over gross rise time and ultimate peak shown by the results, this capability will provide useful guidance in assessing the validity of postulated surge environment characteristics.

\section{Comparing measurement results and EMTP results}

First exposure scenario: Two systems serving one appliance

In this scenario, a modem-equipped PC is connected by its power port to a branch circuit, and by its modem port to the telephone service of the house. For a worstcase scenario, the power and telephone services enter the house at opposite ends (Figure 3). A surge is impinging on the telephone service entrance, and is diverted to the facility ground (typically the multi-grounded neutral system) by the telephone "Network Interface Device" (NID) installed at the point of entry. The surge current flows in the copper pipe, radiating a magnetic field that induces a voltage in the loop formed by the copper pipe and the telephone line between the entrance and the modem port of the PC. This voltage in effect appears between the modem port and the equipment-grounding conductor of the power port of the PC.

For this test, the applied surge was that obtained when applying the output of a KeyTek $801+$ surge generator delivering a standard surge, CCTTT $0.5 / 700 \mu$ s to the pair of telephone wires at the entrance, and returning from the grounding point of the Upside-Down House. The generator was set for a particular peak value of this well-defined waveform; however, the relatively large impedance of the loop presented to the surge generator resulted in the surge current waveform shown in the oscillograms of Figure 9, with a rate of rise of $75 \mathrm{~A} / \mu \mathrm{s}$. As we will see from the results, shown later in Tables 4 and 6 , the crucial parameter is the initial rate of current rise, not the amplitude or duration of the current surge. This fact makes any conclusions on the level of the threat directly dependant on the rate of rise, a parameter not well known in the real environment, compared to arbitrary, welldefincd tcst waveforms. For this rcason, the complete study includes some parametric variations, a few of which are presented later in this paper. 
Figure 9 shows the recording of the voltage measured between the power port and telephone port, as well as the EMTT-computed voltage for the same current waveform. The similarity of the two oscillograms is remarkable. The only (small) difference appears to be the damping; this damping is of course the result of the effective resistance of the circuit, including skin effect and current diffusion. During the EMTP modeling, several representations were used for the effective resistance, showing small differences in the damping. The oscillogram of Figure 9 was obtained for a frequency-dependent model of the resistance.

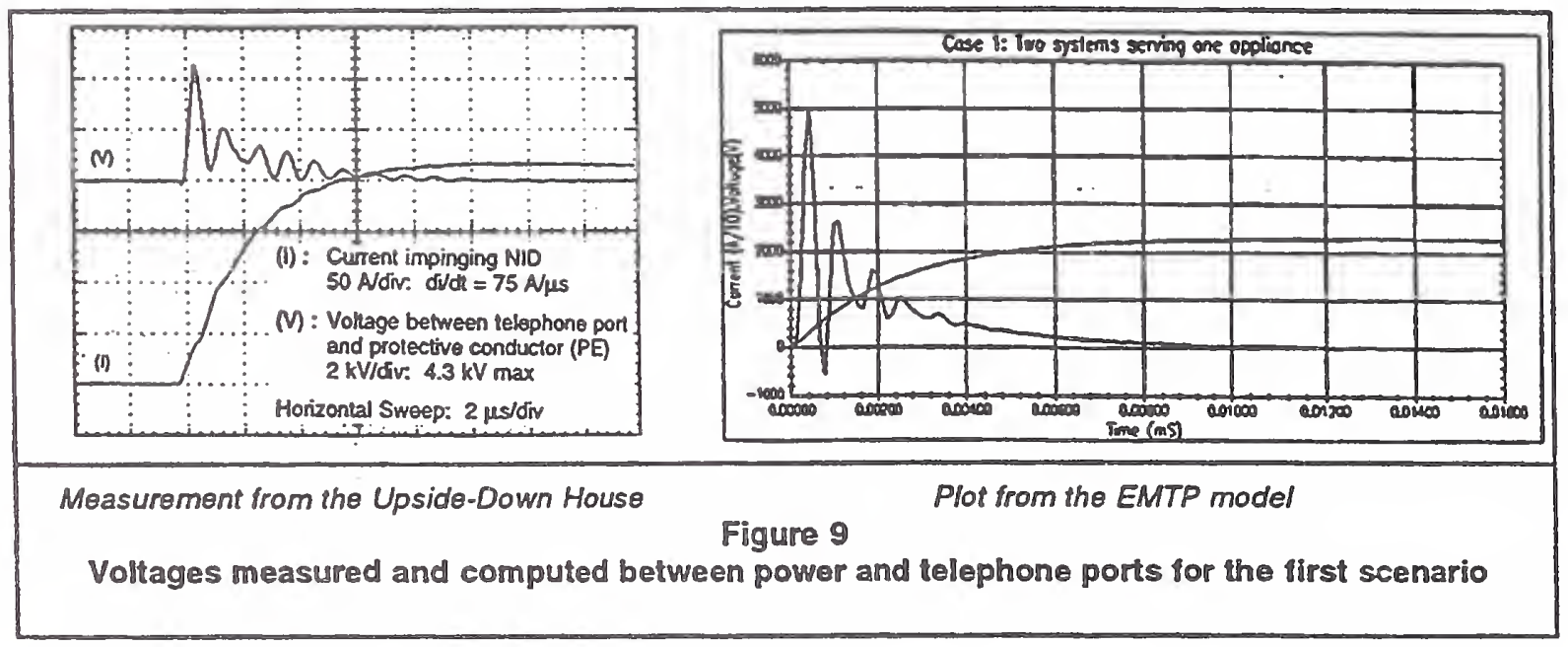

Second exposure scenario: One system serving two appliances

In this scenario, a PC and the associated printer are connected by the usual communications cable, and each is powered by a separate branch circuit. This situation is often encountered when a printer is shared among several users, or when an installation has been deliberately configured to provide a separation of the "clean" branch circuit supplying the PC from the "noisy" branch circuit supplying the printers and other peripherals (Figure 4). As a worst-case scenario, it is postulated that the PC power supply includes an SPD with line-to-ground protection (either built-in or provided as a plug-in addition by a careful, surge-conscious user), while the printer is postulated to have no line-to-ground SPD protection.

In an actual situation, the surge could occur internally on the "noisy" circuit, or occur from the outside. In the example of Figure 10, the surge was applied line-to-neutral at the service entrance, with an initial current rate of rise of $400 \mathrm{~A} / \mu \mathrm{s}$, the result of injecting a surge of $1400 \mathrm{~A}$ peak and $8 \mu$ sise time. Figure 10 shows the recording of the voltage measured between the two data ports of the printer and the PC, as well as the voltage computed by EMTP. As in the first scenario, the measured and the simulated oscillograms exhibit essentially the same characteristics, with only minor differences in damping. 


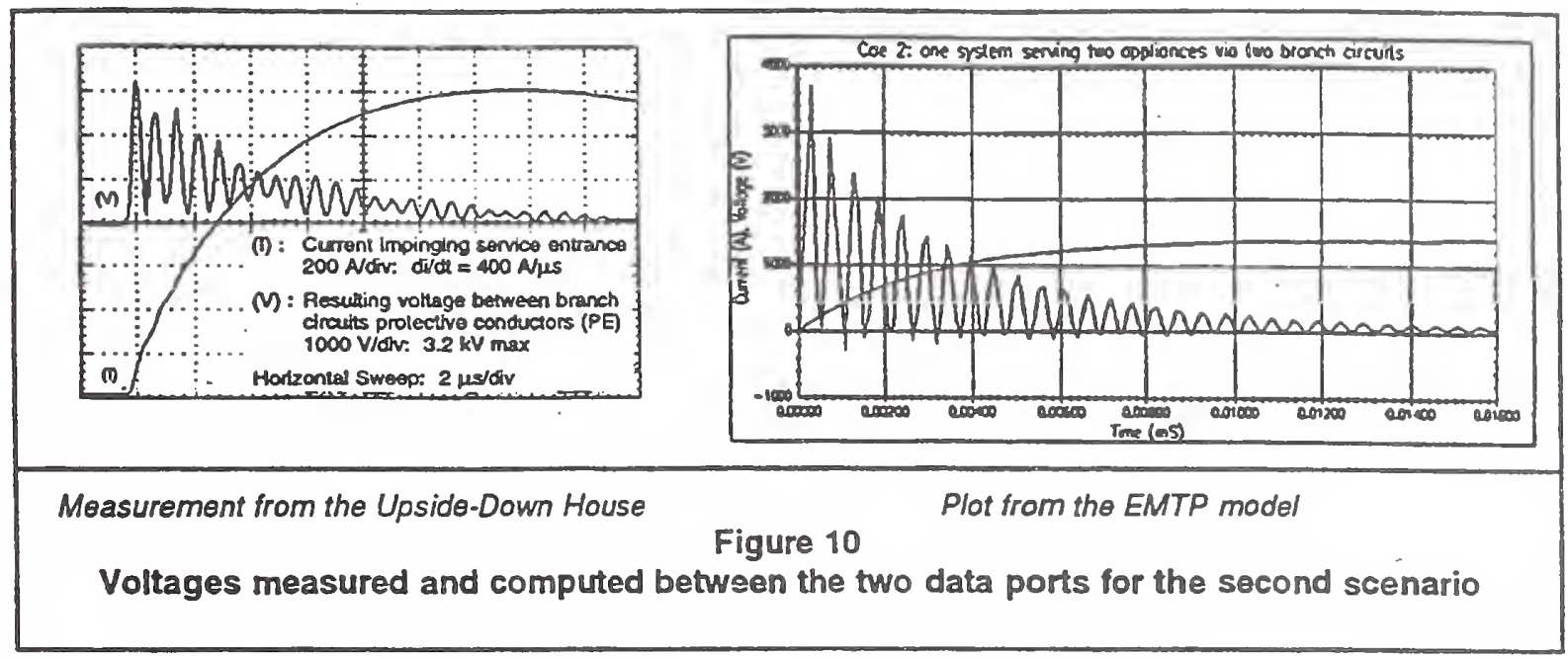

\section{Expansion of the scenario matrix through numerical modeling}

To illustrate the capability of simulation, several parametric variations were performed with the EMTP model. The following tables provide examples for the two scenarios.

\section{Parametric Variations for First Scenario}

\section{Table 2}

Effect of Distance from Telephone Wire to Copper Pipe on Voltage between PC-Modem Ports

\begin{tabular}{|l|c|c|c|c|c|c|c|c|}
\hline Distance $(\mathrm{m})$ & 0.1 & 0.2 & 0.3 & 0.4 & 0.5 & 0.6 & 0.8 & 1.0 \\
\hline Voltage $(\mathrm{kV})$ & 3.16 & 3.94 & 4.34 & 4.62 & 4.87 & 5.07 & 5.63 & 5.58 \\
\hline
\end{tabular}

The voltage increases as the separation of the telephone wire from the copper pipe increases, but at a slower rate $\cdots$ not surprisingly, the same observation was made in the discussion of Figure 2.

Table 3

Effect of Distance from Power to Tolephone Entrances on Voltage between PC-Modem Ports

\begin{tabular}{|l|c|c|c|c|c|c|c|c|}
\hline Distance $(\mathrm{m})$ & 10 & 20 & 30 & 40 & 50 & 60 & 80 & 100 \\
\hline Voltage $(\mathrm{kV})$ & 1.25 & 2.34 & 3.66 & 4.34 & 5.86 & 7.33 & 10.2 & 12.9 \\
\hline $\begin{array}{l}\text { Highest frequency } \\
\text { of overvoltage }(\mathrm{MHz})\end{array}$ & 5.0 & 3.3 & 2.5 & 1.5 & 1.2 & 1.0 & 0.66 & 0.59 \\
\hline
\end{tabular}

Thic tablc chows, predictably, the linearity between the separation between the two service entrances. The effect should be a strong incentive to providing entrances for the services at the same point of a building, a classic recommendation in EMC guidelines. 
Table 4

Effect of Surge Current Rate of Rise on Voltage between PC-Modem Ports

\begin{tabular}{|l|c|c|c|c|c|c|}
\hline Surge current rate of rise (A/L) & 25 & 50 & 75 & 100 & 150 & 200 \\
\hline Voltage (kV) & 1.20 & 2.27 & 4.34 & 5.98 & 10.9 & 20.2 \\
\hline
\end{tabular}

The increase in voltage is approximately proportional to the increase in the rate of rise. This should be expected because the circuit is essentially linear and, as discussed earlier, the inductive coupling of voltage in the loop is directly related to the rate of flux variation in the loop.

\section{Parametric Variations for Second Scenario}

Table 5

Effect of Branch Circuit Lengths on Voltage between Data Ports of PC and Printer

\begin{tabular}{|c|c|c|c|c|c|c|}
\hline Length of PC branch circuit (m) & \multicolumn{3}{|c|}{16} & 10 & 16 & 20 \\
\hline Length of printer branch circuit (m) & 10 & 21 & 30 & \multicolumn{3}{|c|}{21} \\
\hline Voltage between ports $(\mathrm{kV})$ & 4.41 & 3.69 & 3.55 & 2.27 & 3.69 & 4.25 \\
\hline
\end{tabular}

This table presents the effect of combining different branch circuit length for the two appliances. The major effect is still the presence of only one SPD connected line-to-ground, but different length of the branch circuits introduces yet another variable.

\begin{tabular}{|l|c|c|c|c|c|c|}
\hline \multicolumn{8}{|c|}{ Table 6} \\
\hline Eurge current rate of rise (A/s) & 200 & 300 & 400 & 500 & 600 & 800 \\
\hline Voltage (kV) & 1.82 & .2 .78 & 3.69 & 4.72 & 5.77 & 8.34 \\
\hline
\end{tabular}

In spite of the presence of a nonlinear element in the circuit (the SPD connected at the power port of one appliance), the proportionality of voltage to the surge current rate. of rise is maintained.

\section{Conclusions}

1. The close similarity of results from measurement and modeling provides mutual validation and gives confidence in the broad parametric studies.

2. The observed values of the overvoltages could be a threat to appliance survival; however, in the absence of reliable information on appliance immunity (which could eventually be provided by the manufacturers or obtained by extensive testing), especially between different system ports, no firm conclusion can be drawn at this time concerning the risks.

3. The most crucial factor for overvoltages is the initial rate of current rise of the surge, not rise time and peak. This fact is a challenge to the development of standards describing the expected surge environment, where arbitrary and always picture-perfect waveforms are defined by the peak amplitude and rise time, not by actual initial rate of rise.

4. Parametric information has been developed to allow defining other scenarios. The authors invite their colleagues to participate in a data base development. 


\section{Acknowledgments}

This project was made possible by the joint support of the National Institute of Standards and Technology (NIST) and the Power Electronics Applications Center (PEAC). NIST granted a sabbatical to Martzloff, allowing him to experiment with his concept of the "Upside-Down House." This Upside-Down House was installed at PEAC, with support of the Electric Power Research Institute, as a permanent facility of the Power Quality Testing Network. Numerical modeling was initially performed at the University of Texas (Austin) with support from PEAC, and pursued further at PEAC. Asif Jakwani performed the parametric variations at the University of Texas.

As noted in the reference section, many researchers have contributed to the general body of knowledge on surge occurrence, propagation, and mitigation. These cumulative contributions are acknowledged here, but not recited exhaustively.

The authors explicitly invite their peers to conduct similar experiments and computations to build a consensus on the threat represented by shifting reference voltages. Such a consensus would be an important step toward the development of standards for system compatibility in the not-quite-yet-defined surge environment.

\section{nererences}

Annotated Bibliography (Unpublished, on-going): Bibliographic information available to the authors includes over one hundred publications, and is still growing, on the subject of surge occurrence, propagation, and mitigation. For the sake of space conservation, these references are not recited here except those having direct bearing on the paper. The authors will gladly share upon request a working copy of this bibliography, and would welcome suggestions for additional listings.

EPRI, "Electromagnetic Transient Program (EMTP), Version 2.0; Volume 1; Main Program; Volume 2: Auxiliary Routines" EPRI Report EL-6421-L, July 1989.

Key, Thomas S. and François D. Martzloff, "Surging the Upside-Down House: Looking into Upsetting Reference Voltages" Proceedings, PQA'94 Conference, 1994.

Standler, R.B., Protection of Electronic Circuits from Overvoltages, New York: Wiley Interscience, May 1989. 


\section{Appendix A \\ Voltage Induced in a Loop Adjacent to the Surge-Carrying Conductor}

The flux density $B$ at a distance $R$ from a thin linear conductor of infinite length ( $R$ small compared to the length of the wire) carrying a current $I$ is given by: .

$$
B=\mu_{0} I / 2 \pi R
$$

For the case of a loop involving the telephone wire and the copper pipe (Scenario 1, Figure 3), the surge current in the copper pipe is approximated by:

$$
I=A\left(e^{C 1 t}-e^{\mathrm{C} 2 t}\right)
$$

Using least-square curve-fitting on the measured current surge waveform, we find the constants of the equation $A=235, C 1=-1600$, and $C 2=-400000$. We assume that for the Upside-Down House dimensions, small compared to the wavelength, the surge is propagated instantaneously around the circuit. The usual criterion for "small" in comparison with the wavelength is a ratio of $1 / 8$, which holds true here for a wavelength of $300 \mathrm{~m}$ at $1 \mathrm{MHz}$, compared to the $18 \mathrm{~m}$ of each half of the loop. According to Faraday's Law, the total emf induced in a closed circuit is equal to the time rate of change of the total magnetic flux linking the circuit. In symbolic form:

$$
v=-d \phi_{m} / d t
$$

The total flux through a circuit is equal to the integral of the normal component of the flux density $B$ over the surface bounded by the circuit. The total magnetic flux is:

$$
\phi_{m}=\int B \cdot d s
$$

Combining the two equations, and substituting the expression for the surge current waveform, we get the peak value of the voltage induced in the loop of unit length and radius $10 \mathrm{~m}$ :

$$
V=\left[\mu_{0} A / 2 \pi\right](C 2-C 1) \ln 10 /\left.R_{0}\right|_{R_{0} \rightarrow \varepsilon}
$$

Thus, the normalized voltage induced in a rectangular loop of unit length and radius $R$, in percent of the total voltage induced in a loop of $10-\mathrm{m}$ radius (Figure $A 1$ ), is:

$$
\% \text { of voltage induced }=\left[\ln R / R_{0}+\ln 10 / R_{0}\right] \times 100 \%
$$

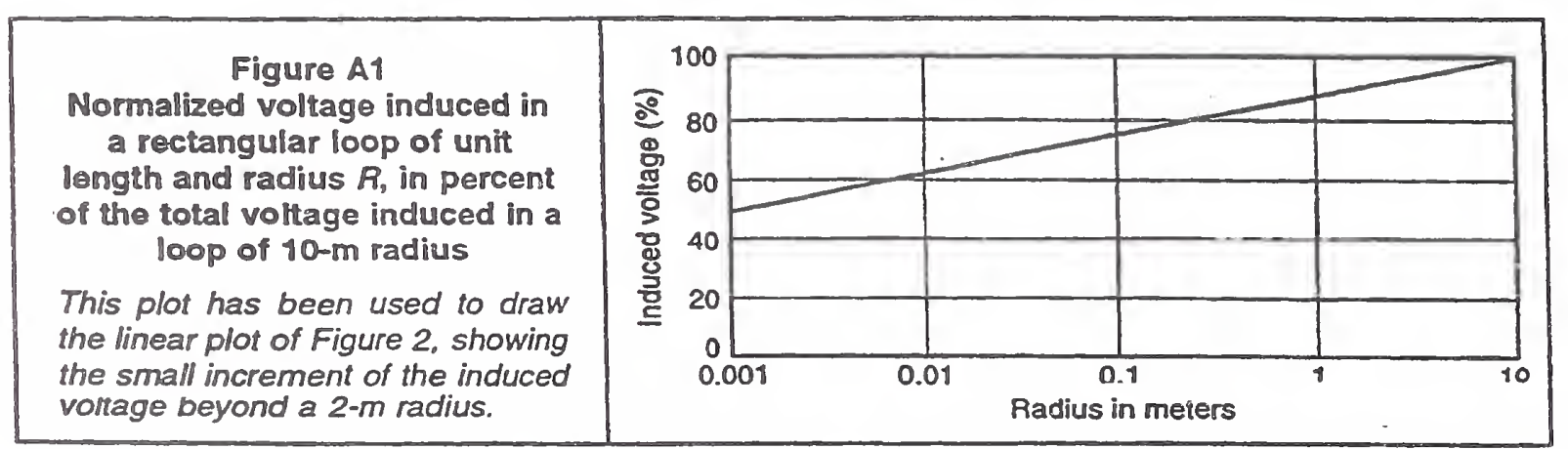




\section{Appendix B \\ EMTP Input Data for Simulation of the Upside-Down House}

\section{B1 - First exposure scenario: Two systems serving one appliance}

Surge Current Model: EMTP Type 15 double-exponential source. The parameter values are: Amplitude 235, Coefficients: $C 1=-1600, C 2=-400000$.

Line model: The EMTP 'Line Constants' auxiliary routine was used to determine the impedance parameters of the telephone wire - copper pipe configuration. The line models that were used for the simulation include frequency dependent, constant parameter traveling wave, and coupled R-L-C lumped model at $500 \mathrm{kHz}$ [EPRI, 1989].

Instead of using impedance measurements results directly in the simulation (as was initially planned when making the experimental measurements), the 'Line Constants' routine was used to allow variation in line configuration for parametric studies. No noticeable difference was observed in the voltage computed between the two ports for the different line models. The input data used for the 'Line Constants' program are:

Telephone wire pair: diameter $0.5 \mathrm{~mm}$ each; $0.25 \mathrm{~mm}$ insulation; $R_{D C}=87.8 \Omega / \mathrm{km}$ Copper pipe: $22.23 \mathrm{~mm}$ outside diameter; $19.05 \mathrm{~mm}$ inside diameter; $\mathbb{R}_{D C}=0.0161 \Omega / \mathrm{km}$

For the loose configuration, the distance between the center of the telephone wire pair and the copper pipe was $300 \mathrm{~mm}$. In contrast, for the lashed configuration, it was only $16 \mathrm{~mm}$ - but not zero, see the plot Al of Appendix A

B2 - Second exposure scenario: Two appliances powered by two branch circuits

Surge Current Model: EMTP Type 15 double-exponential source. The parameter values are: Amplitude 1400, Coefficients: $\mathrm{C} 1=-50, C 2=-340000$.

Surge-Protective Device Model: The SPD connected at the end of one branch circuit is modeled as a piecewise linear resistance using the Type-92 nonlinear device model in EMTP. The I-V characteristic of the device is obtained from experimental measurements on the actual device and interpolation from typical characteristics for such devices, as shown in Table B1.

Table B1

I-V Characteristic of SPD connected Line-to-Ground at end of one branch circuit

\begin{tabular}{|l|c|c|c|c|c|c|c|}
\hline Amperes & 0.001 & 001 & 01 & 1.0 & 100 & 1000 & 10000 \\
\hline Volts & 199 & 218 & 239 & 263 & 316 & 360 & 380 \\
\hline
\end{tabular}

Line model: The input data used for the 'Line Constants' program are:

Conductor diameter $=2.05 \mathrm{~mm}$; insulation thickness $=1.0 \mathrm{~mm} ; R_{D C}=5.21 \Omega / \mathrm{km}$ 
Q 


\section{Driving High Surge Currents into Long Cables: More Begets Less}

\author{
Arshad Mansoor, Member, IEEE \\ Power Electronics Applications Center \\ Knoxville TN 37932 USA \\ Amansoor@epri-peac.com
}

\author{
François Martzloff, Life Fellow, IEEE \\ National Institute of Standards and Technology \\ Gaithersburg MD 20899 USA \\ f.martzloff@ieee.org
}

\section{Significance:}

Part 2 Development of Standards - Reality checks

Part 4 Coupling and propagation of surges

In the propagation of a surge current injected at the service entrance of a building, two significant factors can prevent the propagation of a postulated "large" surge current to the end of the branch circuits of the facility.

1. The combination of the inherent inductance of the wiring and the high rate of current change for such a current to begin flowing into the branch circuit results in a high voltage at the driving end ( $V=L x d i / d t)$.

2. In the absence of a surge=protective device at the service entrance, the withstand voltage of the wiring devices at the driving end - the service entrance - is very likely to be exceeded by the voltage that this rising current will develop along the branch circuit.

The resulting flashover will abort further propagation of the surge current toward the far end, thus establishing a limit to what is physically possible. If there is a surge-protective device at the service entrance, the scenario becomes a matter of cascade coordination.

The paper provides quantitative information on this limitation, as a function of wiring length and current rate of rise. 
Q 


\section{Driving High Surge Currents into Long Cables: More Begets Less}

\author{
Arshad Mansoor, Member, IEEE \\ Power Electronics Applications Center \\ Knoxville, TN 37932 USA
}

\author{
François D. Martzloff, Life Fellow, IEEE \\ National Institute of Standards and Technology ' \\ Gaithersburg, MD 20899 USA
}

\begin{abstract}
Reality checks can and should be applied to proposals for characterizing the surge environment and application of surgeprotective devices (SPDs) to end-user, low-voltage power systems. One such check is the fact that driving a large current with steep front toward an SPD installed at the far end of a branch circuit cable could require such a high voltage that the connections at the near end of the cable will flashover, limiting the stress applied to the far-end SPD. Tests and numerical modeling were performed to support this thesis. The results of real-world measurements and modeling, presented in the paper, are in good agreement and validate each other. From that point on, the model allows parametric variations of cable length and surge current amplitude and waveform, of which several examples are presented.
\end{abstract}

\section{INTRODUCTION}

In the never-ending quest for better data on the frequency of 'occurrence and level of threat of overvoltages, we should not overlook some "reality checks" that can be applied to proposals for characterizing the surge environment. One such check is the fact that forcing a large surge current with steep front toward a surge-protective device (SPD) installed at the far end of a branch circuit cable could require such a high voltage that the wiring device connections at the near end of the cable will flashover, limiting the stress applied to the far-end SPD.

1 Electricity Division, Electronics and Electrical Engineering Laboratory, Technology Administration, U.S. Department of Commerce

96 SM 399-6 PWRD A paper recommended and approved by the IEEE Surge Protective Devices Committee of the IEEE Power Engineering Society for presentation at the 1996 IEEEJPES Summer Meeting, July 28 - August 1, 1996, in Denver, Colorado. Manuscript submitted December 28, 1995; made available for printing June 19, 1996.
Large surge currents considered by standards-writing bodies and discussed in this paper are presumed to impinge from the outside of a building, as a result of a direct or indirect lightning flash. These involve postulated rise times in the order of a few microseconds, with a duration ranging from a few tens to a few hundreds of microseconds. While there are different propositions made on what duration should be considered as "representative" waveforms, there is a consensus on rise times ranging from about $4 \mu \mathrm{s}$ to $20 \mu \mathrm{s}$ [1]. However, consensus on what value to select for "representative" amplitude(s) has been challenged by proposals to increase the current surge capability of devices intended for installation at the end of branch circuits.

A growing trend in the application of SPDs to residential or commercial installations is to provide "whole-house protection" with an upstream SPD connected at the service entrance, and downstream SPDs in the form of plug-in devices installed at receptacles. Selecting the ratings for these two devices is the subject of some debate. The voltage rating of the devices introduces the issue of cascade coordination which has been addressed at length in the literature [2]-[8] and will not be discussed here. At this point in time, the vast majority of installations do not include an upstream SPD intentionally connected at the service entrance, other than a gap in the revenue-meter socket. This gap is provided by the meter manufacturer to protect the meter more than the downstream installation. Nevertheless, there are other "gaps" at the service panel - the clearances of the wiring devices, which have some limits to their voltage withstand capability.

\section{SURGE PROPAGATION IN WIRING}

The possibility of a clearance flashover is the basis of our thesis: If a large surge current is postulated as propagating downstream (and then taken as a requirement for the downstream SPD), the propagation characteristics of this surge current would result in high voltages at the service entrance, upstream. In turn, the high voltage would cause flashover of upstream clearances, acting as a relief valve for the surge energy headed for the downstream SPD. This relief action would then contradict the proposed requirement for high energy-handling capability of the downstream SPD. Thus, appropriate selection of current ratings for the downstream SPD, in the light of our thesis. should take into consideration this reality check that defines an upper limit for the current rating required for the downstream SPD. 
The surge propagation characteristics mentioned in the preceding paragraph are controlled by three parameters: the impinging surge, the impedance of the wiring from the service entrance to the downstream SPD, and the I-V response of the downstream SPD. The impinging surge could be considered either as a voltage source or as a current source. The present consensus is to consider it as a current source, resulting from the coupling and subsequent division of a lightning surge, part of which impinges on a given service entrance.

The impedance of the wiring is that of two parallel wires of known dimensions and separation. It can be represented either by lumped parameters - series $\mathrm{R}$ and $\mathrm{L}$ and parallel $\mathrm{C} \mathrm{--} \mathrm{or} \mathrm{by} \mathrm{a}$ "short" transmission line. The reason for placing quote marks around the qualifier of "short" is that the term is to be viewed by comparing travel time over the length of the transmission line and duration of the traveling pulse - another subject discussed in the literature [9] that we will not discuss here, with the exception of a brief comparison of results obtained when modeling the propagation with lumped parameters or with a transmission line.

When using the lumped RLC model, during the rise of the surge current, the significant parameter of the wiring impedance is its inductance, $\boldsymbol{L}$. The voltage at the upstream end resulting from driving the surge current into such an impedance is primarily $L \times d i / d t$, with didt determined by the amplitude and rise time.

By performing surge measurements on real-world wiring components, followed by numerical modeling with the ElectroImagnetic Transients Program (EMTP) ${ }^{2}$ [10], this proposition can be verified and applied to a range of postulated surge waveforms and typical configurations found in the premises wiring of lowvoltage systems. These results will allow developing realistic recommendations for the rating of SPDs offered for surge protection at the equipment location - either as plug-in additions by the end-user, or as permanently wired devices at the end of typical branch circuits. The measurement results also show the need to consider the possibility of "blind spots" in the protection schemes, and illustrate our title paradox of "more begets less."

Measurements were conducted on a simple circuit consisting of 9 meters of nonmetallic jacket cable typical of residential installations, with a metal-oxide varistor connected downstream at the far end. A Combination Wave surge generator, suitable for producing the waveform described in IEEE/ANSI C62.411992 [1] was used to inject a surge current at the upstream end of the cable. Current and voltage waveforms were recorded. The current waveform resulting from this injection was duplicated in a closed-form equation to be applied as the postulated surge current injected into the EMTP model of the circuit, allowing computation of the corresponding voltages.

\footnotetext{
${ }^{2}$ Certain commercial instruments and software packages are identified in this paper in order to adequately specify the experimental procedure. such tdenturication does not umply recommendation or endorsement by the National Institure of Standards and Technology, nor does it imply that these are necessarily the best available for the purpose.
}

\section{MEASUREMENTS AND MODELING}

\section{A. Characterizing the varistor}

First, the varistor to be connected at the far end was tested to determine its I-V response and demonstrate that the model to be used for this highly nonlinear component would be adequate to simulate its behavior in the circuit when connected at the downstream end. Figure 1 shows the test circuit used for making that measurement. The surge generator used for the tests was the KeyTek 711 with a P7 wave-shaping output network.

The varistor used in these tests was a 20-mm diameter metaloxide varistor (MOV) disc, rated $130 \mathrm{~V} \mathrm{rms} \mathrm{(200} \mathrm{V} \mathrm{at} 1 \mathrm{~mA} \mathrm{dc}$ ). The inductance $L p$ shown in series with the varistor is not a deliberate addition of a real component, but is the representation of the coupling between the loop where the surge current flows and the voltage measurement loop formed by the varistor leads and the two probes used for the differential measurement. That inductance is included in the model as a discrete series inductance, with a value of $0.5 \mu \mathrm{H}$ selected to emulate the observed voltage at the point of measurement -- which is not the "pure" varistor voltage, as discussed in the narrative of Figure 2.

Figure 2 shows the recording obtained for a particular setting of the surge generator, and Figure 3 shows the result of modeling the circuit shown in Figure 1 for an injected current surge corresponding to the actual current surge recorded in Figure 2. The equation used for the modeling is a damped sine wave that allows a close approximation of the current delivered by typical Combination Wave generators into inductive loads [7]. It is known that actual generators tend to produce an "undershoot" when connected to an inductive load, and this test was no exception. However, computational artifacts occur when using a simple damped sine wave because its di/dt derivative (a cosine) is not zero at time zero. Furthermore, we know that nature does not allow an instantaneous jump of current from zero to a steep rise. By adding a multiplier term [1- $\left.e^{(-t)}\right]$, these artifacts are eliminated and the waveform has a "gentle toe" which is a better model of reality. This improved equation is then:

$$
I=4200 * \sin (0.126 t) * \mathrm{e}^{(-1 / 28.1)} *\left[1-\mathrm{e}^{(-t)}\right]
$$

with $I$ in amperes and $t$ in microseconds.

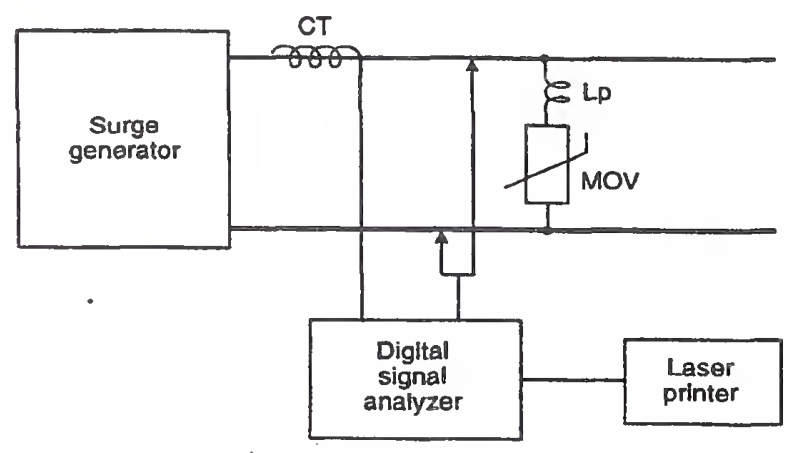

Figure 1- Test circuit for determination of the I-V characteristics of the varistor 


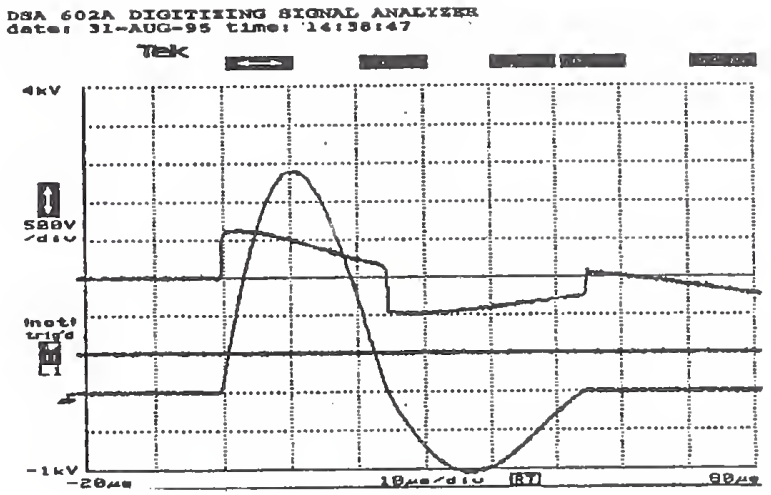

Top trace: Voltage, $500 \mathrm{~V} / \mathrm{div}$

(Center trace: inactive)

Bottom trace: Current, $500 \mathrm{Avdiv}$

Sweep: 10 us/div

Figure 2 - Real-world recording

Inspection of Figures 2 and 3 clearly shows the agreement between real-world measurements ${ }^{3}$ and model, and thus merits some observations. One might have expected a flat-top voltage waveform reflecting the clamping action of the varistor. Instead, a drooping waveform is observed. This droop is caused by the parasitic inductance $L p$ in series with the ideal varistor. At the time of current peak ( $d i / d t=0)$, the "true" varistor voltage is seen on the oscillogram. Before the peak, the positive $L p \times d i / d t$ adds a spurious voltage to the recording. After the peak, the Inegative $L_{p} \times d i / d t$ subtracts the spurious voltage.

These observations are significant in appreciating the allimportant inductive effects during the rise and fall of a surge current in the wiring of branch circuits. The issue of the importance of inductance versus other circuit parameters [11] hopefully has been put to rest by the surge and impedance measurements with corresponding computations performed in the so-called "Upside-Down House" [12], a real-world replica of a typical residential wiring system. In [12], it was shown that inductive effects prevail, so that rate of rise of the surge current and circuit inductance, more than any other parameter, are the significant parameters for the voltage necessary at the upstream end to drive a given current into the branch circuit.

The model used in the simulation for the varistor is derived from the published varistor I-V characteristic (general shape and slope of the curve) with one specific point defined by the "true" varistor voltage read from the oscillogram of Figure 2 at the point of zero $L p \times d i / d t$ contribution. In turn, this varistor model will be used for the modeling of a varistor connected at the downstream end of a branch circuit, as discussed in the following reported measurements and simulations.

${ }^{3}$ The measurements reported in this paper have been made with instrumentation for which the cumulative uncertainty should not exceed I to $0 \%$. Given the process of applytng the measurement results to the response of surge-protective devices exposed to environment with lcharacteristics that are at best known within an order of magnitude, this level of uncertainty does not affect the practical conclusions.

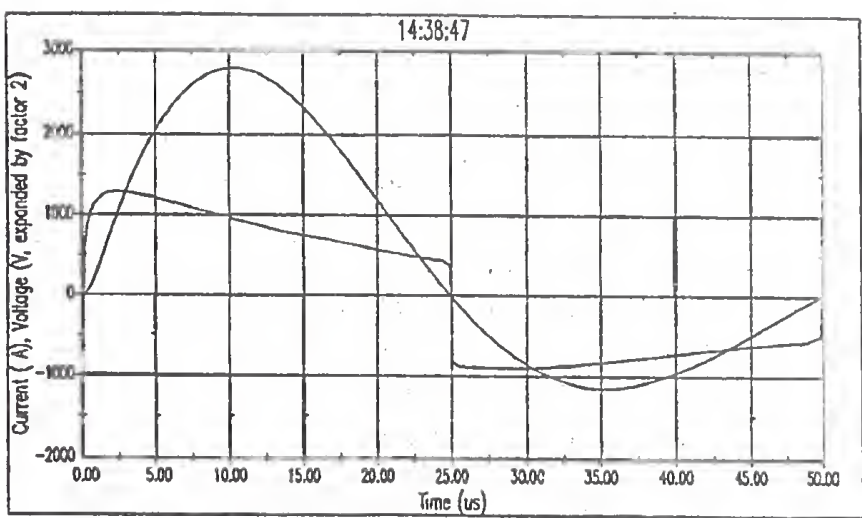

Note: the voltage trace has been expanded by a factor of 2 to enhance resolution on the vertical scale.

Figure 3 - Modeling the circuit of Figure 1 with the impinging current set to match the test current, as shown in Figure 2

\section{B. Measurement and modeling with varistor installed at the downstream end of a branch circuit}

The circuit of Figure 4 shows the varistor characterized by the test and modeling in the preceding paragraphs, connected at the downstream end of a "branch circuit" consisting of two copper conductors of $2-\mathrm{mm}^{2}$ cross-section (\#12 AWG) with solid insulation and a separation of $6 \mathrm{~mm}$ between centers. The first current transformer monitors the total current impinging at the upstream end. The second current transformer monitors the current flowing toward the downstream end, which will be imposed on the varistor. The clearances at the upstream end, such as clearances in a service-entrance panel, are represented by a discrete gap that will be set to produce sparkover at some given voltage during the test as well as in the model.

Figure 5 shows the recording obtained with the circuit of Figure 4, with the surge generator left at the same setting as that used for Figure 2. To determine the response of the circuit without the clearance limitation, the gap setting was adjusted for this test so that no sparkover occurred at the upstream voltage developed for the current delivered by the generator.

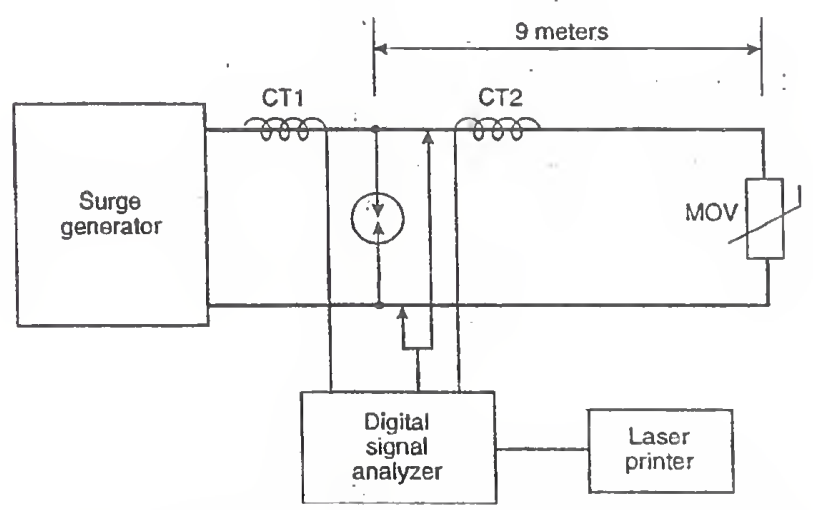

Figure 4 - Test circuit for determination of the voltage necessary at the sending end to drive a givem current into the far-end SPD 


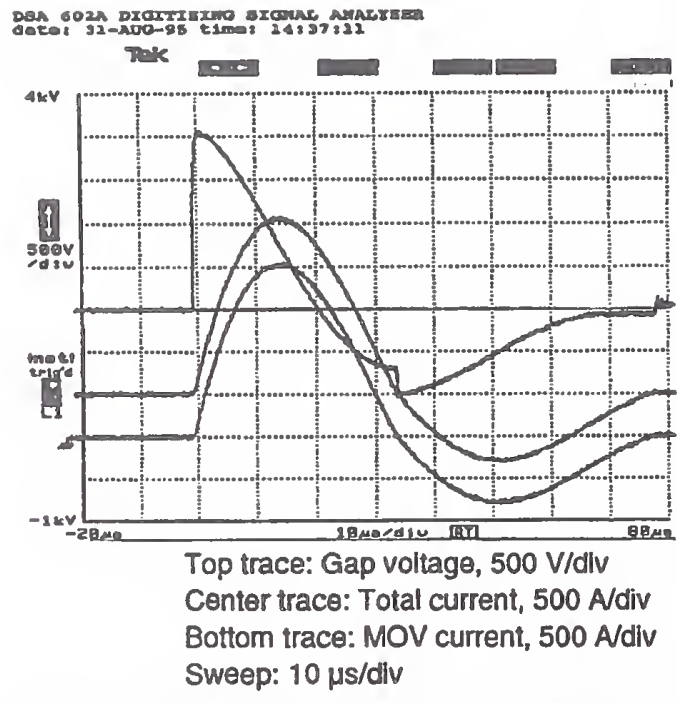

Figure 5 - Real-world recording of sending-end vollage with gap set for no sparkover

Comparing the traces of Figure 5 and Figure 2, the addition of the inductance of the 9 meters of branch circuit changes the load on the surge generator, reducing the current peak from the $2.8 \mathrm{kA}$ in Figure 2 down to $2 \mathrm{kA}$ in Figure 5 .

The two current traces of Figure 5 are identical. Since there is no current diverted by the gap, the current in the branch circuit is the same as the current delivered by the surge generator.

Another effect of the added inductance is the increase in the time from origin to the first current zero, $33 \mu \mathrm{s}$ in Figure 5, compared to $25 \mu \mathrm{s}$ in Figure 2. In the subsequent model, that change of the actual impinging current surge is taken into consideration by modifying the current equation as follows:

$$
I=3571 * \sin (0.095 t) * \mathrm{e}^{(-t / 26.1)} *\left[1-\mathrm{e}^{(-t)}\right]
$$

with $I$ in amperes and $t$ in microseconds.

Turning to the modeling, Figures 6 and 7 show the waveforms of the impinging current, as defined by Eq. (2), and the resulting voltage at the upstream end. To address some concerns expressed by colleagues in discussions of this subject, the EMTP modeling was also done with the transmission-line model which is readily available in the EMTP code. Figure 6 was obtained with the lumped-parameter circuit model, and Figure 7 was obtained with the transmission-line model.

Inspection of the two figures reveals no difference in the results. The only difference is in the consumption of computing time: with the transmission line model, the computation timestep has to be significantly shorter $(0.02 \mu \mathrm{s}$ in this case) than the travel time for the reflections, while in the case of the lumped model, the time-step can be longer ( $0.1 \mu \mathrm{s}$ in that case). The result is that the simulation of Figure 6 took 43 seconds on a 486-based PC, compared to 263 seconds for Figure 7. Therefore. the lumped-narameter morlel ic perfertly arlequate to represent reality, and performing a transmission-line analysis [5] is an unnecessary consumption of computing time and resources.

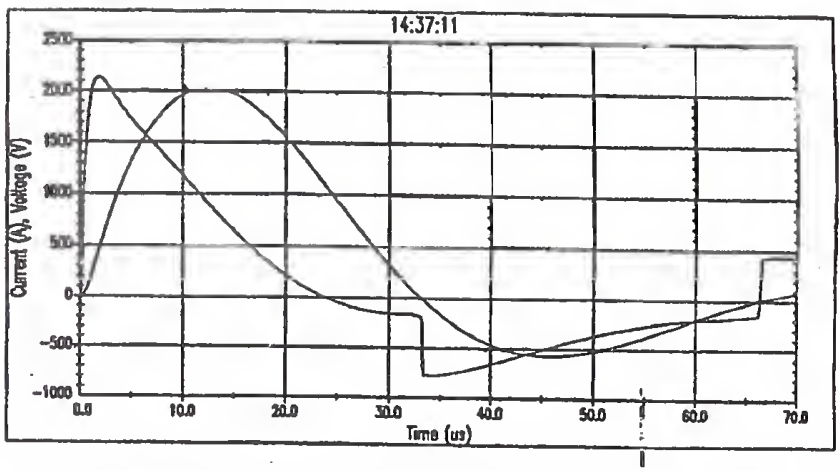

Figure 6 - Impinging current and resullting upstream voltage as computed with lumped-parameters model

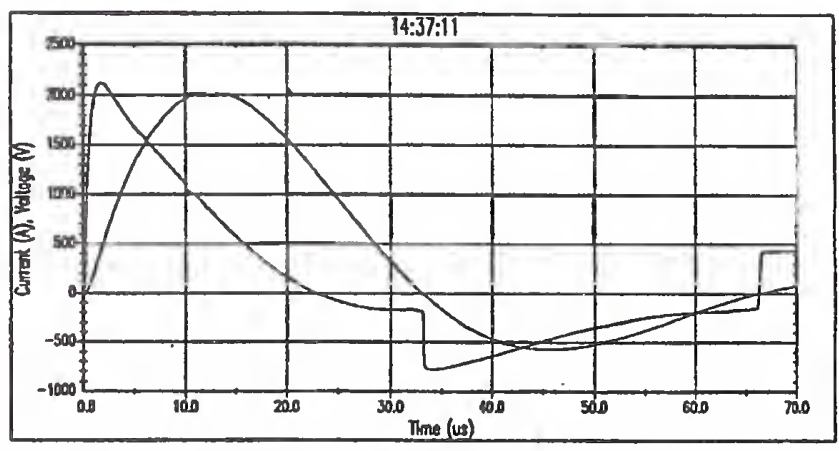

Figure 7 - Impinging current and resulting upstream voltage as computed with transmission-line model

In both Figures 6 and 7, the effect of the branch circuit inductance on the resulting voltage is apparent as the peak voltage occurs at the beginning of the rise (as soon as the "gentle toe" effect ceases), not at the peak of the current. The step change in the voltage trace corresponds to the reversal of the current in the varistor, showing the relative contributions of the varistor effect and of the inductive effect as seen from the upstream end.

Table 1 below shows the results of such computations for the waveform of Figures 5, 6 and 7. As mentioned above, the insertion of an inductance in the load connected to the surge generator increased the rise time beyond the standard $8 \mu \mathrm{s}$. In making the parametric computations, we chose to stay with this $10 \mu$ s value to maintain continuity with the test/model validation.

\section{TABLE 1}

Upstream voltage (in $\mathrm{kV}$ ) necessary to drive a current of the peak value shown (collumns) and rise time of $10 \mu$ into a branch circuit of length as shown (rows), terminated with a $130-\mathrm{V}$ rated varistor

\begin{tabular}{cccccc}
\hline Length $\backslash$ Peak & $2 \mathrm{kA}$ & $3 \mathrm{kA}$ & $5 \mathrm{kA}$ & $7 \mathrm{kA}$ & $10 \mathrm{kA}$ \\
\hline $10 \mathrm{~m}$ & 2.3 & 3.3 & 5.2 & 7.2 & 10.1 \\
$30 \mathrm{~m}$ & 5.8 & 8.5 & 13.9 & 10.1 & 27.0 \\
$50 \mathrm{~m}$ & 9.3 & 13.7 & 22.7 & 31.6 & 45.0 \\
\hline
\end{tabular}




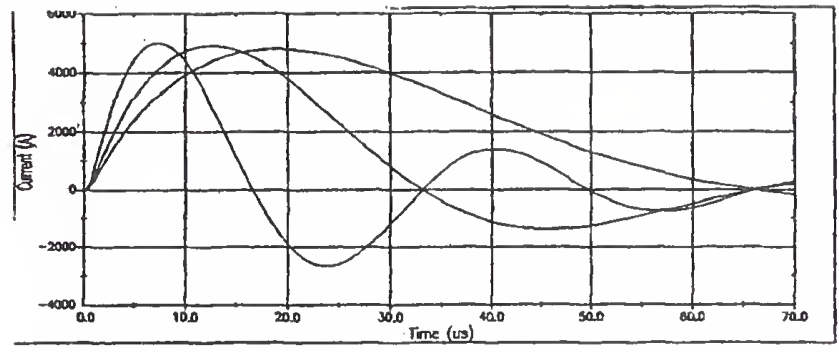

Figure 8 - Three surge current waveforms with different rise times used to compute the values of Table 2

Figure 8 shows three waveforms of same amplitude, with nominal rise time of $5 \mu \mathrm{s}, 10 \mu \mathrm{s}$, and $20 \mu \mathrm{s}$, obtained by taking half or double of the frequency used in Eq. (2). The actual rise time $[1.25 \times$ (time from $10 \%$ to $90 \%$ )], as opposed to the nominal rise time used to describe the waveforms, was computed as well as the maximum rate of rise for each wave. The maximum rate of rise (which is obtained when the second derivative of the current is equal to zero) occurs initially, once the gentle toe is over, and determines the maximum resulting voltage produced by the inductive effect. Table 2 shows the corresponding values of the rise time, maximum rate of rise, and resulting voltage for a branch circuit length of $10 \mathrm{~m}$ and amplitude of $5 \mathrm{kA}$. Note that for a 1-to-4 increase in nominal rise time, the maximum di/dt decreases only by one half, with the same decrease appearing in the resulting voltage, showing once again that initial rate of rise is more important than rise time and amplitude.

TABLE 2

Effect of the rate of rise of the postulated current on the resuiting voltage at the upstreame end of the branch circuit

\begin{tabular}{lccc}
\hline Nominal rise time, $\mu \mathrm{s}$ & 5 & 10 & 20 \\
\hline Actual rise time, $\mu \mathrm{s}$ & 4.3 & 9.5 & 13.5 \\
\hline Maximum di/dt, $\mathrm{A} / \mu \mathrm{s}$ & 1250 & 850 & 630 \\
\hline Resulting voltage, $\mathrm{kV}$ & 7.0 & 5.2 & 3.6 \\
\hline
\end{tabular}

In the scenario tested and modeled so far, no flashover possibility was considered. Nevertheless, the values shown in Table 1 clearly indicate that some real-world circuit lengths and surge parameters postulated in some SPD application standards under development can produce high upstream voltages that will cause a flashover of the upstream wiring devices.

\section{The paradox of "more begets less"}

Common-sense intuition might lead the unwary to expect that higher surge currents would impose a greater stress on the circuit components, including the downstream varistor. Also, a longer branch circuit, with its corresponding higher inductance, could be expected to have the capability of storing more energy during build-up of the surge current toward the downstream varistor, into which that storod onorgy ultimately' has to be dissipated. Cascade coordination studies [4], [6], [8], have shown that in some cases, the downstream varistor continues to carry current long after the impinging surge current has gone past its peak.
To explore the validity of such expectations, we performed tests and modeling, with an actual gap in the test circuit, and a switch in the model circuit, to bypass the current at the upstream end when sparkover voltage is attained. By measuring the current that flows in the branch circuit toward the downstream varistor and the voltage across the varistor, the energy deposited in the varistor during the total surge event can be determined. Likewise, the modeling can determine the current in the varistor, hence the voltage across it, and allow computation of the energy.

In [4], agreement was reported between, on the one hand, computing the deposited energy through actual measurement of the current and voltage, followed by computation of the energy by means of the digital signal analyzer usèd for measurements and, on the other hand, the model computations. Therefore, in the tests reported here, we were satisfied to verify waveform agreement between the actual varistor current measurement and the computed varistor current, and let the model alone compute the energy deposited in the downstream varistor.

Figure 9 shows the real-world recording of the situation that develops for a "clearance" sparkover of $2 \mathrm{kV}$. This relatively low value, compared to the $6 \mathrm{kV}$ to $10 \mathrm{kV}$ level that we might expect from typical low-voltage wiring devices, is made necessary for the test case where only 9 meters of branch circuit were considered, and the setting of the surge generator was maintained at the same nominal $3 \mathrm{kA}$ short-circuit current. The object, of course, is to demonstrate that the clearances are likely to flash over, as indicated by progressively higher values of the necessary upstream driving (or resulting) voltage shown in Table 1.

Under the conditions of Figure 9, sparkover of the gap occurred at approximately $1 \mu \mathrm{s}$. After sparkover, the current delivered by the surge generator is the sum of the currents in the gap and in the branch circuit. Its peak $(3.2 \mathrm{kA})$ is greater than those of Figures 2 and 5 because the generator does not need to overcome the varistor that reduced the voltage available for driving the current, nor the impedance of the 9 meters of cable.

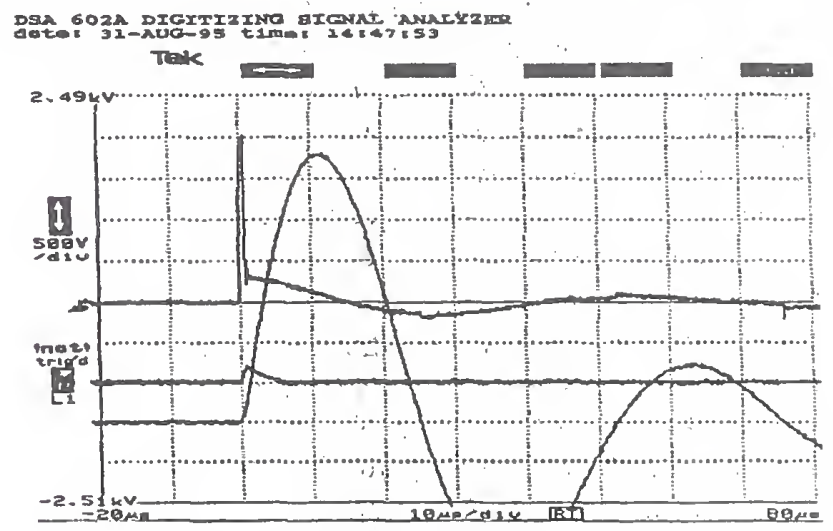

Top trace: Resulting voltage, $500 \mathrm{~V} / \mathrm{div}$

Center trace: MOV current, $500 \mathrm{~A}$ div Botrom irace: I olail currenl, suU Avalv Sweep: $10 \mu$ s/div

Figure 9 - Voltage and currents with gap sparkover at $2 \mathrm{kV}$ 
Figures 10 and 11 show the results obtained by the model for voltages and current in the circuit. In the modeling, only one current waveform was applied to the circuit, the one prevailing until flashover occurs, which the postulated current-source real world would maintain. In contrast, the surge current delivered by the surge generator (Figure 9) increases after the flashover, but that is not relevant to our consideration of what happens to the circuit before and up to the time of flashover.

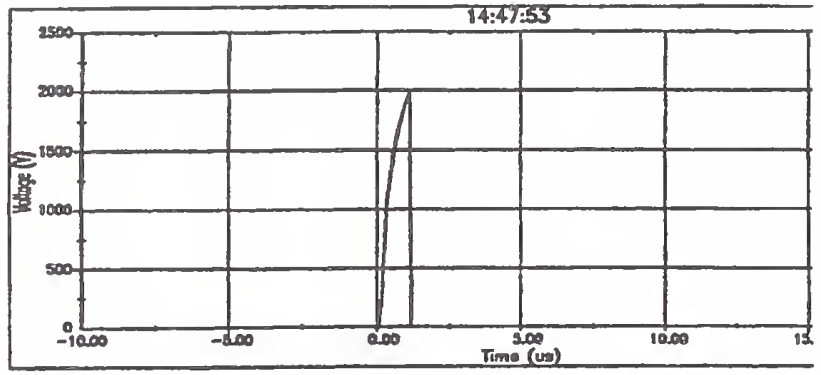

Figure 10 - Voltage across the gap set to sparkover at $2 \mathrm{kV}$

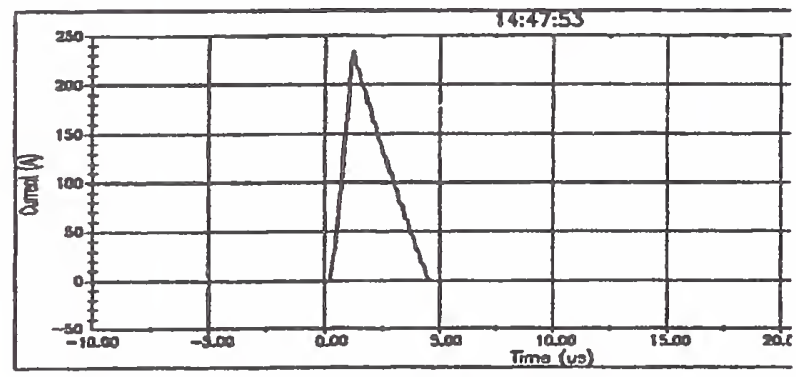

Figure 11 - Current in downstream varistor

The waveforms of Figures 10 and 11 are shown with an expanded scale, compared to that of Figure 9, that gives a better resolution for the gap voltage and current in the varistor. There is good correspondence between the waveforms of the two traces and the gap voltage and downstream current traces of Figure 9. In Figure 10, however, the gap voltage collapses to zero, while it does not in Figure 9. The difference is that the real-world circuit has a parasitic inductive voltage added to the true gap voltage, already discussed for the varistor of Figure 2. Figure 11 shows the linear ramps typical of current changes in an inductance.

As mentioned above, we can expect that the energy deposited in the downstream varistor for a given impinging surge will be influenced by the length of the branch circuit. Using the model developed and validated according to Figures 5 and 6 , the energy can be readily computed. In the case described by Figures 9,10 , and 11 , the gap sparkover voltage was preset at $2 \mathrm{kV}$ so that sparkover could indeed occur for the surge current available from the real-world generator and the resulting upstream voltage.

Now that we are in the (validated) model-world, we can arbitrarily set the eparkover voltage at a lovel more typical of the flashover point of clearances, say $6 \mathrm{kV}$. Of course, we have the possibility of assessing energy for a wide range of parameters.
In the example reported below, we kept the same three values of branch circuit length and performed the computations for the same five values of impinging current as those used for the computations of Table 1. Table 3 shows the energy deposited in the downstream varistor for these combinations of branch circuit length and peak current values, for the applied current waveform of Figure 5 , and a $6 \mathrm{kV}$ flashover point.

\section{TABLE 3}

Energy deposited into a $130-V$ rated far-end varistor as a function of the branch circuit length shown (rows), current peak (columns) of waveform shown in Figure 5 , and flashover of the clearances set to occur at $6 \mathrm{kV}$

\begin{tabular}{cccccc}
\hline Peak/Length & $2 \mathrm{kA}$ & $3 \mathrm{kA}$ & $5 \mathrm{kA}$ & $7 \mathrm{kA}$ & $10 \mathrm{kA}$ \\
\hline $10 \mathrm{~m}$ & $17 \mathrm{~J}$ & $27 \mathrm{~J}$ & $51 \mathrm{~J}$ & $670 \mathrm{~mJ}$ & $218 \mathrm{~mJ}$ \\
$30 \mathrm{~m}$ & $17 \mathrm{~J}$ & $128 \mathrm{~mJ}$ & $30 \mathrm{~mJ}$ & $23 \mathrm{~mJ}$ & $18 \mathrm{~mJ}$ \\
$50 \mathrm{~m}$ & $69 \mathrm{~mJ}$ & $34 \mathrm{~mJ}$ & $17 \mathrm{~mJ}$ & $11 \mathrm{~mJ}$ & $10 \mathrm{~mJ}$ \\
\hline
\end{tabular}

The results shown in Table 3 merit close examination as they reveal some counter-intuitive trends: we might have expected that for higher impinging current values, the resulting energy deposited in the downstream varistor would be higher. Likewise, we might also have expected that for a longer branch circuit, the greater inductance would store more energy, ultimately to be deposited in the varistor. In fact, the opposite occurs. The table also reveals the interesting finding that the first three -lowercurrent, short-line cases (bold face type in the table) produce larger energy deposition, compared to the other cases. Actually, the explanation that follows is simple and might be anticipated (especially with hindsight, illustrating that intuition is a hazardous process when dealing with nonlinear circuit components).

Starting with the second observation (more joules at lower threat levels), we have a beautiful illustration of the blind spot effect - not limiting tests and designs to the maximum stress of a worst-case scenario - [13]: for 10 meters of circuit and at the lower current levels, the resulting voltage at the clearance is not sufficient to cause flashover, and all the energy has to go to the downstream varistor. At the higher threat level of $7 \mathrm{kA}$, the voltage produced in the inductance of 10 meters of line, added to the varistor voltage, is sufficient to sparkover the $6 \mathrm{kV}$ gap, relieving the varistor from further involvement beyond that of discharging the energy stored in the line. In the case of the 30-m long line, this transition occurs between $2 \mathrm{kA}$ and $3 \mathrm{kA}$.

Turning now to the first observation, that higher current or greater inductance result in less stress, this apparent paradox is caused by the fact that with the higher values of $d i / d t$ and $L$, the voltage at the clearance rises more quickly to the flashover point. Consequently, the build-up of energy in the line inductance is shut-off earlier so that the current level in the line reached at that point is lower and, in spite of the greater inductance, the stored energy $1 / 2 \mathbb{L} i^{2}$ is lower for higher applied current peaks and longer branch circuits. 


\section{CONCLUSIONS}

The development of a validated EMTP model using existing computational tools allows us to look into all scenarios of surge propagation and surge mitigation schemes. The reality check proposed by the measurements and modeling reported in this paper should be useful in the process of selecting stress levels to be specified in the application of SPDs downstream from the service entrance, from the point of view of successful cascade coordination as well as integrity of electromagnetic compatibility. Specific conclusions can be drawn:

1. Realistic surge current amplitudes and rise times can be defined for SPDs installed at the end of branch circuits, with upper limits set by the laws of physics applied to real-world conditions.

2. The general practice for describing surge waveforms is to cite "rise time" or "front time", followed by duration, as in $8 / 20$. However, when the effects of circuit inductance are assessed, in particular by numerical modeling, the maximum rate of rise must be considered, not an average over the rise time. It is especially important to define the conditions at the origin of the waveform, such as inclusion of a gentle toe.

3. The importance of looking for blind spots is, once again, demonstrated by the parametric computations, a much simpler task than exhaustive equipment-exhausting tests.

4. Reliable computational tools make it possible to obtain a wide range of parametric assessments, and thus avoid recourse to intuition when dealing with nonlinear circuits, where blind reliance on common-sense may lead to flawed conclusions.

5. The parametric computations offered in the paper point out the need to consider a balance or trade-off among several critical factors in the design of branch circuit protection, in particular the uncontrollable length of branch circuits in actual installations.

\section{ACKNOWLEDGMENTS}

The measurements reported in this paper were conducted by Kermit Phipps at the EPRI Power Electronics Applications Center. Support for the modeling was provided by the Electric Power Research Institute. Support for the development of this reality check, motivated by the discussions and contributions of IEEE and IEC colleagues, was provided by Delmarva Power \& Light and by Pacific Gas \& Electric.

\section{REFERENCES}

[1] IEEE/ANSI C62.41-1991, "Recommended Practice on Surge Voltages in Low-Voltage AC Power Circuits."

[2] Martzloff, F.D. "Coordination of Surge Protectors in Low-Voltage AC rower Circuiss," IEEE Iransacrons PAS-99, IVo.1, January' February 1980, pp 129-133.

[3] Goedde, G.L., Marz, M.B., and Henry, D.C., "Coordinating Lightning Stroke Protection From the Utility System to Load Devices."
In Proceedings, Second International Power Quality ASD Conference, October 1990, Philadelphia.

[4] Lai, J.S. and Martzloff, F.D., "Coordinating Cascaded Surge Protection Devices: High-Low versus Low-High," In Conference Record, IEEE-LAS 1991 Anrual Meeting, pp 1812-1819. Also in IEEE Transactions, IAS-29 No.4, July/August 1993, pp 680-687.

[5] Standler, R.B., "Coordination of Surge Arresters and Suppressors for Use on Low-Voltage Mains." In Proceedings, 1991 Zürich EMC Symposium, pp 517-524.

[6] Hostfet, O.T., Hervland, T., Nansen, B. and Huse, J., "Coordination of of surge-protective devices in power supply systems: Needs for secondary protection," In Proceedings, 20th International Conference on Lightning Protection, 1992.

[7] Hasse, P., Wiesinger, J., Zahlmann, P. and Zischank, W., "Principle for an advanced coordination of surge protective devices in low voltage systems," In Proceedings, 22nd Inter-national Conference on Lightning Protection, 1994.

[8] Rousseau, A. and Perche, T., "Coordination of Surge Arresters in the Low-Voltage Field," In Proceedings, Seventeenth International Telecommunications Conference (INTELEC 95), 95CH35824, pp 119 125.

[9] Martzloff, F.D., "Coupling, Propagation, and Side Effects of Surges in an Industrial Building Wiring System," IEEE Trans-actions IA-26, No.2, March/April 1990, pp 193-203.

[10] EPRI, "Electromagnetic Transients Program (EMTP), Version 2.0; Volume 1; Main Program; Volume 2: Auxiliary Routines" EPRI Report EL-6421-L, July 1989.

[11] Standler, R.B., "Transmission Line Models for Coordination of Surge-Protective Devices," In Proceedings, IEEE Inter-national Symposium on Electromagnetic Compatibility, 1993, pp 358-362.

[12] Martzloff, F.D., Mansoor, A., Phipps, K.O. and Grady, M. "Surging the Upside-Down House: Measurements and Modeling Results," In Proceedings, PQA'95 Conference, EPRI, 1995.

[13] IEEE/ANSI C62.45-1992 "Guide on Surge Testing for Equipment Connected to Low-Voltage AC Power Circuits."

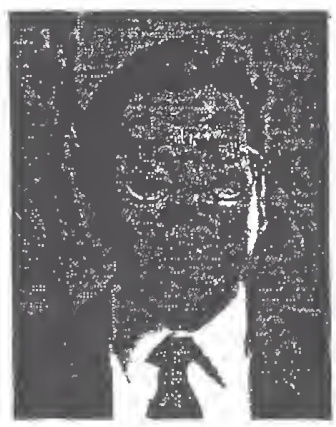

Arshad Mansoor (M' 1995) Is Electrical Systems Engineer at the EPRI Power Electronics Applications Center (PEAC). He received his MS and Ph.D. in electrical engineering from the University of Texas, Austin, in 1992 and 1994 respectively. His areas of interest include power quality, power systems transients, harmonics, surge protection, and EMTP model development.

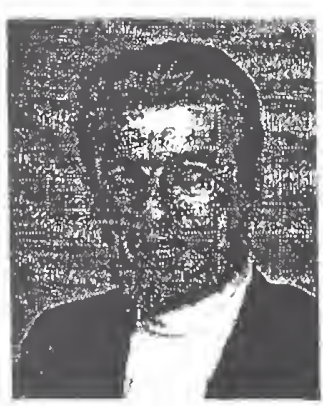

François Martzloff (M'1956, F'1983) Born and educated in France, with additional MS degrees from Georgia Tech and from Union College, worked at General Electric for 29 years and now ten years at the National Institute of Standards and Tcchnology. IIc is contributing to several committees for development of standards on EMC and surge protection in the IEEE and the IEC. 


\section{Discussion}

\section{Darveniza (University of Queensland, Australia 4072):}

The authors are to be congratulated for drawing attention to an important feature in surge protection. Namely, the magnitude of the voltage up-line from a surge protective device will exceed the protective level of the SPD, the extent of the over-voltage depending on distance and on waveshape of the incident surge. Because of this, flashover at an upstream device (for example, another SPD) will limit the severity of the surge stressing the downstream SPD.

Two examples are offered which support the author's statement "more begets less" and which can be rephrased by saying that in some cases, a less onerous surge may impose more severe overstress than a more onerous incident surge. The two examples are:

1. A cable-entry substation protected by an upstream SPD connected at the overhead line-to-cable junction. The most severe stress at the substation occurs when the surge incident from the line onto the cable is just not large enough for operation of the SPD at the line-cable junction.

2. A hybrid surge protection system. for low-voltage and electronic equipment involving two SPD's coordinated by an intervening series impedance. The series impedance is selected to ensure that the downstream SPD is not overstressed, by virtue of operation of the upstream SPD caused by the voltage drop in the impedance (which adds to the clamp voltage of the downstream SPD). However, if the voltage drop is not large enough to "turn-on" the upstream SPD, either because the magnitude or the steepness of the incident surge current is not sufficiently large, then the downstream SPD may still be overstressed if the duration of the surge current is too long. Paradoxically, a more severe incident surge will "turn-on" the upstream SPD, thus protecting the downstream SPD from excessive overstress.

Manuscript received October 4, 1996.

\section{François Martzloff :}

We are glad that the message we were presenting has found a favorable echo with Professor Darveniza, and appreciate his kind words. The two examples he cites are indeed good illustrations of the "more begets less" theme which we have expressed in the manner of a paradox/epigram to make it easy to remember. This reality check on the likelihood of a stress-limiting flashover should be applied whenever a scenario is proposed that involves the propagation of surge currents. We hope that our colleagues involved in standards development will remember this well and assess some of the proposals now under consideration for SPD requirements in the light of that epigram.

Manuscript received November 13, 1996. 


\section{The Effect of Neutral Earthing Practices on Lightning Current Dispersion in a Low-Voltage Installation}

\author{
Arshad Mansoor, Member, IEEE \\ Power Electronics Applications Center \\ Knoxville TN 37932 USA \\ Amansoor@epri-peac.com
}

François Martzloff, Life Fellow, IEEE

National Institute of Standards and Technology

Gaithersburg MD 20899 USA

f.martzloff@ieee.org

\section{Significance:}

Part 2 Development of standards - Reality checks

Part 4 Propagation and coupling of surges

In the case of a direct lightning stroke to a building, the earth-seeking current is dispersed among all available paths to earthing electrodes, including intentional made electrodes and opportunistic electrodes. A substantial part of that current will exit the building via its connection to the power distribution system.

The configuration of this power distribution system (daisy chain from the transformer or radial from the transformer) influences the sharing of the current among these possible paths.

From simulations performed with a 10/350 waveform, the paper provides quantitative information on these effects. 
(1) 


\section{The Effect of Neutral Earthing Practices on Lightning Current Dispersion in a Low-Voltage Installation}

\author{
Arshad Mansoor, Member, IEEE \\ Power Electronics Applications Center \\ Knoxville TN 37932 USA
}

\author{
François Martzloff, Life Fellow, IEEE \\ National Institute of Standards and Technology* \\ Gaithersburg MD 20899 USA
}

\begin{abstract}
Computer modeling with the EMTP code has been applied to several configurations and earthing practices in use in various countries to show the effect of any differences in the dispersion (sharing) of a lightning stroke current among the available paths for the earth-seeking lightning current. Simplifying assumptions have been made to some details of the configurations to focus on the main difference -- earthing practices. Identifying such differences provides the necessary perspective on their significance and the strong need to take them into consideration when developing international standards on surge-protective device applications.
\end{abstract}

\section{INTRODUCTION}

When designing a lightning protection scheme for a lowvoltage power system within a building, several scenarios must be considered for the point of termination of the lightning stroke. Common wisdom classifies these by decreasing order of severity: directly to the building, directly to overhead lowvoltage distribution lines (or other utilities) outside of the building, to other objects near the building, distant cloud-toearth strokes, and finally perhaps cloud-to-cloud discharges. Several standards-writing projects are underway, at the IEEE and at the IEC, based on present knowledge of the lightning flash characteristics and on assumptions about the way the lightning current divides among the many paths available for distributing (dispersing) this current to the ill-defined "earth" which is the termination of the cloud-to-earth strike.

The purpose of our paper is to show the effect that different practices for neutral earthing in the low-voltage distribution system can have on the relative dispersion of the lightning current which is seeking the path of least impedance to earth.

* Electricity Division, Electronics and Electrical Engineering Labo-
ratory, Technology Administration, U.S. Department of Commerce.

PE-968-PWRD-0-05-1997 A paper recommended and approved by the IEEE Surge Protective Devices Committee of the IEEE Power Engineering Society for publication in the IEEE Transactions on Power Delivery. Manuscript submitted January 2, 1997; made available for printing May 23, 1007.
To accomplish this purpose in an eight-page paper, and to concentrate on the essential difference, the models we present are simplified from the detailed reality, so that one of our first tasks will be to explain and justify the simplification. To avoid confusion in the meaning of the word "distribution" which can relate to the distribution of electric power by the utility or to the distribution of the lightning current among the available paths, we will use the term "dispersion" for the second meaning, lighting current dispersion. Another term used by some authors to convey the concept is "sharing" (among available paths). Note that the actual return stroke actually goes from earth to cloud in the majority of cases, but the scenario is generally described as if the stroke "terminated" on earthbound objects.

In the case of a low-voltage power distribution system, different countries have adopted different practices on earthing the neutral conductor, and writing a history of why that is so would give an interesting insight into the development of power systems. The fact is that today, two approaches are well entrenched in their respective territories, the so-called TN system and TT system where the difference lies in the mode of earthing the neutral. We will give a brief overview of the differences in a following section. Our purpose is to show how the difference in these practices affect the sharing, or dispersion, of the lightning current among the available paths to earth, and consequently affect the rating of surge-protective devices which may be included in these paths. We used the EMTP simulation code [1] to model several scenarios in each of the TN and TT systems, with small but possibly significant differences in the configuration. By postulating a direct stroke to one building, and requesting EMTP to compute currents in the (simplified) complete power system, we obtained results for the two most severe cases of lightning termination: the case of a direct stroke to one building, and the case of a nearby stroke which propagates and impinges at the service entrance of many buildings on that part of the low-voltage distribution system.

The literature and draft standards contain many examples of such scenarios, but it seems that each is confined to a specific approach or power system configuration with fairly detailed arrangements of load connections. The result is that from this plurality of examples, it is difficult to extract a clear perception of the significant parameters in the dispersion of the lightning curront reculting from differont oarthing praotioos. In this paper, we will simplify the scenarios to concentrate on the fundamental difference between the neutral earthing practices. 


\section{THE TT AND THE TN SYSTEMS}

The IEC has promulgated a letter code system describing the arrangement of the neutral earthing in single-phase and polyphase power systems [2]. For the purposes of our paper, we can summarize the TT system as being a distribution system where the neutral is earthed only at the distribution transformer secondary, and the protective earth in a building is obtained from a local earth electrode. This system is used in some countries. The TN system has its neutral earthed at any available opportunity outside of a building, including the distribution transformer secondary, some or all poles, and the service entrance. In the United States, an "Equipment Grounding Conductor" (EGC) is created at the service entrance, bonded to the incoming power system neutral and to the common local earthing point, after which the neutral conductor and the EGC are carefully (and by mandate from the National Electrical Code [3]) kept separate from one another.

\section{NECESSARY SIMPLIFICATIONS}

Another difficulty in making a detailed comparison of results from different authors is that different models are often used. When apparently different results are reported, a lingering question is that of differences attributable to the simplifying assumptions and possible modeling artifacts. We have used the well-known EMTP code [1] for which our previous experience in cross-validation between the computer model and full-scale experimental measurements [4], [5] gave us great confidence in the validity of the results.

The literature offers many contributions on the system simulation but our purpose is not literature review -- again, our purpose is only to focus on the neutral practices considerations. However, to support some of our postulates, we will cite some papers to show that in the maze of assumptions, simplifications, and simulations, we are not alone.

\section{A. Down-conductor representation}

Some authors have included in their modeling a downconductor feeding the stroke current to the common bonding point of the building [6]. In our model, since we postulate that the current is delivered from a current source, the impedance of the down-conductor has no effect on the current being injected at the common bonding point which is the point at which dispersion (sharing) begins. Therefore, we did not include a down-conductor in our models.

\section{B. Earthing impedance as a function of time and current}

Some authors consider the fact that the exact value of the earthing impedance is variable as a function of time and current level. For instance, [6] initially proposes a model involving resistance, capacitance, and inductance, with some dependency on time or current, or both. But after studying the problem closer, the authors of [6] conclude that a reasonable approximation is merely a fixed $10-\Omega$ resistance. We have used this value in our models of the building earthing, and postulated an improved, lower $5-\Omega$ resistance at the earthing electrode of the distribution transformer.

\section{Other available current paths}

Some standard proposals include telephone, water and gas connections as possible paths for the earth-seeking lightning current. Considering that the telephone service is a balanced system normally isolated from earth (until a network interface device becomes involved), that some water and gas services can include a cathodic-protection isolation or be implemented with plastic pipes, we chose a conservative approach of not including these as additional paths to earth.

\section{Actual Circuit Configuration for Service Entrances}

Figure 1 shows a schematic of a single-phase 3-wire TN $120 / 240$-V service to a building. One surge-protective device (SPD) is connected between each of the two lines and the common earth at the service entrance, ignoring any SPDs within the building under the assumption that in a well-coordinated cascade [7] the majority of the current is carried by the service entrance SPD which has the lowest limiting voltage in the installation. The stroke current, postulated to have terminated on a point of the earthing system of the building, can seek a path to earth in two ways: directly through the earth electrode of the building, and by means of the three conductors back toward the power system.

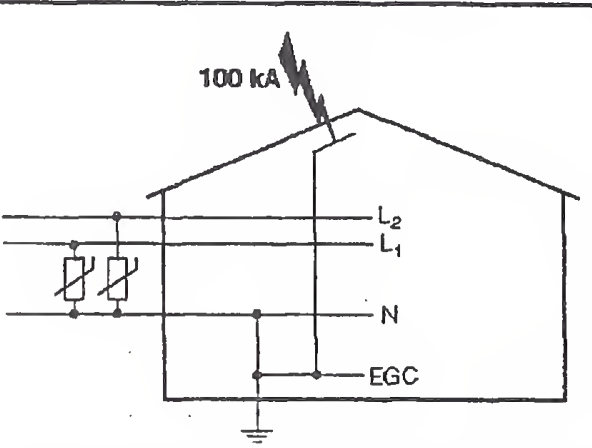

Figure 1. Service connections in a 3-wire TN system

Figure 2 shows a schematic of a three-phase 4-wire TT 230/400-V service to a building. A dedicated protective earth is created and connected to a local earth electrode, while the incoming neutral of the power distribution system is not bonded to this protective earth. At the service entrance, SPDs are connected between the local earth and each of the incoming lines and the neutral.

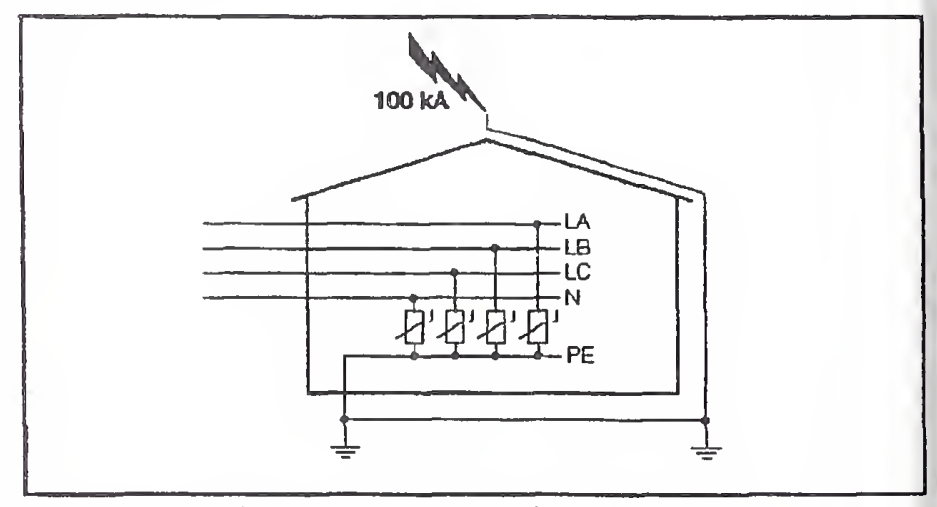

Figure 2 - Service entrance connections in a 3-phase, 4-wire TT system 


\section{E. Postulated lightning stroke current}

While some authors propose a $200 \mathrm{kA}, 10 / 350 \mu$ s surge [8], [9], others suggest that even a $100 \mathrm{kA}$ peak might already be too high a value [6], [10], [11]. In agreement with the latter three references, we postulated a $100 \mathrm{kA}$ peak, $10 / 350 \mu$ s surge current. This selection also offers the convenience that when we report current levels in kiloamperes in the various circuits, the numbers also represent the percentage of the sharing, making it easier to follow the process. Since many standards for surges impinging on SPDs (at the service entrance) are still based on an $8 / 20 \mu$ s current waveform, we will also show one example of the energy deposition in the SPDs when such an $8 / 20 \mu$ s surge is postulated.

The surge currents are modeled using the EMTP Type 60 Slave Source. Using the "Freeform FORTRAN" expression, any surge current waveform that can be expressed as a closedform equation can be used as signal source in the main EMTP program. The equations for the $10 / 350 \mu$ s and $8 / 20 \mu$ s waveforms with a $100 \mathrm{kA}$ peak are respectively (1) and (2) below:

$10 / 350 \mu s: \quad I(t)=\left[I_{p} / \eta\right]\left[\exp \left(-t / \tau_{\nu}\right)-\exp \left(-t / \tau_{2}\right)\right]$

$$
\text { where } \begin{aligned}
I_{p} & =100 \mathrm{kA} \\
\eta & =0.9542 \\
\tau_{1} & =480 \\
\tau_{2} & =4
\end{aligned}
$$

8/20 $\mu s: \quad I(t)=A I_{p} t^{3} \exp (-t / \tau)$

$$
\text { where } \begin{aligned}
I_{p} & =100 \mathrm{kA} \\
A & =0.01243 \\
\tau & =3.911
\end{aligned}
$$

(In both equations, $t$ and $\tau$ s are in $\mu$ s; $I(t)$ is in same units as $I_{p}$ )

\section{F. Influence of Distribution Transformer Simplification}

The presence of distribution transformers has been included in many models in the literature, but their characteristics are not the same among authors. Some authors have used a coupled inductor with parasitic capacitor to represent the inter-winding capacitor in the transformer model [12].

While these models are more accurate in studying transformer failure modes due to low-side surges, for our main focus which is current dispersion among available paths, we have chosen the simple model postulated in [8] of a simple inductor to represent the winding. As results show, the presence of a transformer at the far end of a daisy-chain lowvoltage distribution system does not have considerable effect on the results. Therefore, we felt justified in adopting the same transformer model as described in [8] for all of our circuit configurations.

\section{G. Simplifying the Circuit for Modeling}

The circuit impedances have been modeled in EMTP using discrete comnnnents The wiring hetween buildings and from building to transformer is modeled as a series inductance with the following parameters: $R=1 \mathrm{~m} \Omega / \mathrm{m}$ and $\mathrm{L}=1 \mu \mathrm{H} / \mathrm{m}$, typical values for aluminum conductors of $34 \mathrm{~mm}^{2}$ cross section (\#2 AWG) [13]. The SPDs are modeled using the EMTP Type 92 Nonlinear Element model. Because of the simplified nature of the model, we performed parametric variations on factors such as line impedance and transformer inductance, and found that their influence on current dispersion is not large enough to warrant concern on the somewhat arbitrary values we have postulated in the baseline scenario.

\section{MODELING RESULTS}

In this section, we present selected results of EMTP nuns for each of three TN or TT system configurations with points of lightning termination next to the distribution transformer ("first" case) or at the opposite end of the transformer ("last" case), for a total of seven scenarios. We postulated a separation of $100 \mathrm{~m}$ between buildings and $20 \mathrm{~m}$ from the transformer.

For each scenario, a pair of figures is given. The first figure of each pair is a schematic showing the configuration and point of stroke, together with indications of the peak current values in the circuit branches. The second figure of each pair shows selected current waveforms, generally currents leaving the house by way of the earthing electrode and the service conductors. Note that the peaks can occur at different times so that the sum of peak branch currents shown on the figures, Kirkhoff notwithstanding, is not always exactly zero.

\section{A. TN-Radial, strike on one of the buildings}

A distribution transformer supplies three buildings in a radial arrangement where all the service drops originate at the pole where the transformer is installed (Figure 3). This configuration is a typical U.S. residential configuration. The lightning stroke is postulated to terminate on the earthing system of one of the three buildings. Figure 4 shows the current waveforms.

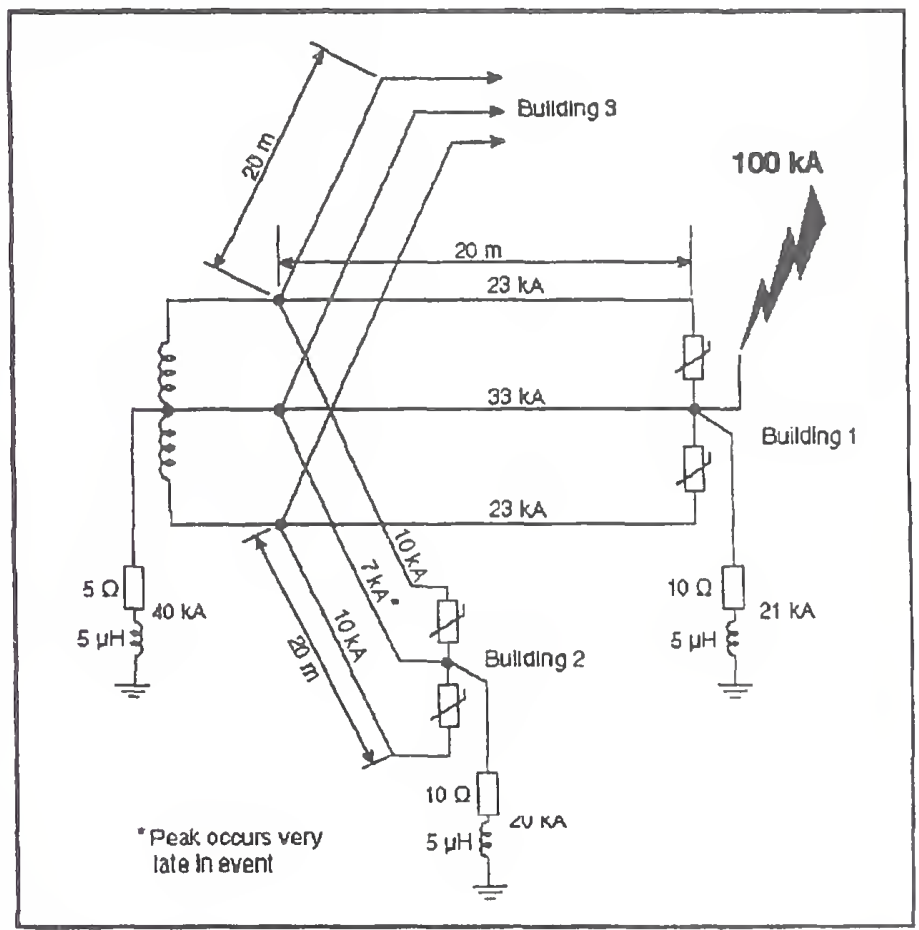

Figure 3 - Radial TN configuration with three buildings supplied by one distribution transformer, one building struck by a $10 / 350 \mu \mathrm{s}, 100 \mathrm{kA}$ surge, showing peak values of currents shared among available paths. 


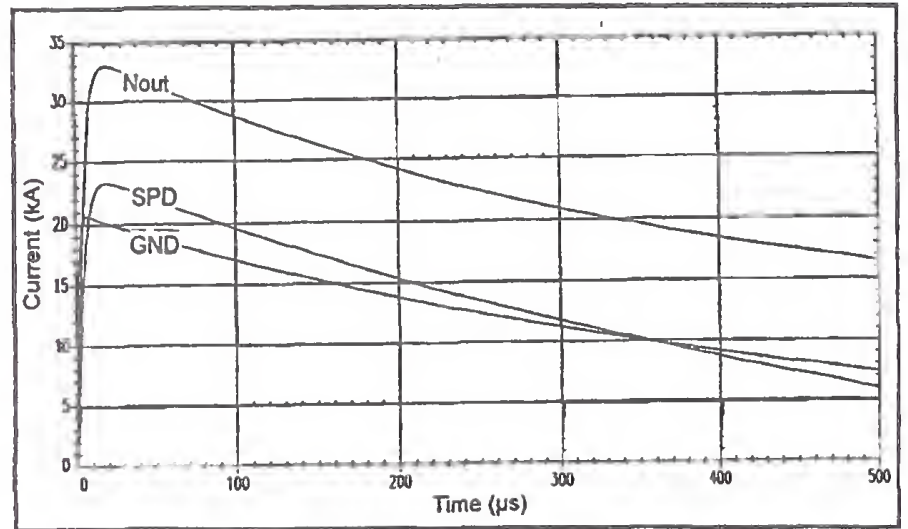

SPD - Current into each line of service drop, through SPDs

GND - Current into local building earth electrode

Nout - Current into neutral conductor of service drop

Figure 4 - Waveforms of currents leaving Building 1, as defined in Figure 3 for a $100 \mathrm{kA}, 10 / 350 \mu$ s surge terminating on the building earthing system

\section{B. TN-Daisy chain, strike on first building}

Another typical arrangement uses a distribution transformer which supplies several buildings along a street, with short service drops from the poles to each building. The lightning stroke is postulated to occur upon the first building, next to the transformer. Figure 5 shows the circuit configuration and the peak currents in the branches; Figure 6 shows the waveforms of the currents leaving the building. Note the early peak of the current in the neutral -- directly connected to earth at the pole, thus a lower inductance compared with the inductance of the line conductors that include the transformer winding.

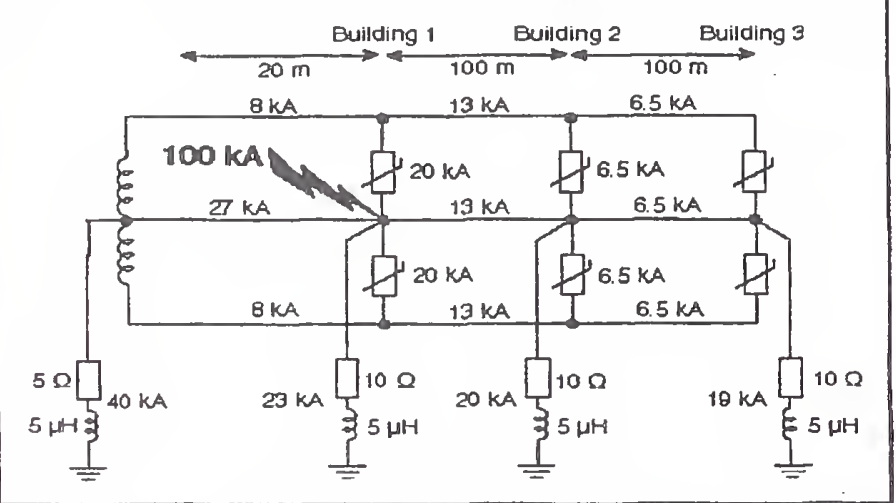

Figure 5 - Daisy chain TN configuration with building next to transformer struck by a $10 / 350 \mu \mathrm{s}, 100 \mathrm{kA}$ surge, showing peak values of currents

\section{TN-Daisy chain, strike on last building}

This is the same configuration as $\mathrm{B}$, but the building being struck is at the opposite end (Figure 7). The difference, if any, wonld give insight on the relative importance of modeling the presence of a specific transformer. In fact, the difference in the SPD stress for a strike on the first building ( $20 \mathrm{kA})$ compared with a strike on the last building $(26 \mathrm{kA})$ is small, showing the small effect of transformer position. In the building earthing, where there are no SPDs, a strike on the last building produces $42 \mathrm{kA}$ compared with $23 \mathrm{kA}$ for a strike on the first building.

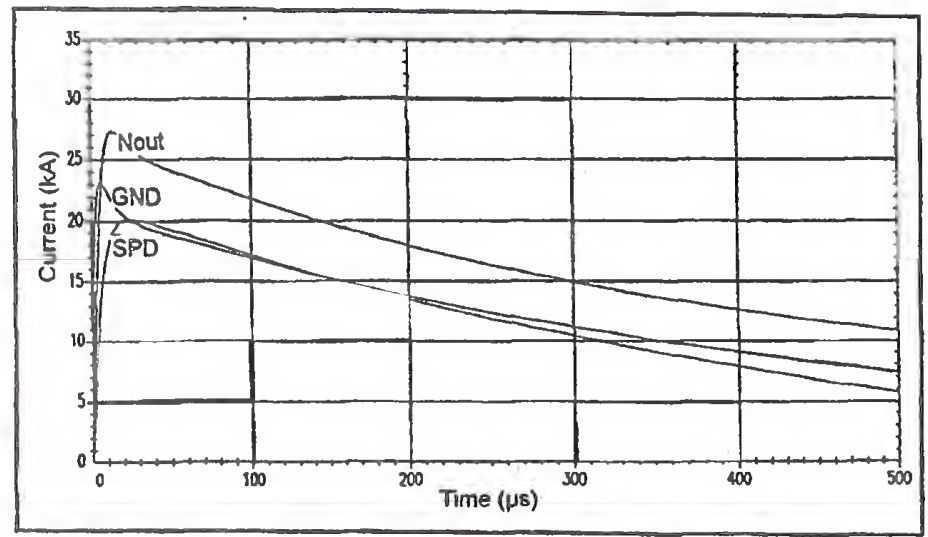

SPD - Current into each line of service drop, through SPDs GND - Current into local building earth electrode

Nout - Current into neutral conductor toward the transformer earth

Figure 6 - Waveforms of currents leaving Building 1, as defined in Figure 5, for a $100 \mathrm{kA}, 10 / 350 \mu$ surge terminating on the building earthing system

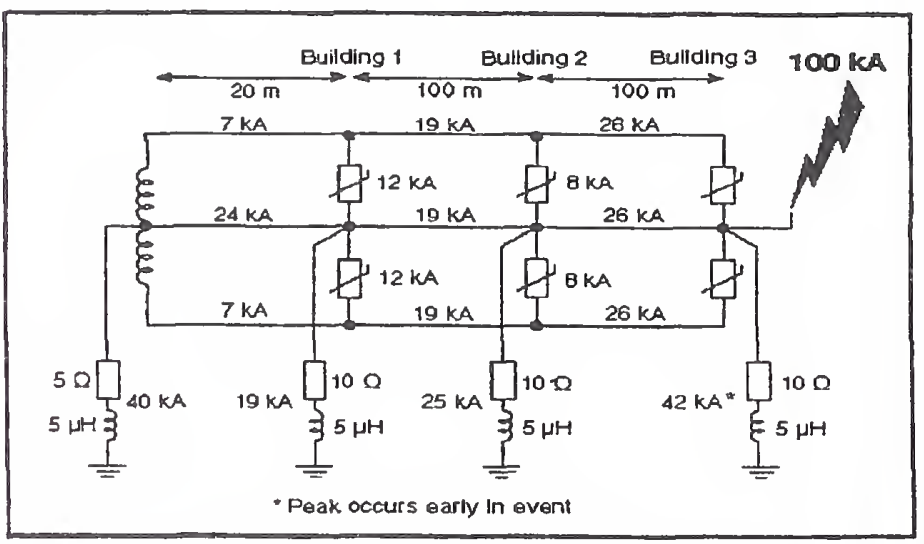

Figure 7 - Daisy chain TN configuration with building at opposite end of transformer struck by a $10 / 350 \mu \mathrm{s}, 100 \mathrm{kA}$ surge, showing peak currents

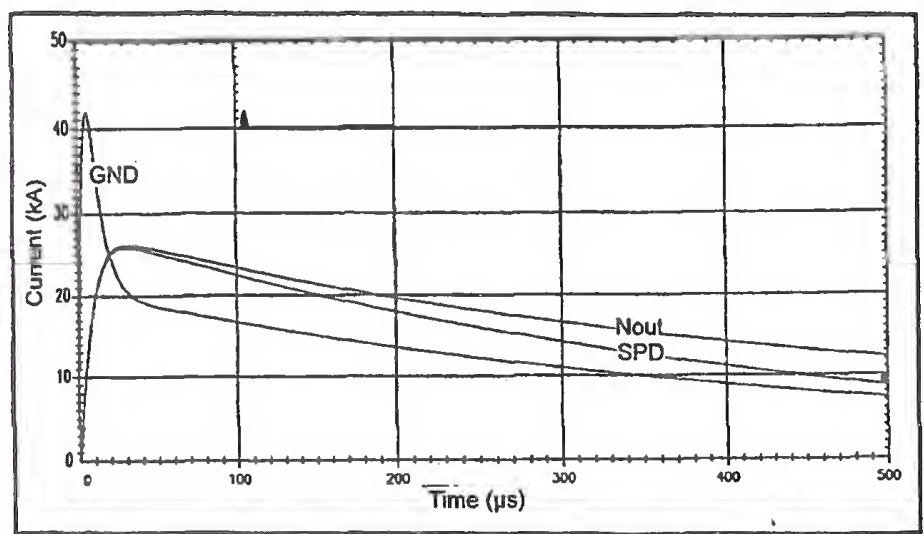

SPD - Current into each line of service drop, through SPDS

GND - Current into local building earth electrode

Nout - Current into neutral conductor toward the transformer earth

rigure 8 - waverorms or currents leaving Dulluing 3 , as uenued in Figuse 7 for a $100 \mathrm{kA}, 10 / 350 \mu$ s surge terminating on the building earthing system

For Figures 7-8, the greater distance (inductance) from the transformer earth electrode forces initially more current flow in the building earth than in Figures 5-6 for a closer transformer. 


\section{TT 2-wire, strike on first building}

A transformer (single-phase or one phase of a three-phase transformer) supplies several buildings along a street, with short service drops from the street poles to each building. The lightning stroke is postulated to occur upon the building next to the transformer (Figure 9). The waveforms of the currents leaving the building are shown in Figure 10.

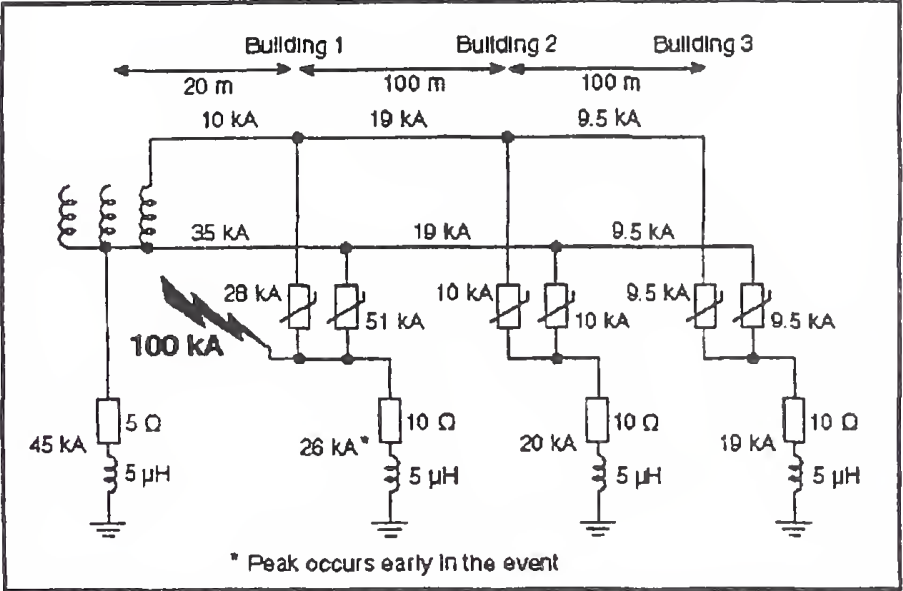

Figure 9 - Daisy chain TT 2-wire configuration with building next to distribution transformer struck by a $10 / 350 \mu \mathrm{s}, 100 \mathrm{kA}$ surge

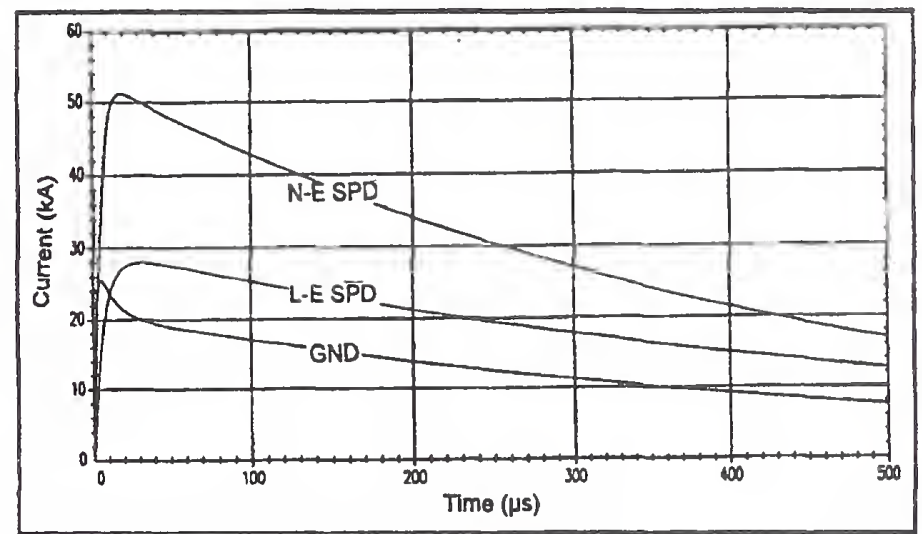

N-E SPD - Current through neutral-to-earth SPD

L-E SPD - Current through line-10-earth SPD

GND - Current Into building earthing electrode

Figure 10. Waveforms of currents leaving Building 1, as defined in Figure 9, for a $100 \mathrm{kA}, 10 / 350 \mu$ s surge terminating on the building earthing system

\section{E. TT 2-wire, strike on last building}

The configuration is the same as in $\mathrm{D}$, but the lightning stroke is postulated to strike the building at the opposite end of distribution line, away from the transformer (Figure 11). Figure 12 shows the waveforms of the currents leaving building 3 .

\section{F. TT 4-wire}

Where end-users are provided with three-phase service, a three-phase transformer supplies several buildings along a street, with short service drops from the street poles to each building. In this configuration, the difference from a 2-wire, single-phase service is that four conductors instead of two are available as exit paths for the lightning current postulated to have struck the building of interest (first or last building).

To conserve space, we do not present two pairs of figures for that configuration, but the summary of Table 1 includes the current values computed by EMTP for the two scenarios in that configuration.

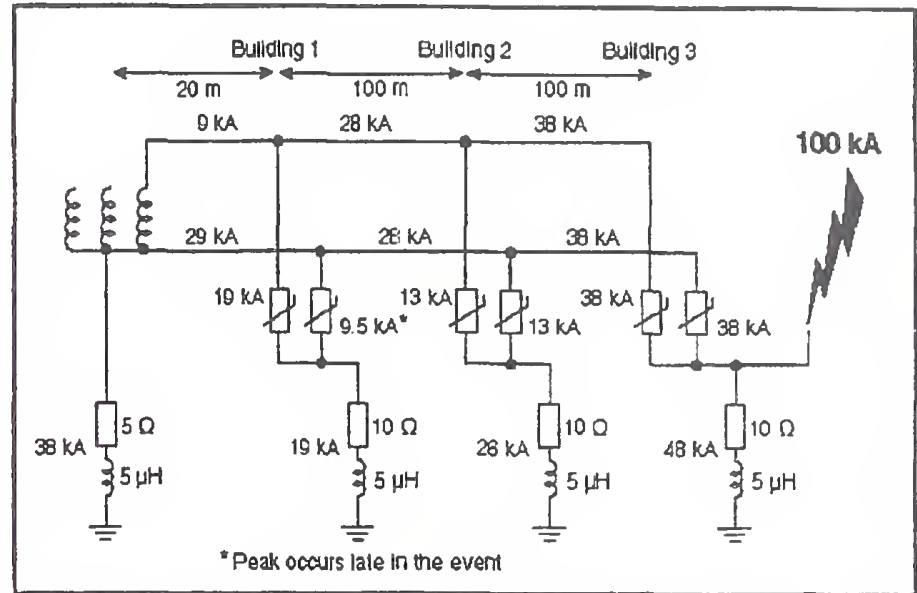

Figure 11 - Daisy chain TT 2-wire configuration with building at opposite end of distribution transformer struck by a $10 / 350 \mu \mathrm{s}, 100 \mathrm{kA}$ surge

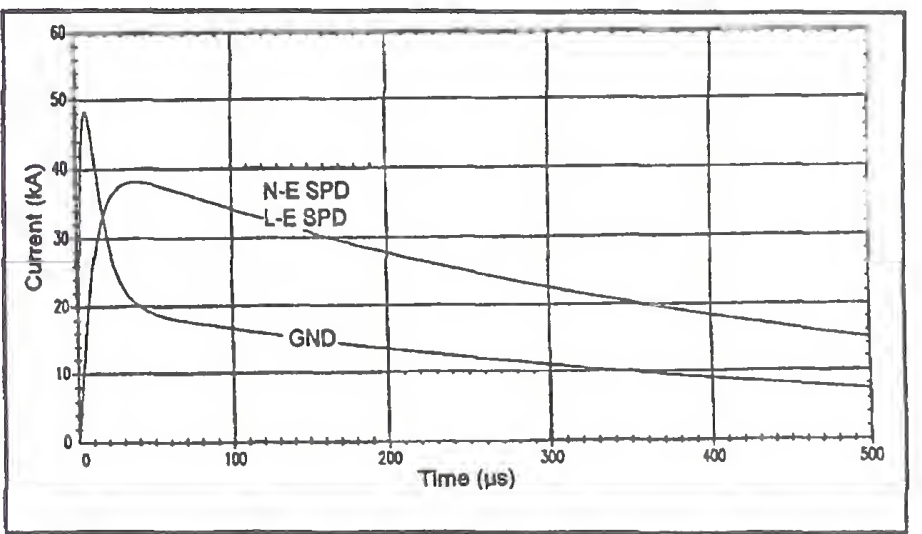

N-E SPD - Current through neutral-to-earth SPD

L-E SPD - Current through line-to-earth SPD

GND - Current into building earthing electrodo

Figure 12 - Waveforms of currents leaving Building 3, as defined in Figure 11, for a $100 \mathrm{kA}, 10 / 350 \mu$ surge terminating on the building earthing system

\section{G. Comparison of the seven scenarios}

Results of our model runs for the seven scenarios (Table 1) show that, contrary to some speculations or intuitive considerations on the sharing among service conductors, the earthing connection of the building does not carry anywhere near the $50 \%$ quoted in some proposed standards [9].

The most severe stress, for the parameters postulated, occcurs in the neutral SPD in Scenario D (TT 2-wire, first building struck) for which the configuration has the lowest impedance to earth and thus invites the largest share. Other scenarios generally reflect primarily the number of service-drop wires available for the current exit. 
TABLE 1

SUMMARY OF CURRENT SHARING AMONG CONDUCTORS FOR THREE CONFIGURATIONS IN SEVEN SCENARIOS FOR I00 KA STROKE

\begin{tabular}{|c|c|c|c|c|c|c|c|c|}
\hline \multirow{2}{*}{$\begin{array}{l}\text { Configuration: } \\
\text { Distribution } \\
\text { system }\end{array}$} & \multirow[t]{2}{*}{$\begin{array}{l}\text { Scenario: } \\
\text { Building } \\
\text { being } \\
\text { struck }\end{array}$} & \multirow[t]{2}{*}{$\begin{array}{c}\text { See } \\
\text { figures }\end{array}$} & \multicolumn{4}{|c|}{$\begin{array}{l}\text { Most severe but rare - Building being directly struck } \\
\text { Currents leaving building via building earthing } \\
\text { and service conductors (peak kA or \%) }\end{array}$} & \multicolumn{2}{|c|}{$\begin{array}{l}\text { Less severe but more frequent } \\
\text { Currents impinging onto } \\
\text { adjacent buildings (peak kA or \%) }\end{array}$} \\
\hline & & & $\begin{array}{l}\text { Building } \\
\text { earthing }\end{array}$ & $\begin{array}{l}\text { Service } \\
\text { neutral }\end{array}$ & $\begin{array}{l}\text { SPD in } \\
\text { the neutral }\end{array}$ & $\begin{array}{l}\text { SPD in } \\
\text { the lines }\end{array}$ & $\begin{array}{l}\text { SPD in } \\
\text { the neutral }\end{array}$ & $\begin{array}{l}\text { SPD in } \\
\text { the lines }\end{array}$ \\
\hline TN Radial & Any & $3-4$ & 21 & 33 & N/A & $23 \times 2$ & N/A & $10 \times 2$ \\
\hline $\begin{array}{l}\text { TN Daisy } \\
\text { TN Daisy }\end{array}$ & $\begin{array}{l}\text { First } \\
\text { Last }\end{array}$ & $\begin{array}{l}5-6 \\
7-8\end{array}$ & $\begin{array}{l}23 \\
42\end{array}$ & $\begin{array}{l}27 \\
26\end{array}$ & $\begin{array}{l}\text { N/A } \\
\text { N/A }\end{array}$ & $\begin{array}{l}20 \times 2 \\
26 \times 2\end{array}$ & $\begin{array}{l}\text { N/A } \\
\text { N/A }\end{array}$ & $\begin{array}{l}7 \times 2 \\
8 \times 2\end{array}$ \\
\hline $\begin{array}{l}\text { TT 2-wire } \\
\text { TT 2-wire }\end{array}$ & $\begin{array}{l}\text { First } \\
\text { Last }\end{array}$ & $\begin{array}{r}9-10 \\
11-12\end{array}$ & $\begin{array}{l}26 \\
48\end{array}$ & $\begin{array}{l}\text { N/A } \\
\text { N/A }\end{array}$ & $\begin{array}{l}51 \\
38\end{array}$ & $\begin{array}{l}28 \times 1 \\
38 \times 1\end{array}$ & $\begin{array}{l}10 \\
13\end{array}$ & $\begin{array}{l}10 \times 1 \\
13 \times 1\end{array}$ \\
\hline $\begin{array}{l}\text { TT 4-wire } \\
\text { TT 4-wire }\end{array}$ & $\begin{array}{l}\text { First } \\
\text { Last }\end{array}$ & -- & $\begin{array}{l}22 \\
38\end{array}$ & $\begin{array}{l}\text { N/A } \\
\text { N/A }\end{array}$ & $\begin{array}{l}32 \\
20\end{array}$ & $\begin{array}{l}16 \times 3 \\
20 \times 3\end{array}$ & $\begin{array}{l}5 \\
6\end{array}$ & $\begin{array}{l}5 \times 3 \\
5 \times 3\end{array}$ \\
\hline
\end{tabular}

* Peak values do not occur at the same time in the different paths so that totals of numbers shown may be more than the impinging $100 \mathrm{kA}$ peak.

\section{ENERGY CONSIDERATIONS}

In the model parameters, to start the iterative process, we have postulated that the SPD consists of a metal-oxide varistor (MOV) with relatively large cross-section that might be capable of absorbing the energy involved in diverting the $10 / 350 \mu \mathrm{s}$ surge. For the TN configurations, we selected a $150 \mathrm{~V}$ rms rating, and a $300 \mathrm{~V}$ rms rating for the TT configurations. For the cross section, we postulated an area equal to ten $20-\mathrm{mm}$ discs in parallel because available manufacturer's data [14] readily gives the $20-\mathrm{mm}$ disc characteristic. Such a combination would have a total one-shot joule rating of 800 joules for a $10 / 1000 \mu$ s surge in the $150 \mathrm{~V}$ rating.

Because we suspect that even this array of ten discs might not be capable of dissipating the energy involved in a $10 / 350 \mu \mathrm{s}$ surge, the next step in this iterative process is then to compute the energy that would be deposited in the SPDs, under the current distribution patterns computed in the seven scenarios.

As one example, Table 2 shows the energy deposited in the MOVs, computed for the case of the TN Radial configuration where one SPD is connected between each of the two lines and the earth point of the installation (Figure 3). Two waveforms are shown in the table, the $10 / 350 \mu$ s and the $8 / 20 \mu$ s surges.

TABLE 2

ENERGY DEPOSITION IN SERVICE ENTRANCE MOVS FOR THE TN RADIAL CONFIGURATION AND TWO WAVEFORMS

\begin{tabular}{cccc}
\hline \multirow{2}{*}{ Waveform } & $\begin{array}{c}\text { Rating for ten } \\
20-\text { mm discs }\end{array}$ & \multicolumn{2}{c}{ Energy deposition } \\
\cline { 3 - 4 } & $800 \mathrm{~J}$ & Direct strike & Nearby strike \\
\hline $10 / 350 \mu \mathrm{s}$ & $800 \mathrm{~J}$ & $200 \mathrm{~J}$ & $840 \mathrm{~J}$ \\
\hline $8 / 20 \mu \mathrm{s}$ & $200 \mathrm{~J}$ & $80 \mathrm{~J}$ \\
\hline
\end{tabular}

For the $10 / 350 \mu$ s waveform, the rare scenario of a direct strike (energy deposited is $3500 \mathrm{~J}$ ) would require a very large varistor at the service entrance -- four times the ten discs we postulated, while this ten-disc array would be sufficient in the less rare scenario of a nearby strike $(840 \mathrm{~J})$.

On the other hand, if we were to stay with the $8 / 20 \mu$ s as a postulated waveform, even the large $100 \mathrm{kA}$ peak would be handled with comfortable margin by the ten-disc array. These results provide quantitative data which we will discuss further under the Cost/Risk heading.

\section{PARAMETRIC VARIATIONS}

We performed several parametric variations for the purpose of exploring the typical "what if" questions, and also to show whether or not our postulated values might be viewed as too arbitrary because of their influence on the results.

\section{A. Line impedance and building separation}

The value of $1 \mu \mathrm{H} / \mathrm{m}$ for conductors has long been used by many researchers as a typical value. To investigate the significance of that postulated $1 \mu \mathrm{H} / \mathrm{m}$ combined with the 100 $m$ separation, we ran two cases, one with half the value and one with double the value. The first case corresponds to either half the separation for the same unit impedance or half the uni ${ }^{+}$ impedance with the same separation. For the second case, one of the parameters is doubled while the other is held constant. Table 3 shows a comparison of the baseline case with these two parametric variations.

TABLE 3

EFFECT OF LINE IMPEDANCE ON SHARING - TN DAISY LAST

\begin{tabular}{lccc}
\hline Percent of $100 \mathrm{kA}$ peak & $\begin{array}{c}\text { Baseline } \\
100 \mathrm{~m}, 1 \mu \mathrm{H} / \mathrm{m}\end{array}$ & $\begin{array}{c}\text { Half } \\
\text { baseline }\end{array}$ & $\begin{array}{c}\text { Double } \\
\text { baseline }\end{array}$ \\
\hline Current into building earthing & 42 & 32 & 53 \\
\hline Current in service neutral & 26 & 27 & 25 \\
\hline Current in SPDs & 26 & 26 & 25 \\
\hline
\end{tabular}

This comparison shows no significant differences in the current sharing for each of the three available conductors (there are two line conductors, each with an SPD) when the postulated unit impedance or building separation is varied over a 1:4 range, so that our selection for these two parameters should not be a matter of concern.

\section{B. Transformer pole earthing resistance and building earthing system resistance}

By their relationship, these parameters can be expected to have an influence on the outcome. In the baseline case, we postulated a $5-\Omega$ pole earthing resistance and a $10-\Omega$ building earthing resistance. Table 4 shows the comparison of the baseline case with the reversed relationship between the pole earthing resistance and the building earthing resistance. 
TABLE 4

EFFECT OF POLE EARTHING/BUILDING EARTHING - TN RADIAL

\begin{tabular}{lcc}
\hline Percent of $100 \mathrm{kA}$ peak & $\begin{array}{c}\text { Baseline } \\
5-\Omega \text { pole, } 10-\Omega \text { bldg. }\end{array}$ & $\begin{array}{c}\text { Reverse baseline } \\
10-\Omega \text { pole, } 5-\Omega \text { bldg. }\end{array}$ \\
\hline Current in building earth & 21 & 31 \\
\hline Current in service earth & 33 & 14 \\
\hline Current in SPD & 23 & 22 \\
\hline
\end{tabular}

Indeed, the relationship of pole versus building earthing resistance has a significant effect on the current carried by the neutral, but not on the current carried by the SPDs. This is particularly true, although not obvious in the table (where only the peak values are shown, reflecting the inductive effect on initial current dispersion), for the tail of the 10/350 $\mu \mathrm{s}$ waveform where the subsequent sharing is determined by the resistance ratios [6], [12].

\section{Length of circuit (more buildings along a street)}

Postulating a greater number of buildings along the daisy chain, while keeping the resistance of the building earthing constant, can be expected to offer a path of lesser impedance to the currents exiting the building, because of the greater number of available earth electrodes. Table 5 shows the effect of going from 3 buildings (baseline) to 9 buildings, still with the last building being struck.

TABLE 5

EFFECT OF NUMBER OF BUILDINGS IN TN CIRCUIT ON SHARING, DISTANT HOUSE STRUCK

\begin{tabular}{lcc}
\hline Percent of 100 kA peak & Baseline 3 buildings & 9 buildings \\
\hline Current in building earth & 42 & 42 \\
\hline Current in service earth & 39 & 14 \\
\hline Current in SPD & 26 & 27 \\
\hline
\end{tabular}

Again in this case, a difference is noticeable in the neutral conductor current, but not in the SPD current. Thus, this parametric variation shows that the number of buildings between the building being struck and the distribution transformer, while affecting the neutral current, does not affect the stress imposed on the SPDs in this TN configuration.

\section{DISCUSSION}

\section{A. Effect of postulated waveform}

While we have adopted for our baseline the 10/350 $\mu$ s waveform, many SPD standards cite an $8 / 20 \mu \mathrm{s}$ or a $4 / 10 \mu \mathrm{s}$ surge waveform as an SPD capability requirement [15], [16] or as a surge environment description [17]. To explore the effect on sharing of the stroke current with different waveforms, in particular during the initial part of the $10 / 350 \mu$ s surge where inductive effects dominate for the circuit parameters selected, we made one run with a $8 / 20 \mu$ s surge instead of the $10 / 350 \mu \mathrm{s}$ used in the baseline case of the TN Radial. Predictably, given the small difference between a $10 \mu$ s and an $8 \mu$ s rise time, little effect was noted in the sharing during the first $20 \mu \mathrm{s}$. Of course, the energy involved for the total surge duration is another matter, already discussed in Section $\mathrm{V}$.

\section{B. Selection of SPDS}

If the design objective is to provide protection for a direct stroke to the building (a topic which will be the subject of the cost/risk analysis mentioned below), the SPDs must be selected with sufficient current-handling capability to survive the surges resulting from the postulated surge.

Alternate proposals have been made to use a spark gap as service entrance SPD. Such a gap must then be capable of clearing the resulting follow current, which may be an issue for systems having a large available fault current, such as the $10 \mathrm{kA}$ rms specified for U.S. installations [3], [18].

We have made one run with a spark gap model instead of a varistor model. From the sharing point of view, the difference is small, which can be readily explained by the fact that inserting in the lightning current paths a varistor with a limiting voltage of $1 \mathrm{kV}$ or so, or a gap with an arc voltage of $100 \mathrm{~V}$ or so, should have a very small effect on the sharing because of the many kilovolts developed by the lightning current flowing in the inductances and resistances of the line conductors and earthing connections.

\section{Cost/Risk Analysis}

An essential aspect of designing an effective surge protection system is to perform a cost/risk analysis involving the probability of a building being struck by a large surge, such as $100 \mathrm{kA}$, versus the cost of ensuring survival of the service entrance SPDs to be installed. This analysis introduces factors such as the flash density in the locale, the randomness of the distribution of the flashes over the area of attraction of the building which depends in part on the height of the building, and the distribution of peak amplitudes of lightning strokes. For instance, [11] reports statistics [19] whereby an $80 \mathrm{kA}$ amplitude is exceeded for less than $5 \%$ of the strokes. Such an analysis is beyond the scope of our paper, but it must be mentioned here to keep the situation in perspective and remind developers of SPD application guides or standards to include it in their recommendations.

\section{Applying field experience to standards}

The ultimate test of the usefulness of a standard is that equipment manufactured according to that standard has satisfactory field experience, while being produced at a cost that users are willing to accept. Very low field failure rates can be seen as overdesign, high failure rates obviously as underdesign. It is the dream of one of the authors to establish a clearinghouse where field experience of manufacturers could be collected and applied to optimize the definition of the environmental stress [20]. Given the competitive nature of the industry, this is likely to remain only a dream. However, many U.S. utilities are now offering to their customers the installation of a meter-base adapter SPD. The field experience for these SPDs might be collected from utilities -. with safeguards on proprietary information -- and become an input to the process of moderating some proposals for high-stress requirements, on the basis of the successful field experience of SPDs with capabilities below those implied in proposed standards. 


\section{CONCLUSIONS}

Modeling several typical TN and TT configurations of neutral earthing practices and scenarios of lightming strike point provides insights on significant effects, which should lead to more effective application of surge-protective devices (SPDs).

1. A direct lightning stroke to a building can produce high stresses on the service entrance SPDs as the earth-seeking current will exit in part by way of the utility service drop. SPDs in that building will be strongly affected, while nearby buildings will be impacted by much lower surge currents.

2. The major difference among the scenarios we have modeled appears in the current carried away from the building by the neutral conductor.

- In a TN system where the neutral is bonded to earth at the service entrance, there is no SPD in that path, and thus no concern about neutral SPD integrity. In typical residential single-phase U.S. systems, the line SPDs can carry about $25 \%$ of the stroke current.

- In a IT system where there is an SPD in the neutral path, a single-phase two-wire configuration can have $50 \%$ of the stroke current being carried by the neutral SPD. In a three-phase TT system where there are four conductors to carry away the stroke current, the neutral SPD can carry up to $30 \%$ of the stroke current.

3. For line conductors, the difference reflects primarily the total number of conductors in the system, which can be two, three or four. The earth-seeking lightning current will divide (but not always equally) among these conductors. While the initial dispersion (during the first $20 \mu \mathrm{s}$ ) is controlled by the inductances, the later dispersion is controlled by the relative values of the earthing resistances.

4. If the postullated stroke is as high as some of the proposed standards suggest, modeling the behavior of service entrance SPDs of the type installed in increasing numbers by U.S. utilities shows that some failures could be expected. As field experience seems to indicate an acceptable failure (if any) rate, one can question the need for imposing such severe requirements, unless the mission of the facility is such that even a rare failure would be unacceptable.

\section{ACKNOWLEDGMENTS}

Support and encouragement for this work was provided by the parent organization of each author. Additional support was received from Delmarva Power Company, from Pacific Gas \& Electric Company, and from PECO Energy Company. Gerald FitzPatrick and Roger Witt contributed comments on the draft.

\section{REFERENCES}

[1] EPRI, "Electromagnetic Transient Program (EMTP), Version 2.0; Volume 1: Main Program: Volume 2: Auxiliary Routines, EPRI Report EL-6421-L, July 1989.

[2] IEC International Standard 364-1, Electrical Installations of Buildings Part I: Scope, Object and Fundamental Principles, 1992.

[3] NFPA 70, National Electrical Code, 1996.
[4] Martzloff, F.D., Mansoor, A., Phipps, K.O., and Grady, W.M., "Surging the Upside-Down House: Measurements and Modeling Results," Proceedings, EPRI PQA'95 Conference, 1995.

[5] Mansoor, A. and Martzloff, F.D., "Driving High Surge Currents into Long Cables: More Begets Less," Paper 96 SM399-6 PWRD, IEEE PES Summer Meeting, Denver CO, 1996.

[6] Rakotomalala, A., Auriol, Ph., and Rousseau, A., "Lightning Distribution Through Earthing System." Symposium Record, IEEE International Symposium on EMC, Chicago IL, USA, August 1994, pp 419-423.

[7] Lai, J.S. and Martzloff, F.D., "Coordinating Cascaded Surge Protection Devices: High-Low versus Low-High," IEEE Transactions IA-29 No.4, July/August 1993, pp 680-687.

[8] Birkl, J., Hasse, P., and Zahlmann, P., "Systemgerechter Einsatz von Ableitern in Niederspannungsnetzen," Elektrotechnische Zeitschrift No.17, 1994, pp 964-971

[9] Flisowski, Z., and Mazzetti, C., "Efficiency of Lightning Protection System as Screening Measure Against LEMP," Proceedings, EMC'96 ROMA, September 1996.

[10] Darveniza, M., Sargent, Limbourn, Liew, Caldwell, Currie, Holcombe, Stillman \& Frowd, "Modelling for Lightning Performance Calculations" IEEE Transactions PAS-98, No.6, Nov/Dec 1979, pp 1900-1908.

[11] Kirder, E.P. and Uman, M.A., "Cloud-to-Ground Lightning Mechanisms of Damage and Methods of Protection," Seminars in Neurology, Vol.15, No.3, September 1995.

[12] Dugan, R.C. and Smith, S.D., "Low-Voltage-Side Current-Surge Phenomena in a Single-Phase Distribution Transformer System," IEEE Transactions PWRD-13, No. 2, April 1988.

[13] Steigerwald, R.L., Ferraro, A., and Tompkins, R.E, "Investigation of a Family of Power Conditioners Integrated into the Utility Grid," Sandia Report SAND81-7031, 1981, page 20.

[14] Transient Voltage Suppression Devices, Harris Corp., 1991.

[15] ANSI/1EEE C62.11.1991, IEEE Standard for Metal-Oxide Surge Arresters for AC Power Circuits.

[16] ANS1/IEEE C62.34-1996, IEEE Standard for Performance of LowVoltage Surge-Protective Devices (Secondary Arresters).

[17] ANSI/IEEE C62.41-1991, IEEE Recommended Practice on Surge Voltages in Low-Voltage AC Power Circuits.

[18] UL Std. 1449, Transient Voltage Surge Suppressors, 1996.

[19] Berger, K., Anderson, R.B., and Kroninger, H., "Parameters of Lightning Flashes," Electra, 1975-80, pp 1548-1565

[20] Martzloff, F.D., "Keeping up with the Reality of Today's Surge Environment," Power Quality Solutions, September 1995 Proceedings, pp 243-249.

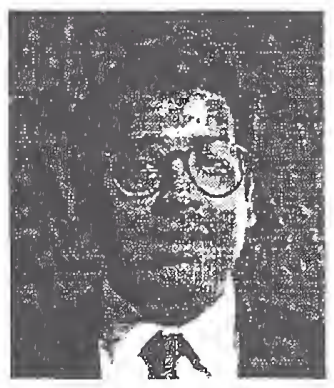

Arshad Mansoor (M' 1995) is an Electrical Systems Engineer at the EPRI Power Electronics Applications Center (PEAC). He received his MS and Ph.D. in electrical engineering from the University of Texas, Austin in 1992 and 1994 respectively. His areas of interest include Power Quality, power systems transients analysis, harmonics, surge propagation and protection, and EMTp model development.

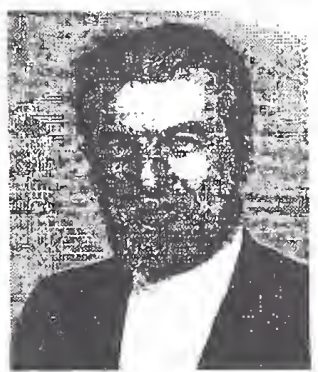

François Martzloff (M'1956, F'1983) Born and educated in France, with additional MS degrees from Georgia Tech and Union College, worked at General Electric for 29 years and now 12 years at the National Institute of Standards and Technology. He is contributing to several committees for the development of standards on EMC, surge protection and Power Quality in the IEEE and the IEC. 


\section{Discussion}

P. Hasse and J. Birk』 (Dehn + Sobne, 92318 Neumarkt, Germany): The problem of lightning current distribution depending on the different kinds of current distribution systems and under the influence of possible variables has been very clearly represented with this contribution.

The curve development gained by the EMTP program matches very well with the simulation calculations conducted in Germany with the PSPICE program.

In respect to the described results, however, a few additions are necessary from our point of view:

\section{Section III. G. and VI. A.:}

The induction of a conductor system always results out of the geometric system of the slip-knot consisting of coming and going conductor. A separation in coming conductor impedance and going conductor impedance is not realistic.

In particular, in case of multiple conductor cables it is to be observed that in case of the same flow direction of the lightning current, the inductivity of the total system differentiates to a single conductor system.

\section{Section VI. Schedules 3 - 5:}

In particular, in case of longer connecting cables between buildings and between building and transformer a change in waveform of the surge flowing through these cables. Only the observance of the amplitude factor of the flowing lightning currents is not sufficient. In this situation, it would be more meaningful to consider also the energy distribution.

\section{Section VII. B.:}

For decades now, in Europe, spark gap arresters, with a mains follow current quenching capability, are being installed successfully as lightning current arresters at the building entrance. In particular, the high down-lead ability and impulse-time shortening of the rest impulse make a favourable co-ordination with connecting MOV's possible.

\section{Section VII. 4:}

The lightning protection necessity for a system, as well as the deduced lightning protection class resulting from this, is described in IEC 1662. At the same time the lightning protection class is determined, the layout of the lightning protection system necessary lightning parameters are defined (IEC 1312-1). A deviating layout of protection measures on the basis of test currents $8 / 20 \mu \mathrm{s}$ is therefore not permissible.

Manuscript received November 3, 1997.
François D. Martzloff (National Institute of Standards and Technology, Gaithersburg MD) :

We thank the two authors of the discussion for taking the time to review our paper and provide comments aimed at broadening the consensus on the subject. In particular, we are delighted to hear that our computations based on EMTP matches very well with the simulation calculations conducted in Germany with the PSPICE program. With respect to their specific four comments, we offer the following responses, preceded by the general remark that the purpose of our computations was to reveal the differences among various postulates for the circuit configurations, as influenced by the grounding practices for the neutral in effect in different countries, rather than the precise values for a particular set of parameters. We emphasize the concept of postulate, lest we fall into the trap of taking electromagnetic environment standards as an exact duplication of reality, while they are in fact only the documentation of an industry consensus on how reality might be represented !

\section{Section II G and IV A}

Indeed, the concept of inductance is based on a conductive loop that carries the current in a closed circuit. However, in the circuits we postulated for our computations, the conductors in question - phase and neutral - may be considered as one part of the closed circuit and might be called "coming," according to the terminology used by our colleagues, while the path consisting of the earth, the distant return to the cloud, the lightning channel, and even the down-conductor (see Section III A) may be considered as the other part of the loop and might be called "going" conductors.

For this reason, we represented in our figures the phase and neutral as if they were separate, while in reality they can be at some finite distance from each other (the so-called "open wiring" used in overhead lines) or in close vicinity, as in the case of an underground cable or an overhead "triplex." Aware of the differences, we started our computations for a given, postulated configuration - always the same for the variations in the neutral grounding - but performed a parametric variation in the line inductance (taking twice or half the value used in the baseline), as stated in the subject paragraph, to convince ourseives that the influence on dispersion is not large enough to cause concern. Space limitations for the paper prevented us from providing detailed numerical results - as they also do here - and we were hoping that our simple statement that we did consider the issue and found little effect on the differences among neutral grounding scenarios might be acceptable.

\section{Section VI 3 to 5}

One of the results of our computations based on a postulated $10 / 350 \mu \mathrm{s}$ waveform was to show that, for the distances we selected, the impedance of the cable between buildings - and therefore their length - has only a small influence on the longterm current waveform and dispersion among conductors, which is primarily influenced by the postulated values for respective earthing resistances. With the values selected for inductances, 
the current dispersion is substantially affected by the respective inductances only for the first 20 or $30 \mu \mathrm{s}$.

We agree that additional information might be conveyed by reporting the energy distribution along the complex path of the lightning current, but here again space limitations intervene. We can offer the response, however, that in view of the large values of the earthing resistance compared to the other resistances in the circuit - cable resistances and dynamic "resistances" of the varistor or gap SPDs - the latter are not a priority in reporting results. The EMTP model of course has the capability of reporting any set of parameters if "asked" to do so.

For specific applications of one type or another of SPD technology, the EMTP model can provide detailed information on the energy that will be deposited in these SPDs for the various scenarios to be considered.

\section{Section VII B}

We are aware that in some countries, the installation of a service-entrance arrester is a common practice, and that gapped arresters may be used for that purpose. The issue is one of cost vs. benefits for an arrester designed for the large lightning currents associated with a rare direct strike to the building. We have observed, during our interactions with several international or IEEE technical committees, that consensus has not been reached on what current waveform and peak amplitudes should be considered when making the cost vs. benefits analysis. Depending on the nature of the installation, the cost vs. benefits equations are different. Several proposals for "risk analysis" are currently under consideration in several standards-developing bodies, and consensus is clearly not achieved at this point. This lingering question is addressed in our response to the fourth and last comment after the present one.

Our intention in making the remark on available fault current in the second paragraph of this section was not to contest the successful European experience cited by our colleagues, but to alert our readers at large to the importance of considering that requirement. The point that mains follow-current quenching capability is not trivial was confirmed in a comment by one of the reviewers of our forthcoming paper, "Gapped Arresters
Revisited" (scheduled for presentation at the IEEE-PES Winter 1998 Meeting and later publication in IEEE Transactions).

\section{Section VII 4}

We are aware of the work conducted in the IEC Technical Committee 81, the responsible body for development of the IEC 61662 and IEC 61312 publications. We are also aware of some discomfort among other parties concerning the stipulations from that body which might result in less than fully cost-effective solutions to the question of real necessity for protection against worst-case scenarios. The footnote offered in support of our introductory remark applies here also. There is a long and successful history of application of surge-protective devices based on a postulated $8 / 20 \mu$ s surge current waveform, using the appropriate values of amplitudes. For that reason, we included in our paper as alternate postulate the $8 / 20 \mu$ s waveform. From the point of view of IEC TC 81, their recommendations might be considered normative and thus non-negotiable, but protection measures in the various countries are typically determined - if at all - by bodies that promulgate codes based on a consensus drawn from experience based not exclusively on TC 81 recommendations. Therefore, the use of the term "not permissible" appears somewhat strong in the context of voluntary or even regulatory practices.

In conclusion, we appreciate the opportunity to present more detailed background information on our computations and underlying postulates, thanks to the discussion contributed by our colleagues.

1. Long ago, my mentor, Frank Fisher, taught me this concept which I recite in the following terms, well worth repeating in the present context: "The criterion of validity of an environment standard is not so much how closely it duplicates reality but rather how well equipment designed in accordance with this standard perform in the field. If equipment designed in accordance with the standard perform well in the field, while equipment ignoring the standard do not perform well, the chances that the standard be a good standard are pretty good."

Manuscript received January 7, 1998. 


\title{
On the Dispersion of Lightning Current After a Direct Flash to a Building
}

\author{
François Martzloff \\ National Institute of Standards and Technology \\ Gaithersburg MD 20899 USA \\ f.martzloff@ieee.org
}

Reprinted with permission from Proceedings, $25^{\text {th }}$ International Conference on Lightning Protection, Rhodes, 2000

\section{Significance:}

Part 2 Development of Standards - Reality checks

Part 4 Propagation and coupling of surges

Comparison between two simplified modeling studies of the dispersion and a documented case of the complexity of a direct flash to a residence.

Reservations on the justification of very high stress requirements for SPDs are expressed in a discussion, followed by a proposal to encourage more information sharing on the subject 
$\varnothing$ 


\title{
ON THE DISPERSION OF LIGHTNING CURRENT AFTER A DIRECT FLASH TO A BUILDING
}

\author{
François Martzlofif \\ f.martzloff@ieee.org \\ National Institute of Standards and Technology* \\ U.S.A.
}

\begin{abstract}
Simplifications often made when simulating the dispersion of lightning current can yield results that depart too much from the complex reality of a direct lightning lash to a building. The unpredictable occurrence of side-flashes increases even more the complexity. Such simulations, if taken at face value, might lead to unrealistic specifications for serviceentrance surge-protective devices (SPDs). A real-world anecdote illustrates both the complexity and a case wbere an SPD with only modest ratings, compared with some present proposals, providied satisfactory protection on the power-port appliances of a residence.
\end{abstract}

Key Words: Lightning current dispersion, sideflashes, surge-protective devices

\section{INTRODUCTION}

Recent discussions among participants in the development of surge-protection standards have shown a lack of consensus on the possible scenarios concerning the dispersion of the lightning current when a direct flash to a building is involved. Skepticism has been expressed both on the simulation of available paths for the dispersion, and on the magnitudes and waveforms postulated for the resulting currents flowing in the conductive elements of the installation - especially the service entrance surgeprotective devices (SPDs). Note that the skepticism does not aim at the parameters of the lightning flash itself, which have been accepted now for many years [1], but at the simulation conclusions concerning requirements for service-entrance SPDs with very high current-handling capability.

Another objection has been that the distinction between a building equipped with a lightning protection system (air terminals, down-conductors and earthing system), on the one hand, and a building without such a system, on the other hand, might be misleading.
Every building that contains electrical circuits (power or communications), electrically-conducting mechanical elements, metallic structures, etc., has a de facto lightning 'protection' system of intended or unintended air terminals and down-conductors - except that their connection to the earthing system might have unpredictable and unwanted side effects.

As an input toward developing consensus, this paper reviews in a first part two examples of simulations that have been performed by others, and in a second part relates a real-world anecdote of a corroborated case of a direct flash to a residence.

\section{SIMULATING DISPERSION}

\subsection{Examples of simulations}

A Joint Working Group of the International Electrotechnical Commission (IEC) has recently developed a Technical Report on surge protection [2]. This four-year effort involved the participation of five IEC Technical Committees interested in the subject. The data base considered by the group included, among many sources, two published papers, identified in the Bibliography of the report, authored independently by members of the group.

In both studies, a 10/350 $\mu$ s waveform was postulated, and a time-invariant earthing resistance and inductance were postulated. Currents in the available paths to earth and voltages at selected points of the systems were computed. For the purpose of this paper, three figures only are reproduced here for a qualitative glimpse on the results.

Figure 1, simplified from Ref [2], shows the nature of circuit components and configuration: two buildings and the distribution transformer linked by a cable in a linear arrangement. The point of strike is Building 1 . The detailed numerical values, which are given in the referenced paper, are not significant for this comparison of the two studies.

* Electricity Division, Electronics and Electrical Engineering Laboratory. Technology Administration. U.S. Department of Commerce Contributions from the National Institute of Standards and Technology are not subject to U.S. Copyright. 


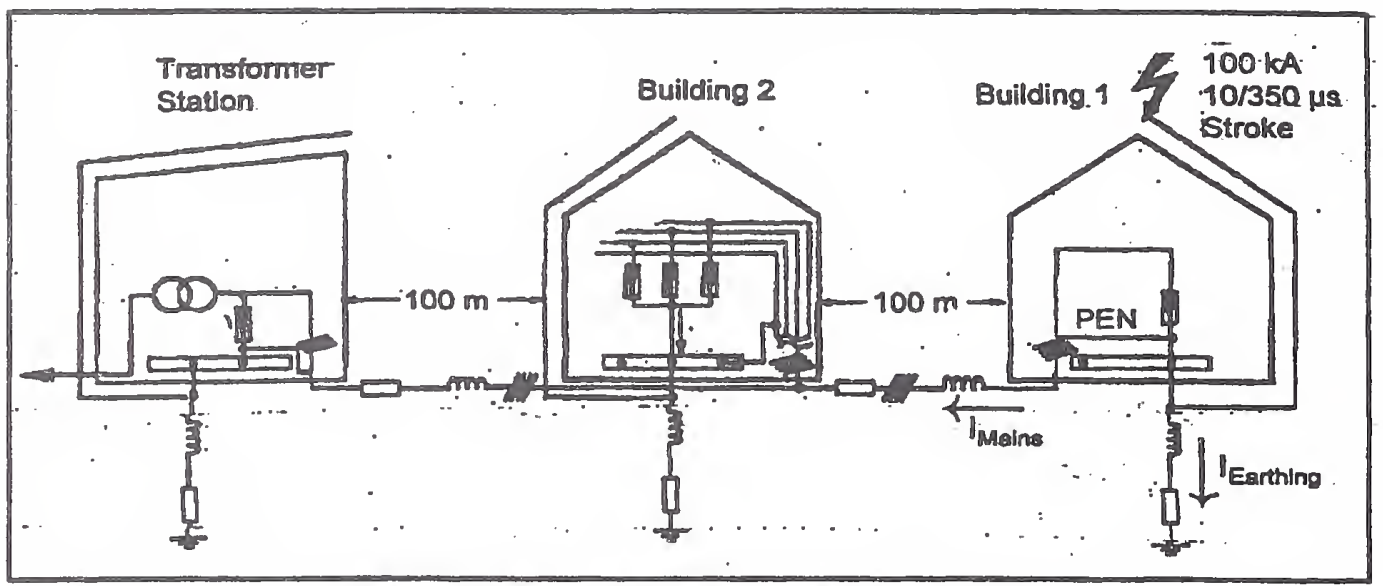

Figure 1 - Circuit components and configuration used in the Hasse simulation (Ref [2])

Figure 2 shows examples of the computed waveforms for currents at selected points of the Figure 1 circuit, from top to bottom : the postulated stroke current, the current exiting Building 1 via the power supply cable, the current in the earthing impedance of the building, and the current in the service-entrance SPDs of Building 2 resulting from the surge that is now, for Building 2, an impinging surge.

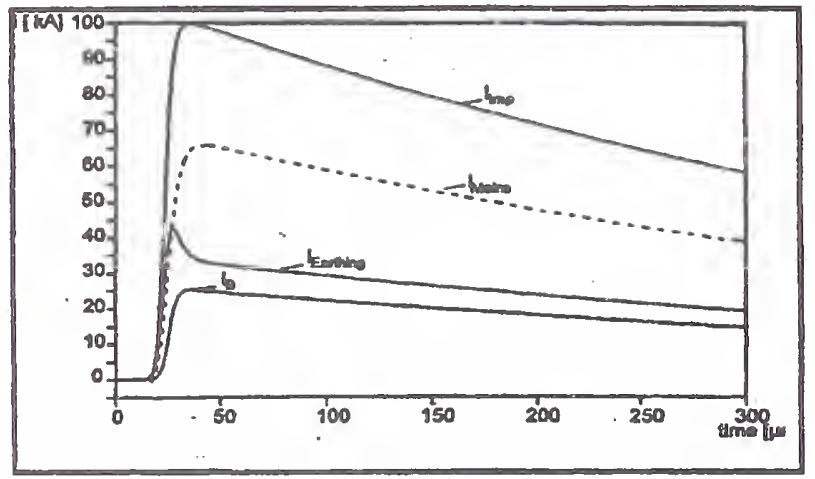

Figure 2 - Current dispersion for Figure 1

The numerical values are not significant, but the waveforms are. The current exiting the building ( $\|_{\text {Mains }}$ ) has the same waveform as that of the stroke. The earthing current ( $\|_{\text {earthing }}$ ) has an initial peak, due to the additional inductance of the power supply cable; in the long term, the inductive effect disappears, and the current division simply reflects relative values of the available earthing resistances.

In contrast with Figure 1 where the buildings are strung along a power supply cable, Figure 3, from Ref [3], shows a radial configuration of three buildings, each supplied by its own service drop, with all three connected directly to the terminals of the common distribution transformer. Varistor-type service-entrance SPDs are provided for each building. The transformer and each building have their own earthing electrode connection, represented by a fixed resistance and an inductance.
The radial service drops also consist of a resistance and an inductance, not drawn in the figure, but modeled in the computation according to the 20 -m length of each radial drop. The point of strike of the flash is the earthing system of Building 1 (to which the neutral is bonded).

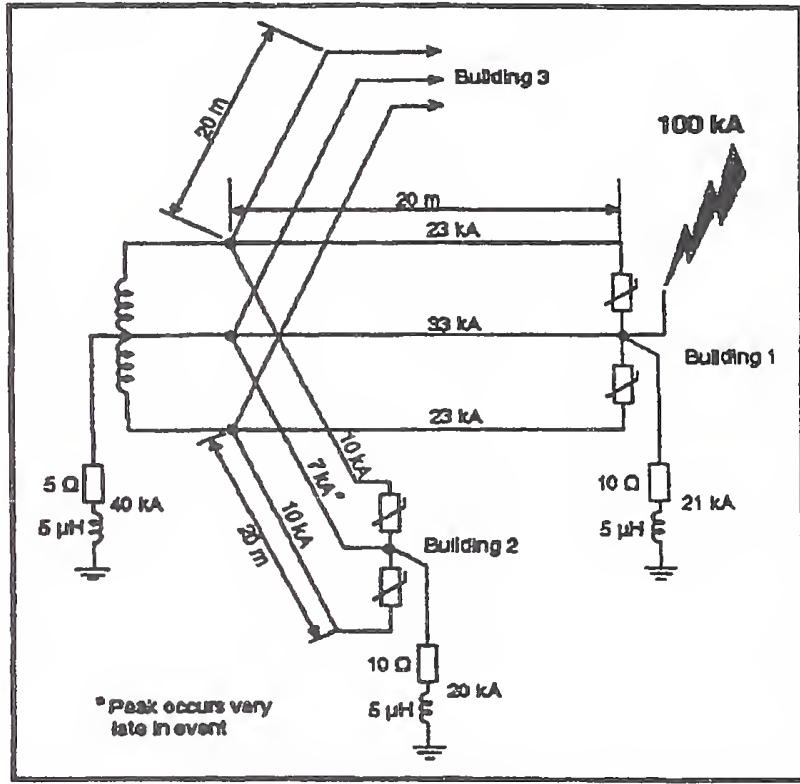

Figure 3 - Buildings configuration and resulting currents, according to Mansoor (Ref [3])

The significance of citing these two independent studies, separated by an ocean, by two different languages used by the authors, and by two different simulation programs, is that quite compatible conclusions were reached after exchanging information, first across the table during IEC working group meetings, then later on, via intensive e-mail messages, as a working relationship blossomed in spite of logistics barriers. This important point will be elaborated further in Section 7 of this paper. 
With hindsight, it appears predictable that the initial current dispersion (the first ten microseconds) should be strongly influenced by the relative values of the postulated inductances, and the later dispersion by the relative values of the postulated (time-invariant) earthing resistances.

\subsection{Involvement of service-entrance SPDs}

The results of these simulations show that the stresses imposed on the service-entrance SPDs that become involved in dispersing the part of the lightning current toward remote earthing electrodes of the power distribution system will reflect the relative values of the earthing impedances. These stresses also vary with the postulated current waveform, ranging from the short $8 / 20 \mu$ s long-used for designing SPDs, to the more recent proposed 10/350 $\mu \mathrm{s}$ and finally to the seldom-considered continuing current within a multiple-stroke fiash.

Performing these simulations was not a futile exercise but provided insight on the influence of significant parameters. However, among end-users, this complexity of postulates decreases the credibility of defining SPD requirements on the basis of simulations, giving a greater credibility to field experience of widely-used SPDs that have demonstrated satisfactory performance over many years.

\section{SIDE FLASH}

One event that contributes to the complexity and uncertainty of lightning current dispersion is the possible occurrence of a side-flash. A side-flash can establish unexpected paths to earth, with two consequences that extend beyond the consideration of service-entrance SPD stresses - the motivating concern for this paper.

- The side-flash itself can have hazardous consequences by acting as an igniter, as will be told in the anecdote of Section 4.

- The side-flash can cause currents to flow along conductive paths within the installation, thereby coupling transient overvoltages in the circuits of the installation, by common path or by induction.

Of course, the latter has the same end-result as what the bonding applied to avoid the side flash will produce, except for its unpredictability.

\section{FROM SIMULATIONS TO REALITY}

\subsection{Setting the stage}

To illustrate the credibility gap that separates reality from simplified representations, the following story should be narrated:

.... Once upon a time, in a far-away land (Upstate New York, U.S.A.) there lived an engineer who was recording surges, writing papers and presenting tutorials on surge protection, including the need for good bonding practices.
This engineer had bought a house from the previous owner who had lived many happy years there without any problem, so that our engineer made the (unwarranted) assumption that the house and its electrical wiring were in good order. The house was surrounded by several tall, mature trees so he thought that the cone of protection from the trees would benefit the house. Alas ! All-knowing Zeus recognized that this engineer needed to be taught a lesson on reality and thus sent a downward stepped leader toward the general area of the engineer's house ...

By now, dear readers, you have guessed that our mythical engineer is none but the author of this paper... who will now offer this true story for your edification. First, the "where" : Figure 4 shows a simplified (here we go again ...) topology of the house, a two-story wood frame with basement and attic. Utilities (power, telephone, and cable TV), all entered, via overhead service drops, at the rear of the house, while water and sewer underground pipes were at the front of the house. The telephone system was not involved in the incident and therefore is not shown in the figure. The power installation included the usual revenue-meter (outside) and service panel (inside) with circuit breakers controlling a multitude of branch circuits. Only three are shown in the figure: lighting fixture in the attic, TV on the second floor, and a counter-top receptacle (via ground-fault interrupter) for the kettle (2) in Figure 4) sitting on the enamelled cast-iron kitchen sink (The significance of this detail will surface shortly.)

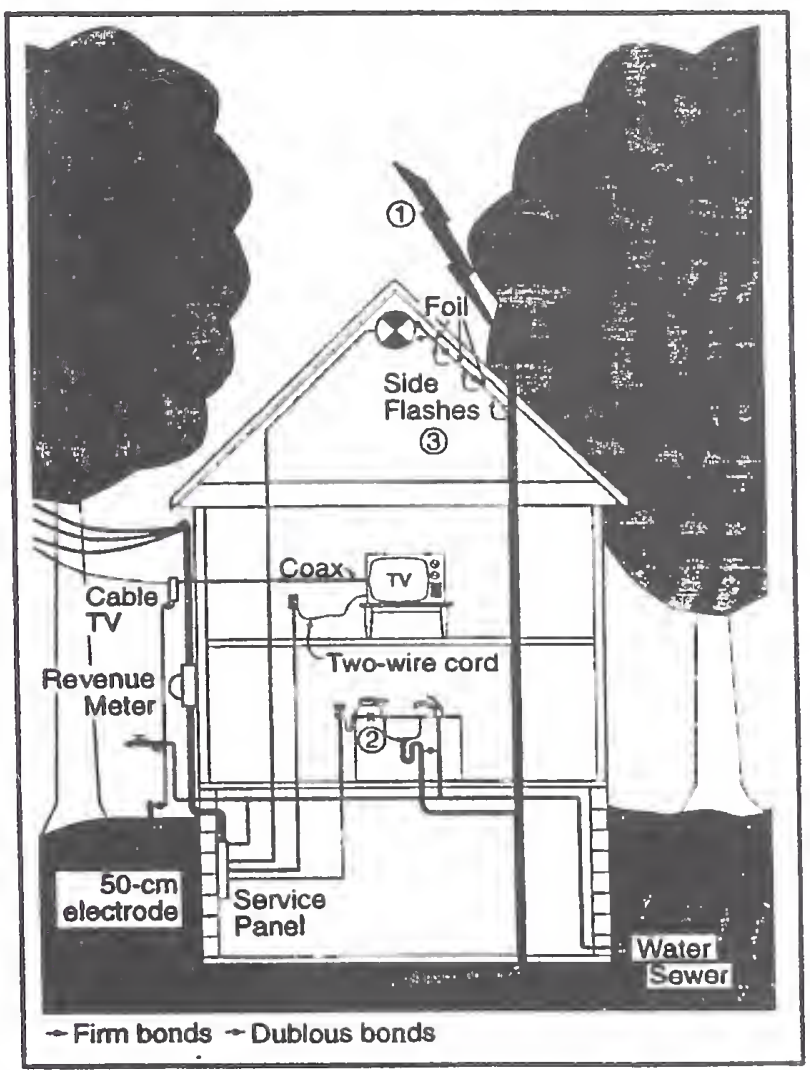

Figure 4 - Simplified configuration of anecdotal story 
Water service and indoor piping were all copper, with $a$ bond betwe en the ground bus of the service panel and the nearest cold-water pipe. There was no visible grounding conductor to a (non-existent) made-electrode, but the perception existed that, given the vintage of the house (circa 1920), the water piping was sufficient, in addition to the multiple-grounded neutral of the power company.

Upon moving in the house, I had installed in the service panel a surge arrester (circa 1965 vintage) consisting of a silicon-carbide disk in series with a stamped-metal air gap. The cable. IV senvice, as originally. installed by the utility, only had a $50-\mathrm{cm}$ long picket allegedly serving as "ground". Having been exposed to the concept of bonding. I hed installed a bond between the picket and the nearby outdoor water faucet. A very passive - but soon to become active - part of the installation was the typical sewer system made of lead-bonded cast-iron pipe extending a to vent through the roof and connected to the street sewer, still with cast-iron pipes and thus offering the topology of a well-grounded air terminal, albeit below the peak of the roof. But I am getsing ahead of myself, as I had never considered this vent as a lightning air terminal, since the house was surrounded by taller trees and thus "obviously" within their cone of protection.

\subsection{Zeus" wrath}

Now for the "When" and "How" : On the day when the tale unfolded, my wife (the corroborating eye-witness) and I were standing in the kitchen, listening to the approaching thunder and watching the big drops of rain just beginning to splash on the window. Then, a bright flash outside, with an immediate, deafening thunderclap. and also we both saw a small flash under the kettle. "That was a close one" we both said, whereupon I proceeded to check all appliances in the house. Several were inoperative, but a check of their branch circuit breakers revealed that they had tripped, and resetting them restored order. The only one that did not work was the old TV set. although there was no evidence of severe damage or burned smell, and we considered ourselves lucky - until a smell from the attic attracted my attention: the ceiling of the atric (which was covered by cellulose-base panels) was smoldering!

Fortunately - and not by accident - a handy fire extinguisher allowed me to quench the smoldering, while my wife called the fire department. To their credit, they were in front of the house within minutes. I told them that $I$ believed that the fire extinguisher had done the job; nevertheless, one fireman proceeded to climb on a ladder to the atric window and hacked it away to let the smoke out, while another entered the house, pushing me aside, with a high power water hose in tow - which fortunately he did not tum on. After ripping several of the ceiling panels to verify that the fire indeed was out, the firemen left, with our emotional thanks and the applause of the neighbours gathered in front of the house.

\subsection{The homeowner's epillogue}

- One obsolescent TV receiver, which was not repaired, but catalysed the purchase of a new and upgraded set (missing the opportunity to do an extensive postmortem as in the "Case of the Cozy Cabin" [4]):

- Several hundred dollars expended to repair the window destroyed by the firemen, install a splice on one attic rafter weakened by charring; and replacing the ripped panels.

- After recovering from the shock, a realization of how lucky to have been in the house at the time of the incident, and glad for the foresight of having a fire extinguisher on every floor of the house !

\subsection{The engineer's epilogue}

Such a traumatic experience called for an investigation of the incident. The first observation was that the previous owner had installed insulation between the attic rafters, stapling the aluminum foil of the bats to the rafters, but not overlapping them across the edges of the rafters. This arrangement, concealed by the panels, created several gaps along the 5-m distance separating the sewer vent pipe from the light fixture at the apex of the attic, but reducing the total gap to a few centimetres - an easy side-flash scenario, resulting in the ignition of the dust and surface fuzz of the rough-from-sawmill rafters.

The second observation, a few days after the incident, was to notice a small rust spot on the kitchen sink where the kettle usually sat: there was a small hole in the otherwise good-condition glaze, exposing the underlying cast iron: The flash seen under the kettle (2) was the cause of the enamel puncture; several kilovolts must have been required to break down the series-connected insulation of the heating element inside the kettle, and the porcelain glaze of the sink. The electronic ground-fault circuit breaker controlling the receptacle had to be reset, but it was not damaged, and subsequent use of the kettle did not cause it to trip, so we concluded that the brief breakdown of the insulation of the heating element was not a massive event.

The immediate action was to install a bond between the sewer vent pipe and all extraneous metal in the attic. The long-term effect on the engineer was a consciousnessraising on the issue of surge protection of multiple-port appliances, even though a bond had been provided between the incoming cable TV service and the power system [5]. At that time, the concept of the surge-reference equalizer [6] had not yet surfaced, and no commercial device was available to provide that function. In fact, the proliferation of plug-in surge-protective devices launched by the introduction of metal-oxide varistors had not yet occurred.

A casual inspection of the fist-sized surge arrester at the service panel showed no distress, an indication of adequate design for the rare scenario of a direct strike to a building [7]. 
This arrester used only a 30-mm diameter silicon carbide disk as varistor, which most likely would be destroyed by the high-energy lightning surges presently considered or recommended by some IEC committees. (Sorry, the house has changed owners and an exhaustive test on that particular surge arrester, desirable as it would be in retrospective, is not possible.)

The attic side-flash (3) in Figure 4) clearly indicated that the sewer vent pipe was the point of strike (1), raising the question of why the tall trees failed in their expected mission of establishing an effective cone of protection. Perhaps one explanation might be that during the initial part of the rainfall, the still-dry trees could not emit a successful competing upward streamer, compared to the wellgrounded cast-iron pipe. Comments from lightning physics experts on this speculation would be welcome.

Thus, our engineer had learned his lesson, and lived happily without further incident for fifteen more years in the far-away land. However one cannot say 'lived happily ever after' : After moving to a new home further South, one night a nearby lightning flash triggered a burglar alarm (which had to be pried open to silence the horn turned on by a failed semiconductor, at 02:00 am no less) and damaged a remote-control garage door opener: Zeus had still kept track of the battle-hardened surge-protection engineer, but that is another story ...

\section{FROM REALITY TO SIMULATION}

Among several investigations based on rockettriggered lightning, the ongoing effort at Camp Blanding in Florida, U.S.A. is aimed at injecting a lightning current at specific points of the replica of a residential power system. Initial results (1997) were inconclusive because of instrumentation problems, but as these are progressively overcome, more definitive information becomes available. Actually, the most recent report [8] provides so many raw measurement results that an effort of synthesis will be necessary to gain a better understanding of the issues.

The major advantage of such systematic projects over a random recitation of anecdotes could be the possibility of going from a real-world configuration to a sufficiently detailed numerical representation of the circuit parameters. A cross-validation of the measurement results and of the simulation results would then significantly increase the credibility of both, and lead to realistic designs and ratings for SPDs.

The challenge, of course, will be to represent enough of the many, many parameters involved in the real world but not so many as to make the simulation model unmanageable. For instance, the real-world situation of the ancedote already simplified in Figure 4 - with the ill-defined bonds and side-flashes - would be difficult to turn into a manageable and credible simulation.

\section{DISCUSSION}

The simplified assumptions on lightning current dispersion illustrated in Section 2 have met with some skepticism among the North-American surge-protection community and perhaps others. Part of this skepticism is also based on the relatively rare occurrence of massive failures for secondary arresters (distribution transformer secondary terminals and residential service entrance) designed to withstand the "classical" $8 / 20 \mu \mathrm{s}$ or $4 / 10 \mu \mathrm{s}$ surges, at crest levels of a few to a few tens of kiloamperes. Furthermore, the two simulations cited in Section 2 were based on the assumption that earthing electrodes have a constant resistance during the flow of the lightning current, an assumption that is questioned on the basis of preliminary results of measurements made in Florida in connection with triggered lightning experiments [8].

In contrast with these simplified scenarios, the realword anecdote would be a challenge for any numerical modelling but demonstrates evidence of substantial overvoltages developed in the installation (insulation puncture at the kettle) during the flow of this undetermined lightning current dispersion among the complex available paths to earth. The anecdote also offers an example of a surge arrester with modest current-handling capability surviving the scenario of a direct strike to a building.

A symptom of the incomplete consensus is the noticeable lack of a discussion of risk analysis in the report developed by the IEC Joint Working Group [2]. This topic was initially included in the document outline, raising high expectations, but, confronted with incompatible proposals, the group gave up on that initiative. The proposed methodologies ranged from elaborate and detailed mathematical formulae - which turned out to be using somewhat arbitrary postulates - to common-sense, almost intuitive considerations.

\section{A PROPOSAL FOR THE DISPERSION OF LIGHTNING INFORMATION}

In a 1963 freedom-seeking speech that still resonates today, the mantra "I have a dream" was coined. On a much more modest scale, the author has a dream of unfettered information-sharing on lightning. Having cited the preceding examples of developing, but still incomplete, consensus on the dispersion of lightning current, here is the proposal (or is it a challenge ?): Hopefully helpful timely participation, on a world-wide basis via electronic mail could supplement - not compete with - the established routes for information sharing, at a much accelerated pace. We are still mostly in a mode of developing standards a notoriously slow process — by volunteers or delegates often hampered by travel budgets, or of publishing peerreviewed papers - unquestionably a wise process, but entailing long delays between generation and ultimate publication of the information. 
This process of information dispersion might take one of the many forms by which the Intemet has revolutionised information sharing. Should this paper be accepted for oral presentation at the Conference, the author would propose to make only a very brief summary of the paper itself available to all in print - and make use of the scheduled presentation time for a cross-pollination of ideas among the attendees (much superior to the one-on-one poster process) on how to implement the proposal, bringing reality to the dream. Pessimists will point out hurdles such as the requirement of "previously unpublished information" for later acceptance of an archival paper reporting research on the subject, or the understandable modesty of researchers who want to be sure that the work is complete before publishing even preliminary results, and so forth. Optimists will find ways to by-pass these hurdles and broaden an early consensus.

\section{CONCLUSIONS}

- While there is no disagreement, or at least very little skepticism, on the specific parameters of the lightning discharge, consensus on the implications of lightning current dispersion for the rating of surge-protective devices has not yet been reached.

- Anecdotal information offered in many countries on their experience with service entrance surge-protective devices having moderate handling capability suggests that the proposed ratings for very high duty levels might be unnecessary and not cost-effective, unless a convincing risk analysis demonstrates otherwise.

- Information dispersion on these issues could be greatly enhanced by establishing an informal and timesensitive world-wide site (in parallel, not in conflict with more formal procedures), which the author is prepared to undertake if encouraged and supported by colleagues in the lightning-protection community.

\section{REFERENCES}

\subsection{General}

Many publishing organizations, in their instructions for the peer-review process, raise the question "Are references adequate to show knowledge of work by others?" or words to that effect. While undoubtedly a valid question, the result is sometimes a lengthy recitation of up to several hundred citations, which seems an overkill.

Standard-writing organizations have evolved the concept of differentiating between, on the one hand "References" - a listing of documents that are made an integral part of the standard by a ritual introductory statement, and, on the other hand, citations - in the form of a "Bibliography" with or without annotations.
For this paper, "References" are limited to the strict minimum necessary to support a particular point being made. To illustrate where extensive listing of "references" might lead, a literature search was conducted with "lightning" as a leading key word, and next with one additional word. The results are listed below, showing the number of "hits" found for the period of just 1969-1999 the accessible on-line data base did not include Benjamin Franklin's seminal letters to the Royal Society on lightning protection of houses and the Purfleet munitions storage [9].

$\begin{array}{lr}\text { Lightming } & 15791 \\ \text { Lightming + surge } & 2348 \\ \text { Lightming + current } & 3306 \\ \text { Lightning + damage } & 1130 \\ \text { Lightming + protection } & 6349 \\ \text { Lightming + arrester } & 1816 \\ \text { Lightming + earth + electrode } & 139\end{array}$

These numbers show that it would be unrealistic for a single researcher to examine in detail the contents of fifteen thousand papers. Injecting the concerted filtering and sharing action of today's active researchers into a readily accessible data base — the author's dream - would be a great improvement.

\subsection{Specific references}

[1] Anderson, R.B. and Eriksson, A.J., "Lightning parameters for engineering applications," ELECTRA, No.69, March 1980.

[2] IEC 62066: 2000, General basic information regarding surge overvoltages and surge protection in low-voliage a.c. power circuirs.

[3]. Mansoor, A. and Martzloff, F.D., "The Effect of Neutral Earthing Practices on Lightning Current Dispersion in a Low-Voltage Installation," IEEE Transactions PWRD:13; July 1998.

[4] Key, T.S., Nastasi, D., Phipps, K.O., and Martzloff, F.D. "Some enlightening case histories on lighoning damage," Submitted for presentation at ICLP 2000, September 2000.

[5] Key, T.S., and Martzloff, F.D., "Surging the Upside-Down House: Looking into Upsetting Reference Voltages," Proceedings, PQA'94 Conference, Amsterdam, October 1995.

[6] IEIEE Std 1100-1999 ("Emerald Book") IEEE Recommended Practice for Powering and Grounding Electronic Equipment, IEEE, 1999.

[7] IEEE PC62.41.1-2000 - Draft IEEE Guide on the Surge Environment in Low-Volsage (1000 V and less) AC Power Circuits.

[8] EPRI "Investigation of lightning entry into a secondary service using rocket-triggered lightning," EPRI Report TR-110418, April 1998.

[9] Cavendish, Watson, Franklin and Robertson, "A report of the Committee appointed by the Royal Society to confider a Method for Jecuring the Powder Magazines at Purfleet," Philosophical Transactions of the Royal Society, London, 1772. 


\section{The role and stress of surge-protective devices in sharing lightning current}

\author{
François D. Martzloff \\ National Institute of Standards and Technology \\ Gaithersburg MD 20899 \\ f.martzloff@ieee.org
}

\author{
Arshad Mansoor \\ EPRI PEAC Corp \\ 942 Corridor Park Blvd \\ Knoxville TN 37932 \\ Amansoor@epri-peac.com
}

Reprint of paper presented at EMC Europe 2002, September 2002

\section{Significance}

Part 2 Development of standards - Reality checks

Part 4 Propagation and coupling - Numerical simulations

Most simulations performed to investigate the sharing (dispersion) of lightning current for the case of a direct flash to a building have focused on the role and stress of surge-protective devices (SPDs) installed at the service entrance of a building and their involvement in that part of the lightning current that exits the building wia the the power supply connection to the energy supply.

The numerical simulations performed for this paper, based on a postulated waveform and am plitude suggested by current standards, include downstream SPDs, either incorporated in equipment or provided by the building occupant; the results show that a significant part of the exiting lightning current can involve those downstream SPDs with some likelihood that their surge withstand capability might be exceeded. Such a possibility then raises questions on the validity of the postulated amplitude in the face of the relatively rare occurence of reported failures. 


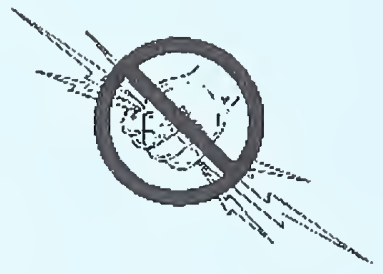




\section{THE ROLE AND STRESS OF SURGE-PROTECTIVE DEVICES IN SHARING LIGHTNING CURRENT}

\author{
François D. Martzloff \\ National Institute of Standards and Technology ${ }^{1}$ \\ Gaithersburg MD 20877 USA \\ f.martzloff@ieee.org
}

\author{
Arshad Mansoor \\ EPRI PEAC Corp. \\ 942 Corridor Park Blvd \\ Knoxville TN 37932 USA
}

\begin{abstract}
This paper examines the sharing of lightning current associated with a direct flash to a building. This sharing involves not just those surgeprotective devices (SPDs) that might be installed at the service entrance, but also all SPDs involved in the exit path of the lightning current. Such sharing might involve built-in SPDs of some equipment located close to the service entrance, but heretofore not included in numerical simulations performed by many researchers. From the numerical simulations reported in this paper, conclusions are offered that may influence the design and EMC testing of equipment, as well as the risk. analysis associated with lightning protection.
\end{abstract}

\section{BACKGROUND AND RATIONALE}

This paper offers additional information to the body of knowledge accumulated on how the lightning current of a direct flash, injected into the earthing system of a building, is shared among the many available paths towards intended or opportunistic earthing electrodes.

Recent developments in the International Electrotechnical Commission (IEC) and the Surge-Protective Devices (SPD) Committee of the Institute of Electronics and Electrical Engineers (IEEE) have focused on the role of SPDs connected at the service entrance of a building in the case of a direct lightning flash to the building. This scenario is described in IEC 61312-3 (2000) [9], IEEE PC62.41.1 [12] and PC62.41.2 [13].

Prior to this new focus, most of the considerations on SPD applications were based on the scenario of surges impinging upon the service entrance of a building as they come from sources external to the building. The new (additional) focus addresses the scenario of the earth-seeking lightning current as it is shared among the many possible paths to earth, including the deliberate and opportunistic exit paths of the building earthing system, services other than the power system connection and, mostly, the power supply connection.

Quite independently from these lightning protection considerations, the IEC Subcommittee SC77B had developed a series of documents on the electromagnetic compatibility of equipment, IEC 61000-4-5, Surge withstand capability [8] in particular. These documents were primarily concerned with immunity against typical disturbances, the rare case of a direct lightning flash to a building containing electronic equipment not included.

Increasing recognition of the need to include the scenario of a direct flash to a building - rare as it might be - has motivated the formation of an IEC Joint Task
Force TC81/SC77B for the purpose of considering surge stresses on equipment higher than those currently described in the IEC document 61000-4-5 on immunity testing [8].

The purpose of the paper is to examine in detail the sharing of lightning current, not just by the SPDs at the service entrance, but also by all SPDs that might be involved in the exit path of the lightning current. Such sharing might well involve SPDs incorporated in the equipment located close to the service entrance, but not always included in the numerical simulations that have been performed by many researchers (Altmaier et al. 1992) [1]; (Standler, 1992) [23]; (Rakotomalala, 1994) [20]; (Birkl et al., 1996) [3]; (Mansoor and Martzloff, 1998 ) [15]; (Mata et al., 2002) [19]. In its recent development of a Guide and a Recommended Practice on surges in low-voltage ac power circuits [13] the IEEE has refrained from identifying SPDs as being those that may be connected at the service entrance. Instead, it refers to "SPDs involved in the exit path" without reference to their point of installation.

Given the tendency of equipment manufacturers to include an SPD at the equipment power input port, the issue of "cascade coordination" arises. Several previous papers (Martzloff, 1980) [17]; (Goedde et al., 1990) 5]; (Lai and Martzloff, 1991) [14]; (Standler, 1991) 22]; (Hostfet et al., 1992) [7]; (Hasse et al., 1994) [6] have explored the concept of cascade coordination involving two or more SPDs connected on the same power supply but at some distance from each other.

The legitimate wish of the energy service providers to specify robust SPDs at the service entrance results in SPDs having a relatively high Maximum Continuous Operating Voltage (MCOV). On the other hand, some equipment manufacturers tend to select SPDs with a low MCOV under the misconception that lower is better (Martzloff and Leedy, 1989) [18]. This dichotomy can result in a situation where the low-MCOV SPDs included in equipment might well become involved in the "exit path" and thus become overstressed in the case of a direct flash to the building. This situation is made more complicated by the fact that commercial SPDs packages are assembled from typical distributors' supplies that can have an allowable tolerance band of $\pm 10 \%$ on the voltage-limiting rating.

To explore the possibility and implications of a questionable coordination, numerical simulations were performed on a simplified model of a building featuring SPDs installed at the service entrance and SPDs that may be incorporated in equipment connected inside the building near the service entrance.

\footnotetext{
${ }^{1}$ Contribution of the National Institute of Standards and Technology; not subject to copyright in the United States.
} 


\section{NUMERICAL SIMULATIONS}

\section{III.1 Basic circunit}

Figure 1 shows a simplified building power system that includes the key elements of this scenario: the building earthing system and all earthing electrodes, with the corresponding exit paths via the service-entrance SPDs and a built-in SPD provided at the power port of a typical item of electronic equipment. In this example, these SPDs are metal-oxide varistors (MOVs) with typical voltage ratings (150 V at the service entrance and $130 \mathrm{~V}$ in the equipment) selected for a 120/240 V residential power system. (The conclusions obtained for this type of power system will also be applicable to $240 / 400 \mathrm{~V}$ systems.)

Numerical analysis of the circuit behavior by EMTP [4] allows inclusion of the SPD characteristics as well as the significant $R$ and $L$ elements of the wiring, with injection of a stroke current of $100 \mathrm{kA} \mathrm{10/350 \mu s}$ at any selected point - the earthing system in this case. The selection of a $100 \mathrm{kA}$ peak is consistent with the postulate made in many published simulations, but might be questioned on the basis of field experience and lightning detection statistics, as will be discussed later in this paper.

In Figure 1, the neutral is defined as part of a "multiplegrounded neutral" system (TN-C-S), with distributed R and $\mathrm{L}$ elements between its earthing electrode connections. The $\mathbb{R}$ and $\mathbb{L}$ values for the cables used in the numerical simulation, but not shown in the figure to avoid clutter, were selected to emulate the typical wire diameters used in low-voltage power distribution systems and building installations.
Previous studies (Birkl et al., 1996) [3]; (Mansoor and Martzloff, 1998) [15] have validated the intuitive expectation that the tail of the $10 / 350 \mu$ s waveform often postulated for simulations will be shared among the available paths simply according to the relative values of resistance in the paths leading to the earthing electrodes. This fact is apparent in the results of Figure 2 , for example at the $350 \mu \mathrm{s}$ time: when inductive effects have dwindled, the current $\mathbb{I}_{H}$ in the $10-\Omega$ earthing resistance of the building is ten times smaller than the total current exiting the building $\left[I_{N}+I_{L 1}+I_{L 2}\right]$ toward the power distribution system in which multiple earthing electrodes offer an effective earthing resistance of only $1 \Omega$. It is also worthy to note that this sharing is controlled by the relative values of the resistances, so that any earth conductivity differences associated with local conditions will wash out.

The combination of the service-entrance $150-\mathrm{V}$ MOV on Line 2 and the $130-\mathrm{V}$ MOV incorporated at the power port of the equipment constitutes a so-called "cascade". When two such cascaded SPDs are to be coordinated, a decoupling impedance must be provided between the two SPDs so that the voltage drop caused by the current flowing in the decoupling impedance - in this example the impedance of the $2,5 \mathrm{~mm}^{2}$ diameter wires - and added to the limiting voltage of the $130-\mathrm{V}$ MOV, will cause enough of the current to flow through the $150-V$ MOV to reduce stress on the $130-\mathrm{V}$ MOV.

The simulation was performed for three values of the impedance (length) of the connection, i.e., $0,1 \mathrm{~m}, 1 \mathrm{~m}$, and $10 \mathrm{~m}$ to assess the effect of this impedance for practical situations. Figure 3 shows the results for these three cases and Table 1 shows the resulting energy deposition in the respective MOVs.

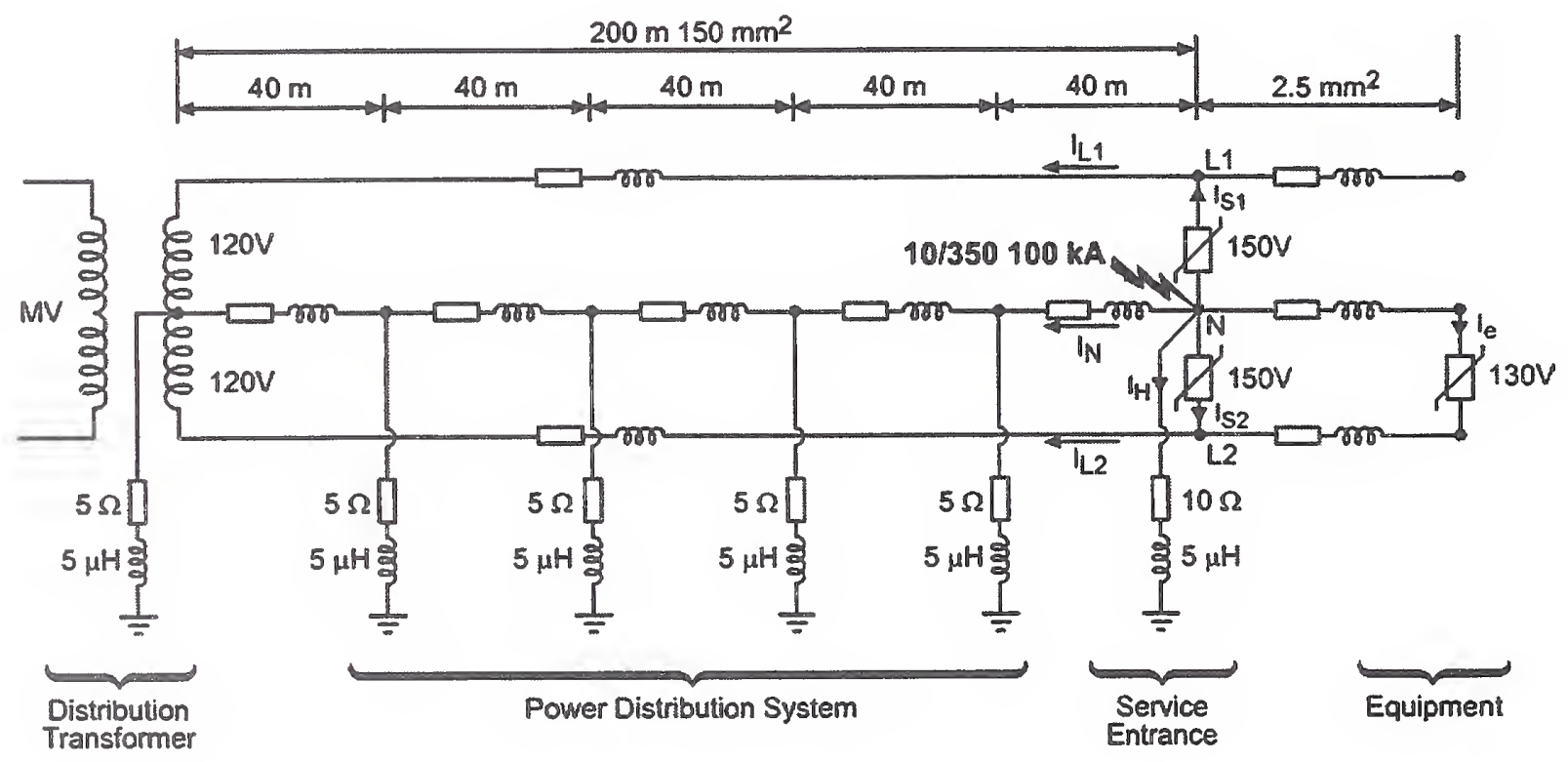

Figure 1 Simplified building schematic with service-entrance SPDs, one built-in equipment SPD, and multiple-grounded power distribution system in case of a direct lightning flash to the earthing system 


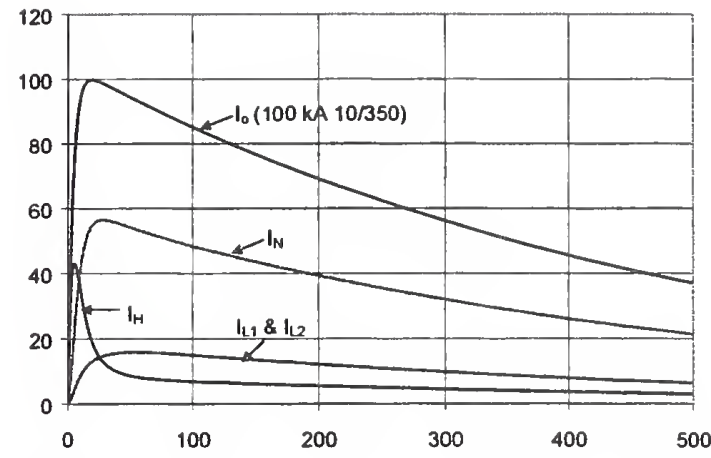

Legend

$\mathrm{I}_{0}: 100 \mathrm{kA}, 10 / 350 \mu \mathrm{s}$ stroke to the building earthing system $I_{N}$ : current exiting via the neutral of the power supply

$I_{L_{1}}, I_{L_{2}}$ : current exiting via the two lines of the power supply $I_{H}$ : current into the building earthing electrode(s)

Vertical scale: current in KA - Horizontal scale: time in $\mu s$

Figure 2 - Sharing of the lightning current among available paths to earth electrodes

In the traces of Figure 3, the total current in Line 2 (sum of the two currents in the two MOVs) remains essentially unchanged for the three combinations, but the sharing of the current between the two MOVs is significantly affected.

Figure $3 \mathrm{a}$, with only $0,1 \mathrm{~m}$ of separation, is not a practical example of connection of equipment that close to the service entrance - except perhaps an electronic residual current device incorporated in the service panel. The two other figures, $3 \mathrm{~b}$ and $3 \mathrm{c}$, show how the $130-V$ MOV that took the largest part of the current in the case of Figure 3a, now takes on less as separation length increases. An interesting situation develops as the current flowing in the $10-\mathrm{m}$ line to the $130-\mathrm{V} \mathrm{MOV}$ stores energy that will cause a stretching of the current in the $130-\mathrm{V}$ MOV long after the $150-\mathrm{V}$ MOV current has decayed. This is significant because the total energy deposited in the MOVs is the criterion used for coordination, even though the current in the $130-\mathrm{V}$ MOV could be lower than the current in the $150-\mathrm{V}$ MOV. Table 1 shows how this energy sharing changes with the length of the decoupling connection, according to the integration of the varistor currents and voltages obtained from EMTP.

Table 1 - Sharing energy between MOVs for three different connection lengths

\begin{tabular}{|l|c|c|c|}
\hline \multirow{2}{*}{ SPD } & \multicolumn{3}{|c|}{ Energy deposition (joules) } \\
\cline { 2 - 4 } & $0,1 \mathrm{~m}$ & $1 \mathrm{~m}$ & $10 \mathrm{~m}$ \\
\hline $150-V$ MOV & 620 & 1090 & 2470 \\
\hline $130-V M O V$ & 2560 & 2030 & 890 \\
\hline
\end{tabular}

These energy levels might be acceptable for a $150-\mathrm{V}$ MOV sized for service entrance duty, but the 890 -joule deposition into the $130-\mathrm{V}$ MOV incorporated in the equipment exceeds common-wisdom ratings for such

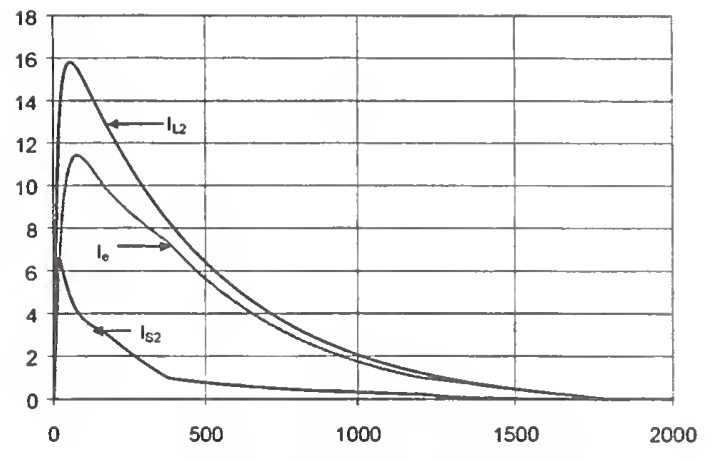

a) 0,1 $m$ connection
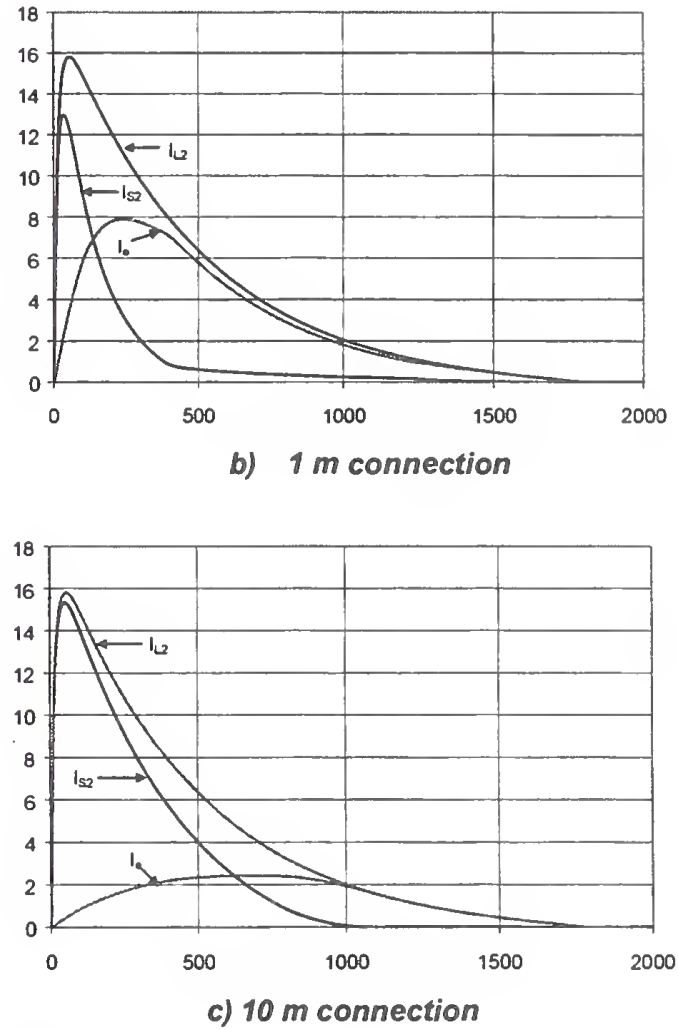

Legend

$\mathrm{I}_{\mathrm{L} 2}$ : current exiting via the power supply phase conductor $I_{I_{2}}$ : current into the service entrance SPD

$\mathrm{I}_{\mathrm{e}}$ : current into the equipment SPD

All vertical scales: current in $\mathrm{KA}$ All horizontal scales: time in $\mu \mathrm{s}$

Figure 3 - Sharing of lightning stroke current

devices. This finding then raises a question on the effectiveness of a cascade for the case of direct flash to the building. In an actual installation, there would be more than one piece of equipment, presumably each with a $130-\mathrm{V}$ built-in MOV at the power port. One might expect that some sharing among these multiple SPDs would reduce the energy stress imposed on these devices. 
To explore this situation, an additional simulation was performed for three branch circuits, respectively $10 \mathrm{~m}$, $20 \mathrm{~m}$, and $30 \mathrm{~m}$, each of them supplying equipment incorporating a built-in $130-\mathrm{V}$ MOV. Figure 4 shows the sharing of current among these three MOVs and the 150 -V service entrance MOV, and Table 2 shows the energy deposition.

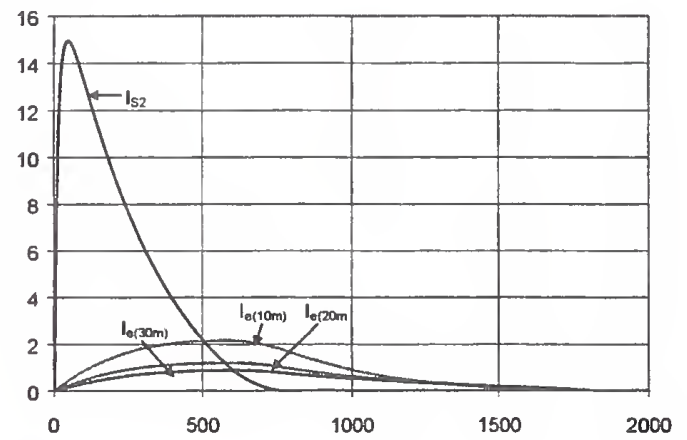

Legend

$1_{S 2}:$ current into the service entrance SPD

$\mathrm{I}_{\mathrm{e}}$ : currents in the three SPDs at end of 10,20 , and $30 \mathrm{~m}$ lines

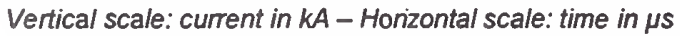

Figure 4-Sharing of current among MOVs

Table 2 - Energy sharing among MOVs

\begin{tabular}{|c|c|c|c|}
\hline \multicolumn{2}{|c|}{$\begin{array}{c}\text { Branch circuit length and energy } \\
\text { deposition into three 130-V MOVs }\end{array}$} & $\begin{array}{c}\text { Service entrance } \\
150 \text {-V MOV }\end{array}$ \\
\cline { 1 - 2 } $10 \mathrm{~m}$ & $20 \mathrm{~m}$ & $30 \mathrm{~m}$ & \\
\hline $620 \mathrm{~J}$ & $370 \mathrm{~J}$ & $280 \mathrm{~J}$ & $1930 \mathrm{~J}$ \\
\hline
\end{tabular}

\section{II.2 Effect of manufacturing tolerances on commercial-grade metal-oxide varistors}

The simulations discussed so far were performed by postulating that both the $150-\mathrm{V} \mathrm{MOV}$ and the $130-\mathrm{V}$ MOV had their measured voltage limiting at the nominal value as specified by typical manufacturer specifications. Such a postulate is of course difficult to ensure in the reality of commercial-grade devices. For instance, the nominal voltage-limiting value of MOVs rated $130 \mathrm{~V}$ rms is $200 \mathrm{~V}$, with lower limit of $184 \mathrm{~V}$ and upper limit of $220 \mathrm{~V}$. To check that aspect of the problem, an arbitrary lot of 300 devices rated $130 \mathrm{~V}$ rms was purchased from a distributor and the actual measured voltage-limiting value at $1 \mathrm{~mA}$ dc was determined in accordance with IEEE Std 62.33-1994 [11]. For this lot, the standard deviation (sigma) was found to be $8 \mathrm{~V}$.

On the basis on these measurements and to give an indication of the significance of tolerance effects, the computations reported for Figure $3 \mathrm{c}$ ( $10 \mathrm{~m}$ separation) were repeated, still with a $150 \mathrm{~V}$ MOV at the service entrance, but with varistors at \pm 1 sigma of the $130 \mathrm{~V}$ rms rating, that is, $122 \mathrm{~V}$ and $138 \mathrm{~V}$ rms. The results are shown in Table 3.
Table 3 Energy sharing for three values of the equipment built-in MOV (10 m separation)

\begin{tabular}{|c|c|c|}
\hline \multirow{2}{*}{$\begin{array}{c}\text { Equipment } \\
\text { MOV rating } \\
\text { N rms) }\end{array}$} & \multicolumn{2}{|c|}{ Energy deposited (J) } \\
\cline { 2 - 3 } & $\begin{array}{c}\text { Equipment } \\
\text { MOV }\end{array}$ & $\begin{array}{c}150-V \text { service } \\
\text { entrance MOV }\end{array}$ \\
\hline 122 & 915 & 2320 \\
\hline 130 & 890 & 2890 \\
\hline 138 & 750 & 2650 \\
\hline
\end{tabular}

These results illustrate the significance of tolerances in a situation where the difference between the two SPDs of the cascade is not large, because of the de facto situation of low values of MCOV that the industry has unfortunately adopted. Of course, if tolerances were also taken into consideration for the service entrance MOV, the extremes of distributions for both MOV would make an effective coordination between a nominal $150-\mathrm{V}$ MOV and a nominal $130-\mathrm{V}$ MOV even more problematic.

\section{3 Nonlinearity of circuit ellements}

Most of the reported simulations, as cited above, have been performed with a conservative postulate of a 100 kA 10/350 lightning discharge. The median of the current peaks compiled in the seminal Berger et al. paper [2] is only $20 \mathrm{kA}$. Occasional reservations have been voiced on the validity of these data collected with technology dating back to the 1970's. A recent (July 2000) actual case history was communicated to the authors by a colleague for two major lightning storms recorded in the area of Tampa in Florida by means of the Lightning Detection System [24], during which over 30000 flashes were detected in a period of less than 12 hours, with only one at the $150 \mathrm{kA}$ level, and a median of $20 \mathrm{kA}$, confirming the Berger at al. data.

One could expect that the dispersion of the lightning current that results from the combined action of linear elements (resistance and inductance) with nonlinear components (MOVs) might produce a different sharing of the current as the decoupling element is linear but the SPDs are nonlinear. To explore this hypothesis, the computations for the case of Figure 4 and Table 2 were repeated, for peak currents of $100 \mathrm{kA}$ (the original value of the computation), $50 \mathrm{kA}$, and $25 \mathrm{kA}$ (about the median of the statistics). Table 4 shows the results of these computations. It is interesting to note that as the applied stroke is decreased 4 to 1 (from 100 to 25 ), the total energy deposited in the varistors is decreased by a factor of $3200 / 610=5.2$. This relative greater decrease is caused by the larger portion of the current exiting via the linear-path neutral, further relief for all the SPDs involved in the exit path.

Table 4 Nonlinear effects on current sharing

\begin{tabular}{|c|c|c|c|c|c|}
\hline \multirow{2}{*}{$\begin{array}{c}10 / 350 \\
\text { stroke } \\
(k A)\end{array}$} & \multicolumn{3}{|c|}{$\begin{array}{l}\text { Branch circuit length and } \\
\text { energy deposited into } \\
\text { three } 130-\mathrm{V} \text { MOVs }\end{array}$} & \multirow{2}{*}{$\begin{array}{l}\text { Energy } \\
\text { into } \\
\text { service } \\
\text { entrance } \\
150 \text {-MOV }\end{array}$} & \multirow{2}{*}{$\begin{array}{l}\text { Total } \\
\text { energy } \\
\text { in the } \\
\text { MOVs }\end{array}$} \\
\hline & $10 \mathrm{~m}$ & $20 \mathrm{~m}$ & $30 \mathrm{~m}$ & & \\
\hline 100 & $620 \mathrm{~J}$ & 37 & $280 \mathrm{~J}$ & $1930 \mathrm{~J}$ & $3200 \mathrm{~J}$ \\
\hline 50 & $329 \mathrm{~J}$ & 215 & $179 \mathrm{~J}$ & $700 \mathrm{~J}$ & $1423 \mathrm{~J}$ \\
\hline 25 & $170 \mathrm{~J}$ & $120 \mathrm{~J}$ & $90 \mathrm{~J}$ & $230 \mathrm{~J}$ & $610 \mathrm{~J}$ \\
\hline
\end{tabular}




\section{DISCUSSION}

We have made all these computations based on postulating that the insulation levels are sufficient to prevent a flashover that would drastically affect the continuing energy deposition in the downstream SPDs. We have not included the limits of energy handling of the devices, which of course should be compared with computed deposited energy levels in a practical case.

Another set of readings from the EMTP computations confirmed that the presence of SPDs at the critical points prevents such overvoltages from occurring (as long as the SPDs can carry the resulting currents)

Not surprisingly, the results of the simulation confirm that the sharing of the lightning current occurs in inverse ratio of the resistances leading to the earthing electrodes after the initial phase of the $10 / 350 \mu$ s stroke. Likewise, one can expect that inductances will limit the current flow so that low-inductive paths, such as intended and opportunistic earth electrodes of the building itself, compared to the longer lines of the power supply, will carry a larger share of the total current during the initial phase of the current. This effect is clearly visible on the $\mathbb{I}_{H}$ of Figure 2, for the relatively slow rise time of $10 \mu$ s of a first stroke. One may expect that for the subsequent strokes, or the flashes associated with triggered lightning experiments that have shorter rise times (Rakov et al., 2001) [21], this effect will be even more apparent.

An important finding - predictable on a qualitative basis but heretofore not quantified for the case of a direct lightning flash to buildings containing electronic equipment - concerns the cascade coordination of builtin SPDs in the equipment. From the simple examples presented, it appears that a cascade of a robust serviceentrance SPD and a built-in SPD sized for limited energy-handling capability, according to the commonwisdom practice, might well be a delusion.

A solution to the difficult coordination could be to replace the all-MOV SPD at the service entrance with a combined series gap-varistor device (Mansoor et al., 1998) [16]. Such a device would also alleviate the concerns about the temporary overvoltage problems associated with MOV-only SPDs. Sparkover of the gap during the initial rise of the lightning current (when the coordination by means of the decoupling inductance occurs) will invite the remainder (continuing rise and tail) of the surge current exiting via SPDs to use the service entrance SPD rather than the simple and less robust built-in MOVs downstream.

Last but not least, the practical question remains open on the need to provide surge protection against worst cases - the combined worst case of a direct flash to the building and the high-level $100 \mathrm{kA}$ stroke, which is only at the $4 \%$ probability, according to the Berger et al. data [2] and even lower in the yet-anecdotal case of the Tampa Bay lightning storm [24]. The nonlinearity effect presented in II. 3 adds further credibility to the overall need to make reasonable risk assessments of costeffectiveness before specifying high surge level requirements, both for the service entrance SPDs and for built-in SPDs in connected equipment.

\section{CONCLUSIONS}

1. When accepting the postulate that the reference parameter of a direct lightning flash to a building should be a $10 / 350 \mu$ s current with a peak of $100 \mathrm{kA}$, the numerical simulations performed for a simplified system with one surge- protective device installed at the service entrance, and one or more built-in SPD in downstream equipment indicate that the downstream SPD is very likely to be overstressed and fail, most likely catastrophically.

2. There are several possible explanations for the apparent contradiction between a prediction of downstream equipment failures based on this postulated lightning parameters, and equipment field experience that does not report such frequent failures, although of course anecdotes abound.

- The occurrence of a direct flash to a building can cause such extensive damage that a post-mortem for investigating the specifics of a prevailing ineffective coordination is not performed at that time and the issue is ignored.

- Enough uncontrolled clearance flashovers occur in the installation to provide significant relief for any atrisk SPDs incorporated in downstream equipment.

- In an installation where many built-in or plug-in SPDs are present, the sharing illustrated by Figure 4 , combined with a low probability of a $100 \mathrm{kA}$ stroke, might reduce the stress on downstream devices to a value within their capability. In particular, many commercial plug-in SPDs advertise capabilities of hundreds of joules, unlike the 20 joules of a single MOV, which might be provided at the input port of electronic equipment.

- Insufficient field failure data have been obtained, compiled, shared, and published to enable realistic assessment of frequency and severity of occurrences involving an unsuccessful cascade coordination.

3. It is impractical at this point to mandate high energy handling capability for built-in SPDs. Such a move might meet with strong objections from manufacturers whose products have satisfactory field experience, and a risk analysis might show it to be not cost-effective.

4. Economic and political realities related to the type and mission of the installations to be protected should be kept in mind. Clearly, mass-market applications such as cost-conscious consumers, in a framework of regulated or unregulated installations, are different from bottom-line-conscious industrial applications, and even more so in the case of national assets - be they cultural or military.

5. Another approach for manufacturers might be to avoid placing low MCOV varistors at the input port of their equipment. Rather, they should select an SPD with an MCOV and resulting surge-protective level as high as their equipment can inherently stand. This is a "selfish" approach which is mentioned here halfseriously, half-facetiously: there are enough low MCOV SPDs installed by users or included in other equipment in a typical system that those unfortunate low-MCOV devices will take up the stress, leaving unscathed the equipment wisely provided with high MCOV SPDs! 


\section{REFERENCES}

Note: The citations that appear in the text are listed here by alphabetical order of the lead author, not by chronological order of appearance in the text.

[1] Altmaier, H., Pelz, D. and Schebe, K., "Computer Simulation of Surge Voltage Protection in LowVoltage Systems," Proceedings, $21^{\text {st }}$ International Conference on Lightning Protection, Berlin 1992.

[2] Berger, K., Anderson, R.B. and Kröniger, H., "Parameters of Lightning Flashes," ELECTRA No.41, 1975.

[3] Birkl, J., Hasse, P., and Zahlmann, P., "Investigation of the Interaction of Lightning Currents with LowVoltage Installations and Their Related Threat Parameters," Proceedings, $23^{\text {rd }}$ International Conference on Lightning Protection, Firenze, 1996.

[4] EPRI, "Electromagnetic Transients Program," (EMTP), Version 2.0, Vol. 1: Main Program; Vol.2: Auxiliary Routines, EPRI Report EL-6421-L, 1989.

[5] Goedde, G.L., Marz, M.B. and Henry, D.C., "Coordinating Lightning Stroke Protection From the Utility System to Load devices," Proceedings, Second International Power Quality /ESD Conference, October 1990.

[6] Hasse, P., Zahlmann, P., Wiesinger, J., and Zischank, W., "Principle for an Advanced Coordination of Surge-Protective Devices in LowVoltage Systems," Proceedings, $22^{\text {nd }}$ International Conference on Lightning Protection, Budapest, 1994.

[7] Hostfet, O.T., Hervland, T., Nansen, B., and Huse, J., "Coordination of Surge Protective Devices in Power Supply Systems: Needs for Secondary Protection," Proceedings, $21^{\text {th }}$ International Conference on Lightning Protection, Berlin, September 1992.

[8] IEC 61000-4-5 (2001) Electromagnetic Compatibility - Part 4: Testing and measurement techniques - Section 5: Surge immunity test.

[9] IEC/TS 61312-3 (2000) Protection against LEMP Part 3: Requirements of Surge Protective Devices.

[10] IEC 61643-1 (2002) Surge protective devices connected to low-voltage power distribution systems - Part 1: Performance requirements and testing methods

[11] IEEE Std 62.33-1994 IEEE Standard Test Specifications for Varistor Surge-Protective Devices.
[12] IEEE C62.41.1-2002 Guide On The Surge Environment In Low-Voltage AC Power Circuits

[13] IEEE C62.41.2-2002 Recommended Practice on Characterization of Surges in Low-Voltage AC Power Circuits

[14] Lai, J.S. and Martzloff, F.D., "Coordinating Cascaded Surge-Protection Devices: High-Low versus Low- High," IEEE Transactions $I A-24$, No.4, 1993.

[15]Mansoor, A. and Martzloff, F.D., "The Effect of Neutral Earthing Practices on Lightning Current Dispersion in a Low-Voltage Installation," IEEE Transactions PWRD-13, 1998.

[16] Mansoor, A., Martzloff, F.D., and Phipps, K., "Gapped Arresters Revisited: A solution to Cascade Coordination," IEEE Transactions PWRD13, 1998.

[17] Martzloff, F.D., "Coordination of Surge Protectors in Low-Voltage AC Power Circuits," IEEE Transactions, PAS-99, 1980.

[18] Martzloff, F.D. and Leedy, T.F., "Selecting Varistor Clamping Voltage: Lower is not Better!," Proceedings, $8^{\text {th }}$ International Zurich Symposium on EMC, 1989.

[19] Mata, C.T., Fernandez, M.T., Rakov, V.A. and Uman, M.A., "EMTP Modeling of a Triggered Lightning Strike to the Phase Conductors of an Overhead Distribution Line," IEEE Transactions PWRD, 2002.

[20] Rakotomalala, A., Rousseau, A., and Auriol, P., "Lightning Distribution Through Earthing Systems," Proceedings, IEEE International Symposium on EMC, 1994.

[21] Rakov, V.A., Uman, M.A., Fernandez, M.I., Mata, C.T., Rambo, K.J., Stapleton, M.V. and Sutil, R.R., "Direct Lightning Strikes to the Lightning Protection System of a Residential Building," IEEE Transactions PE-032PRD, 2001.

[22] Standler, R.B., "Coordination of Surge Arresters and Suppressors for Use on Low-Voltage Mains,' Proceedings, $9^{\text {th }}$ International Zürich Symposium on Electromagnetic Compatibility, 1991

[23] Standler, R.B., "Calculations of Lightning Surge Currents Inside Buildings," Proceedings, IEEE EMC Symposium, August 1992.

[24] Waterer, S.F., Personal communication on the Lightning Storm in Tampa Bay Area, July 15, 2000. 
221

Annex A

Citations Part 4

Propagation and coupling of surges (Experiments and numerical simulations) 


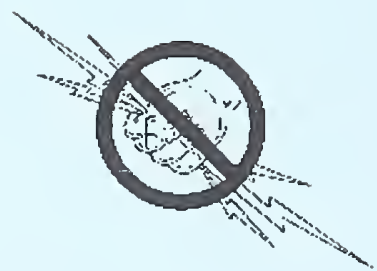




\section{Annex A}

Citations Part 4 - Propagation and coupling of surges (Experiments and numerical simulations)

[Alphabetical order by first author, as listed in Part 1]

ALTMAIER, H., PELZ, D., and SCHEIBE, K., "Computer Simulation of Surge Voltage Protection in Low-voltage Systems," Proceedings, $21^{\text {th }}$ International Conference on Lightning Protection, Berlin 1992

- Presents simulations of direct lightning strikes to the building for TN, TT, and IT power distribution systems.

- Makes the statement "Coordination must be done on a basis of lightning currents with the 10/350 waveform."

- 31 references

BIRKL, J., HASSE, P., and ZAHLMANN, P., "Investigation of the Interaction of Lightning Currents with Low-voltage Installations and Their Related Threat Parameters," Proceedings, $23^{\text {rd }}$ International Conference on Lightning Protection, Florence, 1996.

- Considers first stroke, subsequent stroke, and continuing current.

- Impact on surge arresters.

- 5 references

CIGRE Study Committee 33, WG 33.01 "Guide to Procedures for Estimating the Lightning Performance of Transmission Lines," Electra Brochure, 1992.

CROUCH, K.E. and MARTZLOFF, F.D., "Lightning Protection of Residential AC Wiring," Declassified GEMemo Report MOR-78-095, 1978.

- Effect of large currents flowing in the neutral/grounding conductor of the service drop to a building.

- A unidirectional $8 / 20 \mu$ s current flowing only in the grounding conductors induces oscillatory transients in the differential mode. (Test results contributed to the data base of IEEE Std C62.41.)

- 5 references

DUGAN, R.B. and SMITH, S.D., "Low-voltage-side Current Surge Phenomena in Single-phase Distribution Transformer Systems," Proceedings, IEEE T\&D Conference, 1986.

- Describes the scenario of a lightning strike to the service drop and resulting surges in the transformer.

- Simulations show the effects of placing surge arresters at the transformer secondary terminals.

- 7 references

DUGAN, R.B., "Conduction of Lightning Stroke Currents from the Utility System to Load Devices," Proceedings, First International Power Quality Conference, October 1989.

- Coupling of surges between grounding conductors, etc., and the line conductors during lightning currents.

- Describes solutions.

- 4 references

DUGAN, R.B., KERSHAW, S.S., and SMITH, S.D., "Protecting Distribution Transformers from Low-Side Current Surges," Proceedings, IEEE T\&D Conference, 1989.

- Discusses effects of the type of windings of the transformer on the resulting surges at the service entrance.

- Recommends installation of SPDs at both transformer secondary and service entrance.

- 7 references

DUGAN, R.B., GOEDDE, G., and HENRY, D.C., "Conduction of Lightning Stroke Currents From the Utility System to Load Devices," Proceedings, $2^{\text {nd }}$ National Conference on Power Quality for End-Use Applications, 1990.

- Describes how lightning surges can enter load circuits through utility system neutral paths.

- Offers comments on protection schemes within the building.

- 4 references

DUGAN, R.B., GOEDDE, G.L., and ROWE, L.D., "Full Scale Lightning Surge Tests of Distribution Transformers and Secondary Systems," Proceedings IEEE PES Transmission and Distribution Conference, Sept., 1991.

- Discusses low side surges and effects on distribution transformers.

- Discusses effect of secondary arresters on distribution transformer failures.

- 11 references 
DUGAN, R.C., "Low-Side Surges -Answers to Common Questions," Cooper Power Systems Bulletin SE9001, 1992.

- Tutorial presentation of the subject of low-side surges

- Laboratory test results from injection of $4 / 10$ strokes at the transformer primary and at the service entrance.

- 9 references

EHRLER, J. and KÜTTNER, H., "Ausbreitung und Begrenzung von Blitzüberspannungen in Nieder-spannungs Anlage" [Propagation and Limitation of lightning overvoltages in low-voltage systems], VDE/ABB Blitzschutztagung, 1997. (In German)

EPRI Electromagnetic Transient Program (EMTP), Version 2.0, Vol. 1, Main Program; Vol. 2, Auxiliary Routines, EPRI Report EL-6421-L, July 1989.

- Description of the public domain version of the original EMTP program, adapted for PC use.

ERIKSSON, A.J., STRINGFELLOW, M.F., and MEAL, D.V., "Lightning-induced Overvoltages on Overhead Distribution Lines," IEEE Transactions PAS-101, No.4, 1982.

- Measurement of voltages induced into an $11-\mathrm{kV}$ line, $10-\mathrm{km}$ long, by nearby and far lightning strikes.

- Model for computing induced voltages.

- 24 references, 2 discussions

FERNANDEZ, M.I., MATA, C.T., RAKOV, V.A., UMAN, M.A., RAMBO, K.J., STAPLETON, M.V., and BEJLERI, M. "Testing of Lightning Arresters and Improved Lightning Protection, Final Results," Technical Report, EPRI 109670, 1998.

- Camp Blanding, Florida facility for rocket-triggered lightning.

- Direct lightning strikes to overhead line and to a simulated house ground.

- 25 references

GREBE, J.E., "Application of Distribution System Capacitor Banks and Their Impact on Power Quality," IEEE Transactions IA-32, No.3, May/June 1996.

- Summary of power quality related concerns associated with the application of utility distribution systems capacitor banks.

- 7 references

HENSLEY, G., SINGH, T., SAMOTYJ, M., McGRANAGHAN, M., and GREBE, T.E, "Impact of Utility Switched Capacitors on Customer Systems Part II -- Adjustable Speed Drive Concerns," IEEE Transactions PWRD-6, No.2, October 1991.

- Computer analysis of nuisance tripping of adjustable speed drives caused by capacitor switching.

- 8 references

HENSLEY, G., SINGH, T., SAMOTYJ, M., McGRANAGHAN, M., and ZAVADIL,R., "Impact of Utility Switched Capacitors on Customer Systems -- Magnification at Low-Voltage Capacitors," IEEE Transactions PWRD- 7, No.2, April 1992.

- Computer and parametric analysis of secondary transient overvoltages caused by utility capacitor switching.

- 5 references

JOHNSON, I.B., SILVA, R.F., and WILSON, D.D., "Switching Surges Due to Energization or Reclosing,"

Proceedings, American Power Conference, vol. XXIII, 1961.

- Transient Network Analyzer study.

- 4 references

KEY, T.S. and MARTZLOFF, F.D. "Surging the Upside-Down House: Looking into upsetting reference voltages,"

Proceedings, EPRI-PQA'94 Conference, Amsterdam, October 1994.

- Describes a test bed for the propagation and mitigation of surges.

- Illustrates the differences of voltage references developed across multiple ports of appliances.

- 8 references

KIMBARK, E.W. and LEGATE, A.C., "Fault Surge Versus Switching Surge - A Study of Transient Overvoltages Caused by Line-to-Ground Faults," IEEE Transactions, PAS-87, No. 9, Sept. 1968.

- Theoretical treatment of the subject.

- 5 references 
LAT, M.V., "Determining Temporary Overvoltage Levels for Application of Metal-Oxide Surge Arresters on Multigrounded Systems," IEEE Transactions PWRD-5, April 1990.

- Presents several calculation methods for temporary overvoltages and an evaluation of these methods.

- Defines limits of applicability of the methods.

- 8 references

LIN, Y.T., UMAN, M.A., and STANDLER, R.B., "Lightning Return Stroke Models," Journal of Geophysical Research vol.85, No. C3, March 1980.

- Tests the two most commonly used lightning return stroke models, Bruce-Golde and transmission line, against subsequent stroke electric and magnetic field measured simultaneously at near and distant stations and shows that these models are inadequate to describe the experimental data.

- A new return stroke model is proposed that is physically plausible and that yields good approximations to the measured two-station fields.

- 38 references

MANSOOR, A. and MARTZLOFF, F.D., "Driving High Surge Currents into Long Cables: More Begets Less," IEEE Transactions PWRD-12, No.3, July 1997.

- Measurements and modeling show the physical impossibility for large surge currents to propagate very far into the branch circuits of a building, because flashover will occur at the service entrance.

- Demonstrates the importance of considering the maximum rate of rise (early in the surge) rather than the peak value and overall rise time.

- 13 references

MANSOOR, A. and MARTZLOFF, F.D., "The Effect of Neutral Earthing Practices on Lightning Current Dispersion in a Low-Voltage Installation," IEEE Transactions PWRD-13, July 1998.

- Compares the TN and TT for dispersion of lightning current in several scenarios.

- Shows the need for careful review of grounding practices in effect at service entrances.

- Questions the applicability of high amplitude, long duration requirement for service entrance SPDs.

- 20 references

MARTZLOFF, F.D., Surge Suppression in a Typical Home Wiring System," Declassified GE TIS Report 63GL97, 1963.

- Injection of voltage surges and their propagation in a residential power system.

- 2 references

MARTZLOFF, F.D. and CROUCH, K. E., "Coordination of Overvoltage Protection in Low-voltage Residential Circuits," - English translation by the author of the original French paper "Coordination de la protection contre les surtensions dans les réseaux basse tension résidentiels," published in Proceedings, 1978 IEEE Canadian

Conference on Communications and Power, 78CH1373-0, 1978.

- Reports laboratory injection of lightning current in house wiring.

- Illustrates conversion of unidirectional surges into oscillatory surges.

- 4 references

MARTZLOFF, F.D., "Coordination of Surge Protectors in Low-Voltage AC Power Circuits," IEEE Transactions, PAS99, No. 1, Jan./Feb. 1980.

- Coordination between gap-type ("voltage switching") and clamp-type ("voltage limiting") protectors.

- Coupling between grounding conductor and phase wires.

- 7 references

MARTZLOFF, F.D., "The Propagation and Attenuation of Surge Voltages and Surge Currents in Low-Voltage AC Power Circuits," IEEE Transactions PAS-102, No. 5, May 1983.

- Propagation and attenuation of $1.2 / 50 \mu \mathrm{s}$ and $100 \mathrm{kHz}$ Ring Wave.

- Coupling of differential mode through isolation transformers.

- 9 references, 1 discussion

MARTZLOFF, F.D. and GAUPER, H.A.,“Surge and High-Frequency Propagation in Industrial Power Lines," IEEE Transactions IA-22, No.4, July/August 1986.

- Propagation of $100 \mathrm{kHz}$ Ring Wave in steel conduit lines.

- Options for coupling one, two, or three surge diverters at line end; resulting mode conversion.

- 8 references 
MARTZLOFF, F.D., "Varistor vs environment: Winning the Rematch," IEEE Transactions PWRD-1, April 1986.

- Propagation of low-frequency, capacitor switching ring waves from distant substation to low-voltage load.

- Coordination between $3 \mathrm{kV}$ and $480 \mathrm{~V}$ varistor-based SPDs.

- 5 references, 1 discussion

MARTZLOFF, F.D. and WILSON, P.F., "Fast Transient Tests - Trivial or Terminal Pursuit ?," Proceedings, $7^{\text {th }}$ International Zürich Symposium on Electromagnetic Compatibility, 1987.

- Measurement and modeling of attenuation of pulses with nanosecond rise time in steel conduit lines.

- 8 references

MARTZLOFF, F.D. and LEEDY, T.F., "Electrical Fast Transients: Application and Limitations," IEEE Transactions IA26, No. 1, Jan./Feb. 1990.

- Measurement and modeling of attenuation of the EFT 5/50 ns pulse in conduit and nonmetallic jacket lines.

- Shows the decrease in pulse front steepness occurring for a relatively short length of line.

- Suggests that the EFT test should be required only when exposure to this type of environment is likely.

- 9 references

MARTZLOFF, F.D., "Coupling, Propagation, and Side Effects of Surges in an Industrial Building Wiring System," IEEE Transactions IA-26, No. 2, March/April 1990.

- Propagation and attenuation in multi-branch systems.

- Surges in power lines can cause failures of data port components when ground loops exist between pieces of equipment powered by separate branch circuits and connected by a data link.

- Findings promoted the concept of a surge reference equalizer.

- 11 references

MARTZLOFF, F.D., "On the Propagation of Old and New Surges," Proceedings, Open Forum on Surge Protection Application, NISTIR-4654, August 1991.

- Measurements on the propagation of the Ring Wave, the Combination Wave, and the $10 / 1000 \mu$ s Wave.

- The lack of effect of wire diameter is documented by a simple experiment.

- 14 references

MARTZLOFF, F.D., "Diverting Surges to Ground: Expectations vs. Reality," Proceedings, Open Forum on Surge Protection Application, NISTIR-4654, August 1991.

- Comparison of the performance of filter-type vs. voltage-limiting type surge-protective devices.

- Experimental demonstration of voltages induced in branch circuit conductors by the flow of surge currents diverted by the action of the two types of SPDs.

- 9 references

MARTZLOFF, F.D., MANSOOR, A., PHIPPS, K.O., and GRADY, W.W., "Surging the Upside-Down House: Measurement and Modeling Techniques," Proceedings, PQA'95 Conference, New York, NY, 1995.

- Describes a test bed for studying the propagation of surges in low-voltage installations.

- Test and computer modeling on appliances connected to different systems show reference voltage shifts.

- 4 references

MARTZLOFF, F.D., "On the Dispersion of Lightning Current for a Direct Flash to a Building," Proceedings, $25^{\text {th }}$ International Conference on Lightning Protection, Rhodes, 2000.

- A review of simulation examples and anecdotal case history.

- 9 references

MASTER, M.J., UMAN, M.A., LIN, Y.T., and STANDLER, R.B., "Calculations of Lightning Return Stroke Electric and Magnetic Fields above Ground," Journal of Geophysical Research vol.86, No.C12, Dec. 1981.

- Detailed calculations of lightning return stroke electric and magnetic fields above ground are presented.

- 16 references

MATA, C.T., FERNANDEZ, M.I., RAKOV, V.A., UMAN, M.A., BEJLERI, M., RAMBO, K.J., and STAPLETON, M.V., "Overvoltages in Underground Systems, Phase 2 Results," Technical Report, EPRI TR-109669-R1, 1998.

- A 200-page report on the results of triggered lightning experiments.

- 43 references 
MATA, C.T., FERNANDEZ, M.I., RAKOV, V.A., and UMAN, M.A., "EMTP Modeling of a Triggered-Lightning Strike to the Phase Conductor of an Overhead Distribution Line," IEEE Transactions PWRD - ( Scheduled for Spring 2002).

- Modeling of the Camp Blanding overhead distribution line subjected to injection of lightning current.

- Model elements include transmission line, MOV arresters, grounding leads, and ground rods.

- 9 references

MIKHAIL, S. and McGRANAGHAN, M, "Evaluation of Switching Concerns Associated with $345 \mathrm{kV}$ Shunt Capacitor Applications," IEEE Transactions PAS-106, No.4, April 1986.

- Results of Transient Network Analyzer study evaluating switched capacitor banks.

- Includes normal energizing, voltage magnification, phase-to-phase transients, inrush, outrush, and restrikes.

- 14 references, 2 discussions

NIGGLI, M.R., YTURRALDE, W.E., NIEBUHR, W.D., ROCAMORA, R.G., and MADZAREVIC, V., "Fault Clearing Overvoltages on Long Transformer Terminated Lines," IEEE Transactions, PAS-98, No. 2, March 1979

- Transient Network Analyzer study.

- 9 references, 4 discussions

PAUL, C.R. and HARDIN, K.B., "Diagnosis and Reduction of Conducted Noise Emissions," IEEE Transactions, EMC, Nov. 1988.

- Method for determination of relative value of common-mode and normal-mode noise, with modeling of candidate mitigation methods.

- 5 references

PFEIFFER, W. and GRÄF, T., "Ausbreitung und Dämpfung von Überspannungen in Niederspannungs-Installationen" [Propagation and Damping of Overvoltages in Low-voltage Installations], Elektrie Bd. 48, 1994.

- A review of the propagation of surge voltages (in German).

RAKOTOMALALA, A., ROUSSEAU, A., and AURIOL, P., "Lightning Distribution Through Earthing Systems," Proceedings, IEEE International Symposium on EMC, 1994.

- Model of electrical installation including power and telecom lines, water pipe, lightning rod and SPDs.

- Sharing of current between various paths including SPDs showing that neutral is more stressed in case of strike on lightning rod. Opposite in case of strike on power lines.

- In general $30 \%$ of lightning current is shared among all power conductors.

- 8 references

RAKOV, V.A., UMAN, M.A., FERNANDEZ, M.I., MATA, C.T., RAMBO, K.J., STAPLETON, M.V., and SUTIL, R.R., "Direct Lightning Strikes to the Lightning Protection System of a Residential Building: Triggered-lightning

Experiments," IEEE Transactions PE-032PRD(11-2001).

- Injection of triggered lightning into a house replica at Camp Blanding.

- Measured data on dispersion of the lightning current among available paths to ground.

- Examples of current waveforms.

- 9 references

ROCHEREAU, H., XEMARD, A., MICHAUD, J., ZEDDAM, A., and BOUTET, F., "ANASTASIA : Un outil de simulation de l'effet de la foudre sur les réseaux aériens de distribution à basse tension" [ANASTASIA: A Simulation Tool for Lightning Effects on Overhead Low-voltage Distribution Lines], Proceedings, CIGRE Conference "Power system electromagnetic compatibility" - Foz do Iguaçu - May 1995.

- Reports an investigation conducted by the French utility (in French).

ROUSSEAU, A., ROY, D., and WARSMANN, P., "What is a Lightning Earth ?" ERA Earthing 2000

- Mathematical model of high frequency lightning earth/ground.

- High frequency is just useful for overvoltages not for energy sharing between various paths.

- Equipment exist for measuring high frequency ground impedance and examples of good "lightning" ground are given based on real measurements.

- 5 references 
SCUKA, V., "EMI Control in Low-Voltage Power Installations." Proceedings, $7^{\text {th }}$ International Zürich Symposium on Electromagnetic Compatibility, 1987.

- Laboratory measurements of propagation parameters on typical wiring practices

- Comparisons between gap-type and varistor SPDs.

- Recommendations on grounding practices and building construction.

- 8 references

STANDLER, R.B., "Equations for Some Transient Overvoltage Test Waveforms," IEEE Transactions EMC-30, Feb. 1988.

- Provides mathematical equations for the $100 \mathrm{kHz}$ Ring Wave and the Combination Wave.

STANDLER, R.B., "Calculation of Lightning Surge Currents Inside Buildings," Proceedings, IEEE EMC Symposium, August 1992.

- Makes computations with SPICE for a 10/350 $\mu \mathrm{s}, 20 \mathrm{kA}$ impinging current.

- MOV arrester at the service entrance and varistors at the end of branch circuits of various lengths.

- Neglects inductance and considers only resistance, justified by the long tail of the surge.

- 11 references

STANDLER, R.B., "Transmission Line Models for Coordination of Surge-protective Devices," Proceedings, IEEE International Symposium on Electromagnetic Compatibility Symposium, 1993.

- The distribution of surge currents between an arrester and suppressor separated by a transmission line is described for six different models of transmission lines.

- Two different surge waveforms are used in the simulation: the 1.2/50 $\mu$ s wave, and the 10/350 $\mu$ s wave.

- Conclusions on the relative accuracy of the various models of transmission lines.

14 references

STANDLER, R.B., "Neutral-Earth Surge Voltages on Low-voltage AC Mains," Proceedings, $10^{\text {th }}$ International Zürich Symposium on Electromagnetic Compatibility, 1993

- Computer simulations of surge suppressor circuits and propagation of surges on transmission lines show surge voltage waveshapes between the reutral and protective earth conductors inside buildings.

- Theoretical discussion is about the common error of approximating a transmission line as a single inductor.

13 references

STRINGFELLOW, M.F. and STONELY, B.T., "Coordination of Surge Suppressors in Low-Voltage AC Power Circuits," Proceedings, Forum on Surge Protection Application, NISTIR-4657, August 1991.

- Experiments showing the effect of line length and surge waveform on sharing energy between service entrance arrester and surge suppressor inside building.

- Metal-oxide varistors were applied at service entrance, distribution panel and load.

- Removal of protection at either load or distribution panel resulted in unacceptably large oscillatory voltages. Best load protection achieved with MOVs in all three locations.

- 4 references

VINES, R.M., TRUSSELL, H.G., GALE, L.J., and OAENEAL, B., "Noise on Residential Power Distribution Circuits," IEEE Transactions, EMC, Nov. 1984.

- Reports conducted noise measurements from typical residential loads.

- 14 references

WIITANEN, D.O., MORGAN, J.D., and GAIBROIS, G.L., "Station Capacitor Switching Transients - Analytical and Experimental Results," IEEE Transactions, PAS-90, No. 4, April 1971.

- Switching transients at the $41 \mathrm{kV}$ level.

- 10 references, 2 discussions 
Q 


